\title{
EMERGING
}
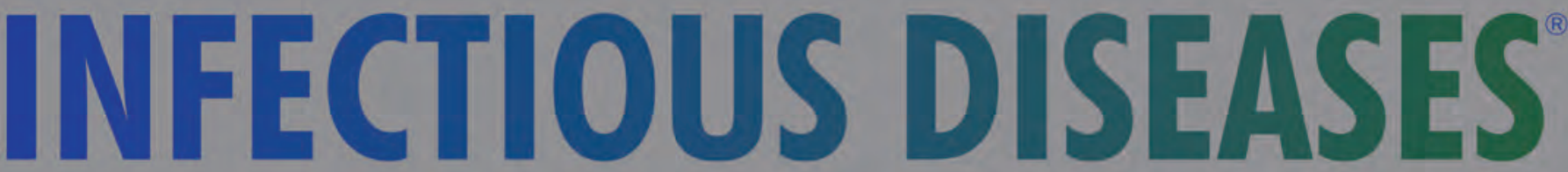

Vectorborne Infections

February 2019

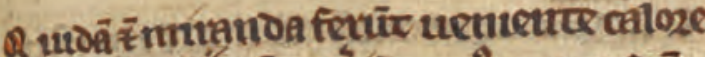

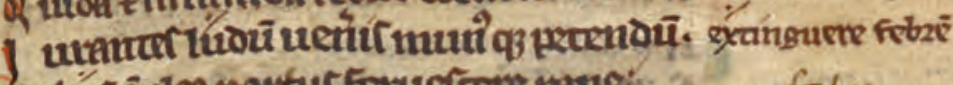
meli' (1)

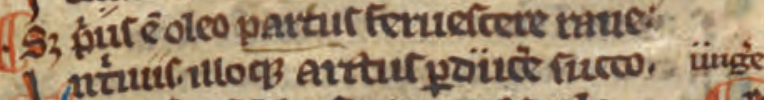

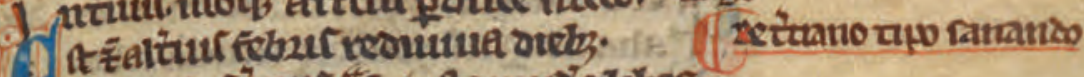
forfur

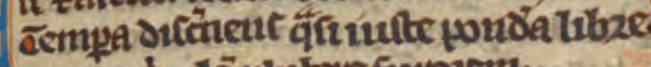

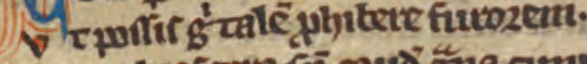

1 nutoluef cota iñ caus guna atmut

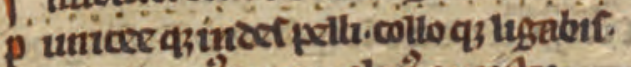

(1) ulegutranti tane uder amutu:

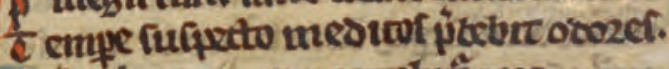

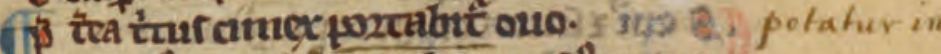

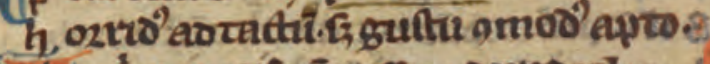

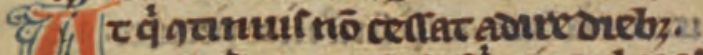

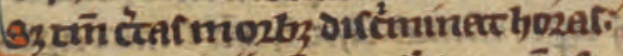

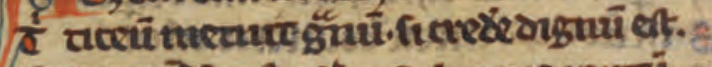

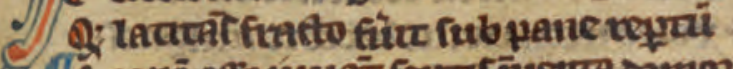

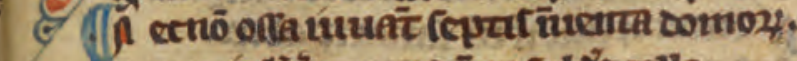

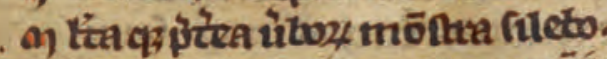

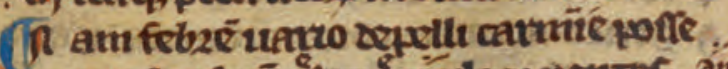

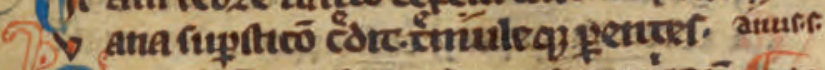

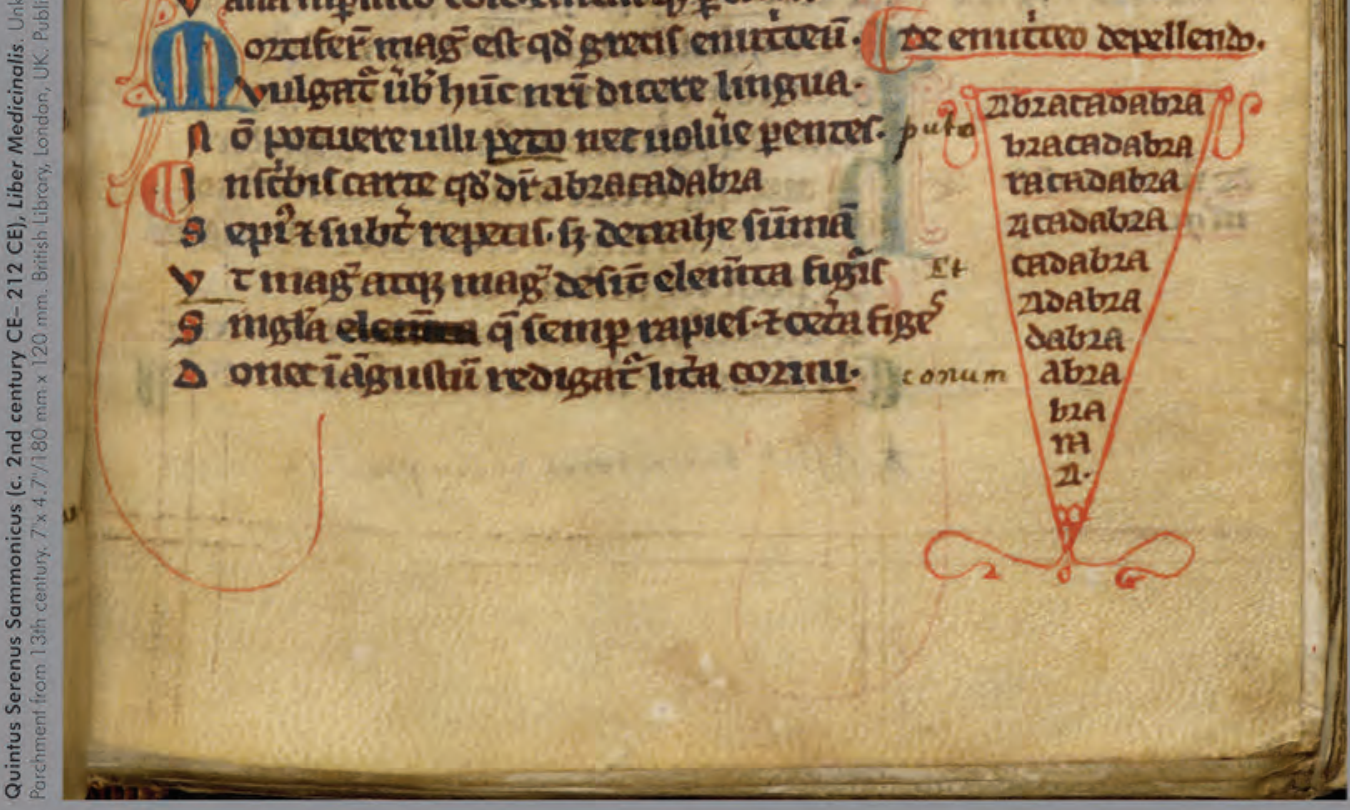




\section{EMERGING INFECTIOUS DISEASES}

\section{EDITOR-IN-CHIEF \\ D. Peter Drotman}

\author{
Associate Editors \\ Paul Arguin, Atlanta, Georgia, USA \\ Charles Ben Beard, Fort Collins, Colorado, USA \\ Ermias Belay, Atlanta, Georgia, USA \\ David Bell, Atlanta, Georgia, USA \\ Sharon Bloom, Atlanta, Georgia, USA \\ Richard Bradbury, Atlanta, Georgia, USA \\ Mary Brandt, Atlanta, Georgia, USA \\ Corrie Brown, Athens, Georgia, USA \\ Charles Calisher, Fort Collins, Colorado, USA \\ Michel Drancourt, Marseille, France \\ Paul V. Effler, Perth, Australia \\ Anthony Fiore, Atlanta, Georgia, USA \\ David Freedman, Birmingham, Alabama, USA \\ Peter Gerner-Smidt, Atlanta, Georgia, USA \\ Stephen Hadler, Atlanta, Georgia, USA \\ Matthew Kuehnert, Edison, New Jersey, USA \\ Nina Marano, Atlanta, Georgia, USA \\ Martin I. Meltzer, Atlanta, Georgia, USA \\ David Morens, Bethesda, Maryland, USA \\ J. Glenn Morris, Gainesville, Florida, USA \\ Patrice Nordmann, Fribourg, Switzerland \\ Johann D.D. Pitout, Calgary, Alberta, Canada \\ Ann Powers, Fort Collins, Colorado, USA \\ Didier Raoult, Marseille, France \\ Pierre Rollin, Atlanta, Georgia, USA \\ Frank Sorvillo, Los Angeles, California, USA \\ David Walker, Galveston, Texas, USA \\ J. Todd Weber, Atlanta, Georgia, USA \\ Managing Editor \\ Byron Breedlove, Atlanta, Georgia, USA
}

Copy Editors Kristina Clark, Dana Dolan, Karen Foster, Thomas Gryczan, Michelle Moran, Shannon O’Connor, Jude Rutledge, P. Lynne Stockton, Deborah Wenger

Production Thomas Eheman, William Hale, Barbara Segal, Reginald Tucker

Editorial Assistants Kristine Phillips, Susan Richardson

Communications/Social Media Sarah Logan Gregory,

Tony Pearson-Clarke

\section{Founding Editor}

Joseph E. McDade, Rome, Georgia, USA

Emerging Infectious Diseases is published monthly by the Centers for Disease Control and Prevention, 1600 Clifton Rd NE, Mailstop H16-2, Atlanta, GA 30329-4027, USA. Telephone 404-639-1960, fax 404-639-1954, email eideditor@cdc.gov.

The conclusions, findings, and opinions expressed by authors contributing to this journal do not necessarily reflect the official position of the U.S. Department of Health and Human Services, the Public Health Service, the Centers for Disease Control and Prevention, or the authors' affiliated institutions. Use of trade names is for identification only and does not imply endorsement by any of the groups named above.

All material published in Emerging Infectious Diseases is in the public domain and may be used and reprinted without special permission; proper citation, however, is required.

\section{EDITORIAL BOARD}

Timothy Barrett, Atlanta, Georgia, USA

Barry J. Beaty, Fort Collins, Colorado, USA

Martin J. Blaser, New York, New York, USA

Christopher Braden, Atlanta, Georgia, USA

Arturo Casadevall, New York, New York, USA

Kenneth C. Castro, Atlanta, Georgia, USA

Benjamin J. Cowling, Hong Kong, China

Vincent Deubel, Shanghai, China

Christian Drosten, Charité Berlin, Germany

Isaac Chun-Hai Fung, Statesboro, Georgia, USA

Kathleen Gensheimer, College Park, Maryland, USA

Rachel Gorwitz, Atlanta, Georgia, USA

Duane J. Gubler, Singapore

Richard L. Guerrant, Charlottesville, Virginia, USA

Scott Halstead, Arlington, Virginia, USA

Katrina Hedberg, Portland, Oregon, USA

David L. Heymann, London, UK

Keith Klugman, Seattle, Washington, USA

Takeshi Kurata, Tokyo, Japan

S.K. Lam, Kuala Lumpur, Malaysia

Stuart Levy, Boston, Massachusetts, USA

John S. MacKenzie, Perth, Australia

John E. McGowan, Jr., Atlanta, Georgia, USA

Jennifer H. McQuiston, Atlanta, Georgia, USA

Tom Marrie, Halifax, Nova Scotia, Canada

Nkuchia M. M'ikanatha, Harrisburg, Pennsylvania, USA

Frederick A. Murphy, Bethesda, Maryland, USA

Barbara E. Murray, Houston, Texas, USA

Stephen M. Ostroff, Silver Spring, Maryland, USA

Marguerite Pappaioanou, Seattle, Washington, USA

Mario Raviglione, Geneva, Switzerland

David Relman, Palo Alto, California, USA

Guénaël Rodier, Saône-et-Loire, France

Connie Schmaljohn, Frederick, Maryland, USA

Tom Schwan, Hamilton, Montana, USA

Rosemary Soave, New York, New York, USA

P. Frederick Sparling, Chapel Hill, North Carolina, USA

Robert Swanepoel, Pretoria, South Africa

Phillip Tarr, St. Louis, Missouri, USA

Duc Vugia, Richmond, California

John Ward, Atlanta, Georgia, USA

Jeffrey Scott Weese, Guelph, Ontario, Canada

Mary E. Wilson, Cambridge, Massachusetts, USA

Use of trade names is for identification only and does not imply endorsement by the Public Health Service or by the U.S. Department of Health and Human Services.

EMERGING INFECTIOUS DISEASES is a registered service mark of the U.S. Department of Health \& Human Services (HHS).

$\infty$ Emerging Infectious Diseases is printed on acid-free paper that meets the requirements of ANSI/NISO 239.48-1992 (Permanence of Paper) 


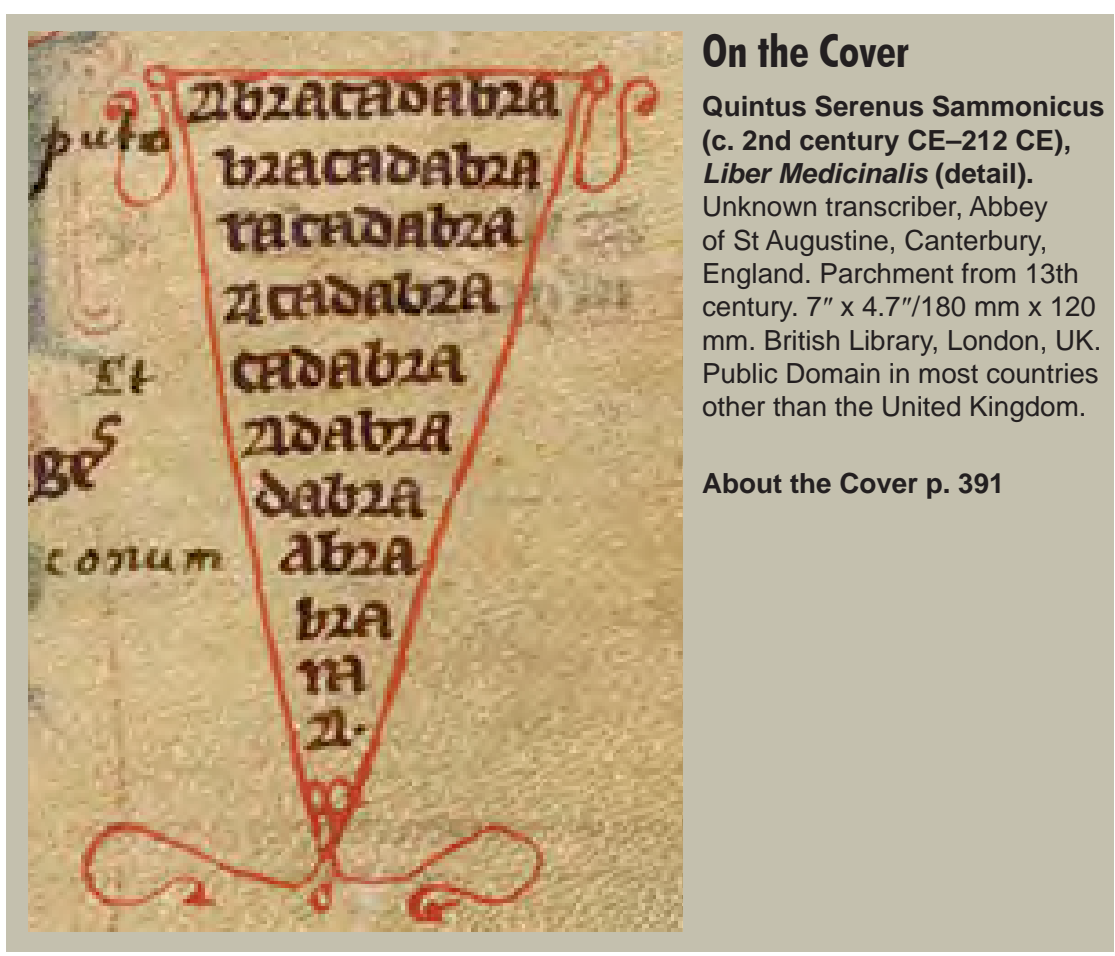

\section{Perspective}

International Biological Reference Preparations for Epidemic I nfectious Diseases

T. Rampling et al.

\section{Synopses}

\section{Atypical Cowpox Virus \\ Infection in Smallpox-Vaccinated Patient, France}

J. Andreani et al.

Related material available online: http://wwwnc.cdc.gov/eid/ article/25/2/17-1433 article

Trends of Human Plague, Madagascar, 1998- 2016

V. Andrianaivoarimanana et al.

Related material available online:

http://wwwnc.cdc.gov/eid/ article/25/2/17-1974_article

\section{Medscape ACTIVITY}

Human Pasteurellosis Health Risk for Elderly Persons Living with Companion Animals

The necessity for diagnosis and treatment of this infection is emphasized by the high number of complications and death rate.

\section{S. Körmöndi et al.}

Lassa Fever in Travelers from West Africa, 1969-2016

A. Kofman et al. Related material available online: http://wwwnc.cdc.gov/eid/ article/25/2/18-0836_article

\section{Ebola Virus I nfection}

Associated with Transmission from Survivors

S. Den Boon et al.

Related material available online: http://wwwnc.cdc.gov/eid/ article/25/2/18-1011 article

\section{Medscape}

EDUCATION

Zika Virus Epidemic in Pregnant Women, Dominican Republic, 2016- 2017

Almost $10 \%$ of pregnancies with acute infections resulted in fetal loss.

F. Peña et al.

\section{Research}

\section{Medscape ACTIVITY}

Acute and Delayed Deaths after West Nile Virus I nfection, Texas, USA, 2002- 2012

Infected patients should be closely monitored to prevent future health problems.

D.C.E. Philpott et al.

Echinococcus multilocularis I nfection, Southern Ontario, Canada

J.D. Kotwa et al.

Epidemiologic and Ecologic I nvestigations of Monkeypox, Likouala Department, Republic of the Congo, 2017

R.H. Doshi et al.

Oasis Malaria, Northern Mauritania

J. Deida et al.

Macrophage Activation Marker Soluble CD163 Associated with Fatal and Severe Ebola Virus Disease in Humans

A.K. McElroy et al.

Zika Virus I gM Detection and Neutralizing Antibody Profiles 12- 19 Months after I Ilness Onset I. Griffin et al.

299

Related material available online: http://wwwnc.cdc.gov/eid/ article/25/2/18-1286_article 


\section{Historical Review}

Killing Clothes Lice by Holding Infested Clothes Away from Hosts for 10 Days to Control Louseborne Relapsing Fever, Bahir Dah, Ethiopia

S.C. Barker, D. Barker

304

\section{Dispatches}

Differential Shedding and Antibody Kinetics of Zika and Chikungunya Viruses, Brazil

F.A. Bozza et al.

Related material available online: http://wwwnc.cdc.gov/eid/ article/25/2/18-0166_article

Clinical Manifestations,

Antimicrobial Drug Susceptibility Patterns, and Outcomes in Melioidosis Cases, India

M. Koshy et al.

Crimean-Congo Hemorrhagic Fever, Kosovo, 2013- 2016

S. Ahmeti et al.

Cumulative I ncidence of West Nile Virus I nfection, Continental United States, 1999- 2016

S.E. Ronca et al.

Related material available online: http://wwwnc.cdc.gov/eid/ article/25/2/18-0765_article

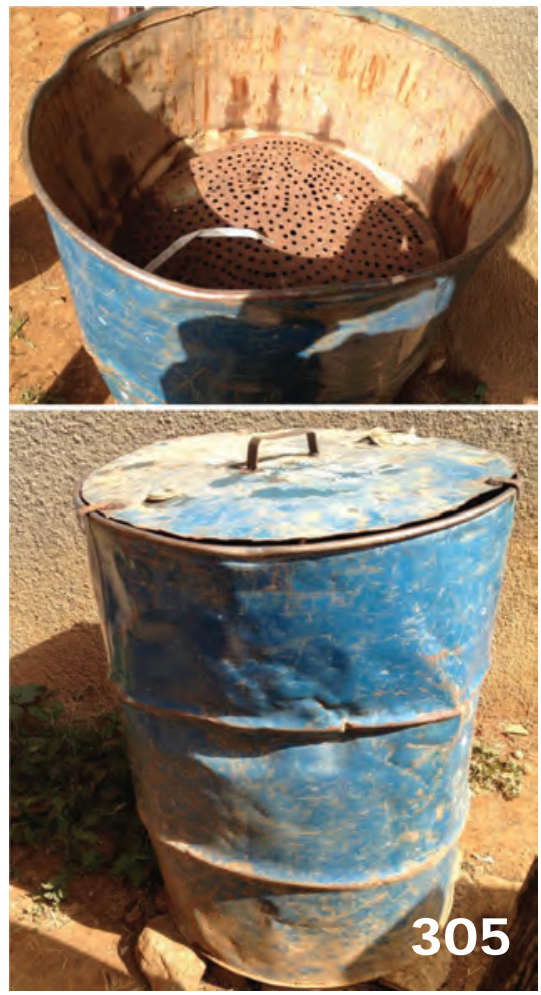

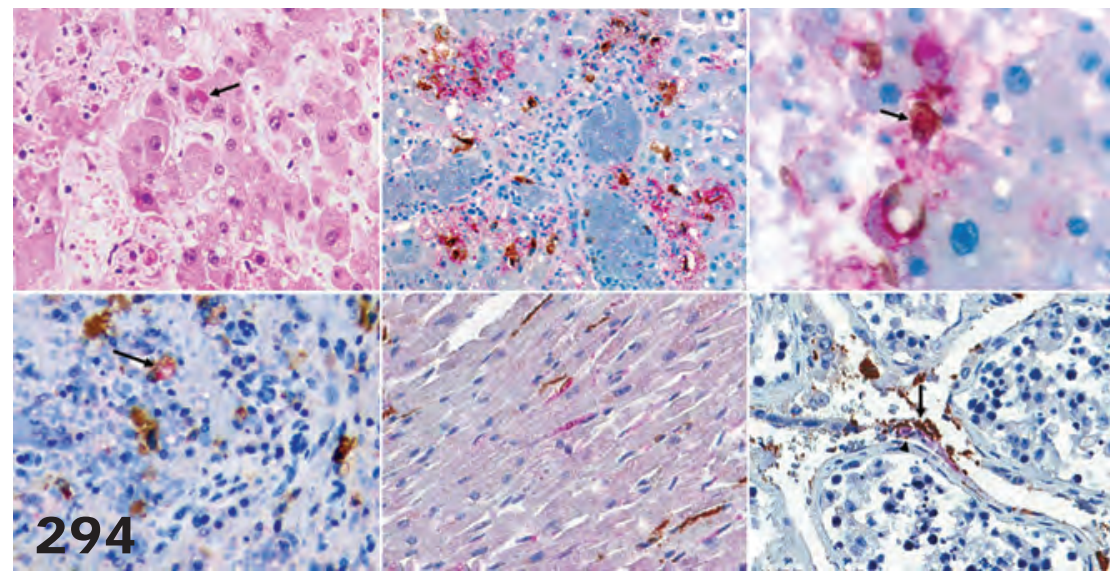

Lyme Disease Emergence after I nvasion of the Blacklegged Tick, I xodes scapularis, Ontario, Canada, 2010-2016 M

A. Kulkarni et al. 328

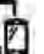
Related material available online: http://wwwnc.cdc.gov/eid/ article/25/2/18-0771_article

Bat Influenza A(HL18NL11) Virus in Fruit Bats, Brazil

A.C.A. Campos et al.

Related material available online: http://wwwnc.cdc.gov/eid/ article/25/2/18-1246 article

Rift Valley Fever Reemergence after 7 Years of Quiescence, South Africa, May 2018

P.J. van Vuren et al.

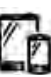

Related material available online: http://wwwnc.cdc.gov/eid/ article/25/2/18-1289_article

Tick-Borne Encephalitis Virus Antibodies in Roe Deer, the Netherlands

J.M. Rijks et al.

Related material available online:

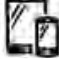
http://wwwnc.cdc.gov/eid/ article/25/2/18-1386_article

Vector Competence of Aedes caspius and Ae. albopictus Mosquitoes for Zika Virus, Spain

R. Gutiérrez-López et al. 346 Related material available online: http://wwwnc.cdc.gov/eid/ article/25/2/17-1123_article
Submicroscopic Malaria in Migrants from Sub-Saharan Africa, Spain

J. Pousibet-Puerto et al.

Cytauxzoon felis I nfection in Domestic Cats, Yunnan Province, China, 2016

F.- C. Zou et al.

353

Molecular Detection and Species Determination of Malaria

Parasites, Venezuela

C. Pacheco et al.

Seroprevalence of Heartland Virus Antibodies in Blood Donors, Northwestern Missouri, USA

N.P. Lindsey et al.

Identification of Leishmania Species in Naturally I nfected Sand Flies from Refugee Camps, Greece

E.A. Fotakis et al.

\section{Research Letters}

Schistosoma haematobiumSchistosoma mansoni Hybrid Parasite in Migrant Boy,

France, 2017

Y. Le Govic et al. 
West Nile Virus I nfection in Travelers Returning to United Kingdom from South Africa

V. Parkash et al.

Related material available online: http://wwwnc.cdc.gov/eid/ article/25/2/18-0765_article

\section{East/ Central/ South African Genotype in Chikungunya Outbreak, Dhaka, Bangladesh, 2017}

M. Rahman et al.

Related material available online:

V) http://wwwnc.cdc.gov/eid/ article/25/2/18-0188_article

Dolphin Morbillivirus in Eurasian Otters, I taly

I. Padalino et al.

Little Evidence of Zika Virus Infection in Wild Long-Tailed Macaques, Peninsular Malaysia

C.L. Chua et al.

Vह Related material available online: http://wwwnc.cdc.gov/eid/ article/25/2/18-0258 article

Severe Fever with

Thrombocytopenia Syndrome Virus in Dogs, South Korea

J.-G. Kang et al. 376

Related material available online: http://wwwnc.cdc.gov/eid/ article/25/2/18-0859_article

Pin-Site Myiasis Caused by Screwworm Fly in Nonhealed Wound, Colombia

W.E. Villamil-Gómez et al.

Oropouche Virus- Associated Aseptic Meningoencephalitis, Southeastern Brazil

S. Vernal et al.

Related material available online: http://wwwnc.cdc.gov/eid/ article/25/2/18-1189 article

Severe Respiratory I IIness Associated with Human Metapneumovirus in Nursing Home, New Mexico, USA

S.A. Peña et al.

Zoonotic Leishmaniasis, Bosnia and Herzegovina

V. Colella et al.

\section{Clinical Characteristics} of Ratborne Seoul Hantavirus Disease

J. Clement et al.

Related material available online:

http://wwwnc.cdc.gov/eid/

article/25/2/18-1643 article

\section{EMERGING INFECTIOUS DISEASES}

February 2019
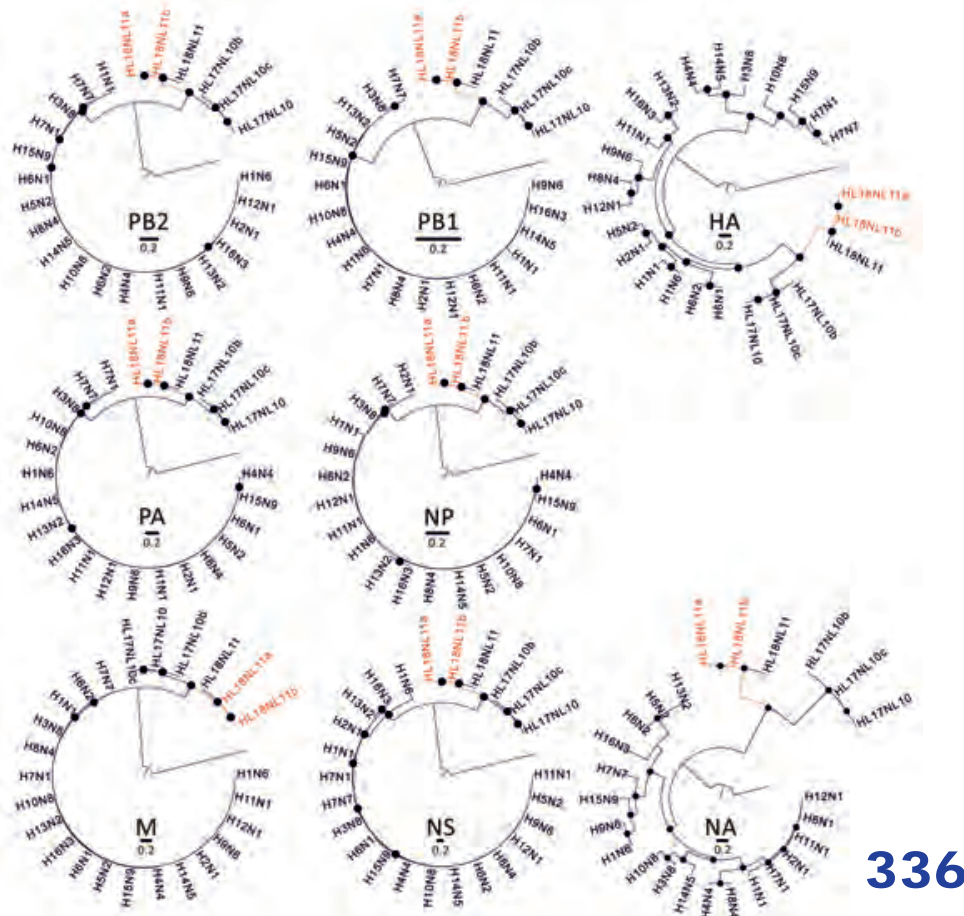

\section{Letter}

Mycobacterium Lepromatosis Lepromatous Leprosy in US Citizen Who Traveled to DiseaseEndemic Areas

G. Sharma, V. Dutt Sharma

389

\section{About the Cover}

\section{Malaria Elimination-Not J ust a Bunch of Hocus-Pocus \\ B. Breedlove, P.M. Arguin}

391

\section{Etymologia}

Cochliomyia hominivorax

R. Henry

\section{Corrections}

Vol. 24, No. 12

In Figure 1 of the article Genomic Characterization of $\beta$-GlucuronidasePositive Escherichia coli O157:H7 Producing Stx2a (Y. Ogura et al.), Shiga toxin-producing Escherichia coli O157 was mislabeled several times, and the term STEC was incompletely defined.
Vol. 25, No. 1

Table 3 misstated the number of animals tested during 2001-2004 and the first author's biographical sketch was incorrect in Multiple Introductions of Domestic Cat Feline Leukemia Virus in Endangered Florida Panthers (E.S. Chiu et al.).

Author Sang-Ho Choi's name was listed incorrectly and author affiliations were unclear in Clinical and Radiologic Characteristics of Human Metapneumovirus Infections in Adults, South Korea (H.J. Koo et al.).

Two locations in Figure 1 were shown incorrectly in Risk Factors for Elizabethkingia Acquisition and Clinical Characteristics of Patients, South Korea (M.H. Choi et al.).

\section{Online Report}

Public Health- Driven Research and I nnovation for Next-

Generation Influenza Vaccines, European Union

A. Navarro-Torné et al.

https://wwwnc.cdc.gov/eid/article/ 25/2/18-0359_article 


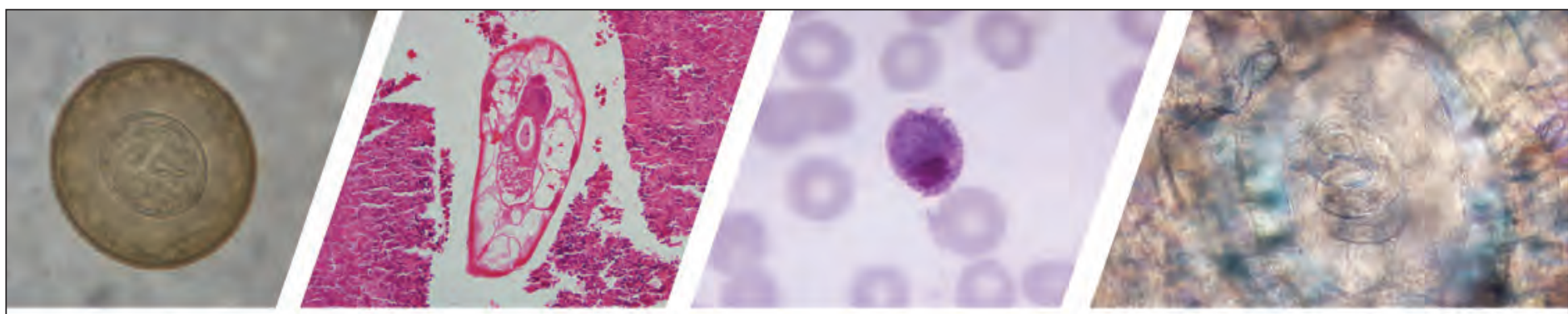

(3DPDx

\section{Diagnostic Assistance and Training in Laboratory Identification of Parasites}

A free service of CDC available to laboratorians, pathologists, and other health professionals in the United States and abroad

(1) Diagnosis from photographs of worms, histological sections, fecal, blood, and other specimen types

(10) Expert diagnostic review 㳕望 Formal diagnostic laboratory report

a Submission of samples via secure file share

Visit the DPDx website for information on laboratory diagnosis, geographic distribution, clinical features, parasite life cycles, and training via Monthly Case Studies of parasitic diseases.

www.cdc.gov/dpdx dpdx@cdc.gov

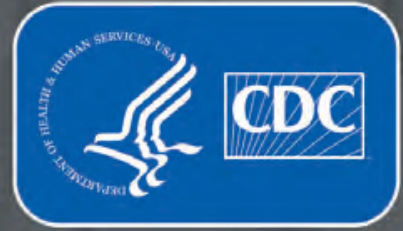

U.S. Department of

Health and Human Services Centers for Disease Control and Prevention 


\title{
I nternational Biological Reference Preparations for Epidemic I nfectious Diseases
}

\author{
Tommy Rampling, Mark Page, Peter Horby
}

Recent years have seen unprecedented investment in research and development for countermeasures for high-threat pathogens, including specific and ambitious objectives for development of diagnostics, therapeutics, and vaccines. The inadequate availability of biological reference materials for these pathogens poses a genuine obstacle in pursuit of these objectives, and the lack of a comprehensive and equitable framework for developing reference materials is a weakness. We outline the need for internationally standardized biological materials for high-threat pathogens as a core element of global health security. We also outline the key components of a framework for addressing this deficiency.

$\mathrm{T}$ he availability of biological reference materials, including antigens, antibodies, and nucleic acids, is essential for development of vaccines, biotherapeutics, and diagnostics (1). Complex macromolecules, such as immunoglobulins, or genetic material often cannot be adequately characterized by chemical or physical means alone, and reference preparations are necessary to enable consistency and comparison across assays. Immunoassays such as ELISAs or molecular methods such as quantitative PCR can be used to quantify biological materials, but these assays are subject to inherent variability between test instances and different laboratories, and require the use of reference preparations to generate a quantitative output (2). Furthermore, a key asset in research progress is the ability to compare results between studies and across different institutions. International reference preparations (IRPs) are internationally agreed upon reference materials that enable consistency and comparison between different studies and laboratories. Use of IRPs also ensures consistency of production and quality of biological medicinal products and is essential for establishment of appropriate clinical dosing.

Author affiliations: Hospital for Tropical Diseases, London, UK (T. Rampling); National Institute for Biological Standards and Control, Potter's Bar, UK (M. Page); University of Oxford, Oxford, UK (P. Horby)

DOI: http://doi.org/10.3201/eid2502.180798

\section{History of Biological Standardization}

The concept of biological standardization and the use of biological reference materials has existed since the turn of the 20th century after simultaneous discovery of diphtheria antitoxin by von Behring and Roux $(3,4)$. Attempts to recreate production of antitoxin in horses were successful in France, but yielded an ineffective product in England. This failure was attributed to weak serum and led Ehrlich to propose use of a standard antitoxin preparation, measured in units, with which to calibrate future batches and ensure potency (5). This concept was applied by Dale in the 1920s to other biological products, such as insulin, but the need for international oversight was recognized (6).

In the 1920s, the League of Nations initiated the provision of IRPs under the Commission on Biological Standardization, and biological standardization was subsequently incorporated into the constitution of the World Health Organization (WHO) upon its creation in 1946 (7). Since 1947, the provision of WHO reference materials has played a vital role in the translation of laboratory science into worldwide clinical practice and has been delivered through the WHO Expert Committee on Biological Standardization, WHO collaborating centers, and various state and nonstate partners. The Expert Committee on Biological Standardization meets annually to establish detailed recommendations and guidelines for manufacturing, licensing, and control of complex biological materials, including blood products, vaccines, and related in vitro diagnostic tests, and to maintain a catalog of IRPs to be distributed globally as required. These WHO IRPs, composed of international reference standards and other reference materials (Table 1), provide a common set of reagents that are used to ensure the quality of biological assays and medicines globally. These IRPs are considered to be the standard against which regional, national, and international laboratories and manufacturers should calibrate their own working standards. Reference materials only become WHO-endorsed IRPs after extensive collaborative studies involving multiple laboratories internationally. This process enables materials to be ascribed defined units of biological activity, most commonly international units. 
Table 1. Types of WHO reference preparations for epidemic infectious diseases*

\begin{tabular}{|c|c|}
\hline Types of reference material & Characteristic \\
\hline International standards & $\begin{array}{l}\text { Extensively characterized following international collaborative studies enable activity of biological } \\
\text { preparations to be expressed in the same way globally, most commonly in international units }\end{array}$ \\
\hline International reference reagents & $\begin{array}{l}\text { Less extensively characterized than international standards. Not assigned international units. } \\
\text { Reference reagents are interim and not intended to be replaced when they expire or are depleted. }\end{array}$ \\
\hline International reference panels & $\begin{array}{c}\text { Group of reference materials established to collectively aid evaluation of assays or diagnostic } \\
\text { tests. Comply with requirements for WHO reference standards/reagents. }\end{array}$ \\
\hline Working or secondary standard & $\begin{array}{c}\text { Reference standards established by regional or national authorities, or by other laboratories, that } \\
\text { are calibrated against, and traceable to, the primary WHO materials and are intended for use in } \\
\text { routine tests. }\end{array}$ \\
\hline
\end{tabular}

Although several hundred centers contribute to WHO collaborative studies, only 3 centers produce and hold IRPs. These centers are the National Institute for Biological Standards and Control in England, the Center for Biologics Evaluation and Research in the United States, and the Paul-Ehrlich Institute in Germany. The role of these institutions is to produce, store, and distribute IRPs and differs from those that distribute repository materials, such as the US Centers for Disease Control and Prevention, the International Reagent Resource, and the National Institute of Allergy and Infectious Diseases Biodefense and Emerging Infections research resources repository.

\section{Utility of IRPs for WHO Research and Development Blueprint Diseases}

In the aftermath of the 2014 West Africa Ebola virus disease (EVD) outbreak, there has been considerable focus on expediting research and development to ensure we are better prepared for future disease outbreaks. In 2015, WHO launched the Research and Development Blueprint for Action to Prevent Epidemics, a global strategy and preparedness plan that seeks to build upon the successes and address the gaps identified during the 2014 EVD outbreak by focusing on severe, emerging diseases with the potential to create a public health emergency and for which inadequate treatment and preventive options are currently available $(8,9)$. The blueprint is organized such that operations fall into 4 clusters of activities: 1) improving coordination, 2) accelerating research and development processes, 3) developing norms and standards, and 4) streamlining operational research and development response during outbreaks. Furthermore, the second cluster, which focused on accelerating research and development processes, is subdivided into 3 distinct areas of work: 1) assessing epidemic threats and defining priority pathogens; 2) developing research and development roadmaps to accelerate evaluation of diagnostics, therapeutics, and vaccines; and 3) outlining appropriate regulatory and ethical pathways.

Central to the research and development blueprint is a list of priority diseases, first published in November 2015, with subsequent revision through a tailored prioritization method in 2017 and 2018 (Table 2) (10,11). For each priority disease on the list, a research and development roadmap is to be produced that encompasses diagnostics, vaccines, and therapeutics. The first research and development roadmap to have been developed and published is for Middle East respiratory syndrome coronavirus (MERS-CoV) (12), which serves to inform the roadmap generation process for other diseases on the priority pathogen list. Within the MERS-CoV roadmap, development of reference reagents has been identified as a priority, but the major operational and ethical issues associated with sourcing and obtaining bulk starting material for such reagents have not been discussed. An allied initiative is the Coalition for Epidemic Preparedness and Innovation (CEPI), whose aim is to accelerate development of vaccines for high-threat pathogens (13). The necessity for reference materials in development and evaluation of new diagnostics, vaccines, and biotherapeutics has been recognized by CEPI by the formation of a Working Group on Standards and Assays, but they are not explicitly considered in the WHO research and development blueprint.

Before the 2014 EVD epidemic, no IRPs existed for any diseases on the research and development bueprint. Expedited development led to production of an interim Ebola antibody reference reagent in October 2015, and the first international standard was endorsed in October 2017 $(14,15)$. Although this accelerated production represents an impressive collaborative feat, the lack of availability of PCR, antigen, and antibody IRPs at the start of this EVD outbreak, and for subsequent outbreaks of infection with MERS-CoV and Zika virus, likely hampered development of accurate diagnostics and vaccines (16). In addition, the exceptional circumstances and unprecedented duration of the 2014 EVD epidemic enabled a major proportion of IRP development to occur while the outbreak was ongoing.

Development of IRPs from sample acquisition to WHO endorsement usually takes $2-3$ years, which is considerably longer than most outbreaks of diseases on the research and development blueprint. The availability of IRPs for often rare and sporadic diseases with epidemic potential before, or soon after, occurrence of outbreaks would facilitate diagnostics and research activities, such as seroepidemiologic studies and immunogenicity assessment of experimental vaccines. At the present time, with the exception of Zaire Ebolavirus antibody, antigen, and nucleic acid 
Table 2. Revised list of World Health Organization priority diseases, February $2018^{*}$

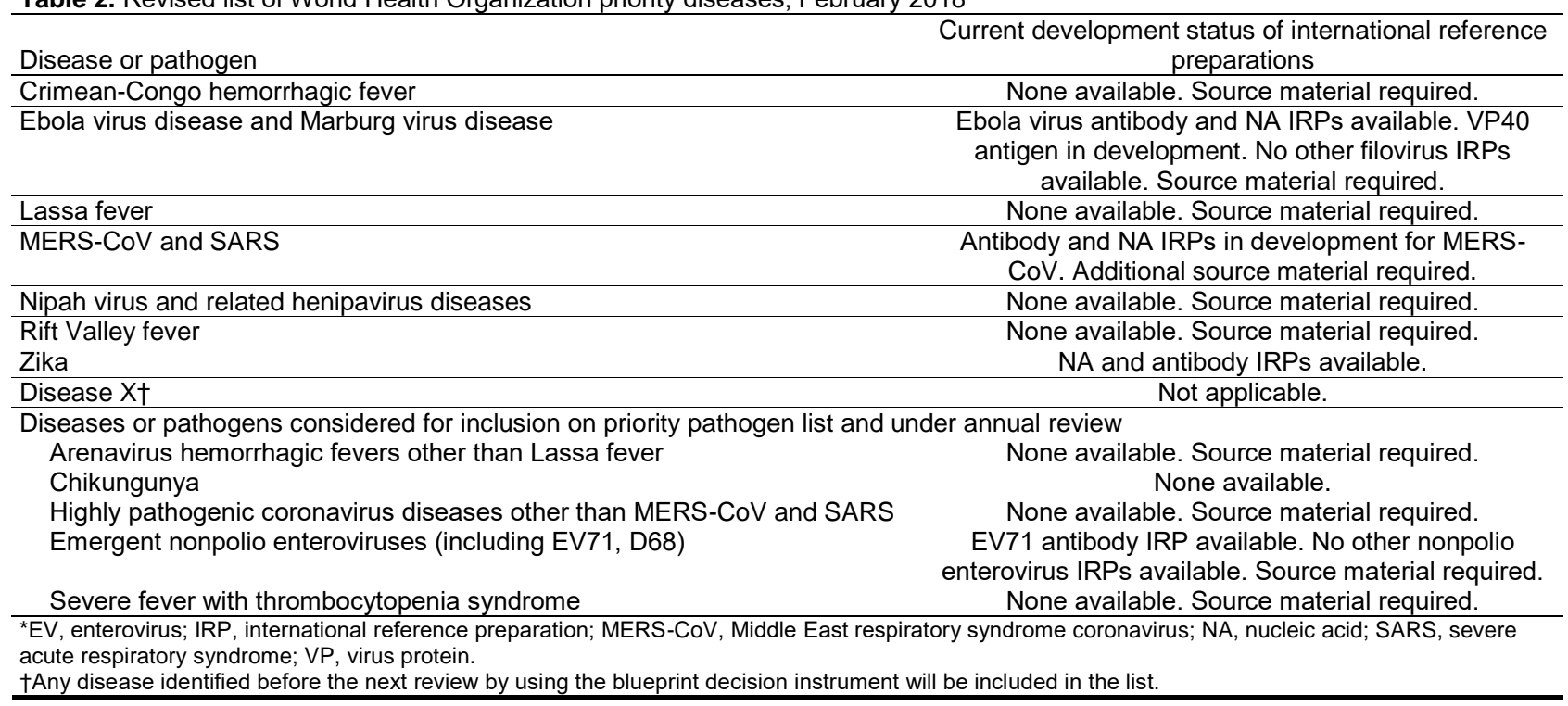

IRPs and a WHO-endorsed Zika virus RNA and antibody standards, no IRPs exist for any other disease on the research and development blueprint. The availability of IRPs for these diseases would facilitate development of essential tools in epidemic preparedness, including diagnostics, vaccines, and therapeutics.

\section{Diagnostics}

Accurate and accessible diagnostic tools are vital in limiting the public health effect of disease outbreaks, in addition to providing reliable data for clinical and epidemiologic studies. A coordinated diagnostic product development effort for epidemic disease threats has been initiated by the Foundation for Innovative New Diagnostics under the auspices of CEPI (17). This initiative seeks to build on collaborations with key diagnostic partners to enable adequate provision of diagnostic capabilities during outbreaks. WHO states that IRPs are major resources for ensuring the reliability of in vitro biological diagnostic procedures used for diagnosis of diseases (18). The recent epidemics caused by MERS-CoV, Ebola virus, and Zika virus have highlighted complexities in prompt development of sensitive and specific assays, particularly those that would be accessible in resource constrained settings (19-21). Availability of international reference standards that encompass genetic material, antigens, and antibodies would enable harmonization and calibration of tests. These standards would facilitate development and validation of diagnostic assays, which include nucleic acid amplification tests, serologic assays, and antigen-based point-of-care tests.

\section{Development of Vaccines and Therapeutics}

No vaccine or therapeutic is currently licensed by regulators in Europe or the United States for use for any disease on the research and development blueprint. On August 8, 2014, WHO declared the Ebola outbreak in West Africa to be a public health emergency of international concern. This declaration led to subsequent concerted efforts from the international scientific community to accelerate development of Ebola vaccines, with funding, regulatory and ethical review, expert advice, and manufacturing support being initiated at extraordinary speed (22). Although vaccine development was considered to be a relatively successful component of the Ebola research and development efforts, and the recombinant vesicular stomatitis virus-Zaire Ebola virus showed high efficacy in a ring vaccination trial (23), this development came too late to have any major effect on the course of the West Africa epidemic. Other candidate vaccines also underwent clinical evaluation, and encouraging safety and immunogenicity data were generated from phase 1 and 2 trials of several candidates. However, studies were performed by different groups with a variety of immunogenicity assays and reference reagents being used, making comparison of immunogenicity results complicated (24-28). A set of biological standards that are common to all assays would enable calibration and harmonization of assay data between trials, and could prove vital in determining correlates of protection and clinical outcomes. These standards would also enable better selection of candidate vaccines to transition from the preclinical stage to clinical evaluation.

There has been considerable interest in biological therapies for emerging epidemic threats (29). Convalescent-phase plasma and monoclonal antibodies have been evaluated as treatment for Ebola $(30,31)$ and have been considered as therapies for Zika virus (32) and MERS-CoV $(33,34)$, forming a key focus of the MERS-CoV research and development blueprint roadmap (12). Availability of 
IRPs would enable characterization of the potency, purity, and identity of complex biological materials, such as antibodies, which would facilitate not only research of immunotherapies but also the standardization of preparations postlicensure.

\section{Challenges in Development of Standards for Research and Development Blueprint Diseases}

Antigen and nucleic acid reference materials can be synthesized through recombinant techniques as long as necessary genomic sequence data are available (35-37), but for some newly emerging pathogens, acquisition of live pathogens might be required. Simple blood draws can complicate field operations in the midst of an epidemic, and logistical issues regarding processing and storage of acute, potentially infectious samples can also present many obstacles. However, the ideal starting material for production of antibodybased reference preparations is serum or plasma from convalescent-phase patients.

Novel methods for generating fully human immunoglobulin for use as reference materials have been explored when human plasma is not readily available, such as inoculation of transchromosomal cattle and subsequent isolation of antibodies $(35,38,39)$. However, this technology is still relatively new, and convalescent-phase serum is considered superior because it will most closely represent a clinical sample and has a polyclonal range of antibody specificities that can be further optimized by pooling samples. Although many previous clinical studies of the research and development blueprint priority diseases have resulted in collection and storage of plasma from convalescent patients, several obstacles would largely preclude these samples being repurposed to generate reference materials. These issues include sample volume, receipt of appropriate consent, appropriate records, documentation of sample provenance, and willingness of researchers to share samples. A more suitable alternative to repurposing old samples would be to initiate clinical studies with objectives that include acquisition of blood samples for production of reference materials for each of the research and development blueprint priority diseases. However, such studies would have several challenges.

\section{Challenge in Identifying Suitable Patients to Donate Material}

Many pathogens on the WHO priority pathogens list cause outbreaks that are difficult to anticipate temporally and geographically, and outbreaks are often limited in numbers of cases and duration. These factors complicate prospective acquisition of appropriate clinical samples for development of reference materials. In addition, these pathogens most commonly cause outbreaks in resource-constrained environments, where poor healthcare infrastructure, limited diagnostic capability, and suboptimal disease reporting systems would limit retrospective identification of suitable patients (40). For development of Ebola antibody IRPs, plasma was obtained either from recovered EVD patients in Sierra Leone who were enrolled in a convalescent-phase plasma trial or as donations from countries not directly involved in the outbreak (Italy, Norway, the United Kingdom, and the United States) $(14,15)$. However, it would be inappropriate to use this example as a model for sample acquisition because it required occurrence of a large and devastating outbreak for a concerted international response to be successful.

Focused efforts to obtain material for the generation of IRPs should be made for high-threat epidemic diseases, and methods to identify and sample patients from previous outbreaks should be explored. In addition, preparation for promptly identifying and sampling patients prospectively given a diagnosis in future outbreaks should be made. This preparation would optimize the likelihood of obtaining high-quality samples for rare and sporadic disease pathogens, such as Nipah virus or Rift Valley fever virus, but would require a systematic and coordinated approach that brings together local investigators with international partners in a transparent and equitable framework. Global initiatives, such as the International Severe Acute Respiratory and Emerging Infections Consortium, exist to facilitate the rapid response to emerging infectious disease and epidemic threats by aiding the sharing of clinical research tools, such as open-access clinical study protocols. Initiatives such as this consortium would be well placed to bring together international partners and coordinate a collaborative framework to outline processes for acquisition of samples for generation of reference materials. Preemptive identification of study sites and preparation of study documents, including template protocols and clinical agreements detailing methods for identifying and recruiting potential donors, sample collection, and processing, and roles and responsibilities would optimize the likelihood of success in this regard.

\section{Ethics Considerations}

In situations in which access to existing samples and appropriate consent for use in reference preparations are unavailable, the process of acquiring new samples for development of reference materials should be registered as a unique study for each prioritized epidemic disease. This process would require ethics approval being sought through appropriate channels, thus enabling appropriate scrutiny by relevant ethics and regulatory bodies in countries coordinating activities in disease-endemic countries where samples are to be collected, and in the countries of international partners. These studies would involve minimal risk to participants because they would not involve administration of 
an investigational medicinal product and in most instances, only a single venesection would be required.

\section{Consent}

Serum, plasma, and plasma-derived products contain insufficient genetic material to be universally considered as human tissue under legislation. However, they must be considered human biological material. Therefore, informed consent is an indispensable requirement for donations. The donor should receive information concerning all aspects of the study, with emphasis placed on the fact that participation is entirely voluntary. The intended use of the blood components for the generation, storage, and international distribution of reference materials must be explained, in addition to the potential beneficiaries and the procedures involved. Appropriate measures should also be taken to ensure protection of personal data and confidentiality, and these issues must be explained to the donor. Such information should be contained in a detailed participant information sheet that should be provided to the donor in advance of providing consent. Consent processes should consist of all participants signing and dating an informed consent form before any study-specific procedures are performed. A collaborative international framework could include template participant information sheets and informed consent forms that could be readily adapted for disease-and country-specific studies when appropriate.

\section{Ownership and Equitable Benefit Sharing}

Sharing of biological materials is a necessity for rapid research progress, but recent experiences during epidemics have highlighted that concerted efforts to establish acceptable processes for obtaining and sharing reference materials are needed. At the present time, only a small number of institutions manufacture and provide reference materials to WHO for use as IRPs. Therefore, export of samples to these institutions is an essential step in the production of IRPs for epidemic diseases. Initiatives exist to facilitate sharing of benefits arising from the use of, and access to, human and nonhuman genetic material. An example of such an initiative is the Pandemic Influenza Preparedness (PIP) framework launched by WHO in 2011. The PIP framework seeks to address concerns of low- and middleincome countries that sharing of influenza virus specimens with WHO was not matched with assurances that benefits derived from such sharing would be equitably distributed (41). Concerns about inequitable sharing of benefits were further exacerbated during the 2009 influenza A(H1N1) pandemic because of unequal access to vaccines (42). Despite the example set by the PIP framework, more recent epidemics of other infectious diseases have continued to raise issues with regard to sample sharing. For example, local export restrictions in Brazil prevented sharing of well-characterized samples during the recent Zika virus epidemic, thereby presenting an obstacle to rapid development and assessment of diagnostics $(43,44)$.

Further generalized guidance on fair and equitable sharing of benefits arising out of use of genetic biological resources is in the Nagoya Protocol (45). This protocol is a supplementary agreement to the Convention on Biological Diversity and contains detailed guidance divided into the following objectives: access obligations, benefit sharing obligations, and compliance obligations. No similar guidance exists for plasma-derived products, such as antibody reference materials. However, many facets of the Nagoya Protocol would remain pertinent to plasma-derived products and could be adapted to inform procedures.

Acceptance that human-derived products should not be an object of commercialization or source of profit is enshrined in several key documents $(46,47)$ that would continue to apply to development of IRPs. WHO distributes IRPs either free of charge to National Control Laboratories or with small handling charges and shipping costs to other organizations. Negotiations between relevant parties and preemptive interaction between researchers and donor country authorities could lead to clearly defined, mutually agreed upon processes for acquisition and export of samples. These processes could subsequently be specified in legally binding clinical study agreements, and thus ensure compliance with principles of equitable benefit sharing and provide solutions to complex issues, such as intellectual property, product ownership, and access rights to IRPs.

\section{Operational Considerations}

Most diseases on the research and development blueprint priority disease list are caused by category A pathogens, and handling of potentially infectious materials often requires Biosafety Level 4 laboratories. In recent years, the threat of bioterrorism has resulted in strict rules and requirements, such as US Federal Select Agent regulations, which can result in increased cost, limited research, and reduced collaboration between institutions (48). However, there is an encouraging increase in the number of Biosafety Level 4 laboratories globally, and initiatives now exist that seek to harmonize practices and facilitate collaboration between laboratories with the ultimate goal of positively contributing to global health $(49,50)$. The safe acquisition, processing, exporting, and importing of samples from recovered emerging high-threat disease patients would require careful planning. Requirements would be based on natural history of a specific disease, study site, and patient characteristics, such as period of convalescence since the acute illness. Liaison with national authorities in donor and recipient countries with regard to exportation and importation regulations and requirements would be necessary. In addition, most of these diseases occur primarily in low- and middle-income 
countries and often in remote or rural settings, where access to accurate medical records and diagnostic tools will be limited. Clear specifications regarding method of diagnosis, patient clinical details and disease course, sample collection date, and storage details would be required.

\section{Conclusions}

Biological IRPs for infectious diseases with epidemic potential are a major global asset that will support timely and efficient development of vaccines, therapeutics, and diagnostics. A critical barrier to development of reference materials for epidemic infections is acquisition of suitable source material. We have highlighted a series of key issues that need to be addressed systematically in a framework that is acceptable to all parties. Work should begin to develop and agree to such a framework and to generate IRPs for these diseases so that drugs, diagnostics, and vaccines are available for future outbreaks.

\section{About the Author}

Dr. Rampling is an infectious diseases clinician and academic clinical fellow at the Hospital for Tropical Diseases and University College London, London, UK. His research interests are virology, epidemic preparedness, and clinical evaluation of vaccines.

\section{References}

1. Page M, Wilkinson DE, Mattiuzzo G, Efstathiou S, Minor P. Developing biological standards for vaccine evaluation. Future Virology. 2017;12:431-7. http://dx.doi.org/10.2217/fvl-2017-0003

2. World Health Organization. Recommendations for the preparation, characterization and establishment of intenational and other biological reference standards. Geneva: The Organization; 2006.

3. Ehrlich and Von Behring. JAMA. 2017;317:1381. http://dx.doi.org/ 10.1001/jama.2017.0642

4. The antitoxin treatment of diphtheria: M. Roux at the Pasteur Institute. BMJ. 1894;2:931-3. http://dx.doi.org/10.1136/ bmj.2.1765.931

5. Bosch F, Rosich L. The contributions of Paul Ehrlich to pharmacology: a tribute on the occasion of the centenary of his Nobel Prize. Pharmacology. 2008;82:171-9. http://dx.doi.org/ $10.1159 / 000149583$

6. Bangham DR. H.H. Dale and the London Centre for WHO standards - some milestones of the early years. Dev Biol Stand. 1999;100:11-5.

7. Cockburn WC. The international contribution to the standardization of biological substances. I. Biological standards and the League of Nations 1921-1946. Biologicals. 1991; 19:161-9. http://dx.doi.org/10.1016/1045-1056(91)90030-N

8. Kieny MP, Rottingen JA, Farrar J; WHO R\&D Blueprint team; R\&D Blueprint Scientific Advisory Group. The need for global R\&D coordination for infectious diseases with epidemic potential. Lancet. 2016;388:460-1. http://dx.doi.org/10.1016/ S0140-6736(16)31152-7

9. World Health Organization. A research and development blueprint for action to prevent epidemics [cited 2018 Nov 7]. http://www.who.int/blueprint/en

10. World Health Organization. Annual review of diseases prioritized under the research and development blueprint: informal consultation., 2017 [cited 2018 Nov 7]. http://www.who.int/ emergencies/diseases/2018prioritization-report.pdf

11. World Health Organization. List of blueprint priority diseases; 2018 [cited 2018 Nov 7]. http://www.who.int/blueprint/priority-diseases/en

12. Modjarrad K, Moorthy VS, Ben Embarek P, Van Kerkhove M, Kim J, Kieny MP. A roadmap for MERS-CoV research and product development: report from a World Health Organization consultation. Nat Med. 2016;22:701-5. http://dx.doi.org/10.1038/nm.4131

13. Plotkin SA. Vaccines for epidemic infections and the role of CEPI. Hum Vaccin Immunother. 2017;13:2755-62. http://dx.doi.org/10.1 080/21645515.2017.1306615

14. World Health Organization. WHO collaborative study to assess the suitability of an interim standard for antibodies to Ebola virus, 2015 [cited 2018 Nov 7]. http://apps.who.int/iris/handle/10665/197777

15. Wilkinson DE, Hassall M, Mattiuzzo G, Stone L, Atkinson E, Hockley J, et al. WHO collaborative study to assess the suitability of the first international standard and the first international reference panel for antibodies to Ebola virus, 2017 [cited 2018 Nov 7]. http://www.who.int/biologicals/expert_committee/ BS2316_Anti-EBOV_Antibodies_WHO_1st_IS_and_WHO_1st_ International_Ref_Panel.pdf

16. Li C, Xu K, Hashem A, Shao M, Liu S, Zou Y, et al. Collaborative studies on the development of national reference standards for potency determination of H7N9 influenza vaccine. Hum Vaccin Immunother. 2015;11:1351-6. http://dx.doi.org/10.1080/21645515 .2015.1032490

17. Perkins MD, Dye C, Balasegaram M, Bréchot C, Mombouli JV, Røttingen JA, et al. Diagnostic preparedness for infectious disease outbreaks. Lancet. 2017;390:2211-4. http://dx.doi.org/10.1016/ S0140-6736(17)31224-2

18. World Health Organization. International reference materials [cited 2018 Nov 7]. http://www.who.int/bloodproducts/ref_materials/en

19. Chan JF, Sridhar S, Yip CC, Lau SK, Woo PC. The role of laboratory diagnostics in emerging viral infections: the example of the Middle East respiratory syndrome epidemic. J Microbiol. 2017;55:172-82. http://dx.doi.org/10.1007/s12275-017-7026-y

20. Shorten RJ, Brown CS, Jacobs M, Rattenbury S, Simpson AJ, Mepham S. Diagnostics in Ebola virus disease in resource-rich and resource-limited settings. PLoS Negl Trop Dis. 2016;10:e004948. http://dx.doi.org/10.1371/journal.pntd.0004948

21. Waggoner JJ, Pinsky BA. Zika virus: diagnostics for an emerging pandemic threat. J Clin Microbiol. 2016;54:860-7. http://dx.doi.org/ 10.1128/JCM.00279-16

22. Venkatraman N, Silman D, Folegatti PM, Hill AVS. Vaccines against Ebola virus. Vaccine. 2017.

23. Henao-Restrepo AM, Camacho A, Longini IM, Watson $\mathrm{CH}$, Edmunds WJ, Egger M, et al. Efficacy and effectiveness of an rVSV-vectored vaccine in preventing Ebola virus disease: final results from the Guinea ring vaccination, open-label, clusterrandomised trial (Ebola ça suffit!). Lancet. 2017;389:505-18. http://dx.doi.org/10.1016/S0140-6736(16)32621-6

24. Ewer K, Rampling T, Venkatraman N, Bowyer G, Wright D, Lambe T, et al. A monovalent chimpanzee adenovirus Ebola vaccine boosted with MVA. N Engl J Med. 2016;374:1635-46. http://dx.doi.org/10.1056/NEJMoa1411627

25. Tapia MD, Sow SO, Lyke KE, Haidara FC, Diallo F, Doumbia M, et al. Use of ChAd3-EBO-Z Ebola virus vaccine in Malian and US adults, and boosting of Malian adults with MVA-BN-Filo: a phase 1 , single-blind, randomised trial, a phase 1 b, open-label and double-blind, dose-escalation trial, and a nested, randomised, double-blind, placebo-controlled trial. Lancet Infect Dis. 2015.

26. Milligan ID, Gibani MM, Sewell R, Clutterbuck EA, Campbell D, Plested E, et al. Safety and immunogenicity of novel adenovirus type 26- and modified vaccinia Ankara-vectored Ebola vaccines: a randomized clinical trial. JAMA. 2016;315:1610-23. http://dx.doi.org/10.1001/jama.2016.4218 
27. Regules JA, Beigel JH, Paolino KM, Voell J, Castellano AR, Hu Z, et al.; rVSV $\triangle$ G-ZEBOV-GP Study Group. A recombinant vesicular stomatitis virus Ebola vaccine. N Engl J Med. 2017;376:330-41. http://dx.doi.org/10.1056/NEJMoa1414216

28. Zhu FC, Wurie AH, Hou LH, Liang Q, Li YH, Russell JB, et al. Safety and immunogenicity of a recombinant adenovirus type-5 vector-based Ebola vaccine in healthy adults in Sierra Leone: a single-centre, randomised, double-blind, placebo-controlled, phase 2 trial. Lancet. 2017;389:621-8. http://dx.doi.org/10.1016/ S0140-6736(16)32617-4

29. Moekotte AL, Huson MA, van der Ende AJ, Agnandji ST, Huizenga E, Goorhuis A, et al. Monoclonal antibodies for the treatment of Ebola virus disease. Expert Opin Investig Drugs. 2016; 25:1325-35. http://dx.doi.org/10.1080/13543784.2016.1240785

30. van Griensven J, Edwards T, de Lamballerie X, Semple MG, Gallian P, Baize S, et al.; Ebola-Tx Consortium. Evaluation of convalescent plasma for Ebola virus disease in Guinea. N Engl J Med. 2016;374:33-42. http://dx.doi.org/10.1056/NEJMoa1511812

31. Davey RT Jr, Dodd L, Proschan MA, Neaton J, Neuhaus Nordwall J, Koopmeiners JS, et al.; Multi-National PREVAIL II Study Team. A randomized, controlled trial of ZMapp for Ebola virus infection. N Engl J Med. 2016;375:1448-56. http://dx.doi.org/10.1056/ NEJMoa1604330

32. Munjal A, Khandia R, Dhama K, Sachan S, Karthik K, Tiwari R, et al. Advances in developing therapies to combat Zika virus: current knowledge and future perspectives. Front Microbiol. 2017;8:1469. http://dx.doi.org/10.3389/fmicb.2017.01469

33. Arabi YM, Hajeer AH, Luke T, Raviprakash K, Balkhy H, Johani S, et al. Feasibility of using convalescent plasma immunotherapy for MERS-CoV infection, Saudi Arabia. Emerg Infect Dis. 2016;22:1554-61. http://dx.doi.org/10.3201/eid2209.151164

34. Mustafa S, Balkhy H, Gabere MN. Current treatment options and the role of peptides as potential therapeutic components for Middle East Respiratory Syndrome (MERS): a review. J Infect Public Health. 2017.

35. Felder E, Wölfel R. Development of a versatile and stable internal control system for RT-qPCR assays. J Virol Methods. 2014; 208:33-40. http://dx.doi.org/10.1016/j.jviromet.2014.07.028

36. Mattiuzzo G, Ashall J, Doris KS, MacLellan-Gibson K, Nicolson C, Wilkinson DE, et al. Development of lentivirus-based reference materials for Ebola virus nucleic acid amplification technologybased assays. PLoS One. 2015;10:e0142751. http://dx.doi.org/ 10.1371/journal.pone.0142751

37. Pasloske BL, Walkerpeach CR, Obermoeller RD, Winkler M, DuBois DB. Armored RNA technology for production of ribonuclease-resistant viral RNA controls and standards. J Clin Microbiol. 1998;36:3590-4.

38. Wilkinson DE, Page M, Mattiuzzo G, Hassall M, Dougall T, Rigsby P, et al. Comparison of platform technologies for assaying antibody to Ebola virus. Vaccine. 2017;35:1347-52. http://dx.doi.org/10.1016/j.vaccine.2016.11.083

39. Dye JM, Wu H, Hooper JW, Khurana S, Kuehne AI, Coyle EM, et al. Production of potent fully human polyclonal antibodies against Ebola Zaire virus in transchromosomal cattle. Sci Rep. 2016;6:24897. http://dx.doi.org/10.1038/srep24897

40. Gostin LO, Tomori O, Wibulpolprasert S, Jha AK, Frenk J, Moon S, et al. Toward a common secure future: four global commissions in the wake of Ebola. PLoS Med. 2016;13:e1002042. http://dx.doi.org/10.1371/journal.pmed.1002042

41. Fidler DP, Gostin LO. The WHO pandemic influenza preparedness framework: a milestone in global governance for health. JAMA. 2011;306:200-1. http://dx.doi.org/10.1001/jama.2011.960

42. Fidler DP. Negotiating equitable access to influenza vaccines: global health diplomacy and the controversies surrounding avian influenza H5N1 and pandemic influenza H1N1. PLoS Med. 2010;7:e1000247. http://dx.doi.org/10.1371/journal.pmed.1000247

43. Haug CJ, Kieny MP, Murgue B. The Zika challenge. N Engl J Med. 2016;374:1801-3. http://dx.doi.org/10.1056/NEJMp1603734

44. Cheng M, Satter R, Goodman J. Health officials want more Zika samples, data from Brazil. The Associated Press, 2016 [cited 2018 Nov 7]. https://www.businessinsider.com/ap-health-officials-wantmore-zika-samples-data-from-brazil-2016-2

45. Diversity SOTCOB. Nagoya protocol on access to genetic resources and the fair and equitable sharing of benefits arising from their utilization to the convention on biological diversity [cited 2018 Nov 7]. https://www.cbd.int/abs/doc/protocol/ nagoya-protocol-en.pdf

46. Council of Europe. Convention for the protection of human rights and dignity of the human bing with regard to the application of biology and medicine: convention on human rights and biomedicine. Treaty no. 1641997 [cited 2018 Nov 7]. https://rm.coe.int/168007cf98

47. Final report to the European Commission on the project Basic Ethical Principles in Bioethics and Biolaw, 1995-1998 Part B 1999 [cited 2018 Nov 7]. http://cometc.unibuc.ro/reglementari/ Basic-Ethical-Principles.pdf

48. Wurtz N, Grobusch MP, Raoult D. Negative impact of laws regarding biosecurity and bioterrorism on real diseases. Clin Microbiol Infect. 2014;20:507-15. http://dx.doi.org/10.1111/ 1469-0691.12709

49. Nisii C, Castilletti C, Raoul H, Hewson R, Brown D, Gopal R, et al. Biosafety level-4 laboratories in Europe: opportunities for public health, diagnostics, and research. PLoS Pathog. 2013;9:e1003105. http://dx.doi.org/10.1371/journal.ppat.1003105

50. Reusken CB, Mögling R, Smit PW, Grunow R, Ippolito G, Di Caro A, et al. Status, quality and specific needs of Ebola virus diagnostic capacity and capability in laboratories of the two European preparedness laboratory networks EMERGE and EVD-LabNet. Euro Surveill. 2018;23:23. http://dx.doi.org/10.2807/ 1560-7917.ES.2018.23.19.17-00404

Address for correspondence: Tommy Rampling, Hospital for Tropical Diseases, University College London Hospital, Mortimer Market Centre, Mortimer Market, Capper St, Fitzrovia, London WC1E 6JB, UK; email: t.rampling@ucl.ac.uk 


\title{
Atypical Cowpox Virus I nfection in Smallpox-Vaccinated Patient, France
}

\author{
Julien Andreani, ${ }^{1}$ Jean-Philippe Arnault, ${ }^{1}$ Jacques Y. Bou Khalil, Jônatas Abrahão, \\ Enora Tomei, Emeline Vial, Marion Le Bideau, Didier Raoult, Bernard La Scola
}

\begin{abstract}
We report a case of atypical cowpox virus infection in France in 2016. The patient sought care for thoracic lesions after injury from the sharp end of a metallic guardrail previously stored in the ground. We isolated a cowpox virus from the lesions and sequenced its whole genome. The patient reported that he had been previously vaccinated against smallpox. We describe an alternative route of cowpox virus infection and raise questions about the immunological status of smallpoxvaccinated patients for circulating orthopoxviruses.
\end{abstract}

The genus Orthopoxvirus (family Poxviridae) is com1 posed of 10 recognized viral species that infect vertebrates and cause serologic cross-reactions. Among the orthopoxviruses, variola virus, which causes smallpox in humans, was associated with the death of millions of persons. An extensive vaccination campaign promoted by the World Health Organization and using multiple vaccinia virus variants (1) during the 1960s and 1970s led to a declaration that smallpox was eradicated in 1980 , and vaccination ceased. Most persons born after 1980 have not received smallpox vaccination, and so there is a reduced level of population-based immunity. Coincidentally or not, some zoonotic orthopoxvirus species are re-emerging in an increasing and alarming number of cases worldwide, including vaccinia virus in Brazil and India (2), monkeypox virus in Africa $(3,4)$, cowpox virus in Europe and Asia (5), and novel orthopoxvirus-related strains in the United States (in Alaska and Georgia) (6-8).

Cowpox virus infection in humans causes local cutaneous pustular affections, which may in some cases disseminate and become fatal in immunocompromised patients

Author affiliations: Institut Hospitalo-Universitaire Méditerranée Infection, Marseille (J. Andreani, J.Y. Bou Khalil, E. Tomei, E. Vial, M. Le Bideau, D. Raoult, B. La Scola); Aix-Marseille Université, Marseille, France (J. Andreani, J.Y. Bou Khalil, D. Raoult,

B. La Scola); Centre Hospitalier Universitaire Amiens-Picardie, Amiens, France (J.-P. Arnault); Universidade Federal de Minas Gerais, Belo Horizonte, Brazil (J. Abrahão)
$(9,10)$. Recent studies showed that cowpox virus is a unique name given to different strains with numerous misnomers (11-13). Rodents seem to be the main reservoirs of cowpox virus (14). Description of cowpox virus infections in cows has been rare in the last years (15). Because cowpox virus can infect a broad range of hosts, viral infections have been reported in cats, monkeys, elephants, llamas, and other vertebrates at zoos in Europe $(16,17)$. Since the 2000s, cowpox virus infections in humans have been frequently associated with direct contact between patients and rodents (18-21), causing lesions mainly on the hands, arms, face, and neck. Human infection can also occur through intermediate hosts, notably by domestic cats, which are commonly infected with cowpox virus through contact with rodents (22). Although infection by fomites is not frequently described for cowpox virus, it is a well-described route of infection for other orthopoxviruses, such as vaccinia virus in Brazil (23).

We report an atypical cowpox virus human infection in France in 2016, in which the patient had a pustular lesion on the laterothoracic area, but reported no direct contact with infected domestic or wild animals. We present our analysis of this novel viral strain, cowpox virus France Amiens 2016, describe its complete genome, review some morphological aspects of its infectious cycle, and discuss the probable way of transmission.

\section{Materials and Methods}

\section{Clinical Examination and Disease Course}

A 45-year-old man, an electrician, had a work accident and was injured by the sharp end of a metallic building site's guardrail, which was stored in the ground. The lesion was superficial; it affected the derma with little bleeding and did not reach the hypoderma tissue. The laterothoracic wound did not heal and turned into a black eschar with painful cellulitis spreading to the front and upward on the laterothoracic area slowly over 4 weeks (Figure 1, panel A). Multiple treatments were administered by the

${ }^{1}$ These first authors contributed equally to this article. 


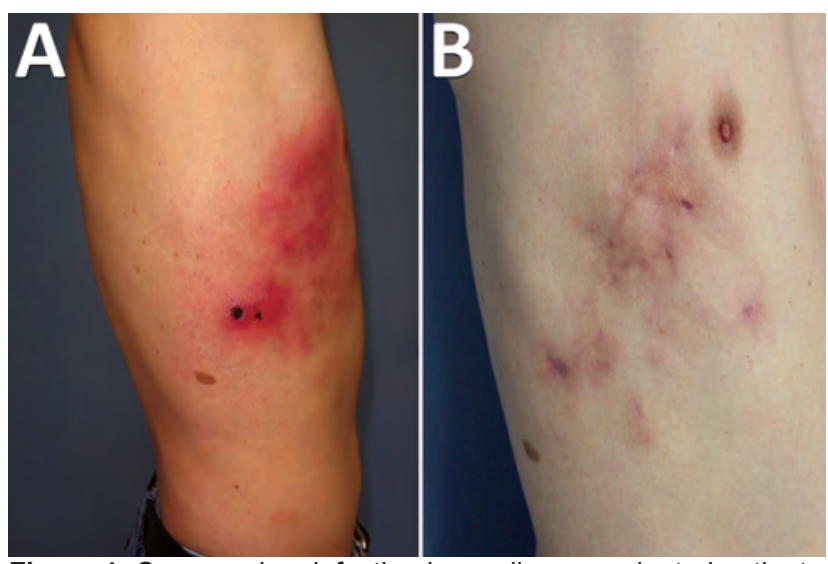

Figure 1. Cowpox virus infection in smallpox-vaccinated patient in France, 2016. A) Profile appearance of the patient's torso 1 month after the initial trauma. B) Appearance 9 months after the initial trauma.

patient's general physician with no effect on the course of the disease: amoxicillin ( $1 \mathrm{~g} 2 \times / \mathrm{d})$, valaciclovir $(1 \mathrm{~g}$ $3 \times / \mathrm{d})$, pristinamycin $(1 \mathrm{~g} 2 \times / \mathrm{d})$, ceftriaxone $(1 \mathrm{~g} 4 \times / \mathrm{d})$, and doxycycline (100 $\mathrm{mg} 2 \times / \mathrm{d})$.

After 4 weeks, the patient sought further care at Centre Hospitalier Universitaire (CHU) Amiens-Picardie in Amiens, France. He was apyretic, with good general condition and normal vital signs. The whole cellulitis was painful, associated with multiple subcutaneous abscesses and axillary adenopathies. Relevant biologic exams showed increased lymphocyte count $(46 \%, 3.6 \mathrm{G} / \mathrm{L})$; mild hepatitis (aspartate aminotransferase 1.5× the upper limit of normal [ULN], alanine-aminotransferase $1.5 \times$ ULN, $\gamma$-glutamyl transferase $1.5 \times \mathrm{ULN})$; and C-reactive protein $(22 \mathrm{mg} / \mathrm{L})$. Electrolytes, prothrombin ratio, partial thromboplastin time, hemoglobin, platelet count, creatinine, procalcitonin, and fibrinogen were normal. Skin biopsy showed a predominantly eosinophilic and neutrophilic necrotizing dermohypodermitis, with intravascular thrombi without vasculitis. Moreover, periodic acid-Schiff (PAS) and Grocott staining showed no pathogens.

At this time, a disease by inoculation was suspected. Results of routine skin biopsy cultures for fungi, bacteria, and mycobacteria were negative, as were intracellular cultures performed on the scar biopsy for Rickettsia spp. Results of molecular detection of herpesviruses, herpes virus $1 / 2$, and varicella zoster virus were negative, as were Bartonella henselae and Franciscela tularensis serologic test results.

The apex of the disease occurred 8 weeks after the initial trauma. Cellulitis grew through the hemithoracic region with purulent discharge from open wounds because of severe delayed healing. The pain required morphine. No wound debridement was needed. Pain spontaneously ceased 4 months after the initial trauma, and the patient was declared healed after 9 months (Figure 1, panel B).

\section{Virus Detection, Isolation, and Production}

Similar to the process Ninove et al. described in 2009 (18), a sample was sent to the Institut Hospitalo-Universitaire Méditerranée Infection, Marseille, France, diagnostic laboratory to explore intracellular microorganisms, especially Rickettsia spp. (intracellular bacteria), suspected by the presence of eschar. Nevertheless, we performed other PCR diagnostics at Centre Hospitalier Universitaire AmiensPicardie. We performed biochemical, hematologic, and serologic examinations using Siemens analyzers (Siemens, http://www.healthcare.siemens.com). We used kits and reagents to detect Bartonella spp., Bartonella henselae, and Bartonella quintana (Eurobio indirect immunofluorescence assay, http://www.eurobio.fr) and the Virion ELISA classic kit (Serion Diagnostics, https://www.serion-diagnostics. de) to detect Francisella tularensis.

At Institut Hospitalo-Universitaire Méditerranée Infection, we performed PCR assays on the cutaneous biopsy taken from the pustular area when the sample was received. To detect orthopoxvirus, we used the primers F-5'-TGATGCAACTCTATCATGTARTCG, R-5'CAAGACGTCGCTTTTRGCAG, and 6FAM- TGCTTGGTATAAGGAGCCCAATTCCA, targeting the hemagglutinin gene. We conducted real-time PCR for varicella zoster virus and herpesvirus using the ARGENE kit (bioMérieux, http:// www.biomerieux-diagnostics.com). We ran PCR for DNA of the 16S RNA gene in parallel, adding to the specific PCR targeting Bartonella spp., Francisella tularensis, and Rickettsia spp. using primers previously reported $(24,25)$.

For culture, we macerated the biopsy sample in Potter-Elvehjem PTFE tissue grinder (Dominique Dutscher Company, http://www.dutscher.com) and resuspended it in Hanks' solution (Thermo Fisher Scientific, http://www. thermofisher.com). Afterward, we inoculated $200 \mu \mathrm{L}$ of the sample containing $1 \mathrm{~mL}$ of Vero (ATCC CCL-81) African green monkey kidney cells at $10^{6}$ cells $/ \mathrm{mL}$ onto each of 2 shell vials using $7 \mathrm{~mL}$ TRAC bottle (Thermo Fisher Scientific). We placed one at $32^{\circ} \mathrm{C}$ and the other at $37^{\circ} \mathrm{C}$ under $5 \% \mathrm{CO}_{2}$ atmosphere and observed the vials daily under an inverted microscope to detect any potential cytopathic effect.

For virus production, we prepared 15 flasks of Vero cells in minimum essential medium (MEM) (Thermo Fisher Scientific) with $5 \%$ of fetal bovine serum and $1 \%$ of glutamine. After the cells reached $80 \%$ confluence, we removed the medium and inoculated the monolayer with 5 $\mathrm{mL}$ of viral suspension with a multiplicity of infection of 0.01 . We incubated the flasks at $37^{\circ} \mathrm{C}$ for 1 hour for adsorption, then added $20 \mathrm{~mL}$ of modified MEM to the flasks and incubated them for 3 days. On the third day, we discarded the supernatant, then washed the cell monolayer 3 times with phosphate buffered saline and removed it using a scraper. After all the flasks were scraped and washed twice 


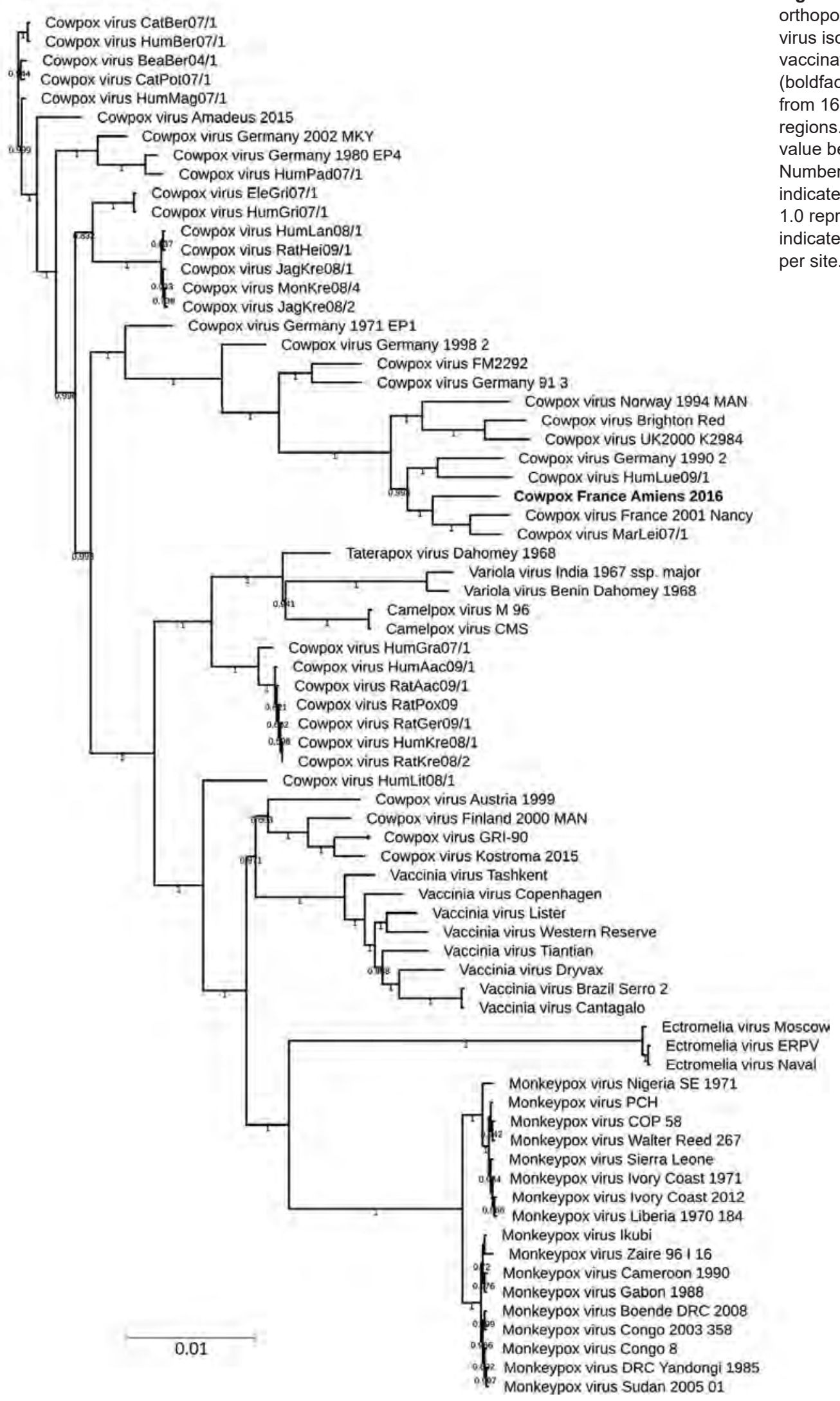

Figure 2. Phylogenetic tree of 73 orthopoxviruses, including cowpox virus isolate obtained from smallpoxaccinated patient in France, 2016 oldface). The tree includes data 162,829 positions on central below 0.5 were deleted. ers shown on branches e.g represents $100 \%)$. Scale bar r site. 
to collect the cells, we transferred the contents to $50-\mathrm{mL}$ falcon tubes that were kept on ice.

We then centrifuged the cells at $1,500 \mathrm{rpm}$ for 10 min, discarded the supernatant, and resuspended the pellet in $10 \mathrm{~mL}$ of a sterile lysis buffer $\left(\mathrm{MgCl}_{2} 1 \mathrm{mmol} / \mathrm{L}\right.$, Tris $10 \mathrm{mmol} / \mathrm{L}, \mathrm{pH} 7.0 \mathrm{KCl} 10 \mathrm{mmol} / \mathrm{L}$ ). We incubated the suspension for $10 \mathrm{~min}$ on ice. We performed mechanical lysis using a sterile tissue grinder (Dominique Dutscher Company, https://www.dutscher.com) (80 cycles on ice). We added $10 \mathrm{~mL}$ of $36 \%$ sucrose to a plastic centrifugation tube and transferred the viral mixture slowly, avoiding mixing with the sucrose solution (biphasic final solution). We centrifuged the tube at $14,000 \mathrm{rpm}$ for $1 \mathrm{~h}$ at $4^{\circ} \mathrm{C}$, collected the pellet, and stored it at $-80^{\circ} \mathrm{C}$ in small aliquots.

\section{Micrograph Embedding and Cell Preparation for the Replicative Cycle}

Hep2 cells (ATCC accession no. CCL-23) were maintained in culture with MEM modified with $10 \%$ of fetal bovine serum. The virus inoculated the Hep2 cell monolayer at a multiplicity of infection of 0.01 . We then collected the content after scraping the flask at $32 \mathrm{~h}$ postinfection. We followed the same protocol of cell embedding as described by Bou Khalil et al. (26), except that we replaced the Epon resin with LR white resin (Agar Scientific, http://www. agarscientific.com). In brief, we fixed cells for $1 \mathrm{~h}$ with $2.5 \%$ glutaraldehyde in a $0.1 \mathrm{mmol} / \mathrm{L}$ sodium cacodylate buffer and washed them with a mixture of $0.2 \mathrm{mmol} / \mathrm{L} \mathrm{sac}-$ charose and $0.1 \mathrm{mmol} / \mathrm{L}$ sodium cacodylate. Postfix was for $1 \mathrm{~h}$ with $1 \% \mathrm{OsO} 4$ diluted in $0.2 \mathrm{mmol} / \mathrm{L}$ potassium hexa-cyanoferrate (III) and $0.1 \mathrm{mmol} / \mathrm{L}$ sodium cacodylate solution. After washing with distilled water, we gradually dehydrated the cells with ethanol, and then gradually replaced the ethanol with LR white resin. We performed polymerization for $24 \mathrm{~h}$ at $60^{\circ} \mathrm{C}$. We used a UC7 ultramicrotome (Leica) to obtain ultrathin 70-nm sections and placed them onto HR25 300 mesh copper/rhodium grids (TAAB Laboratories Equipment Ltd., http://www.taab.co.uk). We colored sections with Reynolds solution and obtained electron micrographs on a Tecnai G2 TEM (FEI, http://www. fei.com) operated at $200 \mathrm{keV}$. We used ImageJ software (https://imagej.nih.gov/ij) to determine particle size.

\section{Genome Sequencing and Assembling}

We sequenced genomic cowpox virus DNA (DNAg) on MiSeq technology (Illumina Inc., http://www.illumina. com) with the paired end strategy and barcoded samples to be mixed with 18 other genomic projects prepared with the Nextera XT DNA sample prep kit (Illumina). We quantified the DNAg by high-sensitivity Qubit assay (Life Technologies, http://www.thermofisher.com) to $0.5 \mathrm{ng} / \mu \mathrm{L}$ and performed dilution requiring $1 \mathrm{ng}$ of each genome as input to prepare the paired end library. The tagmentation step fragmented and tagged the DNA. Twelve cycles of limitedcycle PCR amplification completed the tag adapters and introduced dual-index barcodes. After purification on AMPure XP beads (Beckman Coulter Inc., http://www.beckman.com), we normalized the libraries on specific beads in accordance with the Nextera XT protocol (Illumina). We pooled normalized libraries into a single library for sequencing on the MiSeq, then loaded the pooled singlestrand library onto the reagent cartridge and then onto the instrument, along with the flow cell. We performed automated cluster generation and paired-end sequencing with dual index reads in a single 39-hour run in $2 \times 250$-bp.

We obtained total information of $4.3 \mathrm{~Gb}$ from a cluster density of $343,000 / \mathrm{mm}^{2}$ with a cluster passing quality control filters of $97.8 \%$ (8,331,000 clusters). Within this run, we determined the index representation for cowpox virus to be $9.74 \%$. We filtered the 811,395 paired-end reads according to the read qualities.

We assembled paired-end reads by using CLC genomics workbench version 7.5 (http://www.clcbio.com/) using 64-world size. The genome's extremities appeared incomplete in comparison to the reference strains. Mapping against cowpox virus France Nancy 2001 (GenBank accession no. HQ420894.1) as reference showed a missing part in the 2 ITRs. We completed the inverted terminal repeat (ITR) regions by PCR followed by sequencing using primers previously designed on primer-Blast (27).

\section{Gene Prediction and Analysis}

We computed gene prediction using Genemarks (28) and confirmed by Prodigal (29). We realized a blastp (https://blast. ncbi.nlm.nih.gov/Blast.cgi?PAGE=Proteins) of all predicted proteins against the nonredundant database. To determine average nucleotide value, we compared close phylogenetic strains using the ANI online calculator (http://www.ezbiocloud.net/tools/ani) based on the OrthoANI algorithm (30). Proteinortho (31) was used to determine best reciprocal hits using coverage of $80 \%$, identity $20 \%$, and an E-value cutoff established at 0.01 . The genome sequenced in this study is available on the EMBLD/EBI website (accession no. LT883663).

\section{Phylogenetic Analysis}

We computed alignments using MAFFT version 7 (32) with fast Fourier transform, a heuristic progressive method (FFT-NS2), on a 73-nt complete genome obtained from the Virus Pathogen Database and Analysis Resource (http:// www.viprbrc.org/brc/home.spg). Alignments were manually controlled on MEGA version 6.0 (33). We used the FastTree program (34) to construct a maximum-likelihood tree using standard parameters with the Jukes-Cantors method for the nucleotide distances calculation with 1,000 local resamples (Shimodaira-Hasegawa test). We visualized trees by using iTol (35). 


\section{Results}

\section{Isolation of the Cowpox Virus and Clinical Context}

All bacterial PCR were negative and excluded any DNA bacterial presence. However, specific orthopoxvirus PCR was positive. In parallel, the inoculation on Vero cell showed a typical cytopathic effect after 4 days at $32^{\circ} \mathrm{C}$ and $37^{\circ} \mathrm{C}$. Because cowpox is a notifiable disease, we reported the case to government authorities.

All vaccinations for the patient were up to date; he had received an injection against smallpox with vaccinia virus strain Lister when he was 1 year of age. Following governmental recommendations, no booster vaccination was given after the first injection. The patient did not report other chronic diseases, allergies, or addictions. He reported having a domestic cat at home who also lived outside. The patient's cat was examined by a veterinarian and showed no sign of cowpox infection during this period. The patient is sure he was not scratched by his cat before the work accident occurred.

\section{Cowpox Virus Strain Genomic Analysis}

We obtained a 219,385-bp genome with a GC content estimated at $33.6 \%$. The gene prediction established the number of open reading frames at 214 . Altogether, $212 / 214$ predicted proteins had results in the nonredundant database; most (191) best-hit results were obtained for cowpox virus from various previously described strains, 9 for vaccinia virus, 4 for variola virus, 3 for monkeypoxvirus, 2 for ectromelia virus, and 1 each for horsepox, camelpox, and taterapox. The 2 other genes were considered as ORFan (Open Reading Frames without detectable homologues in other lineages), located in the ITR regions. We decided to explore the phylogeny of this new isolate.

A central part of the orthopoxvirus genome is extremely conserved. Regarding the recent proposed classifying elements of cowpox virus $(12,13,36,37)$, we performed phylogenetic analysis on the available whole genome. We observed a subtype containing the novel strain, cowpox virus France Amiens 2016, along with the Nancy 2001 strain, the MarLei07/1, the HumLue09/1, and the Germany 1990 strains (Figure 2). Using the OrthoANI algorithm, we observed that France Amiens 2016 presented the highest similarity, 98.54\%, with the cowpox France Nancy 2001 virus (Appendix Table 1, https://wwwnc.cdc.gov/EID/ article/25/2/17-1433-App1.xlsx). Moreover, the amino acid comparison of the main functional proteins showed a clear difference between the reference cowpox virus Brighton

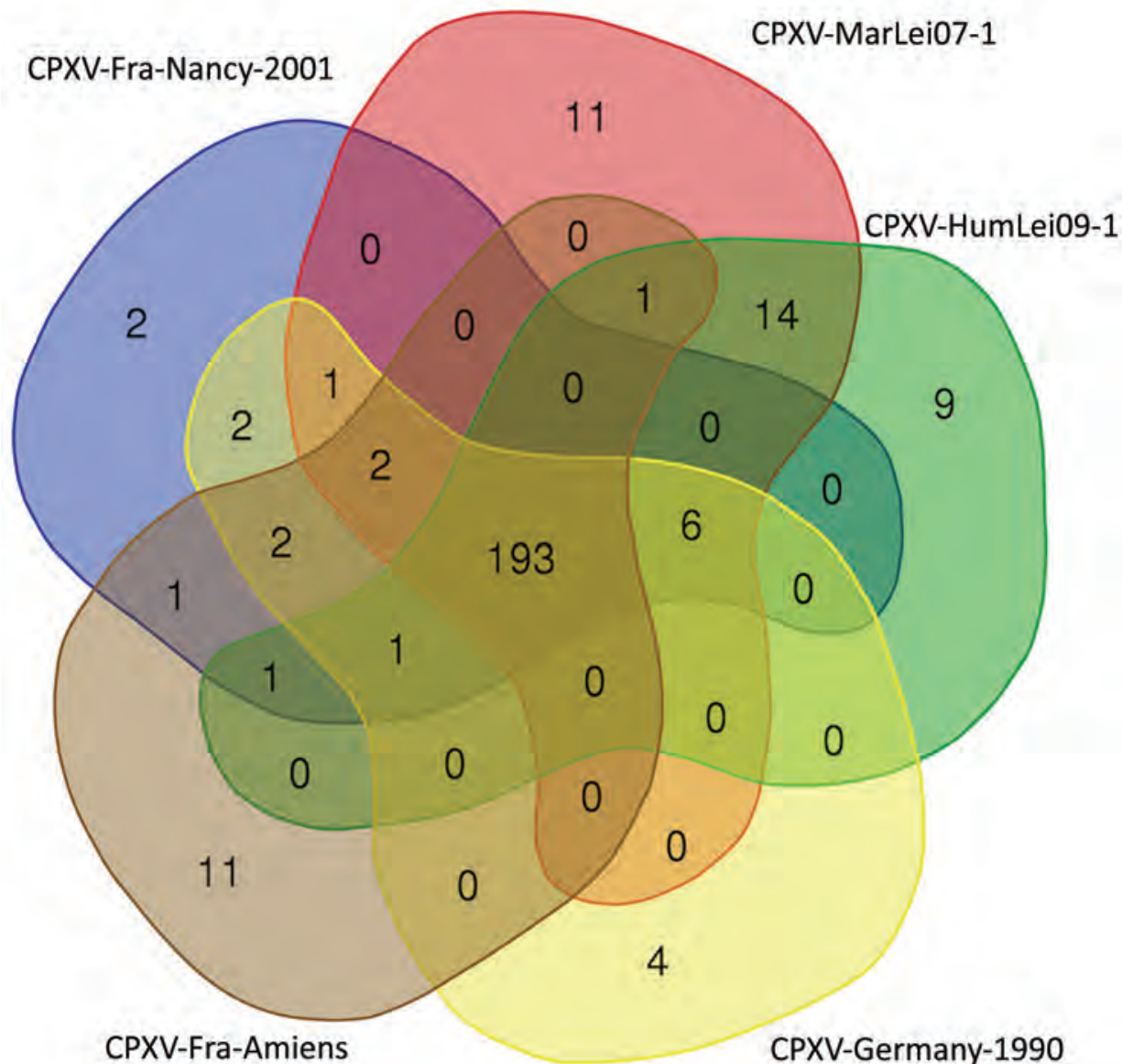

Figure 3. Venn diagram of reciprocal best hit obtained in the CPXV subclade $\mathrm{E} 3$, including the isolate obtained from a smallpoxvaccinated patient in France in 2016 (CPXV-Fra-Amiens). Diagram created by using the Bioinformatics \& Evolutionary Genomics visualization tool (http://bioinformatics.psb.ugent. be/webtools/Venn). CPXV, cowpox virus. 

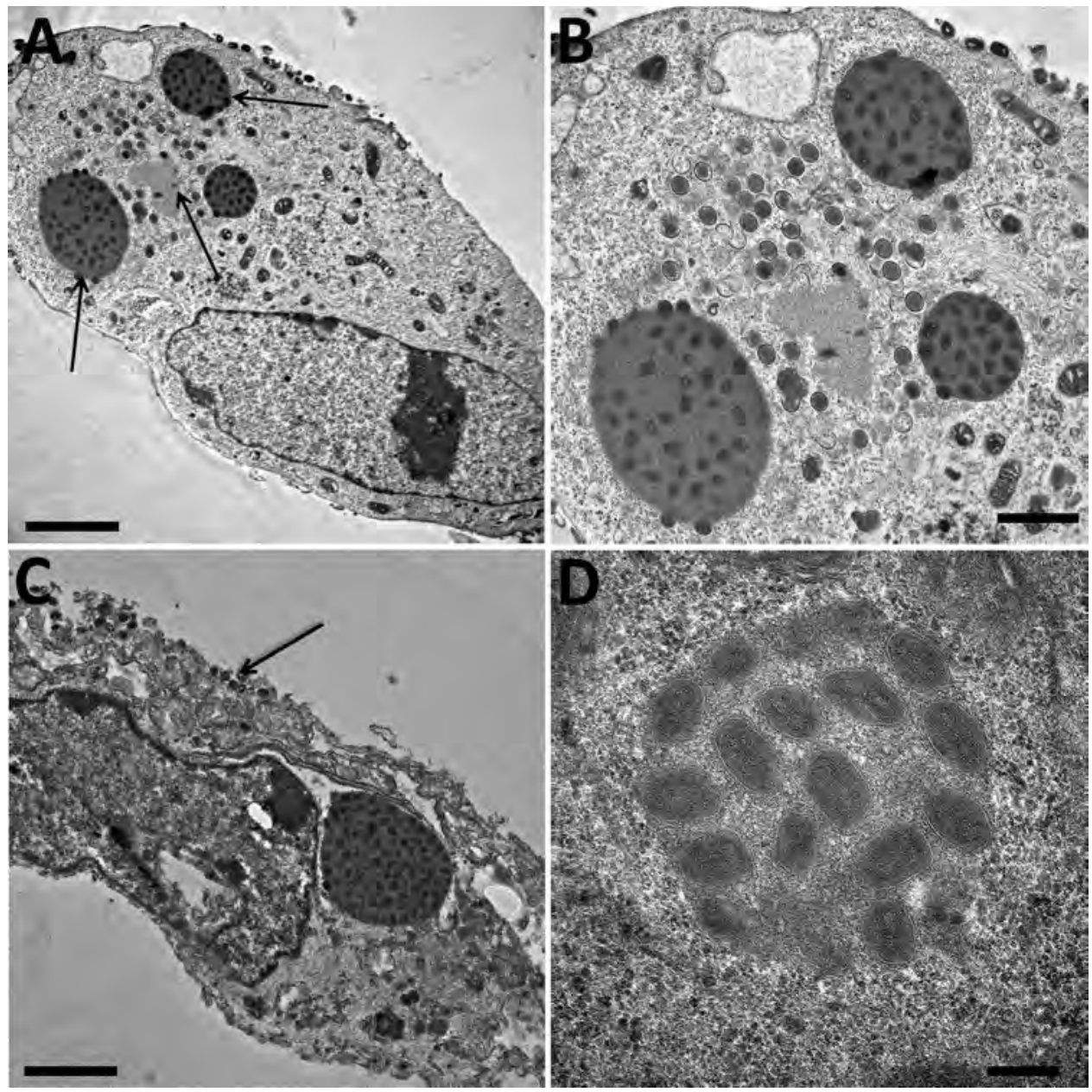

Figure 4. Electron microscopy imaging of cowpox virus France Amiens 2016, obtained from a smallpox-vaccinated patient in France in 2016. A) Ultrathin sections of a Hep2 cell at 32 hours postinfection. The cell harbors, which is undergoing its replicative cycle. Arrows indicate dense inclusion bodies as well as its viral factory containing viral crescents in the cell cytoplasm. Scale bar indicates $2 \mu \mathrm{m}$. B) Higher magnification of Hep2 cell in panel A; scale bar indicates $1 \mu \mathrm{m}$. C) Ultrathin sections of a Hep2 cell with a typical inclusion of cowpox virus detected near the nucleus. Arrow indicates extracellularenveloped viruses or cellassociated enveloped particles. Scale bar indicates $2 \mu \mathrm{m}$. D) Electron-dense inclusion body containing mature viral particles. Scale bars indicate $200 \mathrm{~nm}$. A color version of this figure is available online (http://wwwnc.cdc.gov/EID/ article/25/2/17-1433-F4.htm).

red strain and the other reported strains of the same cluster (Appendix Table 2). Taking all of these elements into consideration, we believe that cowpox virus France Amiens 2016 represents a new original strain clustering with the proposed E3 subclade in Europe (12).

Among the orthopoxvirus genus, the genomes' evolution seems to be driven by numerous deletions affecting the number of predicted proteins, which could lead to a reduction of the genome length (38). To investigate predicted proteins in this group, we defined the cluster of orthologous proteins by reciprocal best hit. Five genomes of the defined E3 clade shared 193 predicted proteins (Figure 3). For the other clusters, we detected only duplicate proteins and variations in the size of the proteins by modifications of the start codon or by the modification of the stop codon (data not shown).

To complete the description of this new isolate, we explored the morphological features in the viral replicative stage. Electron microscopy showed a typical A type inclusion (Figure 4) in the cytoplasm, classifying the cowpox France Amiens 2016 virus in the V+ subtype (39).

\section{Discussion}

The story of orthopoxviruses seems to be clear, but many clues are still missing and ambiguous, where the literature shows much divergent data regarding traced sources, reservoirs, and contamination routes and tools. We are aware that rats, mice, raccoons, and field and bank voles are all recognized as susceptible to cowpox virus, and some of these animals can be associated with human cowpox virus infections. Moreover, serologic evidence highlights wide cowpox virus distribution in rodents and in cats $(40,41)$. Bovids were considered a reservoir before the studies of Baxby $(14,42)$ hypothesized that infections in cows and humans occurred when contaminated brambles and barbed wire were in the proximity of the cattle, but no data confirmed this last assertion. Nevertheless, it is important to highlight that transmission of other orthopoxviruses by fomites is well documented, especially for vaccinia virus, which can be transmitted among cattle by milking devices, as in Brazil (43).

This transmission by fomites should be integrated into upcoming studies with the availability of improved tools, 
notably in molecular biology, cell culture, and genome sequencing. Nevertheless, the case we report highlights that cowpox virus infection can be misdiagnosed by an atypical clinical presentation, resembling varicella zoster lesions or even noninfectious related rashes. In addition, for this case, it was not possible to establish an epidemiologic link between the patient and the typical sources of infection. Because the tool that caused the wound was kept on the ground, it is possible that it had been contaminated by contact with rodent or cat urine or feces. As is the case in almost all reported infection cases where the diagnosis occurs months later, it becomes difficult to retrace and investigate the route, initial host, or reservoir at an early time of infection. Another scenario is contact between patient and cat after the patient injury, something that was not reported by the patient, but this second potential route of infection appeared doubtful when we examined the co-localization between the injury with the guardrail and the eschar.

Smallpox vaccination is known to confer cross-immunity against other orthopoxviruses $(44,45)$ with a high rate of success when the injection was done in preexposure conditions compared with postexposition. However, despite the patient's smallpox vaccination, novel infections by orthopoxvirus (46) could have occurred. This cowpox infection is the result of a nonprotective status for the patient; possible causes include an absence of cross-reaction between vaccinia strain and cowpox virus subclade E3 or too long a period between immunization and exposition (nearly 44 years). We have no access to serologic tests or other analyses that were performed before the infection that could be used to confirm one of these hypotheses over another.

Finally, this case is the third reported in Europe within a year $(10,47)$. As confirmed by genomic comparison in some geographic clusters, various strains seem to be circulating in wildlife in Europe, which is alarming because the diagnosis is always delayed when orthopoxvirus infection is not an initial suspect. In this context, the emergence and reemergence of diverse strains of orthopoxvirus must be seriously taken into consideration (48), as should the lack of investigation of potential outbreaks. Multiplying new genome sequences associated with exhaustive clinical reports seems to be an appropriate strategy $(12,49)$ to explore cowpox virus diversity and variants in Europe in general and France in particular.

\section{Acknowledgments}

We thank Claire Andréani for her help with the English correction.

This work was supported by the Government of France under the Investissements d'avenir (Investments for the Future) program managed by the Agence Nationale de la Recherche (ANR; National Agency for Research) (reference: Méditerranée Infection 10-IAHU-03).

\section{About the Author}

Dr. Andreani is a PharmD-PhD student in the INSERM program at Aix-Marseille University, Marseille, France. His research interests include virology, new isolates, and genomic characterization. Dr. Arnault is a physician at University Hospital, Amiens, France. His major clinical interest is the management of skin cancer including sonographic early diagnosis, surgery, and systemic treatment.

\section{References}

1. Qin L, Favis N, Famulski J, Evans DH. Evolution of and evolutionary relationships between extant vaccinia virus strains. J Virol. 2015;89:1809-24. https://doi.org/10.1128/JVI.02797-14

2. Abrahão JS, Campos RK, Trindade GS, Guimarães da Fonseca F, Ferreira PCP, Kroon EG. Outbreak of severe zoonotic vaccinia virus infection, Southeastern Brazil. Emerg Infect Dis. 2015;21:695-8. https://doi.org/10.3201/eid2104.140351

3. Rimoin AW, Mulembakani PM, Johnston SC, Lloyd Smith JO, Kisalu NK, Kinkela TL, et al. Major increase in human monkeypox incidence 30 years after smallpox vaccination campaigns cease in the Democratic Republic of Congo. Proc Natl Acad Sci USA. 2010;107:16262-7. http://dx.doi.org/10.1073/pnas.1005769107

4. Reynolds MG, Carroll DS, Karem KL. Factors affecting the likelihood of monkeypox's emergence and spread in the postsmallpox era. Curr Opin Virol. 2012;2:335-43. http://dx.doi.org/ 10.1016/j.coviro.2012.02.004

5. Vorou RM, Papavassiliou VG, Pierroutsakos IN. Cowpox virus infection: an emerging health threat. Curr Opin Infect Dis. 2008;21:153-6. http://dx.doi.org/10.1097/QCO.0b013e3282f44c74

6. Vora NM, Li Y, Geleishvili M, Emerson GL, Khmaladze E, Maghlakelidze G, et al. Human infection with a zoonotic orthopoxvirus in the country of Georgia. N Engl J Med. 2015; 372:1223-30.

7. Springer YP, Hsu CH, Werle ZR, Olson LE, Cooper MP, Castrodale LJ, et al. Novel orthopoxvirus infection in an Alaska resident. Clin Infect Dis. 2017;64:1737-41. http://dx.doi.org/ $10.1093 / \mathrm{cid} / \mathrm{cix} 219$

8. Gao J, Gigante C, Khmaladze E, Liu P, Tang S, Wilkins K, et al. Genome sequences of Akhmeta virus, an early divergent Old World orthopoxvirus. Viruses. 2018;10:252. https://doi.org/10.3390/ v10050252

9. Eis-Hübinger AM, Gerritzen A, Schneweis KE, Pfeiff B, Pullmann H, Mayr A, et al. Fatal cowpox-like virus infection transmitted by cat. Lancet. 1990;336:880. http://dx.doi.org/ 10.1016/0140-6736(90)92387-W

10. Gazzani P, Gach JE, Colmenero I, Martin J, Morton H, Brown K, et al. Fatal disseminated cowpox virus infection in an adolescent renal transplant recipient. Pediatr Nephrol. 2017;32:533-6. http://dx.doi.org/10.1007/s00467-016-3534-y

11. Carroll DS, Emerson GL, Li Y, Sammons S, Olson V, Frace M, et al. Chasing Jenner's vaccine: revisiting cowpox virus classification. PLoS One. 2011;6:e23086. https://doi.org/10.1371/ journal.pone.0023086

12. Mauldin MR, Antwerpen M, Emerson GL, Li Y, Zoeller G, Carroll DS, et al. Cowpox virus: what's in a name? Viruses. 2017; 9:101. https://doi.org/10.3390/v9050101

13. Franke A, Pfaff F, Jenckel M, Hoffmann B, Höper D, Antwerpen M, et al. Classification of cowpox viruses into several distinct clades and identification of a novel lineage. Viruses. 2017;9:142. http://dx.doi.org/10.3390/v9060142

14. Baxby D. Is cowpox misnamed? A review of 10 human cases. Br Med J. 1977;1:1379-81. http://dx.doi.org/10.1136/ bmj.1.6073.1379 
15. Meyer H, Schay C, Mahnel H, Pfeffer M. Characterization of orthopoxviruses isolated from man and animals in Germany. Arch Virol. 1999;144:491-501. http://dx.doi.org/10.1007/ s007050050520

16. Baxby D, Shackleton WB, Wheeler J, Turner A. Comparison of cowpox-like viruses isolated from European zoos. Arch Virol. 1979;61:337-40. http://dx.doi.org/10.1007/BF01315021

17. Baxby D, Ashton DG, Jones DM, Thomsett LR. An outbreak of cowpox in captive cheetahs: virological and epidemiological studies. J Hyg (Lond). 1982;89:365-72.

18. Ninove L, Domart Y, Vervel C, Voinot C, Salez N, Raoult D, et al. Cowpox virus transmission from pet rats to humans, France. Emerg Infect Dis. 2009;15:781-4. http://dx.doi.org/10.3201/ eid1505.090235

19. Campe H, Zimmermann P, Glos K, Bayer M, Bergemann H, Dreweck C, et al. Cowpox virus transmission from pet rats to humans, Germany. Emerg Infect Dis. 2009;15:777-80. http://dx.doi.org/10.3201/eid1505.090159

20. Vogel S, Sárdy M, Glos K, Korting HC, Ruzicka T, Wollenberg A. The Munich outbreak of cutaneous cowpox infection: transmission by infected pet rats. Acta Derm Venereol. 2012;92:126-31. http://dx.doi.org/10.2340/00015555-1227

21. Ducournau C, Ferrier-Rembert A, Ferraris O, Joffre A, Favier A-L, Flusin $\mathrm{O}$, et al. Concomitant human infections with 2 cowpox virus strains in related cases, France, 2011. Emerg Infect Dis. 2013;19:1996-9. http://dx.doi.org/10.3201/eid1912.130256

22. Żaba R, Jałowska M, Kowalczyk MJ, Bowszyc-Dmochowska M, Adamski Z, Szkaradkiewicz A. Cowpox virus infection in a child after contact with a domestic cat: a case report. New Microbiol. 2017;40:148-50.

23. Wood JP, Choi YW, Wendling MQ, Rogers JV, Chappie DJ. Environmental persistence of vaccinia virus on materials. Lett Appl Microbiol. 2013;57:399-404.

24. Angelakis E, Roux V, Raoult D, Rolain JM. Real-time PCR strategy and detection of bacterial agents of lymphadenitis. European Journal of Clinical Microbiology. 2009;28:1363-8.

25. Sokhna C, Mediannikov O, Fenollar F, Bassene H, Diatta G, Tall A, et al. Point-of-care laboratory of pathogen diagnosis in rural Senegal. PLOS Neglected Tropical Diseases. 2013;7:e1999. http://dx.doi.org/10.1371/journal.pntd.0001999

26. Bou Khalil JY, Benamar S, Di Pinto F, Blanc-Tailleur C, Raoult D, La Scola B. Protochlamydia phocaeensis sp. nov., a new Chlamydiales species with host dependent replication cycle. Microbes Infect. 2017;19:343-50. https://doi.org/10.1016/ j.micinf.2017.02.003

27. Ye J, Coulouris G, Zaretskaya I, Cutcutache I, Rozen S, Madden TL. Primer-BLAST: A tool to design target-specific primers for polymerase chain reaction. BMC Bioinformatics. 2012;13:134. https://doi.org/10.1186/1471-2105-13-134.

28. Besemer J, Lomsadze A, Borodovsky M. GeneMarkS: a self-training method for prediction of gene starts in microbial genomes. Implications for finding sequence motifs in regulatory regions. Nucl Acids Res. 2001;29:2607-18. https://doi.org/10.1093/ nar/29.12.2607

29. Hyatt D, Chen G-L, LoCascio PF, Land ML, Larimer FW, Hauser LJ. Prodigal: prokaryotic gene recognition and translation initiation site identification. BMC Bioinformatics. 2010;11:119.

30. Lee I, Ouk Kim Y, Park S-C, Chun J. OrthoANI: An improved algorithm and software for calculating average nucleotide identity. Int J Syst and Evol Microbiol. 2016;66:1100-3. https://doi.org/ 10.1099/ijsem.0.000760

31. Lechner M, Findeiß S, Steiner L, Marz M, Stadler PF, Prohaska SJ. Proteinortho: detection of (co-)orthologs in large-scale analysis. BMC Bioinformatics. 2011;12:124. https://doi.org/10.1186/ 1471-2105-12-124
32. Katoh K, Misawa K, Kuma K-I, Miyata T. MAFFT: a novel method for rapid multiple sequence alignment based on fast Fourier transform. Nucl Acids Res. 2002. 30:3059-66.

33. Tamura K, Stecher G, Peterson D, Filipski A, Kumar S. MEGA6: Molecular Evolutionary Genetics Analysis version 6.0. Mol Biol Evol. 2013;30:2725-9. https://doi.org/10.1093/molbev/mst197

34. Price MN, Dehal PS, Arkin AP. FastTree: computing large minimum evolution trees with profiles instead of a distance matrix. Mol Biol Evol. 2009;26:1641-50.

35. Letunic I, Bork P. Interactive tree of life (iTOL) v3: an online tool for the display and annotation of phylogenetic and other trees. Nucl Acids Res. 2016;44:W242-5. https://doi.org/10.1093/nar/ gkw290

36. Dabrowski PW, Radonić A, Kurth A, Nitsche A. Genome-wide comparison of cowpox viruses reveals a new clade related to variola virus. PLoS One. 2013;8:e79953. https://doi.org/10.1371/ journal.pone.0079953

37. Babkin IV, Babkina IN. The origin of the variola virus. Viruses. 2015;7:1100-12.

38. Hatcher EL, Hendrickson RC, Lefkowitz EJ. Identification of nucleotide-level changes impacting gene content and genome evolution in orthopoxviruses. J Virol. 2014;88:13651-68. http://dx.doi.org/10.1128/JVI.02015-14

39. Hoffmann D, Franke A, Jenckel M, Tamošiūnaitè A, Schluckebier J, Granzow H, et al. Out of the reservoir: phenotypic and genotypic characterization of a novel cowpox virus isolated from a common vole. J Virol. 2015;89:10959-69.

40. Nowotny N. Serologic studies of domestic cats for potential human pathogenic virus infections from wild rodents[in German]. Zentralbl Hyg Umweltmed. 1996;198:452-61.

41. Tryland M, Sandvik T, Holtet L, Nilsen H, Olsvik O, Traavik T. Antibodies to orthopoxvirus in domestic cats in Norway. Vet Rec. 1998;143:105-9. http://dx.doi.org/10.1136/vr.143.4.105

42. Baxby D. The natural history of cowpox. Bristol Med Chir J. 1982;97:12-6.

43. Kroon EG, Mota BEF, Abrahão JS, da Fonseca FG, de Souza Trindade G. Zoonotic Brazilian vaccinia virus: from field to therapy. Antiviral Res. 2011;92:150-63. http://dx.doi.org/ 10.1016/j.antiviral.2011.08.018

44. Keckler MS, Reynolds MG, Damon IK, Karem KL. The effects of post-exposure smallpox vaccination on clinical disease presentation: addressing the data gaps between historical epidemiology and modern surrogate model data. Vaccine. 2013;31:5192-201. http://dx.doi.org/10.1016/j.vaccine.2013.08.039

45. Sánchez-Sampedro L, Perdiguero B, Mejías-Pérez E, García-Arriaza J, Di Pilato M, Esteban M. The evolution of poxvirus vaccines. Viruses. 2015;7:1726-803.

46. Eder I, Vollmar P, Pfeffer M, Naether P, Rodloff A, Meyer H. Two distinct clinical courses of human cowpox, Germany, 2015. Viruses. 2017;9:375.

47. Grönemeyer L-L, Baltzer A, Broekaert S, Schrick L, Möller L, Nitsche A, et al. Generalised cowpox virus infection. Lancet. 2017;390:1769. https://doi.org/10.1016/S0140-6736(17)31428-9

48. Shchelkunov SN. An increasing danger of zoonotic orthopoxvirus infections. PLOS Pathogens. 2013;9:e1003756.

49. Duraffour S, Mertens B, Meyer H, van den Oord JJ, Mitera T, Matthys $\mathrm{P}$, et al. Emergence of cowpox: study of the virulence of clinical strains and evaluation of antivirals. PLoS One. 2013;8:e55808.

Address for correspondence: Didier Raoult or Bernard La Scola, Aix-Marseille Université, IHU Méditerranée Infection, 19-21 Bd Jean Moulin 13005 Marseille, France; email: didier.raoult@gmail.com; bernard.la-scola@univ-amu.fr 


\title{
Trends of Human Plague, Madagascar, 1998-2016
}

\author{
Voahangy Andrianaivoarimanana, ${ }^{1}$ Patrice Piola, ${ }^{1,2}$ David M. Wagner, \\ Fanjasoa Rakotomanana, Viviane Maheriniaina, Samuel Andrianalimanana, \\ Suzanne Chanteau, ${ }^{3}$ Lila Rahalison, ${ }^{4}$ Maherisoa Ratsitorahina, Minoarisoa Rajerison
}

\begin{abstract}
Madagascar is more seriously affected by plague, a zoonosis caused by Yersinia pestis, than any other country. The Plague National Control Program was established in 1993 and includes human surveillance. During 1998-2016, a total of 13,234 suspected cases were recorded, mainly from the central highlands; $27 \%$ were confirmed cases, and $17 \%$ were presumptive cases. Patients with bubonic plague (median age 13 years) represented $93 \%$ of confirmed and presumptive cases, and patients with pneumonic plague (median age 29 years) represented 7\%. Deaths were associated with delay of consultation, pneumonic form, contact with other cases, occurrence after 2009, and not reporting dead rats. A seasonal pattern was observed with recrudescence during September-March. Annual cases peaked in 2004 and decreased to the lowest incidence in 2016. This overall reduction occurred primarily for suspected cases and might be caused by improved adherence to case criteria during widespread implementation of the $\mathrm{F} 1$ rapid diagnostic test in 2002.
\end{abstract}

$\mathrm{P}$ lague, caused by the bacterium Yersinia pestis, produced some of the most devastating epidemics in human history; it is endemic to regions of Asia, the Americas, and Africa. Africa accounts for $>90 \%$ of global human plague cases, and most cases are reported from Madagascar and the Democratic Republic of the Congo (1).

Plague was introduced to Madagascar in 1898 at the port of Toamasina and reached the capital (Antananarivo) in 1921. It is endemic to the central and northern highlands (elevation $>800 \mathrm{~m}$ ). The main reservoir is the black rat (Rattus rattus), and 2 main flea species (Xenopsylla cheopis, a cosmopolitan species, and Synopsyllus fonquerniei, an endemic species) are involved in transmission. S. fonquerniei fleas show a greater transmission efficiency $(2,3)$.

Author affiliations: Institut Pasteur, Antananarivo, Madagascar (V. Andrianaivoarimanana, P. Piola, F. Rakotomanana,

S. Chanteau, L. Rahalison, M. Rajerison); Northern Arizona University, Flagstaff, Arizona, USA (D.M. Wagner); Ministry of Public Health, Antananarivo (V. Maheriniaina, S. Andrianalimanana, M. Ratsitorahina)

DOI: https://doi.org/10.3201/eid2502.171974
Restriction of plague primarily to the highlands is probably caused by the absence of $S$. fonquerniei fleas at elevations $<800$ m (4).

Human plague has 2 primary clinical forms, bubonic and pneumonic (5). Bubonic plague (BP), the predominant form, is acquired by fleabite. Pneumonic plague (PP), which is less common, might arise from BP by hematogenous spread to lungs or inhalation of aerosols during human-tohuman transmission. Without treatment, case-fatality rates (CFRs) are 40\%-70\% for BP and 100\% for PP (2,6,7).

In Madagascar, per the Plague National Control Program (PNCP), reporting of suspected human cases by health centers is mandatory. Confirmation is performed by the Central Laboratory for Plague of the Malagasy Ministry of Health, which is hosted at the Plague Unit of the Institut Pasteur (Antananarivo, Madagascar). We report epidemiologic data and trends for human plague in Madagascar over 19 years of surveillance, analyze risk factors associated with plague complications, and evaluate the specificity and sensitivity of the rapid diagnostic test for $Y$. pestis antigen fraction 1 detection (F1RDT) (8) after 15 years of use.

\section{Data Analysis}

We analyzed data for human plague surveillance activities (Appendix, https://wwwnc.cdc.gov/EID/article/25/2/171974-App1.pdf) by using Stata 14 (StataCorp LLC, https:// www.stata.com). We also analyzed epidemiologic trends of calculated suspected, presumptive, and confirmed cases. Cases were considered confirmed if $Y$. pestis was isolated by culture or mouse inoculation, presumptive if positive results were obtained by F1RDT or microscopy (i.e., gramnegative coccobacilli showing bipolar staining) without isolation of $Y$. pestis, or suspected if no samples were available for testing or all test results were negative (9).

Changes in screening tests resulted in different case definitions: before 2002, the screening test was

\footnotetext{
${ }^{1}$ These authors contributed equally to this article.

${ }^{2}$ Current affiliation: Institut Pasteur, Phnom Penh, Cambodia. ${ }^{3}$ Retired.

${ }^{4}$ Current affiliation: Centers for Disease Control and Prevention, Atlanta, Georgia, USA.
} 
microscopy, but during 2002-2008, F1RDT replaced microscopy. We estimated performance of microscopy (1998-2001) and F1RDT (2002-2007) by measuring sensitivity and specificity compared with bacteriological culture; from 2008 on, only positive F1RDT results at the Central Laboratory for Plague were confirmed by culture. Cases for which samples were not available for testing are listed as unknown (Figure 1) and were excluded from sensitivity and specificity analyses.

A retrospective case-control study identified death risk factors for confirmed plus presumptive cases. Casepatients were persons who died shortly before or after diagnosis of plague; controls were persons who survived. Potential factors examined included delay to consultation after symptom onset (categorized as 0,1 , or $\geq 2$ days); clinical form (BP or PP); time period (before 2009 or from 2009 on); contact with another confirmed plus presumptive case; reporting presence of dead rats (yes/no); age ( $\leq 18$ years of age); sex; recent travel in a plague-endemic focus area (yes/no); month of plague reporting; and mean elevation of district residence. Clinical form was defined on the basis of when the case was initially examined. Thus, PP cases included persons with primary PP and secondary PP arising from BP. Recent travel was defined as traveling in a plagueendemic focus area within 10 days before disease onset. Elevation was included because it has been described as a risk factor for death from pneumonia (10).

To assess death risk factors, we also analyzed all variables associated with death in univariate analysis at the $\mathrm{p}<0.2$ level in a multivariate fashion by using logistic regression. Only confirmed plus presumptive cases were used for additional analyses, including estimation of plague incidence, geographic localization of outbreaks, description of infection clusters (groups of $\geq 2$ confirmed case-patients or presumptive case-patients who reported physical contact, close proximity, or other possible infection links with each other), and environmental risk factors of plague endemicity.

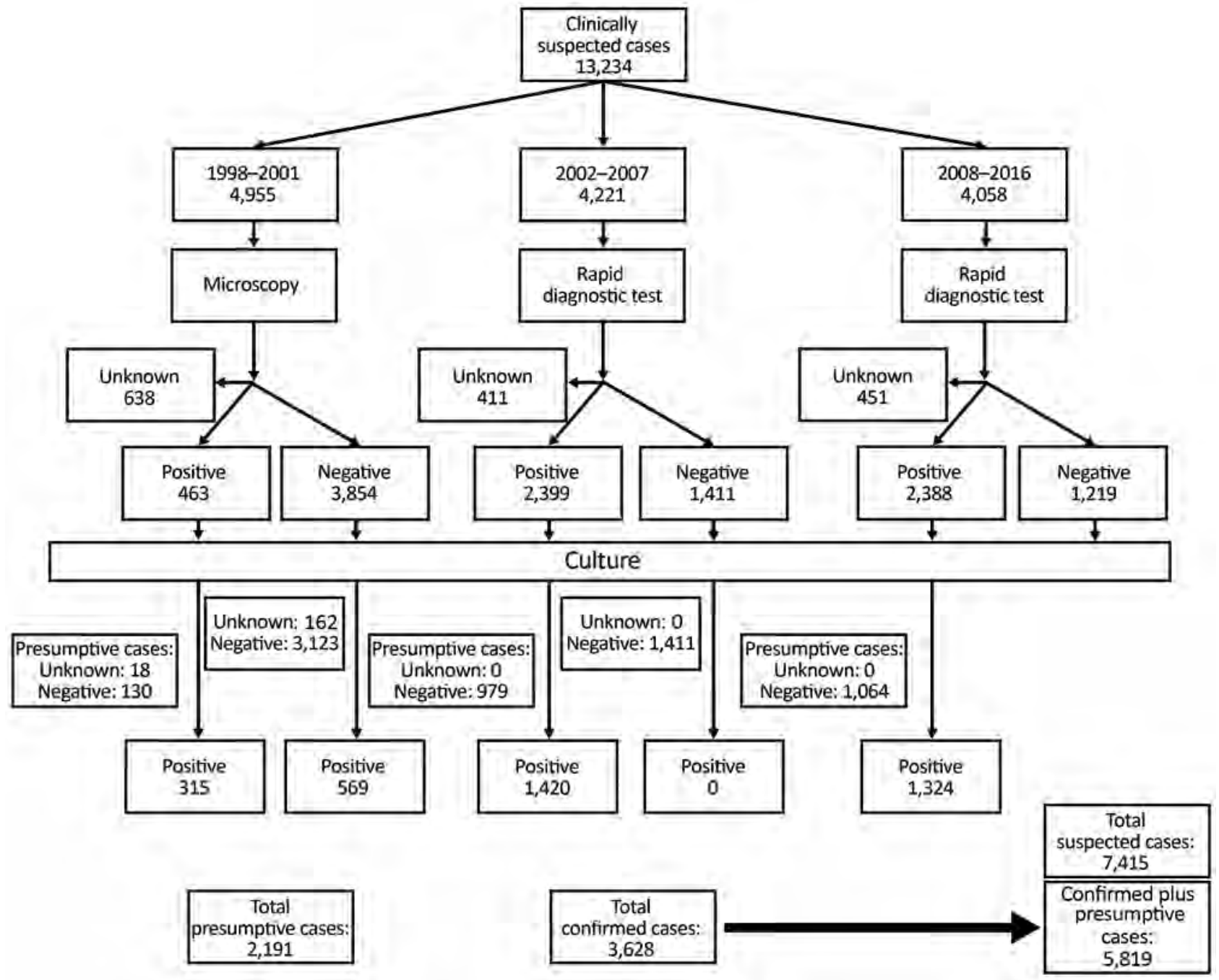

Figure 1. Diagnostic flowchart for suspected cases of plague, Madagascar, 1998-2016. 


\section{General Trends}

During January 1, 1998-December 31, 2016, a total of 13,234 clinically suspected plague cases were reported to the PNCP. Of these cases, 3,628 (27\%) were classified as confirmed and 2,191 (17\%) as presumptive (Figures 1,2); the confirmation rate improved gradually over time (Figure 2). For the 5,819 confirmed plus presumptive cases, PP represented 7\% (409) and BP 88\% (5,132). The remaining $278(5 \%)$ were categorized as neither PP or BP; because the reporting form only included information on symptoms of BP and PP and not other forms of plague, these other cases were not further differentiated in terms of clinical manifestation.

Yearly proportion of PP for confirmed plus presumptive cases ranged from $0.3 \%$ (1/308) during 2002 to $14.7 \%(20 / 136)$ during 2015 ; there was a statistically significant increase in proportion of PP during 1998-2016 (slope $0.0055 ; \mathrm{p}<0.0001$ ). We found no significant difference in proportion of PP and BP between suspected cases $(91.7 \% \mathrm{BP})$ and confirmed plus presumptive cases $(92.6 \%$ $\mathrm{BP} ; \mathrm{p}=0.08)$.

The CFR was $18 \%(1,057 / 5,819)$ for confirmed plus presumptive case-patients and significantly higher for patients with PP $(25 \%, 102 / 409)$ than for patients with BP $(15 \%, 747 / 5,132 ; p<0.001)$. The yearly CFR for BP ranged from $8.2 \%$ (2010) to $28.4 \%$ (2015) but was much wider for PP (0\% during 2005-2006, 100\% during 2002) (Figure $3)$, likely because of relatively few PP cases. Annual confirmed plus presumptive cases peaked in $2004(\mathrm{n}=739 ; 9 \%$ were reported from Antananarivo-Renivohitra) and were lowest in $2016(n=126)$. Monthly distribution of cases showed an increase in September, a peak in November, a progressive decrease until April, and then few cases until August (Figure 3).

\section{Performance of Microscopy and F1RDT}

Using culture as a reference, we determined that microscopy had a sensitivity of $35.6 \%$ (315/884; samples from
1998-2001) and a specificity of $96 \%(3,123 / 3,253)$. F1RDT sensitivity was $100 \%(1,411 / 1,411$; samples from 2002-2007) and specificity was 59\% $(1,420 / 2,399)$; F1RDT specificity was higher for BP $(60.5 \%$; samples from 2002-2007) than for PP $(44.7 \%$; $<<0.001)$. Because of $100 \%$ sensitivity of F1RDT (Table 1), only positive F1RDT results were confirmed by culture since 2008 . Thus, it was not possible to examine specificity of F1RDT during 2008-2016.

\section{Risk Factors Associated with Plague}

Sociodemographic and epidemiologic characteristics did not vary between confirmed plus presumptive cases and suspected cases (Table 2). For confirmed plus presumptive case-patients, we found a significant age difference between PP cases (median 29 years) and BP cases (median 13 years; $p<0.001$ ). In addition, reporting dead rats was higher for BP (18.6\%) than PP $(9.3 \%)$ case-patients $(\mathrm{p}<0.001)$, and the proportion of recent trips (i.e., trip in a plague-endemic area for 10 days before reporting) was almost 2-fold greater for PP (13.7\%) than for BP $(6.9 \%)$ case-patients $(\mathrm{p}<0.001)$.

Confirmed plus presumptive cases were concentrated mostly in the central highlands (Figure 4). Most BP cases occurred in the west-northwest region, whereas hotspots of PP were found in the northeastern central highlands. Median elevation of district of residence was similar for BP and PP case-patients (Table 2), within 1,200 m-1,300 m. In the 415 communes where plague cases were reported, yearly incidence estimates from census population data were $0.03-63$ cases/100,000 persons/year (median 1.4 cases/100,000 persons/year, interquartile range $0.7-3.2$ cases/100,000 persons/year). Of 5,819 confirmed plus presumptive cases, $473(8.1 \%)$ were in an infection cluster; many infection clusters occurred in the middle of the central highlands (Figure 4). There were 211 infection clusters: $76 \%$ involved 2 contacts (of which $10 \%$ involved PP), $18 \%$ involved 3 contacts (11\% PP), $4 \%$ involved 4 contacts (16\% PP), and 1\% involved 5 contacts (10\% PP).

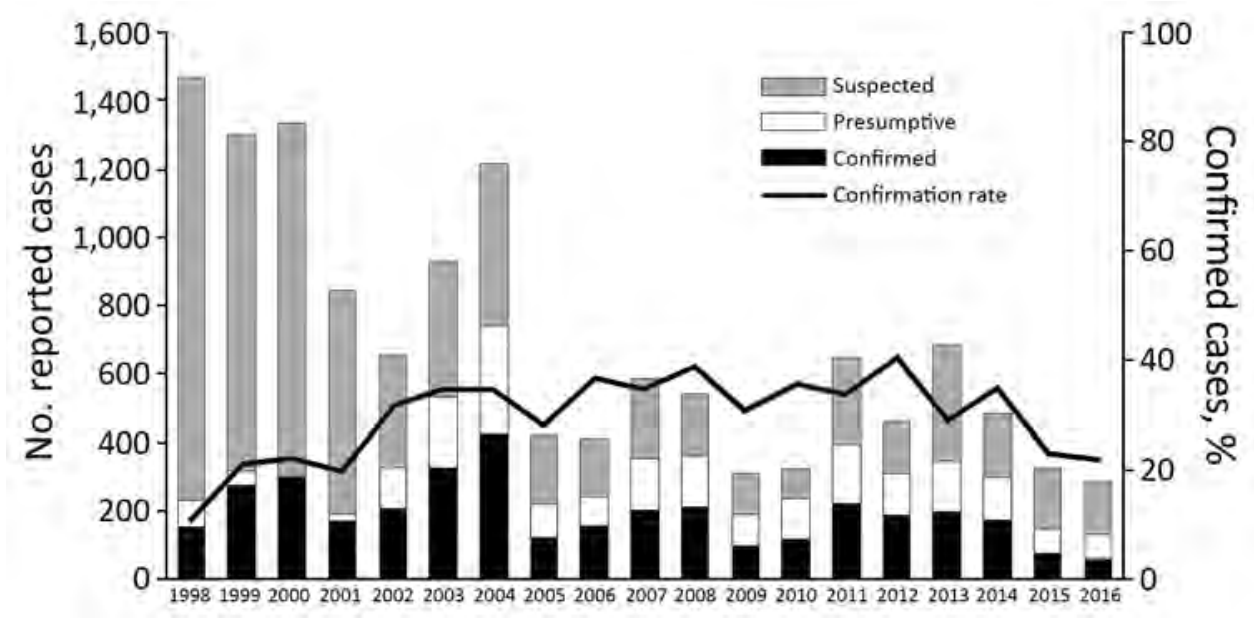

Figure 2. Classification of reported plague cases and confirmation rate, Madagascar, 1998-2016. 

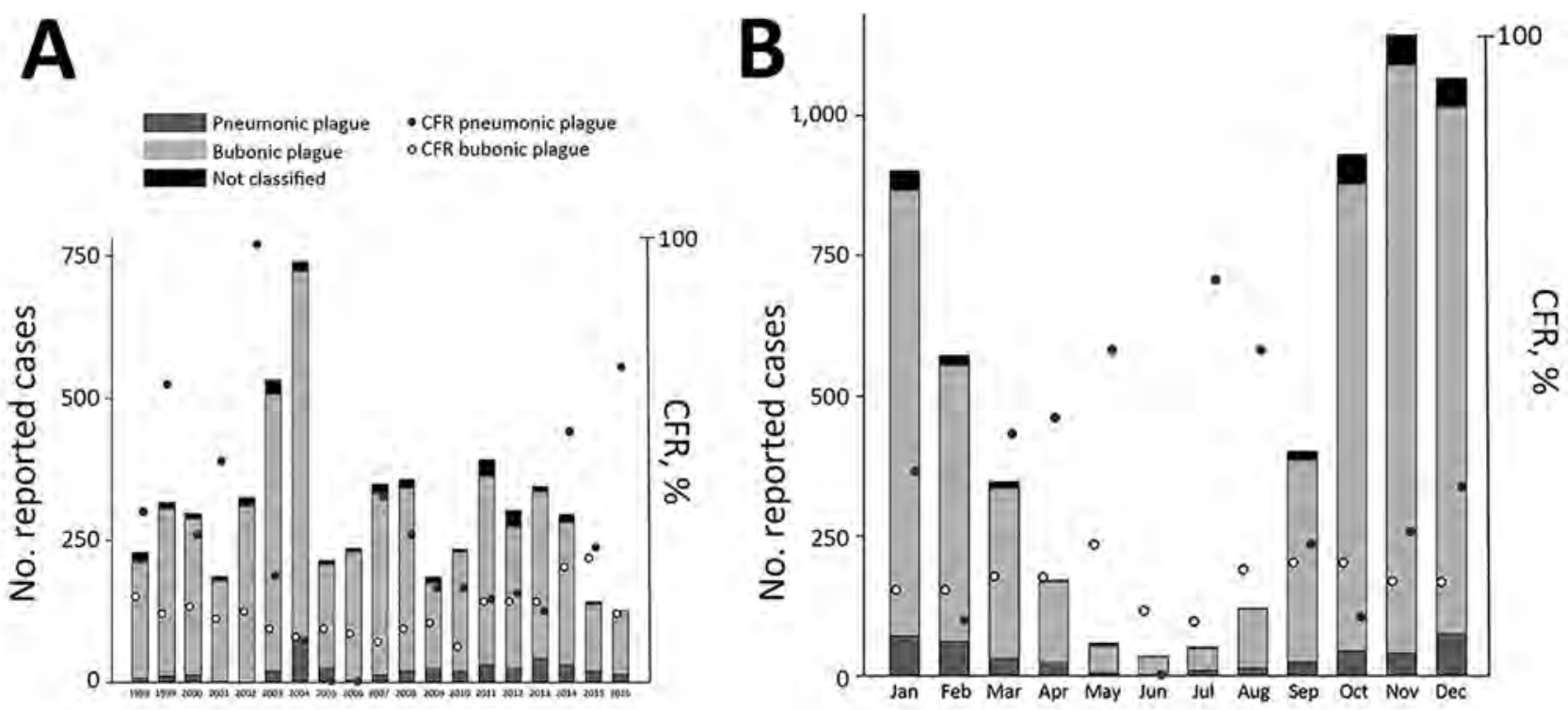

Figure 3. Yearly (A) and monthly (B) distributions of bubonic and pneumonic plague and their CFR, Madagascar, 1998-2016. CFR, case-fatality rate.

We found by univariate analysis that death was associated more with PP (odds ratio [OR] 2.0, 95\% CI 1.57-2.53) than with BP. For PP case-patients, death was associated with delayed consultations (OR 2.7, 95\% CI 1.70-4.37), occurrence after 2009 (OR 1.60, 95\% CI 1.02-2.52), and age group (OR $0.50,95 \%$ CI $0.29-0.85$ ). For BP casepatients, death was associated with delayed consultations (OR 3.44, 95\% CI 2.92-4.04), contact with another casepatient (OR 1.86, 95\% CI 1.45-2.37), occurrence after 2009 (OR 1.56, 95\% CI 1.33-1.83), and not reporting dead rats (OR 0.67, 95\% CI 0.54-0.85).

When we combined BP and PP case-patients (Table 3), we found that death was associated with age, sex, and recent travel. However, month and mean elevation of district of residence were not associated with death, except for the month of August. In the multivariate model (Table 3), we found that the remaining factors with an association after adjustments were delayed consultation (from OR 3.2 at day 2 up to OR 5.0 at day 4), pneumonic plague (OR 1.6), contact with another plague case (OR 1.9), year 2009 or after (OR 1.6), and not reporting dead rats (OR 0.7 ) (all p values $<0.001$ ). Persons $>35$ years of age had a moderately higher risk for death than did persons $\leq 35$ years of age (OR 1.25, $\mathrm{p}=0.04$ ).

Death predictions of the model for BP and PP by day of consultation ranged from $5 \%$ to $32 \%$. Predicted CFR of
PP increased from 9\% (95\% CI 6.2\%-11.1\%) when consulting on first day of symptoms to $32 \%$ when consulting after the second day ( $95 \%$ CI $26.8 \%-38.1 \%$ ); these values for BP were 5\% (95\% CI 4.3\%-6.4\%) and 23\% (95\% CI 20.8\%-24.4\%) (Figure 5).

\section{Discussion}

Analysis of 19 years of human plague surveillance in Madagascar showed a distinct peak of confirmed plus presumptive cases during 2003 and 2004. This peak, which might have been influenced by global climate phenomena, such as the El Niño Southern Oscillation and Indian Ocean Dipole $(11,12)$, was partly caused by an increase in plague cases reported primarily from districts in rural areas of middle-west (including Ambohidratrimo, Miarinarivo, and Tsiroanomandidy) and central (Antananarivo-Renivohitra) Madagascar. The first 3 districts have long been considered plague hotspots (13); they reported at least twice the mean confirmed plus presumptive reports during the 5 years before 2004. In 2004, Antananarivo-Renivohitra had a PP outbreak, which was restricted mostly to Arrondissement II of the capital (Antananarivo). This unusual event caused panic among the population and resulted in overreporting, which, combined with misdiagnosis, resulted in a high number of suspected cases that were not confirmed.

\begin{tabular}{|c|c|c|c|c|}
\hline \multirow[b]{2}{*}{ Clinical form } & \multicolumn{2}{|c|}{ Microscopy, 1998-2001 } & \multicolumn{2}{|c|}{ F1RDT, 2002-2008 } \\
\hline & Sensitivity & Specificity & Sensitivity & Specificity \\
\hline Bubonic & $34 \%(31 \%-38 \%)$ & $96 \%(95 \%-97 \%)$ & $100 \%(99 \%-100 \%)$ & $60 \%(58 \%-62 \%)$ \\
\hline Pneumonic & $53 \%(34 \%-71 \%)$ & $94 \%(84 \%-98 \%)$ & $100 \%(90 \%-100 \%)$ & $45 \%(37 \%-52 \%)$ \\
\hline Total & $35 \%(32 \%-39 \%)$ & $96 \%(95 \%-97 \%)$ & $100 \%(99 \%-100 \%)$ & $59 \%(57 \%-61 \%)$ \\
\hline
\end{tabular}


Table 2. Sociodemographic and epidemiologic characteristics of persons with confirmed, presumptive, and suspected plague cases, Madagascar, 1998-2016*

\begin{tabular}{|c|c|c|c|c|}
\hline \multirow[b]{2}{*}{ Characteristic } & \multicolumn{2}{|c|}{ Bubonic plague case status, no. patients } & \multicolumn{2}{|c|}{ Pneumonic plague case status, no. patients } \\
\hline & Suspected, $n=6,454$ & $\begin{array}{c}\text { Confirmed and } \\
\text { presumptive, } n=5,132\end{array}$ & Suspected, $n=579$ & $\begin{array}{c}\text { Confirmed and } \\
\text { presumptive, } n=409\end{array}$ \\
\hline Median age, y (IQR) & $11(6-20)$ & $13(8-24)$ & $26(17-40)$ & $29(20-42)$ \\
\hline Sex ratio $(\mathrm{M}: \mathrm{F})$ & $1.44(3,803: 2,639)$ & $1.38(2,972: 2,157)$ & $1.08(300: 278)$ & $1.28(230: 179)$ \\
\hline Presence of rats, $\%$ & 15.1 & 18.6 & 11.3 & 9.3 \\
\hline Recent trip, \% & 6.4 & 6.9 & 7.0 & 13.6 \\
\hline Mean (SE) days to care & $2.0(0.05)$ & $1.7(0.03)$ & $2.61(0.15)$ & $2.21(0.18)$ \\
\hline Median elevation, m (IQR) & $1,262(1,111-1,384)$ & $1,275(1,063-1,409)$ & $1,228(921-1,333)$ & $1,284(1,111-1,355)$ \\
\hline Contact with other plague cases, $\%$ & 7 & 11 & 21 & 23 \\
\hline
\end{tabular}

A similar situation occurred in 1994, when a suspected plague outbreak affected the cities of Surat and Beed in India and caused 54 deaths in 876 reported case-patients (9). However, $Y$. pestis was not isolated from this outbreak, and many patients were subsequently given a diagnosis of fatal illnesses resembling acute pneumonia and not plague (14).

In our study, total annual cases peaked in 2004 and decreased to the lowest value during 2016 (Figure 2). This reduction occurred primarily in suspected cases and might be caused by improved adherence to case criteria after training and education that occurred during widespread national implementation of the F1RDT starting in 2002.

Monthly distribution of human plague cases in Madagascar in this study was consistent with previous findings, except for a troubling recent trend of the season starting earlier during the year (Figure 3). In general, the human plague season in Madagascar started with early recrudescence in September and peaked in November $(5,15)$; this pattern is associated with temperature effects on flea abundance and climate and weather patterns (16). In more recent years, overall confirmed plus presumptive cases and CFR have both increased in August, during what is typically low season for human plague in Madagascar. Increased CFR in August might have been caused by misdiagnosis by health workers unaccustomed to suspecting plague cases in this month or delayed treatment.

Relatively low specificity ( $59 \%$ overall, $44.7 \%$ for PP) of the F1RDT compared with that for culture might be caused by several factors, including badly preserved and contaminated field samples and long delays in transport to laboratory; both factors could lead to negative results from culture even if the cultured material originated from a true plague case. In addition, negative culture results might have resulted from administration of antimicrobial drugs by local health officials before sampling (17), whereas F1RDT results remained positive $>3$ weeks after treatment initiation (18). Moreover, pain, fever, and cough are often treated with self-medication in Madagascar (19). Thus, specificity of the F1RDT test is almost certainly underestimated by

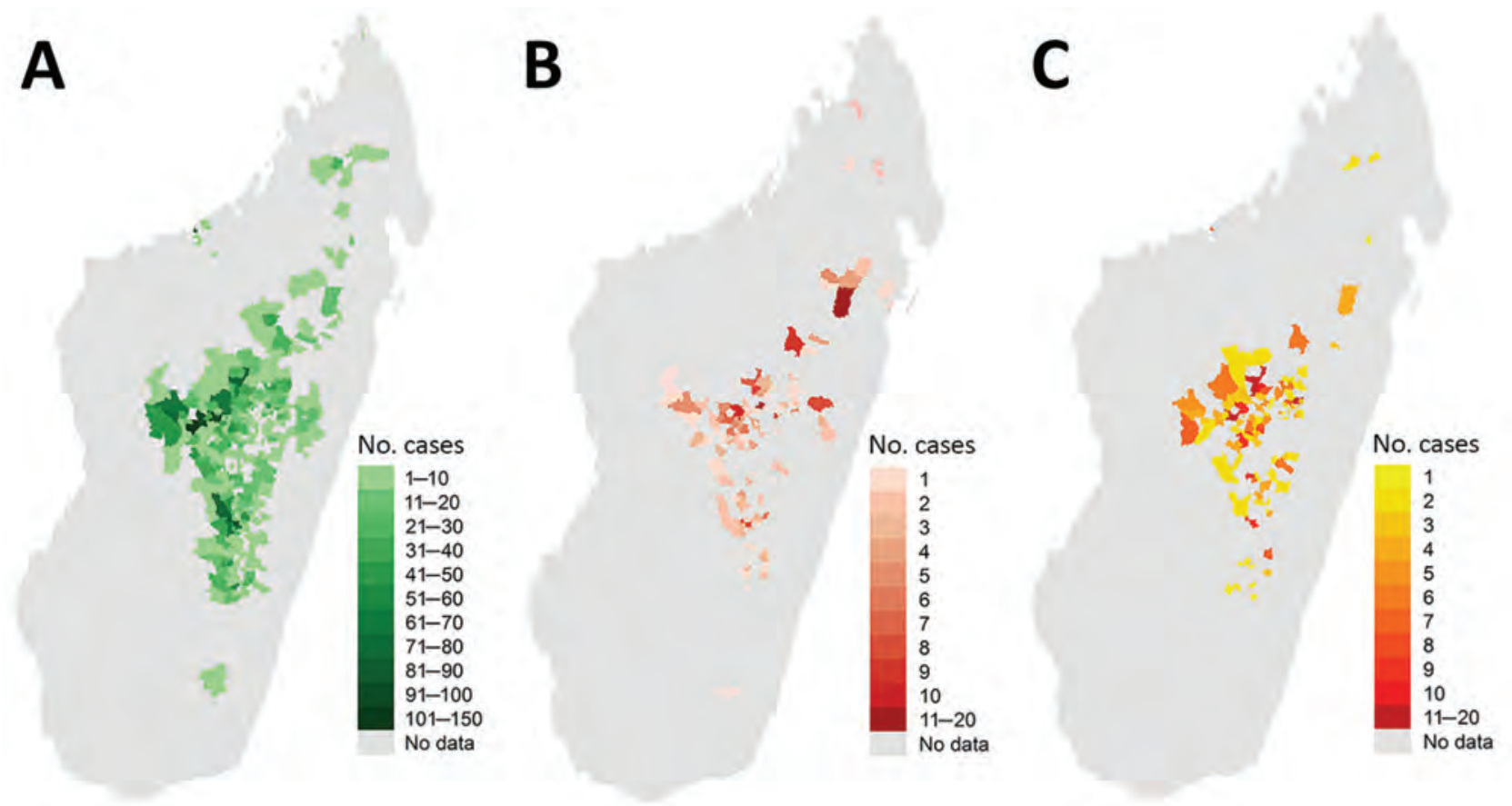

Figure 4. Geographic distributions of bubonic plague (A), pneumonic plague (B), and infection clusters (C), Madagascar, 1998-2016. 
Human Plague in Madagascar, 1998-2016

Table 3. Risk factors for death from plague, Madagascar, 1998-2016*

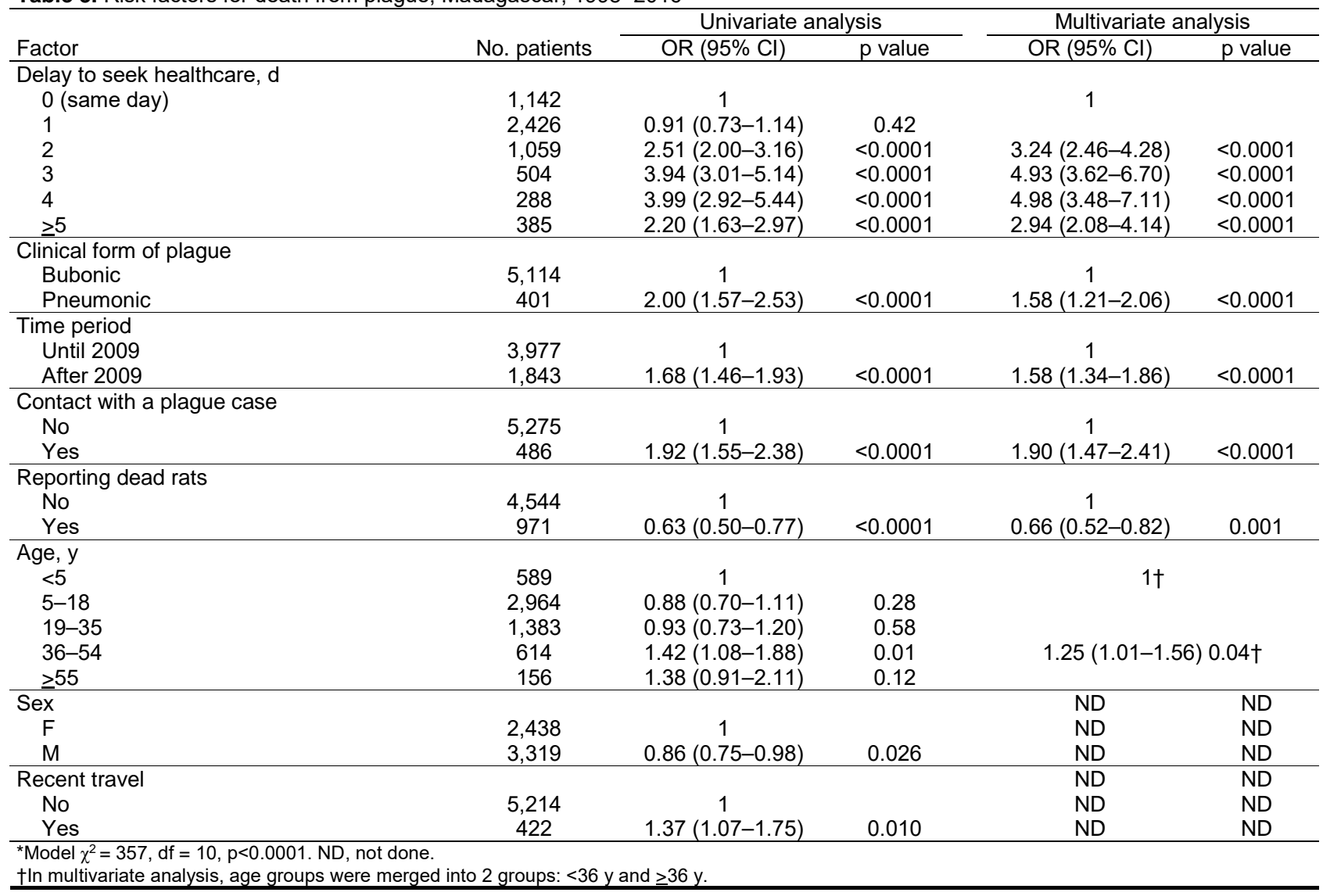

comparing it with culture. Whatever the true rate, F1RDT does lack specificity, which could lead to false-positive results and treatment for persons not truly infected with $Y$. pestis. Fortunately, the sensitivity of F1RDT was 100\%, mitigating dangers associated with false-negative results.

Consistent with previous findings from Madagascar during 1957-2001 (5), we found that BP occurred most commonly in children and adolescents 5-19 years of age, which might be associated with several factors. First, young children in Madagascar are more likely to be employed in agricultural settings, thus providing increased contact with rodents and fleas (20). Second, children sleeping or playing on the ground are exposed to more flea bites (15). In Madagascar and other plague-endemic countries (Tanzania, Uganda, and Mozambique), a higher risk for contracting BP is associated with sleeping habits; women and children are at greater risk for exposure to fleas when sleeping directly on the floor or on simple mats (21-23), and mats are more likely to be infested with fleas than other bedding (23).

In contrast, but in agreement with previous findings from Madagascar (5), PP was more frequent in adults $>30$ years of age. High frequency of PP in adults is caused mainly by delayed diagnosis of BP, which then progresses to secondary PP. This delay is associated with multiple behaviors, including self-medication, ignorance of the disease, and trust in traditional healers, which contribute to delay in administration of appropriate treatment by health workers (2,24-26). Also, early clinical symptoms of PP are unspecific, leading to misdiagnosis. PP in adults might also result from participation in funeral ceremonies and attention given to plague patients (25).

Death was more common for PP case-patients who had recently traveled to a plague-endemic region (Table 3). Field investigations often found that index case-patients had traveled long distances (50-200 km) between probable places of infection and their home villages $(24,25)$; this finding was observed in India $(27,28)$ and the Democratic Republic of the Congo (29). Our multivariable model showed that declaring contact with another plague case-patient is a death risk factor after adjustment for PP. This finding could be explained by situations or factors not available in the dataset that are common during major outbreaks and would reduce the survival rate. The model also suggests that lack of observation of dead rats is associated with death. Plague outbreaks are usually associated with observations of dead rats, raising awareness for healthcare providers. Plague case management might be poorer in locations where clinicians are unaware of this indicator. 


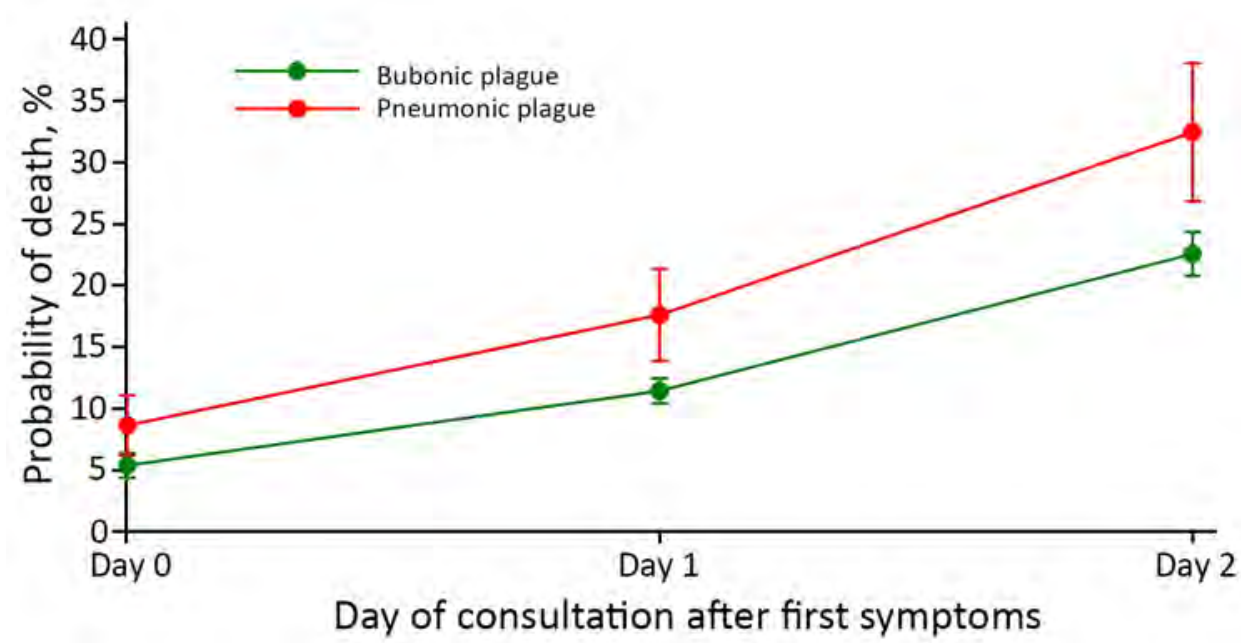

Figure 5. Predictive mortality rate according to clinical form and day of consultation for cases of plague, Madagascar, 1998-2016. Error bars indicate $95 \% \mathrm{Cl}$.

Spatially, most confirmed plus presumptive cases during 1998-2016 were confined to the Central Highlands, but some occurred in other regions where plague has been historically absent (Figure 4). Concentration of human plague in the Central Highlands, consistent with past trends in Madagascar (5), is likely caused by long-term persistence of plague in this region within rodent reservoirs. A recent phylogeographic analysis showed that different and distinct $Y$. pestis subpopulations largely persist at the same geographic locations in the Central Highlands over time, suggesting that plague is constantly and stably maintained locally in rodent populations in this region and not regularly reintroduced from other locations (13). During this period, BP cases occurred throughout the Central Highlands, especially in the central and western portions (Figure 4). PP cases were scattered throughout the Central Highlands but concentrated in the northeastern portion in areas that typically report few human plague cases (Figure 4). The relatively high number of PP cases in these areas was caused by misdiagnosis and ignorance of plague by health workers and the local population, which delayed treatment and enabled $\mathrm{BP}$ to progress to $\mathrm{PP}$.

Human plague is now occurring in some regions of Madagascar where it was historically absent. An outbreak of BP emerged in southeast Madagascar (Befotaka and Iakora Districts) in November 2016, outside previously known limits of plague-endemic foci. It is not clear whether plague has always been present in these regions and not previously detected or was recently transported to these regions. Imported plague caused by human movements or transportation has been documented for Mahajanga, a coastal location outside the traditional regions of plague in Madagascar, resulting in reintroduction and establishment of plague in this port city. It then cycled in local rodent and flea populations for several years before apparently disappearing (30). Because plague can suddenly occur in new locations in Madagascar, clinicians and authorities outside traditional plague foci need to be aware of this risk.

It has been long speculated that plague epidemics in Madagascar occur in 4-5-year cycles; however, no clear periodicity could be defined at the level of rural districts (15), which could be attributed to dynamics of plague in rodents and fleas. BP outbreaks are preceded by rodent epizootics (3), which reduce local rodent populations; it is unknown how long it takes for rodent populations to recover sufficiently to support another epizootic. Fluctuation in rodent abundance caused by plague might vary depending on species, fecundity, availability of food, or lifespan, or larger factors, such as weather and climate. High abundance of rodents might lead to more contact between humans and animals and, therefore, to outbreaks (31). In Himachal Pradesh, India, examination of past plague epidemics showed that outbreaks occur in cycles of 10-15 years (28).

Tools for early detection and treatment, as well as properly trained health workers, are critical to reducing overall plague deaths and progression of BP to PP. Just a 2-day delay in treatment dramatically increased death rates for BP and PP (Figure 5); these national findings for PP are similar to those from a single PP plague outbreak in Moramanga in 2015 (26). That study highlighted the need for education and rapid clinical decision-making for reducing deaths because the average duration from full onset of PP to death was 1.9 days. Because it is highly sensitive and can be used in remote settings, F1RDT is a proven preliminary diagnosis tool that has led to earlier detection of outbreaks and rapid implementation of control measures in multiple countries in Africa (32-34). This more local and focused diagnostic capability provides considerable savings in terms of treatment, chemoprophylaxis, and pesticide treatment; in Madagascar, these activities are conducted systematically and free of charge when a plague case is suspected. 
An increase in the proportion of PP cases over time (Figure 3) was caused by untreated BP cases progressing to PP and is symptomatic of the deteriorating health system in Madagascar, a result of sociopolitical and economic crises of 2002 and 2009 (1). Specifically, this deterioration is likely caused by fast turnover of health workers in plague-endemic regions, especially after changes in the government in Madagascar or political crises; new workers were not always properly trained for plague diagnosis. Surveillance and control activities throughout Madagascar are also affected by lack of financial support. Discontinuation of regular plague surveillance in Antananarivo during 2006-2018, caused by financial shortages, likely contributed to the reappearance of plague in its suburbs 6 years after the previous last reported case. In 2011, two human cases were confirmed there outside the typical season, and $Y$. pestis was also isolated from the spleen of an $R$. rattus rat (2). More concerning, in 2017 a large PP outbreak occurred in Madagascar, with many cases in Antananarivo (35). A similar overall situation has transpired in the Democratic Republic of the Congo, where civil war and political crisis, leading to a lack of resources, has adversely affected plague control activities (9).

Control and prevention of human plague cases in Madagascar faces challenges. BP acquired from a $Y$. pestis-infected flea is the most common form and the ultimate source of PP cases and outbreaks. Thus, prevention strategies are focused on rodent hosts and flea vectors. Unfortunately, inappropriate use of chemical insecticides, contrary to PNCP recommendations, has promoted emergence in Madagascar of fleas resistant to multiple classes of insecticides, leading to survival of $Y$. pestis-infected fleas $(36,37)$. Human contact with rodent hosts, and consequently flea vectors, is increased by common practices of storing food and disposing of garbage near households (21) and close proximity of households in many locations. Fortunately, control of human plague cases is still possible by use of standard antimicrobial drugs (assuming treatment is started in time) because only a few $Y$. pestis strains of $>4,000$ strains examined have been resistant to major antimicrobial drugs, such as streptomycin and doxycycline (38-40). Also, plague diagnosis by using F1RDT on dead rodent samples can also contribute to efficient plague prevention (8).

This study has major strengths and potential limitations. Strengths include the length of the study and large sample sizes. These sample sizes benefit from the fact that all suspected plague in Madagascar must be reported with standard epidemiologic information. One possible limitation is that diagnostic tools used for case definition evolved during the study. Also, only confirmed plus presumptive cases were analyzed, which might not fully represent the national situation. Furthermore, samples for confirmation were often unavailable from regions where plague had not previously been reported or not reported for several years, a limitation evident for the reemerging focus in Moramanga (26) and the recent outbreak in southeastern Madagascar, where many deaths were reported but samples were not always available for confirmation. Thus, risk factors associated with complications were not analyzed for these cases.

In summary, a seasonal pattern of plague was observed in Madagascar during September-March. Annual cases of plague peaked in 2004 and decreased in 2016. This reduction might be caused by improved adherence to case criteria during implementation of the $\mathrm{F} 1$ rapid diagnostic test in 2002. Because plague can suddenly occur in new locations in Madagascar, clinicians and authorities outside traditional plague foci need to be aware of this risk.

\section{Acknowledgments}

We thank Mamy Ratsimba for data collection and Bienvenue S. Rahoilijaona and the Clinical Research Unit of the Institut Pasteur de Madagascar for plague mapping.

\section{About the Author}

Dr. Andrianaivoarimanana is a researcher at RahoilijaoanaEpidemiology and in the Plague Unit at the Institut Pasteur de Madagascar, Antananarivo, Madagascar. Her research interests are immune response between $Y$. pestis and its hosts and plague epidemiology.

\section{References}

1. Bertherat E. Plague around the world, 2010-2015. Wkly Epidemiol Rec. 2016;91:89-93.

2. Andrianaivoarimanana V, Kreppel K, Elissa N, Duplantier JM, Carniel E, Rajerison M, et al. Understanding the persistence of plague foci in Madagascar. PLoS Negl Trop Dis. 2013;7:e2382. http://dx.doi.org/10.1371/journal.pntd.0002382

3. Duplantier JM, Duchemin JB, Chanteau S, Carniel E. From the recent lessons of the Malagasy foci towards a global understanding of the factors involved in plague reemergence. Vet Res. 2005;36:437-53. http://dx.doi.org/10.1051/vetres:2005007

4. Brygoo ER. Epidemiology of plague in Madagascar [in French]. Arch Inst Pasteur Madagascar. 1966;35:9-147.

5. Migliani R, Chanteau S, Rahalison L, Ratsitorahina M, Boutin JP, Ratsifasoamanana L, et al. Epidemiological trends for human plague in Madagascar during the second half of the 20th century: a survey of 20,900 notified cases. Trop Med Int Health. 2006; 11:1228-37. http://dx.doi.org/10.1111/j.1365-3156.2006.01677.x

6. Neerinckx S, Bertherat E, Leirs H. Human plague occurrences in Africa: an overview from 1877 to 2008. Trans R Soc Trop Med Hyg. 2010; 104:97-103. http://dx.doi.org/10.1016/j.trstmh.2009.07.028

7. Pollitzer R. Plague. World Health Organization Monograph Series 22. Geneva: The Organization; 1954.

8. Chanteau S, Rahalison L, Ralafiarisoa L, Foulon J, Ratsitorahina M, Ratsifasoamanana L, et al. Development and testing of a rapid diagnostic test for bubonic and pneumonic plague. Lancet. 2003;361:211-6. http://dx.doi.org/10.1016/S0140-6736(03)12270-2

9. World Health Organization. International meeting on preventing and controlling plague: the old calamity still has a future. Wkly Epidemiol Rec. 2006;81:278-84. 
10. Pérez-Padilla R, Franco-Marina F. The impact of altitude on mortality from tuberculosis and pneumonia. Int J Tuberc Lung Dis. 2004;8:1315-20.

11. Kreppel KS, Caminade C, Telfer S, Rajerison M, Rahalison L, Morse A, et al. A non-stationary relationship between global climate phenomena and human plague incidence in Madagascar. PLoS Negl Trop Dis. 2014;8:e3155. http://dx.doi.org/10.1371/ journal.pntd.0003155

12. Ben-Ari T, Neerinckx S, Gage KL, Kreppel K, Laudisoit A, Leirs H, et al. Plague and climate: scales matter. PLoS Pathog. 2011;7:e1002160. http://dx.doi.org/10.1371/journal.ppat.1002160

13. Vogler AJ, Andrianaivoarimanana V, Telfer S, Hall CM, Sahl JW, Hepp CM, et al. Temporal phylogeography of Yersinia pestis in Madagascar: Insights into the long-term maintenance of plague. PLoS Negl Trop Dis. 2017;11:e0005887. http://dx.doi.org/10.1371/ journal.pntd.0005887

14. Ramalingaswami V. Plague in India. Nat Med. 1995;1:1237-9. http://dx.doi.org/10.1038/nm1295-1237

15. Chanteau S, Ratsitorahina M, Rahalison L, Rasoamanana B, Chan F, Boisier P, et al. Current epidemiology of human plague in Madagascar. Microbes Infect. 2000;2:25-31. http://dx.doi.org/ 10.1016/S1286-4579(00)00289-6

16. Kreppel KS, Telfer S, Rajerison M, Morse A, Baylis M. Effect of temperature and relative humidity on the development times and survival of Synopsyllus fonquerniei and Xenopsylla cheopis, the flea vectors of plague in Madagascar. Parasit Vectors. 2016;9:82. http://dx.doi.org/10.1186/s13071-016-1366-Z

17. Forrester JD, Apangu T, Griffith K, Acayo S, Yockey B, Kaggwa J, et al. Patterns of human plague in Uganda, 2008-2016. Emerg Infect Dis. 2017;23:1517-21. http://dx.doi.org/10.3201/ eid2309.170789

18. Andrianaivoarimanana V, Bertherat E, Rajaonarison R, Rakotondramaro T, Rogier C, Rajerison M. Mixed pneumonic plague and nosocomial MDR-bacterial infection of lung: a rare case report. BMC Pulm Med. 2018;18:92. http://dx.doi.org/10.1186/ s12890-018-0656-y

19. Sendrasoa FA, Razanakoto NH, Ranaivo IM, Andrianasolo RL, Randria MJDD, Rakotoarivelo RA. Antibiotic and antimalarial self-medication in Antananarivo, Madagascar. International Journal of Infectious Diseases and Therapy. 2016;1:1-5. 10.11648/ j.ijidt.20160101.11

20. Boisier P, Rahalison L, Rasolomaharo M, Ratsitorahina M, Mahafaly M, Razafimahefa M, et al. Epidemiologic features of four successive annual outbreaks of bubonic plague in Mahajanga, Madagascar. Emerg Infect Dis. 2002;8:311-6. http://dx.doi.org/10.3201/eid0803.010250

21. Kilonzo BS, Mvena ZS, Machangu RS, Mbise TJ. Preliminary observations on factors responsible for long persistence and continued outbreaks of plague in Lushoto district, Tanzania. Acta Trop. 1997;68:215-27. http://dx.doi.org/10.1016/S0001-706X(97)00096-X

22. Barreto A, Aragon M, Epstein PR. Bubonic plague outbreak in Mozambique, 1994. Lancet. 1995;345:983-4. http://dx.doi.org/ 10.1016/S0140-6736(95)90730-0

23. Eisen RJ, MacMillan K, Atiku LA, Mpanga JT, Zielinski-Gutierrez E, Graham CB, et al. Identification of risk factors for plague in the West Nile Region of Uganda. Am J Trop Med Hyg. 2014;90:1047-58. http://dx.doi.org/10.4269/ ajtmh.14-0035

24. Richard V, Riehm JM, Herindrainy P, Soanandrasana R, Ratsitoharina M, Rakotomanana F, et al. Pneumonic plague outbreak, Northern Madagascar, 2011. Emerg Infect Dis. 2015;21:8-15. http://dx.doi.org/10.3201/eid2101.131828

25. Ratsitorahina M, Chanteau S, Rahalison L, Ratsifasoamanana L, Boisier P. Epidemiological and diagnostic aspects of the outbreak of pneumonic plague in Madagascar. Lancet. 2000;355:111-3. http://dx.doi.org/10.1016/S0140-6736(99)05163-6

26. Ramasindrazana B, Andrianaivoarimanana V, Rakotondramanga JM, Birdsell DN, Ratsitorahina M, Rajerison M. Pneumonic plague transmission, Moramanga, Madagascar, 2015. Emerg Infect Dis. 2017;23:521-4. http://dx.doi.org/10.3201/eid2303.161406

27. Gupta ML, Sharma A. Pneumonic plague, northern India, 2002. Emerg Infect Dis. 2007;13:664-6. http://dx.doi.org/10.3201/ eid1304.051105

28. Joshi K, Thakur JS, Kumar R, Singh AJ, Ray P, Jain S, et al. Epidemiological features of pneumonic plague outbreak in Himachal Pradesh, India. Trans R Soc Trop Med Hyg. 2009;103:455-60. http://dx.doi.org/10.1016/j.trstmh.2008.11.026

29. Bertherat E, Lamine KM, Formenty P, Thuier P, Mondonge V, Mitifu A, et al. Major pulmonary plague outbreak in a mining camp in the Democratic Republic of Congo: brutal awakening dof an old scourge [in French]. Med Trop (Mars). 2005;65:511-4.

30. Vogler AJ, Chan F, Wagner DM, Roumagnac P, Lee J, Nera R, et al. Phylogeography and molecular epidemiology of Yersinia pestis in Madagascar. PLoS Negl Trop Dis. 2011;5:e1319. http://dx.doi.org/10.1371/journal.pntd.0001319

31. Davis S, Calvet E, Leirs H. Fluctuating rodent populations and risk to humans from rodent-borne zoonoses. Vector Borne Zoonotic Dis. 2005;5:305-14. http://dx.doi.org/10.1089/vbz.2005.5.305

32. Bertherat E, Bekhoucha S, Chougrani S, Razik F, Duchemin JB, Houti L, et al. Plague reappearance in Algeria after 50 years, 2003. Emerg Infect Dis. 2007;13:1459-62. http://dx.doi.org/10.3201/ eid1310.070284

33. Cabanel N, Leclercq A, Chenal-Francisque V, Annajar B, Rajerison M, Bekkhoucha S, et al. Plague outbreak in Libya, 2009, unrelated to plague in Algeria. Emerg Infect Dis. 2013;19:230-6. http://dx.doi.org/10.3201/eid1902.121031

34. Bertherat E, Thullier P, Shako JC, England K, Koné ML, Arntzen L, et al. Lessons learned about pneumonic plague diagnosis from two outbreaks, Democratic Republic of the Congo. Emerg Infect Dis. 2011;17:778-84. http://dx.doi.org/10.3201/ eid1705.100029

35. Roberts L. Echoes of Ebola as plague hits Madagascar. Science. 2017;358:430-1. http://dx.doi.org/10.1126/science.358.6362.430

36. Boyer S, Miarinjara A, Elissa N. Xenopsylla cheopis (Siphonaptera: Pulicidae) susceptibility to Deltamethrin in Madagascar. PLoS One. 2014;9:e111998. http://dx.doi.org/10.1371/journal.pone.0111998

37. Miarinjara A, Boyer S. Current perspectives on plague vector control in Madagascar: susceptibility status of Xenopsylla cheopis to 12 insecticides. PLoS Negl Trop Dis. 2016;10:e0004414. http://dx.doi.org/10.1371/journal.pntd.0004414

38. Galimand M, Guiyoule A, Gerbaud G, Rasoamanana B, Chanteau S, Carniel E, et al. Multidrug resistance in Yersinia pestis mediated by a transferable plasmid. N Engl J Med. 1997;337:67780. http://dx.doi.org/10.1056/NEJM199709043371004

39. Guiyoule A, Gerbaud G, Buchrieser C, Galimand M, Rahalison L, Chanteau S, et al. Transferable plasmid-mediated resistance to streptomycin in a clinical isolate of Yersinia pestis. Emerg Infect Dis. 2001;7:43-8. http://dx.doi.org/10.3201/ eid0701.010106

40. Cabanel N, Bouchier C, Rajerison M, Carniel E. Plasmid-mediated doxycycline resistance in a Yersinia pestis strain isolated from a rat. Int J Antimicrob Agents. 2018;51:249-54. http://dx.doi.org/ 10.1016/j.ijantimicag.2017.09.015

Address for correspondence: Minoarisoa Rajerison, Plague Unit, Institut Pasteur de Madagascar, BP 1274 Ambatofotsikely, Antananarivo 101, Madagascar; email: mino@pasteur.mg 


\section{Human Pasteurellosis Health Risk for Elderly Persons Living with Companion Animals}

Sándor Körmöndi, Gabriella Terhes, Zoltán Pál, Endre Varga, Mária Harmati, Kriszina Buzás, Edit Urbán

\section{$\underset{\text { MDUCATION }}{\text { Medscape ACTIVITY }}$}

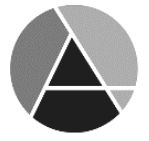

JOINTLY ACCREDITED PROVIDER ${ }^{\text {N }}$ INTERPROFESSIONAL CONTINUING EDUCATION

In support of improving patient care, this activity has been planned and implemented by Medscape, LLC and Emerging Infectious Diseases. Medscape, LLC is jointly accredited by the Accreditation Council for Continuing Medical Education (ACCME), the Accreditation Council for Pharmacy Education (ACPE), and the American Nurses Credentialing Center (ANCC), to provide continuing education for the healthcare team.

Medscape, LLC designates this Journal-based CME activity for a maximum of 1.00 AMA PRA Category 1 Credit(s) ${ }^{\mathrm{TM}}$. Physicians should claim only the credit commensurate with the extent of their participation in the activity.

All other clinicians completing this activity will be issued a certificate of participation. To participate in this journal CME activity: (1) review the learning objectives and author disclosures; (2) study the education content; (3) take the post-test with a $75 \%$ minimum passing score and complete the evaluation at http://www.medscape.org/journal/eid; and (4) view/print certificate. For CME questions, see page 393.

Release date: January 18, 2018; Expiration date: January 18, 2019

\section{Learning Objectives}

Upon completion of this activity, participants will be able to:

- Describe baseline characteristics and epidemiological features of patients with Pasteurella spp. Infection, according to a retrospective study and comprehensive review

- Determine characteristics of localized and invasive pasteurellosis, according to a retrospective study and comprehensive review

- Explain complications and mortality after localized and invasive pasteurellosis, according to a retrospective study and comprehensive review

\section{CME Editor}

Deborah Wenger, MBA, Copyeditor, Emerging Infectious Diseases. Disclosure: Deborah Wenger, MBA, has disclosed no relevant financial relationships.

\section{CME Author}

Laurie Barclay, MD, freelance writer and reviewer, Medscape, LLC. Disclosure: Laurie Barclay, MD, has disclosed the following relevant financial relationships: owns stock, stock options, or bonds from Pfizer.

\section{Authors}

Disclosures: Sándor Körmöndi, MD; Gabriella Terhes, MSc, PhD; Zoltán Pál, MD, PhD; Endre Varga, MD, PhD, DSc; Mária Harmati, MSc; Kriszina Buzás, MSc, PhD; and Edit Urbán, PharmD, PhD, Habil, DSc, have disclosed no relevant financial relationships.

Pasteurella spp. infection is becoming more noteworthy because of increasing numbers of pets in households and changes in pet-keeping habits. Our aim was to collect epidemiologic and clinical data about infections caused by Pasteurella spp. to achieve a comprehensive review. We studied 162 patients in Hungary who had positive Pasteurella

Author affiliations: University of Szeged, Szeged, Hungary

(S. Körmöndi, G. Terhes, Z. Pál, E. Varga, K. Buzás, E. Urbán);

Hungarian Academy of Sciences, Szeged (M. Harmati, K. Buzás)

DOI: https://doi.org/10.3201/eid2502.180641 spp. culture results during 2002-2015. An increasing tendency in rates of pasteurellosis could be observed from year to year. A total of $70(43.2 \%)$ cases were detected in patients $>60$ years of age. Localized infections caused by bites and scratches were the most common ( $n=114,70.4 \%)$; invasive infections were recorded in 48 patients $(29.6 \%)$. In localized infections, animal contact was common; in most invasive infections, the source of pasteurellosis could not be determined. The high number of complications and the unusually high death rate $(8 \%)$ emphasize the importance of diagnosing and treating human pasteurellosis. 
$P$ asteurella spp. infections can cause various diseases in wild and domestic animals; in humans, most infections are associated with cat or dog bites, licks, and scratches (1). Annually, in the United States, $\approx 300,000$ visits to emergency departments for animal bites or scratch wounds are recorded; however, not all of these are associated with infections. Regarding animal bites, 3\%-18\% of dog bites and 28\%-80\% of cat bites become infected (2,3); $50 \%$ of dog bites and $75 \%$ of cat bites are associated with the presence of Pasteurella multocida (3), which can be frequently detected as part of the oral microbiota in various animals such as cats, dogs, pigs, and various wild animals $(2,3)$.

Data about injuries associated with animal bites or scratches in Hungary are not available; however, rabies vaccines are given to $>4,000$ patients annually $(4,784$ in 2017) (4). This number represents mainly cases in which the animal could not be observed after an accident or injury (4). Of the 35,000 traumatic injury cases (such as various injuries from accidents, bites, scratches, sport injuries, falls, and injuries that occur at home) that are recorded annually at our university hospital in Szeged, Hungary, 14-37 (0.04\%-0.1\%) are associated with animal bites or scratches.

Localized infections caused by Pasteurella spp. are characterized by cutaneous inflammation that usually develops shortly after animal bites or scratches. Later, local complications including osteomyelitis, septic arthritis, and abscess formation or systemic infection such as infection of large articulated joints, meningitis, intraabdominal infection, sepsis, and pneumonia may develop (5). In immunocompromised patients, the infection may manifest as severe pneumonia, sepsis, or a fatal form of pasteurellosis. In patients with underlying pulmonary disease, pneumonia, empyema, and lung abscess caused by Pasteurella spp. can be detected, whereas in patients with liver dysfunction, sepsis has been described (3). Other severe invasive infections (meningitis, endocarditis, and peritonitis) caused by various Pasteurella spp. have also been described; however, their incidences are rare (6).

During the past 10 years, we have observed that the rate of human pasteurellosis is rising in Hungary, and in several cases of invasive pasteurellosis, animal contacts are usually not mentioned. In the literature, most papers dealing with human pasteurellosis are reports of individual cases; only a few papers have reported on all cases recognized in a hospital. To achieve better knowledge of human pasteurellosis, we collected data about both localized and invasive forms of human infections and compared the results with international data.

\section{Methods}

\section{Study Design and Patients}

We included patients in this study if they had microbiological investigation with positive results for Pasteurella spp. in the local university hospitals in Szeged, Hungary (intensive care unit and departments of traumatology, surgery, pediatrics, dermatology, ophthalmology, obstetrics and gynecology, otorhinolaryngology, and head and neck surgery), during 2002-2015. For culture, we used Columbia agar with 5\% sheep's blood and chocolate agar with PolyViteX (bioMérieux, https://www.biomerieux. com) and incubated the cultures at $37^{\circ} \mathrm{C}$ for $24 \mathrm{~h}$ in a $5 \% \mathrm{CO}_{2}$ incubator. We performed identification using the VITEK 2 GN ID and API NH Systems (bioMérieux) before 2012; after 2012, we used matrix-assisted laser desorption/ionization time-of-flight (MALDI-TOF) mass spectrometry (Bruker Daltonik, https://www.bruker.com). We obtained patients' medical history from the local medical database. We identified local pasteurellosis if the patient had a superficial wound or tenosynovitis or if small joints were involved. Invasive pasteurellosis was present if large joints, including shoulder, hip, knee, or prostheses, were inflamed or if the patient had neurologic, pulmonary, cardiovascular, abdominal, or pelvic involvements or had septic shock or bacteremia.

This retrospective study was approved by the University Research Ethics Committee, Faculty of Medicine, University of Szeged, Hungary. Collection of data about participating patients was in accordance with ethical standards at the institutional and/or national research committee and with the 1964 Helsinki Declaration and its later amendments.

\section{Data Analysis}

We collected the following data from the medical database: age, sex, concurrent medical conditions, animal exposure history, outcomes, and laboratory findings at hospital admission. For statistical analysis, we collected and analyzed demographic and clinical data about the patients. We used descriptive statistics including means or medians with ranges and percentages to characterize data; in this case, we used Microsoft Excel 2013 (https:// www.microsoft.com). We used Mann-Whitney U-test or $\chi^{2}$ tests with Yates' correction to compare groups. A p value $<0.05$ was considered statistically significant. We analyzed the data using GraphPad Prism version 5.03 (https://www.graphpad.com/scientific-software/prism).

\section{Results}

\section{Baseline Characteristics of Patients with Pasteurella spp. Infection}

For 2002-2015, we isolated 211 Pasteurella spp. from 162 patients; we found that the number of isolates and human pasteurellosis cases has increased from year to year (Figure 1). The median age of patients with positive culture results was 57 (range 0-97) years. The proportion of Pasteurella spp. isolation was approximately equal for men $(n=78$, 


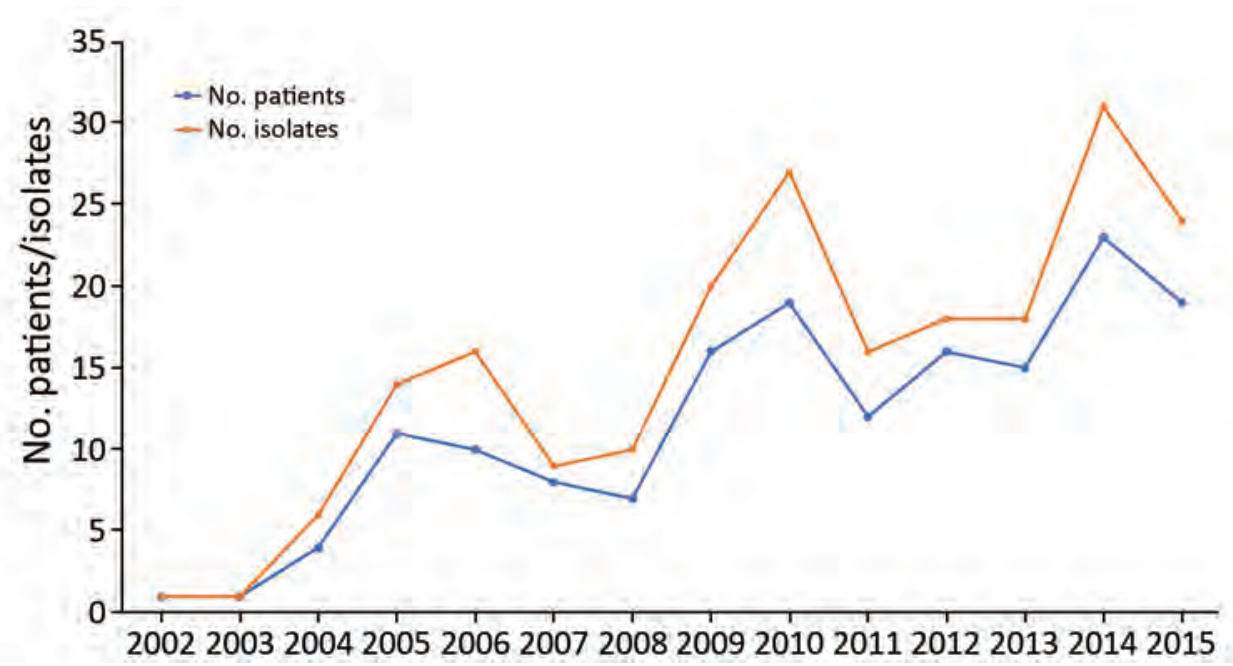

Figure 1. Increasing tendency in annual rates of human pasteurellosis and in the number of Pasteurella isolates, Szeged, Hungary, 2002-2015.

$48.1 \%)$ and women $(\mathrm{n}=84,51.9 \%)$, and we observed increasing rates of pasteurellosis cases by advanced age in both sexes (Figure 2).

We determined the distribution of Pasteurella spp. in clinical specimens (wounds, respiratory tract, and abdominal specimens; blood, synovial, cerebrospinal, and pleural fluids) (Table 1). Most strains $(\mathrm{n}=155,73.5 \%)$ were isolated from wound specimens (Table 2), but some strains originated from unusual sites such as synovial fluid, pleural fluids, and abdominal specimens. In the respiratory specimens $(n=23), 5$ strains were isolated from the upper respiratory tract; among these, asymptomatic carriages were considered in 3 patients. Two $P$. multocida strains isolated from the upper respiratory tract were also present in pleural fluid and bronchoalveolar lavage of the same patient with severe respiratory failure. In lower respiratory specimens, invasive infections were documented when pure cultures of Pasteurella spp. and high numbers of granulocytes were detected and the patient had symptoms of lower respiratory tract infections. All strains $(n=18)$ isolated from the lower respiratory specimens were grouped into the invasive infection cluster.

\section{Polymicrobial Pasteurella sp. Infections}

In 79 patients, Pasteurella sp. was the only isolate, whereas polymicrobial infections were detected in 83 patients (51.2\%). In these cases, the most frequent anaerobic bacteria isolated from clinical specimens were Fusobacterium nucleatum $(\mathrm{n}=18)$, Peptostreptococcus anaerobius $(\mathrm{n}=$ 11), Prevotella oralis $(\mathrm{n}=10)$, Prevotella melaninogenica $(\mathrm{n}=7)$, Prevotella loescheii $(\mathrm{n}=7)$, and Bacteroides pyogenes $(\mathrm{n}=7)$. Among facultative anaerobic bacteria, Staphylococcus aureus $(\mathrm{n}=12)$ and Escherichia coli $(\mathrm{n}=$ 5) were the most common species.

\section{Characteristics of Localized and Invasive Pasteurellosis}

Localized infections secondary to bites, scratches, or licking were the most prevalent type during the study period $(\mathrm{n}=114,70.4 \%)$. Most patients with localized infections were female $(\mathrm{n}=68,59.6 \%)$. For invasive infections

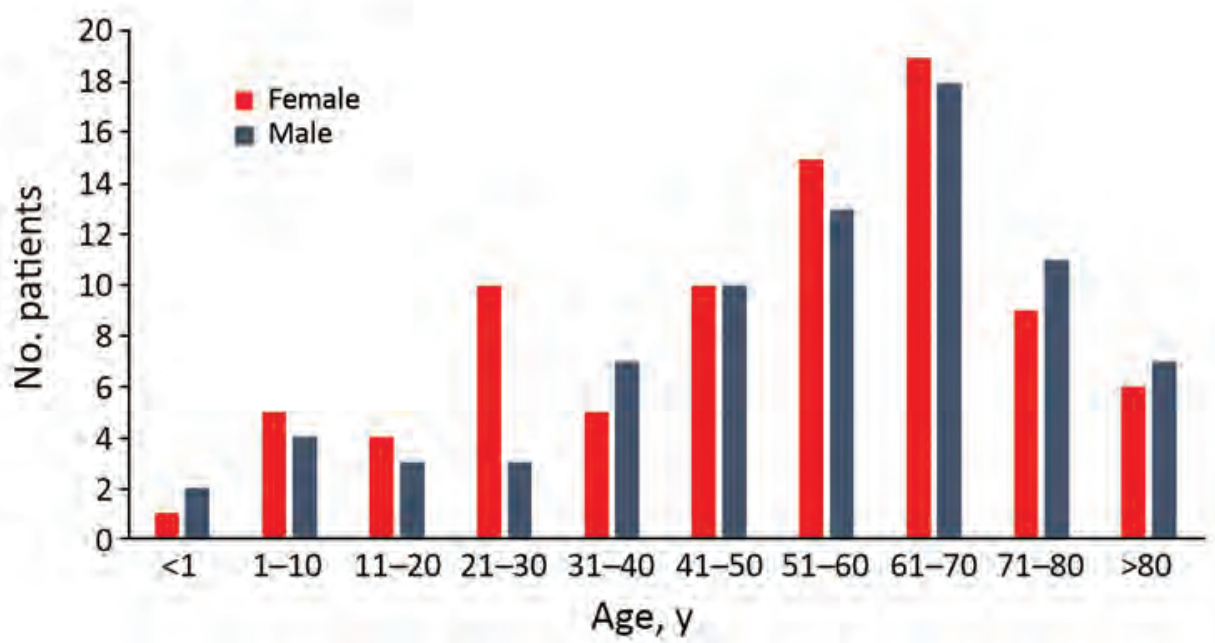

Figure 2. Distribution of pasteurellosis cases $(\mathrm{N}=162)$ according to age group and sex, Szeged, Hungary, 2002-2015. 
Table 1. Distribution of Pasteurella spp. in clinical specimens from patients in Szeged, Hungary, 2002-2015

\begin{tabular}{lc}
\hline Species & No. $(\%)$ isolated strains \\
\hline$P$. multocida & $160(75.8)$ \\
$P$. canis & $36(17.1)$ \\
$P$. pneumotropica & $11(5.2)$ \\
$P$. dagmatis & $2(0.9)$ \\
$P$. stomatis & $1(0.5)$ \\
$P$. aerogenes & $1(0.5)$ \\
\hline Total & $211(100)$ \\
\hline
\end{tabular}

$(\mathrm{n}=48)$, however, male predominance $(\mathrm{n}=32,66.7 \%)$ was observed, and that difference was statistically significant $\left(\chi^{2}=8.345, \mathrm{df}=1, \mathrm{p}=0.004\right)$. The difference in the age distribution among those with localized (median age 53.5 [range 0-97] years) and invasive (median age 63 [range 0 -87] years) infection was also statistically significant (Mann-Whitney $\mathrm{U}=2142 ; \mathrm{p}=0.029$ ). In the invasiveinfection group, the largest number of patients $(n=12$, 25\%) had various abscesses (e.g., liver abscess, pulmonary abscess, abscesses after sigmoid resection); 8 (16.7\%) patients had pneumonia, and 8 (16.7\%) had bacteremia. Respiratory failure was diagnosed in 6 (12.5\%) patients, osteomyelitis was in 4 (8.3\%) patients, pleurisy in 2 (4.2\%) patients, and arthritis in 2 (4.2\%) patients. Central nervous system infection, adnexitis associated with pelvic inflammatory disease, peritonitis, pacemaker infection, cirrhosis, and gangrene were also recorded.

In 8 (7\%) patients with localized infections and 37 (77.1\%) patients with invasive infections, underlying diseases were recorded in the medical history (Table 3); the difference between the 2 groups was statistically significant $\left(\chi^{2}=72.59, \mathrm{df}=1, \mathrm{p}<0.0001\right)$. Some patients with invasive infections had multiple underlying disorders. Cardiovascular disease, diabetes, and malignancy were the most frequent underlying diseases.

Of 114 patients with localized infection, 94 (82.5\%) had contact with a dog $(n=41,43.6 \%)$ or cat $(n=53$, $56.4 \%)$. Ten patients had no animal contact, and no data were available for 10 patients. Animal contacts were recorded in 10 (20.8\%) of 48 cases of invasive infection; no information about animal contacts was available in 16 (33.3\%) cases. Twenty-two (45.8\%) of 48 patients with invasive pasteurellosis had no animal contact.

\begin{tabular}{lc}
\hline \multicolumn{2}{l}{ Table 2. Distribution of clinical specimens positive for Pasteurella } \\
spp. from patients in Szeged, Hungary, 2002-2015 \\
\hline Specimens & No. (\%) isolates \\
\hline Wound & $155(73.5)$ \\
Respiratory tract specimen & $23(10.9)$ \\
Blood & $14(6.6)$ \\
Synovial and pleural fluids & $4(1.9)$ \\
Abdominal & $3(1.4)$ \\
Cerebrospinal fluid & $1(0.5)$ \\
Others (middle ear, sinus, conjunctiva, & $11(5.2)$ \\
dialysis catheter) & \\
\hline Total & $211(100)$
\end{tabular}

Most injuries (74.6\%) in the localized-infection group were attributed to animal bites. Scratch wounds caused by cats were recorded in 12 patients; however, some of them had simultaneous bite injuries. Six cases of cat-associated injury were observed in women 21-30 years of age; in the same age group of male patients (3 patients), none had animal contact (Figure 2). Differences in the distribution of various Pasteurella spp. between localized and invasive infections could not be detected (Figure 3).

When we compared data about hospitalization in patients with localized and invasive infections, we found 71 (62.3\%) of 114 patients with localized infections had hospitalizations; the average length of stay was 8 (range 1-30) days. In the invasive-infection group, 40 of 48 patients (83.3\%) were hospitalized, and the average length of hospital stay was 12.7 (range 1-60) days. Patients with invasive infections were more frequently hospitalized than patients with localized infections $\left(\chi^{2}=5.999, \mathrm{df}=1, \mathrm{p}=\right.$ 0.014 ), and the average length of stay among patients with invasive pasteurellosis was also longer. Hospital admission was almost the same in patients with dog bites (68.3\%) and in patients with cat-induced injury (64.2\%). The average length of hospital stay was longer (11 [range 1-60] days) in cases of dog bites than in cases of cat bites or scratches (8.3 [range 3-41] days). In patients with localized infections, injuries affected mostly the upper extremities ( 75 patients, $65.8 \%$ ); in 23 patients, lower extremities were affected, mainly shins; in 6 patients, the face; in 1 patient, the eye; and in 1 patient, the genitals.

\section{Complications after Localized and Invasive Pasteurellosis}

Ileostomy, hysterectomy, skin transplantation, and amputation were documented in 4 cases of invasive pasteurellosis. Ileostomy was performed because of sudden onset of perforation; during the surgical procedure, a sample from the abdominal cavity was collected for microbiological culture, and P. multocida was isolated. Total abdominal hysterectomy and bilateral salpingo-oophorectomy were performed in a young woman with bilateral tubo-ovarian abscess due to P. multocida infection. A pacemaker electrode, a prosthesis, and a catheter were removed in 3 different cases because of endocarditis, recurrent inflammations around knee prosthesis, and purulent drainage around the dialysis catheter.

After localized Pasteurella sp. infection, severe complications were registered in 23 cases (20.2\%); functional disability, mainly in fingers, developed in 10 patients (6 cases associated with dog bites, 4 cases with cat bites and scratches); and lymphangitis was observed in 7 of 53 (13.2\%) patients. Following bites and scratches, 3 patients had amputations ( 2 from dog bites, 1 from a cat bite), affecting mainly the fingers; 3 patients had osteomyelitis (associated with dog bites) as a consequence of pasteurellosis. 
The high number of complications emphasizes the importance of localized and invasive pasteurella infections.

Of the 162 patients with pasteurellosis, 143 (88.2\%) patients recovered; in 6 cases, no data were available about the outcome of pasteurellosis (in these cases, patients were transferred to other hospitals). Thirteen of the 162 patients died; all these patients had invasive pasteurellosis infections. Seven of these 13 patients had pneumonia and respiratory failure, 5 patients had bacteremia, and 1 patient had panencephalitis after traumatic brain injury. The median age of patients who died was 69.5 (range 39-84) years; most of them had multiple underlying diseases. Laboratory investigations revealed elevated leukocytes, C-reactive protein levels, and liver enzymes in all patients who died from pasteurellosis. In 4 cases, animal contacts, including dogs, cats, and other animals, were recorded in the patient's medical history. No information about animal contact was available in 5 cases, and in 4 cases, no animal contact could be found. In cases of animal contacts, no bite or scratch was mentioned by the patients or relatives.

From clinical specimens (respiratory tract specimens, cerebrospinal fluid, and blood), P. multocida was isolated from 12 patients, and $P$. canis from 1 patient. All 13 of these patients were hospitalized; the average of length of hospital stay was 10.3 (range 1-30) days. Pasteurella sp. was isolated from respiratory specimens or pleural fluid from 6 patients, from blood culture from 4 patients, from 2 wound specimens, and from 1 cerebrospinal fluid specimen.

\section{Discussion}

According to data in the literature, two thirds of human infections are zoonotic in origin. Among these infections, human pasteurellosis is not a common cause of death in humans because of commonly used prophylactic treatment after animal bites or scratches; however, deaths caused by Pasteurella sp. infection have been increasing in the United States (3). We found that 162 patients had Pasteurella infections during 2002-2015 in our university hospital in Hungary. We found a higher number of cases caused by various Pasteurella species than similar surveys showed earlier, such as those by Giordano et al. (7) and Nollet et al. (5). To our knowledge, most publications dealing with human pasteurellosis showed only a few cases or reviewed only unusual infections caused by certain Pasteurella spp.; only 1 publication (5) presented data, from $\approx 102$ patients, to determine risk factors for invasive pasteurellosis. Those surveys showed that higher mean age and underlying diseases, mainly chronic liver disease and neoplasia, are commonly associated with invasive pasteurellosis. Our data confirmed that invasive infections are more frequent in elderly patients and that these patients usually have 1 or more underlying diseases.

Giordano et al. (7) and our results also showed that the detection of Pasteurella spp. from the blood or respiratory
Table 3. Presence of underlying disease in cases of local and invasive Pasteurella spp. infections among patients in Szeged, Hungary, 2002-2015

\begin{tabular}{lcc}
\hline & \multicolumn{2}{c}{ No. (\%) patients } \\
\cline { 2 - 3 } Underlying disease & Local infection & Invasive infection \\
\hline Malignancy & 0 & $10(20.8)$ \\
Cardiac & 0 & $6(12.5)$ \\
Diabetes mellitus & $4(3.5)$ & $6(12.5)$ \\
Pulmonary & 0 & $2(4.2)$ \\
Hepatic (cirrhosis) & 0 & $2(4.2)$ \\
Prosthesis & 0 & $2(4.2)$ \\
Psychiatric & $1(0.9)$ & $1(2.1)$ \\
Genetic (Down & 0 & $1(2.1)$ \\
syndrome) & & \\
Multiple & $1(0.9)$ & $7(14.6)$ \\
No data & $106(93)$ & $11(22.9)$ \\
\hline Total & $114(100)$ & $48(100)$ \\
\hline
\end{tabular}

tract was frequently associated with the absence of animal bites; at the same time, skin infections were usually attributed to animal bites. Most hospitalized patients with animal bites were admitted because of cat bites. Patients without animal bites were more frequently hospitalized, and their length of stay was longer, compared with patients who had animal bites. Patients treated in the ICU did not have animal bites, and most of them had no animal contact, as well. In our study, among patients with invasive pasteurellosis, the death rate was $27.1 \%$. Similarly, the death rate was $21 \%$ in Giordano et al.'s observational study (7); in Nollet's study, the death rate from invasive infections was $11 \%$ and the death rate for localized infections was 1.4\% (5).

The French Pasteurella National Center has reported that the prevalence of central nervous system infection caused by Pasteurella spp. is $<1 \%$ of all Pasteurella infections (8). In adults, meningitis caused by Pasteurella infection is usually associated with cranial trauma or surgery or chronic otitis (9). Our data confirmed these findings. The prevalence of central nervous system infection caused by Pasteurella sp. was $0.6 \%$. One patient with meningitis had a traumatic injury to his head from a car accident and was found near a stable; thus, the source of this infection was deemed to be the environment.

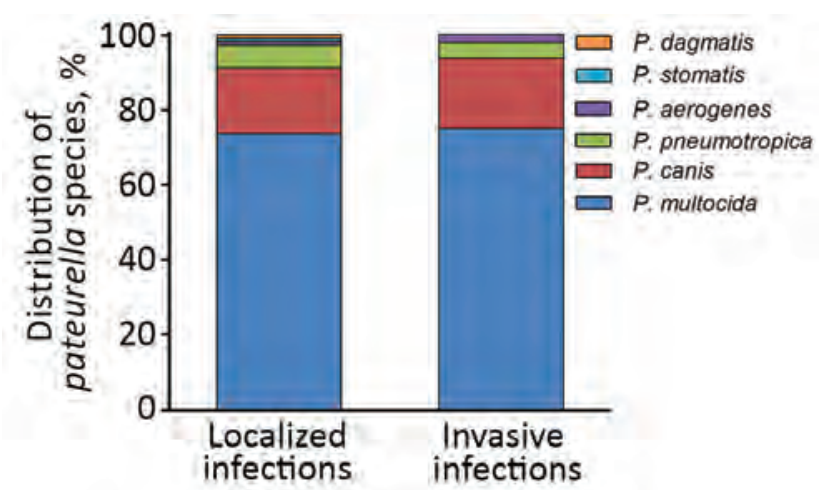

Figure 3. Distribution of various Pasteurella spp. in localized and invasive infections, Szeged, Hungary, 2002-2015. 
In the literature, dog bite is the most common cause of bite injury, followed by cat bite. Most bite injuries are minor wounds; thus, patients generally do not seek medical attention. Therefore, the reported prevalence of biterelated wounds is probably the tip of the iceberg. Dog bites may be associated with fractures because of their high energy, whereas cat bites frequently cause puncture wounds, leading to the development of tenosynovitis (10). Wounds caused by dog bites are less frequently infected than wounds caused by cat bites. Our investigations supported this observation, because patients with cat bites or scratches have pasteurellosis more frequently than do patients with dog bites. Literature data show that cat bites or scratches are more dangerous than dog bites because the injuries tend to be deep and are therefore difficult to clean properly (2). When we studied the complications following dog or cat bites, we observed that after dog bites, the rates of functional disability, osteomyelitis, and amputation were slightly higher than for those after cat bites. Lymphangitis could not be detected after dog bites; this finding was not described earlier.

P. multocida subsp. multocida is the most frequent clinical Pasteurella isolate in humans, ahead of $P$. canis and P. multocida subsp. septica (11). This fact was also confirmed by our investigations; $68.7 \%$ of Pasteurella strains were $P$. multocida, the second most common species was $P$. canis (17.1\%), and third was $P$. pneumotropica (5.2\%). Differences between species isolated from localized and invasive infections could be detected in our study, a finding also confirmed by Nollet et al. (5).

We followed the rates of human pasteurellosis and changes in the number of Pasteurella isolates from year to year, and we observed increasing tendencies in both groups. This finding may be explained by the increasing number of animals in households, and close intimate contact with pets. Approximately $57 \%$ of households in Canada own $\geq 1$ companion animal, whereas only $39 \%$ of persons $>65$ years of age have a pet (12). Similar data are not available in Hungary, but according to unofficial data, $>3$ million dogs and $\approx 3$ million cats live in Hungary (human population 9.938 million). In the Canada survey, the rate of pet ownership was the highest among middle age person (12), and pet-associated infections usually originated from injuries or animal bites; we saw a similar trend in our survey. In elderly patients, because of age-related dysfunction of the immune system or underlying disease, the risks for pet-associated disease and invasive infections are increased.

Another possible explanation for the increasing tendency in the rate of human pasteurellosis is the development of microbiological methods for identification, such as use of MALDI-TOF mass spectrometry and molecular methods. However, the possible role of these methods in explaining the higher number of isolates or human pasteurellosis cases could be excluded in study because we started to use MALDI-TOF mass spectrometry after 2012 but the increasing tendency in pasteurellosis could be observed before 2012. In addition, the spectrum of isolated various Pasteurella spp. did not change after the introduction of MALDI-TOF mass spectrometry and molecular methods; earlier automated identification systems provided adequate identification of Pasteurella strains.

The retrospective nature of this study and data interpretation have some limitations. Medical records for inpatients are completed better than those for outpatients; this may lead to an underestimate of concurrent conditions for outpatients, who fall mostly into the localized-infection group. In several cases, medical records did not contain information about animal contact (mainly in case of nonbite-associated pasteurellosis), which may also cause underestimation of the number of animal contacts. The number of infections caused by Pasteurella spp. is probably higher than we observed, because patients, mainly those in small villages, can receive emergency treatment from a local general practice physician.

Pets, including dogs and cats, are frequently recommended to patients with chronic illness because animal therapy might provide a potential health benefit. Elderly patients may also own companion animals to combat loneliness; however, pets may be the potential source of various infections or injuries (13). Our retrospective survey showed that the rate of human pasteurellosis over a 13-year study period in Hungary increased from year to year and with advanced age, and the number of Pasteurella infections was higher than it was in earlier studies. We observed that Pasteurella patients with cat- and dogassociated injuries were frequently hospitalized. In cases of invasive infections, the source of Pasteurella infection was frequently unknown. In spite of the adequate treatment on the basis of medical chart review and antimicrobial drug susceptibility of the isolated strain, the death rate from these infections was $27.1 \%$ in our study. We also found that complications after localized infections were detected frequently, and certain complications, such as lymphangitis, are associated only with injuries caused by cat bites; this connection was not described in earlier publications. We think that the rate of pasteurellosis is much higher than estimated because many patients with smaller injuries do not seek medical advice, and in many cases, general practice physicians try to treat smaller injuries and do not perform sample collection or order microbiological investigations. Our results, as well as international results, show that education about the possible health hazards associated with pet ownership should be provided, and the increased risks for infection in elderly and immunocompromised patients should be emphasized. 


\section{About the Author}

Dr. Körmöndi is an orthopedic surgeon in the Department of Traumatology, University of Szeged, Szeged, Hungary. His primary research interests are studies on injuries commonly affecting the musculoskeletal system, use of cutting-edge methods and treatment techniques in traumatology, investigation of bacterial infections following traumatic injury, and treatment of surgical site infections.

\section{References}

1. Shirzad Aski H, Tabatabaei M. Occurrence of virulence-associated genes in Pasteurella multocida isolates obtained from different hosts. Microb Pathog. 2016;96:52-7. http://dx.doi.org/10.1016/ j.micpath.2016.04.008

2. Christenson ES, Ahmed HM, Durand CM. Pasteurella multocida infection in solid organ transplantation. Lancet Infect Dis. 2015;15:235-40. http://dx.doi.org/10.1016/S1473-3099 (14)70895-3

3. Wilson BA, Ho M. Pasteurella multocida: from zoonosis to cellular microbiology. Clin Microbiol Rev. 2013;26:631-55. http://dx.doi.org/10.1128/CMR.00024-13

4. Megbetegedési veszély esetén kötelező védőoltások Magyarországon a 2017. évben. EMMI Kórházhigiénés és Járványügyi Felügyeleti Főosztály, editor. Védőoltás 2017. OSAP 1566. 2018 [cited 2018 Sep 3]. https://www.antsz.hu/data/ cms87737/Vedooltas_2017.pdf

5. Nollet V, Souply L, Rosolen B, Mohseni-Zadeh M, Martinot M. Risk factors for invasive pasteurellosis: a retrospective case study. Eur J Clin Microbiol Infec Dis. 2016;35:1975-81 https://dx.doi.org/10.1007/s10096-016-2749-y

6. Branch J, Kakutani T, Kuroda S, Shiba Y, Kitagawa I. Pasteurella multocida infective endocarditis: a possible link with primary upper respiratory tract infection. Intern Med. 2015;54:3225-31. http://dx.doi.org/10.2169/internalmedicine.54.4973

7. Giordano A, Dincman T, Clyburn BE, Steed LL, Rockey DC. Clinical features and outcomes of Pasteurella multocida infection. Medicine (Baltimore). 2015;94:e1285. http://dx.doi.org/10.1097/ MD.0000000000001285

8. Escande F, Lion C. Epidemiology of human infections by Pasteurella and related groups in France. Zentralbl Bakteriol. 1993;279:131-9. http://dx.doi.org/10.1016/S0934-8840(11)80499-8

9. Kumar A, Devlin HR, Vellend H. Pasteurella multocida meningitis in an adult: case report and review. Rev Infect Dis. 1990;12:440-8. http://dx.doi.org/10.1093/clinids/12.3.440

10. Raval P, Khan W, Haddad B, Mahapatra AN. Bite injuries to the hand-review of the literature. Open Orthop J. 2014;8:204-8. http://dx.doi.org/10.2174/1874325001408010204

11. Holst E, Rollof J, Larsson L, Nielsen JP. Characterization and distribution of Pasteurella species recovered from infected humans. J Clin Microbiol. 1992;30:2984-7.

12. Alberta Ministry of Agriculture and Rural Development. Consumer corner: Canadian pet market outlook, June 2014 [cited 2018 Jan 8]. http://www1.agric.gov.ab.ca/\$department/deptdocs.nsf/all/ sis14914/\$file/sarah_pet_june20_2014.pdf

13. Cherniack EP, Cherniack AR. The benefit of pets and animalassisted therapy to the health of older individuals. Curr Geronotol Geriatr Res. 2014;2014:623203. http://dx.doi.org/10.1155/ $2014 / 623203$

Address for correspondence: Gabriella Terhes, University of Szeged, Institute of Clinical Microbiology, Semmelweis Street 6, Szeged H-6725 Hungary; email: terhesga@gmail.com

\section{EI D Podcast: A Worm's Eye View}

Ben Taylor, cover artist for the August 2018 issue of EID, discusses how his personal experience with the Loa loa parasite influenced this painting.
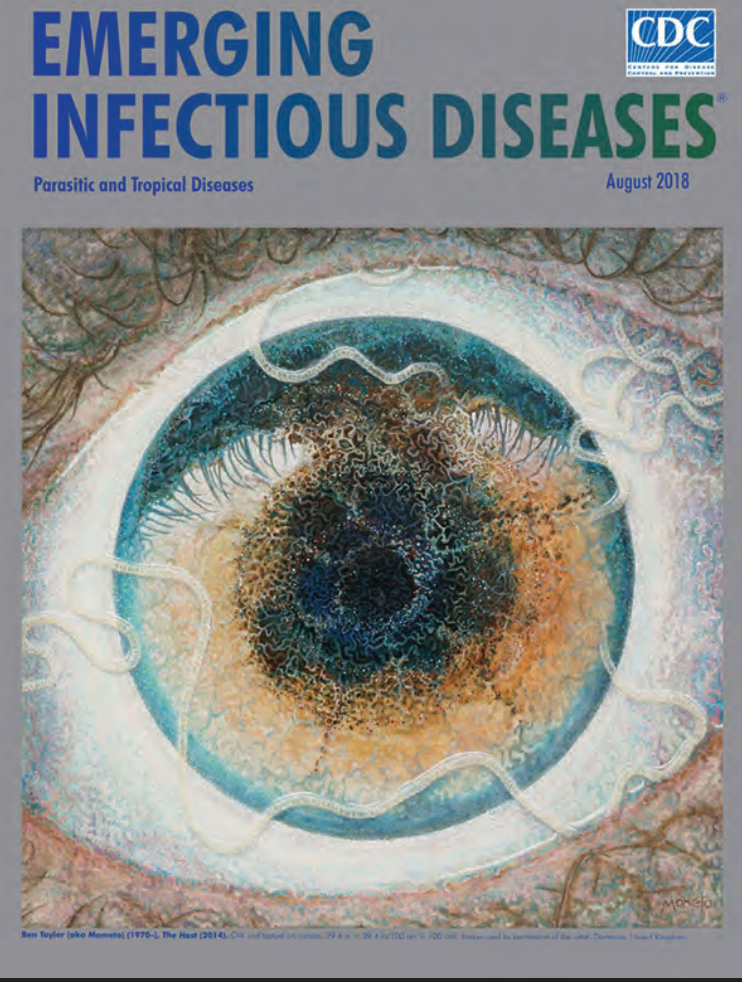

Visit our website to listen: https;/ / tools.cdc.gov/ medialibrary/ index.aspx\#/ media/ id/ 392605

EMERCINC INFECTIOUS DISEASES 
SYNOPSIS

\title{
Lassa Fever in Travelers from West Africa, 1969- 2016
}

\author{
Aaron Kofman, Mary J. Choi, Pierre E. Rollin
}

\begin{abstract}
Lassa virus is a rodentborne arenavirus responsible for human cases of Lassa fever, a viral hemorrhagic fever, in West Africa and in travelers arriving to non-Lassa-endemic countries from West Africa. We describe a retrospective review performed through literature search of clinical and epidemiologic characteristics of all imported Lassa fever cases worldwide during 1969-2016. Our findings demonstrate that approximately half of imported cases had distinctive clinical features (defined as fever and $\geq 1$ of the following: pharyngitis, sore throat, tonsillitis, conjunctivitis, oropharyngeal ulcers, or proteinuria). Delays in clinical suspicion of this diagnosis were common. In addition, no secondary transmission of Lassa fever to contacts of patients with lowrisk exposures occurred, and infection of high-risk contacts was rare. Future public health investigations of such cases should focus on timely recognition of distinctive clinical features, earlier treatment of patients, and targeted public health responses focused on high-risk contacts.
\end{abstract}

$\mathrm{O}$ riginally discovered in 1969, Lassa fever is a rodentborne viral hemorrhagic fever endemic to West Africa and caused by Lassa virus (1). The clinical course of Lassa fever is either not recognized or mild in $80 \%$ of patients; however, $\approx 20 \%$ of patients might experience severe disease, including facial swelling, hepatic and renal abnormalities, pulmonary edema, and hemorrhage. Although overall case-fatality rates for patients with Lassa fever is $\approx 1 \%$, rates among hospitalized case-patients are $\geq 15 \%$ (2). Intravenous adminstration of the antiviral drug ribavirin has become the standard of care for treatment of Lassa fever, but data on the efficacy of intravenous ribavirin are limited. The original study among Lassa fever patients in Sierra Leone found survival to be significantly higher $(p=0.0002)$ among those who obtained ribavirin within the first 6 days of illness (55\%) compared with those who never received the drug (5\%) (3). In the United States, intravenous ribavirin use is still considered investigational and may only be obtained through Emergency Investigational New Drug application to the US Food and Drug Administration (4).

Author affiliation: Centers for Disease Control and Prevention, Atlanta, Georgia, USA

DOI: https://doi.org/10.3201/eid2502.180836
Diagnosis of Lassa fever in patients arriving from West Africa might be challenging for healthcare providers unfamiliar with the spectrum of its clinical presentation, a challenge that is also common to the consideration of other viral hemorrhagic fevers in returning travelers (5-7). Additionally, although Lassa virus is not transmitted through casual contact, contact-tracing investigations of returning case-patients have often been large in scale (8). To quantify the frequency of case-patients having distinctive clinical features, time from patient presentation to clinical suspicion of a Lassa fever diagnosis, and the risk for secondary Lassa virus transmission, we performed a retrospective review of all 33 reported cases of Lassa fever imported from West Africa during 1969-2016.

\section{Methods}

We searched PubMed for publications using the terms "Lassa" and "Lassa fever." We identified additional articles by reviewing references in retrieved reports (9) and official correspondence by public health officials involved in these cases. We selected 74 publications discussing clinical or epidemiologic aspects of the 33 imported Lassa fever cases for review and collected information pertaining to case demographics, distinctive clinical features suggestive of Lassa fever, time from patient seeking care to clinical suspicion of Lassa fever, and number of contacts traced. We defined distinctive clinical features as fever and $\geq 1$ of the following: sore throat or pharyngitis, retrosternal chest pain, or proteinuria. We selected these features on the basis of the cumulative positive predictive value for fever, sore throat, retrosternal chest pain, and proteinuria for Lassa fever of 0.81 in a case-control study among 441 hospitalized patients in Sierra Leone (10). Although precise definitions varied between investigations, high-risk contacts were typically defined as contacts with substantial direct contact with patients or their body fluids.

\section{Findings}

During 1969-2016, a total of 33 patients traveling from 7 West Africa countries to 9 other countries were diagnosed with Lassa fever (Appendix Table 1, https://wwwnc.cdc. gov/EID/article/25/2/18-0836-App1.pdf). The median age of these patients was 45 years (range 18-72 years). Potential sources of Lassa fever exposures varied. Eleven 
patients were healthcare workers working in West Africa with either known or suspected exposures to Lassa fever patients; 4 patients had known exposure to rodents or history of travel to rural areas in West Africa. The only known risk factor for 18 patients was living in or traveling to West Africa. Twenty patients had illness onset during the West Africa dry season (November-April), and 10 patients had onset during the wet season (May-October); time of year for disease onset was not specified for 3 patients.

Twenty patients traveled to their destination on a commercial airliner; of these, 12 were symptomatic during flight. Ten patients were medically evacuated, 6 of whom had a known or suspected exposure to Lassa fever at the time of evacuation. Information on method of travel was not available for 3 patients. At the time patients sought care, medical providers were aware of travel history to West Africa for $26(87 \%)$ of 30 patients; ascertainment of travel histories by medical providers was not described for 3 cases.

Of the 29 patients for whom clinical information was available (Appendix Table 2), 17 (59\%) had fever and $\geq 1$ distinctive clinical features of Lassa fever. Time from patients seeking medical care to clinical suspicion of Lassa fever by clinical providers in their destination country ranged from 1 to 22 days (median 5 days). The time from when patients sought care to patient isolation ranged from 1 to 25 days (median 7 days). We found no reports of Lassa virus PCR testing performed on any patient before 2000; however, 9 of 16 patients (56\%) in 2000 and later years had a positive Lassa virus PCR test within 1-2 days of hospital admission. Of the 32 patients for whom information on isolation procedures were described, 24 patients were isolated at some point during their hospitalizations in their destination countries. Of these, 11 (34\%) patients were placed in a form of isolation immediately after they sought medical care; 3 patients were transferred to biocontainment units, and the remaining 8 patients were isolated with techniques ranging from standard precautions to a combination of contact, droplet, and airborne precautions. Of the 13 patients who were isolated later in their hospital stay, 2 patients were isolated with contact and airborne precautions, and 11 were subsequently transferred to specialized hospitals with infection control capacity designed for the care of patients with highly infectious diseases. Time to isolation ranged from 3 to 15 days after hospital admission (11). The last 2 patients who sought care in the United States were admitted to dedicated Ebola treatment units established during the 2014-2015 West Africa Ebola epidemic. Of the 31 patients for whom outcomes were described, 12 patients died, yielding a case-fatality rate of $39 \%$.

Treatment regimens were described for 23 patients. Twelve (52\%) patients initially received antimalarial medications or antimicrobial drugs because of clinical suspicion of malaria or another infectious disease during their treatment course. In total, intravenous ribavirin was ordered for 7 (30\%) patients. Four patients received intravenous ribavirin; 2 received a full course, and the other 2 died during treatment. Three patients had intravenous ribavirin ordered but died before receiving the medication.

Contact tracing investigations were either not performed or not described in the literature for 16 (48\%) patients. For the remaining 17 (52\%) patients, a total of 3,420 contacts were followed; the number of contacts followed per investigation ranged from 3 to 552 (median 173). Eleven contact investigations stratified contacts into high-risk and low-risk contacts, with some further separating high-risk contacts into first-line or second-line contacts (12). High-risk contacts were defined as having substantial exposure to patients or their body fluids, such as through direct unprotected exposure to blood or other body fluids from a case-patient. By these criteria, 139 total contacts were defined as being high-risk across 11 investigations. In 9 investigations, high-risk contacts accounted for $2 \%-8 \%$ of total contacts; in 2 investigations, they accounted for $40 \%-60 \%$ of total contacts.

Only 2 cases of secondary transmission of Lassa virus occurred, both in Germany. Neither of the source casepatients for these 2 patients was isolated. The first instance of transmission occurred to a physician who performed a physical examination, obtained intravenous access, and obtained blood samples from a Lassa fever patient without wearing any personal protective equipment (13). Because of the physician's high-risk exposure, ribavirin prophylaxis was initiated and completed. Serologic testing was performed and yielded IgG titers of 1:320 specific to the strain of Lassa virus from the case-patient, indicating probable seroconversion in the physician. However, the physician remained asymptomatic.

The second instance of secondary transmission, reported in 2016, occurred in a mortician who handled the body of a healthcare worker who was evacuated from Togo to Germany and diagnosed with Lassa fever retrospectively. The mortician reported wearing 2 pairs of gloves when handling the corpse but did not wear an apron or a facial mask. The mortician reported mild upper respiratory tract symptoms before contact with the deceased patient. However, 4 days after handling the corpse, his symptoms worsened. Six days after handling the corpse, the mortician tested positive for Lassa virus by real-time reverse transcription PCR. The mortician's clinical course was notable for fever, upper respiratory tract symptoms, and pharyngeal erythema with exudates, myalgias, and arthralgias. He received intravenous ribavirin for 10 days and oral favipiravir for 4 days, with gradual resolution of his symptoms and clinical recovery $(14,15)$. Contacts of this secondary casepatient were followed but did not indicate any evidence of further transmission. 


\section{Discussion}

The 33 cases of imported Lassa fever that occurred during 1969-2016 posed a similar set of challenges: timely diagnosis of a rare infectious disease not endemic to the patient's destination country, timely treatment, and prevention of Lassa virus transmission to contacts. Among patients who were not medically evacuated, the median number of days from patient presentation to clinical suspicion of Lassa fever by clinicians in the destination country was 5 days. Several factors might have contributed to this delay in diagnosis. First, patients were seen by providers in countries where Lassa fever is not endemic, requiring consideration of a travel-associated illness infrequently encountered outside of West Africa. Second, in many cases, the patients' travel to West Africa was not known at the time they initially sought care. Third, the clinical findings of Lassa fever are variable, ranging from nonspecific symptoms, such as fever, nausea, and myalgias in the early phase, to more distinctive features later, including pharyngitis, sore throat, tonsillitis, oropharyngeal ulcers, facial and neck swelling, conjunctival injection, and proteinuria. Hemorrhage is usually seen only in a minority of cases. Although fever and $\geq 1$ distinctive clinical features can be suggestive of the diagnosis, they were only present in $59 \%$ of patients. In addition, of patients with a known travel history to West Africa, 12 (48\%) did not demonstrate distinctive clinical features of Lassa fever. As such, providers encountering patients who have a nonspecific febrile illness after travel to West Africa should elicit a travel history and consider Lassa fever early in the differential diagnosis. Suspicion should be especially high for those patients with fever and $\geq 1$ of the distinctive features we have described. Although most returning travelers from West Africa with Lassa fever in 2000 or later had viremia confirmed through a positive Lassa virus test obtained within 1-2 days of admission, some patients did not have their illness diagnosed until weeks into their illness. Samples of patients with suspected Lassa fever should be obtained as early as possible and tested by Lassa virus PCR at a reference laboratory; most reference laboratories in Europe and elsewhere have demonstrated proficiency in performing Lassa virus molecular diagnostics $(16,17)$.

Treatment of Lassa fever comprises effective supportive care and use of intravenous ribavirin. Although timely treatment with intravenous ribavirin depends on successful procurement of the drug, it also rests on early consideration of the diagnosis, and might even be administered before laboratory confirmation of Lassa fever diagnosis in patients with severe illness. The relative minority of case-patients who received intravenous ribavirin in our review highlights the importance of early consideration of Lassa fever in the differential diagnosis for appropriate patients.

Infection control was another challenge encountered by medical providers and healthcare systems caring for
Lassa fever patients. The lack of appropriate use of isolation or barrier precautions in the 2 instances of secondary transmission speaks to the importance of adhering to standard precautions when caring for all patients, regardless of their diagnosis or presumed infectious status. In addition, the case of secondary transmission to the mortician in Germany illustrates the importance of maintenance of standard precautions during autopsy. Early consideration of Lassa fever as a diagnosis might also enable early institution of isolation and prevention of secondary transmission. Among those case-patients for whom a specific form of isolation was specified, most were admitted to high-security containment facilities or negative-pressure rooms with airborne precautions. Although these forms of isolation can prevent secondary transmission of Lassa virus, simple barrier or contact precautions have also been demonstrated to be safe and are less expensive and labor-intensive $(5,18)$.

Contact tracing investigations frequently involved hundreds of contacts and a substantial investment of time and labor on the part of public health teams. One investigation noted that "active surveillance of contacts by public health teams was impracticable and required enormous resources, involving over 3,000 communications” (6). Most investigations were similarly comprehensive, involving identification and longitudinal follow-up of case-patients' friends, family, and casual contacts, including airplane passengers, as well as numerous healthcare staff. Contacts were often separated into 2 categories: high-risk (i.e., having substantial exposure to case-patients) and low-risk (i.e., having only casual contact or proximity to case-patients). However, body temperature monitoring, home visits, and serologic testing were frequently coordinated for contacts in both high- and low-risk categories. To minimize the burden on public health systems and maximize the likelihood of successful secondary case identification, future responses should consider focusing on investigating high-risk contacts exclusively.

Our review had several limitations. Information on historic cases, particularly those before 1985, was incomplete and limited. In some cases, reports provided scant or no information on the physical examination or laboratory studies of patients upon admission. Reports on contact tracing provided different degrees of detail, and levels of risk assessment were variable between investigations.

With the ease and frequency of international travel, Lassa fever will continue to be encountered by healthcare providers in countries where Lassa fever is not endemic. Strict maintenance of standard infection control precautions in healthcare is critical for all patients and will help prevent secondary transmission of Lassa virus. Timely recognition of distinctive clinical features, earlier treatment of patients, and targeted public health responses focused on high-risk contacts will also be important components of future responses to imported cases of Lassa fever. 


\section{About the Author}

Dr. Kofman is an Epidemic Intelligence Service Officer in the Viral Special Pathogens Branch, Division of HighConsequence Pathogens and Pathology, National Center for Emerging and Zoonotic Infectious Diseases, CDC. His research interests are viral hemorrhagic fevers, including Lassa fever and Ebola virus disease.

\section{References}

1. Frame JD, Baldwin JM Jr, Gocke DJ, Troup JM. Lassa fever, a new virus disease of man from West Africa. I. Clinical description and pathological findings. Am J Trop Med Hyg. 1970;19:670-6. http://dx.doi.org/10.4269/ajtmh.1970.19.670

2. World Health Organization. Lassa fever fact sheet [cited 2018 May 15]. http://www.who.int/mediacentre/factsheets/fs179

3. McCormick JB, King IJ, Webb PA, Scribner CL, Craven RB, Johnson KM, et al. Lassa fever. Effective therapy with ribavirin. N Engl J Med. 1986;314:20-6. http://dx.doi.org/10.1056/ NEJM198601023140104

4. Riner A, Chan-Tack KM, Murray JS. Original research: Intravenous ribavirin — review of the FDA's Emergency Investigational New Drug Database (1997-2008) and literature review. Postgrad Med. 2009;121:139-46. http://dx.doi.org/10.3810/ pgm.2009.05.2014

5. Fisher-Hoch SP, Price ME, Craven RB, Price FM, Forthall DN, Sasso DR, et al. Safe intensive-care management of a severe case of Lassa fever with simple barrier nursing techniques. Lancet. 1985;2:1227-9. http://dx.doi.org/10.1016/S0140-6736(85)90752-4

6. Crowcroft NS, Meltzer M, Evans M, Shetty N, Maguire H, Bahl M, et al. The public health response to a case of Lassa fever in London in 2000. J Infect. 2004;48:221-8. http://dx.doi.org/ 10.1016/j.jinf.2003.11.009

7. Beeching NJ, Fletcher TE, Hill DR, Thomson GL. Travellers and viral haemorrhagic fevers: what are the risks? Int J Antimicrob Agents. 2010;36(Suppl 1):S26-35. http://dx.doi.org/10.1016/ j.ijantimicag.2010.06.017

8. Galbraith NS, Berrie JRH, Forbes P, Young S. Public health aspects of viral haemorrhagic fevers in Britain. R Soc Health J. 1978; 98:152-60. http://dx.doi.org/10.1177/146642407809800407

9. Macher AM, Wolfe MS. Historical Lassa fever reports and 30-year clinical update. Emerg Infect Dis. 2006;12:835-7. http://dx.doi.org/10.3201/eid1205.050052
10. McCormick JB, King IJ, Webb PA, Johnson KM, O’Sullivan R, Smith ES, et al. A case-control study of the clinical diagnosis and course of Lassa fever. J Infect Dis. 1987;155:445-55. http://dx.doi.org/10.1093/infdis/155.3.445

11. Smith PW, Anderson AO, Christopher GW, Cieslak TJ, Devreede GJ, Fosdick GA, et al. Designing a biocontainment unit to care for patients with serious communicable diseases: a consensus statement. Biosecur Bioterror. 2006;4:351-65. http://dx.doi.org/10.1089/bsp.2006.4.351

12. Cooper CB, Gransden WR, Webster M, King M, O’Mahony M, Young S, et al. A case of Lassa fever: experience at St Thomas's Hospital. Br Med J (Clin Res Ed). 1982;285:1003-5. http://dx.doi.org/10.1136/bmj.285.6347.1003

13. Haas WH, Breuer T, Pfaff G, Schmitz H, Köhler P, Asper M, et al. Imported Lassa fever in Germany: surveillance and management of contact persons. Clin Infect Dis. 2003;36:1254-8. http://dx.doi.org/10.1086/374853

14. Raabe VN, Kann G, Ribner BS, Morales A, Varkey JB, Mehta AK, et al.; Emory Serious Communicable Diseases Unit. Favipiravir and Ribavirin Treatment of Epidemiologically Linked Cases of Lassa Fever. Clin Infect Dis. 2017;65:855-9. http://dx.doi.org/ $10.1093 / \mathrm{cid} / \mathrm{cix} 406$

15. Ehlkes L, George M, Samosny G, Burckhardt F, Vogt M, Bent S, et al. Management of a Lassa fever outbreak, RhinelandPalatinate, Germany, 2016. Euro Surveill. 2017;22:1-8. http://dx.doi.org/10.2807/1560-7917.ES.2017.22.39.16-00728

16. Nikisins S, Rieger T, Patel P, Müller R, Günther S, Niedrig M. International external quality assessment study for molecular detection of Lassa virus. PLoS Negl Trop Dis. 2015;9:e0003793. http://dx.doi.org/10.1371/journal.pntd.0003793

17. Trombley AR, Wachter L, Garrison J, Buckley-Beason VA, Jahrling J, Hensley LE, et al. Comprehensive panel of real-time TaqMan polymerase chain reaction assays for detection and absolute quantification of filoviruses, arenaviruses, and New World hantaviruses. Am J Trop Med Hyg. 2010;82:954-60. http://dx.doi.org/10.4269/ajtmh.2010.09-0636

18. Helmick CG, Webb PA, Scribner CL, Krebs JW, McCormick JB. No evidence for increased risk of Lassa fever infection in hospital staff. Lancet. 1986;2:1202-5. http://dx.doi.org/10.1016/ S0140-6736(86)92206-3

Address for correspondence: Aaron Kofman, Centers for Disease Control and Prevention, 1600 Clifton Rd NE, Atlanta, GA 30329-4027, USA; email: yct7@cdc.gov 


\title{
Ebola Virus I nfection Associated with Transmission from Survivors
}

\author{
Saskia Den Boon, ${ }^{1}$ Barbara J. Marston, ${ }^{1}$ Tolbert G. Nyenswah, Amara Jambai, \\ Moumie Barry, Sakoba Keita, Kara Durski, Schabbethai S. Senesie, Devin Perkins, Anita Shah, \\ Hugh H. Green, Esther L. Hamblion, Margaret Lamunu, Alex Gasasira, Nuha O. Mahmoud, \\ Mamadou H. Djingarey, Oliver Morgan, Ian Crozier, Christopher Dye
}

\begin{abstract}
Ebola virus (EBOV) can persist in immunologically protected body sites in survivors of Ebola virus disease, creating the potential to initiate new chains of transmission. From the outbreak in West Africa during 2014-2016, we identified 13 possible events of viral persistence-derived transmission of EBOV (VPDTe) and applied predefined criteria to classify transmission events based on the strength of evidence for VPDTe and source and route of transmission. For 8 events, a recipient case was identified; possible source cases were identified for 5 of these 8 . For 5 events, a recipient case or chain of transmission could not be confidently determined. Five events met our criteria for sexual transmission (male-to-female). One VPDTe event led to at least 4 generations of cases; transmission was limited after the other events. VPDTe has increased the importance of Ebola survivor services and sustained surveillance and response capacity in regions with previously widespread transmission.
\end{abstract}

The 2014-2016 outbreak of Ebola virus disease (EVD) 1 in West Africa was the largest since the discovery of the Ebola virus (EBOV) in 1976 (1). More than 28,000 cases and 11,000 deaths were reported from the 3 most affected countries (Guinea, Liberia, and Sierra Leone) (2). An unprecedented number of persons survived; $>4,500$ of the estimated total of $>10,000$ survivors have been registered in the 3 countries (3).

Author affiliations: World Health Organization, Geneva,

Switzerland (S. Den Boon, K. Durski, D. Perkins, A. Shah,

O. Morgan, I. Crozier, C. Dye); Centers for Disease Control and

Prevention, Atlanta, Georgia, USA (B.J. Marston, S.S. Senesie,

H.H. Green, O. Morgan); National Public Health Institute,

Monrovia, Liberia (T.G. Nyenswah); Ministry of Health and

Sanitation, Freetown, Sierra Leone (A. Jambai); Ministry of Health,

Conakry, Guinea (M. Barry, S. Keita); World Health Organization,

Monrovia, Liberia (E.L. Hamblion, A. Gasasira, N.O. Mahmoud);

World Health Organization, Freetown, Sierra Leone (M. Lamunu);

World Health Organization, Conakry (M.H. Djingarey); University

of Oxford, Oxford, UK (C. Dye)

DOI: https://doi.org/10.3201/eid2502.181011
EVD survivors often have substantial long-term medical sequelae (4), and viable EBOV can persist in immunologically protected body sites, such as the male gonads and the chambers of the eye $(5,6)$. Viral persistence in body fluids, such as semen, creates the potential for transmission and initiation of new chains of transmission weeks or months after continuous community transmission has ended (7). On January 14, 2016, the World Health Organization (WHO) declared that human-to-human transmission had been stopped in West Africa. However, WHO and its partners indicated that the 3 affected countries remained at high risk for additional EVD outbreaks because of virus persistence in survivors and emphasized the need for strong surveillance and response systems (8). A new EVD case was confirmed in Sierra Leone the following day (9), and another outbreak comprising cases in both Guinea and Liberia was recognized in March $2016(2,10)$.

Infectious virus has been isolated from semen of Ebola survivors 82 days after symptom onset (11), and EBOV RNA has been detected by reverse transcription PCR (RT-PCR) in semen 531 days after symptom onset (10). Other body fluids, such as vaginal fluids, breast milk, urine, feces, sweat, and saliva, also have been shown to be RT-PCR-positive for short periods after recovery of the patient (11). Some evidence indicates that transmission could occur through breast milk (12), but confirmed transmission from viral persistence in the other body fluids has not been described (13). Before the West Africa EVD outbreak, 1 case of Marburg disease (14) and 1 possible case of EVD (15) attributed to sexual transmission had been reported. From the EVD outbreak in West Africa, several incidents of possible sexual transmission of EBOV from EVD survivors have been described in detail (10,16-19), as have viral persistence-derived transmission of EBOV (VPDTe) events for which the mode of transmission was unknown (12,20-22).

We describe a series of EBOV transmission events with evidence of transmission related to viral persistence in EVD survivors. Our findings are relevant for response planning, especially related to surveillance

\footnotetext{
${ }^{1}$ These authors contributed equally to this article.
} 
and response capacity, and for the development of policies and guidelines regarding survivor counseling, care, and management.

\section{Methods}

We defined VPDTe as the person-to-person transmission of EBOV from an EVD survivor (source) to another person (recipient) that occurred $>21$ days after the source case recovered from acute infection. The WHO definition of recovery is $\geq 3$ days without any fever or symptom and negative blood RT-PCR for EBOV; however, this documentation was not available for all patients (23). The 21-day period reflects the upper limit of the incubation period for EVD; incorporating this period into the definition reduces the likelihood that the recipient was not infected during the period of acute infection of the source. The recipient is the person who becomes infected as a result of VPDTe. A recipient might or might not be the first person (index person) detected in a newly identified cluster of EVD cases (and in some situations, clearly identifying the recipient might not be possible). We defined confirmed, probable, and suspected cases of EVD and EVD survivors in accordance with WHO definitions (24).

We focused our identification of VPDTe events on the period after control of the most intense periods of transmission in the affected countries and retrieved information about possible VPDTe events identified after February 19, 2015 (after the initial interruption of ongoing transmission in Liberia). During this time, low case counts facilitated recognition and subsequent in-depth case investigation of new EVD cases that were not clearly related to continuous disease transmission in the community and might have resulted from exposure to a survivor with viral persistence. In September 2015, we began to maintain a formal list of suspected VPDTe events identified by staff involved in epidemiologic investigations in the 3 countries. The data were entered retrospectively or prospectively into the formal list.

For all events, the field teams collected information at the time the case or cluster of cases was detected. We extracted data from available databases, WHO Situation Reports, region- and country-specific situation reports, email correspondences to the WHO Ebola Response Information Management team, case investigation reports, transmission chains (including the number of additional cases and generations in the cluster), and genetic sequencing results. We captured demographic data; dates of symptom onset, diagnosis, discharge, and death; laboratory results; epidemiologic investigation details; sequencing data; data on how the cases were initially recognized; information on encounters with healthcare providers; details of outbreak control efforts; and information about the secondary cases.

We developed criteria to determine which transmission events qualified as resulting from viral persistence (Table 1).
We also developed criteria for source of transmission (Table 2), mode of transmission, and the strength of the evidence for transmission (strong, moderate, or weak) (Table 3). If the investigation identified $>1$ possible mode of transmission, these criteria for strength of evidence and evaluation of the route of transmission were not tabulated. Two investigators (S.D., B.J.M.) independently reviewed and classified each transmission event, and a third (S.S.S.) resolved differences.

The WHO Ethics Review Committee (ERC.0002736) approved this activity, and the Centers for Disease Control and Prevention classified it as a nonresearch program activity. The analysis of these surveillance data from the EVD epidemic was approved by representatives of the Ministry of Health in each of the 3 countries and was not considered to require additional ethics review. In accordance with the approved protocols, we have omitted information that would enable identification of specific persons.

\section{Results}

We identified 13 transmission events that met criteria for VPDTe during the evaluation period (Appendix, https:// wwwnc.cdc.gov/EID/article/25/2/18-1011-App1.xlsx). We identified a recipient for 8 events; among these, 7 were female. Ages of all recipients ranged from 16 to 55 years. For the remaining 5 events, the recipient was not clearly identified, and the first person identified in the cluster might or might not have been the recipient. For these VPDTe events, we report details for the first person identified. Eight of the 13 events have previously been described separately in the context of outbreak investigations $(10,12,16-22)$.

\section{Description of VPDTe Events Not Previously Described Elsewhere}

\section{Event 1}

Postmortem testing determined the recipient in this event had EVD. No cases had occurred in the immediate area during the 7 weeks before the report of the index person. Although initial epidemiologic investigation suggested possible exposures through funeral attendance, viral sequencing suggested a link to an EVD cluster that had occurred in a nearby geographic area $\approx 7$ weeks earlier. That cluster included 1 male survivor; he reported sexual contact with the recipient. A semen sample from the survivor tested positive for EBOV RNA by RT-PCR. Sexual contact was considered the likely route of transmission.

\section{Event 5}

The recipient in this event died in the community the same day as symptom onset; EVD was confirmed by testing of a postmortem oral swab sample. Based on genetic sequencing, the virus from the recipient did not group with ongoing 
chains of transmission but did group with sequences from viruses identified earlier in the epidemic. Epidemiologic investigations showed the recipient had had sexual contact with a male EVD survivor 2 months after his discharge from an Ebola treatment unit and $\approx 1-3$ weeks before she became symptomatic. Semen from the survivor was not tested, but EBOV RNA from a stored blood sample collected during the survivor's initial illness showed genetic sequence that was similar to that of the recipient.

\section{Event 6}

In this event, a young woman with symptoms of EVD sought care at a healthcare facility, and EVD was confirmed by RT-PCR. Epidemiologic investigation found no history of travel, funeral attendance, or bush meat consumption. There was no known ongoing transmission in the village or district. Sequences of viral RNA from the recipient clustered with isolates from cases that occurred in the same area 5-11 months earlier but differed substantially from available individual sequences from persons with contemporaneous confirmed EVD. The route of transmission is unknown.

\section{Event 8}

In this event, a man had EVD confirmed based on a swab specimen collected after his death. Sequencing linked his virus to viruses from cases 5 months earlier in a different district. No specific epidemiologic links to recent or more remote cases were identified. The source and route of transmission are unknown.

\section{Event 9}

This event involved EVD reported in a woman 2 days after her death and confirmed by testing of a postmortem oral swab sample. Her viral sequence did not match contemporary circulating strains of EBOV but did link to strains from $\approx 5-6$ months earlier. Her husband spent time in both the community where she lived and in the capital city; he had experienced an illness compatible
Table 1. Criteria for the qualification of Ebola virus persistencederived transmission event*

\begin{tabular}{lc}
\hline Criteria no. & Explanation \\
\hline 1 & $\begin{array}{c}\text { Sequencing provides links to a case or cases that } \\
\text { occurred }>21 \text { days before the index person and not } \\
\text { to a more recent case } \\
\text { OR }\end{array}$ \\
\hline 2 & $\begin{array}{c}\text { Absence of known exposure of the presumed } \\
\text { recipient (or index person) to a person with Ebola } \\
\text { virus disease in the 21 days before infection } \\
\text { AND }\end{array}$ \\
No evidence of ongoing transmission in the \\
community where case or cluster was recognized \\
AND
\end{tabular}

with EVD 5-6 months earlier but had not been tested. Two other persons had died recently in the family (a cowife and the child of the co-wife), and a stillbirth occurred (to the niece of the index person); no testing for EVD had been conducted in these situations. Transmission had not been recognized in the community before the recognition of this cluster of illness, and there was no known exposure to an ill person or funeral. The source and route of transmission are unknown. One possible explanation is that the husband was an EVD survivor and had transmitted EBOV through sexual or other contact to $\geq 1$ members of the family; direct transmission also might have occurred from close contact.

\section{Mode of Transmission and Strength of Evidence}

For 4 events, we could not identify a single clear hypothesis for how transmission occurred. All 4 of these have been described in separate publications $(12,16,21,22)$. Five events met our defined criteria for sexual transmission (Appendix Table). The evidence was strong for 4 events and moderate for 1 event. Among these 5 VPDTe events of suspected sexual transmission, we identified the survivor believed to be the source; all were male. The other 8 VPDTe transmission events for which the mode of transmission is unknown were considered to be due to survivor transmission because

Table 2. Strength of evidence and criteria for source person for Ebola virus disease*

Strength of evidence Criteria

Strong, A+B + C A. Epidemiologic link between recipient or index person and single proposed/probable source established AND

B. EBOV RNA detected in a specimen taken from the proposed/probable source after recovery AND

C. Sequencing indicates linkage to virus recovered from recipient or index person

Moderate, $A+B$ or A + C A. Epidemiologic link between recipient or index person and proposed/probable source established AND

B. EBOV RNA detected in a specimen taken from the proposed/probable source after recovery OR

C. Sequencing indicates linkage to virus recovered from recipient or index person

\begin{tabular}{ll} 
Weak & Epidemiologic link between recipient or index person and proposed/probable source established \\
\hline Not identified & $\begin{array}{l}\text { No epidemiologic link between recipient or index person and proposed/probable source could be } \\
\text { established }\end{array}$
\end{tabular}

${ }^{*}$ Results of application of these criteria were included in the Appendix Table (https://wwwnc.cdc.gov/EID/article/25/2/18-1011-App1.xlsx) only when a single possible transmission scenario emerged after case investigation and review. EBOV, Ebola virus. 
Table 3. Strength of evidence and criteria for sexual transmission of Ebola virus*

\begin{tabular}{|c|c|}
\hline Strength of evidence & Criteria \\
\hline Strong, $A+B+C$ & $\begin{array}{l}\text { A. Epidemiologic investigation identified sexual contact between recipient or index person and single } \\
\text { proposed/probable source } \\
\text { AND } \\
\text { B. EBOV detected in single proposed/probable source's semen or vaginal secretions (by a vaginal } \\
\text { swab) by RT-PCR } \\
\text { AND } \\
\text { C. Sequencing indicates high likelihood of transmission to recipient }\end{array}$ \\
\hline Moderate, $A+B$ or $A+C$ & $\begin{array}{l}\text { A. Epidemiologic investigation identified sexual contact between recipient or index person and single } \\
\text { proposed/probable source } \\
\text { AND } \\
\text { B. EBOV detected in single proposed/probable source's semen or vaginal secretions (by a vaginal } \\
\text { swab) by RT-PCR } \\
\text { OR } \\
\text { C. Sequencing indicates high likelihood of transmission to recipient }\end{array}$ \\
\hline Weak & $\begin{array}{l}\text { Epidemiologic investigation identified sexual contact between recipient or index person and single } \\
\text { proposed/probable source } \dagger\end{array}$ \\
\hline None & No report of sexual contact \\
\hline
\end{tabular}

they were isolated cases and sequencing results linked them to previous transmission chains. The routes of transmission are unknown.

\section{Detection and Response}

In 10 VPDTe events, EBOV infection was diagnosed in the index person on the basis of a postmortem sample, or it was preceded by deaths that met the definition for probable EVD; ultimately, all but 1 of the index persons or recipients of VPDTe died. Eight recipients had reported encounters with health providers before being tested for and receiving a diagnosis of EVD. For 6 VPDTe events, cases occurred in addition to the first index person (range 1-12 cases; Appendix Table). Most clusters were limited to 0 or 1 additional generation of cases, but in 1 cluster, several additional generations occurred.

After detection of the index person, response activities such as isolation and management of the index patient and contact tracing with isolation of high-risk and symptomatic contacts were initiated for all events. Seven cases occurred after initial control of ongoing transmission in a specific country and required reactivation of some response resources. Searches for missing contacts were intense and continued until at least the end of the initial 21-day follow-up period. For some clusters, there were difficulties engaging with local communities, complicating contact tracing. For at least 8 events, Ebola vaccine was provided to contacts and to contacts of contacts under research protocols and emergency use licensure.

\section{Discussion}

On March 29, 2016, WHO declared the end of the Public Health Emergency of International Concern regarding the EVD outbreak in West Africa (25). In the declaration, WHO emphasized that new EVD clusters would continue to occur because of reintroductions of EBOV from survivors. Our case series summarized 13 such events.

Most of the events we describe were initially recognized because they occurred in isolation, in areas that EBOV had not previously affected, or well after community transmission had ended. Plausible explanations for such cases include recrudescence of prior EVD, reintroduction from a zoonotic reservoir, transmission resulting from unrecognized contact with a person with active EVD, or transmission related to viral persistence. Recrudescence might have played a role in event 11, but EVD was not confirmed in the mother of the index person at the time of her initial EVD-like illness, and there was no documentation that she was shedding EBOV in the period preceding illness in the index person (22). We do not believe any of the other events described here occurred because of EBOV recrudescence. Based on sequencing data, the cases we describe were genetically related to other cases that occurred as part of human-to-human transmission in the West Africa epidemic; no evidence exists to indicate these cases resulted from reintroduction from a zoonotic reservoir. Given the absence of additional recognized transmission events, we believe it highly unlikely that the cases we summarized were part of undetected transmission chains.

Routes of VPDTe are not fully understood. We found evidence of sexual transmission in at least 5 of the events; sexual transmission might have played a role in additional events, but we cannot exclude other modes of VPDTe. EBOV was found in the breast milk of a woman in 1 cluster; transmission through breast milk might have occurred in this event.

We are unable to quantify the risk for VPDTe over time. There have been a limited number of cases of recognized sexual transmission, even though $>10,000$ persons are estimated to have survived (3). The number of male survivors who have EBOV persisting in semen declines 
over time, reducing the likelihood of events caused by sexual transmission (26). Transmission because of viral persistence in body fluids other than semen might occur but probably less frequently $(3,12,13)$.

WHO's interim advice on the sexual transmission of EBOV is that male EVD survivors should continue to practice safer sex (i.e., correct and consistent condom use or abstinence) for at least 12 months after symptom onset or until their semen has twice tested negative (27). This case series highlights 2 events of VPDTe that occurred $>1$ year after recovery by the source case. This information, along with information about the duration of persistence of EBOV RNA in the semen of survivors and data showing that EBOV RNA can be detected intermittently $(7,28)$, needs to be considered in the development of recommendations for EVD survivors. Furthermore, recommendations on semen testing and safer sex practices, including timely updates if recommendations are revised in light of new evidence, must be clearly communicated to EVD survivors and to the public.

Ideally, counseling and testing should be offered as part of a comprehensive package of care for survivors that recognizes the challenges faced by survivors, including health problems, mental health problems, rejection, and stigma (29-33). Furthermore, partners and family members of EVD survivors need to be counseled, and community education about VPDTe needs to be provided.

An important element of surveillance for EVD is that early recognition of isolated cases is difficult. Despite the context of a recently controlled enormous EVD epidemic, most of the VPDTe cases were recognized very late in illness or after death. This finding speaks to the nonspecificity of EVD symptoms; the high prevalence of other diseases with similar symptoms; and the limited resources for identifying the specific cause of disease in low-resource settings, such as West Africa. Wider availability of diagnostic testing, for example with rapid tests, may support more timely diagnosis than would otherwise have been possible.

One new case of EVD could potentially result in large numbers of secondary cases (34). Therefore, it is critical to sustain the capacity to respond rapidly, particularly after an EVD outbreak, including the capacity to conduct outbreak investigation and trace contacts; efficient collection, transport, and laboratory diagnosis of specimens; isolation and clinical management of cases; and, as appropriate, vaccination of contacts and contacts of contacts.

The responses to the events we describe were generally robust, and transmission was in most instances limited to 1 generation. This observation reflects the control capacity generated in the context of the broad outbreak response, a result of enormous effort on behalf of the governments and ministries of health of the affected countries and immense mobilization of resources from the international community and international partners.

Identifying routes of EBOV transmission is not straightforward. Rigorous epidemiologic investigation and evaluation of viral RNA sequences can provide helpful information. Sequencing helped to confirm the link to an epidemiological source for several cases and for some cases suggested a link that was later confirmed epidemiologically. Given this contribution, we believe that sequencing can play a critical role in efforts to control infectious diseases. Still, for several situations that appeared to involve viral persistence, the route of transmission was unclear, and even when we identified a single likely route of transmission, we could not exclude the possibility that we missed alternate possible routes of transmission.

Our findings are subject to several additional limitations. Specifically, our list of described events is unlikely to include all events of VPDTe. Particularly at the height of the outbreak, distinguishing between direct transmission from active EVD cases and VPDTe was not possible, and we therefore concentrated on describing cases that occurred after control of the most intense periods of transmission in the affected countries. Another study identified 2 additional EVD clusters possibly resulting from VPDTe by using the signature of a reduced evolutionary rate (21). Further analysis of sequence data from cases in West Africa might identify additional events of possible VPDTe. In the future, expanded use of sequencing and semen testing could help identify additional events.

Taking these limitations into consideration, the number of events identified here most likely underestimates VPDTe in West Africa. Furthermore, the information and evidence for each event was collected on an ad hoc basis, depending on the characteristics of the particular event. Where available, we collected information about viral sequence using various methods, and we relied on the reports and interpretations of sequence data rather than an analysis of the primary data. In some instances, source case documents included conflicting information and the deaths of all but 1 recipient or index person limited the epidemiologic investigations. As a result, information about some of the events might be incomplete; despite intense investigation, in some cases, critical questions remain about how transmission occurred.

Our report has several key implications. EVD cases and clusters might occur after initial control of an EVD outbreak. Although previously available science supported the possibility of viral persistence, the West Africa outbreak clearly illustrated the potential consequences of EBOV persistence in terms of program needs, stigmatization of survivors, and risk that transmission from a survivor with persistent virus will trigger a new cluster. With this new reality, it is critical that the responses to EVD clusters include 
sustained vigilance, maintenance of response capacity, and continued efforts to reduce the risks that survivors in whom EBOV persists will transmit infection.

\section{Acknowledgments}

We thank the many field staff from Guinea, Liberia, and Sierra Leone involved in EVD case finding, treatment, and testing of patients; contact tracing; epidemiologic investigations;

sequencing; data collection; and data entry, including all members of the Guinea National Ebola Response team; Boubacar Diallo, Luke Bawo, Mosoka Fallah, all members of the Liberia Ebola Incidence Management System; Roland Conteh, and all members of the Sierra Leone National Ebola Response Centre; as well as Pierre Formenty, Stéphane Hugonnet, Patrick Otim, Dhamari Naidoo, Philomena Raftery, Shalini Singaravelu, Lisa Thomas, Annika Wendland, Sina Zintmeyer, Mame A. Akyeampong, M. Balihe, Sarah D. Bennett, David Blackley, A. Christie, B. Dahl, Emily K. Dokubo, David L. Fitter, S. Hersey, Barbara Knust, Anthony S. Laney, Lise D. Martel, Dan W. Martin, Eric O.K. Mensah, E. Meyer, Maria Negron, Fatima Ravat, John T. Redd, Pierre Rollin, Kendra Stauffer, Brittany Sunshine, Emily Weston, Desmond Williams, Mary Claire Worrell, Jonathan S. Yoder, James Zingeser, and F.-W. Tremblay.

\section{About the Author}

Dr. Den Boon is an epidemiologist and health economist currently working as a freelance consultant. Her primary research interests include priority setting of health interventions and implementation research to improve access to medicines.

\section{References}

1. Ebola haemorrhagic fever in Sudan, 1976. Report of a WHO/ International Study Team. Bull World Health Organ. 1978; 56:247-70.

2. World Health Organization. Ebola situation report 30 March 2016 [cited 2016 Apr 11] http://apps.who.int/ebola/current-situation/ ebola-situation-report-30-march-2016

3. World Health Organization. Clinical care for survivors of Ebola virus disease. Interim guidance [cited 2016 Apr 11]. http://www.who.int/ $\mathrm{csr} /$ resources/publications/ebola/guidance-survivors/en/

4. Clark DV, Kibuuka H, Millard M, Wakabi S, Lukwago L, Taylor A, et al. Long-term sequelae after Ebola virus disease in Bundibugyo, Uganda: a retrospective cohort study. Lancet Infect Dis. 2015;15:905-12. http://dx.doi.org/10.1016/ S1473-3099(15)70152-0

5. Bausch DG, Towner JS, Dowell SF, Kaducu F, Lukwiya M, Sanchez A, et al. Assessment of the risk of Ebola virus transmission from bodily fluids and fomites. J Infect Dis. 2007;196(Suppl 2):S142-7. http://dx.doi.org/10.1086/520545

6. Varkey JB, Shantha JG, Crozier I, Kraft CS, Lyon GM, Mehta AK, et al. Persistence of Ebola virus in ocular fluid during convalescence. N Engl J Med. 2015;372:2423-7. http://dx.doi.org/ 10.1056/NEJMoa1500306

7. Deen GF, Broutet N, Xu W, Knust B, Sesay FR, McDonald SLR, et al. Ebola RNA persistence in semen of Ebola virus disease survivors-final report. N Engl J Med. 2017;377:1428-37. http://dx.doi.org/10.1056/NEJMoa1511410
8. World Health Organization. Latest Ebola outbreak over in Liberia; West Africa is at zero, but new flare-ups are likely to occur [cited 2016 Mar 1]. http://www.who.int/mediacentre/news/releases/2016/ ebola-zero-liberia/en/

9. World Health Organization. New Ebola case in Sierra Leone. WHO continues to stress risk of more flare-ups [cited 2016 Mar 1]. http://www.who.int/mediacentre/news/statements/2016/new-ebolacase/en/

10. Diallo B, Sissoko D, Loman NJ, Bah HA, Bah H, Worrell MC, et al. Resurgence of Ebola virus disease in Guinea linked to a survivor with virus persistence in seminal fluid for more than 500 days. Clin Infect Dis. 2016;63:1353-6. http://dx.doi.org/10.1093/cid/ciw601

11. Rodriguez LL, De Roo A, Guimard Y, Trappier SG, Sanchez A, Bressler D, et al. Persistence and genetic stability of Ebola virus during the outbreak in Kikwit, Democratic Republic of the Congo, 1995. J Infect Dis. 1999;179(Suppl 1):S170-6. http://dx.doi.org/ 10.1086/514291

12. Sissoko D, Keïta M, Diallo B, Aliabadi N, Fitter DL, Dahl BA, et al. Ebola virus persistence in breast milk after no reported illness: a likely source of virus infection from mother to child. Clin Infect Dis. 2017;64:513-6.

13. Thorson A, Formenty P, Lofthouse C, Broutet N. Systematic review of the literature on viral persistence and sexual transmission from recovered Ebola survivors: evidence and recommendations. BMJ Open. 2016;6:e008859. http://dx.doi.org/10.1136/ bmjopen-2015-008859

14. Martini GA, Schmidt HA. Spermatogenic transmission of the "Marburg virus". (Causes of "Marburg simian disease") [in German]. Klin Wochenschr. 1968;46:398-400. http://dx.doi.org/ 10.1007/BF01734141

15. Rowe AK, Bertolli J, Khan AS, Mukunu R, Muyembe-Tamfum JJ, Bressler D, et al. Clinical, virologic, and immunologic follow-up of convalescent Ebola hemorrhagic fever patients and their household contacts, Kikwit, Democratic Republic of the Congo. Commission de Lutte contre les Epidémies à Kikwit. J Infect Dis. 1999;179(Suppl 1):S28-35. http://dx.doi.org/10.1086/514318

16. Keita M, Duraffour S, Loman NJ, Rambaut A, Diallo B, Magassouba N, et al. Unusual ebola virus chain of transmission, Conakry, Guinea, 2014-2015. Emerg Infect Dis. 2016;22:2149-52. http://dx.doi.org/10.3201/eid2212.160847

17. Christie A, Davies-Wayne GJ, Cordier-Lassalle T, Blackley DJ, Laney AS, Williams DE, et al. Possible sexual transmission of Ebola virus_Liberia, 2015. MMWR Morb Mortal Wkly Rep. 2015;64:479-81. Erratum in Morb Mortal Wkly Rep 2015;64:1180.

18. Mate SE, Kugelman JR, Nyenswah TG, Ladner JT, Wiley MR, Cordier-Lassalle T, et al. Molecular evidence of sexual transmission of Ebola virus. N Engl J Med. 2015;373:2448-54. http://dx.doi.org/10.1056/NEJMoa1509773

19. Arias A, Watson SJ, Asogun D, Tobin EA, Lu J, Phan MVT, et al. Rapid outbreak sequencing of Ebola virus in Sierra Leone identifies transmission chains linked to sporadic cases. Virus Evol. 2016;2:vew016.

20. Alpren C, Sloan M, Boegler KA, Martin DW, Ervin E, Washburn F, et al.; Interagency Investigation Team. Notes from the field: Ebola virus disease cluster - northern Sierra Leone, January 2016. MMWR Morb Mortal Wkly Rep. 2016;65:681-2. http://dx.doi.org/10.15585/mmwr.mm6526a4

21. Blackley DJ, Wiley MR, Ladner JT, Fallah M, Lo T, Gilbert ML, et al. Reduced evolutionary rate in reemerged Ebola virus transmission chains. Sci Adv. 2016;2:e1600378. http://dx.doi.org/ 10.1126/sciadv. 1600378

22. Dokubo EK, Wendland A, Mate SE, Ladner JT, Hamblion EL, Raftery P, et al. Persistence of Ebola virus after the end of widespread transmission in Liberia: an outbreak report. Lancet Infect Dis. 2018;18:1015-24. http://dx.doi.org/10.1016/ S1473-3099(18)30417-1 
23. World Health Organization. Clinical management of patients with viral haemorrhagic fever. A pocket guide for front-line health workers. Interim emergency guidance for country adaptation. February 2016 [cited 2016 Mar 1]. http://apps.who.int/iris/ bitstream/handle/10665/205570/9789241549608_eng.pdf

24. World Health Organization. Case definition recommendations for Ebola or Marburg virus diseases [cited 2016 Feb 16]. http://www.who.int/csr/resources/publications/ebola/case-definition/en/

25. Statement WHO. Statement on the 9th meeting of the IHR Emergency Committee regarding the Ebola outbreak in West Africa [cited 2016 Apr 4]. http://www.who.int/mediacentre/news/ statements/2016/end-of-ebola-pheic/en/

26. Eggo RM, Watson CH, Camacho A, Kucharski AJ, Funk S, Edmunds WJ. Duration of Ebola virus RNA persistence in semen of survivors: population-level estimates and projections. Euro Surveill. 2015;20:30083. http://dx.doi.org/10.2807/1560-7917. ES.2015.20.48.30083

27. World Health Organization. Interim advice on the sexual transmission of the Ebola virus disease. January 2016 [cited 2016 Feb 8]. http://www.who.int/reproductivehealth/topics/rtis/ ebola-virus-semen/en/

28. Fischer WA, Brown J, Wohl DA, Loftis AJ, Tozay S, Reeves E, et al. Ebola virus ribonucleic acid detection in semen more than two years after resolution of acute Ebola virus infection. Open Forum Infect Dis. 2017;4:ofx155. http://dx.doi.org/10.1093/ofid/ofx155

29. Clark DV, Kibuuka H, Millard M, Wakabi S, Lukwago L, Taylor A, et al. Long-term sequelae after Ebola virus disease in Bundibugyo, Uganda: a retrospective cohort study. Lancet Infect Dis. 2015;15:905-12. http://dx.doi.org/10.1016/ S1473-3099(15)70152-0

30. Davtyan M, Brown B, Folayan MO. Addressing Ebola-related stigma: lessons learned from HIV/AIDS. Glob Health Action. 2014;7:26058. http://dx.doi.org/10.3402/gha.v7.26058

31. Reardon S. Ebola's mental-health wounds linger in Africa. Nature. 2015;519:13-4. http://dx.doi.org/10.1038/519013a

32. Yadav S, Rawal G. The current mental health status of Ebola survivors in Western Africa. J Clin Diagn Res. 2015;9:LA01-02.

33. Sprecher A. Handle survivors with care. N Engl J Med. 2017;377:1480-2. http://dx.doi.org/10.1056/NEJMe1512928

34. Althaus CL. Ebola superspreading. Lancet Infect Dis. 2015;15:507-8. http://dx.doi.org/10.1016/S1473-3099(15)70135-0

Address for correspondence: Saskia Den Boon, World Health Organization, 22 Avenue Appia, Geneva 1200, Switzerland; email: saskiadenboon@hotmail.com

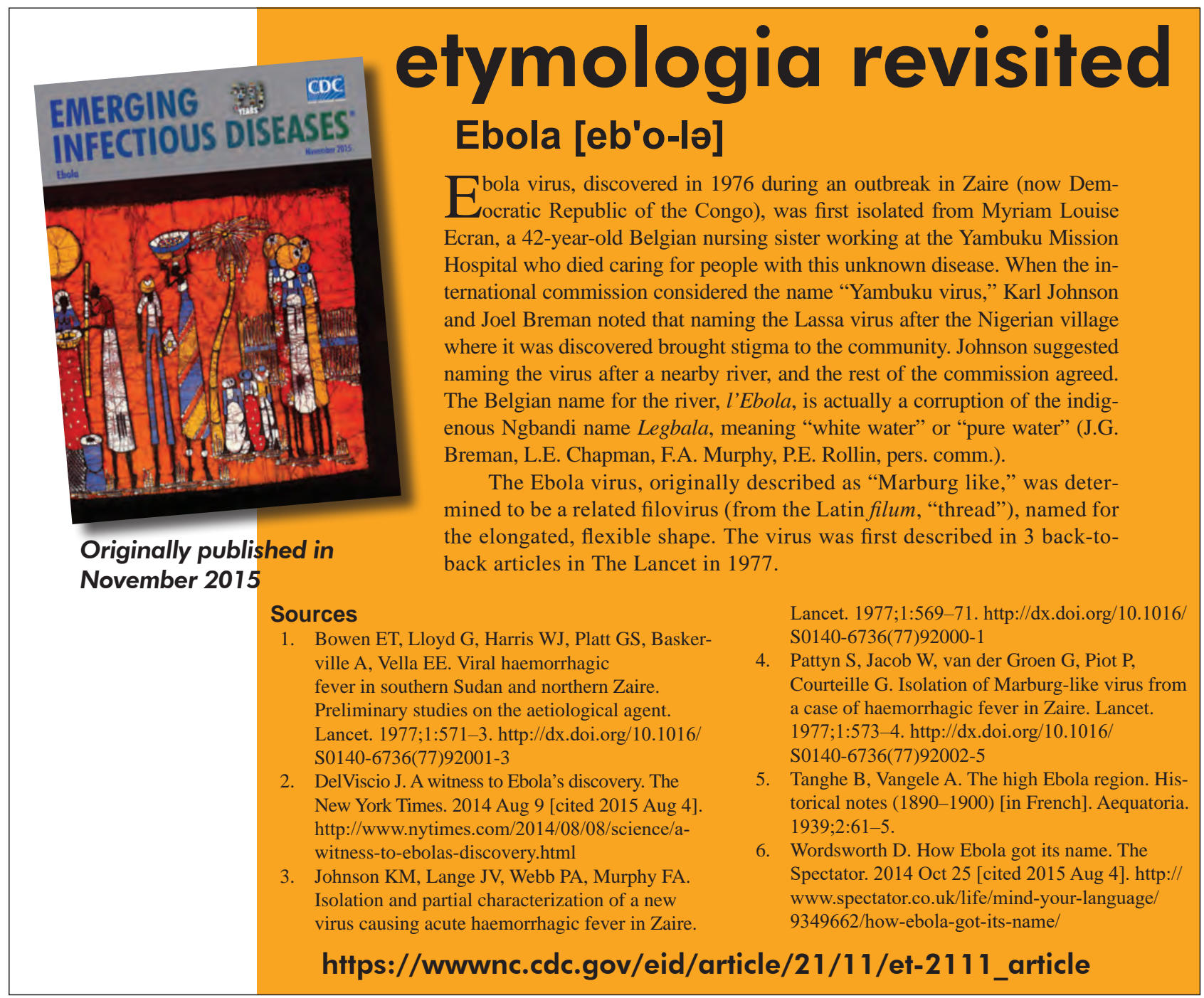




\title{
Zika Virus Epidemic in Pregnant Women, Dominican Republic, 2016- 2017
}

\author{
Farah Peña, Raquel Pimentel, Shaveta Khosla, Supriya D. Mehta, Maximo O. Brito
}

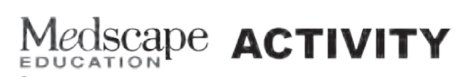

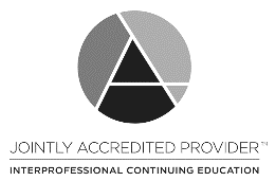

\section{Medcarcape ACTIVITY}

In support of improving patient care, this activity has been planned and implemented by Medscape, LLC and Emerging Infectious Diseases. Medscape, LLC is jointly accredited by the Accreditation Council for Continuing Medical Education (ACCME), the Accreditation Council for Pharmacy Education (ACPE), and the American Nurses Credentialing Center (ANCC), to provide continuing education for the healthcare team.

Medscape, LLC designates this Journal-based CME activity for a maximum of 1.00 AMA PRA Category 1 Credit(s) ${ }^{\mathrm{TM}}$. Physicians should claim only the credit commensurate with the extent of their participation in the activity.

All other clinicians completing this activity will be issued a certificate of participation. To participate in this journal CME activity: (1) review the learning objectives and author disclosures; (2) study the education content; (3) take the post-test with a $75 \%$ minimum passing score and complete the evaluation at http://www.medscape.org/journal/eid; and (4) view/print certificate. For CME questions, see page 394.
\end{abstract}

Release date: January 17, 2018; Expiration date: January 17, 2019

\section{Learning Objectives}

Upon completion of this activity, participants will be able to:

- Describe characteristics of pregnant women and pregnancy outcomes of women infected with Zika virus during the Dominican Republic outbreak in 2016-2017, according to a retrospective report

- Provide infant outcomes for pregnant women infected with Zika virus during the Dominican Republic outbreak in 2016-2017, according to a retrospective report

- Determine factors associated with birth outcomes and clinical implications of the findings for pregnant women infected with Zika virus during the Dominican Republic outbreak in 2016-2017, according to a retrospective report

\section{CME Editor}

Dana C. Dolan, BS, Copyeditor, Emerging Infectious Diseases. Disclosure: Dana C. Dolan, BS, has disclosed no relevant financial relationships.

\section{CME Author}

Laurie Barclay, MD, freelance writer and reviewer, Medscape, LLC. Disclosure: Laurie Barclay, MD, has disclosed the following relevant financial relationships: owns stock, stock options, or bonds from Pfizer.

\section{Authors}

Disclosures: Farah Peña, MD; Raquel Pimentel, MD; Shaveta Khosla, MPH; and Supriya D. Mehta, MHS, PhD, have disclosed no relevant financial relationships. Maximo O. Brito, MD, has disclosed the following relevant financial relationships: served as a speaker or a member of a speakers bureau for Janssen Pharmaceuticals, Inc.

Zika virus infection during pregnancy may result in birth defects and pregnancy complications. We describe the Zika virus outbreak in pregnant women in the Dominican Republic during 2016-2017. We conducted multinomial logistic regression to identify factors associated with fetal losses and preterm birth. The Ministry of Health identified 1,282 pregnant

Author affiliations: Ministry of Health, Santo Domingo, Dominican Republic (F. Peña, R. Pimentel); University of Illinois at Chicago, Chicago, Illinois, USA (S. Khosla, S.D. Mehta, M.O. Brito)

DOI: https://doi.org/10.3201/eid2502.181054 women with suspected Zika virus infection, a substantial proportion during their first trimester. Fetal loss was reported for $\approx 10 \%$ of the reported pregnancies, and 3 cases of fetal microcephaly were reported. Women infected during the first trimester were more likely to have early fetal loss (adjusted odds ratio $5.9,95 \% \mathrm{Cl} 3.5-10.0)$. Experiencing fever during infection was associated with increased odds of premature birth (adjusted odds ratio 1.65, 95\% Cl 1.03-2.65). There was widespread morbidity during the epidemic. Our findings strengthen the evidence for a broad range of adverse pregnancy outcomes resulting from Zika virus infection. 
$\mathrm{Z}$ ika virus is a flavivirus transmitted by the bite of the Aedes mosquito (1), horizontally through sexual transmission (2-4), and vertically during pregnancy and delivery (5). Most persons infected with Zika virus are asymptomatic or experience a relatively mild self-limited illness characterized by fever, conjunctivitis, arthralgia, and rash. In adults, Zika virus infection has been associated with Guillain-Barré Syndrome (GBS) and meningoencephalitis (6-8). When acquired during pregnancy, however, the infection has been linked to fetal microcephaly, intrauterine growth retardation, and ophthalmologic abnormalities in the infant (9-12). There is evidence that fetal neurologic abnormalities are most severe when infection occurs in early pregnancy, during embryological development of the central nervous system (13).

The current Zika virus pandemic began in French Polynesia and in Yap Island, Federated States of Micronesia, in 2013 (14,15). An explosive outbreak began in the Americas in 2014 with a cluster of cases reported in Easter Island, Chile (16), eventually moving to northeastern Brazil, where a large number of cases occurred over the span of 1 year $(17,18)$. Subsequently, the epidemic progressed to the north of South America and to the Caribbean basin $(19,20)$.

The Ministry of Health $(\mathrm{MoH})$ of the Dominican Republic instituted epidemiologic surveillance for Zika infection in December 2015 in preparation for the possible introduction of the virus. In January 2016, serum samples of suspected case-patients were sent to the US Centers for Disease Control and Prevention (CDC), which assisted in confirming the first 10 cases of Zika virus infection in the provinces of Santo Domingo, Jimaní, and Barahona (21). By end of April 2017, >5,000 cases (suspected and confirmed) had been reported in 28/32 country provinces (22). Considering the public health implications of Zika virus acquired during pregnancy, we sought to describe the characteristics of the outbreak among pregnant women and to analyze outcomes of pregnancy for women reported to the Dominican Republic MoH during the surveillance period.

\section{Materials and Methods}

\section{Study Design and Setting}

We conducted a cross-sectional analysis of suspected Zika infections among pregnant women reported to the Dominican Republic MoH during the countrywide outbreak, January 2016-April 2017. The Dominican Republic, with a population of nearly 9.5 million, occupies the eastern two thirds of the Caribbean island of Hispaniola (23). The Dominican healthcare system is administratively divided in 9 healthcare regions (0-VIII), which include the country's 31 provinces, 155 municipalities, and the capital city of Santo Domingo (24). This study was approved by the
Institutional Review Board of the University of Illinois at Chicago (Chicago, IL, USA).

\section{Surveillance}

Epidemiologic surveillance for Zika virus was instituted in December 2015. We trained Dominican Republic $\mathrm{MoH}$ personnel on surveillance methods and disseminated public information on the disease and its complications. The MoH assembled a multidisciplinary team of epidemiologists, entomologists, and clinicians from the Epidemiology Directorate and the National Center for the Control of Tropical Diseases to assess the countrywide risk and identify the communities most vulnerable to the spread of the disease. The $\mathrm{MoH}$ conducted rapid surveys of syndromic symptomatology in areas suspected to have persons infected with Zika virus (e.g., by informal communications from healthcare providers and local municipalities) to confirm circulation of the virus. In April 2016, the $\mathrm{MoH}$ mandated reporting of all suspected cases of GBS, microcephaly, and other congenital abnormalities that might be related to Zika infection. To support this, the MoH introduced a single reporting form for individual cases that was completed by all public and private health centers countrywide with suspected cases. Healthcare facilities transmitted the data via the National System of Epidemiologic Surveillance (SINAVE), the online platform for individual case and outbreak reporting of the $\mathrm{MoH}$.

\section{Case Definition}

We used criteria from the Pan American Health Organization (25) to classify cases reported during January 2016April 2017. Suspected cases were defined as illness in patients with acute onset of rash, fever $\left(>38.2^{\circ} \mathrm{C}\right)$, or both and $\geq 1$ of the following: arthralgia or myalgia, nonpurulent conjunctivitis or conjunctival hyperemia, and headaches not explained by other medical conditions. Probable cases were suspected cases with positive results for Zika virus IgM and no evidence of other arboviral diseases. Confirmed cases were suspected cases with Zika virus RNA detected in urine or blood. Microcephaly was defined as head circumference $<2 \mathrm{SD}$ below the mean, adjusted for gestational age and sex, $24 \mathrm{~h}$ after birth. Trained $\mathrm{MoH}$ staff followed published CDC procedures for measuring head circumference in infants (26).

\section{Laboratory Testing}

Testing was performed at CDC's laboratories in San Juan, Puerto Rico, or at the Dr. Defilló National Public Health Laboratory in Santo Domingo. Laboratory personnel tested available blood or urine specimens with reverse transcription PCR with primers to detect Zika virus RNA. Serum PCR was obtained for patients who sought care within 5 days of symptom onset, whereas urine PCR was obtained 
for patients who sought care 5-15 days after symptom onset. Samples were discarded if their collection or transportation did not follow the appropriate protocol (i.e., inadequate refrigeration, incorrect sample labeling, insufficient quantity). All women with discarded samples were included in the final analysis as suspected cases.

\section{Data Collection}

The standardized case report form for suspected Zika cases included information on age, sex, pregnancy status, insurance status, place of residence, care setting, signs/symptoms, comorbidities, fetal vital status, and pregnancy or fetal complications. We exported the SINAVE database to a spreadsheet in Excel (Microsoft, http://www.microsoft.com) for daily and weekly analyses and drafted weekly epidemiologic bulletins that were made available on the website of the Epidemiology Directorate of the $\mathrm{MoH}$ (www.digepisalud.gob. do). We contacted women to confirm pregnancy outcomes.

\section{Study Variables}

For this analysis, we classified newborns weighing $<2,500 \mathrm{~g}$ at birth as low birth weight for a full-term newborn. We dichotomized maternal age as $\leq 30$ years and $>30$ years for the multivariate analysis. We chose to dichotomize at 30 years instead of 35 years because there were relatively few women $>35$ years of age. We dichotomized region of residence as Greater Santo Domingo, which included the capital city of Santo Domingo and its suburbs, or others. We categorized insurance status as having any insurance or no insurance. We categorized care setting as hospitalized or nonhospitalized (outpatient medical care and at-home care). We categorized gestational age at the time of maternal Zika virus infection as $\leq 12$ weeks or $>12$ weeks. Birth was either premature ( $\leq 37$ weeks) or full term ( $>37$ weeks). We grouped miscarriages and intrauterine fetal demises (IUFD) and categorized them as fetal loss for the multivariable analysis.

\section{Statistical Analysis}

We downloaded data from SINAVE to Excel and imported into SAS version 9.3 (http://www.sas.com) for analyses. We conducted univariate analysis, generated frequencies for categorical variables, and calculated measures of central tendency for continuous variables. We generated an epidemic curve for 2016-2017 by epidemiologic week. We compared distributions of demographic and clinical findings by pregnancy outcome and used the $\chi^{2}$ test to obtain $\mathrm{p}$ values. We conducted multinomial logistic regression to identify factors associated with early fetal losses (miscarriages and IUFD) and to compare preterm live birth with term live birth. We conducted multivariable analyses using variables that were significant at $\mathrm{p}<0.20$ in unadjusted analyses. Final models retained variables with $\mathrm{p}<0.10$ except for age, which was kept in all modeling due to its potential influence on pregnancy complications. We geomapped cases and created the map in ArcGIS version 10.4.1 (http://www.arcgis.com).

\section{Results}

\section{Characteristics of Pregnant Women}

We recorded 1,282 pregnant women with suspected Zika virus infection during the study period. Their median age was 26 (IQR 21-30) years; 16\% $(201 / 1,282)$ were $\leq 19$ years of age (range 12-19 years). Most (91\%) infections occurred during April-September 2016 (Figure 1), and a substantial proportion (28\%) of suspected cases were diagnosed during the first trimester of pregnancy.

Of 799 women we tested for Zika virus by PCR, 296 (37\%) infections were confirmed (Table 1; Figure 2). We did not perform testing in 481 women, and we discarded 98 samples because of problems during collection or transportation. One woman had positive serologic results for $\operatorname{IgM}$, meeting the definition of a probable case. We found no significant differences in the distribution of the groups, except for age, in which we observed a higher proportion of women $>30$ years of age testing PCR negative.

Most women (99.3\%) were from the Dominican Republic; the remainder were from Haiti $(n=7)$, the United States $(\mathrm{n}=1)$, and the Democratic Republic of the Congo $(n=1)$. Almost half the women $(42 \%)$ lived in Greater Santo Domingo (Figure 3). Most (86\%) received outpatient treatment, and $14 \%$ required hospitalization for severe $\mathrm{Zi}$ ka-related symptoms at the time of acute illness. Thirty-two women (4\%) required a cesarean section.

Clinical data were available for 911 (71\%) women. The most commonly reported symptoms were rash and arthritis/arthralgia (Table 2). The groups were homogeneous except for the finding of a higher occurrence of conjunctivitis among women who tested negative by PCR.

\section{Pregnancy Outcomes}

Data on the outcome of pregnancy were available for 788 (61\%) women. A total of 718 (91\%) were live births, 24

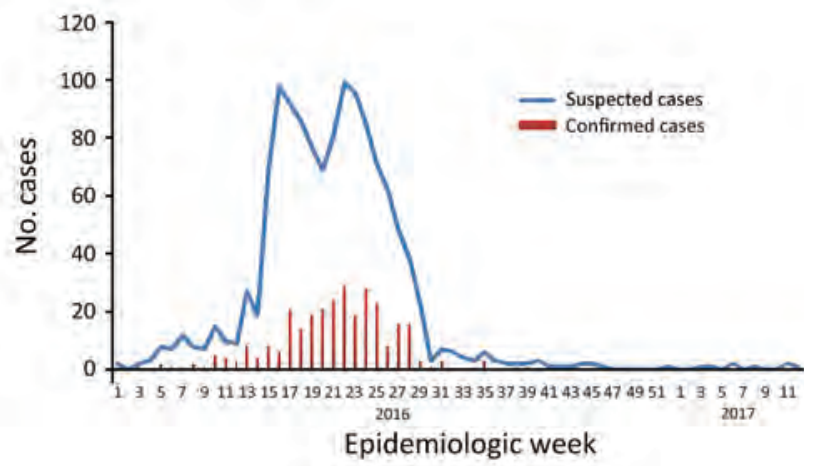

Figure 1. Epidemic curve of Zika virus infections among pregnant women by epidemiologic week, Dominican Republic, January 2016-April 2017. 
Table 1. Characteristics of pregnant women with suspected Zika virus infection, Dominican Republic, 2016-2017*

\begin{tabular}{|c|c|c|c|c|c|}
\hline Characteristic & $\begin{array}{c}\text { No. (\%) women, } \\
n=1,282\end{array}$ & $\begin{array}{c}\text { No. (\%) PCR } \\
\text { positive, } n=296\end{array}$ & $\begin{array}{c}\text { No. }(\%) \text { PCR } \\
\text { negative, } n=406\end{array}$ & $\begin{array}{c}\text { No. (\%) not tested or } \\
\text { sample discarded, } \mathrm{n}=580\end{array}$ & $\mathrm{p}$ value $\dagger$ \\
\hline \multicolumn{6}{|l|}{ Age, y } \\
\hline$>30$ & $308(24.0)$ & $60(20.3)$ & $113(27.8)$ & $135(23.3)$ & \multirow[t]{2}{*}{0.02} \\
\hline$\leq 30$ & $974(76.0)$ & $236(79.7)$ & $293(72.2)$ & $445(76.7)$ & \\
\hline \multicolumn{6}{|l|}{ Age distribution, $\mathrm{y}$} \\
\hline $12-19$ & 201(15.7) & $45(15.2)$ & $59(14.5)$ & $97(16.7)$ & \multirow[t]{4}{*}{0.23} \\
\hline $20-29$ & 704 (54.9) & $173(58.4)$ & $211(52.0)$ & $320(55.2)$ & \\
\hline $30-39$ & $357(27.8)$ & $73(24.7)$ & $126(31.0)$ & $158(27.2)$ & \\
\hline$>40$ & $20(1.6)$ & $5(1.7)$ & $10(2.5)$ & $5(0.9)$ & \\
\hline \multicolumn{6}{|l|}{ Insurance status } \\
\hline Yes & $762(59.5)$ & $168(56.8)$ & $225(55.4)$ & $369(63.6)$ & \multirow{3}{*}{0.83} \\
\hline No & $362(28.2)$ & $87(29.4)$ & $118(29.1)$ & $157(27.1)$ & \\
\hline Unknown & $158(12.3)$ & $41(13.8)$ & $63(15.5)$ & $54(9.3)$ & \\
\hline \multicolumn{6}{|l|}{ Region of residence } \\
\hline Greater Santo Domingoł & $536(41.8)$ & $106(35.8)$ & $165(40.6)$ & $265(45.7)$ & \multirow[t]{2}{*}{0.19} \\
\hline Other & $746(58.2)$ & $190(64.2)$ & $241(59.4)$ & $315(54.3)$ & \\
\hline \multicolumn{6}{|l|}{ Country of origin } \\
\hline Dominican Republic & $1273(99.3)$ & $293(99.0)$ & $402(99.0)$ & $578(99.7)$ & \multirow{3}{*}{1.00} \\
\hline Haiti & $7(0.5)$ & $2(0.7)$ & $3(0.7)$ & $2(0.3)$ & \\
\hline Other & $2(0.2)$ & $1(0.3)$ & $1(0.3)$ & & \\
\hline \multicolumn{6}{|l|}{ Care setting } \\
\hline Ambulatory/at home & $1,098(85.6)$ & $263(88.8)$ & $349(86.0)$ & $486(83.8)$ & \multirow[t]{3}{*}{0.26} \\
\hline Hospital & $174(13.6)$ & $33(11.2)$ & $54(13.3)$ & $87(15.0)$ & \\
\hline Unknown (includes referred) & $10(0.8)$ & 0 & $3(0.7)$ & $7(1.2)$ & \\
\hline \multicolumn{6}{|l|}{ Complications } \\
\hline None & $128(10.0)$ & $24(8.1)$ & $41(10.1)$ & $63(10.8)$ & \multirow[t]{3}{*}{0.41} \\
\hline Difficulty breathing & $3(0.2)$ & 0 & $2(0.5)$ & $1(0.2)$ & \\
\hline Unknown & $1151(89.8)$ & 272 (91.9) & $363(89.4)$ & $516(89.0)$ & \\
\hline \multicolumn{6}{|l|}{ Diagnosis } \\
\hline Confirmed & $296(23.1)$ & & & & \\
\hline Suspected & 983 (76.9) & & & & \\
\hline Missing & 3 & & & & \\
\hline \multicolumn{6}{|l|}{ Time of suspected Zika infection } \\
\hline$\leq 12$ wk gestation & $364(28.4)$ & $106(35.8)$ & $152(37.4)$ & $106(18.3)$ & \multirow[t]{2}{*}{0.66} \\
\hline$>12$ wk gestation & $918(71.6)$ & $190(64.2)$ & $254(62.6)$ & $474(81.7)$ & \\
\hline \multicolumn{6}{|l|}{ Condition of newborn at birth } \\
\hline IUFD/miscarriage & $70(8.9)$ & $26(13.1)$ & $22(8.8)$ & $22(6.5)$ & \multirow[t]{3}{*}{0.15} \\
\hline Live birth & $718(91.1)$ & $173(86.9)$ & $228(91.2)$ & $317(93.5)$ & \\
\hline Missing & 494 & 97 & 156 & 241 & \\
\hline \multicolumn{6}{|c|}{ Premature birth, live born only, $n=718$} \\
\hline Yes & $78(10.9)$ & $21(12.1)$ & $24(10.5)$ & $33(10.5)$ & \multirow[t]{3}{*}{0.61} \\
\hline No & $638(89.1)$ & $152(87.9)$ & $204(89.5)$ & $282(89.5)$ & \\
\hline Missing & 2 & & & 2 & \\
\hline \multicolumn{6}{|l|}{ Birthweight, live born only, $n=718$} \\
\hline$<2,500 \mathrm{~g}$ & $107(15.4)$ & $27(16.2)$ & $36(16.6)$ & $44(14.2)$ & 0.91 \\
\hline$\geq 2,500 \mathrm{~g}$ & $588(84.6)$ & $140(83.8)$ & $181(83.4)$ & $267(85.8)$ & \\
\hline Missing & 23 & 6 & 11 & 6 & \\
\hline Microcephaly§ & 3 & 0 & 1 & 2 & \\
\hline $\begin{array}{l}{ }^{*} \text { IUFD, intrauterine fetal demise. } \\
\dagger x^{2} \mathrm{p} \text { value for the comparison of co } \\
\ddagger \text { Includes residents of Monte Plata } \\
\text { 乌Defined as head circumference }<2\end{array}$ & R positive witl & negative. & 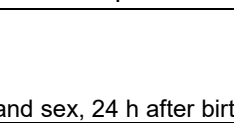 & & \\
\hline
\end{tabular}

(3\%) ended in IUFD, and 46 (6\%) ended in miscarriage. Among live births, the median birthweight was 3,175 g (IQR 2,722-3,402 g), and $11 \%(78 / 718)$ were born prematurely. In most premature births (72\%), the mother acquired Zika virus infection in the second or third trimester.

\section{Infant Outcomes}

A total of 14 congenital malformations were reported through SINAVE: suspected microcephaly $(\mathrm{n}=9)$, anencephaly $(n=1)$, hydrocephaly $(n=1)$, palate fissure $(n=1)$, "small heart" ( $n=1)$, and other or unspecified $(n=1)$. In 6 of these cases, the mother was Zika positive by PCR (suspected microcephaly in 5 and 1 "small heart"). Only 3 cases of microcephaly met the case definition of head circumference $<2$ SD below the mean (attack rate among all pregnant women $=0.2 \%$; attack rate among women for whom pregnancy outcome was determined $=0.4 \%$ ). One of the 3 mothers, 34 years of age, was symptomatic with Zika infection in the first month of pregnancy. The second mother, 17 years of age, was symptomatic early in the third trimester (29.5 


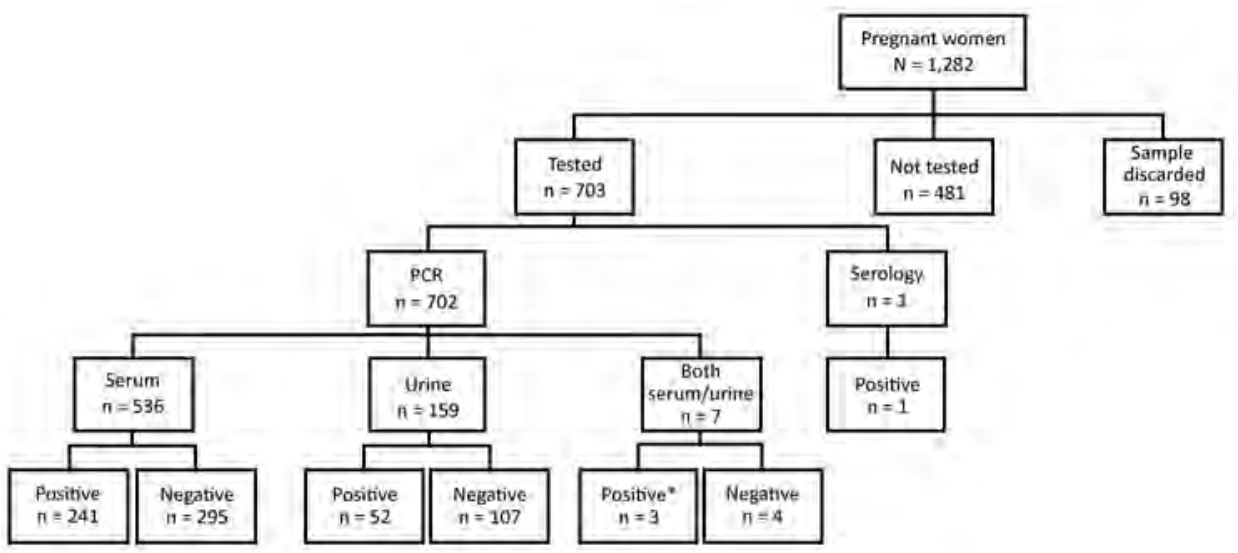

Figure 2. Flowchart of laboratory testing for Zika virus during the Zika epidemic in the Dominican Republic, 2016-2017. *Indicates that either sample tested positive.

wks) and required hospitalization for Zika-related illness. The third mother, 16 years of age, became symptomatic in the second trimester (21 wks).

\section{Factors Associated with Birth Outcomes}

Multivariable analysis included the 788 women with a known pregnancy outcome. In crude analysis (Table 3), the odds of fetal loss were increased among women with confirmed Zika diagnosis, those who were infected in the first trimester, and those who had fever at the time of infection. The odds of premature live birth were also increased for women with fever at time of infection. In multivariable adjusted analyses, women infected with Zika virus during the first trimester were more likely to have an early fetal loss (adjusted odds ratio 5.9, 95\% CI 3.5-10.0) than term birth, controlling for maternal age and symptom of fever at infection. We found no association between maternal age or timing of Zika infection in pregnancy and premature birth compared with term birth, although experiencing fever during the infection remained associated with increased odds of premature birth (adjusted odds ratio 1.65, 95\% CI 1.03-2.65).

\section{Discussion}

This report describes a cohort of suspected and confirmed Zika virus-infected pregnant women in the Dominican Republic during 2016-2017. Our analysis demonstrated substantial maternal and infant illness during the epidemic.

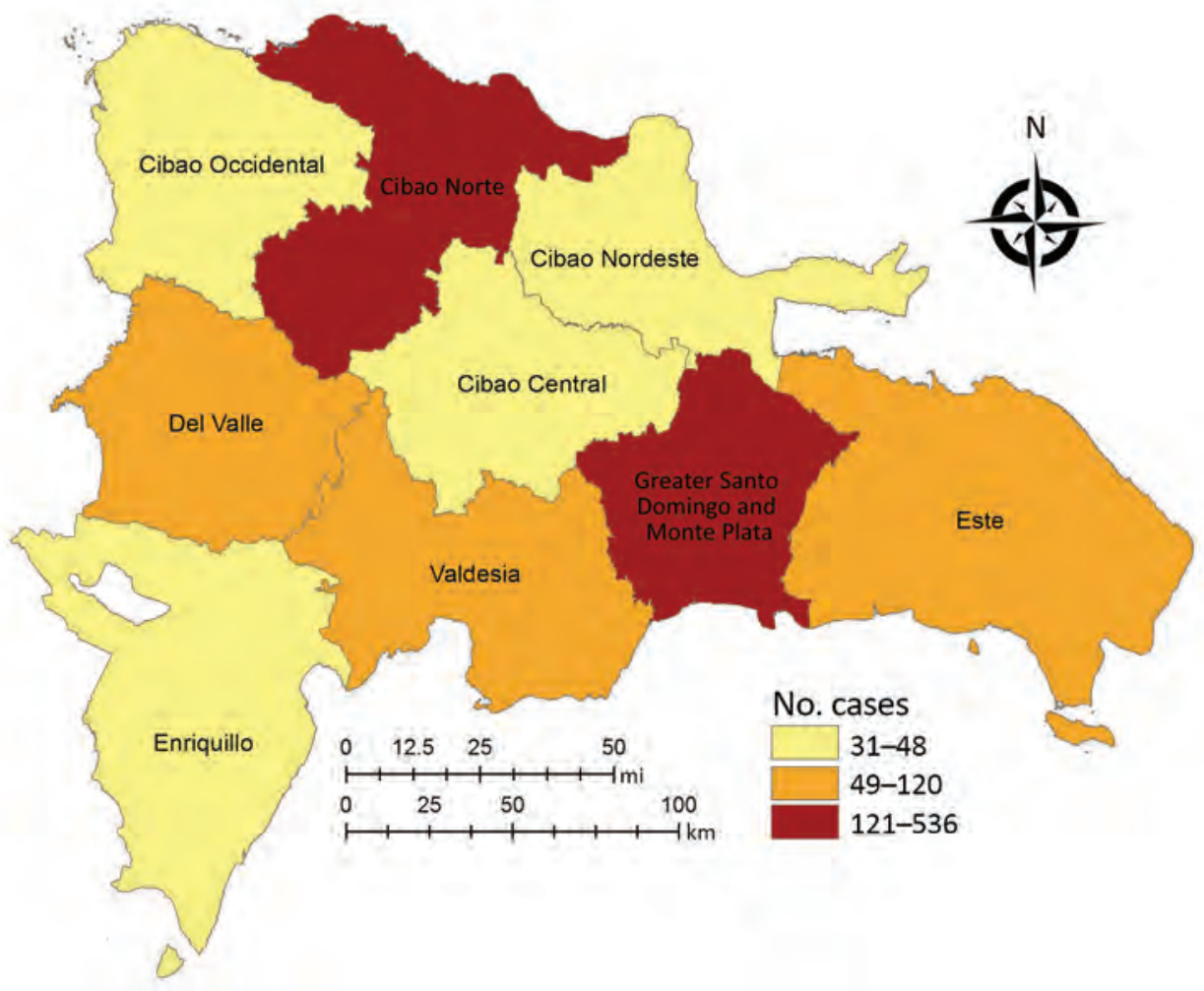

Figure 3. Distribution of suspected Zika virus infection in pregnant women in the Dominican Republic, by region, 2016-2017. 
Table 2. Symptoms by PCR test result in pregnant women with suspected Zika virus infection with available clinical data, Dominican Republic, 2016-2017

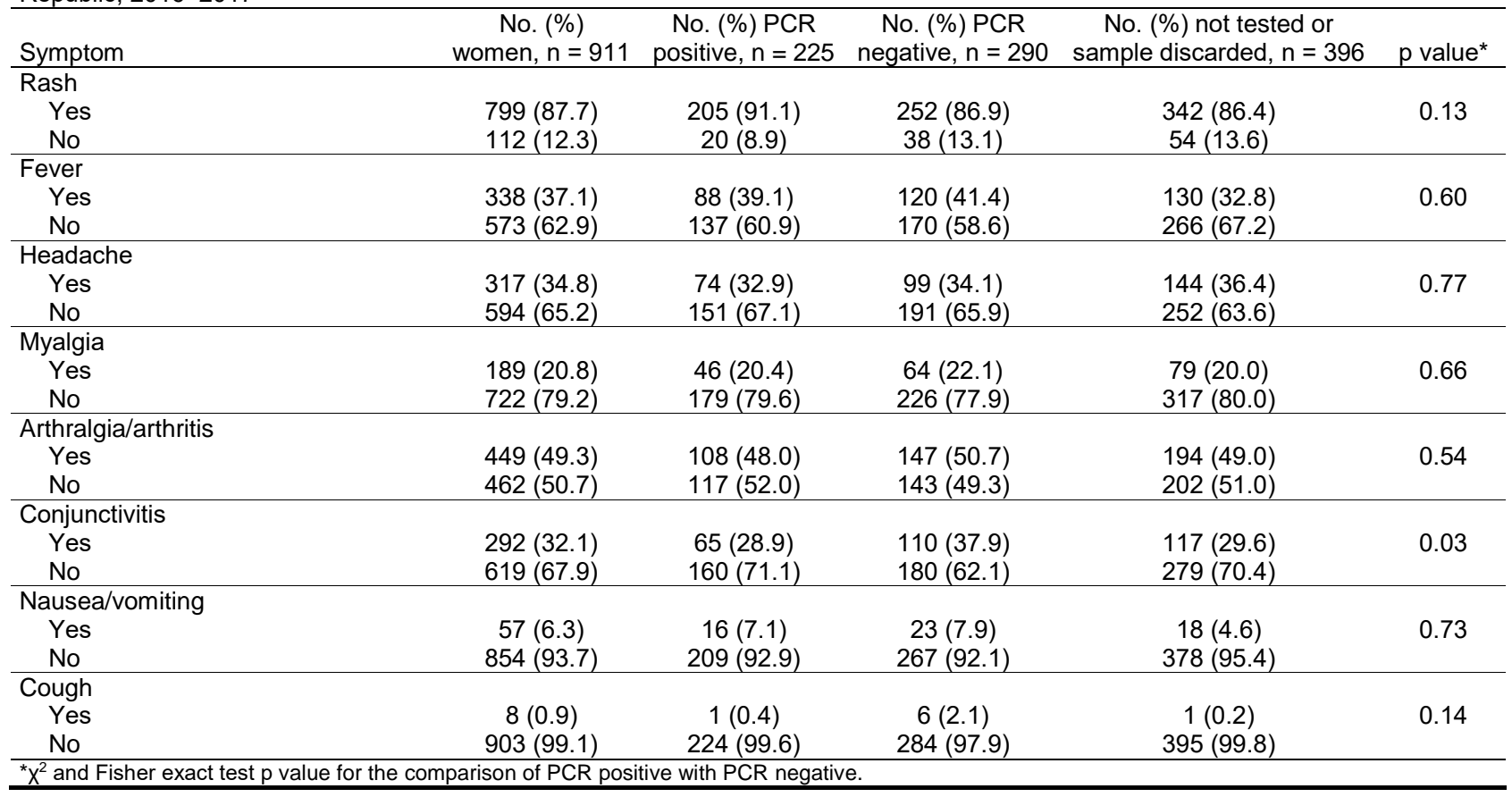

Almost $10 \%$ of pregnancies with a known outcome resulted in early fetal loss, and there were 3 cases of microcephaly. First-trimester prenatal exposure was highly associated with fetal loss, and fever was associated with prematurity.

The frequency of symptoms in women of this cohort was consistent with other studies. Rash and arthralgia were also the most prevalent symptoms in a cohort of pregnant women with confirmed Zika virus infection in Rio de Janeiro, Brazil (27). The type of exanthem most commonly described in our study and others was maculopapular rash (28). Similarly, rash and arthralgia were the most common signs during the Zika virus outbreak on Yap Island (14).

Consistent with our findings, fever was present in $<50 \%$ of confirmed cases in various studies $(28,29)$. We observed a link between the presence of fever and prematurity. Fever in the mother may reflect a more inflammatory infection or may be unrelated to Zika virus and result from co-infection with other pathogens. Fever can also be associated with other conditions, such as premature rupture of membranes resulting from genital tract infection. The limited available information on women's prenatal and peripartum care precludes drawing sound conclusions on this observation. Data from ongoing prospective cohort studies may help further elucidate this finding.

Advanced maternal age was not associated with prematurity or fetal loss in our study, a finding that is not surprising in this cohort because most older women (92\%) were 30-35 years of age, a range below the usual threshold for pregnancy complications. Zika virus infection can lead to birth defects and pregnancy complications even when the mother is asymptomatic, but this report contains only surveillance data. Women had to be symptomatic to trigger reporting to the $\mathrm{MoH}$, and thus, it is not possible to estimate the burden of disease in asymptomatic women and their infants. The $\mathrm{MoH}$ prioritized and directed its limited resources to testing of symptomatic pregnant women during this relatively sudden and explosive epidemic.

Fetal loss has been documented in an experimental animal model of marmoset monkeys. The inoculation of Zika virus into pregnant females caused prolonged fetal and placental viral replication and a maternal associated host response and increased activity of proinflammatory cytokines (30). The rate of fetal loss in Zika virus-infected women is estimated at $3 \%$, and rate of birth defects is $\approx 4 \%-8 \%$, depending on the trimester of infection (31). In our study, women reported as symptomatic during the first trimester of pregnancy had 4 times greater odds of fetal loss that those with later symptoms, after controlling for maternal age. Similar pregnancy complications have been documented in other recent cohorts. In Brazil, $13(7 \%)$ fetal losses and 4 cases of microcephaly were reported among 186 women with known pregnancy outcome. Cesarean sections were more prevalent in Brazil compared with our cohort in the Dominican Republic (81\% vs. 4\%) (27). The proportion of pregnancy losses was $11 \%$ (47/442) among women with possible Zika infection included in the US Zika Pregnancy Registry (32). In our cohort, $11 \%$ of births were premature, a proportion 
Zika Virus in Pregnant Women, Dominican Republic

Table 3. Bivariate and multivariate analyses of independent variables with multinomial pregnancy outcome for women in Zika virus epidemic, Dominican Republic, 2016-2017*

\begin{tabular}{|c|c|c|c|c|c|c|c|c|}
\hline \multirow[b]{2}{*}{ Characteristic } & \multicolumn{3}{|c|}{ Birth outcome } & \multirow[b]{2}{*}{$\begin{array}{c}\mathrm{p} \text { value } \\
\text { by } \chi^{2} \text { test }\end{array}$} & \multicolumn{2}{|c|}{$\begin{array}{c}\text { Bivariate crude OR } \\
(95 \% \mathrm{Cl})\end{array}$} & \multicolumn{2}{|c|}{$\begin{array}{c}\text { Multivariate adjusted OR } \\
(95 \% \mathrm{Cl}), \mathrm{n}=786\end{array}$} \\
\hline & $\begin{array}{c}\text { Miscarriage } \\
\text { or IUFD, } \\
\mathrm{n}=70\end{array}$ & $\begin{array}{c}\text { Premature } \\
\text { live birth, } \\
\mathrm{n}=78\end{array}$ & $\begin{array}{c}\text { Term live } \\
\text { birth, } \\
\mathrm{n}=638\end{array}$ & & $\begin{array}{c}\text { Fetal loss } \\
\text { vs. term live } \\
\text { birth }\end{array}$ & $\begin{array}{l}\text { Premature } \\
\text { vs. term live } \\
\text { birth }\end{array}$ & $\begin{array}{c}\text { Fetal loss } \\
\text { vs. term live } \\
\text { birth }\end{array}$ & $\begin{array}{l}\text { Premature } \\
\text { vs. term live } \\
\text { birth }\end{array}$ \\
\hline \multicolumn{9}{|l|}{ Maternal age, y } \\
\hline$>30$ & $24(34.3)$ & $20(25.6)$ & $162(25.4)$ & 0.27 & $\begin{array}{c}1.53 \\
(0.91-2.59)\end{array}$ & $\begin{array}{c}1.01 \\
(0.59-1.74)\end{array}$ & $\begin{array}{c}1.48 \\
(0.86-2.56)\end{array}$ & $\begin{array}{c}1.02 \\
(0.60-1.76)\end{array}$ \\
\hline$\leq 30$ & $46(65.7)$ & $58(74.4)$ & $476(74.6)$ & NA & NA & NA & NA & NA \\
\hline \multicolumn{9}{|c|}{ Residence in Greater Santo Domingo† } \\
\hline Yes & $27(38.6)$ & $39(50.0)$ & $262(41.1)$ & 0.27 & $\begin{array}{c}0.90 \\
(0.54-1.50)\end{array}$ & $\begin{array}{c}1.44 \\
(0.90-2.30)\end{array}$ & NA & NA \\
\hline No & $43(61.4)$ & $39(50.0)$ & $376(58.9)$ & NA & NA & NA & NA & NA \\
\hline \multicolumn{9}{|l|}{ Diagnosis } \\
\hline Confirmed & $26(37.1)$ & $21(26.9)$ & $152(23.9)$ & 0.05 & $\begin{array}{c}1.88 \\
(1.12-3.16)\end{array}$ & $\begin{array}{c}1.18 \\
(0.69-2.00)\end{array}$ & NA & NA \\
\hline Suspected & $44(62.9)$ & $57(73.1)$ & $485(76.1)$ & NA & NA & NA & NA & NA \\
\hline \multicolumn{9}{|c|}{ Timing of suspected Zika infection, wks gestation } \\
\hline$\leq 12$ & $46(65.7)$ & $22(28.2)$ & $156(24.4)$ & $<0.0001$ & $\begin{array}{c}5.92 \\
(3.50-10.0)\end{array}$ & $\begin{array}{c}1.21 \\
(0.72-2.05)\end{array}$ & $\begin{array}{c}5.92 \\
(3.49-10.0)\end{array}$ & $\begin{array}{c}1.22 \\
(0.72-2.07)\end{array}$ \\
\hline$>12$ & $24(34.3)$ & $56(71.8)$ & $482(75.6)$ & NA & NA & NA & NA & NA \\
\hline \multicolumn{9}{|l|}{ Symptomsł } \\
\hline Rash & $60(85.7)$ & 70 (89.7) & $568(89.0)$ & 0.68 & $\begin{array}{c}0.74 \\
(0.36-1.51)\end{array}$ & $\begin{array}{c}1.08 \\
(0.50-2.33)\end{array}$ & NA & NA \\
\hline No rash & $10(14.3)$ & $8(10.3)$ & $70(11.0)$ & NA & NA & NA & NA & NA \\
\hline Fever & $31(44.3)$ & $36(46.2)$ & $218(34.2)$ & 0.04 & $\begin{array}{c}1.53 \\
(0.93-2.52)\end{array}$ & $\begin{array}{c}1.65 \\
(1.03-2.65)\end{array}$ & $\begin{array}{c}1.63 \\
(0.97-2.75)\end{array}$ & $\begin{array}{c}1.66 \\
(1.03-2.66)\end{array}$ \\
\hline No fever & $39(55.7)$ & $42(53.8)$ & $420(65.8)$ & NA & NA & NA & NA & NA \\
\hline
\end{tabular}

that is higher than the reported national average of 8 per 100 live births (33). IUFD was 3\% of deliveries, which is higher than the reported national average of $1.1 \%$ (34)

This type of analysis of public health surveillance data has inherent limitations. First, not all women were tested for Zika virus, and their diagnosis relied on clinical reports. It is plausible that some of the suspected cases were caused by dengue virus, which is the most common arboviral illness in the country, or another infection (syphilis, toxoplasmosis, rubella, cytomegalovirus, and herpes simplex virus, the STORCH infections). However, many distinguishing clinical and laboratory features between dengue virus and Zika virus are familiar to clinicians adept at diagnosing dengue virus infection. The fact that a higher proportion of women who tested PCR negative had conjunctivitis is reassuring, given its presence helps to differentiate dengue from Zika. Second, our assessment of birth defects is limited to visible abnormalities, such as microcephaly, in live births. Birth defects were not reported on fetal losses, and there were no radiographic, ophthalmologic, or audiologic assessments to ascertain inconspicuous birth defects. Most women delivered at public hospitals and clinics with limited resources. These centers are not equipped to evaluate brain radiographic abnormalities associated with Zika virus infection. Third, clinical data are missing for almost one third of the women and pregnancy outcome is not known in 39\% of cases. Fourth, true disease burden in pregnancy is underestimated because we have no data for asymptomatic women not captured by passive surveillance.

The main strength of this study is that it includes a large group of pregnant women with suspected Zika virus infection in the Caribbean region. We used the Dominican Republic government's main reporting platform to analyze multicenter and countrywide population-level data. Our finding of increased likelihood of miscarriage and IUFD in a large population-based sample strengthens the evidence for a broad range of adverse pregnancy outcomes, building upon case reports and countrywide evaluations.

In conclusion, we documented substantial illnesses of pregnant women and their children stemming from the 2016-2017 Zika virus outbreak in the Dominican Republic. Our analysis highlights gaps in our epidemiologic understanding of the course of the Zika virus epidemic and affected populations (e.g., data not uniformly collected). Accordingly, we need to strengthen passive surveillance, implement sentinel active surveillance, and improve the timeliness and reliability of in-country diagnostic testing. The results of lessons learned about the severity of Zika and breadth of adverse outcomes and the role of surveillance in detecting and preventing adverse outcomes need to be put in place before the next outbreak. 


\section{About the Author}

Dr. Peña is the coordinator of the continuous improvement unit of the Epidemiology Directorate, Ministry of Health, Dominican Republic. Her research interests include arboviral diseases and outbreak investigations.

\section{References}

1. Fauci AS, Morens DM. Zika virus in the Americas-yet another arbovirus threat. N Engl J Med. 2016;374:601-4. http://dx.doi.org/ 10.1056/NEJMp1600297

2. Deckard DT, Chung WM, Brooks JT, Smith JC, Woldai S, Hennessey M, et al. Male-to-male sexual transmission of Zika virus-Texas, January 2016. MMWR Morb Mortal Wkly Rep. 2016;65:372-4. http://dx.doi.org/10.15585/mmwr.mm6514a3

3. Fréour T, Mirallié S, Hubert B, Splingart C, Barrière P, Maquart M, et al. Sexual transmission of Zika virus in an entirely asymptomatic couple returning from a Zika epidemic area, France, April 2016. Euro Surveill. 2016;21:30254. http://dx.doi.org/ 10.2807/1560-7917.ES.2016.21.23.30254

4. Russell K, Hills SL, Oster AM, Porse CC, Danyluk G, Cone M, et al. Male-to-female sexual transmission of Zika virus-United States, January-April 2016. Clin Infect Dis. 2017;64:211-3. http://dx.doi.org/10.1093/cid/ciw692

5. Besnard M, Lastere S, Teissier A, Cao-Lormeau V, Musso D. Evidence of perinatal transmission of Zika virus, French Polynesia, December 2013 and February 2014. Euro Surveill. 2014;19:20751. http://dx.doi.org/10.2807/1560-7917.ES2014.19.13.20751

6. Araujo LM, Ferreira ML, Nascimento OJ. Guillain-Barré syndrome associated with the Zika virus outbreak in Brazil. Arq Neuropsiquiatr. 2016;74:253-5. http://dx.doi.org/10.1590/0004282X20160035

7. Brito Ferreira ML, Antunes de Brito CA, Moreira AJP, de Morais Machado MI, Henriques-Souza A, Cordeiro MT, et al. Guillain-Barré syndrome, acute disseminated encephalomyelitis, and encephalitis associated with Zika virus infection in Brazil: detection of viral RNA and isolation of virus during late infection. Am J Trop Med Hyg. 2017;97:1405-9. http://dx.doi.org/10.4269/ajtmh.17-0106

8. Cao-Lormeau VM, Blake A, Mons S, Lastere S, Roche C, Vanhomwegen J, et al. Guillain-Barré syndrome outbreak associated with Zika virus infection in French Polynesia: a case-control study. Lancet. 2016;387:1531-9. http://dx.doi.org/ 10.1016/S0140-6736(16)00562-6

9. Besnard M, Eyrolle-Guignot D, Guillemette-Artur P, Lastère S, Bost-Bezeaud F, Marcelis L, et al. Congenital cerebral malformations and dysfunction in fetuses and newborns following the 2013 to 2014 Zika virus epidemic in French Polynesia. Euro Surveill. 2016; 21:30181. http://dx.doi.org/10.2807/1560-7917. ES.2016.21.13.30181

10. de Paula Freitas B, de Oliveira Dias JR, Prazeres J, Sacramento GA, Ko AI, Maia M, et al. Ocular findings in infants with microcephaly associated with presumed Zika virus congenital infection in Salvador, Brazil. JAMA Ophthalmol. 2016 Feb 9 [cited 2018 Nov 23]. http://dx.doi.org/10.1001/jamaophthalmol.2016.0267

11. de Souza Campos Fernandes RC, de Souza TL, Medina-Acosta E. Congenital Zika syndrome in Brazil. Lancet Infect Dis. 2016;16:772. http://dx.doi.org/10.1016/S1473-3099(16)30079-2

12. Rasmussen SA, Jamieson DJ, Honein MA, Petersen LR. Zika virus and birth defects - reviewing the evidence for causality. N Engl J Med. 2016;374:1981-7. http://dx.doi.org/10.1056/NEJMsr1604338

13. Chimelli L, Avvad-Portari E. Congenital Zika virus infection: a neuropathological review. Childs Nerv Syst. 2018;34:95-9. http://dx.doi.org/10.1007/s00381-017-3651-3

14. Duffy MR, Chen TH, Hancock WT, Powers AM, Kool JL, Lanciotti RS, et al. Zika virus outbreak on Yap Island, Federated
States of Micronesia. N Engl J Med. 2009;360:2536-43. http://dx.doi.org/10.1056/NEJMoa0805715

15. Cao-Lormeau VM, Roche C, Teissier A, Robin E, Berry AL, Mallet HP, et al. Zika virus, French Polynesia, South Pacific, 2013. Emerg Infect Dis. 2014;20:1085-6. http://dx.doi.org/10.3201/ eid2011.141380

16. Tognarelli J, Ulloa S, Villagra E, Lagos J, Aguayo C, Fasce R, et al. A report on the outbreak of Zika virus on Easter Island, South Pacific, 2014. Arch Virol. 2016;161:665-8. http://dx.doi.org/ 10.1007/s00705-015-2695-5

17. Heukelbach J, Alencar CH, Kelvin AA, de Oliveira WK, Pamplona de Góes Cavalcanti L. Zika virus outbreak in Brazil. J Infect Dev Ctries. 2016;10:116-20. http://dx.doi.org/10.3855/ jidc. 8217

18. Zanluca C, Melo VC, Mosimann AL, Santos GI, Santos CN, Luz K. First report of autochthonous transmission of Zika virus in Brazil. Mem Inst Oswaldo Cruz. 2015;110:569-72. http://dx.doi.org/10.1590/0074-02760150192

19. Pacheco O, Beltrán M, Nelson CA, Valencia D, Tolosa N, Farr SL, et al. Zika virus disease in Colombia-preliminary report. N Engl J Med. 2016;NEJMoa1604037. http://dx.doi.org/10.1056/ NEJMoa1604037

20. Thomas DL, Sharp TM, Torres J, Armstrong PA, Munoz-Jordan J, Ryff KR, et al. Local transmission of Zika virus-Puerto Rico, November 23, 2015-January 28, 2016. MMWR Morb Mortal Wkly Rep. 2016;65:154-8. http://dx.doi.org/10.15585/mmwr.mm6506e2

21. Ministry of Health. Epidemiology Directorate. Epidemiological bulletin-epidemiological week no. 3 [in Spanish]. 2016 [cited 2018 Nov 23]. http://digepisalud.gob.do/documentos/ ?drawer= Boletines\%20epidemiologicos*Boletines\%20semanales*2016

22. Ministry of Health. Epidemiology Directorate. Epidemiological bulletin —epidemiological week no. 08 [in Spanish]. 2017 [cited 2018 Nov 23]. http://digepisalud.gob.do/documentos/ ?drawer $=$ Boletines $\% 20$ epidemiologicos*Boletines $\% 20$ semanales*2016

23. National Bureau of Statistics. IX Census of population and household, 2010 [in Spanish]. 2012 May 5 [cited 2018 Nov 23]. https://www.one.gob.do/Multimedia/Download?ObjId=3817

24. Center for Demographic Studies. Health and demographic survey_Dominican Republic, 2007 [in Spanish]. 2007 [cited 2018 Nov 23]. https://dhsprogram.com/pubs/pdf/FR205/FR205.pdf

25. Pan American Health Organization. Zika resources: case definitions. 2016 [cited 2018 Nov 23]. https://www.paho.org/hq/ index.php?option $=$ com_content $\&$ view $=$ article $\&$ id $=11117$ : zika-resources-case-definitions\&Itemid=41532\&lang=en

26. Centers for Disease Control and Prevention. Measuring head circumference. 2016 [cited 2018 Nov 23]. https://www.cdc.gov/ zika/pdfs/microcephaly_measuring.pdf

27. Brasil P, Pereira JP Jr, Moreira ME, Ribeiro Nogueira RM, Damasceno L, Wakimoto M, et al. Zika virus infection in pregnant women in Rio de Janeiro. N Engl J Med. 2016;375:2321-34. http://dx.doi.org/10.1056/NEJMoa1602412

28. Lin HZ, Tambyah PA, Yong EL, Biswas A, Chan SY. A review of Zika virus infections in pregnancy and implications for antenatal care in Singapore. Singapore Med J. 2017;58:171-8. http://dx.doi.org/10.11622/smedj.2017026

29. Brasil P, Calvet GA, Siqueira AM, Wakimoto M, de Sequeira PC, Nobre A, et al. Zika virus outbreak in Rio de Janeiro, Brazil: clinical characterization, epidemiological and virological aspects. PLoS Negl Trop Dis. 2016;10:e0004636. http://dx.doi.org/10.1371/ journal.pntd.0004636

30. Seferovic M, Martín CS, Tardif SD, Rutherford J, Castro ECC, $\mathrm{Li} \mathrm{T}$, et al. Experimental Zika virus infection in the pregnant common marmoset induces spontaneous fetal loss and neurodevelopmental abnormalities. Sci Rep. 2018;8:6851. http://dx.doi.org/10.1038/s41598-018-25205-1 
31. Shapiro-Mendoza CK, Rice ME, Galang RR, Fulton AC, VanMaldeghem K, Prado MV, et al.; Zika Pregnancy and Infant Registries Working Group. Pregnancy outcomes after maternal Zika virus infection during pregnancy-US territories, January 1, 2016-April 25, 2017. MMWR Morb Mortal Wkly Rep. 2017;66:615-21. http://dx.doi.org/10.15585/mmwr.mm6623e1

32. Honein MA, Dawson AL, Petersen EE, Jones AM, Lee EH, Yazdy MM, et al.; US Zika Pregnancy Registry Collaboration. Birth defects among fetuses and infants of US women with evidence of possible Zika virus infection during pregnancy. JAMA. 2017;317:59-68. http://dx.doi.org/10.1001/ jama.2016.19006
33. Ministerio de Salud Publica. Practical clinical guide for the care of the premature newborn [in Spanish]. Dominican Ministry of Health/Pan American Health Organization. Santo Domingo, Dominican Republic. 2018.

34. World Health Organization. Country stillbirth rates per 1,000 total births for 2009. 2011 [cited 2018 Nov 23]. http://www.who.int/ pmnch/media/news/2011/stillbirths_countryrates.pdf

Address for correspondence: Maximo O. Brito, University of Illinois at Chicago, Division of Infectious Diseases, 808 S Wood St (MC735), Chicago, IL 60612, USA; email: mbrito@uic.edu

\section{The Public Health Image Library (PHIL)}
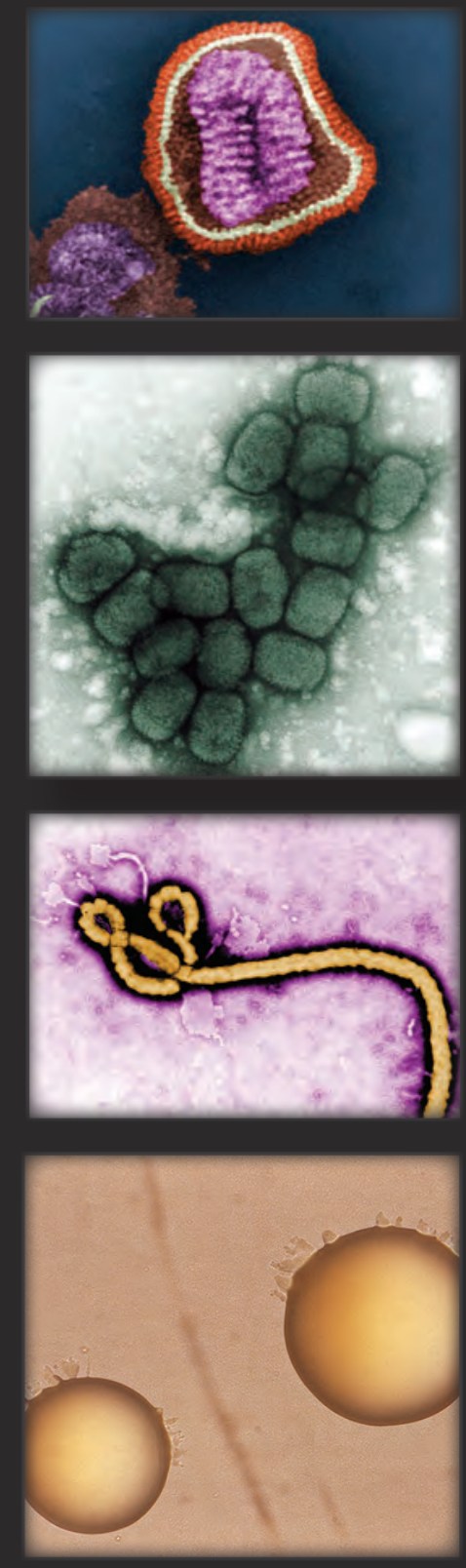

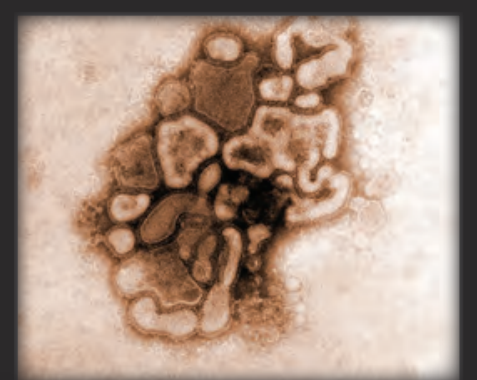

The Public Health I mage Library (PHIL), Centers for Disease Control and Prevention, contains thousands of public health-related images, including highresolution (print quality) photographs, illustrations, and videos.

PHIL collections illustrate current events and articles, supply visual content for health promotion brochures, document the effects of disease, and enhance instructional media.

PHIL images, accessible to PC and Macintosh users, are in the public domain and available without charge.

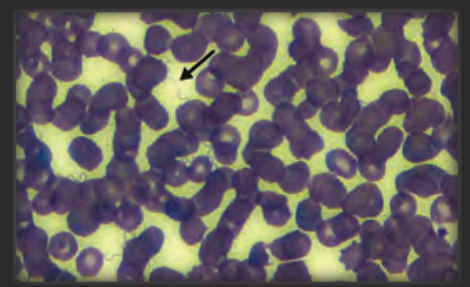

Visit PHI L at: http:/ / phil.cdc.gov 


\title{
Acute and Delayed Deaths after West Nile Virus I nfection, Texas, USA, 2002- 2012
}

\author{
David C.E. Philpott, ${ }^{1}$ Melissa S. Nolan, Nicole Evert, Bonny Mayes, \\ Dawn Hesalroad, Eric Fonken, Kristy O. Murray
}

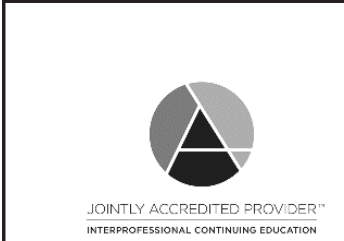

\section{Medscape ACTIVITY}

In support of improving patient care, this activity has been planned and implemented by Medscape, LLC and Emerging Infectious Diseases. Medscape, LLC is jointly accredited by the Accreditation Council for Continuing Medical Education (ACCME), the Accreditation Council for Pharmacy Education (ACPE), and the American Nurses Credentialing Center (ANCC), to provide continuing education for the healthcare team.

Medscape, LLC designates this Journal-based CME activity for a maximum of 1.00 AMA PRA Category 1 Credit(s) ${ }^{\mathrm{TM}}$. Physicians should claim only the credit commensurate with the extent of their participation in the activity.

All other clinicians completing this activity will be issued a certificate of participation. To participate in this journal CME activity: (1) review the learning objectives and author disclosures; (2) study the education content; (3) take the post-test with a $75 \%$ minimum passing score and complete the evaluation at http://www.medscape.org/journal/eid; and (4) view/print certificate. For CME questions, see page 395.

Release date: January 18, 2018; Expiration date: January 18, 2019

\section{Learning Objectives}

Upon completion of this activity, participants will be able to:

- $\quad$ Assess short-term mortality outcomes after infection with West Nile virus

- $\quad$ Distinguish long-term risk factors for mortality after West Nile virus infection

- $\quad$ Evaluate the risk for long-term mortality associated with West Nile virus infection

- Analyze causes of long-term mortality associated with West Nile virus infection

\section{CME Editor}

Thomas J. Gryczan, MS, Technical Writer/Editor, Emerging Infectious Diseases. Disclosure: Thomas J. Gryczan, MS, has disclosed no relevant financial relationships.

\section{CME Author}

Charles P. Vega, MD, Clinical Professor, Health Sciences, Department of Family Medicine, University of California, Irvine School of Medicine, Irvine, California. Disclosure: Charles P. Vega, MD, FAAFP, has disclosed the following relevant financial relationships: served as an advisor or consultant for Johnson \& Johnson Pharmaceutical Research \& Development, L.L.C.; Shire; and Sunovion Pharmaceuticals Inc.; served as a speaker or a member of a speakers bureau for Shire.

\section{Authors}

Disclosures: David C.E. Philpott, MD, MPH; Melissa S. Nolan, MPH, PhD; Nicole Evert, MS; Bonny Mayes, MA; Dawn Hesalroad, MEd; Eric Fonken, DVM, MPAff; and Kristy O. Murray, DVM, PhD, have disclosed no relevant financial relationships.

Infection with West Nile virus (WNV) has a well-characterized acute disease process. However, long-term consequences are less understood. We searched death records for 4,142 residents of Texas, USA, infected with WNV during

Author affiliations: Baylor College of Medicine and Texas Children's Hospital, Houston, Texas, USA (D.C.E. Philpott, M.S. Nolan, K.O. Murray); Texas Department of State Health Services, Austin, Texas, USA (N. Evert, B. Mayes, D. Hesalroad, E. Fonken)

DOI: https://doi.org/10.3201/eid2502.181250
2002-2012 and identified 557 (13\%) deaths. We analyzed all-cause and cause-specific deaths after WNV infection by calculating standardized mortality ratios and using statewide mortality data. Acute-phase deaths ( $<90$ days after symptom onset) occurred in 289 (7\%) of case-patients; of those deaths, 289 (92\%) were cases of West Nile neuroinvasive disease (WNND). Convalescent-phase deaths ( $\geq 90$ days after symptom onset) occurred in 268 (7\%) of the

\footnotetext{
${ }^{1}$ Current affiliation: Johns Hopkins Children's Center, Baltimore, Maryland, USA.
} 
remaining 3,853 case-patients; 210 (78\%) of these deaths occurred in patients with WNND. Convalescent-phase WNND case-patients showed excess deaths from infectious and renal causes; case-patients $<60$ years of age had increased risk for all-cause death, specifically from renal, infectious, digestive, and circulatory causes. We provide population-level evidence of increased risk for death after WNV infection resulting in WNND.

$\mathrm{W}$ Test Nile virus (WNV) is an arbovirus that can result in severe disease and death in humans. Since the first outbreak of infection with this virus in the United States during 1999, it has emerged across the country and resulted in $>46,000$ clinical cases of infection across all contiguous states (1). Uncomplicated febrile illness, known as West Nile fever (WNF), will develop in $20 \%$ of persons acutely infected, and severe West Nile neuroinvasive disease (WNND) will develop in $<1 \%$ (2). Acute WNV infection can cause substantial long-term disability resulting in neurologic, neuropsychologic, and kidney disease outcomes; higher risks for poor outcome are associated with a diagnosis of WNND (3-9). In addition to continual illness, evidence from 2 small cohorts suggested that WNV can result in excessive deaths $(10,11)$.

Death registry-based linkage studies on other virus diseases, such as hepatitis, have characterized the patterns and risk for death at the population level (12-15). We used a similar death registry-based method to describe specific causes of death for WNV case-patients to determine whether this population shows excess death years after initial onset. We analyzed acute-phase and convalescentphase specific causes of death in WNV case-patients given a diagnosis in Texas, USA, during 2002-2012 to determine whether persons with WNV had an increased risk for death than the general population. Our study objectives were to 1) describe causes of death in our population and identify any potential covariates, with particular attention to age because it is a known risk factor for severe disease; 2) compare all-cause and cause-specific mortality rates with those of the underlying Texas population by using standardized mortality ratios (SMRs); and 3) examine yearly deaths for WNV-infected case-patients as they progress through time.

\section{Methods}

\section{Study Population}

In Texas, WNV infections are reported to the Texas Department of State Health Services (TXDSHS) by a passive surveillance system and coded by using standard case definitions for neuroinvasive and nonneuroinvasive diseases (16). WNND includes meningitis, encephalitis, meningoencephalitis, and acute flaccid paralysis; non-WNND includes only WNF. Asymptomatic viremic blood donors were not included in the available TXDSHS database. During July 3, 2002-December 6, 2012, a total of 4,162 WNV cases were reported to TXDSHS; 4,142 cases had complete data on age and US Social Security numbers and were included in our analysis.

We linked the WNV case dataset of TXDSHS to the Texas Death Registry by using Social Security numbers. All deaths identified through December 31, 2012 in the registry were included in this study, regardless of cause or timing of death. Death records were abstracted for age, sex, race, date of death, and underlying cause of death by the International Classification of Diseases, 10th Revision (ICD10), code listed on the death certificate. Underlying cause of death is defined by the National Center for Health Statistics as "the disease or injury which initiated the train of morbid events leading directly to death or the circumstances of the accident or violence which produced the fatal injury" (17).

We chose underlying cause of death because it is commonly used in death studies and because it indicates what the clinician believed was the major cause of death, even accounting for other concurrent illnesses that might also have contributed to the death of a given individual. In addition, because data were incomplete for contributing and immediate causes of death, we were unable to obtain reliable estimates for these causes. Underlying causes of death were grouped according to ICD-10 chapters: infectious, renal, neoplasms, blood/immune, endocrine, nervous, circulatory, respiratory, digestive, genitourinary, other, and external forces. Twenty-four deaths did not have cause of death data and were excluded from specific cause of death analysis; however, all 24 of these persons died during first 88 days after infection, and thus their exclusion did not affect cause-specific death analysis. In addition, 151/557 deaths did not include an ICD-10 code for cause of death; however, records for 127/151 of those case-patients included written cause of death data corresponding to an ICD-10 code that we then added to our dataset.

\section{Statistical Analyses}

We calculated survival time for each patient in personyears from the date of acute WNV onset and ended at either reported date of death or on December 31, 2012. We computed Kaplan-Meier survival curves and stratified by diagnosis of WNND. To identify covariates in our data associated with death, we used Cox proportional hazards regression to determine hazard ratios (HRs) for WNND, age, race, and sex on survival. All variables were coded as nominal variables except age at onset, which was coded as an ordinal variable with 10-year age groupings. We used a backward selection technique to construct a multivariable model. Covariates with $\mathrm{p}<0.2$ were included in multivariable analysis, and variables with $\mathrm{p}<0.05$ were retained in the final model. 
Testing of the validity of the proportional hazards assumption by log-log plots and Schoenfeld residuals indicated that the hazard caused by WNND was not constant over time. Therefore, we divided our study population into an acute phase of deaths that occurred within the first 90 days of WNV symptom onset and a convalescent phase of deaths that occurred after the first 90 days of symptom onset. We retained this division for all subsequent analyses because it is standard in chronic death studies. We then developed a Cox model of deaths occurring in the convalescent phase and verified that it met the proportional hazards assumption.

We calculated descriptive statistics to describe acutephase deaths. We then compared convalescent-phase deaths with those in the Texas population by using SMRs. We obtained all-cause and ICD-10 chapter-specific underlying cause mortality rates for Texas by using the Centers for Disease Control and Prevention WONDER database for calendar years 2002-2012 (18). We adjusted for age group, sex, and calendar year and used age group and calendar year as time-varying covariates. We calculated the expected number of deaths in the population by multiplying the person-years by the calendar year-specific and age-specific Texas mortality rates. If a Texas rate was suppressed in the database because of low cell counts, we used US mortality rates.

We then calculated all-cause and cause-specific SMRs and stratified by WNND disease status, age group, and follow-up year. With regards to age grouping, we first stratified by 10 -year intervals, then divided the population as $\geq 60$ and $<60$ years of age because previous studies found a major increase in severe disease and death risk for persons $>60$ years of age (19-21). We computed all statistics and survival curves by using Stata software version 15 (https://www.stata.com).

\section{Ethics Considerations}

This study was approved by the TXDSHS Institutional Review Board (\#13-060). Because data transferred from TXDSHS to Baylor College of Medicine for analysis had all identifying information removed, the study was determined exempt by the Baylor College of Medicine Institutional Review Board (H-32097).

\section{Results}

During July 3, 2002-December 31, 2012, a total of 557 (13.4\%) deaths occurred among the 4,142 WNV case-patients reported to TXDSHS (Table 1). Time to death ranged from 0 to 3,765 days after onset of symptoms of WNV infection (median 73 days).

\section{Acute-Phase Deaths}

Approximately half of the deaths $(\mathrm{n}=289,51.9 \%)$ occurred during the acute phase after WNV symptom onset. Most (n $=267,92.4 \%$ ) of these deaths occurred among WNND casepatients (median age at onset 75 years). For case-patients who died during the acute phase, the most common underlying cause of death was infectious (181 deaths; 62.6\%); 142 deaths $(49.1 \%)$ were specifically attributed to complications from WNV infection (ICD-10 code A923) (Figure 1).

Table 1. Demographic and clinical characteristics of case-patients with fatal and nonfatal West Nile virus infections, Texas, USA, 2002-2012*

\begin{tabular}{|c|c|c|c|}
\hline \multirow[b]{2}{*}{ Characteristic } & \multirow{2}{*}{$\begin{array}{l}\text { Nonfatal, } \\
\mathrm{n}=3,585\end{array}$} & \multicolumn{2}{|c|}{ Fatal, $\mathrm{n}=557$} \\
\hline & & Acute phase, $n=289$ & Convalescent phase, $n=268$ \\
\hline Median age at symptom onset, y (range) & $52(0-98)$ & $75(19-100)$ & $70.5(17-99)$ \\
\hline \multicolumn{4}{|l|}{ Sex, \% } \\
\hline M & $2,015(56.2)$ & $175(60.6)$ & $182(67.9)$ \\
\hline $\mathrm{F}$ & $1,570(43.8)$ & $114(39.4)$ & $86(32.1)$ \\
\hline \multicolumn{4}{|l|}{ Race, \% } \\
\hline White, non-Hispanic & $2,630(73.4)$ & $195(67.5)$ & $182(67.9)$ \\
\hline White, Hispanic & $753(21.0)^{\prime}$ & $64(22.2)$ & $59(22.0)$ \\
\hline Black & $202(5.6)$ & $30(10.4)$ & $27(10.1)$ \\
\hline Median no. days until death after symptom onset (range) & NA & $19(0-88)$ & $1,171.5(92-3,765)$ \\
\hline WNND, no. (\%) & $1,902(53.1)$ & $267(92.4)$ & $210(78.4)$ \\
\hline \multicolumn{4}{|l|}{ Case counts by year of infection } \\
\hline 2002 & 203 & 13 & 25 \\
\hline 2003 & 598 & 50 & 94 \\
\hline 2004 & 137 & 18 & 24 \\
\hline 2005 & 154 & 13 & 33 \\
\hline 2006 & 279 & 37 & 41 \\
\hline 2007 & 209 & 25 & 26 \\
\hline 2008 & 57 & 2 & 6 \\
\hline 2009 & 103 & 10 & 1 \\
\hline 2010 & 76 & 9 & 4 \\
\hline 2011 & 22 & 4 & 1 \\
\hline 2012 & 1,747 & 108 & 13 \\
\hline
\end{tabular}

*Acute indicates that death occurred $<90 \mathrm{~d}$ after symptom onset after infection with West Nile virus. Convalescent phase indicates that death occurred $\geq 90 \mathrm{~d}$ after symptom onset. NA, not available; WNND, West Nile neuroinvasive disease. 


\section{Convalescent-Phase Deaths}

During the convalescent phase, 268 (7.0\%) patients died. Most deaths occurred in case-patients with WNND $(210 / 2,112$; case-fatality rate $9.9 \%)$. This rate was much higher than the case-fatality rate of 3.3\% for patients with non-WNND $(58 / 1,741)$. WNND case-patients contributed 9,573 total years of follow-up time (median 4.37 years/ patient), and non-WNND case-patients contributed 5,772 total years (median 0.46 years/patient). The median time elapsed from symptom onset until death was 3.0 years for convalescent-phase WNND patients and 4.1 years for nonWNND case-patients. The disparity in follow-up time between WNND and non-WNND case-patients occurred because a larger proportion of non-WNND case-patients were reported later in the study period. Specifically, $58.1 \%$ of non-WNND case-patients were reported in 2012 compared with $35.4 \%$ of WNND case-patients.

We constructed Kaplan-Meier curves comparing deaths for WNND case-patients and deaths for non-WNND case-patients (Figure 2). We found by Cox proportional hazards regression strong associations for death with WNND (HR 1.67, 95\% CI 1.24-2.23), age at symptom onset (HR 1.63, 95\% CI 1.53-1.75/10-year increase), black race (HR 1.68, 95\% CI 1.12-2.52), and male sex (HR 1.42, 95\% CI 1.10-1.84).

Among deaths that occurred during the convalescent phase, the incidence of death from any cause for WNND case-patients was much higher per 10,000 person-years (rate 219.4, 95\% CI 191.6-251.1) than for non-WNND case-patients(100.5, 95\% CI 77.7-129.9). All-cause deaths for WNND case-patients were not increased compared with deaths for the Texas population (SMR 1.13) (Table 2). Conversely, all-cause deaths for non-WNND case-patients were reduced compared with deaths for the Texas population (SMR 0.72, 95\% CI 0.55-0.93).
When we examined cause-specific deaths (Table 2), non-WNND cases were not different for any cause when compared with those in the Texas population. However, among WNND cases, we found increased mortality rates caused by infectious (SMR 4.74) and genitourinary (SMR 2.41) complications. Deaths from infections were caused by primarily WNV complications (ICD-10 code A923, 13/26 deaths), sepsis caused by an unspecified organism (A419, 5/26 deaths), or sequelae of other specified infectious diseases (B948, 4/26 deaths). Deaths from infectious causes occurred at a median of 0.60 years (range 0.25 6.70 years) after symptom onset. Most (11/13) deaths from genitourinary causes were specifically from renal causes (ICD-10 codes N00-N19), which had an increased SMR of 2.59. Renal deaths were caused by chronic kidney disease (ICD-10 code N18, 8/11 deaths), unspecified kidney failure (N19, 2/11 deaths), chronic nephritic syndrome (N039, 1/11 deaths), and acute kidney failure (N179, 1/11 deaths). Deaths caused by renal disease occurred a median of 4.03 years (range 1.36-10.3 years) after symptom onset.

When we stratified by 10 -year age groups at onset (Figure 3), we found that for WNND case-patients, allcause SMRs were considerably increased for age groups $<60$ years; SMRs were 2.18 (95\% CI 1.04-4.56) for persons <40 years of age, 1.73 (95\% CI 1.00-2.97) for persons 40-49 years of age, and 2.06 (95\% CI 1.46-2.92) for persons 50-59 years of age. All-cause deaths were also increased for persons 60-69 years of age (SMR 1.41, 95\% CI 1.06-1.87). For non-WNND case-patients, deaths were lower for persons $\geq 70$ years of age at symptom onset (SMR 0.69, 95\% CI 0.46-0.94).

We divided the WNND case deaths into 2 groups to examine cause-specific deaths for patients $<60$ years of age and for those $\geq 60$ of age at disease onset (Table 3). The

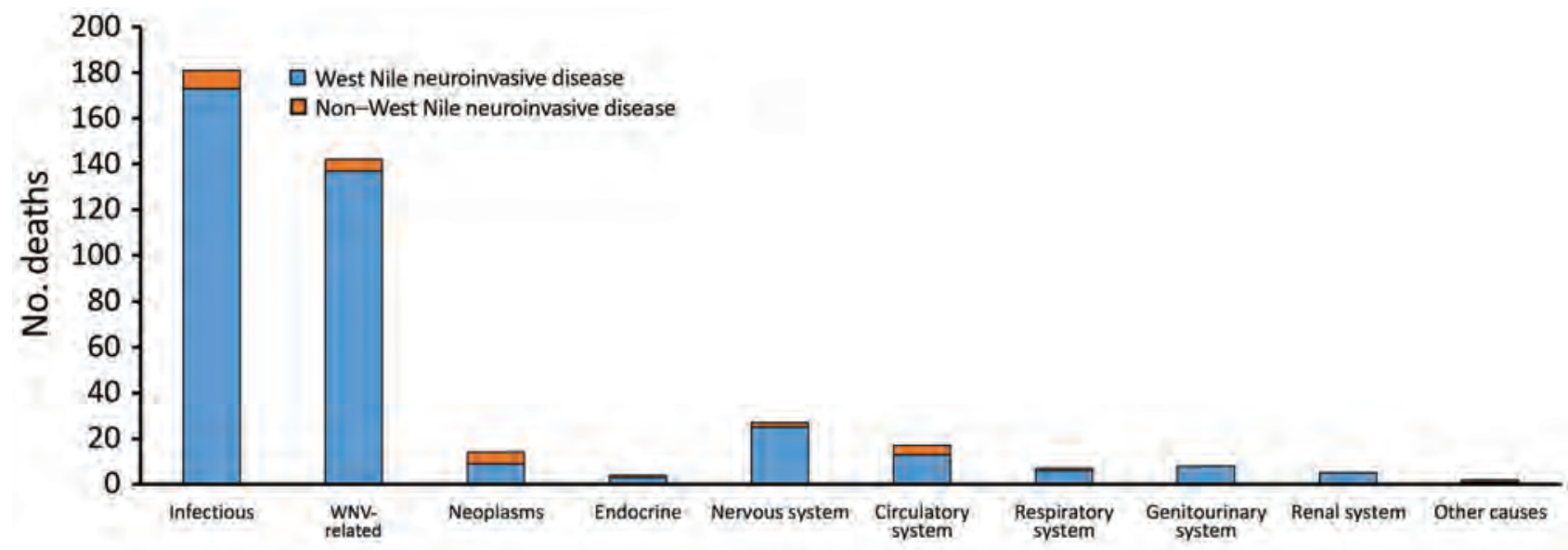

Figure 1. Causes of death in acute cases (within 90 days of WNV disease onset) by condition, Texas, USA, 2002-2012. Most deaths were related to infectious causes (International Classification of Diseases, 10th Revision [ICD10], chapters A00-B99), with a subset of those specifically stating a diagnosis of WNV infection (ICD-10 code A923). Both causes are included in this figure. WNV, West Nile virus. 


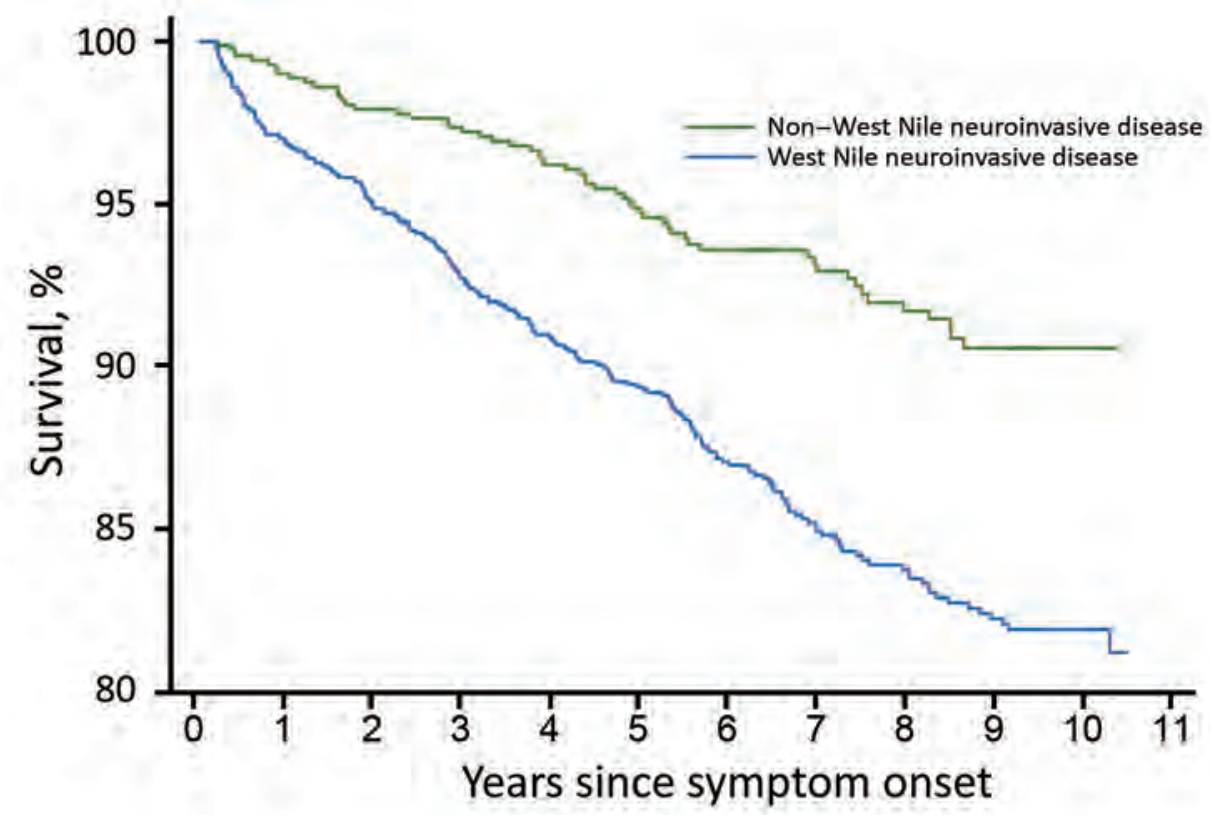

Figure 2. Kaplan-Meier survival curve for case-patients infected with West Nile virus, Texas, USA, 2002-2012, stratified by severity of presenting illness (deaths within 90 days excluded).

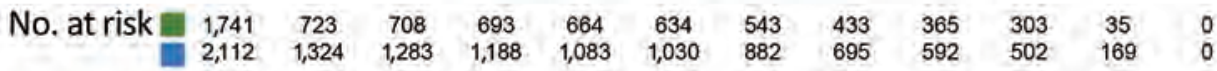

absolute mortality rate was higher in persons $\geq 60$ years of age (444.7 deaths $/ 10,000$ person-years, $95 \%$ CI $380.5-$ 519.8 deaths $/ 10,000$ person-years) than in persons $<60$ years of age (86.4 deaths/10,000 person-years, $95 \%$ CI 65.8-113.4 deaths/10,000 person-years). However, allcause deaths for persons $<60$ years of age was nearly twice the rate for the entire population of Texas (SMR 1.98). Deaths from infectious causes was increased in both age groups (SMRs 5.33 persons $\geq 60$ years of age, 4.55 for persons $<60$ years of age). For patients $<60$ years of age, we found major increases in deaths from renal (SMR 11.37), mental and behavioral (SMR 6.28), digestive (SMR 3.87), and circulatory (SMR 2.02) causes.
When we stratified by year of follow-up, we found that SMRs were not increased in any year for non-WNND casepatients; however, we did see a difference among WNND case-patients. We identified a statistically significant increase in SMR for all WNND case-patients in the first year after infection (SMR 1.75, 95\% CI 1.32-2.32; p<0.001); this increase continued into years 2 (SMR 1.15) and 3 (SMR 1.33), but not at a statistically significant level.

We then repeated our analysis while stratifying WNND case-patients $\geq 60$ years of age and those $<60$ years of age at symptom onset (Figure 4). For case-patients $\geq 60$ of age, we found increased deaths in the first year after symptom onset (SMR 1.55, 95\% CI 1.13-2.14) but not in subsequent

\begin{tabular}{|c|c|c|c|c|c|c|c|}
\hline \multirow[b]{2}{*}{$\begin{array}{l}\text { ICD-10 } \\
\text { code }\end{array}$} & \multirow[b]{2}{*}{$\begin{array}{c}\text { Cause of death or } \\
\text { disorder }\end{array}$} & \multicolumn{3}{|c|}{ WNND } & \multicolumn{3}{|c|}{ Non-WNND } \\
\hline & & $\begin{array}{c}\text { No. deaths } \\
\text { observed }\end{array}$ & $\begin{array}{l}\text { No. deaths } \\
\text { expected }\end{array}$ & SMR $(95 \% \mathrm{Cl})$ & $\begin{array}{c}\text { No. deaths } \\
\text { observed }\end{array}$ & $\begin{array}{l}\text { No. deaths } \\
\text { expected }\end{array}$ & SMR $(95 \% \mathrm{Cl})$ \\
\hline Any & All cause & 210 & 187 & $1.13(0.99-1.29)$ & 58 & 81.08 & $0.72(0.55-0.93)$ \\
\hline A00-B99 & Infectious & 26 & 5.49 & $4.74(3.22-6.94)$ & 3 & 2.57 & $1.17(0.38-3.62)$ \\
\hline C00-D48 & Neoplasms & 33 & 43.89 & $0.75(0.53-1.06)$ & 12 & 19.06 & $0.63(0.36-1.11)$ \\
\hline E00-E90 & Endocrine & 11 & 8.13 & $1.35(0.75-2.44)$ & 3 & 3.60 & $0.83(0.27-2.58)$ \\
\hline F00-F99 & Mental and behavioral & 13 & 8.96 & $1.45(0.84-2.50)$ & 1 & 3.86 & $0.26(0.04-1.84)$ \\
\hline G00-G99 & Nervous system & 11 & 10.70 & $1.03(0.57-1.86)$ & 4 & 4.51 & $0.89(0.33-2.36)$ \\
\hline $100-199$ & Circulatory system & 64 & 63.44 & $1.01(0.79-1.29)$ & 18 & 26.99 & $0.67(0.42-1.06)$ \\
\hline J00-J99 & Respiratory system & 13 & 19.70 & $0.66(0.38-1.14)$ & 7 & 8.12 & $0.86(0.41-1.81)$ \\
\hline K00-K93 & Digestive system & 9 & 6.82 & $1.32(0.69-2.53)$ & 1 & 3.24 & $0.31(0.04-2.19)$ \\
\hline N00-N99 & Genitourinary system & 13 & 5.40 & $2.41(1.40-4.15)$ & 2 & 2.30 & $0.87(0.22-3.47)$ \\
\hline N00-N19 & Renal disease & 11 & 4.25 & $2.59(1.43-4.67)$ & 1 & 1.81 & $0.55(0.08-3.92)$ \\
\hline R00-R99 & Other & 5 & 2.53 & $1.97(0.82-4.74)$ & 2 & 1.18 & $1.70(0.43-6.80)$ \\
\hline W00-Y98 & External forces & 10 & 6.86 & $1.46(0.78-2.71)$ & 3 & 3.77 & $0.80(0.26-2.47)$ \\
\hline
\end{tabular}




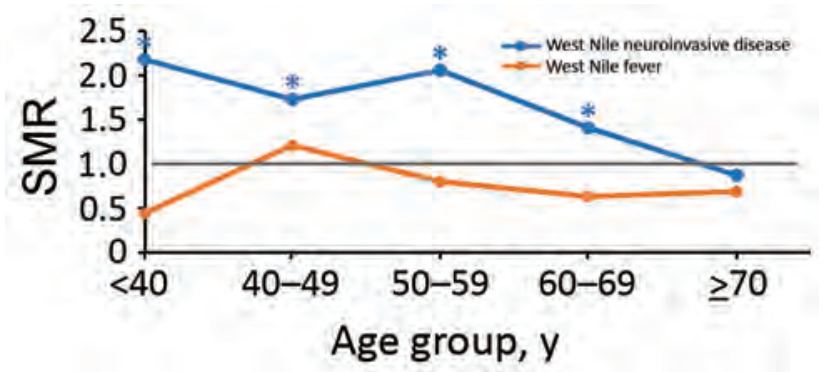

Figure 3. SMRs by age at onset of persons with West Nile virus infection, Texas, USA, 2002-2012. SMRs were adjusted for current age, sex, and calendar year. Deaths and SMRs were calculated only for case-patients with information about age available and in whom death occurred $>90$ days after symptom onset. SMR $=1$ when there is no increased risk. *Indicates where a $95 \% \mathrm{Cl}$ does not include 1 . SMR, standardized mortality ratio.

years. However, for case-patients $<60$ years of age, we found increased mortality rates, more than twice the full Texas population rate, until 5 years after WNV infection; deaths were only slightly increased during year 6 . Specifically, SMRs were $3.2(95 \%$ CI 1.8-5.8; $\mathrm{p}=0.0001)$ in year $1,2.4(95 \%$ CI $1.1-5.0 ; \mathrm{p}=0.002)$ in year $2,2.7(95 \% \mathrm{CI}$ $1.3-5.4 ; \mathrm{p}=0.006)$ in year $3,2.0(95 \%$ CI $0.9-4.5 ; \mathrm{p}=$ $0.09)$ in year 4 , and $2.6(95 \%$ CI $1.3-5.3 ; \mathrm{p}=0.008)$ in year 5. This increase reached statistical significance in 4 of the 6 years (years 1, 2, 3, and 5).

\section{Discussion}

We present population-level evidence of excess acute and delayed deaths for a large sample size of case-patients with a history of WNV infection resulting in WNND. Across our full sample, although we did not find increased all-cause mortality rates at a significant level, we did find that deaths from renal and infectious causes for WNND case-patients occurred at a higher rate than would be expected for the full population of Texas. When we stratified by age, we found a major increased risk for all-cause death for case-patients who were $<60$ years of age at the time of symptom onset. The greatest risks for death in this group were attributed to renal, infectious, digestive, and circulatory causes.

Our data provide further evidence supporting excess illness and death years after WNV infection resulting from WNND. In addition, we found that reported case-patients with non-WNND had all-cause mortality rates that were lower than the Texas population rate. Our study is unique when compared with previous cohort studies because our large sample size enabled us to explore the progression of deaths for WNV case-patients over a greater period, stratify by age group, stratify by disease presentation, and examine cause-specific deaths $(10,11)$.

In our study, we found that among persons given a diagnosis of WNND, deaths from renal causes occurred at 2.5 times the rate for the Texas population. Furthermore, when stratifying by age, we found that persons $<60$ years of age had an 11 times greater risk for dying from renal causes. Deaths caused by kidney disease occurred at median of 4 years after infection, and most were caused by chronic kidney disease (CKD). If one considers that almost half of all of the case-patients in the dataset were infected in 2012, we have comparatively much less follow-up data for later years, when these delayed deaths could occur. It will be useful to conduct a follow-up study on the 2012 cases to determine whether this major finding will continue to be evident.

Increased risk for death from renal causes certainly warrants further investigation. In previous studies that investigated risk factors for WNND, renal disease was not found to be significant (22); however, traditional risk factors

Table 3. SMRs for convalescent-phase deaths caused by WNND stratified by age at WNV infection symptom onset, Texas, USA, 2002-2012*

\begin{tabular}{|c|c|c|c|c|c|c|c|}
\hline \multirow[b]{2}{*}{$\begin{array}{l}\text { ICD-10 } \\
\text { code }\end{array}$} & \multirow[b]{2}{*}{$\begin{array}{c}\text { Cause of death or } \\
\text { disorder }\end{array}$} & \multicolumn{3}{|c|}{$<60$ years of age } & \multicolumn{3}{|c|}{$\geq 60$ years of age } \\
\hline & & $\begin{array}{c}\text { No. deaths } \\
\text { observed }\end{array}$ & $\begin{array}{l}\text { No. deaths } \\
\text { expected }\end{array}$ & SMR (95\% CI) & $\begin{array}{l}\text { No. deaths } \\
\text { observed }\end{array}$ & $\begin{array}{l}\text { No. deaths } \\
\text { expected }\end{array}$ & SMR (95\% Cl) \\
\hline Any & All cause & 52 & 26.26 & $1.98(1.51-2.60)$ & 158 & 159.76 & $0.99(0.84-1.16)$ \\
\hline A00-B99 & Infectious & 7 & 1.31 & $5.33(2.54-11.17)$ & 19 & 4.18 & $4.55(2.90-7.13)$ \\
\hline C00-D48 & Neoplasms & 8 & 7.24 & $1.11(0.55-2.21)$ & 25 & 36.73 & $0.68(0.46-1.01)$ \\
\hline E00-E90 & Endocrine & 1 & 1.29 & $0.78(0.11-5.51)$ & 10 & 6.686 & $1.46(0.79-2.72)$ \\
\hline F00-F99 & Mental and behavioral & 2 & 0.32 & 6.28 (1.57-25.12) & 11 & 8.64 & $1.27(0.70-2.30)$ \\
\hline G00-G99 & Nervous system & 2 & 0.61 & $3.27(0.82-13.07)$ & 9 & 10.09 & $0.89(0.46-1.71)$ \\
\hline $100-199$ & Circulatory system & 14 & 6.94 & 2.02 (1.19-3.41) & 50 & 56.50 & 0.88 (0.67-1.17) \\
\hline J00-J99 & Respiratory system & 2 & 1.42 & $1.40(0.35-5.62)$ & 11 & 18.27 & 0.60 (0.33-1.09) \\
\hline K00-K93 & Digestive system & 7 & 1.81 & 3.87 (1.85-8.12) & 2 & 5.01 & $0.400 .10-1.60)$ \\
\hline N00-N99 & Genitourinary system & 6 & 0.51 & $11.72(5.26-26.08)$ & 7 & 4.89 & $1.43(0.68-3.00)$ \\
\hline N00-N19 & Renal system & 5 & 0.44 & $11.37(4.73-27.31)$ & 6 & 3.81 & $1.58(0.71-3.51)$ \\
\hline R00-R99 & Other & 0 & 0.42 & $0(\mathrm{NA})$ & 5 & 2.11 & $2.36(0.98-5.68)$ \\
\hline W00-Y98 & External forces & 3 & 2.83 & $1.06(0.34-3.29)$ & 7 & 4.01 & $1.75(0.83-3.66)$ \\
\hline
\end{tabular}

*Deaths and SMR were calculated only for cases with information about age available and in which death occurred $>90 \mathrm{~d}$ after symptom onset. SMR was 1 when there was no increased risk. Bold indicates statistical significance. ICD-10, International Classification of Diseases, 10th Revision; NA, not applicable; SMR, standardized mortality ratio adjusted for current age, sex, and calendar year; WNND, West Nile neuroinvasive disease; WNV, West Nile virus. 


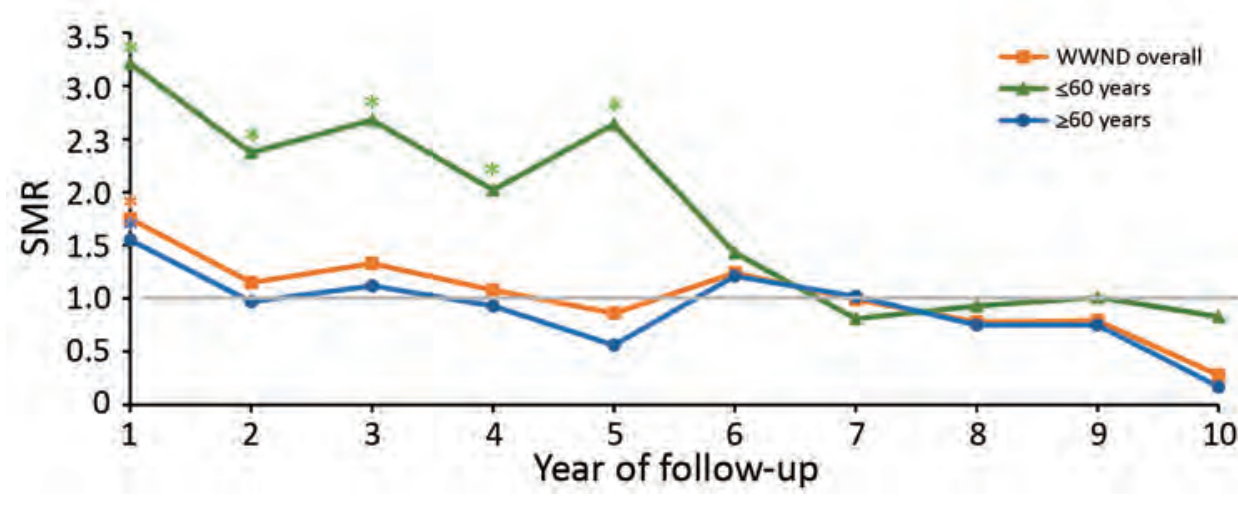

Figure 4. SMRs for case-patients with WNND by year of follow-up stratified by age at symptom onset, Texas, USA, 2002-2012. SMRs were adjusted for current age, sex, and calendar year. Deaths and SMRs were calculated only for case-patients with information about age available and in whom death occurred $\geq 90$ days after symptom onset. SMR $=1$ when there is no increased risk. *Indicates where a 95\% Cl does not include 1. SMR, standardized mortality ratio; WNND, West Nile neuorinvasive disease. for CKD (advanced age, hypertension, and diabetes) were found to be associated with WNND. In 1 study, a history of renal disease was found to be associated with an increased risk for death during the acute phase of WNV illness. It is possible that underlying concurrent conditions that increase the risk for WNND in our population could also contribute to death related to renal causes. Unfortunately, our method of only collecting data from death certificates did not enable us to fully examine the medical history. This examination would be critical to further evaluate because previous studies that involved animal models found evidence of persistent WNV infection in renal tissue (23-26). A study from a Houston WNV cohort isolated WNV RNA from the urine of 5 study participants with a history of WNND (27). In a separately published study, Nolan et al. identified CKD in $40 \%$ of cohort participants, with history of WNND being the sole independent predictor for CKD as opposed to traditional risk factors (i.e., hypertension, diabetes, or being $>65$ years of age) (8), in comparison with a prevalence of kidney disease in only $8 \%$ of patients in this cohort during the acute phase of WNV disease onset (20). Although detection of persistent infection of the kidneys in humans has been controversial (28), the findings of our study of increased mortality rates from renal causes, particularly CKD, and median renal death occurring 4 years postinfection lends support to studies that have identified renal disease as a possible sequelae of infection with WNV.

WNND case-patients $<60$ years of age at the time of symptom onset had mortality rates twice the rate expected for the Texas population. These younger patients had excess deaths from renal causes ( $>11$ times) and infectious causes ( $>5$ times) compared with deaths among the general population. In addition, these patients had excess deaths from mental and behavioral, circulatory, and digestive system causes. Conversely, patients $\geq 60$ years of age at symptom onset had all-cause mortality rates similar to those for the Texas population. However, mortality rates for infectious causes were $\approx 5$ times those for the Texas population. The finding that the convalescent-phase mortality rate was increased for younger patients was unexpected because advanced age is known to be a risk factor for death from infection with WNV during the acute phase of the disease. It will be helpful to expand this study to review these case-patients and determine whether concurrent conditions, particularly hypertension or immunosuppression (28), could contribute to the risk for severity of WNV disease and, thereby, increased risk for death.

The pattern through time indicated increased mortality rates for all WNND case-patients for the first year after symptom onset, even after excluding deaths within the first 90 days. WNND case-patients died from infectious causes at $>5$ times the expected rate, and deaths occurred primarily during the first 2 years: half (13/26) of these deaths were coded as caused by WNV infection, and 4 were attributed to sequelae of other specified infectious disease. Similar results have been reported in cohort studies in Colorado, USA (10), and in Israel (11), in which increased mortality rates were observed within the first year after infection and there was some evidence of later delayed deaths that did not reach statistical significance.

Non-WNND case-patients unexpectedly had mortality rates lower than those for the Texas population. The reasons for this finding are not clear. However, the population that seeks care resulting in a non-WNND diagnosis might be healthier than the general Texas population. In our study, half of the non-WNND case-patients were given a diagnosis during 2012, which was during an outbreak in Texas that was larger than any previously recorded and well publicized in the media (21). Because of increased awareness, more healthy persons might have sought care resulting in a diagnosis of non-WNND.

Our study had several limitations. First, because of our register-based method, we were unable to assess previous concurrent conditions in the study population. Major 
known contributory concurrent conditions from previous mortality studies include dementia, cardiovascular disease, hepatic disease, immunodeficiency, autoimmune disease, use of tobacco, alcoholism, and intubation during acute WNV illness $(10,11)$. The increased mortality rate we observed in younger patients might be caused by this population being less healthy than the underlying Texas population and possessing $\geq 1$ of these risk factors. This hypothesis is supported by the increased mortality rate for infectious, circulatory, and digestive system causes among younger case-patients. However, for these younger case-patients, deaths from renal causes were most increased in comparison with those for the Texas population, and deaths from infectious causes were primarily the result of direct WNV infection or sequelae of WNV infection. Moreover, when examined within the context of the whole study population, we found that deaths from renal and infectious causes remained higher than those for the Texas population, although all other causes were not. Analysis of contributing cause of death data might enable greater assessment of concurrent conditions for deaths caused by WNV.

Second, our study might have undercounted deaths in our population because of effects of interstate and international migration. We were only able to obtain death certificate data for WNV case-patients who died in Texas. Thus, we are likely underestimating the SMRs in our population, given substantial levels of migration in and out of Texas. Finally, our study has limited generalizability: $<1 \%$ of WNV infections result in WNND, and most of these patients are elderly (>60 years of age) (2). We found mortality rates to be most increased in younger patients with WNND and found no evidence of deaths for case-patients with a history of WNF.

In conclusion, arboviruses continue to be an emerging global threat, and defining the long-term consequences of WNV is critical. We present population-level evidence for increased risk for death, particularly for patients $<60$ of age who have a history of WNND. For these patients, excess deaths were related to infectious and renal causes, and excess all-cause deaths were evident for $\leq 5$ years after onset of symptoms. No specific treatment is available for WNV infection; therefore, prevention of infection is key, either through education efforts to encourage avoiding mosquito bites, comprehensive mosquito surveillance and control, or a greater emphasis on developing an effective vaccine. WNND patients should be closely followed by clinicians to prevent future health problems.

This study was supported by the National Institute of Allergy and Infectious Diseases/National Institutes of Health (grant R01 AI091816-01).

\section{About the Author}

Dr. Philpott is a first-year pediatrics resident at Johns Hopkins Children's Center, Baltimore, MD. His research interests are health services research and infectious diseases.

\section{References}

1. Centers for Disease Control and Prevention. Final cumulative maps and data for 1999-2016. West Nile virus, 2016 [cited 2018 Apr 15]. https://www.cdc.gov/westnile/statsmaps/ cumMapsData.html

2. Mostashari F, Bunning ML, Kitsutani PT, Singer DA, Nash D, Cooper MJ, et al. Epidemic West Nile encephalitis, New York, 1999: results of a household-based seroepidemiological survey. Lancet. 2001;358:261-4. http://dx.doi.org/10.1016/S0140-6736 (01)05480-0

3. Sejvar JJ, Leis AA, Stokic DS, Van Gerpen JA, Marfin AA, Webb R, et al. Acute flaccid paralysis and West Nile virus infection. Emerg Infect Dis. 2003;9:788-93. http://dx.doi.org/ 10.3201/eid0907.030129

4. Sejvar JJ, Curns AT, Welburg L, Jones JF, Lundgren LM, Capuron L, et al. Neurocognitive and functional outcomes in persons recovering from West Nile virus illness.

J Neuropsychol. 2008;2:477-99. http://dx.doi.org/10.1348/ $174866407 X 218312$

5. Carson PJ, Konewko P, Wold KS, Mariani P, Goli S, Bergloff P, et al. Long-term clinical and neuropsychological outcomes of West Nile virus infection. Clin Infect Dis. 2006;43:723-30. http://dx.doi.org/10.1086/506939

6. Murray KO, Garcia MN, Rahbar MH, Martinez D, Khuwaja SA, Arafat RR, et al. Survival analysis, long-term outcomes, and percentage of recovery up to 8 years post-infection among the Houston West Nile virus cohort. PLoS One. 2014;9:e102953. http://dx.doi.org/10.1371/journal.pone.0102953

7. Weatherhead JE, Miller VE, Garcia MN, Hasbun R, Salazar L, Dimachkie MM, et al. Long-term neurological outcomes in West Nile virus-infected patients: an observational study. Am J Trop Med Hyg. 2015;92:1006-12. http://dx.doi.org/10.4269/ ajtmh.14-0616

8. Nolan MS, Podoll AS, Hause AM, Akers KM, Finkel KW, Murray KO. Prevalence of chronic kidney disease and progression of disease over time among patients enrolled in the Houston West Nile virus cohort. PLoS One. 2012;7:e40374. http://dx.doi.org/10.1371/journal.pone.0040374

9. Ouhoumanne N, Lowe A-M, Fortin A, Kairy D, Vibien A, K-Lensch J, et al. Morbidity, mortality and long-term sequelae of West Nile virus disease in Québec. Epidemiol Infect. 2018;146:867-74. http://dx.doi.org/10.1017/S0950268818000687

10. Lindsey NP, Sejvar JJ, Bode AV, Pape WJ, Campbell GL. Delayed mortality in a cohort of persons hospitalized with West Nile virus disease in Colorado in 2003. Vector Borne Zoonotic Dis. 2012;12:230-5. http://dx.doi.org/10.1089/vbz.2011.0721

11. Green MS, Weinberger M, Ben-Ezer J, Bin H, Mendelson E, Gandacu D, et al. Long-term death rates, West Nile virus epidemic, Israel, 2000. Emerg Infect Dis. 2005;11:1754-7. http://dx.doi.org/ 10.3201/eid1111.040941

12. Amin J, Law MG, Bartlett M, Kaldor JM, Dore GJ. Causes of death after diagnosis of hepatitis B or hepatitis $C$ infection: a large community-based linkage study. Lancet. 2006;368:938-45. http://dx.doi.org/10.1016/S0140-6736(06)69374-4

13. Duberg AS, Törner A, Davidsdóttir L, Aleman S, Blaxhult A, Svensson A, et al. Cause of death in individuals with chronic HBV and/or HCV infection, a nationwide community-based register study. J Viral Hepat. 2008;15:538-50. http://dx.doi.org/10.1111/ j.1365-2893.2008.00982.x 
14. McDonald SA, Hutchinson SJ, Bird SM, Mills PR, Dillon J, Bloor M, et al. A population-based record linkage study of mortality in hepatitis C-diagnosed persons with or without HIV coinfection in Scotland. Stat Methods Med Res. 2009;18:271-83. http://dx.doi.org/10.1177/0962280208094690

15. Yu A, Spinelli JJ, Cook DA, Buxton JA, Krajden M. Mortality among British Columbians testing for hepatitis C antibody. BMC Public Health. 2013;13:291. http://dx.doi.org/10.1186/ 1471-2458-13-291

16. Centers for Disease Control and Prevention. Arboviral diseases, neuroinvasive and nonneuroinvasive. 2004 case definition [cited 2016 Nov 17]. https://wwwn.cdc.gov/nndss/conditions/ arboviral-diseases-neuroinvasive-and-non-neuroinvasive/ case-definition/2004/

17. National Center for Health Statistics. Instruction manual, part 2a, instructions for classifying the underlying cause of death, 2017 [cited 2018 Oct 7]. https://www.cdc.gov/nchs/data/ dvs/2a_2017.pdf

18. Centers for Disease Control and Prevention, National Center for Health Statistics. Underlying cause of death 1999-2013 on CDC WONDER online database, 2015 [cited 2016 Feb 20]. https://wonder.cdc.gov/ucd-icd10.html

19. Nolan MS, Schuermann J, Murray KO. West Nile virus infection among humans, Texas, USA, 2002-2011. Emerg Infect Dis. 2013;19:137-9. http://dx.doi.org/10.3201/eid1901.121135

20. Murray K, Baraniuk S, Resnick M, Arafat R, Kilborn C, Cain K, et al. Risk factors for encephalitis and death from West Nile virus infection. Epidemiol Infect. 2006;134:1325-32. http://dx.doi.org/ $10.1017 / \mathrm{S} 0950268806006339$

21. Murray KO, Ruktanonchai D, Hesalroad D, Fonken E, Nolan MS. West Nile virus, Texas, USA, 2012. Emerg Infect Dis. 2013;19:1836-8. http://dx.doi.org/10.3201/eid1911.130768

22. Yeung MW, Shing E, Nelder M, Sander B. Epidemiologic and clinical parameters of West Nile virus infections in humans: a scoping review. BMC Infect Dis. 2017;17:609. http://dx.doi.org/ 10.1186/s12879-017-2637-9

23. Saxena V, Xie G, Li B, Farris T, Welte T, Gong B, et al. A hamster-derived West Nile virus isolate induces persistent renal infection in mice. PLoS Negl Trop Dis. 2013;7:e2275. http://dx.doi.org/10.1371/journal.pntd.0002275

24. Tesh RB, Siirin M, Guzman H, Travassos da Rosa AP, Wu X, Duan T, et al. Persistent West Nile virus infection in the golden hamster: studies on its mechanism and possible implications for other flavivirus infections. J Infect Dis. 2005;192:287-95. http://dx.doi.org/10.1086/431153

25. Tonry JH, Xiao S-Y, Siirin M, Chen H, da Rosa AP, Tesh RB. Persistent shedding of West Nile virus in urine of experimentally infected hamsters. Am J Trop Med Hyg. 2005;72:320-4. http://dx.doi.org/10.4269/ajtmh.2005.72.320

26. Pogodina VV, Frolova MP, Malenko GV, Fokina GI, Koreshkova GV, Kiseleva LL, et al. Study on West Nile virus persistence in monkeys. Arch Virol. 1983;75:71-86. http://dx.doi.org/10.1007/BF01314128

27. Murray K, Walker C, Herrington E, Lewis JA, McCormick J, Beasley DW, et al. Persistent infection with West Nile virus years after initial infection. J Infect Dis. 2010;201:2-4. http://dx.doi.org/10.1086/648731

28. Gibney KB, Lanciotti RS, Sejvar JJ, Nugent CT, Linnen JM, Delorey MJ, et al. West Nile virus RNA not detected in urine of 40 people tested 6 years after acute West Nile virus disease. J Infect Dis. 2011;203:344-7. http://dx.doi.org/10.1093/infdis/jiq057

Address for correspondence: Kristy O. Murray, National School of Tropical Medicine, Baylor College of Medicine, 1102 Bates St, Ste 550, Houston, TX 77030, USA; email: kmurray@bcm.edu

\section{EI D Podcast: Why We Need West Nile Testing}

Arboviruses (arthropodborne viruses) are viruses that can infect humans via arthropod vectors, including mosquitoes, ticks, and sand flies. In the United States, the most common arboviral disease is infection with West Nile virus (WNV), which is transmitted largely by mosquitoes of the genus Culex. Since the first detection of WNV in the United States in 1999, several outbreaks of WNV infection have occurred in cyclic patterns. Texas is considered to be an area where transmission of WNV is endemic and occasionally epidemic; to date, more than 4,000 clinical cases in Texas have been reported.

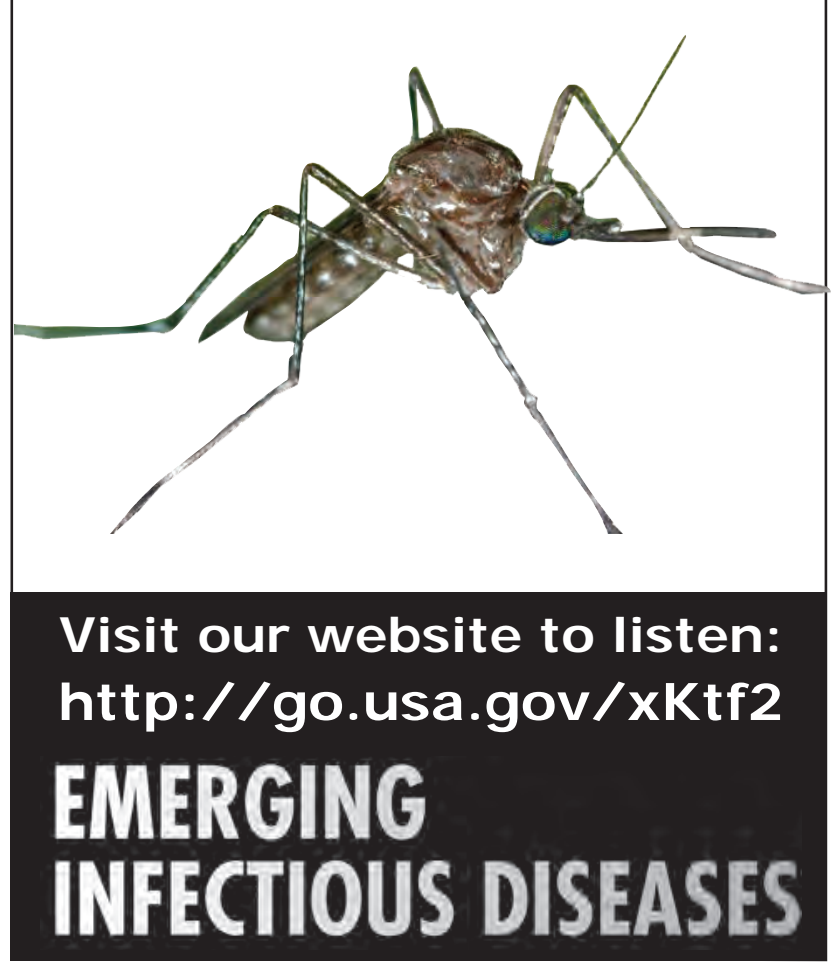




\title{
Echinococcus multilocularis I nfection, Southern Ontario, Canada
}

\author{
Jonathon D. Kotwa, Mats Isaksson, Claire M. Jardine, G. Douglas Campbell, \\ Olaf Berke, David L. Pearl, Nicola J. Mercer, Eva Osterman-Lind, Andrew S. Peregrine
}

\begin{abstract}
Alveolar echinococcosis, the disease caused by infection with the intermediate stage of the Echinococcus multilocularis tapeworm, is typically fatal in humans and dogs when left untreated. Since 2012, alveolar echinococcosis has been diagnosed in 5 dogs, 3 lemurs, and 1 chipmunk in southern Ontario, Canada, a region previously considered free of these tapeworms. Because of human and animal health concerns, we estimated prevalence of infection in wild canids across southern Ontario. During 2015-2017, we collected fecal samples from 460 wild canids (416 coyotes, 44 foxes) during postmortem examination and analyzed them by using a semiautomated magnetic capture probe DNA extraction and real-time PCR method for $E$. multilocularis DNA. Surprisingly, 23\% (95\% Cl 20\%-27\%) of samples tested positive. By using a spatial scan test, we identified an infection cluster (relative risk 2.26; $p=0.002$ ) in the western-central region of the province. The cluster encompasses areas of dense human population, suggesting zoonotic transmission.
\end{abstract}

\begin{abstract}
A lveolar echinococcosis (AE) is a chronic infection caused by the larval stage of the Echinococcus multilocularis tapeworm and commonly manifests within the liver. In humans and dogs, AE is typically fatal when left untreated. E. multilocularis has a wide distribution in the Northern Hemisphere, including extensive endemic regions in North America, Europe, and Asia (1), and is usually maintained in a life cycle that involves 2 mammalian hosts. Wild canids (e.g., foxes and coyotes), dogs, and (less commonly) cats act as definitive hosts, which harbor adult parasites in the small intestine without apparent clinical disease. Once mature, adult parasites release eggs, which are shed in the definitive host's feces. Intermediate hosts (e.g., small rodents) acquire the larval stage by ingestion of infective eggs in the environment.

Author affiliations: University of Guelph, Guelph, Ontario, Canada (J.D. Kotwa, C.M. Jardine, G.D. Campbell, O. Berke, D.L. Pearl, A.S. Peregrine); National Veterinary Institute, Uppsala, Sweden (M. Isaksson, E. Osterman-Lind); Canadian Wildlife Health Cooperative, Guelph (C.M. Jardine, G.D. Campbell); WellingtonDufferin-Guelph Public Health, Guelph (N.J. Mercer)
\end{abstract}

DOI: https://doi.org/10.3201/eid2502.180299
The life cycle is completed when a definitive host consumes an intermediate host containing the larval stage. Humans and dogs can experience AE when eggs of the parasite are consumed.

In humans, $\mathrm{AE}$ is characterized by a lengthy clinical incubation period of 5-15 years, during which the larval stage typically proliferates within the liver, behaving similarly to infiltrative hepatic neoplasia (2). Humans with clinical AE cases typically experience cholestatic jaundice, abdominal pain, fatigue, and weight loss (3). The preferred treatment is complete excision of parasitic tissue and radical resection of host tissue, depending on the site and size of the lesion, presence of metastases, and patient comorbidities (4). Benzimidazole chemotherapy is initiated at the time of diagnosis (5). In cases of total surgical resection, treatment is continued for a minimum of 2 years to reduce the likelihood of relapse (5). In case-patients who are not surgical candidates, chemotherapy treatment might be prescribed indefinitely to slow the progression of disease (6). Historically, in patients from Alaska, France, and Germany, the average survival rate 10 years after diagnosis was $29 \%$ when left untreated (7). The advent of benzimidazole chemotherapy has increased the 10-year survival rate to $\approx 80 \%$ (8).

Red foxes (Vulpes vulpes) are commonly the primary definitive host for E. multilocularis tapeworms in Europe and North America (1). More recently, studies have shown that coyotes (Canis latrans) also maintain the parasite in North America $(9,10)$. This development is important because coyotes can expedite the spread of E. multilocularis because they have larger home ranges compared with red foxes (11).

The area of endemicity of E. multilocularis in North America was thought to include 2 distinct regions: the north tundra zone and the north central region. The north tundra zone begins on the west coast of Alaska and extends north and east to occupy most of the Canadian Arctic; the distribution is consistent with that of the Arctic fox $(10,12)$. The north central region includes the southern portions of the Canada provinces of Alberta, Saskatchewan, and Manitoba, along with 13 neighboring US states (North Dakota, South Dakota, Iowa, Minnesota, Montana, 
Wyoming, Nebraska, Illinois, Wisconsin, Indiana, Ohio, Missouri, and Michigan) $(9,10,13)$. Recent reports suggest that the distribution is expanding or perhaps is wider than previously thought; for example, in 2009, a dog from the Quesnel region in British Columbia, with no travel history outside of that province, was diagnosed with AE (14). A subsequent study determined that $\approx 33 \%$ of wild canids in that region were infected with E. multilocularis tapeworms, suggesting a new endemic area (15).

Before 2012, Ontario was considered free of E. multilocularis. Since then, AE has been diagnosed in 5 dogs, 3 privately owned lemurs (Lemur catta), and a wild-caught eastern chipmunk (Tamias striatus) in the region surrounding the western shores of Lake Ontario in southern Ontario (16-21; A.S. Peregrine, unpub. data). The primary organ of involvement was the liver in all except 1 case, which involved only a subcutaneous lesion. To the authors' knowledge, only 1 of the aforementioned dogs had traveled outside this region; the other animals must have acquired the infection locally, probably as a result of ingestion of canid feces containing E. multilocularis eggs. Canine AE is a rare disease that most likely occurs when dogs ingest a substantial number of eggs (22). Collectively, these cases suggest that parts of southern Ontario have substantial levels of infection among wild canids.

Although southern Ontario encompasses an extensive geographic area $\left(136,907 \mathrm{~km}^{2}\right)$, it is the most densely populated region of the province, with $\approx 12$ million residents (23). At the time of the aforementioned cases of $\mathrm{AE}$ in animals, human AE was not a disease of public health importance (i.e., it was not reportable) in Ontario; therefore, whether autochthonous human cases were occurring in the province was unknown. Nevertheless, the presence of $E$. multilocularis represented a potentially serious threat to human and animal health.

In light of these developments, we sensed an urgent need to accurately define areas in southern Ontario where the E. multilocularis occurs and to identify the areas of highest risk within this region. We therefore conducted a study to estimate the prevalence and geographic distribution of E. multilocularis infection among foxes and coyotes across southern Ontario.

\section{Materials and Methods}

\section{Carcass Collection and Necropsy}

We obtained wild canid carcasses through collaboration with licensed hunters and trappers and the Ontario Ministry of Natural Resources and Forestry. We disseminated information about the project to hunter and trapper groups in southern Ontario that ordinarily harvest coyotes and foxes for their pelts. Submission of a carcass was contingent on provision of the geographic location of origin of the harvested carcass. We obtained carcasses over 2 collection periods: November 1, 2015-August 10, 2016, and August 30, 2016-March 27, 2017. During each collection period, hunters and trappers were limited to 10 carcass submissions of each species. No animals were killed for the purpose of this study. We submitted frozen and fresh carcasses for a limited postmortem examination. We removed the large intestine from each carcass and stored it at $-80^{\circ} \mathrm{C}$ for a minimum of 5 days to eliminate infectivity of the eggs (24), after which we collected 2 aliquots of rectal fecal material (3 g each) from each intestinal sample and stored them at $-20^{\circ} \mathrm{C}$ before analysis.

\section{Magnetic Capture Probe DNA Extraction and Real-Time PCR}

At the end of each collection period, we sent fecal samples to the Section for Microbiology at the National Veterinary Institute, Uppsala, Sweden, for analysis using a semiautomated magnetic capture probe DNA extraction and real-time hydrolysis PCR (MC-PCR) method for the presence of E. multilocularis DNA (25). Compared with the sedimentation and counting technique, which is typically considered the reference standard for the diagnosis of infection in wild canids (26), the MC-PCR method is less labor intensive and is well suited for processing large numbers of samples (25). When applied to foxes, MCPCR has an overall sensitivity of $88 \%$ (81\% with $<100$ parasites and $96 \%$ sensitivity with $>100$ parasites) and a minimum specificity of $99.9 \%(25,27)$. For each batch of extracted samples that was examined, we used 1 positive and 2 negative controls to validate the extraction process and real-time PCR; the positive control was a known positive fox fecal homogenate. We analyzed all samples in duplicate and considered a sample positive if $\geq 1$ of the duplicates tested positive.

\section{Statistical and Spatial Analyses}

Human exposure or case follow-up of AE falls within the legislative mandate for public health in Ontario on the basis of the geographic boundaries of each public health unit (PHU). Therefore, we visualized the prevalence of infection in wild canids across southern Ontario by using choropleth maps organized by the administrative boundaries of the 29 southern Ontario PHUs (Figure 1). To account for potentially unreliable prevalence estimates in certain PHUs resulting from small sample sizes, we used a Bayesian estimation method with local priors to smooth prevalence estimates $(28,29)$. We performed Bayesian smoothing by using $\mathrm{R}$ 3.4.2 with $\mathrm{R}$ packages maptools 0.8-39 and spdep 0.6-13 (R Foundation for Statistical Computing, http://cran.r-project.org). Graphic displays were produced by using QGIS 2.14.3 (http://www.qgis.org). 


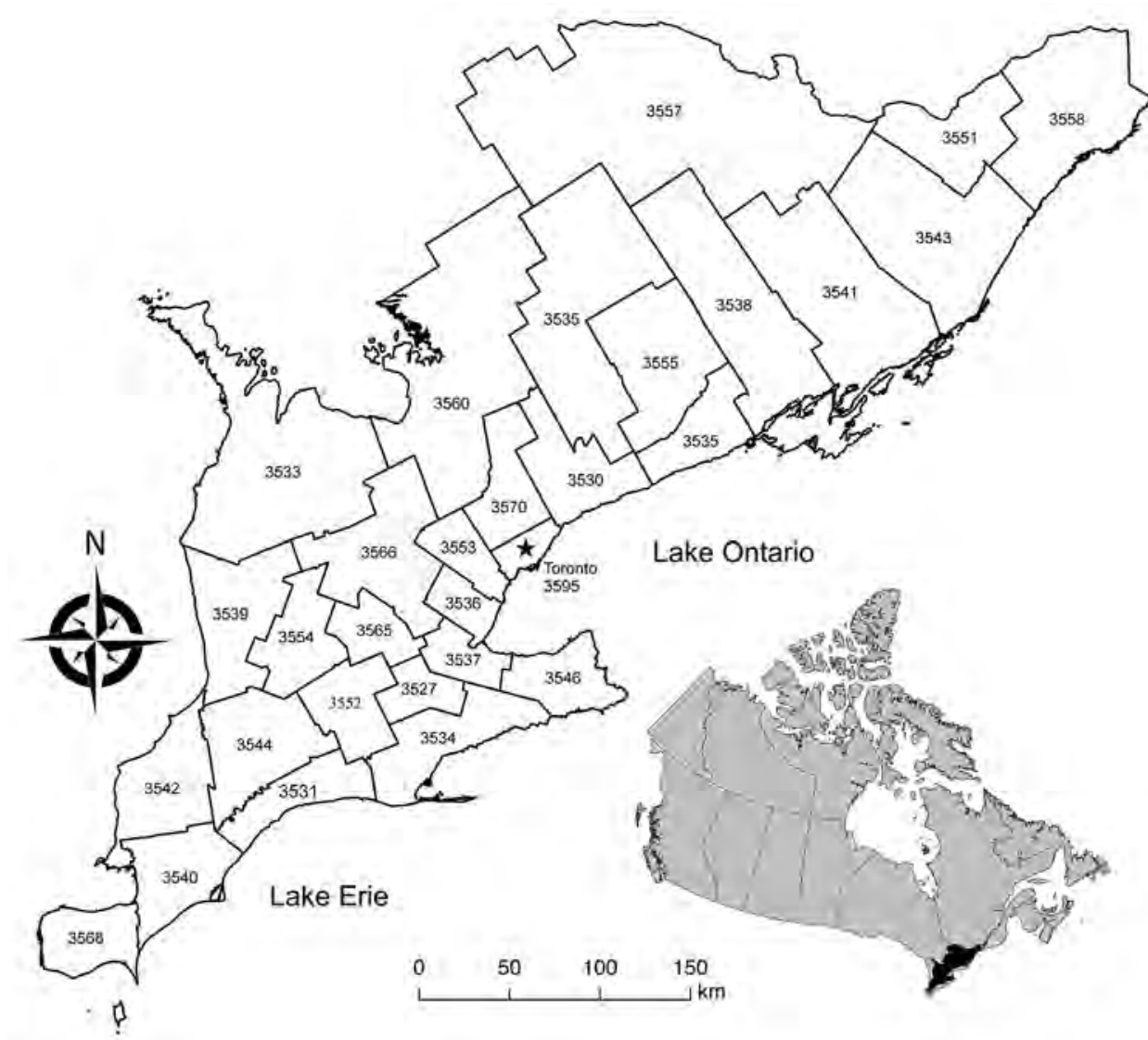

Figure 1. Map of the 29 southern Ontario public health units' boundaries and corresponding identification numbers (see Table). Inset shows location of southern Ontario within Canada.

An underlying assumption for constructing CIs is independence of observations. Our data fail to meet this assumption because we cannot assume that the infection status of a wild canid is independent of others in the population. Thus, the dependence of the observations must be considered. Therefore, we constructed Agresti-Coull CIs for prevalence estimates by using Stata/SE 15.1 (StataCorp, http://www.stata.com) (30); this method has been recommended for data that violate the assumption of independence (31).

To assess for areas of high risk for infection (hotspots), we performed a 1-tailed spatial scan statistic by using a Bernoulli probability model with SaTScan 9.4.4 (https:// www.satscan.org). We set the maximum size of the circular scanning window size to $50 \%$ of the total population. We estimated the statistical significance of the spatial clusters by using Monte Carlo hypothesis testing based on 999 iterations. We reported statistically significant primary and secondary nonoverlapping spatial clusters. We set the significance level for all analyses at $5 \%(\alpha=0.05)$. We performed the spatial scan test with the observations georeferenced to the centroids of the PHUs and then according to the latitude and longitude of PCR-positive and -negative tested wild canids to assess the consistency of results using different levels of spatial resolution.

\section{Results}

During November 2015-March 2017, we collected 460 wild canids (416 coyotes and 44 foxes) from 25 of the 29 southern Ontario PHUs and tested them for the presence of E. multilocularis DNA by using MC-PCR. We collected 205 wild canids ( 183 coyotes and 22 foxes) in the first collection period and 255 wild canids (233 coyotes and 22 foxes) in the second. During both collection periods, we collected $>80 \%$ of the wild canids during the months of January, February, and March. Hunters and trappers consistently reported low fox population numbers throughout the duration of the project, resulting in a low number of sampled foxes. No canids were collected from PHUs 3535, 3553, 3555, and 3595 (Figure 1). Overall, 23\% (95\% CI 20\%-27\%) of wild canids, from 18 PHUs, tested positive for E. multilocularis (Table). Among coyotes, 24\% (95\% CI $20 \%-28 \%$ ) tested positive; $21 \%(95 \%$ CI $11 \%-35 \%)$ of foxes tested positive. Raw prevalence ranged from $0 \%$ to $100 \%$ among PHUs (Figure 2). Smoothed prevalence by PHU estimates ranged from $4 \%$ to $46 \%$ (Table) and varied on a gradient of higher to lower prevalence from the southwestern to northeastern regions of southern Ontario (Figure 2).

The spatial scan test, georeferenced by PHU, detected a significant spatial cluster of high prevalence of infection 
Table. Prevalence of Echinococcus multilocularis infection and Bayesian-smoothed prevalence estimates in wild canids, by public health unit, southern Ontario, 2015-2017*

\begin{tabular}{|c|c|c|c|c|c|}
\hline \multirow[b]{2}{*}{ ID } & \multirow[b]{2}{*}{ Public health unit } & \multicolumn{2}{|c|}{ No. wild canids } & \multicolumn{2}{|c|}{ Prevalence } \\
\hline & & Tested & Positive & $\begin{array}{c}\text { Unadjusted, \% } \\
(95 \% \mathrm{Cl}) \dagger\end{array}$ & $\begin{array}{c}\text { Bayesian } \\
\text { estimate, \% }\end{array}$ \\
\hline 3527 & Brant County Health Unit & 14 & 10 & $71(45-89)$ & 46 \\
\hline 3530 & Durham Regional Health Unit & 2 & 0 & $0(0-71)$ & 27 \\
\hline 3531 & Elgin-St. Thomas Health Unit & 15 & 5 & $33(15-58)$ & 30 \\
\hline 3533 & Grey Bruce Health Unit & 56 & 6 & $11(5-22)$ & 13 \\
\hline 3534 & Haldimand-Norfolk Health Unit & 10 & 4 & $40(17-69)$ & 36 \\
\hline 3535 & Haliburton, Kawartha, Pine Ridge District Health Unit & 0 & NA & NA & NA \\
\hline 3536 & Halton Regional Health Unit & 11 & 5 & $45(21-72)$ & 28 \\
\hline 3537 & City of Hamilton Health Unit & 12 & 5 & $42(19-68)$ & 34 \\
\hline 3538 & Hastings and Prince Edward Counties Health Unit & 1 & 1 & $100(17-100)$ & 25 \\
\hline 3539 & Huron Health Unit & 39 & 3 & $8(2-21)$ & 19 \\
\hline 3540 & Chatham-Kent Health Unit & 1 & 1 & $100(17-100)$ & 31 \\
\hline 3541 & Kingston, Frontenac and Lennox and Addington Health Unit & 2 & 0 & $0(0-71)$ & 5 \\
\hline 3542 & Lambton Health Unit & 1 & 0 & $0(0-83)$ & 21 \\
\hline 3543 & Leeds, Grenville and Lanark District Health Unit & 44 & 2 & $5(<1-16)$ & 4 \\
\hline 3544 & Middlesex-London Health Unit & 41 & 14 & $34(21-50)$ & 28 \\
\hline 3546 & Niagara Regional Health Unit & 19 & 6 & $32(15-54)$ & 37 \\
\hline 3551 & City of Ottawa Health Unit & 3 & 0 & $0(0-62)$ & 4 \\
\hline 3552 & Oxford County Health Unit & 36 & 7 & $19(9-35)$ & 28 \\
\hline 3553 & Peel Regional Health Unit & 0 & NA & NA & NA \\
\hline 3554 & Perth District Health Unit & 35 & 10 & $29(16-45)$ & 24 \\
\hline 3555 & Peterborough County-City Health Unit & 0 & NA & NA & NA \\
\hline 3557 & Renfrew County and District Health Unit & 1 & 0 & $0(0-83)$ & 5 \\
\hline 3558 & Eastern Ontario Health Unit & 1 & 0 & $0(0-83)$ & 4 \\
\hline 3560 & Simcoe Muskoka District Health Unit & 1 & 0 & $0(0-83)$ & 17 \\
\hline 3565 & Waterloo Health Unit & 12 & 3 & $25(8-54)$ & 28 \\
\hline 3566 & Wellington-Duferin-Guelph Health Unit & 55 & 12 & $22(13-35)$ & 20 \\
\hline 3568 & Windsor-Essex County Health Unit & 40 & 10 & $25(14-40)$ & 27 \\
\hline 3570 & York Regional Health Unit & 8 & 3 & $38(13-70)$ & 27 \\
\hline 3595 & City of Toronto Health Unit & 0 & NA & NA & NA \\
\hline
\end{tabular}

(relative risk 2.26; $\mathrm{p}=0.002$ ) centered in PHU 3534, consisting of 10 contiguous PHUs (3527, 3531, 3534, 3536, 3537, 3544, 3546, 3552, 3554, and 3565) (Figure 2). The prevalence of infection among the 205 wild canids included in the cluster was 34\% (95\% CI 28\%-40\%). A second spatial scan test, using data georeferenced to each wild canid's location of origin, detected a significant spatial cluster of high prevalence of infection (relative risk 2.53; $\mathrm{p}=0.001$ ), with a radius of $120 \mathrm{~km}$ also centered in PHU 3534. The prevalence of infection among the 216 wild canids included in the cluster was 34\% (95\% CI 28\%-41\%). No statistically significant nonoverlapping secondary high-risk spatial clusters were identified at either level of spatial resolution.

\section{Discussion}

This report describes the prevalence of E. multilocularis infection in wild canids in Ontario. Because Ontario was previously considered free of E. multilocularis, we were surprised that $23 \%$ of the wild canids (107/460) tested positive for the parasite in our study. This finding is comparable to recent wild canid prevalence data from Edmonton, Alberta, Canada (9), where E. multilocularis has been recognized for decades (32). We anticipated that infection among wild canids would be confined to the region surrounding the western shores of Lake Ontario in southern Ontario, where the aforementioned cases of AE were observed. However, our findings indicate that $E$. multilocularis infection in wild canids is widely distributed across the western, central, and eastern regions of southern Ontario, with a high prevalence hotspot consisting of 10 PHUs in the western-central region (Figure 2). The combination of the high prevalence and wide geographic distribution of infection suggests that E. multilocularis was not a recent introduction into Ontario. In addition, to the authors' knowledge, only 1 other study has investigated E. multilocularis in the province; a survey of 302 red foxes from southern Ontario during 1979-1980 did not detect evidence of the parasite (33). Therefore, E. multilocularis probably was introduced sometime after 1980.

How E. multilocularis were introduced into Ontario is unclear. However, the spatial pattern of high infection prevalence among wild canids in the southern PHUs that border the northern shores of Lake Erie (Figure 2) might indicate a natural northeastern expansion from Michigan, 


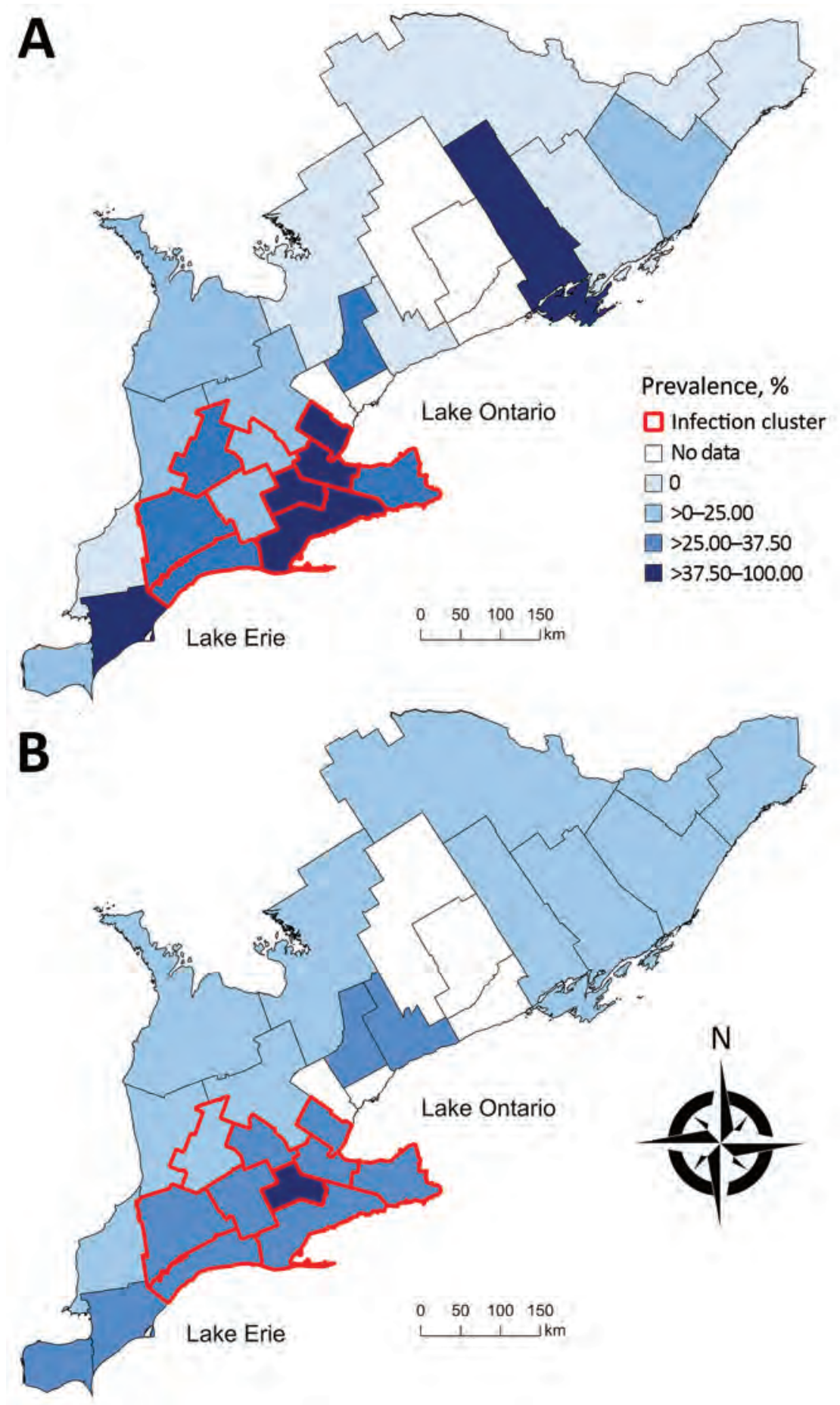

Figure 2. Choropleth maps of A) the unadjusted prevalence and $B$ ) the empirical Bayesian-smoothed prevalence of Echinococcus multilocularis tapeworms in coyotes and foxes across 25 southern Ontario public health units, 2015-2017. Unadjusted and smoothed prevalence estimates are categorized by quartiles on the basis of unadjusted prevalence estimates. Red boundaries indicate a significant spatial cluster of high prevalence identified by using a spatial scan test with a Bernoulli model on the basis of data georeferenced to their public health units (relative risk 2.26; $p=0.002$ ).

a known endemic area (33). Also, the importation of dogs from endemic areas in North America or Europe, without any requirement for cestocide treatment, might have contributed to the introduction of E. multilocularis tapeworms into the province. Notably, molecular characterization of the metacestode stage from 1 of the southern Ontario dogs diagnosed with AE without travel history was consistent with E. multilocularis of possible European origin (1), whereas another appeared to be North American in origin (K. Gesy, pers. comm., 2017 Dec 14). These findings strengthen the possibility that an importation event occurred, perhaps in addition to a natural range expansion. However, the meaning of this information remains unclear because data concerning 
the epidemiologic importance of individual strain variants are limited $(34,35)$.

We measured an infection prevalence of 34\% (95\% CI $28 \%-40 \%$ ) among wild canids within the southern Ontario hotspot. Consequently, a question of public health importance is to what extent the human population in southern Ontario is at risk for human AE. Across the endemic countries in Europe, where the prevalence of E. multilocularis infection in wild canids ranges from $<1 \%$ to $>50 \%$ (1), human $\mathrm{AE}$ is rare; the overall average annual incidence in these countries ranges from 0.03 to 0.3 cases $/ 100,000$ residents (36). However, substantial variation in risk exists across regions. For example, in areas with consistently high prevalence in wild canids (i.e., $35 \%-65 \%$ prevalence), the annual incidence of human $\mathrm{AE}$ can be as high as 8.1 cases $/ 100,000$ residents $(37,38)$, which is similar to the prevalence estimates among wild canids in the southern Ontario hotspot that we describe. Furthermore, the location of the infection cluster encompasses multiple urban areas with human population densities of up to 1,700 residents $/ \mathrm{km}^{2}$ (23). Therefore, transmission of E. multilocularis should be considered a public health risk.

In areas endemic for E. multilocularis, dog ownership has been associated with increased risk for human AE (37,39-41). Dog ownership might entail various human and dog behaviors that might lead to an increased risk for human infection with E. multilocularis. These behaviors include leaving dogs outside unattended, walking dogs without a leash, allowing dogs to consume rodents, and inconsistent deworming of dogs (40). As such, monthly treatment with praziquantel is recommended for dogs that consume rodents in AE-endemic areas to prevent patent intestinal infections and therefore mitigate the risk for transmission to humans (36). The same is also recommended for dogs with hepatic AE because such dogs might also have concurrent intestinal infections (42). Thus, even in instances of canine hepatic AE, a follow-up investigation of possible exposure to E. multilocularis for in-contact humans is warranted (43).

As of January 1, 2018, E. multilocularis infection was designated a reportable disease in animals in Ontario (44). Veterinarians and diagnostic laboratories are required to report animal cases directly to their local PHUs to minimize potential risks to human and public health. Furthermore, as of May 1, 2018, E. multilocularis infection in humans was designated a disease of public health importance (i.e., a disease that must be reported) in Ontario (45). Although human $\mathrm{AE}$ was not reportable before 2018, data from the Canadian Institute for Health Information indicate that $\geq 3$ cases of human AE have been diagnosed in Ontario since 2014 (46); however, these data do not include information regarding patient travel or exposure histories. Therefore, whether these cases were locally acquired is unknown. Designating E. multilocularis infection as reportable in humans and animals is potentially important because, in AE-endemic areas (i.e., Europe), a large proportion of the economic burden associated with human AE is attributable to patients typically being diagnosed in the late stages of the disease, requiring lifelong chemotherapy and occasionally interventional procedures (e.g., percutaneous biliary and centroparasitic abscess drainage) $(5,36)$. Therefore, the ability to anticipate $E$. multilocularis exposure and to diagnose early-stage human $\mathrm{AE}$ is essential to reduce the need for long-term treatment, thereby minimizing the economic burden associated with the disease. A limitation of having the infection reportable only in humans is that, given the long clinical incubation period of $\mathrm{AE}$ in humans, other persons potentially at risk would likely have been infected years earlier. Thus, in areas where E. multilocularis infection is endemic, a One Health surveillance approach that also requires mandatory reporting of $E$. multilocularis infection in animals to public health authorities could improve rates of prompt investigation of suspected exposure in persons and lead to earlier diagnosis.

Our study has several limitations. First, sample collection depended on carcass submission from hunters, trappers, and the Ontario Ministry of Natural Resources and Forestry. Although this convenience sampling allowed us to achieve a large sample size, it resulted in underrepresentation of parts of the study area. Because this approach resulted in PHUs with low sample sizes and thus potentially unreliable prevalence estimates, we used a Bayesian estimation method to smooth prevalence estimates. Second, the MC-PCR method used to detect E. multilocularis DNA is imperfect, having an overall sensitivity of $88 \%$ and specificity of $99 \%(25,27)$. However, we chose to employ this method because it is suitable for large-scale screening and its performance is comparable to what is considered the reference standard for diagnosis of infection in wild canids, the sedimentation and counting technique (26).

Our findings underscore the importance for continued surveillance among wild canids within and outside endemic areas in North America to monitor the spread of E. multilocularis tapeworms. In addition, an understanding of the prevalence of intestinal infections among dogs in AE-endemic areas would provide valuable information on potential exposure risk in human populations. Collectively, the data would guide public health and veterinary efforts in the development of targeted prevention strategies in this region.

\section{Acknowledgments}

We thank the southern Ontario hunters and trappers, Aylmer District Stakeholders Committee, Nuisance Wildlife Control Inc., and the Ontario Ministry of Natural Resources and Forestry for coyote and fox submissions. The Canadian Wildlife Health Cooperative contributed invaluable resources and support for the processing of coyote and fox samples. 
This study was supported by Bayer Animal Health, the National Center for Veterinary Parasitology, Natural Sciences and Engineering Research Council of Canada, Ontario Veterinary College, Ontario Animal Health Network, and Burroughs-Wellcome Fund.

\section{About the Author}

Mr. Kotwa is a PhD candidate in the Department of Pathobiology at the University of Guelph. His research interests include interdisciplinary perspectives for evaluating emerging zoonotic diseases, with a specific concentration on investigating the role of wild canids as sentinel species for pathogens of public health and veterinary significance.

\section{References}

1. Deplazes P, Rinaldi L, Alvarez Rojas CA, Torgerson PR, Harandi MF, Romig T, et al. Global distribution of alveolar and cystic echinococcosis. Adv Parasitol. 2017;95:315-493. http://dx.doi.org/10.1016/bs.apar.2016.11.001

2. Kadry Z, Renner EC, Bachmann LM, Attigah N, Renner EL, Ammann RW, et al. Evaluation of treatment and long-term ollow-up in patients with hepatic alveolar echinococcosis. Br J Surg. 2005;92:1110-6. http://dx.doi.org/10.1002/bjs.4998

3. Brunetti E, Kern P, Vuitton DA; Writing Panel for the WHO-IWGE. Expert consensus for the diagnosis and treatment of cystic and alveolar echinococcosis in humans. Acta Trop. 2010;114:1-16. http://dx.doi.org/10.1016/j.actatropica.2009.11.001

4. Kern P. Clinical features and treatment of alveolar echinococcosis. Curr Opin Infect Dis. 2010;23:505-12. http://dx.doi.org/10.1097/ QCO.0b013e32833d7516

5. Brunetti E, White AC Jr. Cestode infestations: hydatid disease and cysticercosis. Infect Dis Clin North Am. 2012;26:421-35. http://dx.doi.org/10.1016/j.idc.2012.02.001

6. Torgerson PR, Schweiger A, Deplazes P, Pohar M, Reichen J, Ammann RW, et al. Alveolar echinococcosis: from a deadly disease to a well-controlled infection. Relative survival and economic analysis in Switzerland over the last 35 years. J Hepatol. 2008;49:72-7. http://dx.doi.org/10.1016/j.jhep.2008.03.023

7. Ammann RW, Eckert J. Cestodes. Echinococcus. Gastroenterol Clin North Am. 1996;25:655-89. http://dx.doi.org/10.1016/ S0889-8553(05)70268-5

8. Pawlowski ZS, Kern EJ, Craig P, Dar KF, De Rosa F, Filice C, et al. Echinococcosis in humans: clinical aspects, diagnosis and treatment. In: Eckert J, Gemmel MA, Meslin F-X, Pawlowski $\mathrm{ZS}$, editors. WHO/OIE manual on echinococcosis in humans and animals: a public health problem of global concern. Paris: World Health Organization/World Health Organization for Animal Health; 2001. p. 47-66.

9. Catalano S, Lejeune M, Liccioli S, Verocai GG, Gesy KM, Jenkins EJ, et al. Echinococcus multilocularis in urban coyotes, Alberta, Canada. Emerg Infect Dis. 2012;18:1625-8. http://dx.doi.org/10.3201/eid1810.120119

10. Massolo A, Liccioli S, Budke C, Klein C. Echinococcus multilocularis in North America: the great unknown. Parasite. 2014;21:73. http://dx.doi.org/10.1051/parasite/2014069

11. Voigt DR, Berg WE. Coyote. In: Novak M, Baker JA, Obbard ME, Malloch B, editors. Wild furbearer management and conservation in North America. Toronto (Canada): Ontario Ministry of Natural Resources; 1987. p. 344-57.

12. Eckert J, Conraths FJ, Tackmann K. Echinococcosis: an emerging or re-emerging zoonosis? Int J Parasitol. 2000;30:1283-94. http://dx.doi.org/10.1016/S0020-7519(00)00130-2
13. Storandt ST, Virchow DR, Dryden MW, Hygnstrom SE, Kazacos KR. Distribution and prevalence of Echinococcus multilocularis in wild predators in Nebraska, Kansas, and Wyoming. J Parasitol. 2002;88:420-2. http://dx.doi.org/ 10.1645/0022-3395(2002)088[0420:DAPOEM]2.0.CO;2

14. Peregrine AS, Jenkins EJ, Barnes B, Johnson S, Polley L, Barker IK, et al. Alveolar hydatid disease (Echinococcus multilocularis) in the liver of a Canadian dog in British Columbia, a newly endemic region. Can Vet J. 2012;53:870-4.

15. Gesy K, Hill JE, Schwantje H, Liccioli S, Jenkins EJ. Establishment of a European-type strain of Echinococcus multilocularis in Canadian wildlife. Parasitology. 2013;140:11337. http://dx.doi.org/10.1017/S0031182013000607

16. Skelding A, Brooks A, Stalker M, Mercer N, de Villa E, Gottstein B, et al. Hepatic alveolar hydatid disease (Echinococcus multilocularis) in a boxer dog from southern Ontario. Can Vet J. 2014;55:551-3.

17. Oscos-Snowball A, Tan E, Peregrine AS, Foster R, Bronsoiler J, Gottstein B, et al. What is your diagnosis? Fluid aspirated from an abdominal mass in a dog. Vet Clin Pathol. 2015;44:167-8. http://dx.doi.org/10.1111/vcp. 12210

18. French SK, Jajou S, Campbell GD, Cai HY, Kotwa JD, Peregrine AS, et al. Echinococcus multilocularis in a wild free-living eastern chipmunk (Tamias striatus) in southern Ontario: a case report and subsequent field study of wild small mammals. Vet Parasitol Reg Stud Reports. 2018;13:234-7. http://dx.doi.org/ 10.1016/j.vprsr.2018.06.009

19. Peregrine AS, Cuq B. Echinococcus multilocularis: an emerging zoonotic disease. In: Proceedings of the American College of Veterinary Internal Medicine Forum; 2016 June 9-11; Denver, Colorado, USA.

20. Pinard CJ, Cuq B, Gibson TWG, Brisson B, Plattner BL, Bienzle D, et al. Intolerance of albendazole therapy and failure to control hepatic alveolar echinococcosis in a dog in southern Ontario. In: Proceedings of the 61st Annual Meeting of the American Association of Veterinary Parasitologists; 2016 August 6-9; San Antonio, Texas, USA.

21. Turner PV, Compo NR, Davidson S, McDowell R, Cai H, Gottstein B, et al. Diagnoses of alveolar echinococcosis in lemurs at an exotic animal sanctuary: implications for public health. In: Proceedings of the 66th Annual Meeting of the James Steele Conference on Diseases in Nature Transmissible to Man (DIN); 2016 May 25-27; San Antonio, Texas, USA.

22. Corsini M, Geissbühler U, Howard J, Gottstein B, Spreng D, Frey CF. Clinical presentation, diagnosis, therapy and outcome of alveolar echinococcosis in dogs. Vet Rec. 2015;177:569.

23. Statistics Canada. Population and dwelling count highlight tables, 2016 census [cited 2017 Sep 12]. http://www12.statcan.gc.ca/ census-recensement/2016/dp-pd/hlt-fst/pd-pl/Table.cfm?Lang= Eng $\& \mathrm{~T}=201 \& \mathrm{~S}=3 \& \mathrm{O}=\mathrm{D}$.

24. Eckert J, Deplazes P, Craig PS, Gemmell MA, Gottstein B, Heath D, et al. Echinococcosis in animals: clinical aspects, diagnosis and treatment. In: Eckert J, Gemmell MA, Meslin FX, Pawlowski ZS, editors. WHO/OIE manual on echinococcosis in humans and animals: a public health problem of global concern. Paris: World Health Organization/World Organization for Animal Health; 2001. p. 80.

25. Isaksson M, Hagström Å, Armua-Fernandez MT, Wahlström H, Ågren EO, Miller A, et al. A semi-automated magnetic capture probe based DNA extraction and real-time PCR method applied in the Swedish surveillance of Echinococcus multilocularis in red fox (Vulpes vulpes) faecal samples. Parasit Vectors. 2014;7:583. http://dx.doi.org/10.1186/s13071-014-0583-6

26. Deplazes P, Eckert J. Veterinary aspects of alveolar echinococcosisa zoonosis of public health significance. Vet Parasitol. 2001;98:6587. http://dx.doi.org/10.1016/S0304-4017(01)00424-1 
27. Wahlström H, Comin A, Isaksson M, Deplazes P. Detection of Echinococcus multilocularis by MC-PCR: evaluation of diagnostic sensitivity and specificity without gold standard. Infect Ecol Epidemiol. 2016;6:30173. http://dx.doi.org/10.3402/iee.v6.30173

28. Mollié A. Bayesian mapping of disease. In: Gilks WR, Richardson S, Spiegelhalter DJ, editors. Markov chain Monte Carlo in practice. London: Chapman \& Hall/CRC Press; 1996. p. 359.

29. Berke O. Choropleth mapping of regional count data of Echinococcus multilocularis among red foxes in Lower Saxony, Germany. Prev Vet Med. 2001;52:119-31. http://dx.doi.org/ 10.1016/S0167-5877(01)00246-X

30. Agresti A, Coul BA. Approximate is better than "exact" for interval estimation of binomial proportions. Am Stat. 1998;52:119-26.

31. Miao W, Gastwirth JL. The effect of dependence on confidence intervals for a population proportion. Am Stat. 2004;58:124-30. http://dx.doi.org/10.1198/0003130043303

32. Holmes JC, Mahrt JL, Samuel WM. The occurrence of Echinococcus multilocularis Leuckart, 1863 in Alberta. Can J Zool. 1971;49:575-6. http://dx.doi.org/10.1139/z71-090

33. Storandt ST, Kazacos KR. Echinococcus multilocularis identified in Michigan with additional records from Ohio. J Parasitol. 2012;98:891-3. http://dx.doi.org/10.1645/GE-3057.1

34. Thompson RC. The taxonomy, phylogeny and transmission of Echinococcus. Exp Parasitol. 2008;119:439-46. http://dx.doi.org/ 10.1016/j.exppara.2008.04.016

35. Lymbery AJ. Phylogenetic pattern, evolutionary processes and species delimitation in the genus Echinococcus. Adv Parasitol. 2017;95:111-45. http://dx.doi.org/10.1016/bs.apar.2016.07.002

36. Gottstein B, Stojkovic M, Vuitton DA, Millon L, Marcinkute A, Deplazes P. Threat of alveolar echinococcosis to public health-a challenge for Europe. Trends Parasitol. 2015;31:407-12. http://dx.doi.org/10.1016/j.pt.2015.06.001

37. Piarroux M, Piarroux R, Knapp J, Bardonnet K, Dumortier J, Watelet J, et al.; FrancEchino Surveillance Network. Populations at risk for alveolar echinococcosis, France. Emerg Infect Dis. 2013;19:721-8. http://dx.doi.org/10.3201/eid1905.120867

38. Said-Ali Z, Grenouillet F, Knapp J, Bresson-Hadni S, Vuitton DA, Raoul F, et al.; FrancEchino Surveillance Network. Detecting nested clusters of human alveolar echinococcosis.
Parasitology. 2013;140:1693-700. http://dx.doi.org/10.1017/ S0031182013001352

39. Kreidl P, Allerberger F, Judmaier G, Auer H, Aspöck H, Hall AJ. Domestic pets as risk factors for alveolar hydatid disease in Austria. Am J Epidemiol. 1998;147:978-81. http://dx.doi.org/ 10.1093/oxfordjournals.aje.a009388

40. Kern P, Bardonnet K, Renner E, Auer H, Pawlowski Z, Ammann RW, et al.; European Echinococcosis Registry. European echinococcosis registry: human alveolar echinococcosis, Europe, 1982-2000. Emerg Infect Dis. 2003;9:343-9. http://dx.doi.org/10.3201/eid0903.020341

41. Conraths FJ, Probst C, Possenti A, Boufana B, Saulle R, La Torre G, et al. Potential risk factors associated with human alveolar echinococcosis: Systematic review and meta-analysis. PLoS Negl Trop Dis. 2017;11:e0005801. http://dx.doi.org/10.1371/ journal.pntd.0005801

42. Deplazes P, Arnold P, Kaser-Holtz B, Gardelle O, Guscetti F, Halle M, et al. Concurrent infections of the liver and intestine with Echinococcus multilocularis in dogs. Arch Int Hidatid. 1997;31:202-3.

43. Trotz-Williams LA, Mercer NJ, Walters JM, Wallace D, Gottstein B, Osterman-Lind E, et al. Public health follow-up of suspected exposure to Echinococcus multilocularis in southwestern Ontario. Zoonoses Public Health. 2017;64:460-7. http://dx.doi.org/10.1111/zph.12326

44. Government of Ontario. R.R.O. 1990, Reg. 557: communicable diseases_-general, s 6.1(3) [cited 2018 Jan 31]. http://www.e-laws. gov.on.ca/html/regs/english/elaws_regs_900557_e.htm

45. Government of Ontario. O. Reg. 135/18: designation of diseases, $\mathrm{s}$ 4 [cited 2018 Oct 3]. https://www.ontario.ca/laws/ regulation/180135

46. Government of Ontario. Infectious diseases protocol appendix A: disease specific chapters. 2018 [cited 2018 Oct 3]. http://www.health.gov.on.ca/en/pro/programs/publichealth/ oph_standards/docs/E_multilocularis_chapter.pdf.

Address for correspondence: Jonathon D. Kotwa, University of Guelph, Department of Pathobiology, 419 Gordon St, Guelph, ON N1G 2W1, Canada; email: jkotwa@uoguelph.ca 


\title{
Epidemiologic and Ecologic I nvestigations of Monkeypox, Likouala Department, Republic of the Congo, 2017
}

\author{
Reena H. Doshi, Sarah Anne J. Guagliardo, Jeffrey B. Doty, Angelie Dzabatou Babeaux, \\ Audrey Matheny, Jillybeth Burgado, Michael B. Townsend, Clint N. Morgan, \\ Panayampalli Subbian Satheshkumar, Nestor Ndakala, Therese Kanjingankolo, Lambert Kitembo, \\ Jean Malekani, Lem's Kalemba, Elisabeth Pukuta, Tobi N'kaya, Fabien Kangoula, Cynthia Moses, \\ Andrea M. McCollum, Mary G. Reynolds, Jean-Vivien Mombouli, Yoshinori Nakazawa, Brett W. Petersen
}

Monkeypox, caused by a zoonotic orthopoxvirus, is endemic in Central and West Africa. Monkeypox has been sporadically reported in the Republic of the Congo. During March 22-April 5, 2017, we investigated 43 suspected human monkeypox cases. We interviewed suspected casepatients and collected dried blood strips and vesicular and crust specimens (active lesions), which we tested for orthopoxvirus antibodies by ELISA and monkeypox virus and varicella zoster virus DNA by PCR. An ecologic investigation was conducted around Manfouété, and specimens from 105 small mammals were tested for anti-orthopoxvirus antibodies or DNA. Among the suspected human cases, 22 met the confirmed, probable, and possible case definitions. Only 18 patients had available dried blood strips; $100 \%$ were IgG positive, and $88.9 \%$ (16/18) were IgM positive. Among animals, only specimens from Cricetomys giant pouched rats showed presence of orthopoxvirus antibodies, adding evidence to this species' involvement in the transmission and maintenance of monkeypox virus in nature.

\footnotetext{
Author affiliations: Centers for Disease Control and Prevention, Atlanta, Georgia, USA (R.H. Doshi, S.A.J. Guagliardo, J.B. Doty, A. Matheny, J. Burgado, M.B. Townsend, C.N. Morgan, P.S. Satheshkumar, A.M. McCollum, M.G. Reynolds, Y. Nakazawa, B.W. Petersen); Ministry of Health, Brazzaville, Democratic Republic of the Congo (A.D. Babeaux, L. Kitembo, F. Kangoula, J.-V. Mombouli); Oak Ridge Institute for Science and Education, Centers for Disease Control and Prevention Fellowship Program, Oak Ridge, Tennessee, USA (A. Matheny, J. Burgado, C.N. Morgan); Centers for Disease Control and Prevention, Kinshasa, Democratic Republic of the Congo (N. Ndakala, T. Kanjingankolo,

J.-V. Mombouli); University of Kinshasa, Kinshasa (J. Malekani,

L. Kalemba); Institut Nationale de Recherche Biomedicale, Kinshasa (E. Pukuta); Ministere de l'Agriculture, de l'Elevage et de la Peche, Brazzaville (T. N'kaya); International Communication and Education Fund, Kinshasa (C. Moses)
}

DOI: https://doi.org/10.3201/eid2502.181222
$\mathrm{M}$ onkeypox virus (MPXV) is a zoonotic orthopoxvirus, endemic to the heavily forested regions of West and Central Africa. MPXV is a close relative of variola virus (the causative agent of smallpox), and its clinical presentation resembles smallpox, with the addition of lymphadenopathy (1-3). Case-fatality rates have been reported to be as high as $11 \%$ (4). Vaccination with a traditional smallpox vaccine has been shown to be protective for monkeypox, but since the eradication of smallpox in 1980, routine smallpox vaccination has ceased $(3,5)$. The incidence of human monkeypox appears to have increased in countries to which the virus is endemic; it is unknown whether this increase is the result of waning population-level immunity or other factors (6-8).

Humans can acquire MPXV via respiratory droplets or other bodily fluids or by direct contact with lesion material of infected patients (9). Zoonotic transmission may occur by direct inoculation via bites and scratches (10) or direct contact with bodily fluids of infected animals when hunting, preparing carcasses for meals, or playing with animals $(4,11)$. The wild animal reservoir of MPXV remains unknown; however, evidence implicates rodents and other small mammals (12-15), whereas infection of humans and monkeys appears to be incidental (16). To date, live MPXV from wildlife species has been isolated only from a rope squirrel (Funisciurus anerythrus) (12) and a sooty mangabey (Cercocebus atys) (17).

More than $90 \%$ of monkeypox cases occur within the Congo Basin, with the largest number of cases reported in the Democratic Republic of the Congo (DRC) $(11,18,19)$. Monkeypox cases have only sporadically been reported in the neighboring Republic of the Congo, generally in remote, heavily forested areas near the border with DRC, where humans are frequently in contact with animals. Previous monkeypox outbreaks occurred in Likouala Department, in 
the northern part of Republic of the Congo, in 2003, 2007, and 2010, in which the agent was closely related to MPXV found in DRC $(20,21)$.

In January 2017, two suspected monkeypox cases were reported in Moualé village in Likouala Department of Republic of the Congo. By March 8, seven additional suspected cases had been reported. We report on the investigation and analysis of human monkeypox cases reported during January-April 2017 (and further investigated during March 22-April 5, 2017) in this area, including epidemiologic description, factors associated with disease acquisition, and a subsequent ecologic investigation of possible zoonotic sources.

\section{Materials and Methods}

\section{Study Sites and Description of Outbreak}

This outbreak investigation involved suspected monkeypox cases from 4 districts, Impfondo, Betou, Dongou, and Enyelle, in Likouala Department. The department is 1 of 12 administrative regions located in northeastern Republic of the Congo and has $\approx 154,000$ residents (Figure 1) (22). The largest town, Impfondo, is the administrative

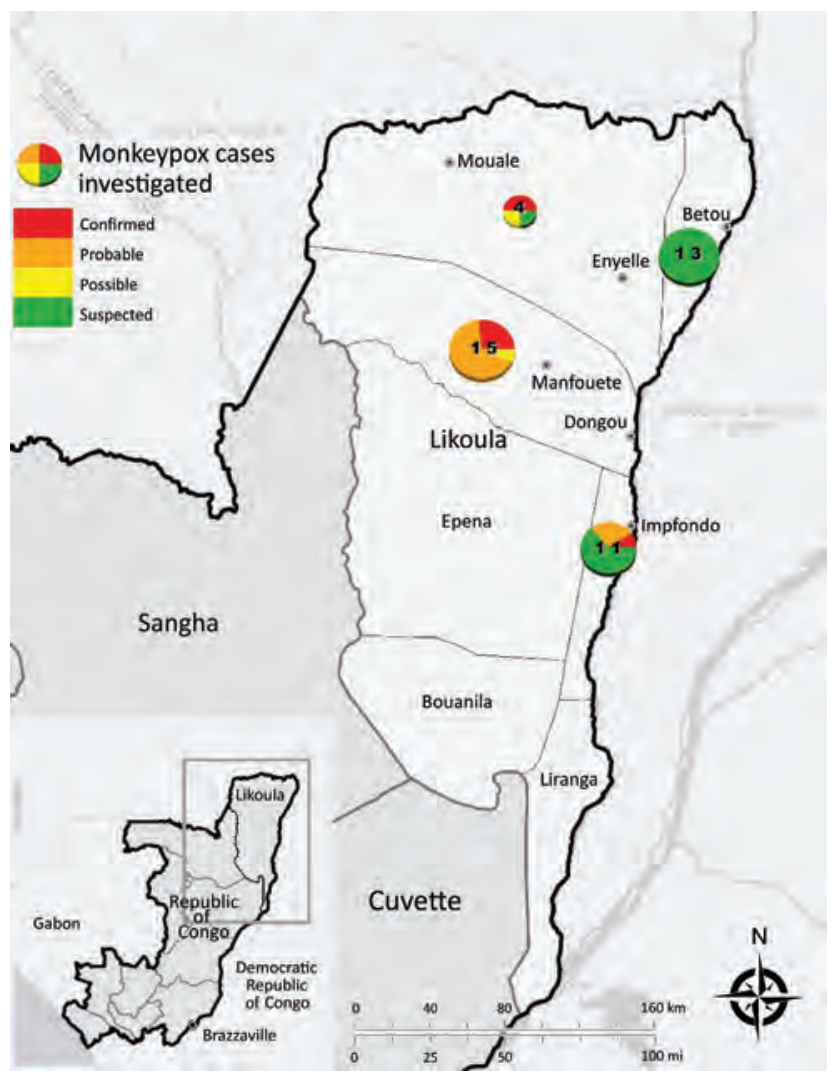

Figure 1. Locations of monkeypox outbreaks and case classifications, Likouala Department, Republic of Congo, 2017. Numbers in circles indicate total number of cases in each area (all case classifications). Inset shows location of study area within Republic of Congo. capital and is located $\approx 185 \mathrm{~km}$ south of Betou. The department is divided into 7 districts and is characterized by dense tropical rainforest (23). Most of the inhabitants rely on subsistence agriculture (cassava, corn, plantains), fish, and consumption of bushmeat and insects (e.g., antelopes, wild pigs, pangolins, small deer, porcupines, small rodents, primates, crocodiles, tortoises, snails, caterpillars) as sources of nutrition.

On January 21, 2017, a 40-year-old fisherman and his 9-year-old son sought care for fever and rash at a local health center in Moualé, Enyelle District. The reported onset of fever was January 18 for the fisherman and January 20 for his son. The fisherman died on February 25 from unknown complications. On January 27, 2017, the General Direction of Epidemiology and Disease Control in Brazzaville, Republic of the Congo, was notified of the 2 suspect monkeypox cases, and an investigation was conducted on January 29. MPXV nucleic acid was detected by PCR in crust/vesicle specimens from both cases on February 13 at the Institut Nationale de Recherche Biomedicale in Kinshasa, DRC. By March 7, an additional 8 suspected cases were reported in Likouala. At the same time, there were also reports of a large measles outbreak in Betou and Enyelle Districts. A multipartner epidemiologic investigation occurred during March 22April 4, 2017.

\section{Epidemiologic and Clinical Information}

Active and retrospective cases were identified and reported by health facilities, patients, and family/community members on the basis of clinical signs and symptoms. Confirmed and suspected monkeypox cases were investigated and data were collected using the Ministry of Health's standardized case report form. In addition, physician notes and hospital records were reviewed when available. An additional risk factor survey was administered to both confirmed and suspected case-patients to identify possible sources of monkeypox exposure during the 4 weeks before symptom onset. For young children and deceased patients, a parent, guardian, or other family member was interviewed. When possible, we constructed transmission chain diagrams to document the spread of disease throughout the community.

Case definitions were adapted from previous investigations and were applied to cases investigated during January 1-April 2, 2017 (Table 1) (24). A suspected case was defined as unexplained rash and fever (subjective or measured temperature of $\geq 99.3^{\circ} \mathrm{F}\left[\geq 37.4^{\circ} \mathrm{C}\right]$ ). A possible case met 1 of the epidemiologic criteria or demonstrated elevated levels of orthopoxvirus-specific $\operatorname{IgM}$ and had unexplained rash and fever and $\geq 2$ other signs or symptoms from the clinical criteria. A probable case met 1 of the epidemiologic criteria and demonstrated 
elevated levels of orthopoxvirus-specific $\operatorname{IgM}$ and had unexplained rash and fever and $\geq 2$ other signs or symptoms from the clinical criteria. A confirmed case involved detection of orthopoxvirus DNA by PCR testing of a clinical specimen (laboratory criterion).

\section{Specimen Collection and Laboratory Analysis}

We collected 2 lesion specimens (crust or vesicle swabs) from case-patients with active rash. In addition, we collected dried blood strips from active suspected case-patients, retrospective suspected case-patients, and household contacts who were available and willing to participate.

Swab and crust specimens were tested at the Institut Nationale de Recherche Biomedicale for orthopoxvirus and, if negative, for varicella zoster virus DNA signatures by PCR. Dried blood strips were tested at CDC (Atlanta, GA, USA) for orthopoxvirus IgG and IgM by ELISA, as previously described (25). All dried blood strip specimens were tested at dilutions of 1:100 or 1:50 in each ELISA while accounting for additional dilution after elution from the dried-blood strips.

\section{Surveillance Strengthening}

During the investigation, healthcare workers in the affected areas received training in monkeypox clinical characteristics and case recognition, case management, surveillance, patient care, and infection prevention and control (26). In addition, the International Communication and Education Foundation provided assistance with community education by screening educational videos, broadcasting radio messages, and facilitating discussions with community members (26).

\section{Ecologic Investigation}

We conducted an ecologic investigation of wildlife in and around the village of Manfouété in Dongou District in
August 2017, five months after the epidemiologic investigation. Manfouété is a small village on the Motaba River. The village has $\approx 1,000$ inhabitants of both Bantu and Autochthon (Pygmy) ethnic groups. The largest number of suspected cases was reported in Manfouété, which is surrounded by dense, moist forest and edaphic forest (27).

For the investigation, we captured small mammals using live traps, snap traps, and pitfall traps to increase the diversity of the sample. Traps were placed in forested areas, heavily disturbed sites, and in homes around the village. All captured animals were transported to a central processing area, where they were anesthetized with halothane or ketamine and then humanely euthanized following CDC Institutional Animal Care and Use Committee approved protocols (DOTMULX2660). Standard measurements (total length, tail length, right hind foot length, ear length, weight) were recorded to help with species identification. The animals were assessed for wounds and poxvirus-like lesions. We collected a variety of specimens from each animal (serum, dried blood, liver, spleen, heart, lung, and kidney). All specimens were stored in liquid nitrogen and shipped to CDC in Atlanta for processing.

Serum and dried blood specimens were assessed by modified ELISA for anti-orthopoxvirus IgG antibodies in specimen dilutions of $1: 100,1: 200$, and 1:400, as previously described $(15,25)$. An animal was confirmed positive for the presence of orthopoxvirus antibodies if the specimen optical density value was above the cutoff values in $\geq 2$ consecutive dilutions (1:100 and 1:200). Tissue specimens were tested for the viral DNA by PCR. DNA extraction was conducted with the MagMAX magnetic particle extraction robot (ThermoFisher, https://www.thermofisher.com), and the presence of viral DNA was assessed using real-time PCR to detect the E9L gene of orthopoxvirus (28). A 400bp fragment of the mitochondrial cytochrome $B$ (cytB)

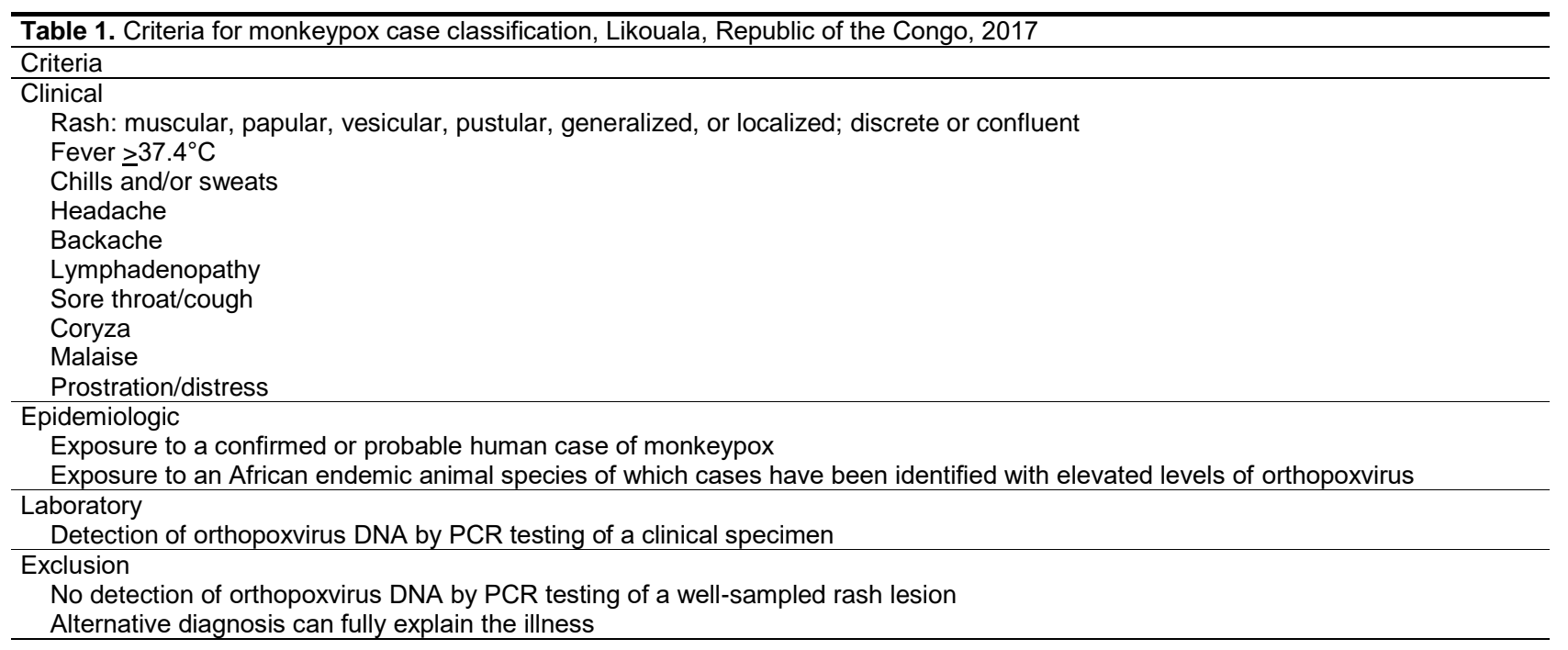


gene was amplified for the 9 Cricetomys giant pouched rat specimens collected in the Manfouété area using primers MVZ05 (29) and R400 (30). The purified PCR products were then sequenced on an ABI PRISM 3130-Avant Genetic Analyzer (Applied Biosystems, https://www.thermofisher.com). Sequences were assembled and proofed in Geneious version 10.2.2 (https://www.geneious.com). Representative sequences of the 6 Cricetomys rat species proposed by Olayemi et al. (31) were selected to conduct a Bayesian inference analysis using MrBayes version 3.2.6 $(32,33)$ to confirm the megaBLAST (https:// blast.ncbi.nlm.nih.gov/Blast.cgi) species identification of these specimens.

\section{Results}

We investigated 43 suspected cases from March 22-April 5, 2017, in Betou, Enyelle, Impfondo, and Manfouété. We also interviewed 11 household contacts who provided dried blood strips. We collected specimens from crust, vesicles, or both from 4 active suspected case-patients in Manfouété.

Among the suspected cases, 7 met the confirmed case definition, 13 met the probable case definition, and 2 met the possible case definition (Table 2). We excluded 6 cases and investigated an additional 15 suspected cases but were unable to classify them because of a missing case report form, missing exposure information, the inability to match specimens with the case report form, or some combination.

Among the 22 confirmed, probable, and possible cases, the median age of patients was 11.5 years (range 1-40 years), and 14 (63.6\%) were female. Three were from Enyelle, 15 from Manfouété in Dongou (2 were seen at the Impfondo Base Hospital), and 4 were from Impfondo. Three investigated case-patients were deceased at the time of the investigation. For the 22 cases we analyzed, 18 patients had available dried blood strips; all $18(100 \%)$ were IgG positive and $88.9 \%(16 / 18)$ were $\operatorname{IgM}$ positive.

\section{Enyelle}

Two of the 3 cases investigated in Enyelle were confirmed, and 1 met the possible case definition. The possible casepatient was a 24-year-old man whose samples tested positive for orthopoxvirus IgG and IgM. It is unknown whether he was in contact with either confirmed case-patient.

\section{Dongou}

We investigated 15 cases in Dongou District, all in Manfouété. All investigated cases were autochthonous. Investigations revealed that the likely first case was in a male autochthon hunter from the Dinyonga/Bimbema camp. Details of the severity or source of his symptoms are unknown. He had been in contact with a 4-year-old girl (casepatient 2d) who developed severe monkeypox and later died in Impfondo. He had also been in contact with most of the other suspected case-patients in Manfouété. On March 24, the 33-year-old full-term pregnant mother (case-patient 5d) of case-patient 2d was admitted to the Impfondo Base Hospital. She was suspected to have been infected while caring for her daughter. Serologic results indicated positivity for orthopoxvirus IgG and IgM.

Samples from case-patient 1d, a 12-year-old female hunter, were confirmed positive by orthopoxvirus PCR and epidemiologically linked to 2 orthopoxvirus PCR-positive cases (case-patients 3d and 4d) and a probable case with an unknown date of symptom onset (case-patient 15d) that was positive for orthopoxvirus IgM and IgG.

Case-patients $6 \mathrm{~d}-14 \mathrm{~d}$ were considered probable or possible cases and were all epidemiologically linked; however, the dates of symptom onset were unavailable. Among this cluster, all were orthopoxvirus IgG positive, and all were orthopoxvirus IgM positive except for case-patients $7 \mathrm{~d}$ and $11 \mathrm{~d}$.

\section{Impfondo}

On March 23, an 8-year-old male suspected case-patient (case-patient 4i) was investigated at the Impfondo Base Hospital for a monkeypox-like rash. The boy regularly shared a bed with his siblings, 1 of whom had laboratory-confirmed MPXV infection. Detailed discussions with the family suggested the first case in the family cluster was a 14-year-old girl (case-patient 1i) who developed a fever on February 2, 2017, and a rash 4 days later. On February 8, she died. The family described consuming bushmeat, including small rodents, and case-patient $1 \mathrm{i}$ reportedly handled and prepared the rodents before the onset of illness. Three siblings of casepatient $1 \mathrm{i}$ subsequently developed similar monkeypox-like symptoms. Fourteen days after the suspected index casepatient's death, her 11-year-old sister (case-patient 2i) was admitted to the hospital with a rash illness consistent with the suspected case definition. Lesion specimens obtained from this patient were confirmed orthopoxvirus positive by PCR. Eight days after fever onset, her 3-year-old male sibling (case-patient 3i) also developed a fever and subsequently a monkeypox rashlike illness. His symptoms were less severe, and he was never admitted to the hospital. A reconstructed transmission chain is shown in Figure 2. All 7 members of the household were tested; 5 were both IgM and IgG positive for monkeypox, but 1 of these never developed monkeypoxspecific signs or symptoms (data not shown).

\section{Betou}

A 12-year-old girl came to the Betou health clinic with a rash illness and fever on March 21, 2017. She was later confirmed PCR negative for monkeypox but was varicella zoster virus positive, suggesting the possibility of a concurrent varicella zoster virus outbreak in the area. We 
Table 2. Exposure histories, illness characteristics, laboratory results, and outcomes for confirmed, probable, and possible monkeypox cases, Likouala Department, Republic of the Congo, 2017

\begin{tabular}{|c|c|c|c|c|c|c|c|c|c|}
\hline Case & Case & Patient & Onset & & Orthopoxvirus* & & & & \\
\hline no. & category & age, y/sex & date & $\lg G$ & $\operatorname{lgM}$ & PCR & District† & Outcome $\ddagger$ & Exposure \\
\hline $1 \mathrm{e}$ & Confirmed & $40 / \mathrm{M}$ & $\operatorname{Jan} 18$ & No specimen & No specimen & Positive & Enyelle & Dead & Unknown \\
\hline $2 e$ & Confirmed & $9 / \mathrm{M}$ & Jan 20 & $\begin{array}{l}\text { Unable to } \\
\text { link }\end{array}$ & $\begin{array}{l}\text { Unable to } \\
\text { link }\end{array}$ & Positive & Enyelle & Alive & Son of $1 e$ \\
\hline $3 e$ & Possible & $24 / M$ & Mar 21 & Positive & Positive & No specimen & Enyelle & Alive & Unknown \\
\hline $1 d$ & Confirmed & $12 / F$ & Jan 28 & Positive & Positive & Positive & Dongou & Alive & Hunter \\
\hline $2 d$ & Confirmed & $4 / F$ & Feb 12 & No specimen & No specimen & Positive & Dongou & Dead & $\begin{array}{l}\text { Contact with } \\
\text { suspected case } \\
\text { (never located) }\end{array}$ \\
\hline $3 d$ & Confirmed & $28 / F$ & Feb 25 & Positive & Positive & Positive & Dongou & Alive & $\begin{array}{l}\text { Hunter/bushmeat } \\
\text { merchant, } \\
\text { contact with 1d }\end{array}$ \\
\hline $4 d$ & Confirmed & $20 / F$ & Mar 15 & Positive & Positive & Positive & Dongou & Alive & $\begin{array}{l}\text { Hunter, contact with } \\
1 \mathrm{~d}, 3 \mathrm{~d}, 15 \mathrm{~d}\end{array}$ \\
\hline $5 d$ & Probable & $33 / F$ & Mar 24 & Positive & Positive & $\begin{array}{l}\text { Collected, } \\
\text { lost }\end{array}$ & Dongou & Alive & Mother of $2 d$ \\
\hline $6 d$ & Probable & $3 / F$ & Mar 30 & Positive & Positive & No specimen & Dongou & Alive & $\begin{array}{l}\text { Family cluster, } \\
\text { contact with } 7 d, 8 d \text {, } \\
10-14 d\end{array}$ \\
\hline $7 d$ & Probable & $1 / F$ & Unknown & Positive & Negative & No specimen & Dongou & Alive & $\begin{array}{l}\text { Family cluster, } \\
\text { contact with } 6 d, 8 d \text {, } \\
10-14 d\end{array}$ \\
\hline $8 d$ & Probable & 30/M & Unknown & Positive & Positive & Not collected & Dongou & Alive & $\begin{array}{l}\text { Hunter/family } \\
\text { cluster, contact with } \\
6 \mathrm{~d}, 7 \mathrm{~d}, 10-14 \mathrm{~d}\end{array}$ \\
\hline $9 d$ & Possible & $27 / F$ & Unknown & Positive & Positive & Not collected & Dongou & Alive & Unknown \\
\hline $10 d$ & Probable & $11 / M$ & Unknown & Positive & Positive & No specimen & Dongou & Alive & $\begin{array}{l}\text { Hunter/family } \\
\text { cluster, contact with } \\
6-8 d, 11-15 d\end{array}$ \\
\hline $11 d$ & Probable & $15 / F$ & Unknown & Positive & Negative & No specimen & Dongou & Alive & $\begin{array}{l}\text { Hunter/family } \\
\text { cluster, contact with } \\
6-8 d, 10 d, 12-14 d\end{array}$ \\
\hline $12 d$ & Probable & $5 / F$ & Unknown & Positive & Positive & No specimen & Dongou & Alive & $\begin{array}{l}\text { Family cluster, } \\
\text { contact with } 6-8 d, \\
10 d, 11 d, 13 d, 14 d\end{array}$ \\
\hline $13 d$ & Probable & $5 / F$ & Unknown & Positive & Positive & No specimen & Dongou & Alive & $\begin{array}{l}\text { Family cluster, } \\
\text { contact with } 6-8 d \text {, } \\
10-12 d, 14 d\end{array}$ \\
\hline $14 d$ & Probable & $28 / F$ & Unknown & Positive & Positive & Not collected & Dongou & Alive & $\begin{array}{l}\text { Hunter/family } \\
\text { cluster, contact with } \\
6-8 d, 10-13 d\end{array}$ \\
\hline $15 d$ & Probable & $1 / \mathrm{M}$ & Unknown & Positive & Positive & Not collected & Dongou & Alive & Child of $3 d$ \\
\hline $1 \mathrm{i}$ & Probable & $14 / F$ & Feb 2 & No specimen & No specimen & No specimen & Impfondo & Dead & $\begin{array}{l}\text { Prepared bush } \\
\text { meat for food (rats, } \\
\text { rodents); sister of } \\
2 \mathrm{i}-4 \mathrm{i} \text {; first family } \\
\text { member to fall ill }\end{array}$ \\
\hline $2 \mathrm{i}$ & Confirmed & $11 / F$ & Feb 24 & Positive & Positive & Positive & Impfondo & Alive & Sister of $1 \mathrm{i}, 3 \mathrm{i}, 4 \mathrm{i}$ \\
\hline $3 i$ & Probable & $3 / \mathrm{M}$ & Mar 4 & Positive & Positive & No specimen & Impfondo & Alive & Brother of $1 \mathrm{i}, 2 \mathrm{i}, 4 \mathrm{i}$ \\
\hline $4 i$ & Probable & 8/M & Mar 20 & Positive & Positive & $\begin{array}{l}\text { Collected, } \\
\text { lost }\end{array}$ & Impfondo & Alive & Brother of 1i, 2i, 3i \\
\hline
\end{tabular}

identified and investigated 13 additional suspected cases in the district. The investigation team was also notified of a confirmed measles outbreak in the district. The team indicated that 4/14 cases investigated were students from the same class at 1 school, suggesting the possibility of school-associated monkeypox or measles virus infection or possibly varicella zoster virus with or without monkeypox co-infection.

\section{Ecologic Investigation}

We obtained samples from 105 mammals during 1,843 trap-nights (number of traps per night multipled by the number of nights) over a period of 9 days (Table 3). The mammals sampled belong to the orders Rodentia (77.1\%), Eulipotyphla (21.0\%), and Chiroptera (1.9\%). We found 2 (1.9\%) of 105 serum specimens to be positive for orthopoxvirus IgG by ELISA (Table 3). Both of the seropositive 
animals were rodents of the species Cricetomys emini $(\mathrm{N}=$ 9, 22.2\%). We found all specimens collected in the study to be negative for the presence of orthopoxvirus DNA by real-time PCR.

Five of the 9 Cricetomys rat sequences obtained in this study were identical (ROC37, ROC38, ROC50, ROC79, and ROC103); we submitted the 5 unique sequences to GenBank (accession nos. MH365330-4). The analyses identified all Cricetomys rat specimens as Cricetomys Sp3, as previously proposed by Olayemi et al. (Figure 3) (31). However, this taxonomy is not currently recognized; therefore these specimens are identified as C. emini rats (34).

\section{Discussion}

We describe epidemiologic and ecologic investigations of monkeypox in a rural region of the Republic of the Congo. Confirmed and probable monkeypox cases were found in the districts of Enyelle, Impfondo, and Dongou, and possible cases were identified in Betou. There were no epidemiologic links between cases from different districts. All hypothesized human-to-human transmission events appeared to have been contained within the individual districts. In Impfondo, transmission was contained to 1 family with a putative 3 generations of interhuman virus transmission. No evidence of virus introduction from neighboring countries was found.

Although Dongou case-patients 2d and 5d were hospitalized in Impfondo, it appears that case-patient 2d contracted the disease from another person in Manfouété and subsequently transmitted the virus to her mother (case-patient $5 \mathrm{~d}$ ). Although we were unable to link case-patient $5 \mathrm{~d}$ directly to the other Manfouété cases, Dongou case-patients $6 \mathrm{~d}-14 \mathrm{~d}$ appear to be part of a family cluster and reported exposure to the same infected individual in Manfouété. Unfortunately, it was not possible to create a transmission chain because the date of symptom onset was not reported for any of these suspected cases.

MPXV is thought to have limited capacity to spread in human populations, as described by stochastic models
$(35,36)$. We documented 3 suspected serial transmission events; the largest number of previously recorded events is 6 (21). Our investigation revealed additional family clusters, suggesting that human-to-human transmission does play a major role in disease transmission.

Most of the suspected cases that could not be further classified were found in Betou, where our investigation did not find any confirmed cases. Additional information would be needed to definitively determine whether monkeypox is actually circulating in this district.

It does appear that independent zoonotic events likely occurred in Enyelle, Impfondo, and Dongou, which are connected by the same forest. These separate events appear to have led to different outbreaks in various parts of Likouala. Although it was previously suspected, our results provide substantial evidence that monkeypox is endemic in this region. Indeed, monkeypox cases have previously been documented in the area, and a 2007 serosurvey found an orthopoxvirus reactive antibody seroprevalence of $56.9 \%$ in Likouala Department (23).

Although past outbreaks and cases have been observed, the reported disease incidence in Republic of Congo is markedly lower in comparison to the neighboring DRC. Given Impfondo's close proximity to the Equateur Province in DRC (directly across the Ubangi River), where monkeypox cases are more frequently reported, it is possible that monkeypox was imported from DRC into Republic of Congo, either through human movements or cross-border transportation of bushmeat (20). Moreover, these 2 countries have notable biogeographic, ecologic, and cultural similarities, suggesting that observed differences in disease incidence are not necessarily the result of underlying ecology but are perhaps attributable to differences in investment in surveillance. Nevertheless, a deeper exploration of cultural differences, including bushmeat preferences, may be warranted.

This outbreak is indicative of endemic transmission of MPXV, which requires the circulation and maintenance of virus in local mammal populations $(18,21)$.
Figure 2. Transmission chain: pattern of virus transmission hypothesized to have occurred during monkeypox outbreak in Impfondo, Likouala Department, Republic of Congo, 2017. Casepatients are arranged according to date of symptom onset. Solid lines indicate probable lines of person-to-person transmission and dashed lines depict undetermined (hypothesized) transmission events. The number of days between onsets (case interval) is approximated by length of lines. Case-patients illustrated are siblings belonging to the same household.
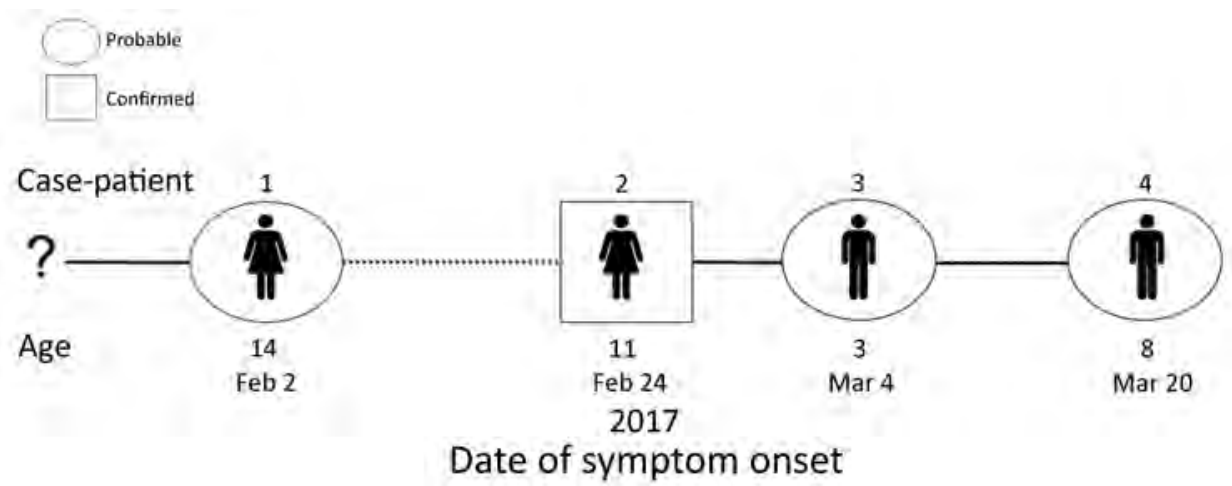
Table 3. Summary of orthopoxvirus IgG ELISA results from mammals sampled in Manfouété, Likouala Department, Republic of the Congo, 2017

\begin{tabular}{|c|c|c|c|c|}
\hline Order & Genus & Common name & No. sampled & No. (\%) positive \\
\hline \multirow[t]{9}{*}{ Rodentia } & Hylomyscus & African wood mouse & 28 & 0 \\
\hline & Malacomys & Long-footed rat & 15 & 0 \\
\hline & Praomys & Soft-furred rat & 15 & 0 \\
\hline & Cricetomys & Giant pouched rat & 9 & $2(22.2)$ \\
\hline & Hybomys & Hump-nosed mouse & 6 & 0 \\
\hline & Rattus & Rat & 3 & 0 \\
\hline & Lemniscomys & Zebra mouse & 2 & 0 \\
\hline & Mastomys & Multimammate rat & 2 & 0 \\
\hline & Atherurus & Brush-tailed porcupine & 1 & 0 \\
\hline \multirow[t]{3}{*}{ Eulipotyphla } & Sylvisorex & Climbing shrew & 8 & 0 \\
\hline & Crocidura & White-toothed shrew & 8 & 0 \\
\hline & Unknown shrew & Shrew & 6 & 0 \\
\hline \multirow[t]{2}{*}{ Chiroptera } & Pipistrellus & Pipistrelle bat & 1 & 0 \\
\hline & Epomops & Singing fruit bat & 1 & 0 \\
\hline Total & & & 105 & $2(1.9)$ \\
\hline
\end{tabular}

Although the ecologic study did not result in isolation of live virus in any of the captured animals, 2 (1.9\%) of $105 \mathrm{blood} /$ serum specimens were positive for orthopoxvirus IgG. We did not detect viable virus in Cricetomys rats, but no data exist regarding how long after infection that virus or viral DNA is detectable in tissue samples. These serologic data support previous published reports $(15,37)$ that found giant pouched rats could be involved in the circulation and maintenance of MPXV in nature
(31). Moreover, the taxonomy of the genus Cricetomys is currently being debated and possibly revised, which highlights the importance of the correct identification of species to make accurate inferences regarding potential MPXV hosts.

Several limitations were associated with this investigation. Lesion specimens were not collected from most suspected cases; as a result, we are confident only that the 7 confirmed cases are monkeypox. Laboratory confirmation

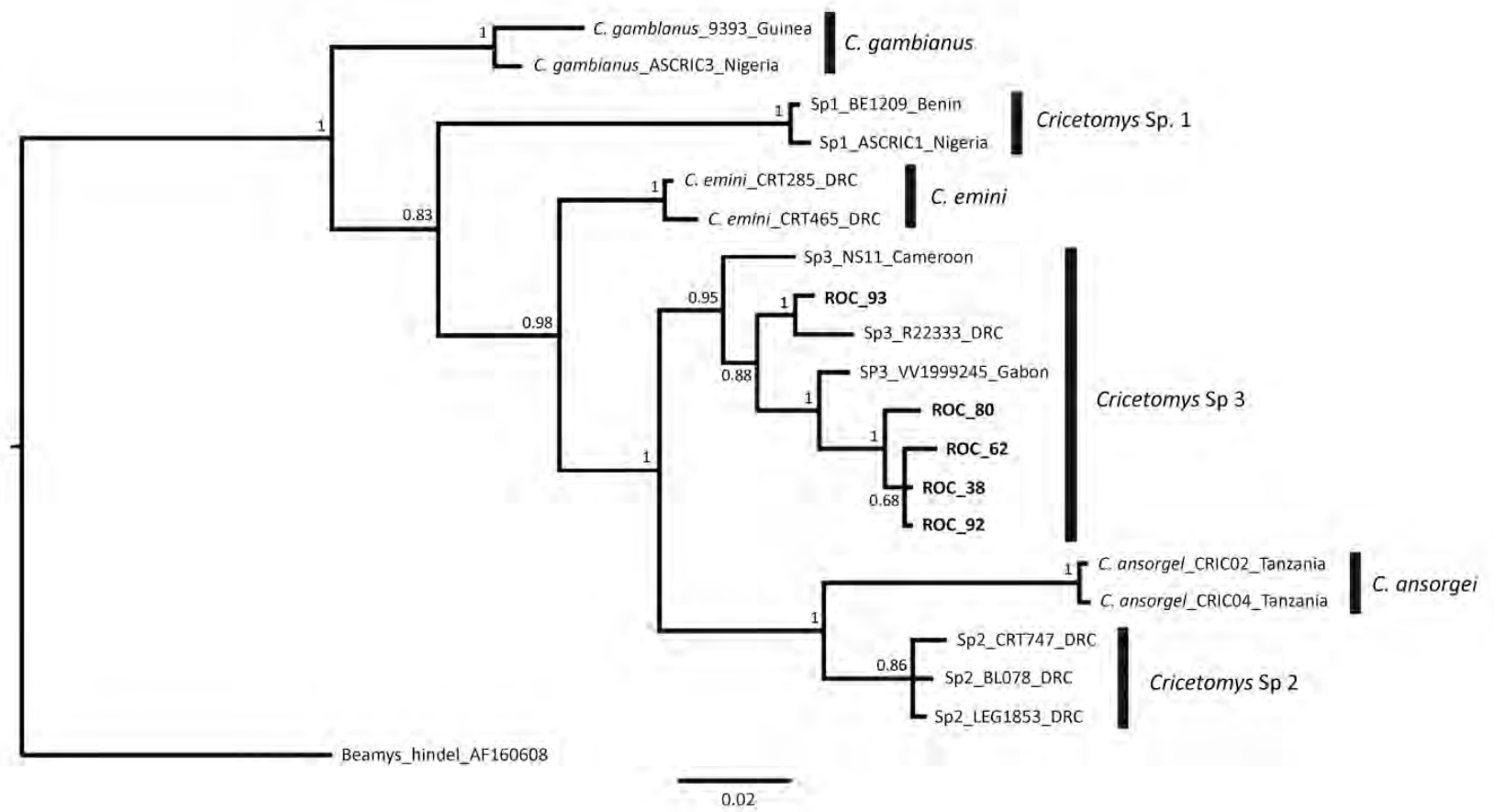

Figure 3. Bayesian majority rules consensus tree comparing sequences obtained from Cricetomys specimens collected in Likouala Department, Republic of the Congo, 2017 (boldface), with sequences from Olayemi et al. (31). Vertical black bars distinguish clades representing Cricetomys giant pouched rat species proposed by Olayemi et al. Tree was constructed on the basis of 2 independent runs, 5 million generations each, based on a 409-bp fragment of the cytochrome $B$ gene. Bayesian posterior probabilities for each node are shown. Scale bar indicates nucleotide substitutions per site. 
by PCR was not possible for many of the suspect cases because patients were interviewed after the rash had resolved. All interviewed patients did provide blood, but serologic results are insufficient for monkeypox confirmation given the cross-reactivity observed among orthopoxviruses. Furthermore, it is difficult to interpret serologic results and differentiate current infection from past exposure, particularly in the absence of detailed clinical and epidemiologic data. Regardless, the IgM data give us confidence that infection was from recent exposure (within the previous 2 months). However, the likelihood of other rash illness outbreaks, such as measles and chickenpox (caused by varicella zoster virus), during the same period make it difficult to determine the true extent of the outbreak. In addition, missing case report forms and data on available forms limited our ability to classify several cases as probable or possible and to identify chains of transmission across contacts.

In general, monkeypox surveillance in the region needs to be strengthened. The challenges associated with this remote region, such as limited health and transportation infrastructure and the absence of specimen collection supplies and a well-functioning cold chain (system of specimen storage and transport at the recommended cold temperatures), have resulted in inconsistent and incomplete reporting. Therefore, is it difficult to determine the true extent of the outbreak, particularly during a period when other rash illnesses were circulating. We attempted to improve diagnostic capabilities by training healthcare workers to use specimen investigation kits designed to collect direct lesion material rather than blood. In addition, during our training, we found that most healthcare workers who attended had little prior knowledge of monkeypox clinical symptoms, monkeypox case management, and infection control practices. Consistent refresher trainings and additional guidance for monkeypox surveillance will be worthwhile to determine the true burden of monkeypox in this region.

\section{Acknowledgments}

We thank all patients and the communities we worked with during this investigation. We also acknowledge the Republic of the Congo Ministry of Health, the Direction Générale du Développement Durable, Ministère de l'Économie Forestière et du Développement Durable, the World Health Organization, the Food and Agriculture Organization of the United Nations, and the United Nations High Commission on Refugees; specifically, Madzou Moukili, Roger Germain Bouka, Clément Diahouata, Fatoumata Binta Diallo, Edouard Ndinga, Aouehougon Ouepake Kobina, and Amadou Damagbe Camara.

\section{About the Author}

Dr. Doshi is an epidemic intelligence service officer with the Division of Global HIV and TB, Center for Global Health,
Centers for Disease Control and Prevention, Atlanta, Georgia, USA. Her interests include emerging infectious diseases, vaccine-preventable diseases, and communitybased initiatives.

\section{References}

1. Breman JG, Kalisa-Ruti, Steniowski MV, Zanotto E, Gromyko AI, Arita I. Human monkeypox, 1970-79. Bull World Health Organ. 1980;58:165-82.

2. Jezek Z, Marennikova SS, Mutumbo M, Nakano JH, Paluku KM, Szczeniowski M. Human monkeypox: a study of 2,510 contacts of 214 patients. J Infect Dis. 1986;154:551-5. http://dx.doi.org/ 10.1093/infdis/154.4.551

3. Jezek Z, Szczeniowski M, Paluku KM, Mutombo M. Human monkeypox: clinical features of 282 patients. J Infect Dis. 1987;156:293-8. http://dx.doi.org/10.1093/infdis/156.2.293

4. Damon IK. Status of human monkeypox: clinical disease, epidemiology and research. Vaccine. 2011;29(Suppl 4):D54-9. http://dx.doi.org/10.1016/j.vaccine.2011.04.014

5. Edghill-Smith Y, Golding H, Manischewitz J, King LR, Scott D, Bray M, et al. Smallpox vaccine-induced antibodies are necessary and sufficient for protection against monkeypox virus. Nat Med. 2005;11:740-7. http://dx.doi.org/10.1038/nm1261

6. Rimoin AW, Mulembakani PM, Johnston SC, Lloyd Smith JO, Kisalu NK, Kinkela TL, et al. Major increase in human monkeypox incidence 30 years after smallpox vaccination campaigns cease in the Democratic Republic of Congo. Proc Natl Acad Sci U S A. 2010;107:16262-7. http://dx.doi.org/10.1073/pnas.1005769107

7. Durski KN, McCollum AM, Nakazawa Y, Petersen BW, Reynolds MG, Briand S, et al. Emergence of Monkeypox-West and Central Africa, 1970-2017. MMWR Morb Mortal Wkly Rep. 2018;67:306-10. http://dx.doi.org/10.15585/mmwr.mm6710a5

8. Yinka-Ogunleye A, Aruna O, Ogoina D, Aworabhi N, Eteng W, Badaru S, et al. Reemergence of human monkeypox in Nigeria, 2017. Emerg Infect Dis. 2018;24:1149-51. http://dx.doi.org/ 10.3201/eid2406.180017

9. Hutson CL, Carroll DS, Gallardo-Romero N, Weiss S, Clemmons C, Hughes CM, et al. Monkeypox disease transmission in an experimental setting: prairie dog animal model. PLoS One. 2011;6:e28295. http://dx.doi.org/10.1371/journal.pone.0028295

10. Reynolds MG, Yorita KL, Kuehnert MJ, Davidson WB, Huhn GD, Holman RC, et al. Clinical manifestations of human monkeypox influenced by route of infection. J Infect Dis. 2006;194:773-80. http://dx.doi.org/10.1086/505880

11. Jezek Z, Fenner F. Human monkeypox. Monographs in virology. Basel: Karger; 1988.

12. Khodakevich L, Jezek Z, Kinzanzka K. Isolation of monkeypox virus from wild squirrel infected in nature. Lancet. 1986;1:98-9. http://dx.doi.org/10.1016/S0140-6736(86)90748-8

13. Khodakevich L, Szczeniowski M, Manbu-ma-Disu, Jezek Z, Marennikova S, Nakano J, et al. The role of squirrels in sustaining monkeypox virus transmission. Trop Geogr Med. 1987;39:115-22.

14. Khodakevich L, Szczeniowski M, Nambu-ma-Disu, Jezek Z, Marennikova S, Nakano J, et al. Monkeypox virus in relation to the ecological features surrounding human settlements in Bumba zone, Zaire. Trop Geogr Med. 1987;39:56-63.

15. Doty JB, Malekani JM, Kalemba LN, Stanley WT, Monroe BP, Nakazawa YU, et al. Assessing monkeypox virus prevalence in small mammals at the human-animal interface in the Democratic Republic of the Congo. Viruses. 2017;9:E283. http://dx.doi.org/ 10.3390/v9100283

16. Essbauer S, Pfeffer M, Meyer H. Zoonotic poxviruses. Vet Microbiol. 2010;140:229-36. http://dx.doi.org/10.1016/j.vetmic. 2009.08.026 
17. Radonić A, Metzger S, Dabrowski PW, Couacy-Hymann E, Schuenadel L, Kurth A, et al. Fatal monkeypox in wild-living sooty mangabey, Côte d'Ivoire, 2012. Emerg Infect Dis. 2014;20:100911. http://dx.doi.org/10.3201/eid2006.131329

18. Ellis CK, Carroll DS, Lash RR, Peterson AT, Damon IK, Malekani J, et al. Ecology and geography of human monkeypox case occurrences across Africa. J Wildl Dis. 2012;48:335-47. http://dx.doi.org/10.7589/0090-3558-48.2.335

19. Jezek Z, Grab B, Szczeniowski M, Paluku KM, Mutombo M. Clinico-epidemiological features of monkeypox patients with an animal or human source of infection. Bull World Health Organ. 1988;66:459-64.

20. Reynolds MG, Emerson GL, Pukuta E, Karhemere S, Muyembe JJ, Bikindou A, et al. Detection of human monkeypox in the Republic of the Congo following intensive community education. Am J Trop Med Hyg. 2013;88:982-5. http://dx.doi.org/10.4269/ajtmh.12-0758

21. Learned LA, Reynolds MG, Wassa DW, Li Y, Olson VA, Karem K, et al. Extended interhuman transmission of monkeypox in a hospital community in the Republic of the Congo, 2003. Am J Trop Med Hyg. 2005;73:428-34. http://dx.doi.org/10.4269/ ajtmh.2005.73.428

22. Ministry of Economy, Territory Development and Integration, Centre National de la Statisque et des Études Economiques. Le RGPH-2007 en quelques chiffres. Brazzaville, Republic of Congo; 2010 [cited 2018 Apr 5]. http://www.cnsee.org/pdf/rgph2007pd.pdf

23. Lederman ER, Reynolds MG, Karem K, Braden Z, Learned-Orozco LA, Wassa-Wassa D, et al. Prevalence of antibodies against orthopoxviruses among residents of Likouala region, Republic of Congo: evidence for monkeypox virus exposure. Am J Trop Med Hyg. 2007;77:1150-6. http://dx.doi.org/10.4269/ajtmh.2007.77.1150

24. MacNeil A, Reynolds MG, Carroll DS, Karem K, Braden Z, Lash R, et al. Monkeypox or varicella? Lessons from a rash outbreak investigation in the Republic of the Congo. Am J Trop Med Hyg. 2009;80:503-7. http://dx.doi.org/10.4269/ ajtmh.2009.80.503

25. Karem KL, Reynolds M, Braden Z, Lou G, Bernard N, Patton J, et al. characterization of acute-phase humoral immunity to monkeypox: use of immunoglobulin M enzyme-linked immunosorbent assay for detection of monkeypox infection during the 2003 North American outbreak. Clin Diagn Lab Immunol. 2005;12:867-72.

26. Doshi RH, Guagliardo SAJ, Dzabatou-Babeaux A, Likouayoulou C, Ndakala N, Moses C, et al. Strengthening of surveillance during monkeypox outbreak, Republic of the Congo, 2017. Emerg Infect Dis. 2018;24:1158-60. http://dx.doi.org/10.3201/eid2406.180248
27. Verhegghen A, Mayaux P, De Wasseige C, Defourny P. Mapping Congo Basin vegetation types from $300 \mathrm{~m}$ and $1 \mathrm{~km}$ multi-sensor time series for carbon stocks and forest areas estimation. Biogeosciences. 2012;9:5061-79. http://dx.doi.org/10.5194/ bg-9-5061-2012

28. Li Y, Olson VA, Laue T, Laker MT, Damon IK. Detection of monkeypox virus with real-time PCR assays. J Clin Virol. 2006;36:194-203. http://dx.doi.org/10.1016/j.jcv.2006.03.012

29. Smith MF, Patton JL. The diversification of South American murid rodents: evidence from mitochondrial DNA sequence data for the akodontine tribe. Biol J Linn Soc Lond. 1993;50:149-77. http://dx.doi.org/10.1111/j.1095-8312.1993.tb00924.x

30. Peppers LL, Bradley RD. Cryptic species in Sigmodon hispidus: evidence from DNA sequences. J Mammal. 2000;81:332-43. http://dx.doi.org/10.1644/1545-1542(2000)081<0332:CSISHE $>2$. $0 . \mathrm{CO} ; 2$

31. Olayemi A, Nicolas V, Hulselmans J, Missoup AD, Fichet-Calvet E, Amundala D, et al. Taxonomy of the African giant pouched rats (Nesomyidae: Cricetomys): molecular and craniometric evidence support an unexpected high species diversity. Zool J Linn Soc. 2012;165:700-19. http://dx.doi.org/ 10.1111/j.1096-3642.2012.00823.x

32. Huelsenbeck JP, Ronquist F. MRBAYES: Bayesian inference of phylogenetic trees. Bioinformatics. 2001;17:754-5. http://dx.doi.org/10.1093/bioinformatics/17.8.754

33. Ronquist F, Huelsenbeck JP. MrBayes 3: Bayesian phylogenetic inference under mixed models. Bioinformatics. 2003;19:1572-4. http://dx.doi.org/10.1093/bioinformatics/btg180

34. Musser GG. Superfamily Muroidea. In: Wilson DE, Reeder DM, editors. Mammal species of the world, 3rd edition. Baltimore: The Johns Hopkins University Press; 2005. p. 894-1531.

35. Fine PE, Jezek Z, Grab B, Dixon H. The transmission potential of monkeypox virus in human populations. Int J Epidemiol. 1988;17:643-50. http://dx.doi.org/10.1093/ije/17.3.643

36. Jezek Z, Grab B, Dixon H. Stochastic model for interhuman spread of monkeypox. Am J Epidemiol. 1987;126:1082-92. http://dx.doi.org/10.1093/oxfordjournals.aje.a114747

37. Hutson CL, Nakazawa YJ, Self J, Olson VA, Regnery RL, Braden Z, et al. Laboratory investigations of African pouched rats (Cricetomys gambianus) as a potential reservoir host species for monkeypox virus. PLoS Negl Trop Dis. 2015;9:e004013. http://dx.doi.org/10.1371/journal.pntd.0004013

Address for correspondence: Reena H. Doshi, Centers for Disease Control and Prevention, 1600 Clifton Road NE, Mailstop E30, Atlanta, GA 30329-4027, USA; email: hqo3@cdc.gov 


\title{
Oasis Malaria, Northern Mauritania ${ }^{1}$
}

\author{
Jemila Deida, Rachida Tahar, Yacoub Ould Khalef, Khadijetou Mint Lekweiry, \\ Abdoullah Hmeyade, Mohamed Lemine Ould Khairy, Frédéric Simard, \\ Hervé Bogreau, Leonardo Basco, Ali Ould Mohamed Salem Boukhary
}

A malaria survey was conducted in Atar, the northernmost oasis city in Mauritania, during 2015-2016. All febrile patients in whom malaria was suspected were screened for malaria by using rapid diagnostic testing and microscopic examination of blood smears and later confirmed by PCR. Of 453 suspected malaria cases, 108 (23.8\%) were positive by rapid diagnostic testing, 154 (34.0\%) by microscopic examination, and $162(35.7 \%)$ by PCR. Malaria cases were observed throughout the year and among all age groups. Plasmodium vivax was present in 120/162 (74.1\%) cases, $P$. falciparum in $4 / 162(2.4 \%)$, and mixed $P$. falciparum-P. vivax in $38 / 162(23.4 \%)$. Malaria is endemic in northern Mauritania and could be spreading farther north in the Sahara, possibly because of human-driven environmental changes. Further entomologic and parasitologic studies and monitoring are needed to relate these findings to major Anopheles mosquito vectors and to design and implement strategies for malaria prevention and control.

$\mathrm{M}$ alaria is one of the major reasons for seeking healthcare in public health facilities in Mauritania. In 2016, among an estimated population of 3,537,368, malaria incidence was 78/1,000 persons at risk (1) and malariaassociated mortality was 30 deaths/100,000 persons (2).

Author affiliations: Unité Mixte de Recherche 216, Institut de Recherche pour le Développement, Université Paris 5,

Sorbonne Paris Cité, Paris, France (J. Deida, R. Tahar); Université de Nouakchott Al-Aasriya, Nouakchott, Mauritania (J. Deida, K. Mint Lekweiry, A. Ould Mohamed Salem Boukhary); Ministry of Health, Nouakchott (Y. Ould Khalef, M.L. Ould Khairy); Ministry of Health, Atar (A. Hmeyade); Maladies Infectieuses et Vecteurs: Ecologie, Génétique, Evolution et Contrôle, Institut de Recherche pour le Développement-Centre National de Recherche Scientifique-Université Montpellier, Montpellier, France (F. Simard); Institut de Recherche Biomédicale des Armées, Marseille (H. Bogreau); Centre National de Référence du Paludisme, Marseille (H. Bogreau); Aix Marseille Université, Institut de Recherche pour le Développement, Assistance Publique-Hôpitaux de Marseille, Service de Santé des Armées, Vecteurs-Infections Tropicales et Méditerranéennes, Marseille, France (H. Bogreau, L. Basco, A. Ould Mohamed Salem Boukhary)

DOI: https://doi.org/10.3201/eid2502.180732
The northern limit where malaria transmission occurs in Mauritania is not well defined. Sporadic suspected cases of malaria were reported in the oasis setting of Atar in the early 2010s, and the first Plasmodium vivax cases were confirmed by microscopic examination in 2012, but PCR was not performed for further confirmation (A. Ould Mohamed Salem Boukhary, unpub. data). Therapeutic efficacy of chloroquine to treat $P$. vivax malaria was also evaluated in 2013 in Atar (3). In that study, patient screening and recruitment were performed during only 1 month, followed by a 28-day follow-up period. Here, we report results of a follow-up study in which we conducted a longitudinal survey in Atar to establish baseline data on malaria burden in this Saharan zone of Mauritania.

\section{Materials and Methods}

\section{Study Site}

During March 2015-December 2016, we conducted a longitudinal study in the Hospital Center of Atar, situated in the regional capital of Adrar Province, northern Mauritania (Figure 1). Atar is the largest oasis city located in the Sahara, $\approx 440 \mathrm{~km}$ to the northeast of Nouakchott, the national capital. According to the latest census of population and housing, the population of Atar in 2013 was 38,803, primarily Moors (1). Rainfall in Atar is scarce (annual mean $50 \mathrm{~mm}$; Office National de la Météorologie, Nouakchott, pers. comm., 2018 Feb 4). During the study period, the total amount of rainfall was $79.2 \mathrm{~mm}$ in 2015 and $65 \mathrm{~mm}$ in 2016. The average temperature during the same period was $29.5^{\circ} \mathrm{C}$ (range $23^{\circ} \mathrm{C}-36^{\circ} \mathrm{C}$ ), and the mean relative humidity was $37.1 \%$ (range $20 \%-54 \%$ ). Date palm culture is the main agricultural activity in Adrar Province; $\approx 1,200,000$ palm trees are distributed across 75 oases (4). Livestock largely consists of dromedary camels (Camelus dromedarius) and small ruminants (goats and sheep).

\section{Inclusion Criteria, Sample, and Data Collection}

The study included all febrile patients in whom malaria infection was suspected, with either a measured body

\footnotetext{
${ }^{1}$ Preliminary results of this study were presented at the 7 th Multilateral Initiative for Malaria (MIM) Pan African Malaria Conference, April 15-20, 2018, Dakar, Senegal.
} 


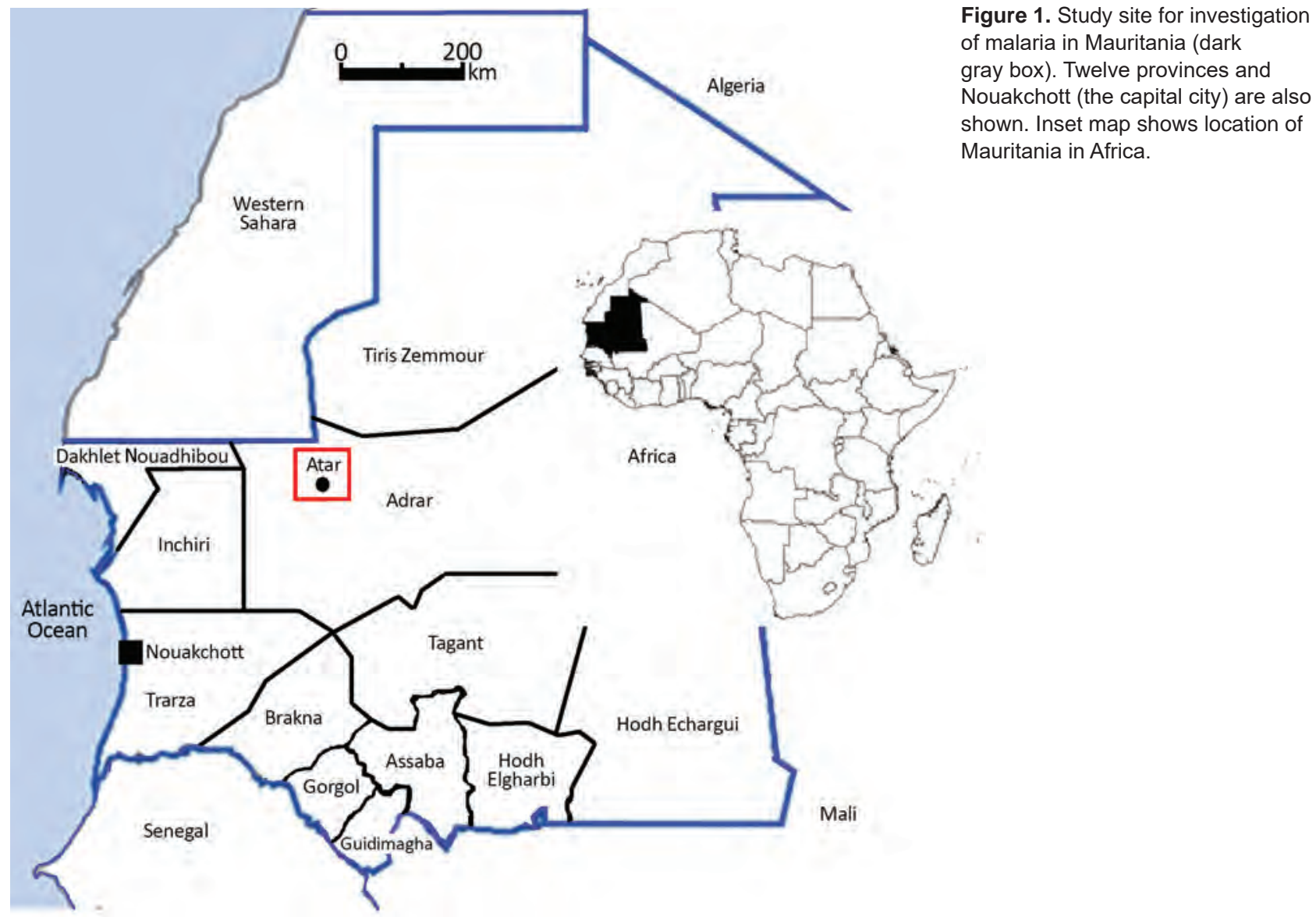

temperature $\geq 37.5^{\circ} \mathrm{C}$ at the time of consultation or history of fever within the previous 48 hours with no other obvious cause (5). After obtaining informed consent, we obtained finger-prick blood samples from patients to prepare thick and thin smears and perform rapid diagnostic testing for malaria. About $100 \mu \mathrm{L}$ of capillary blood was spotted and dried on Whatman 3MM filter paper (GE Healthcare Europe $\mathrm{GmbH}$, https://www.gehealthcare.com) for PCR diagnosis.

During the consultation, we interviewed patients by using a standard, pretested questionnaire covering sociodemographic data, including detailed recent travel history outside the region and bed net use. We classified frequency of bed net use as always, often, seldom, or never.

\section{Malaria Detection Methods}

\section{Rapid Diagnostic Test}

We used Bioline Malaria Antigen Pf/Pan test (Standard Diagnostics/Abbott, https://www.abbott.com) to screen malaria-infected patients. This rapid diagnostic test (RDT) detects $P$. falciparum-specific histidine-rich protein 2 , referred to here as the Pf band, and Plasmodium genus-specific lactate dehydrogenase, referred to as the Pan band.
RDT results were blinded with regard to microscopic examination and PCR results.

\section{Microscopic Examination}

We dried blood films and stained them with 5\% Giemsa solution for $20 \mathrm{~min}$ and examined them for the presence of malaria parasites. We counted the number of asexual parasites against 200 leukocytes and expressed parasite density as the number of asexual parasites $/ \mu \mathrm{L}$ of blood, assuming a leukocyte count of $8,000 / \mu \mathrm{L}$ of blood (6). We recorded the average count of 2 experienced technicians as the final parasite density. We considered a thick blood film as negative if no asexual stage of Plasmodium spp. was found after an examination of 100 fields under oil immersion at a magnification of $\times 1,000$. An experienced microscopist performed quality control by reexamining all positive samples and $10 \%$ of negative blood smears blindly.

\section{PCR}

We extracted parasite DNA by using the Chelex method (7). We identified Plasmodium species by using a species-specific nested PCR targeting mitochondrial cytochrome $b$ gene (8). 


\section{Statistical Analysis}

We initially entered data into an Excel 2003 spreadsheet (Microsoft, http://www.microsoft.com). We evaluated performance (sensitivity, specificity, positive and negative predictive values, and accuracy) of 2 diagnostic tools (microscopic examination and RDT) against PCR as the reference method by using MedCalc statistical calculator software (https://www.medcalc.org/calc/diagnostic test. php). We used the Cohen $\kappa$ statistic to estimate the degree of agreement (9-11), classified as follows: $<0$, very poor; $0-0.20$, poor; $0.21-0.40$, fair; $0.41-0.60$, moderate; $0.61-0.80$, good; and $>0.80$, very good. We used a $\chi^{2}$ test or Fisher exact test to compare proportions or to test association between qualitative variables. We calculated odds ratios and CIs by using the fisher.test function of the $\mathrm{R}$ statistical software package (12). We measured associations between quantitative variables by using the Kendall rank correlation $\tau$ with cor.test function in R. We implemented comparison of true positive and false negative parasitemia diagnosed with RDT by using the Mann-Whitney-Wilcoxon test (wilcox.test function). We determined CIs of binomial proportion by using the binom.test function in $\mathrm{R}$ (12). For all statistical tests, we considered $\mathrm{p}<0.05$ significant.

\section{Ethics Considerations}

The study protocol was reviewed and approved by the Institutional Ethics Committee of the Université de Nouakchott Al-Aasriya and the Institutional Ethics Committee of the Institut de Recherche pour le Développement, Marseille, France. We obtained written informed consent from adult patients or the parents or legal guardians of children.

\section{Results}

\section{General Characteristics of the Study Population}

We screened a total of 453 febrile patients (235 in 2015 and 218 in 2016; male-to-female sex ratio 1.2) for malaria parasites (Table 1). The mean age of the participants was 29.2 ( $\pm 18.3 \mathrm{SD}$ ) years (range 3 months-80 years; median 27 years). The largest age group was persons $\geq 20$ years of age (65\%). The mean axillary temperature at the time of consultation was $39.2^{\circ} \mathrm{C}\left( \pm 0.7^{\circ} \mathrm{C}\right)$. At the time of consultation, 448 (87\%) patients had fever (axillary temperature $\geq 37.5^{\circ} \mathrm{C}$ ). Most of the study population were white Moors (77.7\%) and black Moors (19.6\%). Ten (2.2\%) patients were black Africans (i.e., persons of Pular [also known as Peul] and Soninke ethnicity), and 2 (0.4\%) patients were foreign expatriates. Almost all patients (441/453 [97.3\%]) were residents of Atar and the neighboring oases.

\section{Malaria Prevalence and Plasmodium Species}

Of 453 enrolled patients, 108 (23.8\%) were positive for malaria by RDT, 154 (34.0\%) were positive by microscopic examination, and 162 (35.8\%) were positive by PCR (Table 2). $P$. vivax was by far the dominant species. Among 108 RDT-positive patients, 92 (85.2\%) were non-P. falciparum and $16(14.8 \%)$ were " $P$. falciparum present" (i.e., infected with $P$. falciparum, with or without non-P. falciparum). PCR confirmed that all non-P. falciparum cases were attributable to pure $P$. vivax, except in 3 patients (1 with pure $P$. falciparum infection, 1 with $P$. falciparum $-P$. vivax mixed infection, and 1 who was negative for Plasmodium spp). P. ovale was detected in 10 (6.5\%) of 154 patients found to be positive by microscopic examination, but PCR results showed that these parasites were all pure P. vivax infections. Among 162 PCR-positive cases, 120 (74.1\%) were attributable to pure P. vivax, 4 (2.5\%) to pure $P$. falciparum, and $38(23.4 \%)$ to P. falciparum-P. vivax mixed infections.

\section{Performance of RDT and Microscopic Examination Compared with PCR}

We compared the performance of RDT and microscopic examination for the diagnosis of malaria using PCR as the reference method. Of 162 cases positive by PCR, 55 (33.9\%) were negative by RDT, and of 291 negative by PCR, 1 (0.3\%) was positive by RDT. In terms of RDT detecting "non- $P$. falciparum only" infections, sensitivity was $63.3 \%$, specificity was $99.3 \%$, positive predictive value was $98.0 \%$, and negative predictive value was 83.5\% (Table 3). In comparison, microscopic examination had $82.9 \%$ sensitivity, $96.9 \%$ specificity, $93.6 \%$ positive predictive value, and $91.4 \%$ negative predictive value for detecting $P$. vivax. In terms of RDT detecting any Plasmodium species, sensitivity was $66.0 \%$ and specificity was $99.7 \%$. Of 162 PCR-positive cases, 14 (8.6\%) were negative by microscopic examination, and of 291 PCRnegative cases, 6 (2.1\%) were positive by microscopic examination. In comparison, microscopic examination had $91.4 \%$ sensitivity and $97.9 \%$ specificity in detecting any Plasmodium species.

The sensitivity of RDT and microscopic examination was low in our study, mainly because of low parasitemia levels. Overall, regardless of the different plasmodial species, parasitemia was significantly higher in true positives than in false negatives diagnosed by RDT $\left(\mathrm{p}=2.6 \times 10^{-8}\right)$. Parasite density among $P$. vivax-infected patients ranged from 12 to 84,800 asexual parasites $/ \mu \mathrm{L}$ of blood with a geometric mean of 1,450 parasites $/ \mu \mathrm{L}$ of blood. Among the 100 true positives detected by RDT, the geometric mean parasitemia of $P$. vivax with or without $P$. falciparum was 2,410 asexual parasites/ $\mu \mathrm{L}$ (range $12-84,800$ asexual parasites $/ \mu \mathrm{L}$ ), and 11 were negative by microscopic examination. By contrast, the geometric mean parasitemia among the 58 false negatives was 251 asexual parasites/ $\mu \mathrm{L}$ (range $40-2,840$ asexual parasites $/ \mu \mathrm{L}$ ), and 5 were negative by 
Table 1. Demographic characteristics of malaria study population, Atar, northern Mauritania, 2015-2016

\begin{tabular}{|c|c|c|c|}
\hline \multirow[b]{2}{*}{ Characteristic } & \multicolumn{3}{|c|}{ No. (\%) patients } \\
\hline & 2015 & 2016 & 2015-2016 \\
\hline \multicolumn{4}{|l|}{ Sex } \\
\hline $\mathrm{F}$ & $111(47.2)$ & $98(45.0)$ & $209(46.1)$ \\
\hline $\mathrm{M}$ & $124(52.8)$ & $120(55.0)$ & 244 (53.9) \\
\hline \multicolumn{4}{|l|}{ Age group, y } \\
\hline$<5$ & $18(7.7)$ & $14(6.4)$ & $32(7.1)$ \\
\hline $5-9$ & $14(6.0)$ & 24 (11.0) & $38(8.4)$ \\
\hline $10-14$ & $19(8.1)$ & $19(8.7)$ & $38(8.4)$ \\
\hline $15-19$ & $33(14.0)$ & $17(7.8)$ & $50(11.0)$ \\
\hline$\geq 20$ & $151(64.3)$ & $144(66.1)$ & $295(65.1)$ \\
\hline \multicolumn{4}{|l|}{ Ethnicity } \\
\hline White Moors & $191(81.3)$ & $161(73.9)$ & $352(77.7)$ \\
\hline Black Moors* & $37(15.7)$ & $52(23.9)$ & $89(19.6)$ \\
\hline Black Africans & $5(2.1)^{\prime}$ & $5(2.3)$ & $10(2.2)$ \\
\hline Foreigners $†$ & $2(0.9)$ & 0 & $2(0.4)$ \\
\hline Total & $235(100)$ & $218(100)$ & $453(100)$ \\
\hline \multicolumn{4}{|c|}{$\begin{array}{l}{ }^{*} \text { Comparison between } 2015 \text { and } 2016 \text { showed that only the proportion of Black Moors was statistically significant }(p<0.05) \text {. The term black Africans refers } \\
\text { to ethnic groups (Soninke and Pular [also known as Peul]) of African origin in Mauritania. } \\
\text { tIncludes } 1 \text { expatriate from India and } 1 \text { from Mali (Bambara ethnicity). }\end{array}$} \\
\hline
\end{tabular}

microscopic examination. As for 6 cases of $P$. falciparum only infection according to RDT (i.e., having a positive Pf band and negative Pan band), parasitemia ranged from 40 to 440 asexual parasites/ $\mu \mathrm{L}(\mathrm{n}=3)$ or was negative $(\mathrm{n}=3)$ by microscopic examination. Among RDT-positive cases with a positive Pf band and positive Pan band ( $P$. falciparum with or without non-P. falciparum), 6 were negative by microscopic examination and 3 had relatively low parasitemias $(<2,000$ asexual parasites $/ \mu \mathrm{L})$. Furthermore, parasite density was not significantly correlated with the age of patients $(r=0.03 ; p=0.28)$. We observed very good agreement between microscopic examination and PCR ( $\kappa$ coefficient 0.95 [95 CI\% 0.92-0.98]), good agreement between RDT and PCR ( $\kappa$ coefficient 0.72 [95 CI\% $0.65-0.78]$ ), and moderate agreement between microscopic examination and RDT ( $\kappa$ coefficient 0.61 [95\% CI 0.54-0.69]).

\section{Seasonality of Malaria}

PCR-positive malaria cases were detected throughout the study period, except in June, July, and October 2016, during which no malaria cases were detected (Figure 2). In 2015, malaria cases were detected more frequently than in 2016 (121 cases in 2015 vs. 42 in 2016). Although rainfall occurred for 3 months (August-October) in 2015 and 2 months (August-September) in 2016, we observed no correlation between amount of rainfall and monthly cases of malaria ( $>0.05)$.

\section{Ethnicity, Travel History, and Bed Net Use}

Malaria cases were observed in all ethnic groups, including $P$. vivax in 6 black Africans (Table 4). Travel history was reported by $202 / 435$ (46.4\%) febrile patients (233 patients had no history of travel and data were missing for 18 patients). Of 162 PCR-positive malaria patients, travel history was available for 151, of whom 48 (31.8\%) reported they had never traveled outside Atar and the neighboring oases, 10 (6.6\%) had traveled to non-malaria endemic northern Saharan regions of the country, and 93 (61.6\%) had a travel history in malaria-endemic regions within the previous 6 months (Table 5). Of the 93 patients with a travel history to malaria-endemic regions, 55 (59.1\%) patients (48 with $P$. vivax infection and 7 with $P$. falciparum- $P$. vivax mixed infections) stayed recently in Nouakchott. Twenty of 42 (47.6\%) patients infected with $P$. falciparum with or without $P$. vivax had a travel history to malaria-endemic areas (including 2 patients who traveled to Côte d'Ivoire) within 6 months before consultation, whereas $6 / 42$ patients had missing data on travel history. Sixteen PCR-positive $P$. falciparum-infected patients (either pure $[\mathrm{n}=3]$ or P. falciparum-P. vivax mixed [n $=13]$ infections) occurred in patients who had never traveled outside Atar and the neighboring oases; 2 patients were $5-9$ years of age, 2 were $10-15$ years of age, and 12 were $>15$ years of age.

Information on bed net use was obtained from 305 patients, 104 (34.1\%) of whom had PCR-confirmed malaria. None of the febrile patients in the always group had malaria.

\begin{tabular}{|c|c|c|}
\hline Plasmodium spp. & $\begin{array}{l}\text { Microscopic } \\
\text { examination }\end{array}$ & PCR \\
\hline P. vivax & 140 & $120(74.1)$ \\
\hline P. falciparum & $4(2.6)$ & $4(2.5)$ \\
\hline P. falciparum-P. vivax & 0 & $38(23.4)$ \\
\hline P. ovale & $10(6.5)$ & 0 \\
\hline Proportions of positive results & $154 / 453(34.0)$ & $162 / 453(35.8)$ \\
\hline \multicolumn{3}{|c|}{$\begin{array}{l}{ }^{*} \text { Results are expressed as the number of malaria-positive samples and the } \\
\text { proportions of malaria species among } 154 \text { samples positive by } \\
\text { microscopic examination and } 162 \text { samples positive by PCR. Proportions of } \\
\text { positive results denote the number of malaria-positive samples among all } \\
\text { tested samples }(n=453) \text {. Rapid diagnostic tests were positive in a total of } \\
108 / 453(23.8 \%) \text { patients and detected } 92 / 108(85.2 \%) \text { non- } P \text {. falciparum } \\
\text { only (i.e., } P \text {. vivax, } P \text {. ovale, and/or } P \text {. malariae) and } 16 / 108(14.8 \%) P . \\
\text { falciparum present }(P \text {. falciparum with or without } P \text {. vivax). PCR did not } \\
\text { detect any } P \text {. ovale or } P \text {. malariae. }\end{array}$} \\
\hline
\end{tabular}


Table 3. Performance of rapid diagnostic testing and microscopic examination in establishing malaria diagnosis in 453 febrile patients, using PCR as reference standard, Atar, northern Mauritania, 2015-2016*

\begin{tabular}{|c|c|c|c|c|c|c|}
\hline \multirow[b]{3}{*}{ Performance } & \multicolumn{6}{|c|}{$\%(95 \% \mathrm{Cl}) \dagger$} \\
\hline & \multicolumn{3}{|c|}{ Rapid diagnostic test } & \multicolumn{3}{|c|}{ Microscopic examination } \\
\hline & $\mathrm{PV}$ & $\mathrm{Pf}$ & $\mathrm{PV}-\mathrm{Pf}$ & PV & $\mathrm{Pf}$ & Pv-Pf \\
\hline Sensitivity & $63.3(55.3-70.8)$ & $28.6(15.7-44.6)$ & $66.0(58.2-73.3)$ & $82.9(76.1-88.4)$ & $4.8(0.6-16.2)$ & $91.4(85.9-95.2)$ \\
\hline Specificity & $99.3(97.6-99.9)$ & $99.0(97.5-99.7)$ & $99.7(98.1-99.9)$ & $96.9(94.3-98.6)$ & 99.5 (98.3-99.9) & 97.9 (95.6-99.2) \\
\hline PPV & $98.0(92.6-99.5)$ & $75.0(50.3-89.9)$ & $99.1(93.8-99.9)$ & $93.6(88.4-96.5)$ & $50.0(12.6-87.4)$ & $96.1(91.8-98.2)$ \\
\hline NPV & $83.5(80.4-86.1)$ & $93.1(91.8-94.3)$ & $84.1(81.0-86.7)$ & $91.4(88.2-93.7)$ & $91.1(90.5-91.6)$ & $95.3(92.5-97.1)$ \\
\hline Accuracy & 86.8 (83.3-89.7) & $92.5(89.7-94.7)$ & $87.6(84.2-90.5)$ & $92.1(89.2-94.4)$ & $90.7(87.7-93.2)$ & $95.6(93.3-97.3)$ \\
\hline & & falciparum plus & & ositive pr & & ivax plus mixed $P$. \\
\hline
\end{tabular}

The frequent use of bed nets (observed in the always and often groups in contrast with the seldom and never groups) protected against malaria infection (odds ratio 0.31 [95\% CI $0.17-0.54] ; \mathrm{p}=0.00001)$.

\section{Discussion}

Northern Mauritania is part of the Sahara, the great desert that lies between sub-Saharan Africa, where P. falciparum malaria is highly endemic, and the northernmost zone along the Mediterranean Sea, where malaria was eliminated decades ago. In the Sahara, oases are the main agro-ecologic environment suitable for malaria transmission. In Mauritania, the number of oases in the Adrar region increased by 140\%, from 31 in 1984 to 75 in 2012, because of the development of hydro-agricultural projects (4). These oases are also the site of increasing tourism by thousands of Mauritanians who visit the Mauritanian Adrar every year during June-August for Guetna, the Arabic name for the season when date palm fruit are harvested, and the return of foreign tourists, particularly from Europe, after a 10-year collapse in tourism. Furthermore, oases in the Sahara constitute a transit zone for thousands of migrants from sub-Saharan Africa on their way to

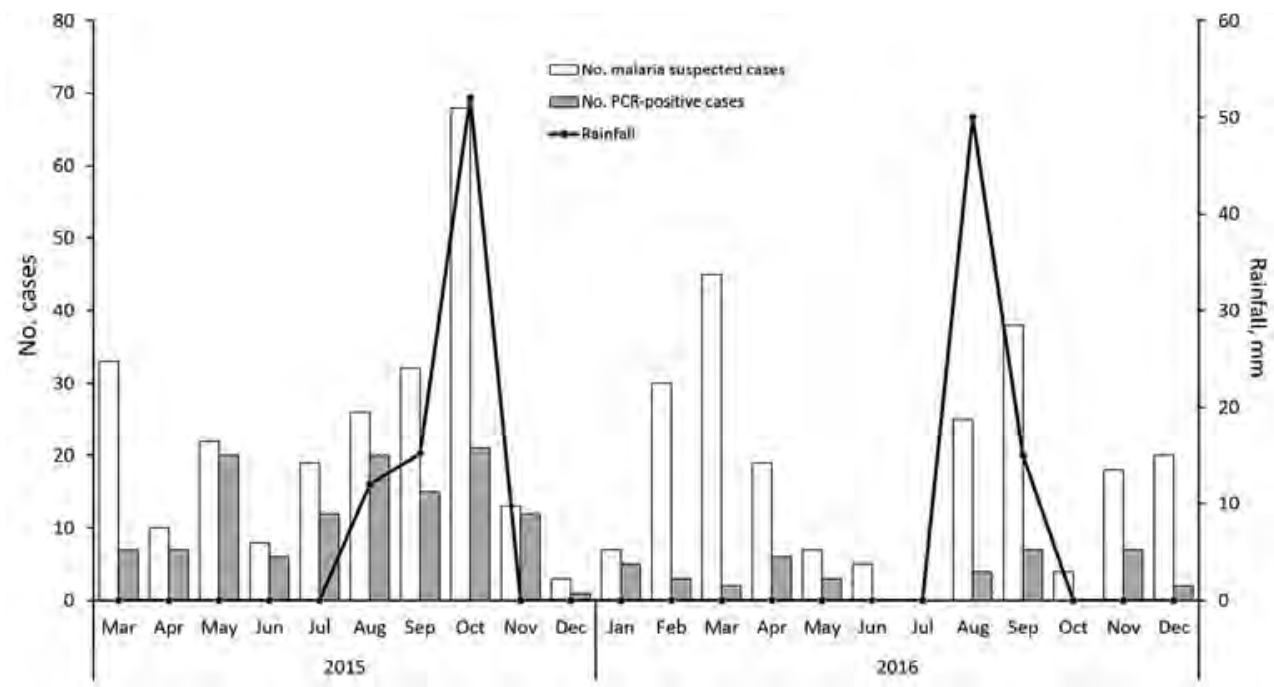

Maghreb countries (countries in North Africa bordering the Mediterranean Sea) and Europe.

Despite the potential risk for malaria transmission, limited data are available on oasis malaria in the Sahara (13-17). In our study, the predominant Plasmodium species found in the population was $P$. vivax, which affected persons of the major ethnic groups present in the country. This finding is consistent with the results of earlier studies conducted in Nouakchott, the capital city of Mauritania situated in the Sahara $(18,19)$. Those studies showed that most $P$. vivax malaria-infected patients were Duffy-positive white Moorish persons. In our study, we also observed $P$. vivax infections among malaria-positive patients of black Moorish and black African ethnicities. Many recent reports, particularly from sub-Saharan Africa countries and Madagascar, also showed that $P$. vivax can infect Duffy-negative black African persons, although at low frequencies (20-22). The existence of a second distinct $P$. vivax erythrocyte-binding protein, which most likely mediates parasite invasion of the reticulocyte, was recently suggested (23).

The origin of $P$. vivax in Mauritania, particularly in the Saharan zone, is not yet clear. Several foci of $P$. vivax
Figure 2. Frequency and monthly distribution of malaria cases diagnosed by using PCR and rainfall amounts in Atar, northern Mauritania, 2015-2016. 
Table 4. Malaria prevalence in 453 febrile patients, by ethnicity, Atar, northern Mauritania, 2015-2016

\begin{tabular}{|c|c|c|c|c|c|}
\hline \multirow[b]{2}{*}{ Ethnicity } & \multirow[b]{2}{*}{ No. patients } & \multirow[b]{2}{*}{ PCR-positive, no. (\%) } & \multicolumn{3}{|c|}{ Plasmodium spp., no. (\%) } \\
\hline & & & P. vivax & P. falciparum & Mixed infection* \\
\hline White Moors & 352 & $129(36.6)$ & $96(74.4)$ & $4(3.1)$ & $29(22.5)$ \\
\hline Black Moors & 89 & $26(29.2)$ & 19 (73.1) & 0 & $7(26.9)$ \\
\hline Black Africans & 10 & $6 †(60.0)$ & $5(83.3)$ & 0 & $1(16.7)$ \\
\hline Foreigners & $2 \ddagger$ & $1(50.0)$ & 0 & 0 & $1(100)$ \\
\hline Total & 453 & $162(35.8)$ & $120(74.1)$ & $4(2.5)$ & $38(23.5)$ \\
\hline
\end{tabular}

were present in parts of Morocco, a country north of Mauritania, but malaria was eliminated from Morocco in 2010 (24). Active foci of $P$. vivax malaria transmission still exist in Algeria, albeit at a very low prevalence (13), and recent reports suggest that the goal of malaria elimination might soon be achieved in Algeria (2). Recently, P. vivax infections were reported from Mali and Senegal, 2 neighboring countries to the east and southeast of Mauritania, in symptomatic patients and in asymptomatic children $(22,25,26)$. More surprisingly, recent evidence showed that $P$. vivax is present in some countries of central Africa, such as Cameroon (21), and that extensive molecular investigations might show that $P$. vivax prevalence in Africa is much higher than previously assumed $(27,28)$. Elsewhere in eastern Africa, such as Sudan (29), Ethiopia (30), and Madagascar (20), P. vivax malaria has been known to exist.

We report that $P$. falciparum also has been diagnosed among febrile patients permanently residing in Atar, albeit at a relatively low rate, a finding that is consistent with previous studies on the geographic distribution of Plasmodium species in Mauritania (31-34). However, the data in our study suggest that $P$. falciparum might have been introduced to Atar by travelers visiting malaria-endemic regions to the south. As far as $P$. falciparum in Atar is concerned, further studies are required to establish whether local transmission of this Plasmodium species occurs. It is worth noting that autochthonous $P$. falciparum malaria was already reported in a village in the Algerian Sahara near the Algeria-Mali border (35).

The sensitivity of RDT and microscopic examination was low in our study. For P. vivax, Plasmodium genusspecific lactate dehydrogenase RDT has low sensitivity to detect this parasite species at low parasitemia levels (36).
Relatively few patients were infected with $P$. falciparum with or without $P$. vivax, and these infections were rarely diagnosed correctly by laboratory technicians, which can lead to problems in the management of symptomatic patients, even with the use of RDT in case of low parasitemia levels. Microscopic examination also misdiagnosed 10 samples as $P$. ovale. PCR showed that these cases were actually $P$. vivax or mixed $P$. vivax-P. falciparum infections. $P$. ovale and $P$. vivax are notoriously difficult to distinguish morphologically by microscopic examination, and accurate identification requires an experienced microscopist, relevant clinical information, and up-to-date epidemiologic data. PCR findings in our study further confirm the results of earlier studies conducted in Nouakchott and some cities in southern Mauritania, indicating that $P$. ovale has not yet been detected by PCR in Mauritania $(3,31)$.

In areas of intense $P$. falciparum transmission, parasite density and age are negatively correlated; children $<5$ years of age are generally infected with higher parasite density than older children and adults (37). In our study, no significant correlation was observed between $P$. vivax parasite density and the age of malaria patients. Similar findings were reported from studies conducted in the Malian Sahara $(14,16)$, suggesting unstable malaria transmission in which adults do not acquire protective immunity because of a lack of continuous exposure to infective bites of the Anopheles mosquito vectors. In Atar, malaria cases were reported throughout the year. At least some of these $P$. vivax cases might be attributable to recurrent infections that result from reactivation of hypnozoites in the liver, which are considered important contributing factors to disease in $P$. vivax infections, accounting for as many as $50 \%$ of $P$. vivax infections in some reports $(38,39)$.

\begin{tabular}{lcccc}
\hline \multicolumn{5}{c}{ Table 5. Travel history of malaria-infected patients, by age group, Atar, northern Mauritania, 2015-2016* } \\
\hline \multicolumn{4}{c}{ No. PCR-positive patients } \\
\cline { 2 - 4 } Age group, y & No travel history & Travel to nonendemic regions & Travel to endemic regions $\dagger$ & Total no. (\%) \\
\hline$<5$ & 2 & 0 & 5 & $7(4.6)$ \\
$5-9$ & 3 & 0 & 0 & $3(2.0)$ \\
$10-15$ & 8 & 0 & 72 & $20(13.2)$ \\
$>15$ & 35 & 10 & $93(61.6)$ & $121(80.1)$ \\
Total, no. (\%) & $48(31.8)$ & $10(6.6)$ & $151(100)$ & \\
\hline
\end{tabular}

${ }^{*}$ Travel history within 6 months before consultation was obtained for 435 febrile patients. Of 162 PCR-positive malaria patients, travel history was available for 151 patients.

†Endemic regions include Nouakchott, the entire southern Sahelian zone of Mauritania, and sub-Saharan Africa countries. 
Alternatively, these cases might be primo-infections and $P$. vivax transmission occurs throughout the year. Autochthonous transmission does occur in Atar, at least during some periods of the year, evidenced by the high number of PCR-confirmed malaria-infected patients who did not report any travel history.

No entomologic evidence exists to indicate that malaria transmission occurs in the oasis setting of Atar. Nevertheless, the protection provided by regular use of bed nets supports the hypothesis that local transmission is occurring. Moreover, the presence of numerous natural water bodies (e.g., rain puddles, small and large ponds locally known as Guelta, and small brooks) and artificial water bodies (e.g., shallow wells, open-pit cement containers, and palm irrigation channels) might serve as breeding habitats for Anopheles mosquitoes. However, water in these potential habitats is generally brackish and often covered with filamentous algae (40). During the study period, the An. rhodesiensis mosquito was the only Anopheles mosquito species collected during both larval and adult surveys (K. Mint Lekweiry, unpub. data). The vector capacity of An. rhodesiensis mosquitoes in Atar is not yet established. The An. rhodesiensis mosquito is considered a secondary malaria vector despite sporadic reports of sporozoite positivity in several geographic areas before $1950(41,42)$. However, its capacity to sustain the development and propagation of Plasmodium spp. cannot be ruled out. Currently available data suggest that the northernmost range limits of the major continental Africa vector, the An. arabiensis mosquito, in Mauritania is Rachid oasis in the province of Tagant, located $\approx 250 \mathrm{~km}$ south of Atar (43). Thus, concern that the recently constructed national road that connects Rachid oasis to Atar might increase the risk for introducing An. arabiensis mosquitoes or other malaria vectors in Atar is warranted.

Although characterized by extreme aridity and low rainfall, $P$. vivax and, to a much lesser extent, $P$. falciparum malaria are present in Atar. Because our data were obtained from a hospital-based study and the numbers of asymptomatic carriers and symptomatic malaria-infected patients who self-medicate with antimalarial drugs or consult the private sector are unknown, the actual malaria burden is probably underestimated. Further entomologic and parasitologic studies are needed to assess the vector capacity of An. rhodesiensis mosquitoes and identify the main malaria vector (or vectors) in Atar. Moreover, regular monitoring of malaria in the Saharan zone, including in other oases, should be implemented.

\section{Acknowledgments}

We thank the patients who participated in the study and the clinical and laboratory staff of Hospital Center of Atar for facilitating patient recruitment.
This research was supported by the Expertise France (Initiative 5\% Project) and Institut de Recherche pour le Développement. J.D. was supported by a doctoral grant from the government of France through the French Embassy in Nouakchott.

\section{About the Author}

Miss Deida is a doctoral student at the University of Nouakchott Al-Aasriya and Université Paris Descartes. Her research interest includes malaria epidemiology and drug-resistant malaria.

\section{References}

1. Mauritania National Statistics Office. General population and housing census, 2013 [in French]. 2013 [cited 2018 Jun 11]. http://www.ons.mr/index.php/publications/operations-statistiques/ 16-rgph-2013

2. World Health Organization. World malaria report 2017. 2017 [cited 2018 Dec 5]. https://www.who.int/malaria/publications/ world-malaria-report-2017

3. Ould Ahmedou Salem MS, Mohamed Lemine YO, Deida JM, Lemrabott MA, Ouldabdallahi M, Ba MDD, et al. Efficacy of chloroquine for the treatment of Plasmodium vivax in the Saharan zone in Mauritania. Malar J. 2015;14:39. http://dx.doi.org/10.1186/ s12936-015-0563-0

4. Oases Sustainable Development Programme. Provisional report on the census of date palms [in French]. Nouakchott (Mauritania): Ministry of Rural Development; 2012.

5. World Health Organization. Guidelines for the treatment of malaria. 3rd edition. 2015 [cited 2018 Dec 5]. https://www.who.int/malaria/ publications/atoz/9789241549127

6. World Health Organization. Assessment and monitoring of antimalarial drug efficacy for the treatment of uncomplicated falciparum malaria. 2003 [cited 2018 Dec 5]. https://www.who.int/ malaria/publications/atoz/whohtmrbm200350

7. Plowe CV, Djimde A, Bouare M, Doumbo O, Wellems TE. Pyrimethamine and proguanil resistance-conferring mutations in Plasmodium falciparum dihydrofolate reductase: polymerase chain reaction methods for surveillance in Africa. Am J Trop Med Hyg. 1995;52:565-8. http://dx.doi.org/10.4269/ajtmh.1995.52.565

8 Canier L, Khim N, Kim S, Sluydts V, Heng S, Dourng D, et al. An innovative tool for moving malaria PCR detection of parasite reservoir into the field. Malar J. 2013;12:405. http://dx.doi.org/10.1186/1475-2875-12-405

9. Cohen J. A coefficient of agreement for nominal scales. Educ Psychol Meas. 1960;20:27-46. http://dx.doi.org/10.1177/ 001316446002000104

10. Fermanian J. Measurement of agreement between 2 judges. Qualitative cases [in French]. Rev Epidemiol Sante Publique. 1984;32:140-7.

11. Altman DG. Practical statistics for medical research. London: Chapman and Hall; 1991.

12. R Core Team. R: A language and environment for statistical computing. Vienna (Austria): R Foundation for Statistical Computing; 2018 [cited 2018 Dec 5]. https//:www.R-project.org

13. Hammadi D, Boubidi SC, Chaib SE, Saber A, Khechache Y, Gasmi M, et al. Malaria in Algerian Sahara [in French]. Bull Soc Pathol Exot. 2009; 102:185-92.

14. Doumbo O, Koita O, Traoré S, Sangaré O, Coulibaly A, Robert V, et al. Parasitological aspects of the epidemiology of malaria in the Malian Sahara [in French]. Med Afr Noire. 1991;38:103-9.

15. Develoux M, Chegou A, Prual A, Olivar M. Malaria in the oasis of Bilma, Republic of Niger. Trans R Soc Trop Med Hyg. 1994;88:644. http://dx.doi.org/10.1016/0035-9203(94)90206-2 
16. Koita OA, Sangaré L, Sango HA, Dao S, Keita N, Maiga M, et al. Effect of seasonality and ecological factors on the prevalence of the four malaria parasite species in northern Mali. J Trop Med. 2012;2012:367160.

17. Bernabeu M, Gomez-Perez GP, Sissoko S, Niambélé MB, Haibala AA, Sanz A, et al. Plasmodium vivax malaria in Mali: a study from three different regions. Malar J. 2012;11:405. http://dx.doi.org/10.1186/1475-2875-11-405

18. Wurtz N, Mint Lekweiry K, Bogreau H, Pradines B, Rogier C, Ould Mohamed Salem Boukhary A, et al. Vivax malaria in Mauritania includes infection of a Duffy-negative individual. Malar J. 2011;10:336. http://dx.doi.org/10.1186/1475-2875-10-336

19. Mint Lekweiry K, Ould Mohamed Salem Boukhary A, Gaillard T, Wurtz N, Bogreau H, Hafid JE, et al. Molecular surveillance of drug-resistant Plasmodium vivax using pvdhfr, pvdhps and pvmdr1 markers in Nouakchott, Mauritania. J Antimicrob Chemother. 2012;67:367-74. http://dx.doi.org/10.1093/jac/dkr464

20. Ménard D, Barnadas C, Bouchier C, Henry-Halldin C, Gray LR, Ratsimbasoa A, et al. Plasmodium vivax clinical malaria is commonly observed in Duffy-negative Malagasy people. Proc Natl Acad Sci U S A. 2010;107:5967-71. http://dx.doi.org/10.1073/ pnas.0912496107

21. Russo G, Faggioni G, Paganotti GM, Djeunang Dongho GB, Pomponi A, De Santis R, et al. Molecular evidence of Plasmodium vivax infection in Duffy negative symptomatic individuals from Dschang, West Cameroon. Malar J. 2017;16:74. http://dx.doi.org/ 10.1186/s12936-017-1722-2

22. Niangaly A, Karthigayan Gunalan, Amed Ouattara, Coulibaly D, Sá JM, Adams M, et al. Plasmodium vivax infections over 3 years in Duffy blood group negative Malians in Bandiagara, Mali. Am J Trop Med Hyg. 2017;97:744-52. http://dx.doi.org/10.4269/ ajtmh.17-0254

23. Ntumngia FB, Thomson-Luque R, Torres LM, Gunalan K, Carvalho LH, Adams JH. A novel erythrocyte binding protein of Plasmodium vivax suggests an alternate invasion pathway into Duffy-positive reticulocytes. MBio. 2016;7:e01261-16. http://dx.doi.org/10.1128/mBio.01261-16

24. World Health Organization. Eliminating malaria. 2016 [cited 2018 Dec 5]. https://www.who.int/malaria/publications/atoz/ eliminating-malaria

25. Niang M, Thiam LG, Sow A, Loucoubar C, Bob NS, Diop F, et al. A molecular survey of acute febrile illnesses reveals Plasmodium vivax infections in Kedougou, southeastern Senegal. Malar J. 2015;14:281. http://dx.doi.org/10.1186/s12936-015-0808-y

26. Niang M, Diop F, Niang O, Sadio BD, Sow A, Faye O, et al. Unexpected high circulation of Plasmodium vivax in asymptomatic children from Kédougou, southeastern Senegal. Malar J. 2017;16:497. http://dx.doi.org/10.1186/s12936-017-2146-8

27. Howes RE, Battle KE, Mendis KN, Smith DL, Cibulskis RE, Baird JK, et al. Global epidemiology of Plasmodium vivax. Am J Trop Med Hyg. 2016;95(Suppl):15-34. http://dx.doi.org/10.4269/ ajtmh.16-0141

28. Zimmerman PA. Plasmodium vivax infection in Duffy-negative people in Africa. Am J Trop Med Hyg. 2017;97:636-8. http://dx.doi.org/10.4269/ajtmh.17-0461

29. Osman MMM, Nour BYMN, Sedig MF, De Bes L, Babikir AM, Mohamedani AA, et al. Informed decision-making before changing to RDT: a comparison of microscopy, rapid diagnostic test and molecular techniques for the diagnosis and identification of malaria parasites in Kassala, eastern Sudan. Trop Med Int Health. 2010;15:1442-8. http://dx.doi.org/10.1111/j.1365-3156. 2010.02659.x

30. Lo E, Hemming-Schroeder E, Yewhalaw D, Nguyen J, Kebede E, Zemene E, et al. Transmission dynamics of co-endemic Plasmodium vivax and $P$. falciparum in Ethiopia and prevalence of antimalarial resistant genotypes. PLoS Negl Trop Dis. 2017;11:e0005806 https://doi.org/10.1371/journal.pntd.0005806. http://dx.doi.org/10.1371/journal.pntd.0005806

31. Lekweiry KM, Basco LK, Salem MS, Hafid JE, Marin-Jauffre A, Weddih AO, et al. Malaria prevalence and morbidity among children reporting at health facilities in Nouakchott, Mauritania. Trans R Soc Trop Med Hyg. 2011;105:727-33. http://dx.doi.org/ 10.1016/j.trstmh.2011.09.004

32. Ba H, Duffy CW, Ahouidi AD, Deh YB, Diallo MY, Tandia A, et al. Widespread distribution of Plasmodium vivax malaria in Mauritania on the interface of the Maghreb and West Africa. Malar J. 2016;15:80. http://dx.doi.org/10.1186/s12936-016-1118-8

33. Ouldabdallahi Moukah M, Ba O, Ba H, Ould Khairy ML, Faye O, Bogreau $\mathrm{H}$, et al. Malaria in three epidemiological strata in Mauritania. Malar J. 2016;15:204. http://dx.doi.org/10.1186/ s12936-016-1244-3

34. Ould Ahmedou Salem MS, Mint Lekweiry K, Bouchiba H, Pascual A, Pradines B, Ould Mohamed Salem Boukhary A, et al. Characterization of Plasmodium falciparum genes associated with drug resistance in Hodh Elgharbi, a malaria hotspot near Malian-Mauritanian border. Malar J. 2017;16:140. http://dx.doi.org/10.1186/s12936-017-1791-2

35. Boubidi SC, Gassen I, Khechache Y, Lamali K, Tchicha B, Brengues C, et al. Plasmodium falciparum malaria, southern Algeria, 2007. Emerg Infect Dis. 2010;16:301-3. http://dx.doi.org/ 10.3201/eid1602.090914

36. Jang JW, Cho CH, Han ET, An SSA, Lim CS. pLDH level of clinically isolated Plasmodium vivax and detection limit of pLDH based malaria rapid diagnostic test. Malar J. 2013;12:181. http://dx.doi.org/10.1186/1475-2875-12-181

37. Smith T, Charlwood JD, Kihonda J, Mwankusye S, Billingsley P, Meuwissen J, et al. Absence of seasonal variation in malaria parasitaemia in an area of intense seasonal transmission. Acta Trop. 1993;54:55-72. http://dx.doi.org/10.1016/0001-706X(93)90068-M

38. Betuela I, Rosanas-Urgell A, Kiniboro B, Stanisic DI, Samol L, de Lazzari E, et al. Relapses contribute significantly to the risk of Plasmodium vivax infection and disease in Papua New Guinean children 1-5 years of age. J Infect Dis. 2012;206:1771-80. http://dx.doi.org/10.1093/infdis/jis580

39. Chu CS, White NJ. Management of relapsing Plasmodium vivax malaria. Expert Rev Anti Infect Ther. 2016;14:885-900. http://dx.doi.org/10.1080/14787210.2016.1220304

40. Hamon J, Maffi M, Grenier P, Ouedraogo CS, Djime D. Note on the mosquitoes of the Islamic Republic of Mauritania (first part) [in French]. Ann Soc Entomol Fr. 1964;69:233-53.

41. De Meillon B. Species and subspecies of vectors and their bionomics. 1950 [cited 2018 Dec 5]. http://apps.who.int/iris/ bitstream/handle/10665/64147/WHO_Mal_54.pdf

42. Kyalo D, Amratia P, Mundia CW, Mbogo CM, Coetzee M, Snow RW. A geo-coded inventory of anophelines in the Afrotropical Region south of the Sahara: 1898-2016. Wellcome Open Res. 2017;2:57. http://dx.doi.org/10.12688/ wellcomeopenres.12187.1

43. Mint Mohamed Lemine A, Ould Lemrabott MA, Hasni Ebou M, Mint Lekweiry K, Ould Ahmedou Salem MS, Ould Brahim K, et al. Mosquitoes (Diptera: Culicidae) in Mauritania: a review of their biodiversity, distribution and medical importance. Parasit Vectors. 2017;10:35. http://dx.doi.org/10.1186/ s13071-017-1978-y

Address for correspondence: Ali Ould Mohamed Salem Boukhary, Unité de Recherche Génomes et Milieux (JEAI), Université de Nouakchott Al-Aasriya, PO Box 5026, Nouakchott, Mauritania; email: alimedsalem@gmail.com 


\title{
Macrophage Activation Marker Soluble CD163 Associated with Fatal and Severe Ebola Virus Disease in Humans ${ }^{1}$
}

\author{
Anita K. McElroy, Punya Shrivastava-Ranjan, Jessica R. Harmon, Roosecelis B. Martines, \\ Luciana Silva-Flannery, Timothy D. Flietstra, Colleen S. Kraft, Aneesh K. Mehta, G. Marshall Lyon, \\ Jay B. Varkey, Bruce S. Ribner, Stuart T. Nichol, Sherif R. Zaki, Christina F. Spiropoulou
}

Ebola virus disease (EVD) is associated with elevated cytokine levels, and hypercytokinemia is more pronounced in fatal cases. This type of hyperinflammatory state is reminiscent of 2 rheumatologic disorders known as macrophage activation syndrome and hemophagocytic lymphohistiocytosis, which are characterized by macrophage and T-cell activation. An evaluation of 2 cohorts of patients with EVD revealed that a marker of macrophage activation (sCD163) but not T-cell activation (sCD25) was associated with severe and fatal EVD. Furthermore, substantial immunoreactivity of host tissues to a CD163-specific antibody, predominantly in areas of extensive immunostaining for Ebola virus antigens, was observed in fatal cases. These data suggest that host macrophage activation contributes to EVD pathogenesis and that directed antiinflammatory therapies could be beneficial in the treatment of EVD.

ت bola virus (EBOV) disease (EVD) in humans is fre-1 quently severe and accompanied by fever, signs of endothelial dysfunction, coagulopathy, shock, and multisystem organ dysfunction. Data from nonhuman primate models and human autopsy cases suggest that EVD severity is not a direct effect of tissue damage resulting from destruction of infected cells because only foci of necrosis are observed $(1,2)$. Therefore, a dysregulated immune response has been hypothesized to contribute to disease severity. The elevated levels of inflammatory cytokines and chemokines (e.g., interleukin [IL] 6, IL-8, macrophage inflammatory protein $1 \alpha$ and $1 \beta$, monocyte chemoattractant protein 1 , and

Author affiliations: University of Pittsburgh, Pittsburgh,

Pennsylvania, USA (A.K. McElroy); Centers for Disease Control and Prevention, Atlanta (A.K. McElroy, P. Shrivastava-Ranjan, J.R. Harmon, R.B. Martines, L Silva-Flannery, T.D. Flietstra, S.T. Nichol, S.R. Zaki, C.F. Spiropoulou); Emory University School of Medicine, Atlanta, Georgia, USA (A.K. McElroy, C.S. Kraft, A.K. Mehta, G.M. Lyon, J.B. Varkey, B.S. Ribner)

DOI: https://doi.org/10.3201/eid2502.181326 macrophage colony-stimulating factor) and immunomodulatory cytokines (e.g., IL-10 and IL-1 receptor antagonist) in fatal EVD cases certainly support this hypothesis (3-7). Hypercytokinemia accompanied by severe clinical disease seen in EVD is reminiscent of what has been described for macrophage activation syndrome (MAS) and hemophagocytic lymphohistiocytosis (HLH). The similarities between EVD and HLH have not gone unnoticed by other clinicians; a group in the Netherlands has published an opinion piece suggesting a connection between the 2 diseases (8).

$\mathrm{HLH}$ can occur as a primary genetic disorder or a secondary consequence of another medical condition, including infection (9). Secondary, virus-associated HLH is most commonly reported after Epstein-Barr virus (EBV) infection, and even though EBV infection is exceedingly common (seroprevalence in adults 80\%-90\%) (10), development of EBV-associated HLH is still a rare event, estimated at 0.4 cases/ 1 million population (9). Other hemorrhagic fever viruses, such as Crimean-Congo hemorrhagic fever virus (11) and dengue virus (12), have also been reported to trigger HLH.

MAS is considered a subgroup of HLH that is more commonly seen in patients with underlying systemic juvenile idiopathic arthritis. However, laboratory findings in both disorders are similar and include cytopenias of several cell types; elevated transaminases, soluble IL-2 receptor (sIL-2R), triglycerides, ferritin, soluble CD163 (sCD163), prothrombin time, partial thromboplastin time, and D-dimer; and low fibrinogen (13).

These MAS markers have been examined in patients with dengue. Elevated sCD163 and ferritin were associated with severe dengue, and sIL-2R was elevated in patients with dengue but did not distinguish between patients with severe dengue and dengue fever (14). Dengue-infected

${ }^{1}$ Preliminary results from this study were presented at the American Association of Immunology annual meeting, May 4-8, 2018, Austin, Texas, USA. 
patients also had decreased monocyte-associated CD163 compared with healthy controls, consistent with the increase in sCD163 observed in their serum.

The proliferation and activation of macrophages and $\mathrm{T}$ cells and their secretion of proinflammatory cytokines has been proposed to contribute to the pathogenesis of both HLH and MAS. In addition, activated macrophages are sometimes noted to phagocytose erythrocytes, hence the term hemophagocytosis (13).

T-cell activation during acute EVD is significantly increased (15). EBOV interactions with $\mathrm{T}$ cells in vitro through T-cell immunoglobulin and mucin domain 1 (TIM-1) can promote a cytokine storm (16), and EBOV can activate macrophages in vitro though the toll-like receptor (TLR) 4 pathway (17). In an effort to determine if macrophage or T-cell activation-mediated mechanisms of pathogenesis (similar to those reported for MAS and HLH) could be contributing to EVD pathogenesis, we evaluated for the inflammatory markers present in MAS and HLH in 2 cohorts of patients with EVD.

\section{Methods}

We conducted all work with human samples under approved institutional review board protocols CDC IRB 1652, CDC IRB 6341, CDC IRB 6643, and Emory IRB00076700. Before analysis, we $\gamma$-irradiated all plasma samples with 5 $\times 10^{4} \mathrm{~Gy}$. We measured triglyceride levels using the Triglycerides Enzymatic Assay (XpressBio, https://xpressbio. com) according to the manufacturer's instructions. We measured fibrinogen, ferritin, and sIL-2R as part of a multiplex immunoassay using methods previously described $(3,18)$ and sCD163 using the Human CD163 Quantikine ELISA Kit (R\&D Systems, https://www.rndsystems.com).

We obtained formalin-fixed paraffin-embedded sections of liver, heart, spleen, and testicle specimens from humans who died of EVD, specimens that were obtained from and previously evaluated by the Centers for Disease Control and Prevention (CDC; Atlanta, Georgia, USA) (2). We performed immunohistochemical stains with a mouse monoclonal antibody against CD163 (clone 10D6, dilution 1:50; Leica Biosystems, https://www.leicabiosystems. com) and polyclonal rabbit antibody against EBOV antigen (dilution 1:1,000; CDC) $(19,20)$. We deparaffinized sections in xylene and rehydrated in a graded ethanol series. For double-stained assays, we used the EnVision G|2 Doublestain System, Rabbit/Mouse (DAB+/Permanent Red) (Dako, https://www.agilent.com/en-us/dako-products) and incubated with the CD163 monoclonal antibody and then the EBOV antibody. We performed all assays according to the manufacturers' guidelines. We used 3,3'-diaminobenzidine (DAB) as the chromogen for the monoclonal antibody against CD163 and permanent red as the chromogen for the polyclonal antibody against EBOV. Negative control samples comprised sequential tissue sections obtained from EVD patients that were incubated with normal mouse serum stained in parallel. Also, as another control, we double-stained heart, liver, spleen, and testicle specimens from patients who died of noninfectious etiologies.

We compared biomarker levels between fatal and nonfatal cases using a previously described statistical analysis (3). In brief, we conducted an analysis of variance with use of the Bonferroni inequality and Bejamini and Hochberg false-discovery rate method to correct for multiple testing. Then, we performed model selection using stepwise regression to determine if biomarkers were significantly associated with death at the various time intervals. We performed posthoc Student $t$-tests for each time interval to determine statistical significance between fatal and nonfatal groups for each analyte.

\section{Results}

We compared the laboratory features of EVD with those common in MAS and HLH, including those apart from the MAS and HLH formal diagnostic criteria (21-23). Cytopenia of erythrocytes, platelets, or neutrophils are common in both MAS and HLH (Table) (13). Complete blood counts (with or without differentials) have not been performed with substantial numbers of patients with EVD, with the exception of 2 reports: 1 report on patients cared for in tertiary care settings during the West Africa outbreak (24) and 1 report including $>100$ patients treated during the West Africa outbreak (25). Anemia to the degree seen in HLH does not appear to be common in patients with EVD. In fact, in the large cohort from West Africa, hemoconcentration, rather than anemia, was associated with fatal outcomes (25). Few patients with EVD have thrombocytopenia $<100 \times 10^{3} / \mathrm{mL}$, and in the West Africa cohort, thrombocytopenia was more common in survivors. Neutropenia has been rarely seen in patients with EVD, and neutrophilia, not neutropenia, was associated with fatal outcomes in patients with EVD in West Africa. Neutrophilia could reflect the presence of a complicating secondary bacteremia that has been reported in patients with EVD (29). Therefore, the degrees of cytopenia seen in patients with EVD are more similar to those of MAS than HLH (Table).

A fasting hypertriglyceridemia and hypofibrinogenemia are often seen in HLH and MAS (Table) (23). Triglyceride levels had not been previously reported for EVD, so we measured them in plasma samples from EVD patients in 2 previously reported groups: 86 persons infected with Sudan virus (SUDV) during an outbreak in Gulu, Uganda, during 2000-2001 (3) (Figure 1, panel A) and 4 persons infected with EBOV treated at Emory University Hospital (Atlanta, Georgia, USA) in 2014 who survived (Figure 1, panel B) (18). Triglyceride levels were $>250 \mathrm{mg} /$ dL in severely ill patient EVD9, and in the SUDV-infected 
Table. Laboratory findings of patients with MAS, HLH, or EVD and their association with fatal EVD outcomes*

\begin{tabular}{|c|c|c|c|c|c|}
\hline Laboratory finding & $\begin{array}{c}\text { MAS diagnostic } \\
\text { value }\end{array}$ & $\begin{array}{c}\text { HLH diagnostic } \\
\text { value }\end{array}$ & EVD & $\begin{array}{c}\text { Associated with } \\
\text { fatal EVD outcome }\end{array}$ & References \\
\hline Cytopenia & - & $\geq 2$ cell types & & & \\
\hline Anemia, g/dL & - & $<9$ & Rarely & No & $(24,25)$ \\
\hline Thrombocytopenia, $\times 10^{3} / \mathrm{mL}$ & $\leq 181$ & $<100$ & Sometimes & No & $(24,25)$ \\
\hline Neutropenia, cells/mL & - & $<1,000$ & Rarely & No & $(16,26)$ \\
\hline Hyperferritinemia, $\mathrm{ng} / \mathrm{mL}$ & $>684$ & $\geq 500$ & Yes & Yes & $(3,18)$ \\
\hline Hypofibrinogenemia, mg/dL & $\leq 360$ & $<150$ & Sometimes & Unknown & $(18)$ \\
\hline Hypertriglyceridemia, mg/dL & $>156$ & $\geq 265$ & Sometimes & Yes & This study \\
\hline sIL-2R (sCD25), U/mL & - & $>\overline{2}, 400$ & Yes & No & (18); this study \\
\hline Low or absent NK cell activity & - & - & Yes & Yes & $(27)$ \\
\hline Hemophagocytosis in BM, spleen, or LN & - & - & None reported & & (2) \\
\hline Soluble CD163 & - & - & Yes & Yes & This study \\
\hline Elevated AST/ALT, U/L & $>48$ & - & Yes & Yes & (28) \\
\hline Elevated D-dimer & - & - & Yes & Yes & $(3,18,28)$ \\
\hline
\end{tabular}

cohort, patients with fatal outcomes had significantly higher triglyceride levels, the caveat being that fasting triglyceride levels could not be determined. However, triglyceride levels in these patients do correlate with both severe and fatal disease. In a previous study, fibrinogen levels were measured in an EBOV cohort (18) and reported to be low in all patients, but an association with severity was not demonstrated.

Patients with MAS or HLH often have elevated ferritin (Table). As has been previously reported $(3,18)$, ferritin levels were well above the MAS and HLH criterion in most patients with EVD (Table; Figure 1, panels C, D). Furthermore, high ferritin levels were associated with fatal outcomes in SUDV-infected patients. In fact, exceptionally high ferritin levels $(>10,000 \mathrm{ng} / \mathrm{mL})$, which were seen in many patients with EVD, have been suggested to be an independent predictor of HLH with high sensitivity and specificity (21).

sIL-2R, also known as soluble CD25, a marker of Tcell activation, has been reported to be elevated in HLH and MAS (Table). We also assessed this marker in the same 2 patient cohorts that we previously described. Many SUDVinfected patients had sIL-2R levels well above the upper limit of normal, but the level did not correlate with fatal outcome (Figure 1, panel E); all EBOV-infected patients had elevated levels of sIL-2R, regardless of disease severity, as previously reported (Figure 1, panel F) (18).

Natural killer [NK] cell activity and hemophagocytosis are often altered in HLH and MAS. Flow cytometric evaluation of NK cell populations typically reveals diminished cell numbers and function, and pathologic analysis of bone marrow biopsies or autopsy specimens might reveal evidence of hemophagocytosis. Advanced flow cytometric evaluations of peripheral blood from EBOV-infected patients were published after the West Africa outbreak $(30,31)$, and a study reported lower numbers of total NK cells in patients with fatal cases of EVD (27). Although the activation status of the NK cells detected did not differ between those who survived and those who died, lower numbers of cells would be consistent with overall decreased NK cell activity in patients with fatal EVD. The lack of human bone marrow biopsy and autopsy specimens limited our ability to look for hemophagocytosis in EVD, but a detailed pathology study did not indicate any signs of hemophagocytosis in spleen, lymph node, or bone marrow samples from patients with EVD, although viral inclusions were noted in these tissues, specifically in cells of the mononuclear phagocytic system (2).

Measurement of sCD163, the haptoglobin-hemoglobin scavenger receptor and a marker of macrophage activation, has been examined in several studies of MAS and HLH (32-34). CD163 expression was reported on hemophagocytic macrophages in the skin of patients with $\mathrm{HLH}$, and high serum levels have been noted in patients with HLH and MAS. sCD163 has also been associated with disease severity in hemorrhagic fever with renal syndrome (which occurs after hantavirus infection) and dengue hemorrhagic fever $(14,35)$. We assessed the levels of sCD163 in the blood of patients of the SUDV and EBOV cohorts. In SUDV-infected patients, the sCD163 level was elevated (Figure 1, panel G), and high sCD163 concentration was associated with fatal outcome. The sCD163 level was high in a severely affected EBOV-infected patient (EVD9) who would not have survived without extracorporeal supportive care (Figure 1, panel H). In this patient, the peak in sCD163 occurred 19 days after symptom onset, at a point when the viremia was well controlled, having peaked at day 10 and declined thereafter (18). In fact, a strong negative correlation between viral load and sCD163 level was evident in EVD9 (Spearman correlation coefficient -0.9059$)$. This patient remained critically ill after viral load control, suggesting that the inflammatory response was a substantial contributor to disease manifestation. 
Two other laboratory findings often reported in HLH and MAS are elevated transaminases and D-dimers (Table) (13). Aspartate aminotransferase and D-dimers are elevated in patients with EVD, and elevated levels of these analytes are associated with fatal outcome $(3,28)$.

Given these laboratory findings suggesting an association between macrophage activation and EVD pathogenesis, we performed an analysis for CD163 protein expression with tissues from patients with fatal EVD. Liver sections from patients with fatal EVD showed hepatocyte necrosis, often with minimal inflammation (Figure 2, panel A). Mild-to-moderate small-droplet steatosis and Kupffer cell hyperplasia were also seen. Hepatocytes had characteristic intracytoplasmic eosinophilic inclusions, which were predominantly found in periportal zones and surrounding areas of necrosis.

We performed double-stained immunoassays to assess for colocalization of EBOV and CD163. Double staining confirmed the presence of viral antigens predominantly within hepatocytes and macrophages (Figure 2, panels B-D), as well as increased levels of CD163 in association with viral antigens. The CD163 immunostaining of the myocardium from a fatal case of EVD did not differ substantially from that of a patient who died from a

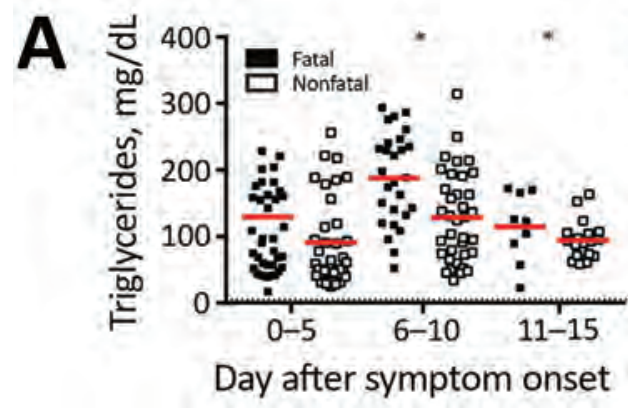

C

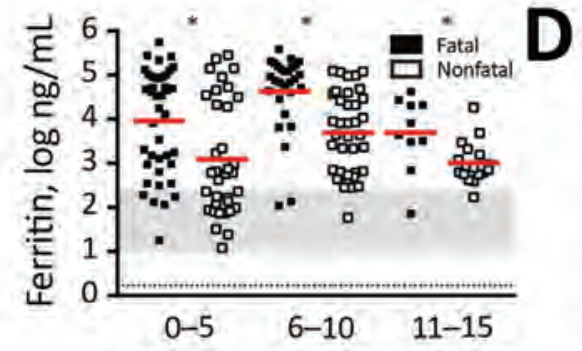

Day after symptom onset
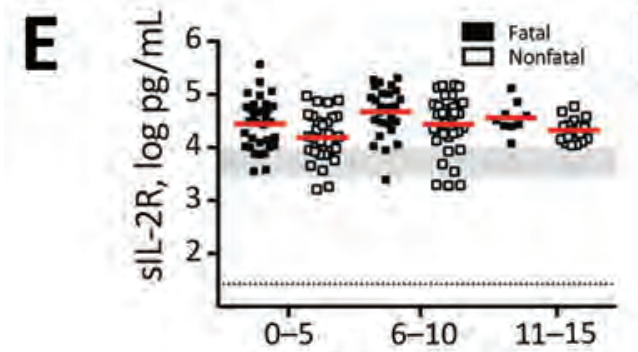

Day after symptom onset

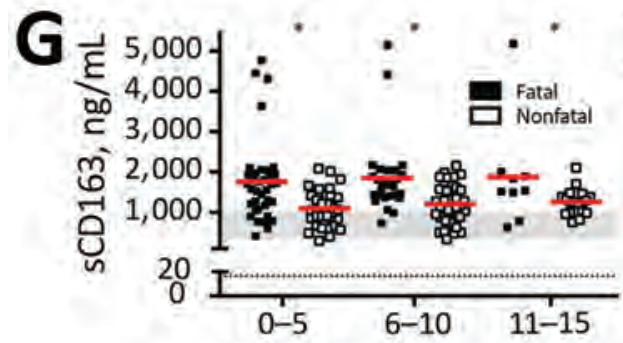

Day after symptom onset
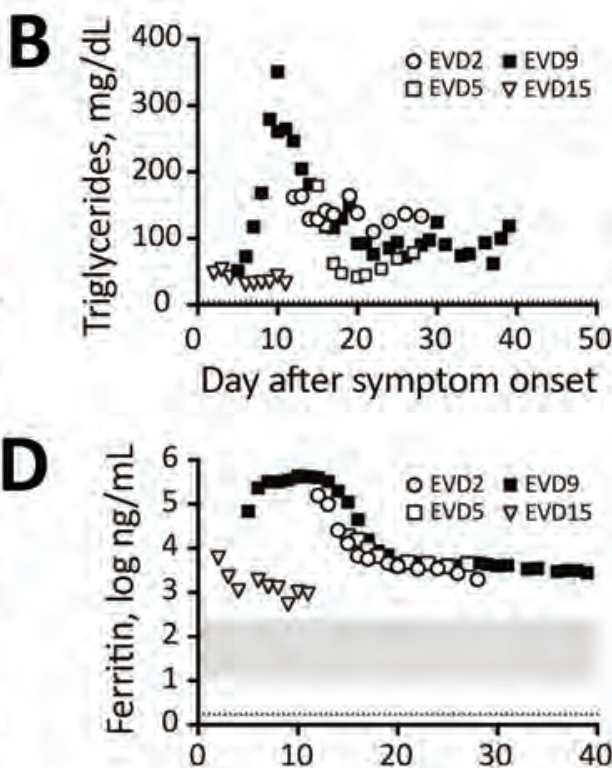

Day after symptom onset

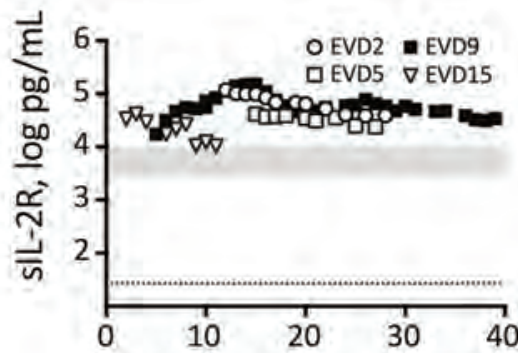

Day after symptom onset
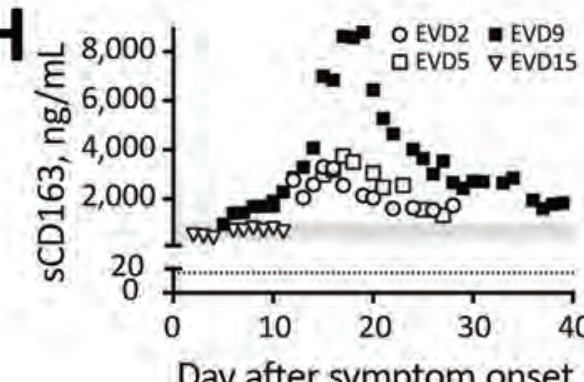

Figure 1. Laboratory findings of patients with EVD that are consistent with laboratory findings in patients with macrophage activation syndrome or hemophagocytic lymphohistiocytosis. A, B) Triglycerides; C, D) ferritin; E, F) sIL-2R; and G, H) sCD163.

Levels were measured in the plasma of a series of 86 Sudan virus-infected patients (left column) or 4 Ebola virusinfected patients (right column). Solid horizontal lines indicate means. Gray shaded areas represent the level of the analyte detected in 10 healthy donors. Dotted lines indicate limit of detection. C) From McElroy AK, Erickson BR, Flietstra TD, Rollin PE, Nichol ST, Towner JS, et al. Ebola hemorrhagic fever: novel biomarker correlates of clinical outcome. J Infect Dis. 2014;210:558-66 (3); reproduced with permission. D, F) From McElroy AK, Harmon JR, Flietstra TD, Campbell S, Mehta AK, Kraft CS, et al. Kinetic analysis of biomarkers in a cohort of US patients with Ebola virus disease. Clin Infect Dis. 2016;63:460-7 (18); reproduced with permission.

* Statistically significant difference between fatal and nonfatal cases $(p<0.05)$. EVD, Ebola virus disease; sCD163, soluble CD163; sIL-2R, soluble interleukin 2 receptor. 


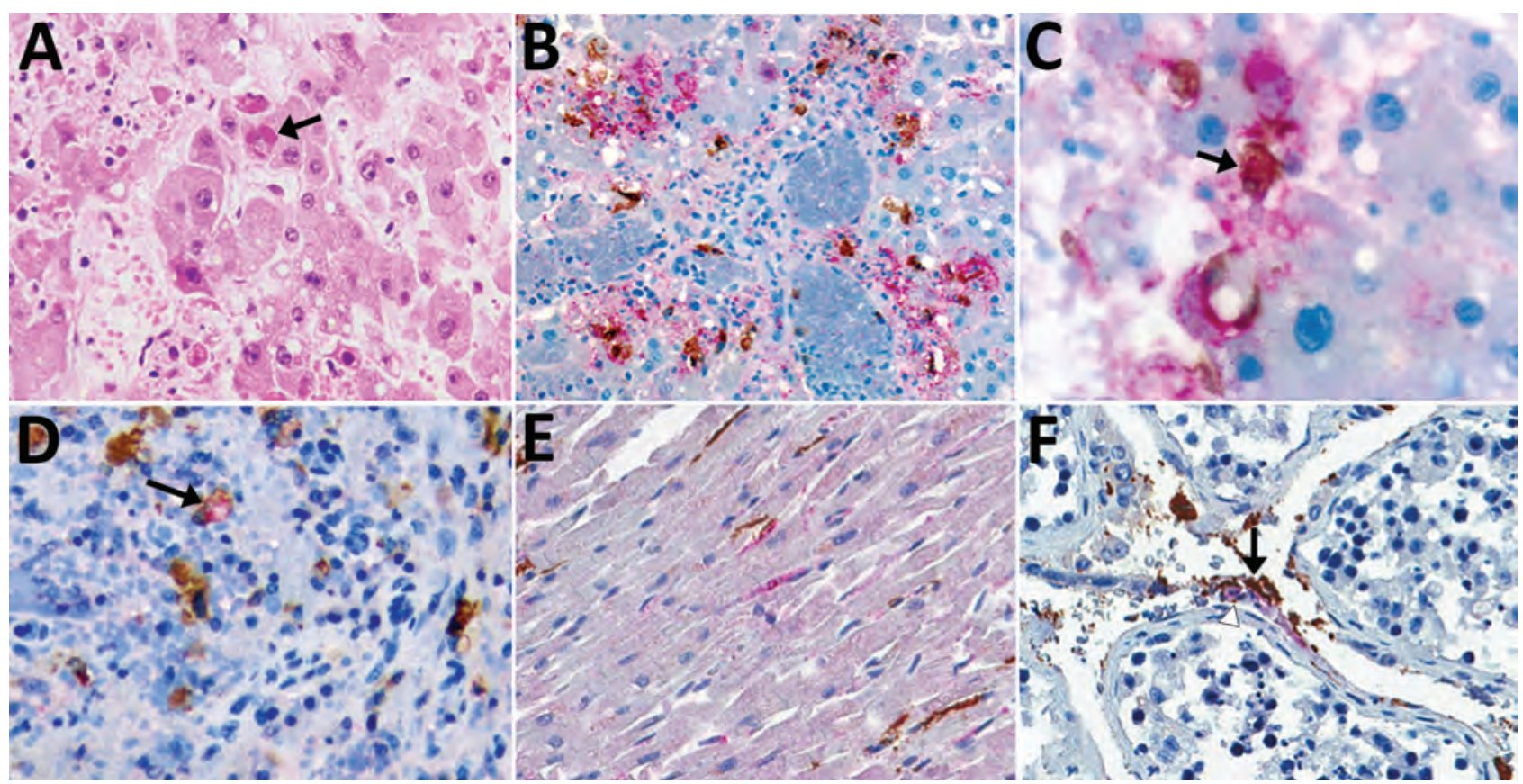

Figure 2. Immunohistochemical stains of tissue from patients with fatal cases of Ebola virus (EBOV) disease showing EBOV (red) and CD163 (brown) antigens. A) Hematoxylin and eosin stain of liver showing hepatocellular necrosis with intracytoplasmic eosinophilic inclusions (arrow). B) EBOV antigens in hepatocytes and CD163 antigens in macrophages. C) High magnification image of double immunohistochemical staining of liver tissue showing colocalization of EBOV and CD163 antigens in macrophage (arrow). D) Colocalization of EBOV and CD163 antigen in macrophage of spleen (arrow). E) Staining of EBOV and interstitial macrophages (CD163) in heart. EBOV found in some cardiomyocytes. F) EBOV and CD163 antigen in endothelial cells (arrowhead) and macrophages of testis (arrow). Original magnification $\times 20(A, B, D, E, F) ; \times 63(C)$.

noninfectious cause (Figure 2, panel E; Figure 3, panel A). Of note, CD163-positive immunostaining in the interstitial space of the testes colocalized with viral antigen (Figure 2, panel F). Tissue-resident macrophages are known to exhibit CD163 staining, so several tissue samples from patients who died of a noninfectious cause were examined to have a baseline for comparison. CD163 staining identified Kupffer cells of the liver (Figure 3, panel B), tissueresident macrophages of the myocardium (Figure 3, panel A) and spleen (Figure 3, panel C), and macrophages in the interstitial space of the testes (Figure 3, panel D). In summary, tissues from patients with fatal EVD showed increased CD163-positive macrophages near the areas of extensive immunostaining for EBOV antigens.

\section{Discussion}

Both HLH and MAS are inflammatory syndromes that are characterized by fever, hypercytokinemia, liver dysfunction, and coagulopathy. EVD shows some striking similarities to these 2 disorders, suggesting a common underlying mechanism of pathology. T-cell activation and proliferation, evidenced by elevated sIL-2R (sCD25) levels, are hypothesized to be responsible for the bulk of the hypercytokinemia in HLH and MAS. CD25 is upregulated on activated T cells, and sCD25 levels correlate with membrane-bound CD25 levels on lymphocytes (36). The interaction between EBOV and TIM-1 on the surface of T cells has been demonstrated to lead to nonspecific T-cell activation and elevation of proinflammatory cytokines (16). However, TIM proteins are expressed on other cell types, so TIM-mediated signaling with cells other than T cells could be involved in EVD. Because all of the EVD patients we studied had elevated levels of sCD25 and Tcell activation has been reported in patients with EVD (15), hypercytokinemia could result from T-cell activation through a nonspecific component. However, a substantial amount of data suggests that T-cell function (presumably antigen-specific T-cell function) is critical for virus control and host survival (37). In addition, no correlation between sCD25 level and disease severity or outcome was evident; thus, the elevation of sCD25 might simply reflect the fact that $\mathrm{T}$ cells are activated after infection. Therefore, any therapeutic attempt to modulate T-cell activity to improve patient outcome must take into account the fact that different populations of $\mathrm{T}$ cells within the host could be simultaneously deleterious and beneficial.

In healthy persons, the ferritin level is $10-250 \mathrm{ng} /$ $\mathrm{mL}$ and used clinically as a marker of iron storage (26). 


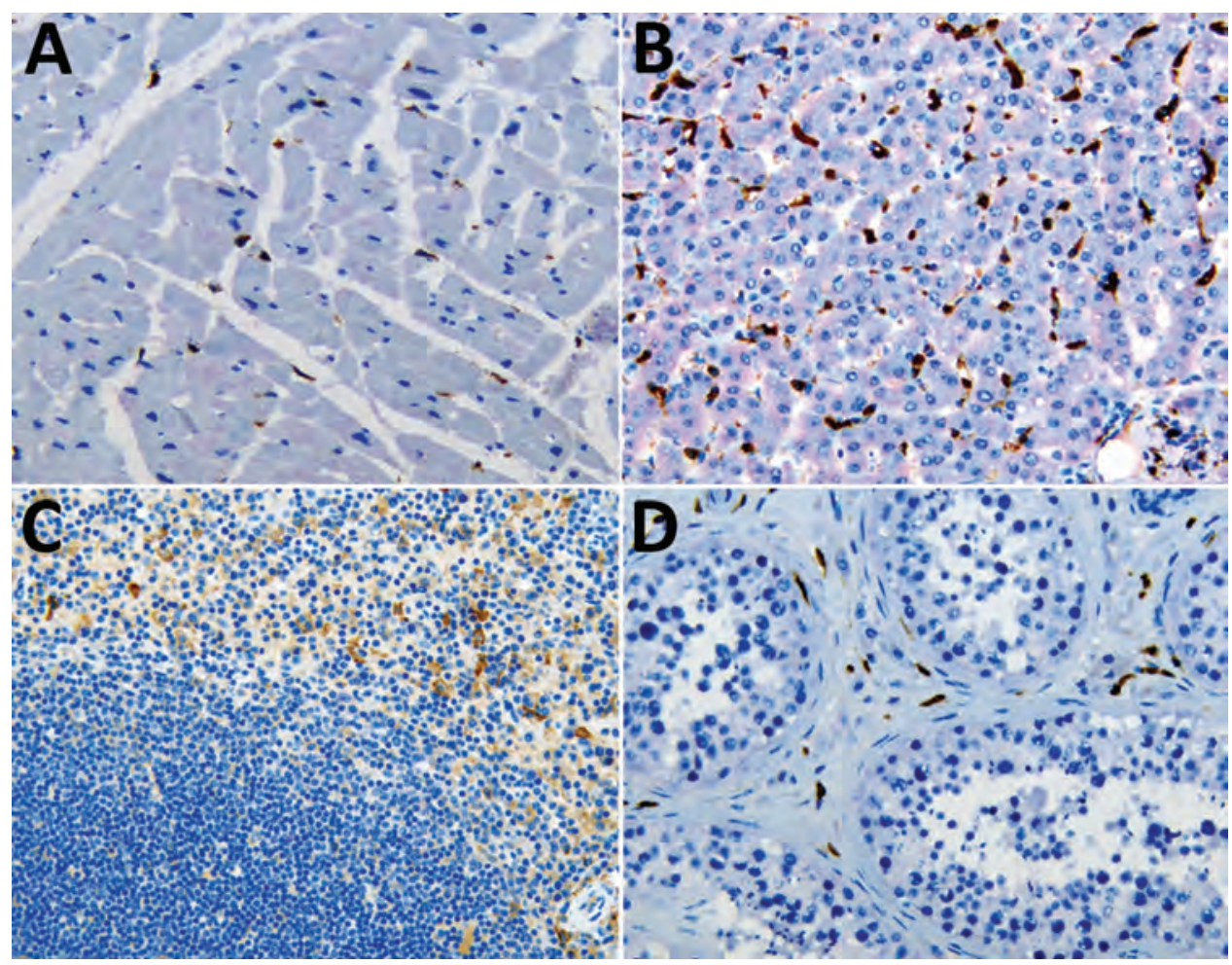

Figure 3. Double

immunohistochemical staining of Ebola virus and CD163 antigen in tissues of patients who died of noninfectious causes. CD163 antigens in macrophages of heart (A), liver (Kupffer cells) (B), spleen (C), and testicle (D). Original magnification $\times 20$.

Ferritin is also known as an acute-phase reactant that is elevated nonspecifically in the context of inflammation. In HLH and MAS, ferritin levels can be markedly high. Hyperferritinemia was observed in patients with EVD, where ferritin levels were as high as $1 \times 10^{5} \mathrm{ng} / \mathrm{mL}$, which is 3 logs of magnitude over the upper limit of normal. In HLH and MAS, the source of ferritin causing the extremely high blood levels is thought to be the activated macrophage population $(38,39)$. In EVD, the liver could also be the source of the ferritin, as has been noted in animal models (40).

Elevations in serum triglycerides can occur in response to inflammation; this rise in concentration is thought to be mediated by cytokine-dependent increases in hepatic secretion (41). The elevated triglycerides seen in severe and fatal cases of EVD would be consistent with this finding, considering these same patients have marked increases in proinflammatory cytokines. Therefore, the finding of elevated triglycerides probably represents a response to rather than an initiator of pathology.

In contrast with the conflicting data on T-cell activation in EVD, the data for a pathogenic role of macrophages is more convincing. Elevated levels of macrophage activation marker sCD163 were seen in all patients with EVD, and this marker was associated with both disease severity and fatal outcome. Elevated levels of sCD163 in disease pathogenesis have also been reported for dengue virus and hantavirus infections $(14,35)$, and sCD163 was an independent predictor of all-cause mortality in HIV-infected patients (42).
CD163 is shed from the surface of activated macrophages or monocytes after stimulation of surface but not intracellular TLRs (43). This shed sCD163 can then bind hemoglobin, an activity theorized to be an innate immune signaling mechanism to help combat microbial pathogens by scavenging available iron. In vivo endotoxin studies in humans have shown that surface CD163 is rapidly replaced on monocytes within 24 hours after lipopolysaccharidemediated TLR-4 stimulation and CD163 shedding (44). Therefore, that we found elevated levels of sCD163 and abundant CD163-positive macrophages in the liver surrounding areas with extensive viral antigen is not surprising. Liver macrophages include mostly Kupffer cells, which are usual constituents of the liver, but during inflammation, monocytes are recruited from the periphery that can differentiate into macrophages in this tissue (45). Kupffer cells express various markers and are thought to have various functions. CD163 is classically considered a reparative marker of an M2 type of macrophage, but this marker is not definitive because inflammatory macrophages can also express CD163 (46). The finding of high levels of sCD163 in fatal cases of EVD and of CD163 immunostaining in association with viral antigen in the tissues of fatal cases suggests that virally mediated activation of macrophages contributes to EVD pathogenesis in vivo.

Activation of macrophages or monocytes after in vitro EBOV infection leads to massive cytokine secretion $(47,48)$, which could also explain the hypercytokinemia that has been 
observed in patients with EVD. Pathogenic EBOVs and not nonpathogenic EBOV (e.g., Reston) were shown to activate macrophages by TLR-4 (17), and treatment of mice with a TLR-4 antagonist improved clinical scores, decreased inflammatory responses, and increased the survival of EBOVinfected mice (49). These in vitro and animal model data combined with the primary human data we present together provide further evidence that not only does EBOV infection activate macrophages in vivo, but this activation also plays a direct role in the pathogenesis of the virus.

A limitation of our study is that the EBOV cohort of patients treated at Emory University Hospital received several different therapeutic interventions (18). Whether these interventions affected the measured parameters is unknown; however, we noted concordance of data between patients with fatal cases of SUDV not treated with therapeutics and EVD9, the patient with severe EBV given therapeutic treatments.

Although EVD does not appear to trigger the development of MAS or HLH, the similarities of their inflammatory profile suggest that some of the therapeutic interventions that have shown success in treating HLH or MAS could be beneficial in treating EVD as well. Corticosteroids, etoposide, and cyclosporine A are mainstays for treatment of $\mathrm{HLH}$, and directed biologic therapies are being assessed. A search of ClinicalTrials.gov reveals ongoing and completed studies of many novel inflammation-targeting biologics for use in either MAS or HLH: blockers of interferon- $\gamma$ signaling (trial nos. NCT03311854, NCT03312751, NCT01818492, and NCT03311854), blockers of IL-6 (NCT02007239), blockers of IL-1 (NCT02780583), and antithymocyte globulin (NCT01104025). All of these therapies target inflammatory mediators or, in the case of antithymocyte globulin, $\mathrm{T}$ cells because $\mathrm{T}$ cells are thought to play a role in the pathogenesis of these inflammatory disorders. Given the acute nature of EVD, we hypothesize that targeting the specific types of inflammation seen in EVD would improve patient outcomes. The TLR-4 signaling that leads to macrophage activation is another potential target for host-directed immunotherapeutics. Clinical trials in humans are underway for biologics that block TLR-4, IL-6, IL-8, IL-1, and tumor necrosis factor $\alpha$ for several different disease conditions. Because all of these cytokines are elevated in EVD, we advise evaluation of these therapies in EVD. In addition, the many immunotherapeutics that modulate T-cell function, both inhibitors (e.g., IL-2 blockers) and activators (e.g., programmed cell death 1 and cytotoxic T-lymphocyte-associated protein 4 antibodies), could also be evaluated as therapeutics. Regardless of which therapeutic modality is chosen, a plethora of host immunomodulatory therapies are available and should be evaluated in nonhuman primate animal models of EVD. In fact, as the marker sCD163 indicates, inflammation can persist, even after viral load control, so improving patient outcomes will probably require both directed antiviral therapies early in the disease course and carefully timed host-directed antiinflammatory therapies.

\section{Acknowledgments}

We thank Tanya Klimova for editing the manuscript.

This work was conducted while A.K.M. held a Burroughs Wellcome Career Award for Medical Scientists (1013362.01) and a National Institutes of Health K08 (AI119448). Additional support was provided by the Defense Advanced Research Projects Agency (W31P4Q-14-1-0010 to A.K.M., B.S.R., G.M.L., and C.S.K.).

\section{About the Author}

Dr. McElroy is a pediatric infectious disease physician and a scientist who studies emerging viruses at the University of Pittsburgh, Pittsburgh, Pennsylvania, USA. She is also a guest researcher with the National Center for Emerging and Zoonotic Infectious Diseases, CDC, Atlanta. Her work focuses on understanding how host physiologic responses to viral infection contribute to disease.

\section{References}

1. Geisbert TW, Young HA, Jahrling PB, Davis KJ, Larsen T, Kagan E, et al. Pathogenesis of Ebola hemorrhagic fever in primate models: evidence that hemorrhage is not a direct effect of virusinduced cytolysis of endothelial cells. Am J Pathol. 2003; 163:2371-82. http://dx.doi.org/10.1016/S0002-9440(10)63592-4

2. Martines RB, Ng DL, Greer PW, Rollin PE, Zaki SR. Tissue and cellular tropism, pathology and pathogenesis of Ebola and Marburg viruses. J Pathol. 2015;235:153-74. http://dx.doi.org/10.1002/ path.4456

3. McElroy AK, Erickson BR, Flietstra TD, Rollin PE, Nichol ST, Towner JS, et al. Ebola hemorrhagic fever: novel biomarker correlates of clinical outcome. J Infect Dis. 2014;210:558-66. http://dx.doi.org/10.1093/infdis/jiu088

4. Wauquier N, Becquart P, Padilla C, Baize S, Leroy EM. Human fatal Zaire Ebola virus infection is associated with an aberrant innate immunity and with massive lymphocyte apoptosis. PLoS Negl Trop Dis. 2010;4:e837. http://dx.doi.org/10.1371/ journal.pntd.0000837

5. Hutchinson KL, Rollin PE. Cytokine and chemokine expression in humans infected with Sudan Ebola virus. J Infect Dis. 2007;196(Suppl 2):S357-63. http://dx.doi.org/10.1086/520611

6. Baize S, Leroy EM, Georges AJ, Georges-Courbot MC, Capron M, Bedjabaga I, et al. Inflammatory responses in Ebola virus-infected patients. Clin Exp Immunol. 2002;128:163-8. http://dx.doi.org/ 10.1046/j.1365-2249.2002.01800.x

7. Villinger F, Rollin PE, Brar SS, Chikkala NF, Winter J, Sundstrom JB, et al. Markedly elevated levels of interferon (IFN)gamma, IFN-alpha, interleukin (IL)-2, IL-10, and tumor necrosis factor-alpha associated with fatal Ebola virus infection. J Infect Dis. 1999;179(Suppl 1):S188-91. http://dx.doi.org/10.1086/514283

8. van der Ven AJ, Netea MG, van der Meer JW, de Mast Q. Ebola virus disease has features of hemophagocytic lymphohistiocytosis syndrome. Front Med (Lausanne). 2015;2:4. http://dx.doi.org/10.3389/fmed.2015.00004

9. George MR. Hemophagocytic lymphohistiocytosis: review of etiologies and management. J Blood Med. 2014;5:69-86. http://dx.doi.org/10.2147/JBM.S46255 
10. Dowd JB, Palermo T, Brite J, McDade TW, Aiello A. Seroprevalence of Epstein-Barr virus infection in U.S. children ages 6-19, 2003-2010. PLoS One. 2013;8:e64921. http://dx.doi.org/ 10.1371/journal.pone.0064921

11. Tasdelen Fisgin N, Fisgin T, Tanyel E, Doganci L, Tulek N, Guler N, et al. Crimean-Congo hemorrhagic fever: five patients with hemophagocytic syndrome. Am J Hematol. 2008;83:73-6. http://dx.doi.org/10.1002/ajh.20969

12. Wan Jamaludin WF, Periyasamy P, Wan Mat WR, Abdul Wahid SF. Dengue infection associated hemophagocytic syndrome: therapeutic interventions and outcome. J Clin Virol. 2015;69:91-5. http://dx.doi.org/10.1016/j.jcv.2015.06.004

13. Grom AA, Horne A, De Benedetti F. Macrophage activation syndrome in the era of biologic therapy. Nat Rev Rheumatol. 2016;12:259-68. http://dx.doi.org/10.1038/nrrheum.2015.179

14. Ab-Rahman HA, Rahim H, AbuBakar S, Wong PF. Macrophage activation syndrome-associated markers in severe dengue. Int $\mathrm{J}$ Med Sci. 2016;13:179-86. http://dx.doi.org/10.7150/ijms.13680

15. McElroy AK, Akondy RS, Davis CW, Ellebedy AH, Mehta AK, Kraft CS, et al. Human Ebola virus infection results in substantial immune activation. Proc Natl Acad Sci U S A. 2015;112:4719-24. http://dx.doi.org/10.1073/pnas.1502619112

16. Younan P, Iampietro M, Nishida A, Ramanathan P, Santos RI, Dutta $\mathrm{M}$, et al. Ebola virus binding to TIM-1 on T lymphocytes induces a cytokine storm. MBio. 2017;8:e0845-17. http://dx.doi.org/10.1128/mBio.00845-17

17. Olejnik J, Forero A, Deflubé LR, Hume AJ, Manhart WA, Nishida A, et al. Ebolaviruses associated with differential pathogenicity induce distinct host responses in human macrophages. J Virol. 2017;91:e00179-17. http://dx.doi.org/ 10.1128/JVI.00179-17

18. McElroy AK, Harmon JR, Flietstra TD, Campbell S, Mehta AK, Kraft CS, et al. Kinetic analysis of biomarkers in a cohort of US patients with Ebola virus disease. Clin Infect Dis. 2016;63:460-7. http://dx.doi.org/10.1093/cid/ciw334

19. Ksiazek TG, Rollin PE, Jahrling PB, Johnson E, Dalgard DW, Peters CJ. Enzyme immunosorbent assay for Ebola virus antigens in tissues of infected primates. J Clin Microbiol. 1992;30:947-50.

20. Zaki SR, Shieh WJ, Greer PW, Goldsmith CS, Ferebee T, Katshitshi J, et al. A novel immunohistochemical assay for the detection of Ebola virus in skin: implications for diagnosis, spread, and surveillance of Ebola hemorrhagic fever. Commission de Lutte contre les Epidémies à Kikwit. J Infect Dis. 1999;179(Suppl 1):S36-47. http://dx.doi.org/10.1086/514319

21. Lehmberg K, Ehl S. Diagnostic evaluation of patients with suspected haemophagocytic lymphohistiocytosis. Br J Haematol. 2013;160:275-87. http://dx.doi.org/10.1111/bjh.12138

22. Henter JI, Horne A, Aricó M, Egeler RM, Filipovich AH, Imashuku S, et al. HLH-2004: diagnostic and therapeutic guidelines for hemophagocytic lymphohistiocytosis. Pediatr Blood Cancer. 2007;48:124-31. http://dx.doi.org/10.1002/ pbc.21039

23. Ravelli A, Minoia F, Davì S, Horne A, Bovis F, Pistorio A, et al.; Paediatric Rheumatology International Trials Organisation; Childhood Arthritis and Rheumatology Research Alliance; Pediatric Rheumatology Collaborative Study Group; Histiocyte Society. 2016 classification criteria for macrophage activation syndrome complicating systemic juvenile idiopathic arthritis: a European League Against Rheumatism/American College of Rheumatology/Paediatric Rheumatology International Trials Organisation collaborative initiative. Arthritis Rheumatol. 2016;68:566-76. http://dx.doi.org/10.1002/art.39332

24. Uyeki TM, Mehta AK, Davey RT Jr, Liddell AM, Wolf T, Vetter P, et al.; Working Group of the U.S.-European Clinical Network on Clinical Management of Ebola Virus Disease Patients in the U.S. and Europe. Clinical management of Ebola virus disease in the
United States and Europe. N Engl J Med. 2016;374:636-46. http://dx.doi.org/10.1056/NEJMoa1504874

25. Hunt L, Gupta-Wright A, Simms V, Tamba F, Knott V, Tamba K, et al. Clinical presentation, biochemical, and haematological parameters and their association with outcome in patients with Ebola virus disease: an observational cohort study. Lancet Infect Dis. 2015;15:1292-9. http://dx.doi.org/10.1016/ S1473-3099(15)00144-9

26. Finch CA, Bellotti V, Stray S, Lipschitz DA, Cook JD, Pippard MJ, et al. Plasma ferritin determination as a diagnostic tool. West J Med. 1986;145:657-63.

27. Cimini E, Viola D, Cabeza-Cabrerizo M, Romanelli A, Tumino N, Sacchi A, et al. Different features of V $\delta 2 \mathrm{~T}$ and NK cells in fatal and non-fatal human Ebola infections. PLoS Negl Trop Dis. 2017;11:e0005645. http://dx.doi.org/10.1371/ journal.pntd.0005645

28. Rollin PE, Bausch DG, Sanchez A. Blood chemistry measurements and D-dimer levels associated with fatal and nonfatal outcomes in humans infected with Sudan Ebola virus. J Infect Dis. 2007;196(Suppl 2):S364-71. http://dx.doi.org/10.1086/520613

29. Kreuels B, Wichmann D, Emmerich P, Schmidt-Chanasit J, de Heer G, Kluge S, et al. A case of severe Ebola virus infection complicated by gram-negative septicemia. N Engl J Med. 2014;371:2394-401. http://dx.doi.org/10.1056/NEJMoa1411677

30. Lüdtke A, Ruibal P, Becker-Ziaja B, Rottstegge M, Wozniak DM, Cabeza-Cabrerizo M, et al. Ebola virus disease is characterized by poor activation and reduced levels of circulating CD16 ${ }^{+}$monocytes. J Infect Dis. 2016;214(suppl 3):S275-80. http://dx.doi.org/10.1093/ infdis/jiw260

31. Ruibal P, Oestereich L, Lüdtke A, Becker-Ziaja B, Wozniak DM, Kerber R, et al. Unique human immune signature of Ebola virus disease in Guinea. Nature. 2016;533:100-4. http://dx.doi.org/ 10.1038/nature17949

32. Bleesing J, Prada A, Siegel DM, Villanueva J, Olson J, Ilowite NT, et al. The diagnostic significance of soluble CD163 and soluble interleukin-2 receptor $\alpha$-chain in macrophage activation syndrome and untreated new-onset systemic juvenile idiopathic arthritis. Arthritis Rheum. 2007;56:965-71. http://dx.doi.org/10.1002/ art.22416

33. Schaer DJ, Schleiffenbaum B, Kurrer M, Imhof A, Bächli E, Fehr J, et al. Soluble hemoglobin-haptoglobin scavenger receptor CD163 as a lineage-specific marker in the reactive hemophagocytic syndrome. Eur J Haematol. 2005;74:6-10. http://dx.doi.org/ 10.1111/j.1600-0609.2004.00318.x

34. Santos-Arroyo A, Barrera-Llaurador J, Sánchez JE, Martín-García R, Sánchez JL. Role of skin biopsies in the diagnosis of hemophagocytic lymphohistiocytosis. Am J Dermatopathol. 2017;39:e86-9. http://dx.doi.org/10.1097/DAD.0000000000000825

35. Wang J, Guo W, Du H, Yu H, Jiang W, Zhu T, et al. Elevated soluble CD163 plasma levels are associated with disease severity in patients with hemorrhagic fever with renal syndrome. PLoS One. 2014;9:e112127. http://dx.doi.org/10.1371/journal.pone.0112127

36. Bogner MP, Voss SD, Bechhofer R, Hank JA, Roper M, Poplack D, et al. Serum CD25 levels during interleukin-2 therapy: dose dependence and correlations with clinical toxicity and lymphocyte surface sCD25 expression. J Immunother (1991). 1992;11:111-8. http://dx.doi.org/10.1097/00002371-199202000-00005

37. McElroy AK, Mühlberger E, Muñoz-Fontela C. Immune barriers of Ebola virus infection. Curr Opin Virol. 2018;28:152-60. $\mathrm{http}: / / \mathrm{dx}$.doi.org/10.1016/j.coviro.2018.01.010

38. Wormsbecker AJ, Sweet DD, Mann SL, Wang SY, Pudek MR, Chen LY. Conditions associated with extreme hyperferritinaemia $(>3000 \mu \mathrm{g} / \mathrm{L})$ in adults. Intern Med J. 2015;45:828-33. http://dx.doi.org/10.1111/imj.12768

39. Cohen LA, Gutierrez L, Weiss A, Leichtmann-Bardoogo Y, Zhang DL, Crooks DR, et al. Serum ferritin is derived 
primarily from macrophages through a nonclassical secretory pathway. Blood. 2010;116:1574-84. http://dx.doi.org/10.1182/ blood-2009-11-253815

40. Naz N, Moriconi F, Ahmad S, Amanzada A, Khan S, Mihm S, et al. Ferritin $\mathrm{L}$ is the sole serum ferritin constituent and a positive hepatic acute-phase protein. Shock. 2013;39:520-6. http://dx.doi.org/10.1097/SHK.0b013e31829266b9

41. Feingold KR, Hardardóttir I, Grunfeld C. Beneficial effects of cytokine induced hyperlipidemia. Z Ernahrungswiss. 1998;37 (Suppl 1):66-74.

42. Knudsen TB, Ertner G, Petersen J, Møller HJ, Moestrup SK, Eugen-Olsen J, et al. Plasma soluble CD163 level independently predicts all-cause mortality in HIV-1-infected individuals. J Infect Dis. 2016;214:1198-204. http://dx.doi.org/10.1093/infdis/ jiw263

43. Weaver LK, Hintz-Goldstein KA, Pioli PA, Wardwell K, Qureshi N, Vogel SN, et al. Pivotal advance: activation of cell surface Toll-like receptors causes shedding of the hemoglobin scavenger receptor CD163. J Leukoc Biol. 2006;80:26-35. http://dx.doi.org/10.1189/jlb.1205756

44. Hintz KA, Rassias AJ, Wardwell K, Moss ML, Morganelli PM, Pioli PA, et al. Endotoxin induces rapid metalloproteinasemediated shedding followed by up-regulation of the monocyte hemoglobin scavenger receptor CD163. J Leukoc Biol. 2002;72:711-7.
45. Sun YY, Li XF, Meng XM, Huang C, Zhang L, Li J.

Macrophage phenotype in liver injury and repair. Scand J Immunol. 2017;85:166-74. http://dx.doi.org/10.1111/sji.12468

46. Barros MH, Hauck F, Dreyer JH, Kempkes B, Niedobitek G. Macrophage polarisation: an immunohistochemical approach for identifying M1 and M2 macrophages. PLoS One. 2013;8:e80908. http://dx.doi.org/10.1371/journal.pone.0080908

47. Gupta M, Mahanty S, Ahmed R, Rollin PE. Monocyte-derived human macrophages and peripheral blood mononuclear cells infected with Ebola virus secrete MIP- $1 \alpha$ and TNF- $\alpha$ and inhibit poly-IC-induced IFN- $\alpha$ in vitro. Virology. 2001;284:20-5. http://dx.doi.org/10.1006/viro.2001.0836

48. Ströher U, West E, Bugany H, Klenk HD, Schnittler HJ, Feldmann H. Infection and activation of monocytes by Marburg and Ebola viruses. J Virol. 2001;75:11025-33. http://dx.doi.org/ 10.1128/JVI.75.22.11025-11033.2001

49. Younan P, Ramanathan P, Graber J, Gusovsky F, Bukreyev A. The toll-like receptor receptor 4 antagonist eritoran protects mice from lethal filovirus challenge. MBio. 2017;8:e0226-17. http://dx.doi.org/10.1128/mBio.00226-17

Address for correspondence: Anita K. McElroy, Centers for Disease Control and Prevention, 1600 Clifton Rd NE, Mailstop G14, Atlanta, GA 30329-4027, USA; email: gsz5@cdc.gov

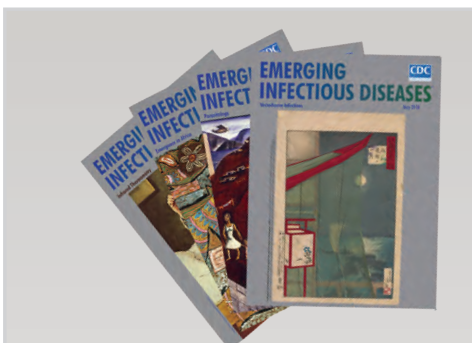

- History of Mosquitoborne Diseases in the United States and Implications for New Pathogens

- Surveillance for Mosquitoborne Transmission of Zika Virus, New York City, NY, USA, 2016

- Two Cases of Israeli Spotted Fever with Purpura Fulminans, Sharon District, Israel

- Antimicrobial Resistance in Invasive Bacterial Infections in Hospitalized Children, Cambodia, 2007-2016

- Epidemic Dynamics of Vibrio parahaemolyticus Illness in a Hotspot of Disease Emergence, Galicia, Spain

- Dynamics of Spirochetemia and Early PCR Detection of Borrelia miyamotoi

- Transmission of Severe Fever with Thrombocytopenia Syndrome Virus by Haemaphysalis longicornis Ticks, China

- Seroprevalence of Severe Fever with Thrombocytopenia Syndrome Virus Antibodies in Rural Areas, South Korea

- Spread of Plague by Respiratory Droplets or Ectoparasites
- Human Usutu Virus Infection with Atypical Neurologic Presentation, Montpellier, France, 2016

- Alkhurma Hemorrhagic Fever Virus RNA in Hyalomma rufipes Ticks Infesting Migratory Birds, Europe and Asia Minor

- Cholera Epidemic in South Sudan and Uganda and Need for International Collaboration in Cholera Control

- External Quality Assessment for Zika Virus Molecular Diagnostic Testing, Brazil

- A Mental Models Approach to Assessing Public Understanding of Zika Virus, Guatemala

- Heartland Virus and Hemophagocytic Lymphohistiocytosis in Immunocompromised Patient, Missouri, USA

- Equine Encephalosis Virus in India, 2008 Epizootic Hemorrhagic Disease Virus Serotype 6 Infection in Cattle, Japan, 2015

- Fatal Visceral Leishmaniasis Caused by Leishmania infantum, Lebanon 


\title{
Zika Virus I gM Detection and Neutralizing Antibody Profiles 12- 19 Months after IIIness Onset
}

\author{
Isabel Griffin, Stacey W. Martin, Marcs Fischer, Trudy V. Chambers, Olga Kosoy, \\ Alyssa Falise, Olga Ponomareva, Leah D. Gillis, Carina Blackmore, Reynald Jean
}

\begin{abstract}
Data on the duration of detectable Zika virus-specific IgM in infected persons are limited. Neutralizing antibody crossreactivity occurs between Zika virus and related flaviviruses, but the degree to which this confounds diagnosis is uncertain. We tested serum specimens collected 12-19 months after illness onset from patients with confirmed Zika virus disease for Zika virus IgM and Zika virus and dengue virus neutralizing antibodies. Among 62 participants, 45 (73\%) had detectable Zika virus IgM and 12 (19\%) had an equivocal result. Although all patients tested had Zika virus neutralizing antibodies, $39(63 \%)$ also had neutralizing antibodies against dengue virus; of those, $12(19 \%)$ had $<4$-fold difference between Zika virus and dengue virus titers, and $5(8 \%)$ had dengue virus titer $\geq 4$-fold higher than Zika virus titer. Prolonged detection of IgM and neutralizing antibody crossreactivity make it difficult to determine the timing of Zika virus infection and differentiate between related flaviviruses.
\end{abstract}

$\mathrm{Z}$ ika virus is a flavivirus closely related to dengue, West Nile, Japanese encephalitis, and yellow fever viruses $(1,2)$. Diagnostic testing for Zika virus infection is conducted using both molecular and serologic methods, which include testing for viral RNA and IgM and neutralizing antibodies (3-5). RNA detection is most sensitive during the acute phase of illness and confirms Zika virus infection, but sensitivity declines after the first week of illness and a negative result does not exclude infection. Zika virus IgM typically develops $\leq 4$ days after symptom onset and remains detectable for at least 12 weeks (6-8). Data on the duration of IgM after Zika virus infection are lacking, but IgM against other flaviviruses can last for months to years following infection (9-13). Neutralizing antibodies

Author affiliations: Florida Department of Health in Miami-Dade County, Miami, Florida, USA (I. Griffin, A. Falise, O. Ponomareva, R. Jean); Centers for Disease Control and Prevention, Fort Collins, Colorado, USA (S.W. Martin, M. Fischer, T.V. Chambers,

O. Kosoy); Bureau of Public Health Laboratories, Miami

(L.D. Gillis); Florida Department of Health, Tallahassee, Florida, USA (C. Blackmore)

DOI: https://doi.org/10.3201/eid2502.181286 develop shortly after IgM, persist for many years, and may confer lifelong immunity $(13,14)$.

Cross-reactivity between Zika virus and other flaviviruses occurs both with IgM and neutralizing antibodies and makes distinguishing Zika virus from dengue virus infections especially challenging. Whereas primary Zika virus infections typically generate highly specific neutralizing antibodies, secondary flavivirus infections show a high degree of cross-reactivity $(6,15,16)$. For secondary infections, it remains uncertain whether the infecting flavivirus neutralizing antibody response is significantly greater than the cross-reacting neutralizing response, allowing for differentiation, and whether cross-reactive neutralizing antibodies are maintained for months to years after infection (16-19).

In July 2016, the first Zika virus outbreak in the continental United States was identified in Florida, culminating in 300 locally acquired cases in $2016(20,21)$. We collected serum specimens from patients with Zika virus infection confirmed by molecular testing to determine the proportion of patients with detectable Zika virus IgM and the ratio of Zika virus and dengue virus neutralizing antibodies at 12-19 months after their acute illness.

\section{Methods}

Eligible participants were residents of Miami-Dade County, Florida, USA, who had Zika virus disease confirmed by real-time reverse transcription PCR (rRT-PCR) and symptom onset during June-October 2016. Persons with asymptomatic infection, pregnant women, and infants with congenital infection were excluded from enrollment. We enrolled participants during October 16, 2017-February 1, 2018. We obtained written consent from study participants or their guardians.

Serum specimens were tested at the Centers for Disease Control and Prevention (Fort Collins, CO, USA) by IgM antibody capture ELISA (MAC-ELISA) for detection of Zika virus and dengue virus IgM and by plaque reduction neutralization test (PRNT) to detect Zika virus and dengue virus neutralizing antibodies $(5,6,22)$. The PRNT endpoint titer was defined as the reciprocal of the dilution reducing the virus plaque count by $90 \%$. 
We obtained descriptive and clinical data for case-patients, including age, gender, race/ethnicity, reported symptoms, symptom onset, and origin of infection, from Merlin, the Florida Department of Health surveillance system. We used Pearson $\chi^{2}$ and Fisher exact tests to examine associations between demographics, symptomology, and Zika virus IgM results. We performed all statistical analyses with SAS statistical software version 9.4 (https://www.sas.com/ en_us/software/sas9.html). This study was approved by the Florida Department of Health Institutional Review Board.

\section{Results}

Of 352 eligible PCR-confirmed Zika virus disease casepatients, 62 (18\%) were enrolled and provided follow-up serum specimens. The 62 enrolled participants and 290 eligible case-patients who were not enrolled were similar with regard to age, sex, race/ethnicity, and clinical manifestations; however, $55 \%$ of enrolled participants acquired their infections in Florida, compared with $45 \%$ of the unenrolled cases (Table 1).

Among the enrolled participants, 8 (13\%) provided a specimen at 12 months after initial symptom onset, 1 (2\%) at 13 months, 13 (21\%) at 14 months, 21 (34\%) at 15 months, $11(18 \%)$ at 16 months, $3(5 \%)$ at 17 months, $3(5 \%)$ at 18 months, and $2(3 \%)$ at 19 months. The median age of participants was 47 years (range 8-70 years); 60 (97\%) were adults $\geq 18$ years of age (Table 1$)$. Overall, 32 (52\%) participants were male, and 42 (68\%) were Hispanic. Two (3\%) participants reported only 1 of the 4 main symptoms (fever, maculopapular rash, arthralgia, and conjunctivitis) at the time of their initial Zika virus diagnosis; 15 (24\%) reported 2, 32 (52\%) reported 3, and 13 (21\%) reported all 4. From case investigations, we determined that
34 (55\%) participants acquired their Zika virus infection locally in Miami-Dade County.

At follow-up, 45 (73\%) patients had detectable Zika virus IgM, 12 (19\%) had an equivocal result, and 5 (8\%) were negative (all laboratory results provided in Appendix, http://wwwnc.cdc.gov/EID/article/25/2/18-1286-App1. pdf). Results by month since Zika virus symptom onset (Figure) showed that, overall, 39 (91\%) of 43 specimens collected at 12-15 months postonset were IgM positive or equivocal, and 18 (95\%) of 19 specimens collected at 16-19 months were positive or equivocal. No significant differences in IgM persistence were identified by age, gender, race/ethnicity, origin of infection, or time since illness onset (Table 2).

All participants had Zika virus neutralizing antibodies at 12-19 months after their acute illness, and 39 (63\%) had dengue virus neutralizing antibody titers at follow-up. Using a definition of positive or equivocal Zika virus IgM with confirmatory Zika virus neutralizing antibodies, 57 (92\%) would have had a diagnosis of recent Zika virus or flavivirus infection on the basis of results from their followup specimens (Table 3). Overall, regardless of Zika virus IgM results, $45(73 \%)$ of the PCR-confirmed cases had Zika virus neutralizing antibody titers that were $\geq 4$-fold higher than dengue virus titers. However, substantial crossreactivity in neutralizing antibodies was still observed; 12 $(19 \%)$ patients had a $<4$-fold difference between Zika virus and dengue virus titers, and 5 (8\%) had dengue virus titers that were $\geq 4$-fold higher than Zika virus titers.

\section{Discussion}

These findings demonstrate that $73 \%$ of persons with PCRconfirmed symptomatic Zika virus disease still had positive

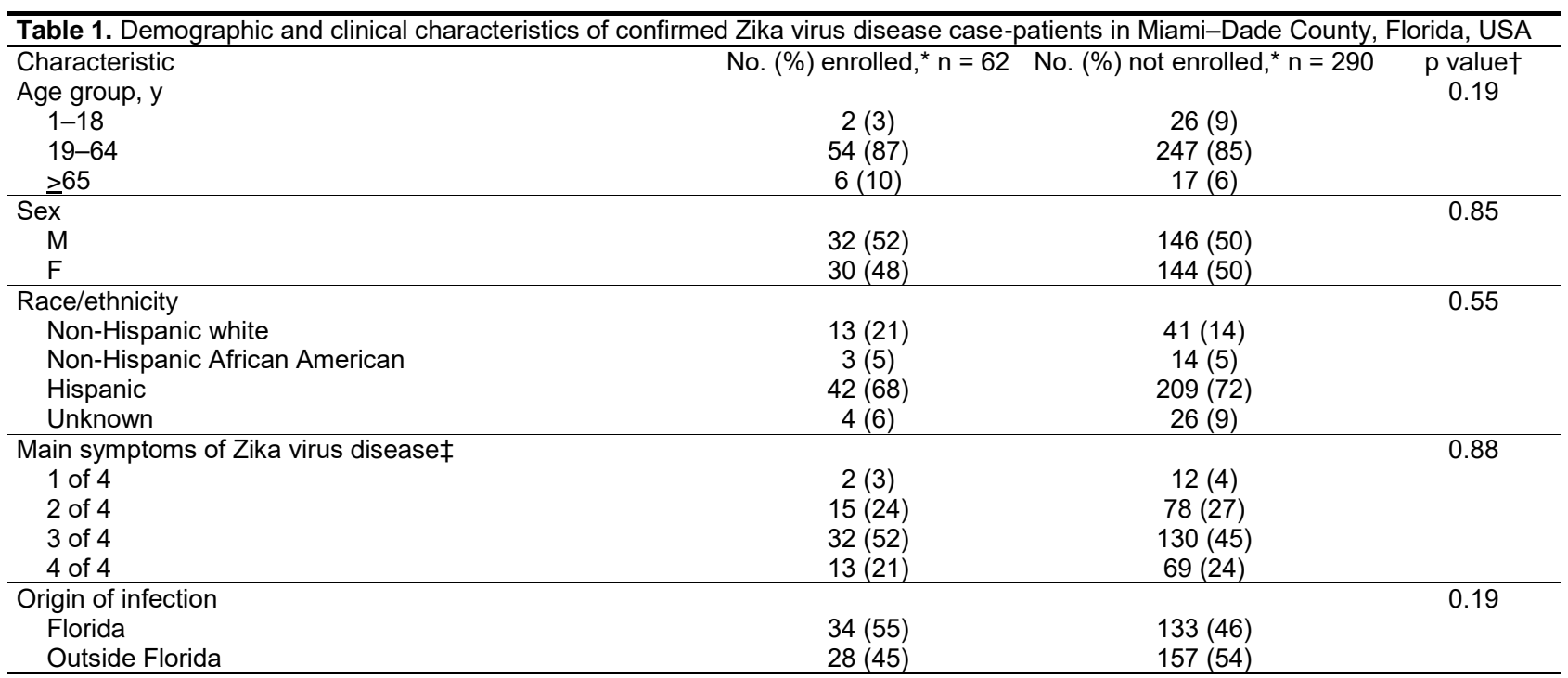

${ }^{*}$ All percentages are column percentages.

†A $p$ value $\leq 0.05$ was considered statistically significant.

‡Main symptoms were defined as fever, maculopapular rash, arthralgia, and conjunctivitis. 


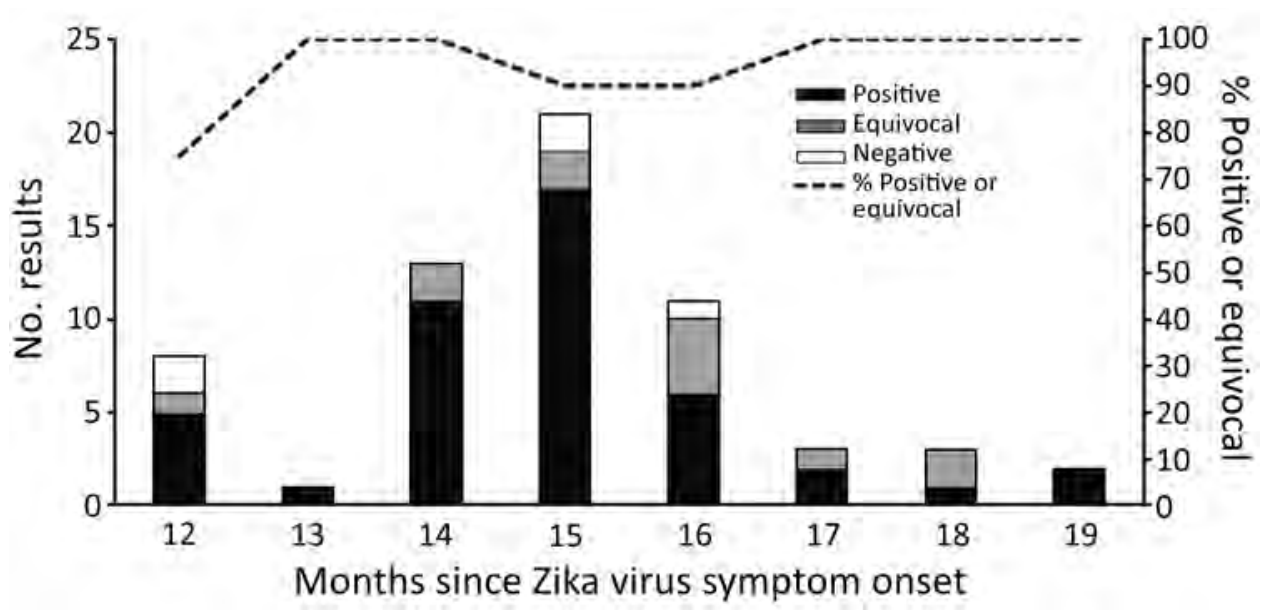

Figure. Zika virus IgM results for 62 participants in MiamiDade County, Florida, USA, with PCR-confirmed Zika virus disease by follow-up specimen collection month.
IgM test results 12-19 months after their initial illness, and another 19\% had equivocal results. Because all participants had Zika virus neutralizing antibodies, a high proportion $(92 \%)$ would have had a recent Zika virus or flavivirus infection diagnosis on the basis of serologic testing performed at the follow-up time point. Current Zika virus testing guidance recommends Zika virus serologic diagnosis only for symptomatic patients with a clinically compatible Zika virus illness (3). However, given the limited specificity of the clinical symptoms associated with Zika virus disease, the prolonged detection of Zika virus IgM presents a particular challenge for serologic diagnosis in pregnant women, given the importance of determining if the infection occurred during the current pregnancy, and complicates the diagnosis of new Zika virus infections in locations with known previous outbreaks.
The prolonged detection of IgM after Zika virus infection is consistent with previous findings for related flaviviruses (9-13). In a study of patients with confirmed West Nile virus encephalitis, 9 (43\%) of 21 patients had detectable IgM 300-400 days after onset of their acute illness, and 5 (42\%) of 12 had IgM detected $>500$ days after onset (11). Among asymptomatic blood donors with West Nile virus viremia detected on routine screening, IgM was still detected an average of 156 days (95\% CI 70-423 days) after the viremic donation (13). A similar finding was observed in a study looking at the immune response to yellow fever vaccine in adults, in which 29 (73\%) of 40 persons had detectable levels of IgM 3-4 years postvaccination (12).

Serologic cross-reactivity has been demonstrated between Zika virus and related flaviviruses, including dengue virus, but the degree to which neutralizing antibody cross-

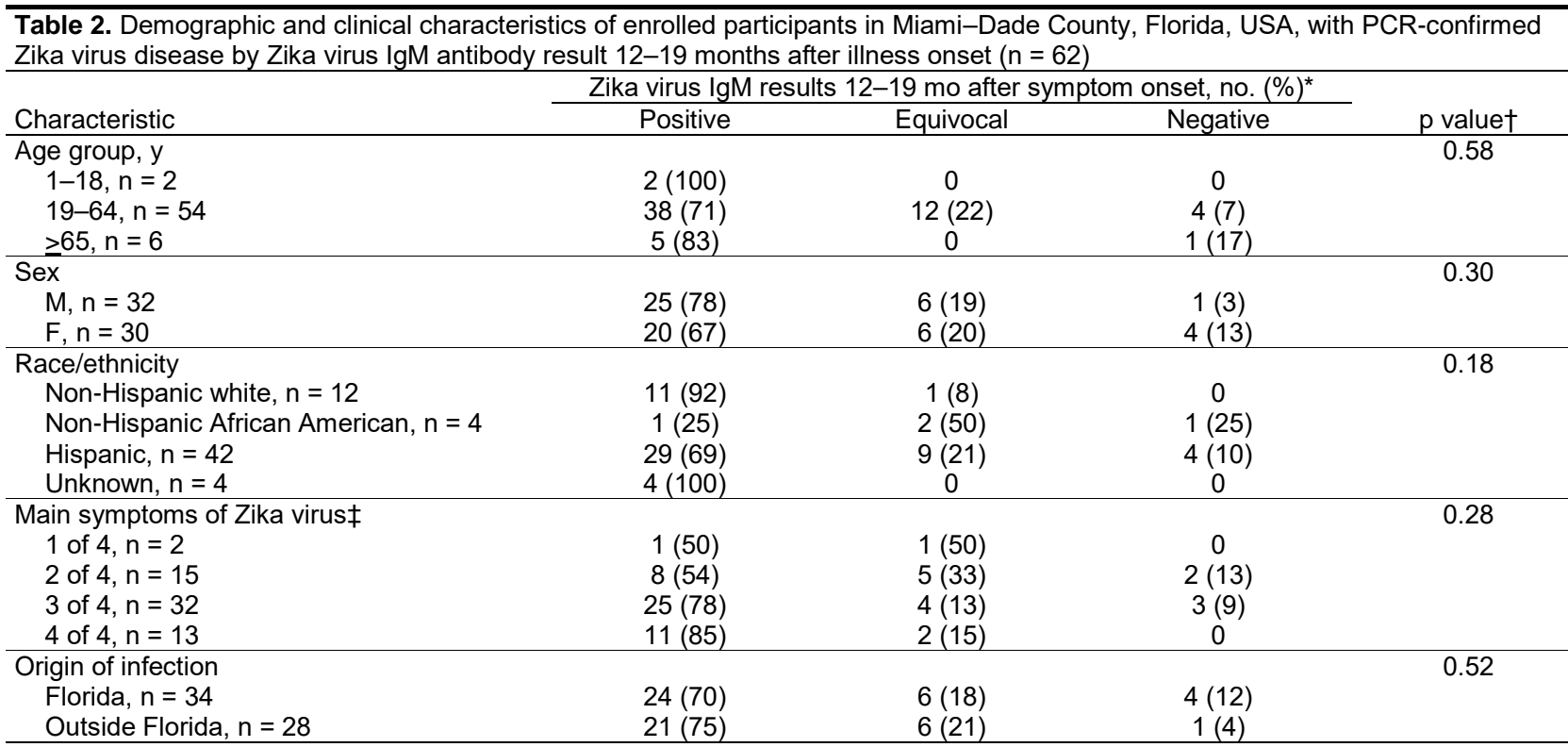

${ }^{*}$ All percentages are row percentages.

†A $p$-value $\leq 0.05$ was considered statistically significant.

$\ddagger$ Main symptoms were defined as fever, maculopapular rash, arthralgia, and conjunctivitis. 
Table 3. Diagnostic test interpretations among participants with PCR-confirmed Zika virus disease in Miami-Dade County, Florida, USA, based on IgM and neutralizing antibody results $12-19$ months after onset*

\begin{tabular}{|c|c|c|}
\hline Test results & No. $(\%), n=62$ & Interpretation† \\
\hline \multicolumn{3}{|l|}{ Zika virus IgM positive or equivocal, $\mathrm{n}=57$} \\
\hline Zika virus PRNT titer $\geq 10$ and DENV PRNT titer $<10$ & $21(34)$ & Recent Zika virus infection \\
\hline Zika virus PRNT titer $\geq 4$-fold higher than DENV PRNT titer & $21(34)$ & Recent flavivirus infection \\
\hline$<4$-fold difference between Zika virus and DENV PRNT titers & $11(18)$ & Recent flavivirus infection \\
\hline DENV PRNT titer $\geq 4$-fold higher than Zika virus PRNT titer & $4(6)$ & Recent flavivirus infection \\
\hline \multicolumn{3}{|l|}{ ZIKV IgM negative, $\mathrm{n}=5$} \\
\hline Zika virus PRNT titer $\geq 10$ and Zika virus PRNT titer $<10$ & $2(3)$ & Previous Zika virus infection \\
\hline Zika virus PRNT titer $\geq 4$-fold higher than DENV PRNT titer & $1(2)$ & Previous flavivirus infection \\
\hline$<4$-fold difference between Zika virus and DENV PRNT titers & $1(2)$ & Previous flavivirus infection \\
\hline DENV PRNT titer $\geq 4$-fold higher than Zika virus PRNT titer & $1(2)$ & Previous flavivirus infection \\
\hline \multicolumn{3}{|c|}{$\begin{array}{l}\text { "DENV, dengue virus; PRNT, plaque reduction neutralization test. } \\
\text { †Recent Zika virus infection: Zika virus IgM positive or equivocal with a Zika virus PRNT titer } \geq 10 \text { and dengue PRNT titer }<10 \text {; recent flavivirus infection: } \\
\text { Zika virus IgM positive or equivocal with a Zika virus PRNT titer } \geq 10 \text { or dengue PRNT titer } \geq 10 \text {; previous Zika virus infection: Zika virus IgM negative with } \\
\text { a Zika virus PRNT titer } \geq 10 \text { and dengue PRNT titer }<10 \text {; previous flavivirus infection: Zika virus IgM negative with a Zika virus PRNT titer } \geq 10 \text { or dengue } \\
\text { PRNT titer }>10 \text {. }\end{array}$} \\
\hline
\end{tabular}

reactivity limits the ability to identify the specific virus responsible for the current infection is unclear $(6,23)$. One published report suggests that relative levels of neutralizing antibody titers can distinguish Zika virus from dengue virus infections, especially in specimens collected months after infection (19). However, we found substantial neutralizing antibody cross-reactivity in $>25 \%$ of specimens collected $\geq 1$ year after symptom onset.

These findings are subject to several limitations. This report presents data from a single follow-up specimen but how long IgM may persist after this timeframe remains unknown. We cannot exclude the possibility that some participants may have been reexposed to Zika virus or another flavivirus between their initial illness and follow-up testing. The timing of the follow-up specimen varied among the participants and was limited to 12-19 months following onset of Zika virus symptoms. This, coupled with the small number of specimens at some time points, prevented us from assessing possible trends in IgM persistence over time. The small sample size and lack of specimens from the acute illness also limited our ability to detect factors that may be associated with prolonged detection of IgM, including possible differences between primary and secondary infections. Our findings of prolonged IgM seropositivity are specific to the Centers for Disease Control and Prevention MAC-ELISA, which targets Zika virus premembrane and envelope glycoproteins; other IgM serologic assays targeting other proteins are currently available and may not produce comparable findings. Finally, because we enrolled only symptomatic disease case-patients, it is uncertain whether persons with asymptomatic infections would exhibit similar IgM persistence.

These findings support data for other flaviviruses and suggest that a substantial proportion of persons with Zika virus disease will still have detectable IgM 1-2 years after their initial infection. The results highlight the complexity of using serologic diagnosis to determine the specific timing of a recent infection, which is particularly important for pregnant women and challenging for residents of areas with previous or ongoing Zika virus activity. As such, the findings further support the current recommendations to use nucleic acid amplification for screening asymptomatic pregnant women with ongoing possible Zika virus exposure (3). Further study is needed to assess IgM persistence using other approved assays, determine the full duration of Zika virus IgM after infection, and evaluate possible differences in IgM duration following primary and secondary infections.

\section{Acknowledgments}

The research team thanks the Miami-Dade County residents who volunteered their time to participate in this study and gave their serum specimens to help further the understanding of Zika virus. The authors also acknowledge the work of the dedicated laboratorians, epidemiologists, and phlebotomists at the Centers for Disease Control and Prevention (Amanda J. Panella, Robert S. Lanciotti); Bureau of Public Health Laboratories; and the Florida Department of Health in Miami-Dade County (Lillian Rivera, Hannah Speaks, Anne Barrera).

\section{About the Author}

Ms. Griffin is an outbreak epidemiologist at the Florida Department of Health in Miami, Florida, USA. Her primary research interest is emerging infectious diseases.

\section{References}

1. Hills SL, Fischer M, Petersen LR. Epidemiology of Zika virus infection. J Infect Dis. 2017;216(suppl_10):S868-74. http://dx.doi.org/10.1093/infdis/jix434

2. Petersen LR, Jamieson DJ, Honein MA. Zika virus. N Engl J Med. 2016;375:294-5. http://dx.doi.org/10.1056/NEJMc1606769

3. Oduyebo T, Polen KD, Walke HT, Reagan-Steiner S, Lathrop E, Rabe IB, et al. Update: Interim guidance for health care providers caring for pregnant women with possible Zika virus exposureUnited States (including U.S. territories), July 2017. MMWR Morb Mortal Wkly Rep. 2017;66:781-93. http://dx.doi.org/10.15585/ mmwr.mm6629e1 
4. Rabe IB, Staples JE, Villanueva J, Hummel KB, Johnson JA, Rose L, et al.; MTS. Interim guidance for interpretation of Zika virus antibody test results. MMWR Morb Mortal Wkly Rep. 2016;65:543-6. http://dx.doi.org/10.15585/mmwr.mm6521e1

5. Theel ES, Hata DJ. Diagnostic testing for Zika virus: a postoutbreak update. J Clin Microbiol. 2018;56:e1972-17. http://dx.doi.org/10.1128/JCM.01972-17

6. Lanciotti RS, Kosoy OL, Laven JJ, Velez JO, Lambert AJ, Johnson AJ, et al. Genetic and serologic properties of Zika virus associated with an epidemic, Yap State, Micronesia, 2007. Emerg Infect Dis. 2008;14:1232-9. http://dx.doi.org/10.3201/eid1408.080287

7. Bingham AM, Cone M, Mock V, Heberlein-Larson L, Stanek D, Blackmore C, et al. Comparison of test results for Zika virus RNA in urine, serum, and saliva specimens from persons with travelassociated Zika virus disease-Florida, 2016. MMWR Morb Mortal Wkly Rep. 2016;65:475-8. http://dx.doi.org/10.15585/ mmwr.mm6518e2

8. Paz-Bailey G, Rosenberg ES, Doyle K, Munoz-Jordan J, Santiago GA, Klein L, et al. Persistence of Zika virus in body fluids-final report. N Engl J Med. 2017;379:1234-43. http://dx/doi.org/10.1056/NEJMoa1613108

9. Centers for Disease Control and Prevention. Prolonged IgM antibody response in people infected with Zika virus: implications for interpreting serologic testing results for pregnant women. CDC Health Advisory. 2017 [cited 2018 May 4]. https://emergency.cdc.gov/ han/han00402.asp

10. Prince HE, Tobler LH, Yeh C, Gefter N, Custer B, Busch MP. Persistence of West Nile virus-specific antibodies in viremic blood donors. Clin Vaccine Immunol. 2007;14:1228-30. http://dx.doi.org/ 10.1128/CVI.00233-07

11. Roehrig JT, Nash D, Maldin B, Labowitz A, Martin DA, Lanciotti RS, et al. Persistence of virus-reactive serum immunoglobulin $\mathrm{M}$ antibody in confirmed West Nile virus encephalitis cases. Emerg Infect Dis. 2003;9:376-9. http://dx.doi.org/10.3201/eid0903.020531

12. Gibney KB, Edupuganti S, Panella AJ, Kosoy OI, Delorey MJ, Lanciotti RS, et al. Detection of anti-yellow fever virus immunoglobulin $\mathrm{m}$ antibodies at 3-4 years following yellow fever vaccination. Am J Trop Med Hyg. 2012;87:1112-5. http://dx.doi.org/10.4269/ajtmh.2012.12-0182

13. Busch MP, Kleinman SH, Tobler LH, Kamel HT, Norris PJ, Walsh I, et al. Virus and antibody dynamics in acute West Nile virus infection. J Infect Dis. 2008;198:984-93. http://dx.doi.org/ $10.1086 / 591467$

14. Poland JD, Calisher CH, Monath TP, Downs WG, Murphy K. Persistence of neutralizing antibody $30-35$ years after immunization with 17D yellow fever vaccine. Bull World Health Organ. 1981;59:895-900.

15. Calisher CH, Karabatsos N, Dalrymple JM, Shope RE, Porterfield JS, Westaway EG, et al. Antigenic relationships between flaviviruses as determined by cross-neutralization tests with polyclonal antisera. J Gen Virol. 1989;70:37-43. http://dx.doi.org/10.1099/0022-1317-70-1-37

16. Johnson BW, Kosoy O, Martin DA, Noga AJ, Russell BJ, Johnson AA, et al. West Nile virus infection and serologic response among persons previously vaccinated against yellow fever and Japanese encephalitis viruses. Vector Borne Zoonotic Dis. 2005;5:137-45. http://dx.doi.org/10.1089/vbz.2005.5.137

17. Halstead SB, Rojanasuphot S, Sangkawibha N. Original antigenic sin in dengue. Am J Trop Med Hyg. 1983;32:154-6. http://dx.doi.org/10.4269/ajtmh.1983.32.154

18. Montoya M, Collins M, Dejnirattisai W, Katzelnick LC, Puerta-Guardo H, Jadi R, et al. Longitudinal analysis of antibody cross-neutralization following Zika virus and dengue virus infection in Asia and the Americas. J Infect Dis. 2018;218:536-45. http://dx.doi.org/10.1093/infdis/jiy164

19. Collins MH, McGowan E, Jadi R, Young E, Lopez CA, Baric RS, et al. Lack of durable cross-neutralizing antibodies against Zika virus from dengue virus infection. Emerg Infect Dis. 2017;23:77381. http://dx.doi.org/10.3201/eid2305.161630

20. Likos A, Griffin I, Bingham AM, Stanek D, Fischer M, White S, et al. Local mosquito-borne transmission of Zika virusMiami-Dade and Broward counties, Florida, June-August 2016. MMWR Morb Mortal Wkly Rep. 2016;65:1032-8. http://dx.doi.org/10.15585/mmwr.mm6538e1

21. Florida Department of Health. 2016 Zika map. 2018 [cited 2018 Jul 19]. https://zikafreefl.org/map

22. Martin DA, Muth DA, Brown T, Johnson AJ, Karabatsos N, Roehrig JT. Standardization of immunoglobulin M capture enzyme-linked immunosorbent assays for routine diagnosis of arboviral infections. J Clin Microbiol. 2000;38:1823-6.

23. Priyamvada L, Hudson W, Ahmed R, Wrammert J. Humoral cross-reactivity between Zika and dengue viruses: implications for protection and pathology. Emerg Microbes Infect. 2017;6:e33. http://dx.doi.org/10.1038/emi.2017.42

Address for correspondence: Isabel Griffin, Florida Department of Health in Miami-Dade County-Epidemiology, Disease Control, and Immunization Services, 8600 NW 17th St, Ste 200, Miami, FL 33126, USA; email: isabel.griffin@flhealth.gov 


\title{
Killing Clothes Lice by Holding I nfested Clothes Away from Hosts for 10 Days to Control Louseborne Relapsing Fever, Bahir Dah, Ethiopia
}

\author{
Stephen C. Barker, Dayana Barker
}

Louseborne relapsing fever (LBRF) was once a cosmopolitan disease, but it now occurs only in the Horn of Africa. Recent cases in refugees to Europe made LBRF topical again. Crowded boarding houses and church dwellings in Ethiopia are analogous to the crowded air-raid shelters of World War II. Thus, we might learn from experiments the London School of Tropical Hygiene and Medicine conducted during World War II. When the vector of Borrelia recurrentis (Pediculus humanus lice) was held away from the host for 10 days, $100 \%$ of nymphal and adult lice starved to death and $100 \%$ of eggs did not hatch. We hypothesize that holding infested clothes away from hosts in plastic shopping bags will kill enough lice to control LBRF in Ethiopia. Owning 2 sets of clothes might be useful; 1 set might be held in a plastic shopping bag for 10 days to kill lice and their eggs.

工 ouseborne relapsing fever (LBRF), which is caused by the spirochete Borrelia recurrentis, once had a cosmopolitan distribution but is now endemic only to countries in the Horn of Africa (Ethiopia, Sudan, South Sudan, and Somalia) $(1,2)$. A recent spate of cases of LBRF in refugees and migrants to Europe from the Horn of Africa underlines the point that LBRF is endemic to and prevalent in this part of Africa (3-19). LBRF is one of the top 10 reasons why persons visit healthcare clinics in Ethiopia (20). Thus, LBRF is a substantial burden on the healthcare system and, moreover, a cause of substantial illness and death, especially in day laborers, street children, and yekolotemaries (live-in church students) in cities such as Bahir Dah in the Amhara Region of the highlands of Ethiopia (altitude 1,800 m).

There have been substantial outbreaks of LBRF in Bahir Dah (21-25). Moreover, some patients with undiagnosed

Author affiliations: University of Queensland, Brisbane, Queensland, Australia (S.C. Barker); University of Queensland School of Veterinary Sciences, Gatton, Queensland, Australia (D. Barker)

DOI: https://doi.org/10.3201/eid2502.181226 febrile disease come to healthcare clinics in Bahir Dah and elsewhere in Ethiopia because of LBRF and other louseassociated diseases, such as louseborne epidemic typhus (LBET) (caused by Rickettsia prowazekii) and trench fever (caused by Bartonella quintana).

LBRF has been eradicated from all regions of the world, except the Horn of Africa, by activities that kill clothes lice (Pediculus humanus), which have also been referred to as body lice. Some of these activities have been organized public health interventions in communities, including mass delousing by steaming infested clothes with Stammers Serbian barrels, which were developed during World War I (26), and are still used today in Ethiopia (Figure 1) and elsewhere. Other activities include parents delousing clothes of their children by washing clothes in hot water $\left(\geq 60^{\circ} \mathrm{C}\right)$.

Some of these activities have been part of intentional schemes to reduce prevalence and intensity of louseborne pathogens, but most of these activities have been unintentional from the point of view of LBRF-programs to improve the cleanliness and social status of persons and their families. Lice are abhorred by most persons, and infestation with clothes lice is invariably associated, right or wrong, with low socioeconomic status. However, regardless of the motivation, activities that reduce prevalence and intensity of infestation with clothes lice have been successful in reducing prevalence and intensity of louseborne pathogens, particularly since World War II $(27,28)$.

In the context of louse-associated diseases, other authors have emphasized the benefits of washing bodies and clothes $(22,29)$; it has been reported that clothes lice prefer a dirty shirt to a clean shirt (30). Washing clothes in hot water $\left(\geq 60^{\circ} \mathrm{C}\right)$ for $>10 \mathrm{~min}$ kills clothes lice and their eggs (30). However, immersion of clothes in water heated to $60^{\circ} \mathrm{C}$ by a charcoal or wood fire is costly and time-consuming for most persons in Ethiopia. 
We have studied head lice and community- and individual-level strategies to control head lice in Brisbane, Queensland, Australia, and elsewhere for many years $(>20$ years for S.C.B. and 5 years for D.B.) (31-33). When we washed the hair of infested children with soap or shampoo or with water alone, we observe deaths of only a few adult lice; nymphal instars 1, 2, and 3; and eggs of lice. It appears that head lice close their spiracles when immersed in water; lice have to be submerged in water for $\geq 19$ hours to be killed (34). Our experience with head lice led us to wash cloth that was infested with clothes lice and eggs of clothes lice only with soap or water. This cloth was naturally infested cloth in several countries and cloth infested in the laboratory with lice and eggs from the Barker isolate of the Culpepper strain of clothes lice.

Our experience with clothes lice was similar to our experience with head lice; washing infested clothes in warm or cold water for 30 min with or without soap or washing detergent kills few lice and their eggs, although it results in clean clothes, clean lice, and clean eggs. Attacking lice and their eggs in clothes and blankets of persons is a simple way to reduce the prevalence and intensity of louseborne pathogens, such as B. recurrentis (cause of LBRF) and $R$. prowazekii (cause of LBET).

Attacking lice in clothes and blankets was the first public health intervention that stopped a budding epidemic of an arthropod-associated disease: the systematic treatment of clothes of many of the 1 million inhabitants of Naples, Italy, with pyrethrum powder and DDT powder in 1943. The account of this delousing campaign in air-raid shelters and other places in Naples has been reported (35-37). This delousing intervention stopped a budding epidemic of LBET. However, systematic treatment of clothes of all of or even a large group of the inhabitants of Bahir Dah with pyrethrum powder, DDT powder, or a synthetic pyrethroid is not ideal because of its immediate and ongoing cost.

After studying data from the London School of Hygiene and Tropical Medicine (London, UK) during World War II, we conceived a strategy that might reduce the number and severity of outbreaks of LBRF in day laborers, street children, and yekolotemaries in Bahir Dah. If successful, this strategy might be adapted to other situations in the Horn of Africa and elsewhere, where louse-associated diseases still occur. The crowded boarding houses (Figure 2) that house day laborers during the heavy rainy season and crowded dwellings of yekolotemaries of Bahir Dah and other cities and towns in Ethiopia are in many ways analogous to the crowded air-raid shelters and trenches that gave respite from bombs in World War II; the boarding houses and church dwellings in Bahir Dah give respite from torrential rains during the rainy season (June-September). Thus, we might learn from the scientific and epidemiologic investigations of medical entomologists during World War
II, such as Patrick Buxton, James Busvine and Major H. S. Leeson of the London School of Tropical Hygiene and Medicine, who found that when clothes lice were held away from their host for 7 days at $10^{\circ} \mathrm{C}$, or for 10 days at any temperature, $100 \%$ of nymphal and adult lice starved and died. Moreover, when clothes lice were held at $\leq 19^{\circ} \mathrm{C}$, $100 \%$ of eggs did not hatch (died).

Our hypothesis, drawn from these data, is that holding infested clothes away from hosts in plastic shopping bags will kill enough clothes lice to control LBRF in Bahir Dah
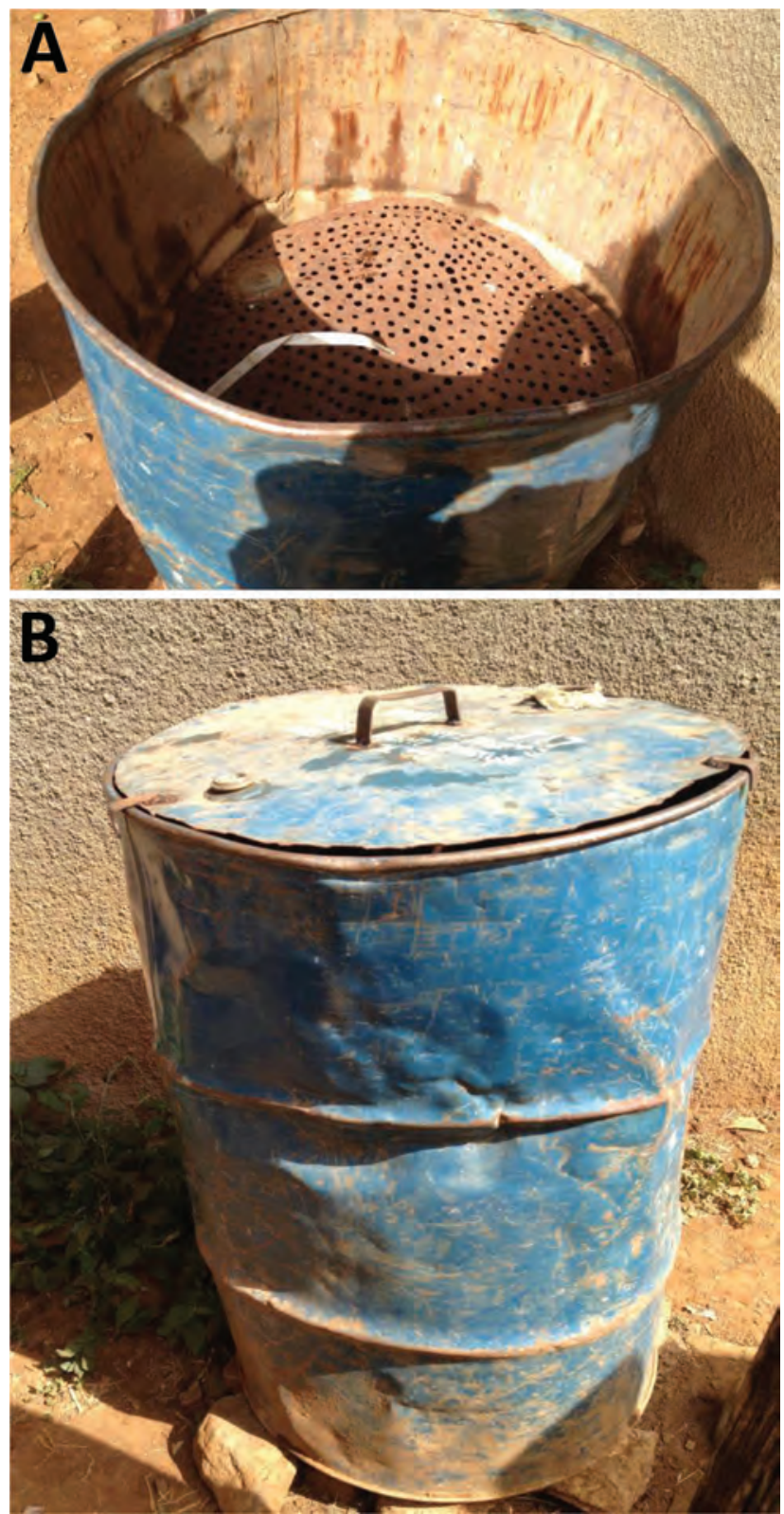

Figure 1. Wood-fired steaming barrel from a healthcare center in the highlands of Ethiopia that is used to kill clothes lice and their eggs during outbreaks of louseborne relapsing fever. A) Top view; B) front view showing lid. This $200-L$ barrel is modeled on the Stammers Serbian barrels. 


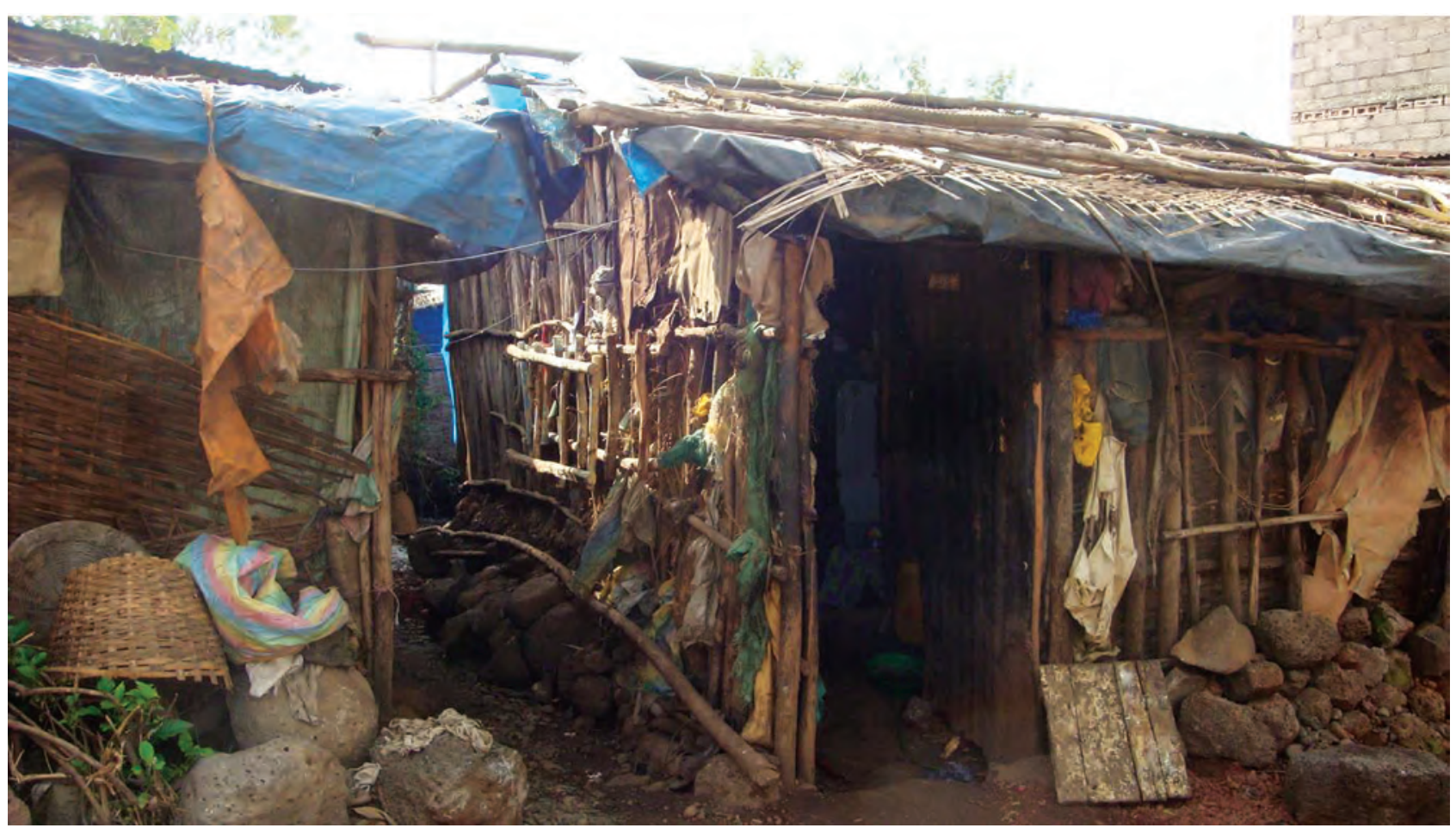

Figure 2. Typical boarding house in Bahir Dah, Ethiopia, in which many day laborers sleep at night during the heavy rainy season (June-September; Table) because it is too wet to sleep outdoors. At other times of the year when it does not rain so heavily and so often, day laborers in Bahir Dah tend to sleep outdoors and, thus, do not have to pay for lodging in boarding houses. Image courtesy of S.C. Barker.

and elsewhere in Ethiopia. Owning 2 sets of clothes would enable 1 set to be held in a plastic shopping bag for 10 days to starve to death adult and nymphal lice; even 7 days away from the host will kill most of the lice and eggs. This hypothesis might be tested in Bahir Dah and elsewhere in Ethiopia and the Horn of Africa.

It is encouraging that in at least 1 part of Ethiopia, the catchment of the Gambo General Rural Hospital in southwestern Ethiopia, the number of cases of LBRF seems to have decreased during 1997-2007 (38). The reason(s) for this decrease are unclear, although louse infestation seems to have become less intense in the patients attending the Gambo General Rural Hospital (38). We can expect a decrease in cases of LBRF in Bahir Dah and other towns and cities in Ethiopia if the prevalence and intensity of clothes lice can be substantially reduced because this has been the experience worldwide. It is not known how low the prevalence and intensity of infestation with clothes lice need to be to prevent periodic outbreaks of LBRF in day laborers, street children, and yekolotemaries in Bahir Dah (22-25). However, low-tech and simple public health strategies aimed at killing the lice and eggs that infest these 3 populations offer the prospect of reducing LBRF in these groups (22-25).

In this study, we use the name clothes lice instead of body lice for $P$. humanus lice because the name clothes

\begin{tabular}{|c|c|c|c|c|c|c|c|c|c|c|c|c|c|}
\hline \multirow[b]{2}{*}{ Variable } & \multicolumn{12}{|c|}{ Month } & \multirow[b]{2}{*}{ Year } \\
\hline & Jan & Feb & Mar & Apr & May & Jun & July & Aug & Sep & Oct & Nov & Dec & \\
\hline $\begin{array}{l}\text { Daily } \\
\text { temp., }{ }^{\circ} \mathrm{C} \\
\text { (range) }\end{array}$ & $\begin{array}{c}18.5 \\
(8-29)\end{array}$ & $\begin{array}{c}20(9- \\
31)\end{array}$ & $\begin{array}{c}21.5 \\
(11-32)\end{array}$ & $\begin{array}{c}22.5 \\
(13-32)\end{array}$ & $\begin{array}{c}22.5 \\
(13-32)\end{array}$ & $\begin{array}{c}15 \\
(13-29)\end{array}$ & $\begin{array}{c}19 \\
(13-26)\end{array}$ & $\begin{array}{c}19 \\
(13-25)\end{array}$ & $\begin{array}{c}19 \\
(12-26)\end{array}$ & $\begin{array}{c}19.5 \\
(12-27)\end{array}$ & $\begin{array}{c}19 \\
(10-28)\end{array}$ & $\begin{array}{c}18 \\
(8-28)\end{array}$ & $\begin{array}{c}20.5 \\
(11.3- \\
28.8)\end{array}$ \\
\hline $\begin{array}{l}\text { No. rainy } \\
\text { days }\end{array}$ & 1 & 1 & 2 & 3 & 10 & 18 & 28 & 28 & 20 & 10 & 3 & 1 & 125 \\
\hline $\begin{array}{l}\text { Monthly } \\
\text { rainfall, } \\
\mathrm{mm}\end{array}$ & 2 & 2 & 12 & 28 & 80 & 205 & 396 & 375 & 211 & 87 & 12 & 6 & 1,416 \\
\hline
\end{tabular}

*All values are averages. Data were obtained from the World Meteorological Organization (https://www.wmo.int/pages/index_en.html). The altitude of Bahir Dah is $1,800 \mathrm{~m}$. During the heavy rain season (June-September), it rains on most days: June, 18/30 d; July 28/31 d; August, $28 / 31 \mathrm{~d}$; and September, 20/30 d. Temp., temperature. 
lice or clothing lice (39) has at least 2 advantages over the name body lice. First, clothes lice is more accurate because, in our experience, most lice on infested persons will be found in the clothes at any time. Second, these lice go to the skin to feed. Once they have fed, they soon return to the clothes. Moreover, these lice lay most, usually all, of their eggs in clothes rather than on the body. Third, the name clothes lice draws our focus to the clothes rather than the body. Treating clothes with insecticides, steaming clothes, and changing clothes regularly has been successful in reducing the prevalence and intensity of these lice over the past 100 years since World War I. Whether clothes lice and head lice are species, subspecies, or ecotypes (sensu bacterial ecotypes) is also controversial. We have previously reviewed the history of this controversy (40), and we will not repeat it here. We will use the name $P$. humanus for clothes lice and $P$. capitis for head lice because in our judgment, the evidence for these lice being separate species is overwhelming (40), regardless of which concept of a species of insect is used.

We studied the data of Leeson (41) and the subsequent interpretation and contextualization of this data by Buxton (42) and Busvine (30). Our laboratory colony of $P$. humanus lice was started in 2000 from eggs, nymphs, and adults of the Orlando strain of $P$. humanus lice. This strain was isolated from lice at the London School of Tropical Hygiene and Medicine that were derived from the Orlando strain that had been kept for many years at the US Agriculture Bureau of Entomology and Plant Quarantine (Orlando, FL, USA). The Orlando strain of $P$. humanus lice was adapted to feeding on the blood of rabbits $(43,44)$.

\section{Killing Eggs of Clothes Lice by Holding Eggs at Suboptimal Temperatures $<32^{\circ} \mathrm{C}$}

Leeson (41) showed that 7 days at $\leq 19^{\circ} \mathrm{C}$ killed $100 \%$ of eggs of $P$. humanus clothes lice. At temperatures $>19^{\circ} \mathrm{C}$, the situation was more complicated, but the longer the eggs were held at temperatures lower than the ideal temperature for eggs $\left(32^{\circ} \mathrm{C}\right)$, the more eggs died $(41)$. We observed a complex relationship between temperatures $>19^{\circ} \mathrm{C}$ and the proportion of eggs that did not hatch (i.e., 89\% did not hatch at $24^{\circ} \mathrm{C}, 66 \%$ at $26^{\circ} \mathrm{C}$, and $12 \%$ at $29^{\circ} \mathrm{C}$ ) (Figure 3). Nonetheless, keeping eggs of clothes lice at virtually any temperature $<32^{\circ} \mathrm{C}$ killed some of the eggs. The lower the temperature, the more eggs died. The longer eggs were held at suboptimal temperature, the more eggs died (41). Leeson (41) reported that favorable temperatures for $P$. humanus lice reared on the legs of humans were $30^{\circ} \mathrm{C}-32^{\circ} \mathrm{C}$ at a relative humidity of $65 \%$. Our results were similar: $29^{\circ} \mathrm{C}-32^{\circ} \mathrm{C}$ at a relative humidity of $65 \%$ for the University of Queensland isolate of the Culpepper strain of $P$. humanus lice at the University of Queensland (S.C. Barker, unpub. data). The data of Leeson (41) showed that relative humidity does not have a substantial effect on the degree of death of eggs, although low relative humidity caused additional deaths of eggs (41).

\section{Killing Nymphal and Adult Clothes Lice by Starvation}

Leeson (41) also showed that $100 \%$ of nymphal and adult clothes lice starved to death in 7 days at $10^{\circ} \mathrm{C}$ and in 10 days regardless of the temperature (Figure 4). Newly hatched nymphs are especially susceptible to starvation. If newly hatched nymphs at $32^{\circ} \mathrm{C}$ do not receive a blood meal within 48 hours of hatching, $100 \%$ will die (S.C. Barker, unpub. data, for the Barker isolate of the Culpepper strain of $P$. humanus lice). Even 24 hours without a blood meal will kill $\approx 50 \%$ of newly hatched nymphs (S.C. Barker, unpub. data, for the Barker isolate of the Culpepper strain of $P$. humanus). The lethal effect of high temperatures $\left(>60^{\circ} \mathrm{C}\right)$ on clothes lice and their eggs is well known in Ethiopia and elsewhere. Healthcare clinics in Ethiopia and elsewhere often have 200-L steel steaming drums (Stammers Serbian barrels) (Figure 1) to kill clothes lice and their eggs in infested clothes during outbreaks of LBRF. Healthcare and medical students are instructed in the steaming drum method of killing clothes lice and their eggs in clothes and on blankets, which was first reported by Hunter in $1918(45,46)$.

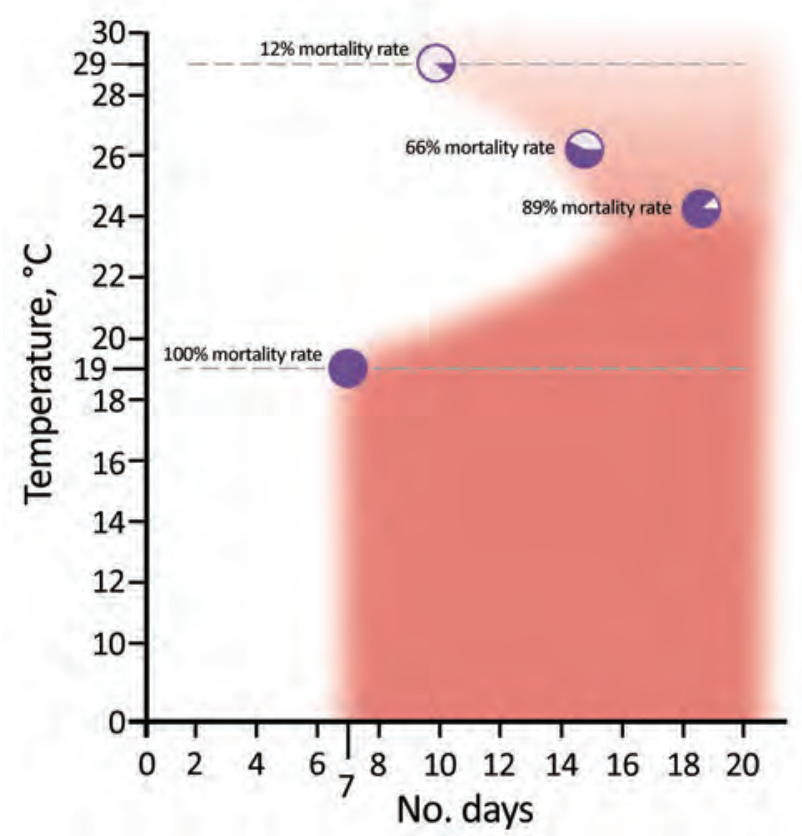

Figure 3. Mortality rates for the eggs of Pediculus humanus clothes lice, Ethiopia. Dark red shading (bottom) indicates $100 \%$ mortality rate and light red shading (top) $<100 \%$ mortality rate for eggs. At $8^{\circ} \mathrm{C}-19^{\circ} \mathrm{C}$, a total of $100 \%$ of eggs did not hatch; at $24^{\circ} \mathrm{C}$, a total of $89 \%$ of eggs did not hatch (those that hatched took 14.5 days [range 13-19 days] to hatch); at $26^{\circ} \mathrm{C}$, a total of $66 \%$ of eggs did not hatch; and at $29^{\circ} \mathrm{C}$, a total of $12 \%$ of eggs did not hatch (88\% hatched). Dotted lines denote $12 \%$ (top) and 100\% (bottom) mortality rate temperatures. Data were obtained from Leeson (41). 


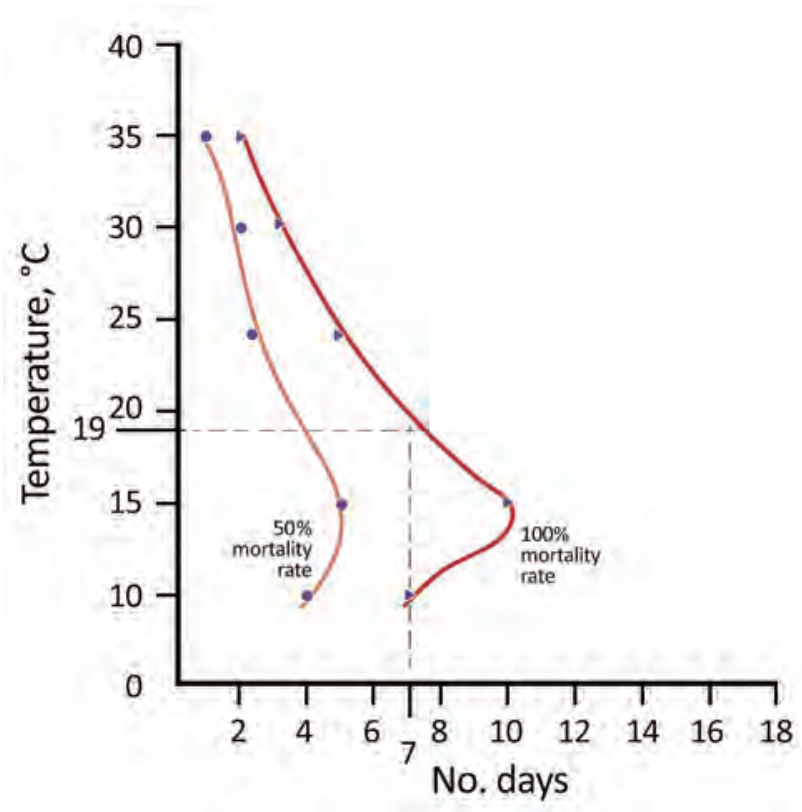

Figure 4. Number of days needed to starve to death adult and nymphal clothes lice (Pediculus humanus) at 5 temperatures $\left(10^{\circ} \mathrm{C}, 15^{\circ} \mathrm{C}, 24^{\circ} \mathrm{C}, 30^{\circ} \mathrm{C}\right.$, and $\left.35^{\circ} \mathrm{C}\right)$, Ethiopia. The mortality rate was $50 \%$ for lice after 5 days without a blood meal (i.e., away from the host) and $100 \%$ after 10 days without a blood meal, regardless of temperature. Dotted lines indicate temperatures of $0^{\circ} \mathrm{C}-19^{\circ} \mathrm{C}$ and days 0-7. Data were obtained from Buxton (42), and the figure was modified from Busvine (30).

The lethal effect of low temperatures $\left(<24^{\circ} \mathrm{C}\right)$ on clothes lice and their eggs is less well known. Clothes lice and their eggs depend on their human host. The long and intimate association between clothes lice and humans have led to clothes lice becoming completely dependent on their host for a warm environment and for food and water. In contrast to many other blood-sucking arthropods, eggs of clothes lice die in a few days at temperatures at little lower than optimum (Figure 3) (30). Moreover, clothes lice, especially newly hatched nymphs easily starve to death (Figure 4) (S.C. Barker, unpub. data). Lloyd and Byam (26), in recounting their experiences as medical servicemen in World War I, emphasized constant changing of underclothing and believed that having 2 shirts rather than 1 helped reduce infestations with clothes lice. We extend this idea to all clothes, which in tropical climates, such as in Bahir Dah, means a shirt, underpants and shorts or trousers, and a jumper or coat. In our experience, all clothes in Bahir Dah, not just underclothes, might be infested with body lice.

\section{Potential Public Health Recommendations}

If our strategy were successful, day laborers, street children, and live-in-church students in Bahir Dah might be encouraged to acquire and keep 2 sets of clothes rather than 1 set so that at any given time, 1 set of clothes might be kept in a plastic shopping bag for ideally 10 days to starve adult and nymphal lice and to kill (prevent hatching) eggs. Ten days in a plastic shopping bag at $\leq 19^{\circ} \mathrm{C}$ (e.g., on cold ceramic tile floors) should kill all eggs and lice in clothes. However, even 7 days should kill most eggs and lice (Figures 3, 4).

This hypothesis needs to be tested on clothes naturally infested with clothes lice and their eggs in Bahir Dah and elsewhere. Simple experiments on the effect of holding clothes away from hosts for 7 days and for 10 days might be conducted in boarding houses and church dwellings in Bahir Dah, and among day laborers of Bahir Dah and other areas in Ethiopia. For example, placing pieces of cloth (e.g., $20 \mathrm{~cm} \times 20 \mathrm{~cm}$ ) that were cut from naturally infested clothes that have only eggs into plastic shopping bags for 7 and 10 days would determine the effect of holding clothes away from hosts on hatching and development of nymphal lice from eggs in the cloth. All nymphal and adult lice would have been gently brushed away so that only eggs are left on the pieces of cloth. In addition, we would repeat this experiment with nymphal and adult lice that were brushed from infested clothes onto uninfested cloth (no eggs present). Likely limitations and complications to our strategy include the cost of acquiring a second set of clothes, that some lice might be displaced from clothes onto sleeping mats, and the perennial problem of reinfestation through contact with other infested clothes.

We note also the prospect of treatment with oral ivermectin to kill clothes lice. Oral ivermectin may be effective against head lice $(47,48)$ and thus might also be effective against clothes lice. Therefore, oral ivermectin might be used alone or in combination with holding infested clothes away from hosts for 10 days to kill enough clothes lice to control LBRF in Ethiopia. However, a perennial problem with any kind of drug treatment is the cost, immediate and ongoing, to day laborers, street children, and yekolotemaries. In addition, resistance to ivermectin might develop in clothes lice.

\section{Acknowledgment}

We thank Richard Pollack and 2 anonymous reviewers for providing useful corrections and suggestions and Kostas Mumcuoglu for providing the Orlando strain of $P$. humanus lice.

\section{About the Authors}

Dr. Barker is a professor of parasitology at the University of Queensland, Brisbane, Queensland, Australia. His primary research interests are the biology, evolution, and control of lice and ticks.

Ms. Barker is a doctoral candidate at the School of Veterinary Science, University of Queensland, Gatton, Queensland, Australia. Her primary research interests are the taxonomy of ticks and control of lice and ticks. 


\section{References}

1. Elbir H, Raoult D, Drancourt M. Relapsing fever borreliae in Africa. Am J Trop Med Hyg. 2013;89:288-92. http://dx.doi.org/ 10.4269/ajtmh.12-0691

2. Boutellis A, Mediannikov O, Bilcha KD, Ali J, Campelo D, Barker SC, et al. Borrelia recurrentis in head lice, Ethiopia. Emerg Infect Dis. 2013;19:796-8. http://dx.doi.org/10.3201/ eid1905.121480

3. Antinori S, Mediannikov O, Corbellino M, Grande R, Parravicini C, Bestetti G, et al. Louse-borne relapsing fever (Borrelia recurrentis) in a Somali refugee arriving in Italy: a re-emerging infection in Europe? PLoS Negl Trop Dis. 2016;10:e0004522. http://dx.doi.org/10.1371/journal.pntd.0004522

4. Antinori S, Mediannikov O, Corbellino M, Raoult D. Louse-borne relapsing fever among East African refugees in Europe. Travel Med Infect Dis. 2016;14:110-4. http://dx.doi.org/10.1016/ j.tmaid.2016.01.004

5. Ciervo A, Mancini F, di Bernardo F, Giammanco A, Vitale G, Dones $\mathrm{P}$, et al. Louseborne relapsing fever in young migrants, Sicily, Italy, July-September 2015. Emerg Infect Dis. 2016;22:1523. http://dx.doi.org/10.3201/eid2201.151580

6. Colomba C, Scarlata F, Di Carlo P, Giammanco A, Fasciana T, Trizzino M, et al. Fourth case of louse-borne relapsing fever in young migrant, Sicily, Italy, December 2015: mini review article. Public Health. 2016;139:22-6. http://dx.doi.org/10.1016/ j.puhe.2016.05.019

7. Costescu Strachinaru DI, Cambier J, Kandet-Yattara H, Konopnicki D. Relapsing fever in asylum seekers from Somalia arriving in Belgium in August 2015. Acta Clin Belg. 2016;Apr 26:1-3.

8. Cutler SJ. Refugee crisis and re-emergence of forgotten infections in Europe. Clin Microbiol Infect. 2016;22:8-9. http://dx.doi.org/10.1016/j.cmi.2015.10.018

9. Cutuli SL, De Pascale G, Spanu T, Dell'Anna AM, Bocci MG, Pallavicini F, et al. Lice, rodents, and many hopes: a rare disease in a young refugee. Crit Care. 2017;21:81. http://dx.doi.org/10.1186/ s13054-017-1666-5

10. Darcis G, Hayette MP, Bontems S, Sauvage AS, Meuris C, Van Esbroeck M, et al. Louse-borne relapsing fever in a refugee from Somalia arriving in Belgium. J Travel Med. 2016;23:taw009. https://doi.org/10.1093/jtm/taw009

11. Grecchi C, Zanotti P, Pontarelli A, Chiari E, Tomasoni LR, Gulletta $\mathrm{M}$, et al. Louse-borne relapsing fever in a refugee from Mali. Infection. 2017;45:373-6. http://dx.doi.org/10.1007/ s15010-017-0987-2

12. Hytönen J, Khawaja T, Grönroos JO, Jalava A, Meri S, Oksi J. Louse-borne relapsing fever in Finland in two asylum seekers from Somalia. APMIS. 2017;125:59-62. http://dx.doi.org/10.1111/ apm.12635

13. Jochum J, Tannich E, Tappe D, Schmiedel S. A Somali refugee with fever and abnormal blood smear [in German]. Internist (Berl). 2017;58:287-92. http://dx.doi.org/10.1007/s00108-016-0154-3

14. Keller C, Zumblick M, Streubel K, Eickmann M, Müller D, Kerwat M, et al. Hemorrhagic diathesis in Borrelia recurrentis infection imported to Germany. Emerg Infect Dis. 2016;22:917-9. http://dx.doi.org/10.3201/eid2205.151557

15. Lucchini A, Lipani F, Costa C, Scarvaglieri M, Balbiano R, Carosella S, et al. Louseborne relapsing fever among East African refugees, Italy, 2015. Emerg Infect Dis. 2016;22:298-301. http://dx.doi.org/10.3201/eid2202.151768

16. Osthoff M, Schibli A, Fadini D, Lardelli P, Goldenberger D. Louse-borne relapsing fever: report of four cases in Switzerland, June-December 2015. BMC Infect Dis. 2016;16:210. http://dx.doi.org/10.1186/s12879-016-1541-z

17. Seilmaier M, Guggemos W, Wieser A, Fingerle V, Balzer L, Fenzl T, et al. Louse-borne-relapsing-fever in refugees from the
Horn of Africa; a case series of 25 patients [in German]. Dtsch Med Wochenschr. 2016;141:e133-42.

18. Seilmaier M, Guggemos W, Alberer M, Wendtner CM, Spinner CD. Infections among refugees [in German]. Rettungsmedizin. 2017;20:216-27. http://dx.doi.org/10.1007/ s10049-016-0252-8

19. Zammarchi L, Antonelli A, Bartolini L, Pecile P, Trotta M, Rogasi PG, et al. Louse-borne relapsing fever with meningeal involvement in an immigrant from Somalia to Italy, October 2015. Vector Borne Zoonotic Dis. 2016;16:352-5. http://dx.doi.org/10.1089/vbz.2015.1928

20. Eguale T, Abate G, Balcha F. Relapsing fever in Hossana, Ethiopia: a clinical and epidemiological study. Ethiopian Journal of Health Science. 2002;12:103-8.

21. Sundnes KO, Haimanot AT. Epidemic of louse-borne relapsing fever in Ethiopia. Lancet. 1993;342:1213-5. http://dx.doi.org/ 10.1016/0140-6736(93)92190-5

22. Kassa AW, Mosie TB. Relapsing fever outbreak investigation in Bahir-Dar, Amhara Region, Ethiopia. Science Journal of Public Health. 2014;2:284-7. http://dx.doi.org/10.11648/ j.sjph.20140204.16

23. Yimer M, Mulu W, Ayalew W, Abera B. Louse-borne relapsing fever profile at Felegehiwot referral hospital, Bahir Dar city, Ethiopia: a retrospective study. BMC Res Notes. 2014b;7:250 http://dx.doi.org/10.1186/1756-0500-7-250

24. Yimer M, Abera B, Mulu W, Bezabib B. Knowledge, attitude and practices of high risk populations on louse- borne relapsing fever in Bahir Dar city, north-west Ethiopia. Science Journal of Public Health. 2014;2:15-22. http://dx.doi.org/10.11648/j.sjph.20140201.13

25. Yimer M, Abera B, Mulu W, Bezabih B, Mohammed J. Prevalence and risk factors of louse-borne relapsing fever in high risk populations in Bahir Dar city northwest, Ethiopia. BMC Res Notes. 2014a;7:615. http://dx.doi.org/10.1186/1756-0500-7-615

26. Lloyd L, Byam W. Lice and their menace to man: Edinburgh (UK): Frowde; 1919.

27. Cutler SJ, Abdissa A, Trape JF. New concepts for the old challenge of African relapsing fever borreliosis. Clin Microbiol Infect. 2009; 15:400-6. http://dx.doi.org/10.1111/j.1469-0691. 2009.02819.x

28. Cutler SJ, Bonilla EM, Singh RJ. Population structure of East African relapsing fever Borrelia spp. Emerg Infect Dis. 2010;16:1076-80. http://dx.doi.org/10.3201/eid1607.091085

29. Gratz NG. Epidemiology of louse infestations. New York: Marcel Dekker; 1985. p. 187-98.

30. Busvine JR. Bionomics of lice. Scientific publication no. 263. Washington (DC): Pan American Health Organization; 1973. p. 149-68.

31. Barker SC, Altman PM. A randomised, assessor blind, parallel group comparative efficacy trial of three products for the treatment of head lice in children-melaleuca oil and lavender oil, pyrethrins and piperonyl butoxide, and a "suffocation" product. BMC Dermatol. 2010;10:6. http://dx.doi.org/10.1186/ 1471-5945-10-6

32. Barker SC, Altman PM. An ex vivo, assessor blind, randomised, parallel group, comparative efficacy trial of the ovicidal activity of three pediculicides after a single application-melaleuca oil and lavender oil, eucalyptus oil and lemon tea tree oil, and a "suffocation" pediculicide. BMC Dermatol. 2011;11:14. http://dx.doi.org/10.1186/1471-5945-11-14

33. Barker SC, Burgess I, Meinking TL, Mumcuoglu KY. International guidelines for clinical trials with pediculicides. Int J Dermatol. 2012;51:853-8. http://dx.doi.org/10.1111/ j.1365-4632.2011.05446.x

34. Mumcuoglu KY, Friger M, Cohen R. Use of temperature and water immersion to control the human body louse (Anoplura: 
Pediculidae). J Med Entomol. 2006;43:723-5. http://dx.doi.org/ 10.1093/jmedent/43.4.723

35. Wheeler CM. Control of typhus in Italy 1943-1944 by use of DDT. Am J Public Health Nations Health. 1946;36:119-29. http://dx.doi.org/10.2105/AJPH.36.2.119

36. Soper FL, Davis WA, Markham F, Eiehl LA, Buck P. Louse powder studies in North Africa. Arch de I'Institut Pasteur d'Algerie. 1943;23:183-223.

37. Service AP. DDT, weapon against disease. In: Service AP, editor. War Department film bulletin. United States: Bethesda (MD): NIH US National Library of Medicine digital Collections; 1945.

38. Ramos JM, Malmierca E, Reyes F, Tesfamariam A. Results of a 10-year survey of louse-borne relapsing fever in southern Ethiopia: a decline in endemicity. Ann Trop Med Parasitol. 2008;102:467-9. http://dx.doi.org/10.1179/136485908X300887

39. Cutler SJ. Relapsing fever borreliae: a global review. Clin Lab Med. 2015;35:847-65. http://dx.doi.org/10.1016/j.cll.2015.07.001

40. Xiong H, Campelo D, Boutellis A, Raoult D, Alem M, Ali J, et al. SNPs in entire mitochondrial genome sequences (approximately $15.4 \mathrm{~kb}$ ) and cox1 sequences (approximately $486 \mathrm{bp}$ ) resolve body and head lice from doubly infected people from Ethiopia, China, Nepal, and Iran but not France. J Med Entomol. 2014a;51: 1199-207. http://dx.doi.org/10.1603/ME14001

41. Leeson HS. The effect of temperature upon the hatching of the eggs of Pediculus humanus corporis de Geer (Anoplura). Parasitology. 1941;33:243-9. http://dx.doi.org/10.1017/S0031182000024434
42. Buxton PA. The louse: an account of the lice which infest man, their medical importance and control. London: Edward Arnold; 1947.

43. Culpepper GH. Factors influencing the rearing and maintenance of a laboratory colony of the body louse. J Econ Entomol. 1946;39:472-4. http://dx.doi.org/10.1093/jee/39.4.472

44. Culpepper GH. The rearing and maintenance of a laboratory colony of the body louse. Am J Trop Med. 1944;s1-24:327-9. http://dx.doi.org/10.4269/ajtmh.1944.s1-24.327

45. Hunter $\mathrm{W}$. A lecture on the prevention and arrest of lice-borne diseases by new methods of disinfection. Lancet. 1918;192:347-51. http://dx.doi.org/10.1016/S0140-6736(00)95758-1

46. Hunter W. New methods of disinfection for the prevention and arrest of lice-borne diseases (typhus, relapsing, and trench fevers). BMJ. 1918;2:198-201

47. Chosidow O, Giraudeau B, Cottrell J, Izri A, Hofmann R, Mann SG, et al. Oral ivermectin versus malathion lotion for difficult-to-treat head lice. N Engl J Med. 2010;362:896-905. http://dx.doi.org/10.1056/NEJMoa0905471

48. Pariser DM, Meinking TL, Bell M, Ryan WG. Topical 0.5\% ivermectin lotion for treatment of head lice. N Engl J Med. 2012;367:1687-93. http://dx.doi.org/10.1056/NEJMoa1200107

Address for correspondence: Stephen C. Barker, Parasitology Section, School Chemistry and Molecular Biosciences, University of Queensland, Brisbane 4072, Queensland, Australia; email: s.barker@uq.edu.au

\section{EI D Podcast: Louseborne Relapsing Fever in Europe}

Louseborne relapsing fever was once widely distributed in all geographic areas, including Europe and North America, occurring in association with poverty and overcrowding. The causative agent is the spirochete bacterium Borrelia recurrentis. In nature, the only relevant vector is the body louse, which feeds only on humans; no other reservoir for this infection is known. 


\section{Differential Shedding and Antibody Kinetics of Zika and Chikungunya Viruses, Brazil}

\author{
Fernando A. Bozza, ${ }^{1}$ Andres Moreira-Soto, ${ }^{1}$ \\ Alexandra Rockstroh, Carlo Fischer, \\ Alessandra D. Nascimento, Andrea S. Calheiros, \\ Christian Drosten, Patrícia T. Bozza, \\ Thiago Moreno L. Souza, \\ Sebastian Ulbert, Jan Felix Drexler
}

In seroconversion panels obtained from patients from Brazil, diagnostic testing for Zika virus infection was improved by combining multiple antibody isotypes, techniques, and antigens, but sensitivity remained suboptimal. In contrast, chikungunya virus diagnostic testing was unambiguous. Recurrent recent arbovirus infections suggested by serologic data and unspecific symptoms highlight the need for exhaustive virologic testing.

$\mathrm{I}^{2}$ n 2013, Zika virus and chikungunya virus (CHIKV) 1 emerged in Latin America $(1,2)$. Their overlapping symptoms challenge accurate diagnosis on the basis of clinical manifestations (3). Direct Zika virus and CHIKV detection is limited to the acute phase of infection (4). Serologic detection of Zika virus-specific antibodies is hampered by low specificity and sensitivity of tests because of immune responses elicited by prior infection with other endemic flaviviruses (e.g., dengue virus [DENV]) $(5,6)$. In addition, lack of adequate specimens limits studies evaluating the performance of diagnostic tests in tropical areas $(7,8)$. To evaluate these challenges, we analyzed virus shedding and antibody responses over time in patients in Brazil sampled during the 2016 Zika virus and CHIKV outbreaks.

Author affiliations: National Institute of Infectious Diseases Evandro Chagas, Oswaldo Cruz Foundation (FIOCRUZ), Rio de Janeiro, Brazil (F.A. Bozza, A.D. Nascimento); D'Or Institute for Research and Education, Rio de Janeiro (F.A. Bozza,

A.D. Nascimento); Charité-Universitätsmedizin Berlin, corporate member of Freie Universität Berlin, Humboldt-Universität zu Berlin, and Berlin Institute of Health, Institute of Virology, Berlin, Germany (A. Moreira-Soto, C. Fischer, C. Drosten, J.F. Drexler); Fraunhofer Institute for Cell Therapy and Immunology, Leipzig, Germany (A. Rockstroh, S. Ulbert); Instituto Oswaldo Cruz, Rio de Janeiro (A.S. Calheiros, P.T. Bozza); German Centre for Infection Research, Berlin (C. Drosten, J.F. Drexler); Center for Technological Development in Health, Rio de Janeiro (T.M.L. Souza) Martsinovsky Institute of Medical Parasitology, Tropical and VectorBorne Diseases, Sechenov University, Moscow, Russia (J.F. Drexler)

DOI: https://doi.org/10.3201/eid2502.180166

\section{The Study}

We prospectively sampled patients in 4 time points up to 90 days post-symptom onset (dpo) (Table 1; Figure 1, panel A; Appendix, https://wwwnc.cdc.gov/EID/article/25/2/180166-App1.pdf). The cohort comprised 15 patients with acute Zika virus infection (5 male, 10 female; median age 39.0 years [interquartile range $31.0-44.0$ years]) and 18 patients with acute CHIKV infection (10 male, 8 female; median age 39.0 years [interquartile range $31.0-57.3$ years]), determined by detection of viral RNA in blood or urine 1-9 dpo (Appendix Figures 1, 2). All Zika virus belonged to the Asian lineage (2), and all CHIKV to the East/Central/South African lineage, according to envelope-based typing.

At enrollment, Zika virus patients most frequently reported fever, rash, and arthralgia (80\% each), and CHIKV patients most frequently reported arthralgia (100\%), fever (89\%), and myalgia (89\%) (Table 2). No co-infection with Zika virus, CHIKV, or DENV was detected by real-time reverse transcription PCR (rRT-PCR). However, serologic analyses found that 4 (27\%) Zika virus-infected patients also had CHIKV IgM at enrollment, and 1 (7\%) had DENV IgM (Appendix Table 1, Figure 3). Similarly, 3 (17\%) CHIKV-infected patients had Zika virus IgM, and 4 (22\%) CHIKV-infected patients had DENV IgM at enrollment (Appendix Figure 4). We cannot exclude the possibility of cross-reactivity between Zika virus-specific and DENVspecific antibodies because 2 CHIKV patients simultaneously showed Zika virus and DENV IgM in an envelopebased ELISA (Appendix Table 2). Seventy-nine percent of Zika virus and $83 \%$ of CHIKV patients showed serologic evidence for past DENV infection at enrollment (Appendix Figures 1, 2). Thus, recent infections with heterologous arboviruses might bias attributing infection-specific symptoms for Zika virus and CHIKV.

Consistent with previous studies $(4,9)$, Zika virus loads in serum and urine were low up to 9 dpo $\left(\approx 10^{4}\right.$ RNA copies/mL) (Figure 1, panel B), whereas CHIKV loads were $\approx 100$-fold higher $\left(\approx 10^{6} \mathrm{RNA}\right.$ copies $/ \mathrm{mL}$ ) (Figure 1 , panel C). However, unlike with Zika virus, CHIKV loads decreased significantly ( $p<0.001$ by $t$ test) from 5 dpo onward, and viral loads in urine were consistently low (Figure 1, panels D, E).

Next, to assess the antibody kinetics of Zika virus and CHIKV, we measured antibody responses over time

${ }^{1}$ These authors contributed equally to this article. 
Table 1. Sampling details for retrospective study of differential shedding and antibody kinetics of Zika virus and CHIKV, Brazil, 2016*

\begin{tabular}{|c|c|c|c|}
\hline Sample no. & $\begin{array}{c}\text { Virus } \\
\text { detected }\end{array}$ & $\begin{array}{l}\text { Days from } \\
\text { symptom onset } \\
\text { to sampling }\end{array}$ & $\begin{array}{c}\text { Collection date } \\
\text { of acute-phase } \\
\text { samples }\end{array}$ \\
\hline DQ005 & Zika virus & 2 & Mar 14 \\
\hline DQ028 & Zika virus & 1 & Mar 21 \\
\hline DQ042 & Zika virus & 3 & Mar 23 \\
\hline DQ47 & Zika virus & 2 & Mar 28 \\
\hline DQ049 & Zika virus & 1 & Mar 28 \\
\hline DQ058 & Zika virus & 4 & Mar 30 \\
\hline DQ60 & Zika virus & 2 & Mar 30 \\
\hline DQ62 & Zika virus & 3 & Mar 30 \\
\hline DQ75 & Zika virus & 3 & Apr 4 \\
\hline DQ77 & Zika virus & 5 & Apr 5 \\
\hline DQ108 & Zika virus & 2 & Apr 13 \\
\hline DQ116 & Zika virus & 2 & Apr 14 \\
\hline DQ125 & Zika virus & 3 & Apr 18 \\
\hline DQ131 & Zika virus & 5 & Apr 18 \\
\hline DQ246 & Zika virus & 5 & Jun 24 \\
\hline DQ030 & CHIKV & 3 & Mar 21 \\
\hline DQ045 & CHIKV & 5 & Mar 24 \\
\hline DQ054 & CHIKV & 2 & Mar 30 \\
\hline DQ056 & CHIKV & 2 & Mar 30 \\
\hline DQ057 & CHIKV & 3 & Mar 30 \\
\hline DQ061 & CHIKV & 2 & Mar 30 \\
\hline DQ071 & CHIKV & 4 & Apr 4 \\
\hline DQ074 & CHIKV & 1 & Apr 4 \\
\hline DQ079 & CHIKV & 3 & Apr 5 \\
\hline DQ083 & CHIKV & 3 & Apr 6 \\
\hline DQ085 & CHIKV & 4 & Apr 7 \\
\hline DQ097 & CHIKV & 3 & Apr 11 \\
\hline DQ113 & CHIKV & 5 & Apr 13 \\
\hline DQ144 & CHIKV & 4 & Apr 25 \\
\hline DQ170 & CHIKV & 2 & May 3 \\
\hline DQ195 & CHIKV & 2 & May 11 \\
\hline DQ210 & CHIKV & 2 & May 16 \\
\hline DQ220 & CHIKV & 4 & May 17 \\
\hline${ }^{*} \mathrm{CHIKV}, \mathrm{ch}$ & nya virus. & & \\
\hline
\end{tabular}

by commercial and in-house serologic tests. In a widely used nonstructural (NS) protein 1 antigen-based ELISA, Zika virus IgM seroconversion was low (33\% [5/15]), whereas CHIKV IgM seroconversion was 100\% using an envelope-based ELISA $(\mathrm{p}<0.0001$ by Fisher exact test) (Figure 2, panel A; Appendix Tables 1, 2). Use of an in-house envelope-based ELISA increased the Zika virus IgM detection rate to $50 \%$ (7/14), and use of a commercially available $\mu$-capture ELISA increased it to $43 \%(6 / 14)$ (Figure 2, panel A). Despite differential sensitivity, concordant results from different assays suggest comparable specificity of IgM detection (Appendix Table 1). The use of NS1-based IgA as a marker of acute infection increased the detection rate to $53 \%(8 / 15)$ over that of the NS1-based IgM ELISA. All IgM-positive patients also showed IgA, which increased during acute and subacute phases of infection and decreased during convalescence (Figure 2, panel B; Appendix Figure 3). This finding supports the usability of IgA-based serologic methods as an alternative or additional marker to IgM-based methods to detect acute Zika virus infection.
The detection rate increased 2-fold when we used NS1based IgA from when we used NS1-based IgM 5-9 dpo, suggesting that IgA could be used at later stages of infection (Appendix Figures 1, 5). Our findings indicate that serologic detection of acute Zika virus infection can be improved $\approx 2$-fold by use of different antibody classes and antigens but remains poorly sensitive in flavivirusendemic areas.

All Zika virus-infected patients showed IgG responses across the 4 time points in $\geq 1$ assay (Figure 2, panels C, D). Plaque reduction neutralization tests (PRNTs) were negative for 2 of 14 rRT-PCR-confirmed Zika virus cases detected by NS1-based IgG ELISA. Without rRT-PCR confirmation, these cases would have been classified false positive (Appendix Table 1). This observation might be explained by differential sensitivity of PRNT and ELISA (10) or false-positive results of the Zika virus NS1-based ELISA in secondary flavivirus infections (6). Similarly, the antibody kinetics of Zika virus NS1-based IgG, envelopebased IgG, and PRNT suggested either relatively early IgG seroconversion or cross-reactivity during acute stages of infection resulting from unspecific immune responses against other flaviviruses (11) (Figure 2, panel D). In contrast, CHIKV IgG seroconversion occurred at later stages (Figure 2, panel D; Appendix Figure 5), possibly associated with strong and long-lasting CHIKV-specific IgM responses (Appendix Figure 4).

\section{Conclusions}

We provide pivotal data on Zika virus and CHIKV diagnostic challenges in a Latin American setting. Limitations of our study include the relatively small number of patients, sampling at heterogeneous dpo and heterogeneous numbers of samples per dpo, and lack of acutely DENVinfected patients to assess test specificity. The strengths of our study include rRT-PCR-confirmed infections, waiving the need to define serologic assays prone to crossreactivity as standards, sampling during Zika virus and CHIKV outbreaks $(1,2)$, sequential sampling of patients up to $90 \mathrm{dpo}$, use of multiple antigens and immunoglobulin classes, and the combination of molecular and serologic testing methods.

Our data suggest reliable diagnostic testing for acute CHIKV infections by IgM detection from 5 dpo onward. This finding might enable waiving labor-intense and costly molecular protocols in many patients, minimizing costs for public health systems and cohort studies investigating arbovirus pathogenesis. However, reliability of CHIKV serologic diagnostic tests must be reevaluated for co-circulating genotypes (12) and for the antigenically related Mayaro virus (13) if it emerges in Latin America.

The difficulties of adequately diagnosing Zika virus infections in areas to which it is endemic have major 

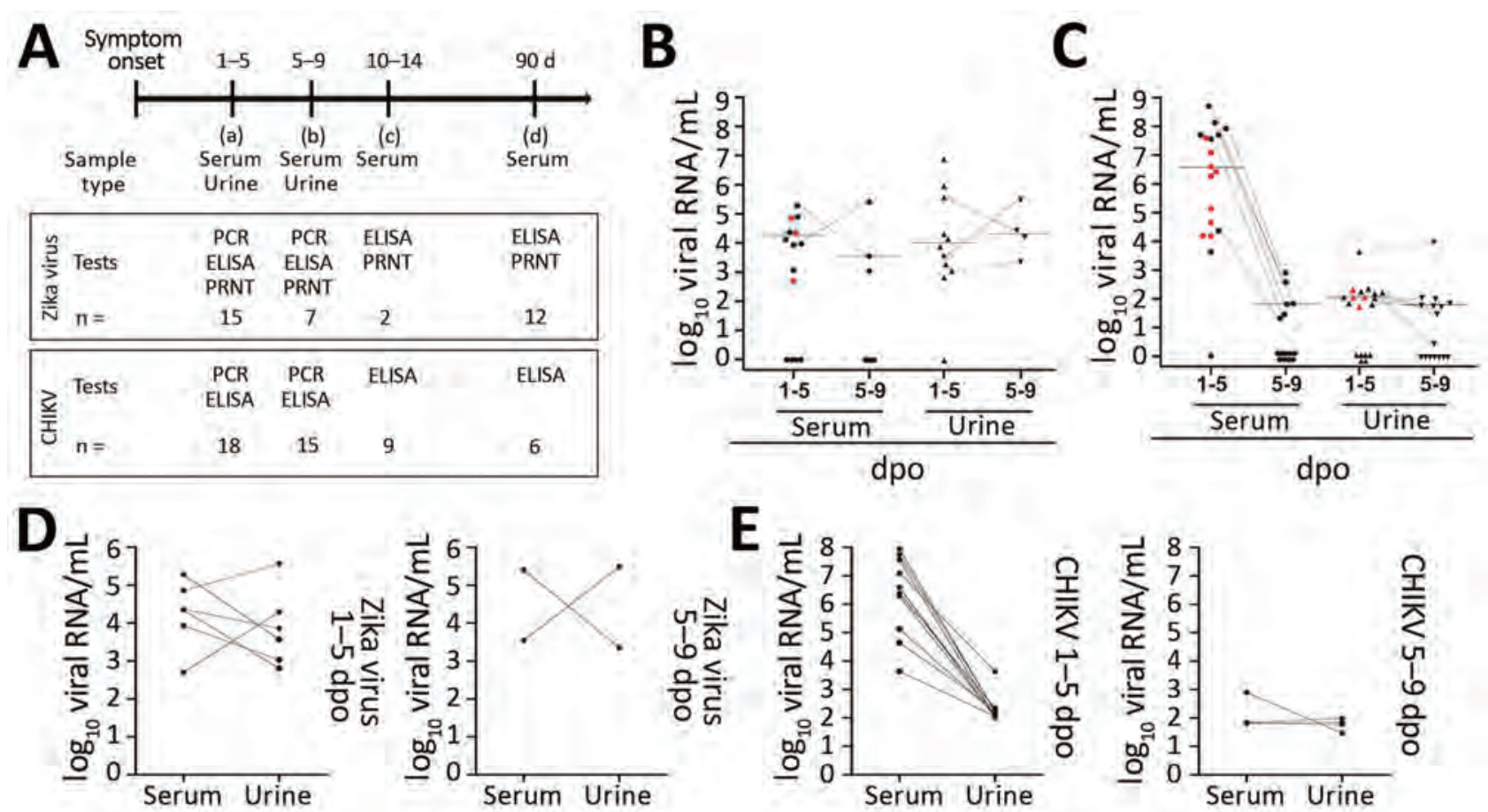

Figure 1. Overview of diagnostic testing and shedding dynamics for Zika virus and CHIKV among patients in Brazil, 2016. A) Timeline of sampling and number of samples for each test. B, C) Zika virus (B) and CHIKV (C) loads in different body fluids at 1-5 and 5-9 dpo. Black dots indicate single samples. Red dots indicate samples taken 1-5 dpo that were negative 5-9 dpo. Dotted lines indicate paired samples that were positive at both time points. Bold line indicates the median. D, E) Viral loads of Zika virus (D) and CHIKV (E) in paired urine and serum samples from individual patients, 1-5 and 5-9 dpo. Data were analyzed using GraphPad Prism 5 (GraphPad Software, Inc., https://www.graphpad.com). CHIKV, chikungunya virus; dpo, days post-symptom onset; PRNT, plaque reduction neutralization test.

implications for public health. Reliable testing for flaviviruses in such areas will be key for epidemiologic studies on Zika virus and assessments of the safety of flavivirus vaccination programs, as illustrated by more severe dengue infections in DENV-seronegative individuals who received a live attenuated dengue vaccine (14).

For pregnant women and couples intending pregnancy, accurate diagnosis of acute or past Zika virus infection is crucial. The steep increase in requests for abortion in Latin America illustrates the effect of the Zika virus outbreak on reproductive medicine (15).

\begin{tabular}{|c|c|c|}
\hline Symptom & $\begin{array}{c}\text { Zika virus, no. (\%), } \\
n=15\end{array}$ & $\begin{array}{c}\text { CHIKV, no. (\%), } \\
n=18\end{array}$ \\
\hline Rash & $12(80)$ & $9(50)$ \\
\hline Fever & $12(80)$ & $16(89)$ \\
\hline Arthralgia & $12(80)$ & $18(100)$ \\
\hline Myalgia & $9(60)$ & $16(89)$ \\
\hline Cephalea & $8(53)$ & $12(67)$ \\
\hline Retro-orbital pain & $5(33)$ & $8(44)$ \\
\hline Edema & $4(27)$ & 3 (17) \\
\hline Nausea, vomiting & $3(20)$ & $6(33)$ \\
\hline Conjunctivitis & $2(13)$ & $5(28)$ \\
\hline
\end{tabular}

Our results highlight that definite exclusion of acute Zika virus infections is challenging in a considerable proportion of patients. However, although limited by a small number of samples, our data highlight the attainability of more accurate Zika virus diagnostic testing by combining molecular and serologic tests using different antibody classes, antigens, and methods and by monitoring an increase of IgG titers in follow-up serum samples. Our data will help clinicians and health authorities build reliable diagnostic algorithms for Zika virus and CHIKV and highlight that exhaustive testing of arboviral infections is required for attributing frequencies of infection-specific symptoms.

\section{Acknowledgments}

We thank Ignacio Postigo-Hidalgo, Jens Miguel Warnecke, and Thiago Carvalho for technical assistance.

This work was supported by the European Union's Horizon 2020 Research and Innovation Programme through the ZIKAlliance project (grant agreement no. 734548), the German Centre for Infection Research through the ZIKApath project, by the Conselho Nacional de Desenvolvimento e Pesquisa (CNPq) and Fundação de Amparo à Pesquisa do Estado do Rio de Janeiro (FAPERJ). 
Figure 2. Zika virus and CHIKV antibody dynamics among samples from patients in Brazil, 2016. A) Percentage seroconversion for markers of acute infection with Zika virus and CHIKV (IgM NS1-based Zika virus ELISA, IgM envelopebased Zika virus ELISA, IgM $\mu$-capture Zika virus ELISA, IgA NS1-based Zika virus ELISA, IgM CHIKV ELISA) at any time point. B) Median ELISA ratios for Zika virus and CHIKV IgM and IgA over time. C) Percentage seroconversion for markers of convalescence after Zika virus and CHIKV infection (IgG NS1based Zika virus ELISA and IgG envelope-based Zika virus ELISA, Zika virus PRNT $_{50}$, IgG CHIKV ELISA) at any time point. D) Median ELISA ratios for Zika virus and CHIKV IgG over time. Numbers of specimens per time point are shown in Figure 1. Dashed lines indicate signal-tocutoff ratios of $\geq 1.1$ considered positive for all ELISAs except $\mu$-capture ELISA, for which the dashed line indicates a signalto-cutoff ratio of $\geq 10$, considered

A

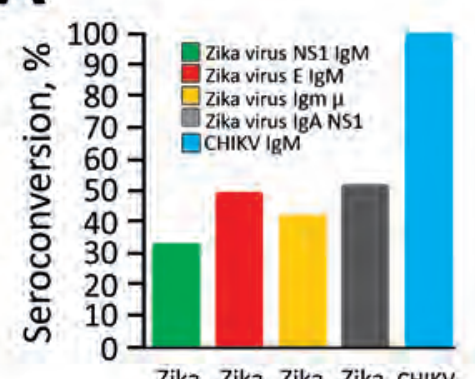

Zika Zika Zika Zika CHIKV virus virus virus virus $\mathrm{IgM}$ $\lg M \lg M \lg M \lg A$ NS1 $E$ H NS1

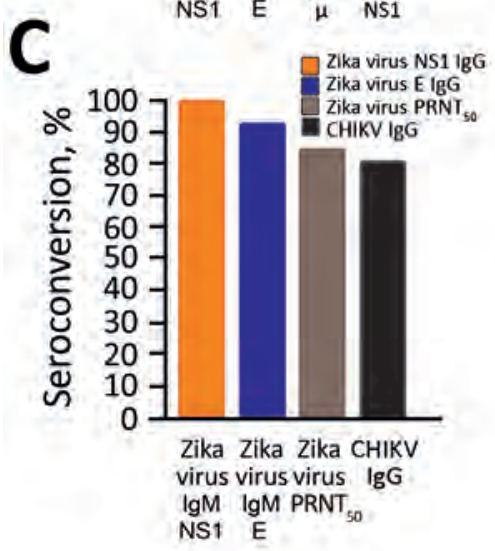

B

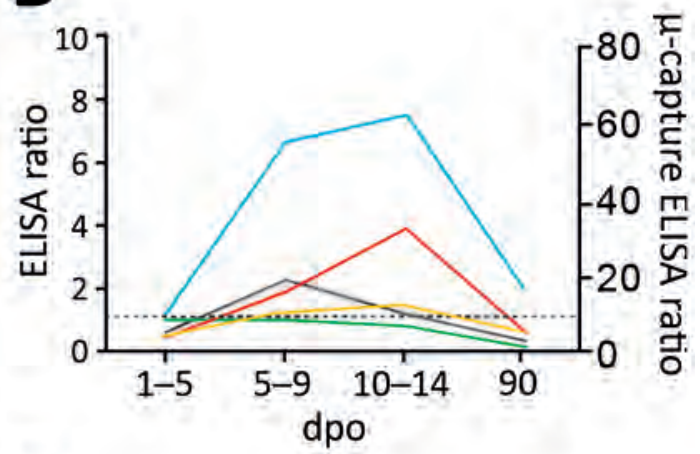

D

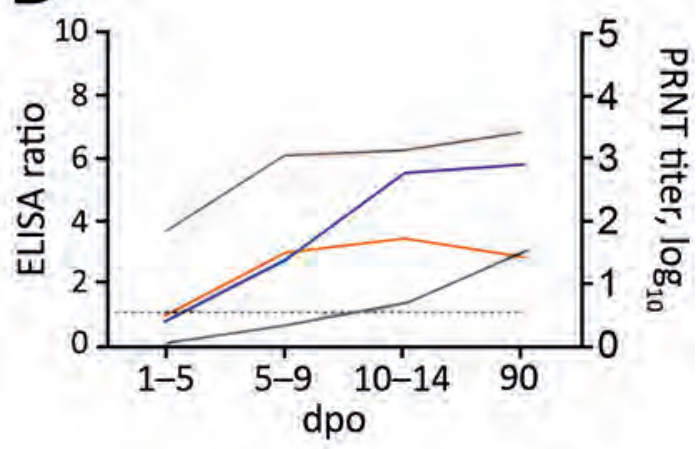
positive by the manufacturer. See Appendix Figure 5 (https://wwwnc.cdc.gov/EID/article/25/2/18-0166-App1.pdf) for the percentage de novo seroconversion of Zika virus and CHIKV in different assays per time point. CHIKV, chikungunya virus; dpo, days postsymptom onset; E, envelope; NS, nonstructural protein; PRNT, plaque reduction neutralization test.

\section{About the Author}

Dr. F.A. Bozza is a senior scientist and head of the Laboratório de Medicina Intensiva, Fundação Oswaldo Cruz Rio de Janeiro. His research focuses on the host immune response and metabolic adaptation to severe infections.

\section{References}

1. Nunes MR, Faria NR, de Vasconcelos JM, Golding N, Kraemer MU, de Oliveira LF, et al. Emergence and potential for spread of chikungunya virus in Brazil. BMC Med. 2015;13:102. http://dx.doi.org/10.1186/s12916-015-0348-x

2. Metsky HC, Matranga CB, Wohl S, Schaffner SF, Freije CA, Winnicki SM, et al. Zika virus evolution and spread in the Americas. Nature. 2017;546:411-5. http://dx.doi.org/10.1038/ nature22402

3. Musso D, Gubler DJ. Zika Virus. Clin Microbiol Rev. 2016;29:487-524. http://dx.doi.org/10.1128/CMR.00072-15

4. Corman VM, Rasche A, Baronti C, Aldabbagh S, Cadar D, Reusken CB, et al. Assay optimization for molecular detection of Zika virus. Bull World Health Organ. 2016;94:880-92. http://dx.doi.org/10.2471/BLT.16.175950

5. Netto EM, Moreira-Soto A, Pedroso C, Höser C, Funk S, Kucharski AJ, et al. High Zika virus seroprevalence in Salvador, northeastern Brazil limits the potential for further outbreaks. MBio. 2017;8:01390-17. http://dx.doi.org/10.1128/mBio.01390-17
6. Felix AC, Souza NCS, Figueiredo WM, Costa AA, Inenami M, da Silva RMG, et al. Cross reactivity of commercial anti-dengue immunoassays in patients with acute Zika virus infection. J Med Virol. 2017;89:1477-9. http://dx.doi.org/10.1002/jmv.24789

7. Steinhagen K, Probst C, Radzimski C, Schmidt-Chanasit J, Emmerich P, van Esbroeck M, et al. Serodiagnosis of Zika virus (ZIKV) infections by a novel NS1-based ELISA devoid of crossreactivity with dengue virus antibodies: a multicohort study of assay performance, 2015 to 2016. Euro Surveill. 2016;21:30426. http://dx.doi.org/10.2807/1560-7917.ES.2016.21.50.30426

8. L'Huillier AG, Hamid-Allie A, Kristjanson E, Papageorgiou L, Hung S, Wong CF, et al. Evaluation of Euroimmun anti-Zika virus IgM and IgG enzyme-linked immunosorbent assays for Zika virus serologic testing. J Clin Microbiol. 2017;55:2462-71. http://dx.doi.org/10.1128/JCM.00442-17

9. Jain J, Nayak K, Tanwar N, Gaind R, Gupta B, Shastri JS, et al. Clinical, serological, and virological analysis of 572 chikungunya patients from 2010 to 2013 in India. Clin Infect Dis. 2017;65:13340. http://dx.doi.org/10.1093/cid/cix283

10. Lindsey NP, Staples JE, Powell K, Rabe IB, Fischer M, Powers AM, et al. Ability to serologically confirm recent Zika virus infection in areas with varying past incidence of dengue virus infection in the United States and U.S. territories in 2016. J Clin Microbiol. 2017;56:e01115-7. http://dx.doi.org/10.1128/ JCM.01115-17

11. Priyamvada L, Quicke KM, Hudson WH, Onlamoon N, Sewatanon J, Edupuganti S, et al. Human antibody responses after dengue virus infection are highly cross-reactive to Zika virus. Proc 
Natl Acad Sci U S A. 2016;113:7852-7. http://dx.doi.org/10.1073/ pnas. 1607931113

12. Weaver SC, Lecuit M. Chikungunya virus and the global spread of a mosquito-borne disease. N Engl J Med. 2015;372:1231-9. http://dx.doi.org/10.1056/NEJMra1406035

13. Hassing RJ, Leparc-Goffart I, Tolou H, van Doornum G, van Genderen PJ. Cross-reactivity of antibodies to viruses belonging to the Semliki forest serocomplex. Euro Surveill. 2010;15:19588.

14. World Health Organization. Updated questions and answers related to the dengue vaccine Dengvaxia ${ }^{\circledR}$ and its use [cited 2018
Jan 30]. http://www.who.int/immunization/diseases/dengue/ q_and_a_dengue_vaccine_dengvaxia_use/en/

15. Aiken ARA, Scott JG, Gomperts R, Trussell J, Worrell M, Aiken CE. Requests for abortion in Latin America related to concern about Zika virus exposure. N Engl J Med. 2016;375: 396-8. http://dx.doi.org/10.1056/NEJMc1605389

Address for correspondence: Jan Felix Drexler, Helmut-Ruska-Haus, Institute of Virology, Campus Charité Mitte, Charitéplatz 1, 10098 Berlin, Germany; email: felix.drexler@charite.de

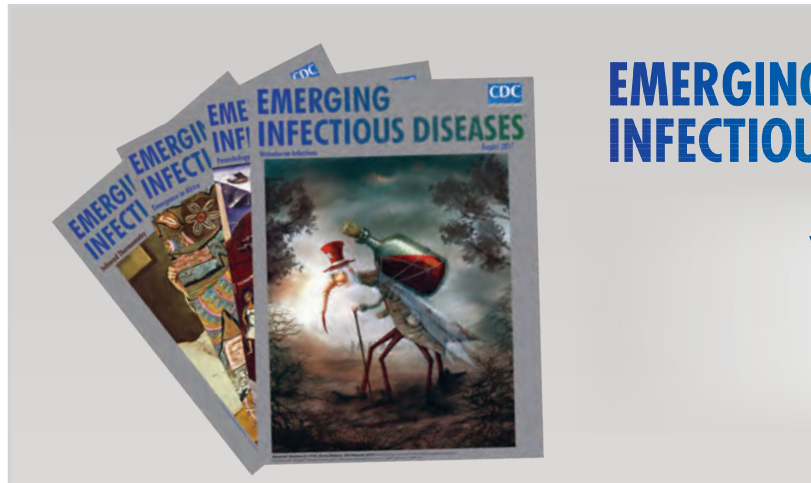

- Added Value of Next-Generation Sequencing for Multilocus Sequence Typing Analysis of a Pneumocystis jirovecii Pneumonia Outbreak

- Bartonella quintana, an Unrecognized Cause of Infective Endocarditis in Children in Ethiopia

- Characteristics of Dysphagia in Infants with Microcephaly Caused by Congenital Zika Virus Infection, Brazil, 2015

- Zika Virus Infection in Patient with No Known Risk Factors, Utah, USA, 2016

- Acute Febrile Illness and Complications Due to Murine Typhus, Texas, USA

- High Infection Rates for Adult Macaques after Intravaginal or Intrarectal Inoculation with Zika Virus

- Lyme Borreliosis in Finland, 1995-2014

- Characterization of Fitzroy River Virus and Serologic Evidence of Human and Animal Infection

- Genomic Characterization of Recrudescent Plasmodium malariae after Treatment with Artemether/Lumefantrine

- Molecular Characterization of Corynebacterium diphtheriae Outbreak Isolates, South Africa, March-June 2015

- Clinical Laboratory Values as Early Indicators of Ebola Virus Infection in Nonhuman Primates

- Maguari Virus Associated with Human Disease

- Human Infection with Highly Pathogenic Avian Influenza $\mathrm{A}(\mathrm{H} 7 \mathrm{~N} 9)$ Virus, China

- Genesis of Influenza A(H5N8) Viruses

\section{August 2017}

\section{Vectorborne Infections}

- Human Metapneumovirus and Other Respiratory Viral Infections during Pregnancy and Birth, Nepal

- Global Spread of Norovirus Gll.17 Kawasaki 308, 2014-2016

- Preliminary Epidemiology of Human Infections with Highly Pathogenic Avian Influenza A(H7N9) Virus, China, 2017

- Real-Time Evolution of Zika Virus Disease Outbreak, Roatán, Honduras

- Clonal Expansion of New Penicillin-Resistant Clade of Neisseria meningitidis Serogroup W Clonal Complex 11, Australia

- Density-Dependent Prevalence of Francisella tularensis in Fluctuating Vole Populations, Northwestern Spain

- Occupational Exposures to Ebola Virus in Ebola Treatment Center, Conakry, Guinea

- West Nile Virus Outbreak in Houston and Harris County, Texas, USA, 2014

- Serologic Evidence of Scrub Typhus in the Peruvian Amazon

- Serologic Evidence of Powassan Virus Infection in Patients with Suspected Lyme Disease

- Influenza D Virus in Animal Species in Guangdong Province, Southern China

- Seroprevalence of Baylisascaris procyonis Infection among Humans, Santa Barbara County, California, USA, 2014-2016

- Opiate Injection-Associated Skin, Soft Tissue, and Vascular Infections, England, UK, 1997-2016 


\section{Clinical Manifestations, Antimicrobial Drug Susceptibility Patterns, and Outcomes in Melioidosis Cases, India}

\section{Maria Koshy, Manjeera Jagannati, Ravikar Ralph, Punitha Victor, Thambu David, Sowmya Sathyendra, Balaji Veeraraghavan, George M. Varghese}

We studied the clinical manifestations and outcomes of 114 patients with culture-confirmed melioidosis treated at a tertiary hospital in southern India. Diabetes mellitus is the main risk factor, and chronic melioidosis mimicking tuberculosis was more common than acute disease. Septicemia and respiratory involvement were associated with poor outcomes.

$\mathrm{M}$ elioidosis is a tropical infection caused by the environmental bacterium Burkholderia pseudomallei (1). The clinical spectrum of melioidosis ranges from the acute septicemic form, which is often fulminant, to chronic disease, which mimics other common infections like tuberculosis (2). Melioidosis is endemic to southeast Asia and northern Australia; seasonal peaks occur during monsoons (3). Infection is acquired by inhalation, inoculation, and ingestion (4).

Melioidosis is often difficult to diagnose because of diverse clinical manifestations, low index of suspicion, and poor availability of good laboratory facilities. Hence, the disease remains underrecognized even in endemic countries. Recent studies have shown that India is at high risk for a surge of cases of melioidosis (5). Our study was undertaken to delineate the clinical manifestations, antimicrobial drug susceptibility patterns, and outcomes of melioidosis cases in India.

\section{The Study}

This retrospective study included 114 adult patients with culture-confirmed melioidosis treated at a tertiary care teaching hospital in southern India during January 2008December 2014. We collected data regarding patient demographics, clinical characteristics, laboratory results, radiologic parameters, and antimicrobial drug susceptibility from medical records. We classified patients on the basis of duration of symptoms: acute ( $<2$ months) or chronic ( $>2$ months) (6). We defined multifocal disease as involvement

Author affiliation: Christian Medical College, Vellore, India

DOI: https://doi.org/10.3201/eid2502.170745 of $\geq 2$ organs and disseminated disease as involvement of 1 organ plus bacteremia (7). We assessed severity of illness (based on sequential organ failure assessment [SOFA] scores), complications, and patient outcomes (8). We used the BacT ALERT (bioMérieux, https://www.biomerieux. com) automated system for blood culture. We plated pus and tissue on blood, chocolate, and MacConkey agar and identified B. pseudomallei according to standard methods and performed antimicrobial drug susceptibility testing according to Clinical and Laboratory Standards Institute standards using E-test for trimethoprim/sulfamethoxazole. We summarized descriptive data and analyzed the association of patient parameters with outcomes by using logistic regression. We considered a 2-sided p value of $\leq 0.05$ statistically significant. We analyzed the data using SPSS Statistics for Windows version 20.0 (IBM, https://www.ibm.com).

Patients were predominantly male (92\%); mean age was 45.6 years (33.5-57.7 years). The patients came from 15 states in India; most were from West Bengal (26.3\%), Jharkhand (22.8\%), and Tamil Nadu (14.9\%) (Figure 1). The common risk factors identified were diabetes mellitus (81.6\%), harmful ethanol consumption (14\%), and chronic kidney disease (3.5\%). Among patients with diabetes, glycemic control was poor (mean hemoglobin A1c 9.7\% [7.1\%-12.3\%]). Other risk factors included sickle cell disease, thalassemia, glucocorticoid use, and liver disease (Table 1). Patients with acute disease more commonly sought care $(80.5 \%, \mathrm{n}=33)$ during the cooler months of August-February.

Chronic melioidosis was more common than acute melioidosis (64\% vs. 36\%) in this patient cohort. Duration of symptoms was 2 days to 5 years (median 60 days; interquartile range [IQR] 30-90 days). Fever was the most consistent symptom (97.2\%). Although other studies have reported lung involvement to be most common (9), we most frequently observed splenic (42.9\%) and musculoskeletal (37.7\%) disease (Table 1). Chronic melioidosis was associated with splenic and genitourinary involvement. Prostatic abscess was the most common genitourinary disease $(87.5 \%, \mathrm{n}=12)$. Multifocal disease was evident in 89 (78\%) patients. Two patients had tuberculosis-melioidosis co-infection and improved with appropriate therapy for both diseases. 


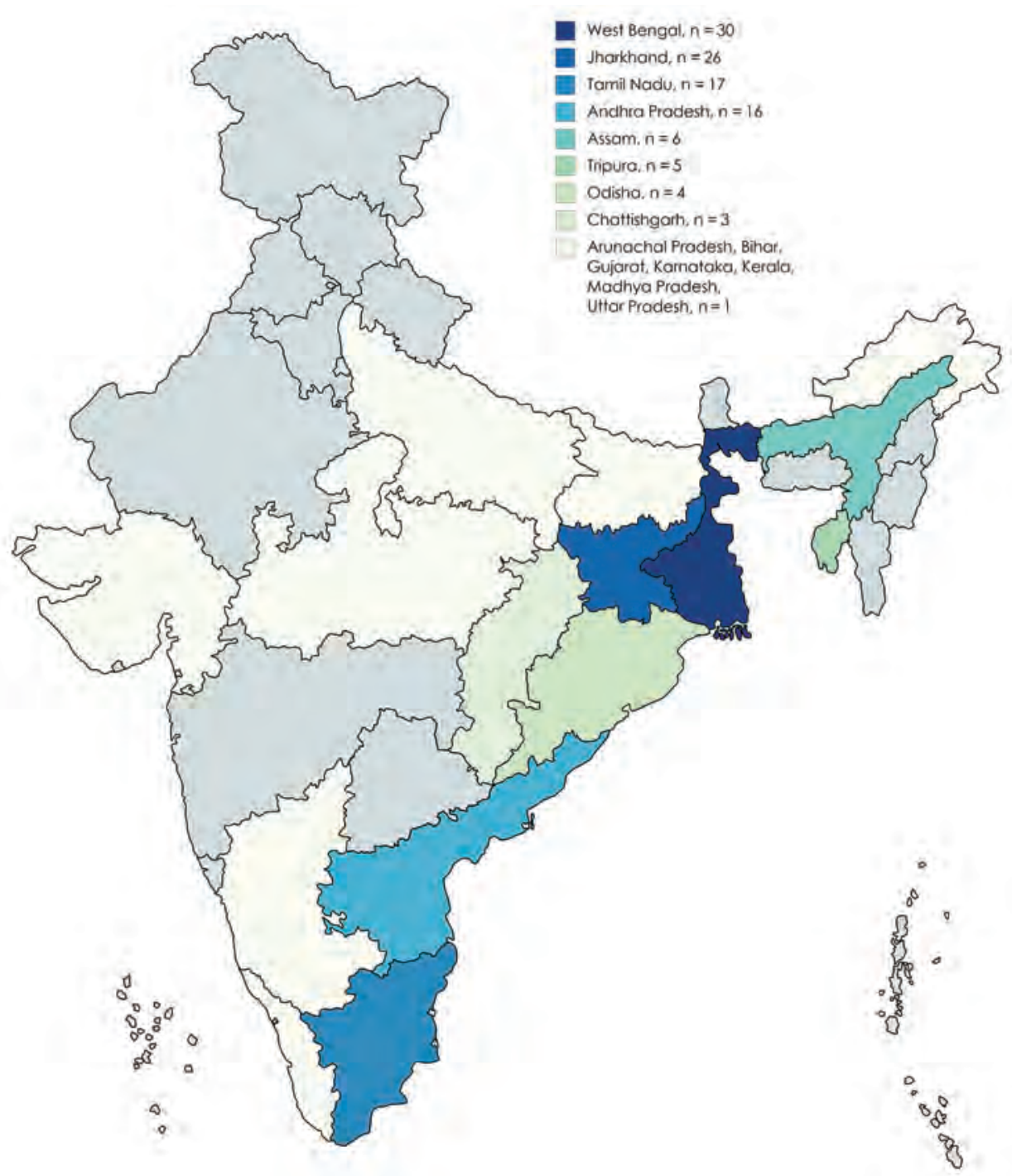

Figure 1. Distribution of patients with melioidosis, by state, India, 2008-2014.
Chest radiograph abnormalities included bilateral fluffy opacities $(16.7 \%, \mathrm{n}=19)$, focal infiltrates $(6.1 \%, \mathrm{n}=7)$, and effusions $(6.1 \%, \mathrm{n}=7)$.

Patients with acute melioidosis frequently had respiratory involvement and bacteremia. Septic arthritis was common in acute disease and usually involved a single large joint. One patient had evidence of multifocal arthritis. Three patients had central nervous system involvement. Five patients had bacteremia without evidence of deep-seated abscesses. We also observed unusual presentations, such as pancreatitis and pericardial involvement. In 11 (15.1\%) patients with chronic melioidosis, the condition worsened because of bacteremia and systemic inflammatory response syndrome. This phenomenon occurred especially in elderly patients and patients with diabetes and was associated with higher case-fatality rates.

A total of 63 (55.2\%) patients had bacteremia, and 25 (21.9\%) patients required admission to intensive care.
Seventy-six (66.6\%) patients required a diagnostic or therapeutic interventional procedure. Antimicrobial drug susceptibility tests revealed $100 \%$ sensitivity to carbapenems and ceftazidime. Resistance to trimethoprim/sulfamethoxazole was noted in $5.9 \%$ and resistance to doxycycline in $2.6 \%$ of cases.

Patients received intensive therapy with meropenem or ceftazidime for a median duration of 16 days (IQR 14-28 days), followed by eradication therapy with trimethoprim/ sulfamethoxazole with or without doxycycline for a median of 90 days (IQR 90-150 days). Most patients were treated successfully with these regimens. Follow-up data were available for $57.9 \%$ patients for a period of 3 months to 1 year. Four (3.5\%) patients had disease recurrence 2-7 years after completion of therapy, of whom 1 received inadequate therapy. A previous study highlighted that multifocal disease, bacteremia, and duration of therapy correlate with risk for relapse (6). 
Table 1. Patient characteristics and outcomes of patients with melioidosis, southern India, 2008-2014*

\begin{tabular}{|c|c|c|c|}
\hline Characteristic & All patients, $\mathrm{N}=114$ & $\begin{array}{c}\text { Acute melioidosis, } \\
n=41\end{array}$ & $\begin{array}{c}\text { Chronic melioidosis } \\
\mathrm{n}=73\end{array}$ \\
\hline Age, $y$, mean $\pm S D$ & $45.6 \pm 12.1$ & $46 \pm 12.6$ & $45.3 \pm 11.9$ \\
\hline Sex, no., M/F & $10 \overline{5} / 9$ & $\overline{38} / 3$ & $6 \overline{7} / 6$ \\
\hline \multicolumn{4}{|l|}{ Comorbid conditions, no. (\%) } \\
\hline Diabetes mellitus & $93(81.6)$ & $36(87.8)$ & $57(78.1)$ \\
\hline Harmful ethanol use & $16(14)$ & $10(24.4)$ & $6(8.5)$ \\
\hline Chronic kidney disease & $4(3.5)$ & $2(4.9)$ & $2(2.8)$ \\
\hline Sickle cell disease & $3(2.6)$ & 0 & $3(4.2)$ \\
\hline No risk factors & $15(13.2)$ & $3(7.3)$ & $12(16.4)$ \\
\hline Duration of symptoms, $\mathrm{d}$, median (IQR) & $60(30-90)$ & $20(7-30)$ & $90(60-210)$ \\
\hline \multicolumn{4}{|l|}{ Clinical symptoms, no. (\%) } \\
\hline Fever & $105(97.2)$ & $41(100)$ & $64(95.5)$ \\
\hline Cough & $17(15.5)$ & $9(21.9)$ & $8(11.7)^{\prime}$ \\
\hline Abdominal pain & $38(34.8)$ & $10(24.3)$ & $28(41.1)$ \\
\hline Joint pain & $27(24.7)$ & $10(24.3)$ & $17(25)$ \\
\hline Breathlessness & $16(14.6)$ & $11(26.8)$ & $5(7.3)$ \\
\hline \multicolumn{4}{|l|}{ Clinical signs, no. (\%) } \\
\hline Tachypnea, reference $>24 / \mathrm{min}$ & $24(21.2)$ & $14(34.1)$ & $10(13.9)$ \\
\hline Tachycardia, reference $>100 /$ min & $33(29.2)$ & $20(48.8)$ & $13(18.1)$ \\
\hline Hypotension, reference $<90 / 60 \mathrm{~mm} \mathrm{Hg}$ & $11(9.7)$ & $6(14.6)$ & $5(6.9)$ \\
\hline \multicolumn{4}{|l|}{ Laboratory parameters } \\
\hline Hemoglobin, $\mathrm{g} / \mathrm{dL}$, mean $\pm \mathrm{SD}$ & $10.2 \pm 2.3$ & $11.3 \pm 2.5$ & $9.6+2$ \\
\hline Lymphocyte count, $\times 10^{9}$ cells/L, median (IQR) & $10.5(7 . \overline{7}-15.4)$ & $14.6(11.1-19.4)$ & $9(6.8-12.2)$ \\
\hline Platelet count, $\times 10^{9} / \mathrm{L}$, median (IQR) & $165(107-272)$ & $177(115-264)$ & $158(102-280)$ \\
\hline Total bilirubin, mg/dl, median (IQR) & $0.7(0.5-1.4)$ & $1.2(0.7-1.8)$ & $0.6(0.4-0.9)$ \\
\hline Total protein, $\mathrm{g} / \mathrm{dL}$, mean $\pm \mathrm{SD}$ & $7.2 \pm 1$ & $6.7 \pm 0.8$ & $7.5 \pm 1$ \\
\hline Albumin, g/dL, mean $\pm \mathrm{SD}^{-}$ & $2.9 \pm 0.8$ & $2.6 \pm 0.7$ & $3.1 \pm 0.7$ \\
\hline AST, IU/mL, median (IQR) & $42(25-85)$ & $48(26-128)$ & $36(24-83)$ \\
\hline ALT, IU/mL, median (IQR) & $29(15-60)$ & $28(13-99)$ & $30(15-56)$ \\
\hline ALP, IU/mL, median (IQR) & $148(85-249)$ & $157(102-239)$ & $137(83-276)$ \\
\hline Serum creatinine, mg/dL, median (IQR) & $1(0.8-1.3)$ & $1.1(0.8-1.3)$ & $1(0.8-1.2)$ \\
\hline Hemoglobin A1C, \%, mean \pm SD & $9.7 \pm 2.6$ & $11.1 \pm 2.9$ & $8.9 \pm 2$ \\
\hline $\mathrm{CRP}, \mathrm{mg} / \mathrm{L}$, mean $\pm \mathrm{SD}$ & $96.6 \pm 64.3$ & $152.7 \pm 57.2$ & $77.4 \pm 55.2$ \\
\hline \multicolumn{4}{|l|}{ Organ involvement } \\
\hline Lung & $28(24.5)$ & $16(39)$ & $12(16.4)$ \\
\hline Bacteremia & $63(55.2)$ & $33(80.4)$ & $30(41)$ \\
\hline Spleen & 49 (42.9) & $12(29.2)$ & $37(50.6)$ \\
\hline Liver & $25(21.9)$ & $9(21.9)$ & $16(21.9)$ \\
\hline Genitourinary & $16(14)$ & $2(4.8)$ & $14(19.1)$ \\
\hline Septic arthritis & $22(19.2)$ & $9(21.9)$ & $13(17.8)$ \\
\hline Osteomyelitis & $12(10.5)$ & $3(7.3)$ & $9(12.3)$ \\
\hline Skin and subcutaneous tissue & $15(13.1)$ & $7(17)$ & $8(10.9)$ \\
\hline Parotid & $2(1.7)$ & $2(4.8)$ & 0 \\
\hline Central nervous system & $3(2.6)$ & $2(4.8)$ & $1(1.3)$ \\
\hline Sequential organ failure assessment score, median (IQR) & $2(1-4)$ & $3(1-6)$ & $1(0-3)$ \\
\hline ICU admission, no. (\%) & $25(21.9)$ & $15(36.6)$ & $10(13.7)$ \\
\hline Mechanical ventilation, no. (\%) & $21(18.4)$ & $13(31.7)$ & $8(11)$ \\
\hline Duration of hospitalization, days, median (IQR) & $16.5(9-24)$ & $18(8.5-30.5)$ & $16(10-21.5)$ \\
\hline Case-fatality rate, no. (\%) & $17(14.9)$ & $7(17.1)$ & $10(13.7)$ \\
\hline
\end{tabular}

The overall case-fatality rate was $14.9 \%(n=17)$ and was higher in patients with acute disease (Table 2). On multivariate analysis of predictors of mortality risk, respiratory involvement (odds ratio [OR] 4.61 [95\% CI 1.57-13.55]; $\mathrm{p}=0.005)$ and bacteremia (OR 17.02 [95\% CI 2.17-133.43]; $\mathrm{p}=0.007$ ) were independent predictors of mortality, along with admission SOFA scores (OR 1.4 [95\% CI 1.1-1.7]; $\mathrm{p}<0.001$ ) and hypoalbuminemia (OR 4.02 [95\% CI 1.21-13.33]; $\mathrm{p}=0.02$ ). We noticed a decline in case-fatality rate from 2008 (25\%) to 2014 (11\%) (Figure 2).

\section{Conclusions}

This study highlights the emergence of melioidosis as a major problem in India. Two thirds of our patient population were from the eastern and northeastern parts of India, which might reflect a referral bias. Infection frequently affected the middle-aged, male working population, highlighting possible occupational exposure. The association of acute melioidosis with the wet season in certain regions concurs with other studies that have shown a correlation between rainfall intensity and disease (10). The higher proportion of patients with diabetes (82.3\%), compared 
Table 2. Bivariate analysis of predictors of mortality from melioidosis, southern India, 2008-2014

\begin{tabular}{lcccc}
\hline Predictors of mortality & Alive, $\mathrm{n}=97$ & Dead, $\mathrm{n}=17$ & Odds ratio $(95 \% \mathrm{Cl})$ & $\mathrm{p}$ value \\
\hline Diabetes mellitus & 79 & 14 & $0.94(0.23-3.62)$ & 0.92 \\
Harmful ethanol use & 14 & 2 & $0.90(0.18-4.43)$ & 0.89 \\
Chronic kidney disease & 3 & 1 & $0.45(0.04-4.65)$ & 0.5 \\
Tachypnea, reference $>24 / \mathrm{min}$ & 12 & 12 & $16.8(5.03-53.11)$ & $<0.001$ \\
Tachycardia, reference $>100 / \mathrm{min}$ & 22 & 11 & $6.16(2.04-18.57)$ & 0.001 \\
Hypotension, reference $<90 / 60 \mathrm{mmHg}$ & 4 & 7 & $16.10(4.00-64.70)$ & $<0.001$ \\
Sequential organ failure assessment score & $1(0-3)$ & $4(2-8)$ & $1.4(1.1-1.7)$ & $<0.001$ \\
Bacteremia & 47 & 16 & $17.02(2.17-133.43)$ & 0.007 \\
Respiratory involvement & 19 & $9.61(1.57-13.55)$ & 0.005 \\
Hypoalbuminemia, reference $<3 \mathrm{~g} / \mathrm{dL}$ & 38 & 13 & $4.02(1.21-13.33)$ & 0.02 \\
Intensive care unit admission & 12 & 13 & $23.02(6.44-82.24)$ & $<0.001$ \\
Mechanical ventilation & 8 & 13 & $36.15(9.52-137.23)$ & $<0.001$ \\
\hline
\end{tabular}

to other studies $(39 \%-60 \%)$, might reflect the emerging diabetes epidemic in India $(4,11)$.

The predominance of chronic melioidosis is a finding not in keeping with other studies $(1,4,10)$ and might be attributed in part to referral bias and referral of undiagnosed cases from relatively dry areas of the country. Patients with acute disease tended to reside near our hospital. The occurrence of an acute worsening in patients with chronic disease was associated with a poor outcome. The observation of tuberculosis-melioidosis co-infection is not unusual given that the risk factors and interferon-mediated host response is common to both conditions (12).

Most patients were treated successfully with intensive therapy followed by eradicative therapy. The case-fatality rate associated with melioidosis was $14.9 \%$, with a decreasing trend over the study period. A study previously conducted from this hospital reported a case-fatality rate of $17 \%(7)$, which is lower than the case-fatality rate in Thailand $(\approx 40 \%)$ (13). We found that bacteremia, respiratory involvement, hypoalbuminemia, and high SOFA scores were associated with poor outcomes.

We found that $5.9 \%$ of B. pseudomallei isolates were resistant to trimethoprim/sulfamethoxazole. This percentage might have been a slight overestimate because of the change in antimicrobial drug susceptibility testing methods during the study period. Although a previously reported trial showed noninferiority of trimethoprim/ sulfamethoxazole to trimethoprim/sulfamethoxazole plus doxycycline, eradication therapy in our clinical setting should be based on antimicrobial drug susceptibility reports (14).

Melioidosis warrants attention from clinicians and public health officials in India. Specific organ involvement can alert clinicians to acute or chronic disease, which might be useful in management of patients in a resource-limited setting. Because of the substantial mortality associated with melioidosis, a high index of suspicion and early initiation of therapy are essential.

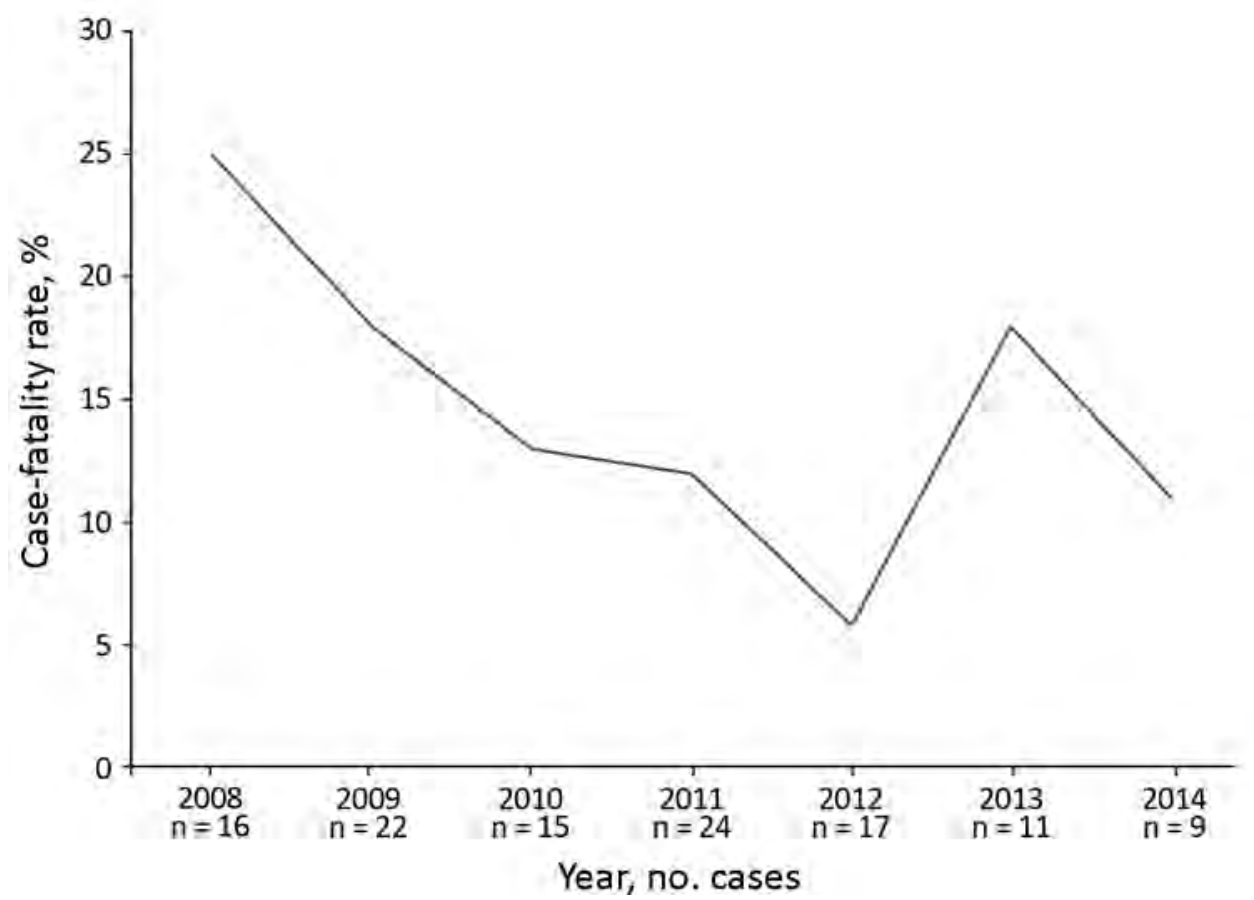

Figure 2. Trend in melioidosis case-fatality rates, southern India, 2008-2014. 


\section{About the Author}

Dr. Varghese is a professor of infectious diseases at Christian Medical College, Vellore, India. His research includes the epidemiology, pathogenesis, early recognition, and management of rickettsial infections, particularly scrub typhus, apart from tropical infections such as melioidosis.

\section{References}

1. Wiersinga WJ, Currie BJ, Peacock SJ. Melioidosis. N Engl J Med. 2012;367:1035-44. http://dx.doi.org/10.1056/NEJMra1204699

2. Dance DAB. Melioidosis. Curr Opin Infect Dis. 2002;15:127-32. http://dx.doi.org/10.1097/00001432-200204000-00005

3. Cheng AC, Currie BJ. Melioidosis: epidemiology, pathophysiology, and management. Clin Microbiol Rev. 2005;18:383-416. http://dx.doi.org/10.1128/CMR.18.2.383-416.2005

4. Currie BJ, Ward L, Cheng AC. The epidemiology and clinical spectrum of melioidosis: 540 cases from the 20 year Darwin prospective study. PLoS Negl Trop Dis. 2010;4:e900. http://dx.doi.org/10.1371/journal.pntd.0000900

5. Limmathurotsakul D, Golding N, Dance DA, Messina JP, Pigott DM, Moyes CL, et al. Predicted global distribution of Burkholderia pseudomallei and burden of melioidosis. Nat Microbiol. 2016;1:15008. http://dx.doi.org/10.1038/nmicrobiol.2015.8

6. Currie BJ, Fisher DA, Anstey NM, Jacups SP. Melioidosis: acute and chronic disease, relapse and re-activation. Trans R Soc Trop Med Hyg. 2000;94:301-4. http://dx.doi.org/10.1016/ S0035-9203(00)90333-X

7. Chrispal A, Rajan SJ, Sathyendra S. The clinical profile and predictors of mortality in patients with melioidosis in South India. Trop Doct. 2010;40:36-8. http://dx.doi.org/10.1258/td.2009.090093

8. Ferreira FL, Bota DP, Bross A, Mélot C, Vincent JL. Serial evaluation of the SOFA score to predict outcome in critically ill patients. JAMA. 2001;286:1754-8. http://dx.doi.org/10.1001/jama.286.14.1754

9. Currie BJ, Fisher DA, Howard DM, Burrow JN, Lo D,

Selva-Nayagam S, et al. Endemic melioidosis in tropical northern Australia: a 10-year prospective study and review of the literature. Clin Infect Dis. 2000;31:981-6. http://dx.doi.org/10.1086/318116

10. Vidyalakshmi K, Lipika S, Vishal S, Damodar S, Chakrapani M. Emerging clinico-epidemiological trends in melioidosis: analysis of 95 cases from western coastal India. Int J Infect Dis. 2012;16:e491-7. http://dx.doi.org/10.1016/j.ijid.2012.02.012

11. Suputtamongkol Y, Chaowagul W, Chetchotisakd P,

Lertpatanasuwun N, Intaranongpai S, Ruchutrakool T, et al. Risk factors for melioidosis and bacteremic melioidosis. Clin Infect Dis. 1999;29:408-13. http://dx.doi.org/10.1086/520223

12. Koh GCKW, Schreiber MF, Bautista R, Maude RR, Dunachie S, Limmathurotsakul D, et al. Host responses to melioidosis and tuberculosis are both dominated by interferon-mediated signaling. PLoS One. 2013;8:e54961. http://dx.doi.org/10.1371/ journal.pone.0054961

13. Limmathurotsakul D, Peacock SJ. Melioidosis: a clinical overview. Br Med Bull. 2011;99:125-39. http://dx.doi.org/10.1093/bmb/ldr007

14. Chetchotisakd P, Chierakul W, Chaowagul W, Anunnatsiri S, Phimda K, Mootsikapun P, et al. Trimethoprim-sulfamethoxazole versus trimethoprim-sulfamethoxazole plus doxycycline as oral eradicative treatment for melioidosis (MERTH): a multicentre, double-blind, non-inferiority, randomised controlled trial. Lancet. 2014;383:807-14. http://dx.doi.org/10.1016/ S0140-6736(13)61951-0

Address for correspondence: George M. Varghese, Christian Medical College, Department of Infectious Diseases, Ida Scudder Rd, Vellore, Tamil Nadu, 632004, India; email: georgemvarghese@hotmail.com

\section{EID Podcast:}

\section{The Mother of All Pandemics}

Dr. David Morens, of the National Institute of Allergy and Infectious Diseases, discusses the 1918 influenza pandemic.

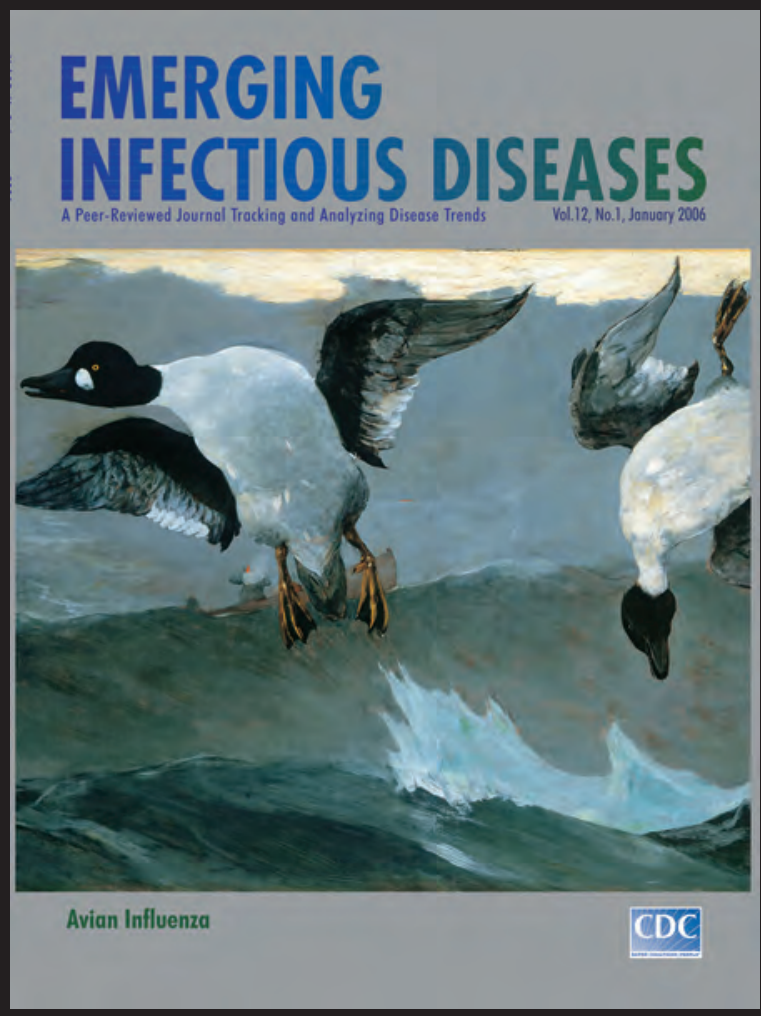

Visit our website to listen: https://tools.cdc.gov/medialibrary/ index.aspx\#/media/id/393805 EMERCING INFECTIOUS DISEASES 


\section{Crimean-Congo Hemorrhagic Fever, Kosovo, 2013-2016}

\section{Salih Ahmeti, ${ }^{1}$ Lindita Berisha, ${ }^{1}$ Bahrije Halili, Florim Ahmeti, Ronald von Possel, Corinna Thomé-Bolduan, Anett Michel, Simone Priesnitz, Emil C. Reisinger, Stephan Günther, Andreas Krüger, Kurtesh Sherifi, Xhevat Jakupi, Christoph J. Hemmer, Petra Emmerich}

During 2013-2016, a total of 32 patients were treated for Crimean-Congo hemorrhagic fever in Prishtina, Kosovo; 11 died. In the 11 patients who died, findings included viral loads $>1 \times 10^{8.5} / \mathrm{mL}$, lactate dehydrogenase $>2,700 \mathrm{U} / \mathrm{mL}$, bleeding, and impaired consciousness. Ribavirin therapy had no noticeable effect in this small patient sample.

C rimean-Congo hemorrhagic fever (CCHF), caused by an orthonairovirus of the Nairoviridae family, is usually transmitted by bites of Hyalomma sp. ticks. Case-fatality rates vary from $10 \%$ to $40 \%$. Most cases are reported from the Balkans, the Middle East, and Asia (1), but CCHF virus is now also found in Hyalomma ticks in Spain, where human CCHF cases have occurred $(2,3)$.

The earliest known case of CCHF in Kosovo was observed in 1954 (4). Since 1989, outbreaks have been seen every 4-5 years (5). CCHF is present in 50\% of the Kosovar territory, especially the central and southwest, which is at low altitude, has a hot climate, and consists mainly of bush and farmland vegetation (6). The same study found a human CCHF seroprevalence in Kosovo of 24.3\%, annual incidence of $0.49 / 100,000$ population, and a case-fatality rate of $26.76 \%$ (for 1995-2009).

Incubation of CCHF may take up to 9 days. Signs and symptoms usually start 1-3 days after the tick bite and

Author affiliations: University Hasan Prishtina, Prishtina, Kosovo (S. Ahmeti); University Clinical Center of Kosovo, Prishtina

(L. Berisha, B. Halili); National Institute of Public Health of Kosovo, Prishtina (F. Ahmeti, X. Jakupi); Bernhard Nocht Institute of Tropical Medicine, Hamburg, Germany (R. von Possel,

C. Thomé-Bolduan, S. Günther, P. Emmerich); Bundeswehr Hospital, Hamburg (A. Michel, S. Priesnitz, A. Krüger); University of Rostock, Rostock, Germany (E.C. Reisinger, C.J. Hemmer, P. Emmerich); University Hasan Prishtina Faculty of Agriculture and Veterinary Science, Prishtina (K. Sherifi)

DOI: https://doi.org/10.3201/eid2502.171999 include sudden onset of fever, myalgia, neck stiffness, photophobia, vomiting, diarrhea, sore throat, agitation, and confusion; 2-4 days later, drowsiness and pain in the right upper quadrant of the abdomen may ensue. Other signs and symptoms include tachycardia, petechiae, and lymphadenopathy. Approximately $30 \%$ of patients die $\geq 5$ days after disease onset or later, typically from bleeding or multiorgan failure (5).

We present a retrospective analysis of all 32 CCHF cases from the Infectious Diseases Hospital of Hasan Prishtina University (Prishtina, Kosovo) during May 2013-July 2016. We obtained a statement of approval from the Committee of Professional Ethics of the University Clinical Center of Kosovo (filed under no. 1555 on October 27, 2017).

\section{The Study}

We analyzed records of 32 patients with CCHF and excerpted demographic patient data, case history, symptoms, clinical signs, laboratory results, and outcome. Viral loads had been determined by reverse transcription PCR (RTPCR) using a RealStar CCHFV RT-PCR Kit version 1.0 (Altona Diagnostics, http://www.altona-diagnostics.com). We used SPSS software (IBM, http://www.ibm.com/analytics/spss-statistics-software) for statistical analysis; $\mathrm{p}$ values of $\leq 0.05$ by $\chi^{2}$ test or logistical regression (2-sided where applicable) were considered significant.

Of the 32 patients, 27 were male and 5 female; 21 patients were from the municipality of Malisheva (district of Prizren) and 9 from municipalities west of Malisheva (Figure 1 ). Median age was 40.5 years (range $0-75$ years) (Figure 2). Most patients were exposed to ticks during farming.

Eleven patients died, including 1 vertically infected female newborn; 21 survived. The median duration between initial symptoms and hospital admission was 2.5 days (range $0-7$ days). Neither $\chi^{2}$ testing nor regression analysis showed a relationship between the duration of symptoms at hospitalization (or at the start of ribavirin) and outcome.

Of the 6 patients who did not receive ribavirin, 2 died. Of the 26 patients who received intravenous ribavirin, 9 died. Ribavirin had no effect on outcome; however, the sample size was small. The median duration between the start of symptoms and administration of ribavirin was 3.5 days (range 1-12 days). Univariate regression (odds radio

\footnotetext{
${ }^{1}$ These first authors contributed equally to this article.
} 


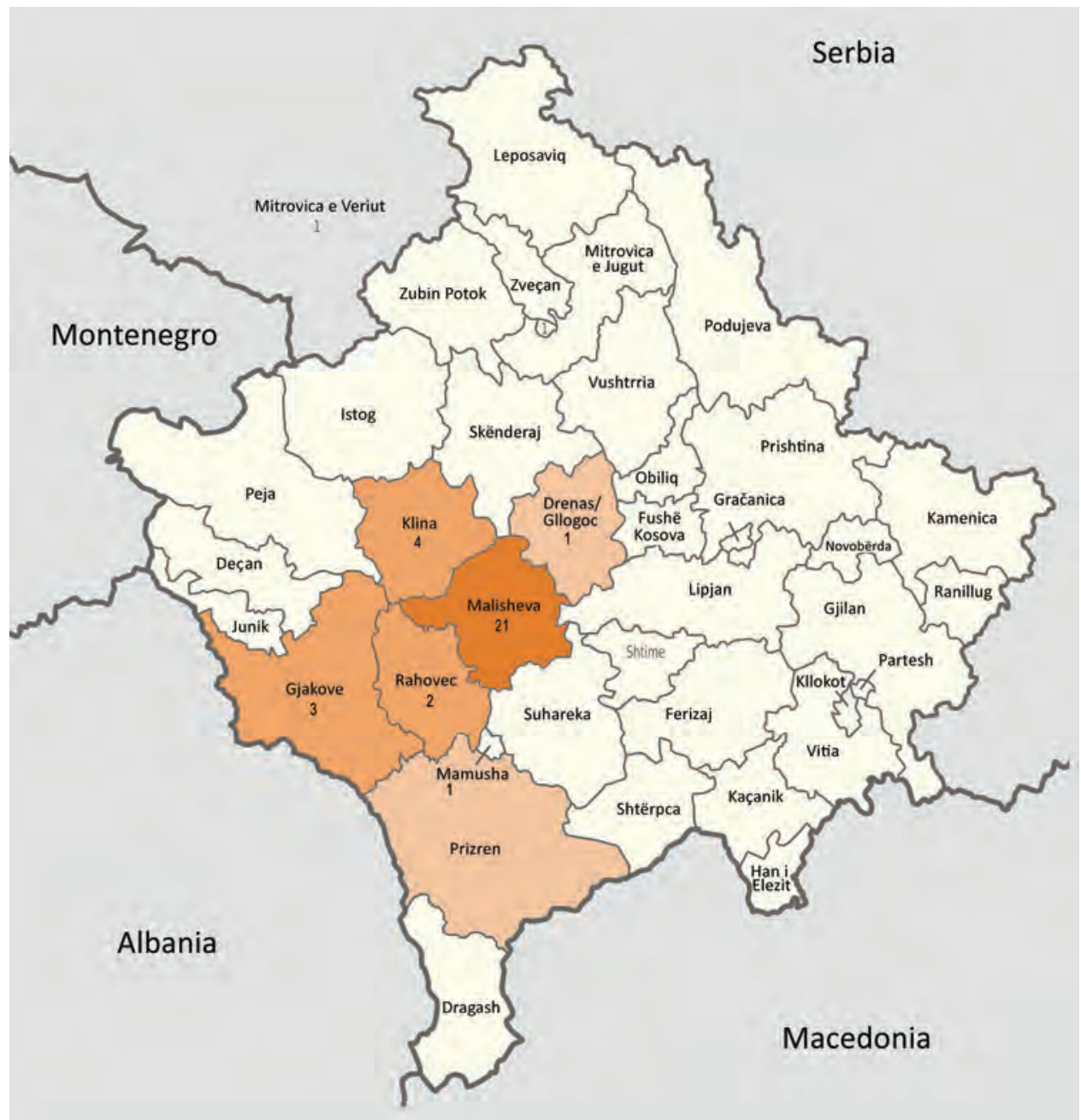

Figure 1. Municipalities

(komunë) in Kosovo, showing number of patients with Crimean-Congo hemorrhagic fever in each municipality. Map was obtained from Wikimedia, where it is available to the public under the GNU Free Documentation License (13).

The original map has no invariant elements; it has been modified to indicate patient locations.

[OR] 13.3, 95\% CI 1.3-134; $\mathrm{p}=0.028)$ and $\chi^{2}$ testing (p $=0.055$ ) suggested a possible association between starting ribavirin $<5$ days after disease onset and an increased probability of death. However, this effect was not significant after controlling for viral load ( $p=0.19$ ).

Signs of central nervous system (CNS) impairment (coma, somnolence, fasciculations) and bleeding showed the strongest interdependence with clinical outcome (Table 1). A weaker interdependence was shown for jaundice, diarrhea, and hiccups. Among the laboratory parameters, a viral load $>1 \times 10^{8.5}$ copies $/ \mathrm{mL}$, lactate dehydrogenase (LDH) $>2,200 \mathrm{U} / \mathrm{mL}$, and leukocyte count $>7,700$ cells/ $\mu \mathrm{L}$ were associated with death. We saw a nonsignificant trend toward interdependence between platelet counts $<50,000 / \mu \mathrm{L}$ and death $(\mathrm{p}=0.057)$. We found no association with outcome for aspartate aminotransferase, alanine aminotransferase, or other laboratory parameters (data not shown).

Of the clinical signs and symptoms, CNS impairment and bleeding predicted death. The death risk increased 35-fold ( $\mathrm{p}=0.003)$ in the presence of coma and 27-fold (p $=0.001$ ) with somnolence; CNS impairment was present in all 11 patients who died. For fasciculations, we could not calculate an OR because no patient with fasciculations survived. Hemoperitoneum increased the death risk 16.6fold $(\mathrm{p}=0.004)$. If 4 of 5 bleeding signs (bleeding gums,

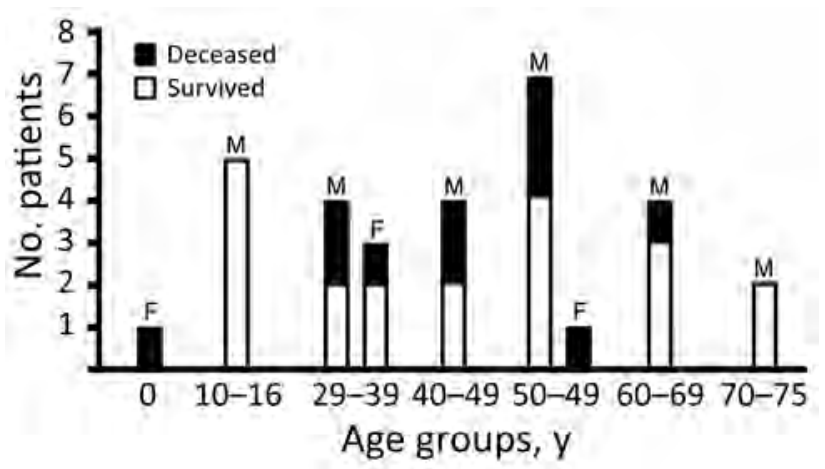

Figure 2. Crimean-Congo hemorrhagic fever cases and deaths by age group and sex, Kosovo, 2013-2016. 
Table 1. Interdependence between clinical and laboratory findings and outcome for patients with Crimean-Congo hemorrhagic fever, Kosovo, 2013-2016*

\begin{tabular}{|c|c|c|}
\hline Finding & $\chi^{2}$ & $p$ value \\
\hline \multirow{2}{*}{\multicolumn{3}{|c|}{ Significant interdependence with outcome, with Yates correction }} \\
\hline & & \\
\hline Fasciculations & 14.0 & $<0.001$ \\
\hline Coma & 13.2 & $<0.001$ \\
\hline Somnolence & 6.5 & 0.010 \\
\hline Hemoperitoneum & 10.4 & 0.001 \\
\hline Bleeding gums & 8.8 & 0.003 \\
\hline Hematemesis & 7.7 & 0.005 \\
\hline Melena & 5.7 & 0.017 \\
\hline Petechiae & 5.7 & 0.017 \\
\hline Ecchymoses & 5.5 & 0.019 \\
\hline Jaundice & 6.2 & 0.013 \\
\hline Diarrhea & 5.7 & 0.017 \\
\hline Hiccup & 4.0 & 0.046 \\
\hline \multicolumn{3}{|l|}{ Laboratory findings } \\
\hline Viral load >1 × 10 $0^{8.5} / \mathrm{mL}$ & 18.5 & $<0.001$ \\
\hline $\mathrm{LDH}>2,200 \mathrm{U} / \mathrm{mL}$ & 9.56 & 0.002 \\
\hline Leukocytes $>7,700 / \mu \mathrm{L}$ & 7.4 & 0.006 \\
\hline \multicolumn{3}{|c|}{ No interdependence with outcome, without Yates correction } \\
\hline \multicolumn{3}{|l|}{ Clinical findings } \\
\hline Vertigo & 2.26 & 0.133 \\
\hline Hypertension & 1.97 & 0.160 \\
\hline Anorexia & 1.72 & 0.189 \\
\hline Nausea & 1.60 & 0.205 \\
\hline Epistaxis & 0.90 & 0.340 \\
\hline Vomiting & 0.74 & 0.388 \\
\hline Joint pain & 0.74 & 0.388 \\
\hline Sweating & 0.23 & 0.631 \\
\hline Headache & 0.13 & 0.722 \\
\hline Conjunctivitis & 0.13 & 0.722 \\
\hline Muscular pain & 0.08 & 0.773 \\
\hline Abdominal pain & 0.05 & 0.830 \\
\hline Hypotension & 0.03 & 0.864 \\
\hline Bradycardia & $<0.01$ & 0.968 \\
\hline \multicolumn{3}{|l|}{ Laboratory findings } \\
\hline $\mathrm{ALT}>168 \mathrm{U} / \mathrm{mL}$ & 1.54 & 0.215 \\
\hline AST $>147 \mathrm{U} / \mathrm{mL}$ & 1.47 & 0.225 \\
\hline $\mathrm{CK}>1,037 \mathrm{U} / \mathrm{mL}$ & 0.79 & 0.373 \\
\hline \multicolumn{3}{|c|}{ Nonsignificant trend toward interdependence with outcome } \\
\hline Platelets $<50,000 / \mu \mathrm{L}$ & 3.68 & 0.055 \\
\hline With Yates correction & 3.63 & 0.057 \\
\hline
\end{tabular}

hematemesis, melena, petechiae, ecchymoses) were present, the death risk increased 24-fold $(p=0.008)$. Diarrhea increased the death risk 7.2-fold ( $\mathrm{p}=0.023$ ).

In multivariate analysis, the effects of bleeding, CNS involvement, and diarrhea on death risk were dependent on viral load and LDH levels. The effect of bleeding signs on death risk was independent of the effects of somnolence and of diarrhea. The effect of somnolence, but not of diarrhea, on death risk was independent of bleeding.

We saw no influence on death risk with other signs or symptoms (Table 2). Ribavirin therapy did not influence death risk (OR 1.059; $p=0.952)$ in the small sample size.

The strongest predictor of death was a viral load $>1 \times$ $10^{8.5}$ viral copies $/ \mathrm{mL}$ of serum (OR 80.0; $\mathrm{p}=0.001$ ), followed by an LDH >2,700 U/mL (OR 37.5; p = 0.006). The probability of death was also increased for leukocyte
Table 2. Clinical and laboratory findings and their association with death in patients with Crimean-Congo hemorrhagic fever, Kosovo, 2013-2016*

\begin{tabular}{|c|c|c|}
\hline Finding & $\begin{array}{l}\text { OR for death if } \\
\text { present }(95 \% \mathrm{Cl})\end{array}$ & $\mathrm{p}$ value \\
\hline \multicolumn{3}{|c|}{ Clinical findings significantly associated with death } \\
\hline Coma & $35.0(3.32-369)$ & 0.003 \\
\hline Somnolence & $27.0(3.80-192)$ & 0.001 \\
\hline Fasciculations $\dagger$ & NA (25.2 [2.45-259]) & NA (0.007) \\
\hline Hemoperitoneum & $16.6(2.47-112)$ & 0.004 \\
\hline Hematemesis & $11.4(1.74-74.7)$ & 0.011 \\
\hline Bleeding gums & $11.3(2.04-63.1)$ & 0.006 \\
\hline Ecchymoses & $7.31(1.25-42.8)$ & 0.027 \\
\hline Melena & $7.20(1.31-39.6)$ & 0.023 \\
\hline Petechiae & $6.67(1.31-34.0)$ & 0.023 \\
\hline $\begin{array}{l}\geq 4 \text { of the } 5 \text { previous } \\
\text { findings }\end{array}$ & $24.0(2.33-247)$ & 0.008 \\
\hline Diarrhea & $7.20(1.31-39.6)$ & 0.023 \\
\hline Jaundice $\dagger$ & NA $(7.87[0.71-87.3])$ & NA (0.093) \\
\hline
\end{tabular}

Clinical findings not significantly associated with death

$\begin{array}{lll}\text { Vertigo } & 5.00(0.53-47.3) & 0.160\end{array}$

Female sex $\quad 3.56(0.50-25.6) \quad 0.206$

Epistaxis $\quad 2.08(0.46-9.51) \quad 0.343$

Sweats $\quad 2.00(0.11-35.4) \quad 0.636$

Joint pain $\quad 1.92(0.43-8.61) \quad 0.391$

Headache $\quad 1.31(0.29-5.89) \quad 0.723$

Conjunctivitis $\quad 1.31(0.29-5.89) \quad 0.723$

Abdominal pain $\quad 1.20(0.23-6.34) \quad 0.830$

Tiredness $\quad 1.05(0.08-13.1) \quad 0.968$

Bradycardia $\quad 1.05(0.08-13.1) \quad 0.968$

Metrorrhagia $\quad 0.95(0.08-11.1) \quad 0.968$

Hypotension $\quad 0.87(0.19-4.03) \quad 0.864$

Muscular pain $\quad 0.75(0.11-5.32) \quad 0.774$

Vomiting $\quad 0.52(0.12-2.32) \quad 0.391$

Hyperemia $\quad 0.42(0.09-1.86) \quad 0.251$

Anorexia $\quad 0.28(0.04-2.01) \quad 0.206$

Nausea $\quad 0.25(0.03-2.40) \quad 0.230$

Hiccup $†$ NA (4.67 [0.37-58.3]) NA (0.232)

Hypertensiont NA (2.10 [0.12-37.1]) NA (0.613)

$\begin{array}{lll}\text { Ribavirin not given } & 1.059(0.162-6.94) & 0.952\end{array}$

Laboratory findings significantly associated with death

$\begin{array}{lll}V L>1 \times 10^{8.5} & 80.0(6.3-1,011) & 0.001\end{array}$

$\mathrm{LDH}>3,500 \mathrm{U} / \mathrm{L} \dagger \quad \mathrm{NA}(26.7[2.24-317]) \quad \mathrm{NA}(0.009)$

$\mathrm{LDH}>2,700 \mathrm{U} / \mathrm{L} \quad 37.5(2.77-507) \quad 0.006$

Leukocytes $>7.7 \quad 15.8(1.53-164) \quad 0.020$

Leukocytes $>8.0 \dagger \quad$ NA (16.7 [1.62-172]) NA (0.018)

Platelets $<50.000 / \mu \mathrm{L} \quad 5.25(1.07-25.8) \quad 0.041$

Laboratory findings not significantly associated with death

\begin{tabular}{lcc} 
ALT $>168 \mathrm{U} / \mathrm{L}$ & $3.20(0.48-21.2)$ & 0.228 \\
$\mathrm{AST}>147 \mathrm{U} / \mathrm{L}$ & $2.75(0.52-14.4)$ & 0.232 \\
$\mathrm{CK}>1,037$ & $1.95(0.44-8.55)$ & 0.376 \\
$\lg \mathrm{C}<2.5 \ddagger$ & $\mathrm{NA}(4.67[0.45-48.3])$ & NA $(0.196)$ \\
$\lg M<2.5 \ddagger$ & $\mathrm{NA}(4.67[0.45-48.3])$ & NA $(0.196)$ \\
\hline
\end{tabular}

${ }^{*} \mathrm{ALT}$, alanine aminotransferase; AST, aspartate aminotransferase; CK, creatine kinase; LDH, lactate dehydrogenase; NA, not applicable; OR, odds ratio; VL, viral load.

†The OR could not be determined because there were no survivors with this symptom. The value in parentheses would have been obtained if 1 hypothetical survivor had this symptom or test result.

$\ddagger$ The OR could not be determined because there were no deaths among patients with this finding. The value in parentheses would have been obtained if 1 hypothetical fatal case had this test result.

counts $>7,700$ cells $/ \mu \mathrm{L}(\mathrm{OR} 37.5 ; \mathrm{p}=0.006)$ and platelet counts $<50,000 / \mu \mathrm{L}(\mathrm{OR} 5.25 ; \mathrm{p}=0.041)$.

In multivariate analysis, viral loads $>1 \times 10^{8.5}$ copies/mL and LDH levels $>2,700 \mathrm{U} / \mathrm{mL}$ independently increased the probability of death (Table 2). However, the 
effect of leukocyte counts $>7,700$ cells $/ \mu \mathrm{L}$ and platelet counts $<50,000 / \mu \mathrm{L}$ did not persist when controlled for viral loads or LDH levels. No other routine laboratory parameters, including hemoglobin, creatine kinase, aspartate aminotransferase, alanine aminotransferase, prothrombin time, partial thromboplastin time, CCHF virus IgG, and CCHF IgM virus, predicted the outcome in the patients we analyzed.

\section{Conclusions}

Our results showed that the strongest clinical predictors of death from CCHF were bleeding and neurologic involvement. We saw somnolence or coma in all $11 \mathrm{fa}-$ tal cases and bleeding in 9 . In 2 patients, intracerebral bleeding could not be excluded because computed tomography or magnetic resonance imaging scans were not available. Therefore, the question whether all fatal neurologic complications in CCHF are caused by hemorrhage remains open.

Of laboratory parameters, the strongest predictors of death were viral load $>1 \times 10^{8.5}$ viral genome copies $/ \mathrm{mL}$ (OR 80) and LDH level >2,700 U/mL (OR 37.5). The predictive value of viral load has been described in Kosovo and Turkey $(7,8)$. High viral loads predicted high LDH levels, which in turn predicted complications and death. CCHF virus infection may induce organ failure by causing apoptosis of several cell types of endothelial and parenchymal origin (9). Other factors probably contribute to CCHF pathology also.

We saw a higher case-fatality rate in Kosovo (34\%) than that reported in Turkey (11\%) (8). Although the virus clade circulating in Kosovo was probably introduced from Turkey in the 1970s, it is possible that the high genetic viral diversity found in fatal CCHF cases in Kosovo increases CCHF pathogenicity (10).

Our study did not detect any benefit of intravenous ribavirin for CCHF; however, even a recent Cochrane meta-analysis has not answered the question whether ribavirin is beneficial in CCHF (11). A murine treatment study suggests that ribavirin is insufficiently effective even when given before disease onset (12). To improve the prognosis for CCHF, new antiviral substances that effectively curb virus replication are needed.

\section{Acknowledgments}

We thank the nurses of the Infectious Diseases Hospital of Prishtina, Kosovo, for their extraordinary dedication and contribution to the care of patients with CCHF.

Funding was provided by the German Ministry of Foreign Affairs (project no. ZMV-16 2513AA0277). The funder had no role in study design, data collection and analysis, decision to publish, or preparation of the manuscript.

\section{About the Author}

Dr. Ahmeti is a professor of infectious diseases at Hasan Prishtina University and head of the Infectious Diseases Hospital of Prishtina, Republic of Kosovo. He has a special interest in CrimeanCongo hemorrhagic fever and other viral hemorrhagic fevers.

\section{References}

1. Appannanavar SB, Mishra B. An update on Crimean Congo hemorrhagic fever. J Glob Infect Dis. 2011;3:285-92. http://dx.doi.org/10.4103/0974-777X.83537

2. Estrada-Peña A, Palomar AM, Santibáñez P, Sánchez N, Habela MA, Portillo A, et al. Crimean-Congo hemorrhagic fever virus in ticks, southwestern Europe, 2010. Emerg Infect Dis. 2012;18:179-80. http://dx.doi.org/10.3201/eid1801.111040

3. Negredo A, de la Calle-Prieto F, Palencia-Herrejón E, Mora-Rillo M, Astray-Mochales J, Sánchez-Seco MP, et al.; Crimean Congo Hemorrhagic Fever @ Madrid Working Group. Autochthonous Crimean-Congo hemorrhagic fever in Spain. N Engl J Med. 2017;377:154-61. http://dx.doi.org/10.1056/NEJ Moa1615162

4. Vesenjak-Hirjan J, Punda-Polić V, Dobe M. Geographical distribution of arboviruses in Yugoslavia. J Hyg Epidemiol Microbiol Immunol. 1991;35:129-40.

5. Ahmeti S, Kutllovci M, Bajrami M. Crimean Congo hemorrhagic fever in Kosova during 1995. Praxis Medica. 1996;39:11-6.

6. Sherifi K, Cadar D, Muji S, Robaj A, Ahmeti S, Jakupi X, et al. Crimean-Congo hemorrhagic fever virus clades V and VI (Europe 1 and 2) in ticks in Kosovo, 2012. PLoS Negl Trop Dis. 2014;8:e3168. http://dx.doi.org/10.1371/journal.pntd.0003168

7. Duh D, Saksida A, Petrovec M, Ahmeti S, Dedushaj I, Panning M, et al. Viral load as predictor of Crimean-Congo hemorrhagic fever outcome. Emerg Infect Dis. 2007;13:1769-72. http://dx.doi.org/10.3201/eid1311.070222

8. Hasanoğlu I, Guner R, Carhan A, Kocak Tufan Z, Yagci-Caglayik D, Guven T, et al. Crucial parameter of the outcome in Crimean Congo hemorrhagic fever: viral load. J Clin Virol. 2016;75:42-6. http://dx.doi.org/10.1016/j.jcv.2015.12.006

9. Karlberg H, Tan YJ, Mirazimi A. Induction of caspase activation and cleavage of the viral nucleocapsid protein in different cell types during Crimean-Congo hemorrhagic fever virus infection. J Biol Chem. 2011;286:3227-34. http://dx.doi.org/10.1074/ jbc.M110.149369

10. Emmerich P, Jakupi X, von Possel R, Berisha L, Halili B, Günther S, et al. Viral metagenomics, genetic and evolutionary characteristics of Crimean-Congo hemorrhagic fever orthonairovirus in humans, Kosovo. Infect Genet Evol. 2018; 65:6-11. http://dx.doi.org/10.1016/j.meegid.2018.07.010

11. Johnson S, Henschke N, Maayan N, Mills I, Buckley BS, Kakourou A, et al. Ribavirin for treating Crimean Congo haemorrhagic fever. Cochrane Database Syst Rev. 2018;6: CD012713. https://doi.org/10.1002/14651858.CD012713.pub2

12. Oestereich L, Rieger T, Neumann M, Bernreuther C, Lehmann M, Krasemann S, et al. Evaluation of antiviral efficacy of ribavirin, arbidol, and T-705 (favipiravir) in a mouse model for CrimeanCongo hemorrhagic fever. PLoS Negl Trop Dis. 2014;8:e2804. http://dx.doi.org/10.1371/journal.pntd.0002804

13. TUBS. Map of administrative divisions of Kosovo. 2013 Oct 22 [cited 2017 Nov 7]. https://commons.wikimedia.org/wiki/ File: Kosovo,_administrative_divisions_(municipalities) _-_de_-_monochrome.svg

Address for correspondence: Christoph J.Hemmer, University of Rostock-Department of Tropical Medicine and Infectious Diseases, Faculty of Medicine, Ernst-Heydemann-Strasse 6, 18057 Rostock, Germany; email: Christoph_Hemmer@medizin.uni-rostock.de 


\section{Cumulative Incidence of West Nile Virus Infection, Continental United States, 1999-2016}

\section{Shannon E. Ronca, Kristy O. Murray, Melissa S. Nolan}

Using reported case data from ArboNET and previous seroprevalence data stratified by age and sex, we conservatively estimate that $\approx 7$ million persons in the United States have been infected with West Nile virus since its introduction in 1999. Our data support the need for public health interventions and improved surveillance.

$\mathrm{W}$ est Nile virus (WNV) is a mosquito-transmitted flavivirus with human health implications. Since its emergence in 1999, WNV has become endemic across the continental United States (1). Seasonal outbreaks occur annually, and large outbreaks occur throughout the country. Infection is commonly asymptomatic; a general febrile illness occurs in $\approx 20 \%$ of the population, and $<1 \%$ progress to West Nile neuroinvasive disease (WNND), which might include encephalitis, meningitis, and acute flaccid paralysis.

WNV infection can cause permanent sequelae, including physical, neurologic, and cognitive disabilities as well as renal impairment and ocular damage (2). The average annual cost to treat hospitalized WNV patients is $\approx$ US \$56 million, and initial and long-term costs can exceed US $\$ 700,000$ per patient $(3,4)$. Considering the clinical and economic impact of acute and long-term WNV outcomes, determining total WNV disease burden in the United States is imperative. ArboNET data indicate that $\approx 40 \%$ of WNND cases occurred during 2011-2016, suggesting a need to update the estimated cumulative WNV incidence previously determined by Petersen et al. in 2010 (5). The objective of our study was to estimate total WNV disease burden in the continental US population during 1999-2016.

\section{The Study}

We collected data from the Centers for Disease Control and Prevention's ArboNET national surveillance system and performed a comprehensive literature search in PubMed for state-specific and national WNV seroestimates. We used the

Author affiliations: Baylor College of Medicine, Houston, Texas, USA (S.E. Ronca, K.O. Murray, M.S. Nolan); Texas Children's Hospital, Houston (S.E. Ronca, K.O. Murray, M.S. Nolan)

DOI: https://doi.org/10.3201/eid2502.180765
2010 US Census database for general population estimates. ArboNET data indicated that the 5 states with the highest clinically reported WNV case counts during 1999-2016 were California (6,504 cases), Texas (5,672 cases), Colorado (5,285 cases), Nebraska (3,911 cases), and South Dakota (2,470 cases) (Appendix Table 3, https://wwwnc.cdc. gov/EID/article/25/2/18-0765-App1.pdf). When evaluating only reported WNND cases, the top 5 states were California (3,390 cases), Texas (3,171 cases), Illinois (1,481 cases), Colorado (1,249 cases), and Louisiana (1,009 cases). The ArboNET dataset demonstrates a cumulative attack rate of 16 cases/100,000 persons in the US population during 1999-2016. When categorizing states into 5 sets by region (Midwest, Northeast, Southeast, Southwest, West), we observed the highest number of cases in the Midwest and West (Figure), a finding that corresponded with the top 5 states of total reported WNV and WNND cases. In the Southwest region, Texas accounts for $>55 \%$ of the total reported cases.

Next, we estimated cumulative WNV cases for the continental United States using ArboNET-reported WNND cases by state. To determine case estimates among persons $\geq 16$ years of age, we used Carson et al.'s WNND:infection ratios and $95 \%$ CIs stratified by age and sex (6). For cases among persons $<16$ years of age, we applied Mandalakas et al.'s 1:4,200 pediatric WNND:infection ratio and their age ranges for stratified estimates (7). We used age groups $<15,15-24,25-44$, $45-64$, and $\geq 65$ years, which is different from the age groups in the original reports $(6,7)$ because ArboNET reports data by 5-year intervals (e.g., 15-19 years). We used reported ArboNET data for comparison purposes.

Using Carson et al.'s estimates of seroprevalence in adults and Mandalakas et al.'s estimates in children $(6,7)$ to stratify by age and sex, we estimate that $\approx 7$ (95\% CI $5.7-$ 8.1) million WNV infections have occurred in the United States since WNV was introduced (Appendix Tables 1, 2). This number equates to $\approx 2.2 \%$ of the US population, greater than the estimate for 1999-2010 reported by Petersen et al. (1.1\% of the population, 3 million infections) (5) and ArboNET ( $0.16 \%$ of the population).

Since Petersen et al.'s previous estimate (5), $40 \%$ of all WNND cases have been reported. Our estimate of infections occurring during 1999-2016 is generally consistent with the incremental infection burden for the last 6 years of our study period. Disease burden estimates might 


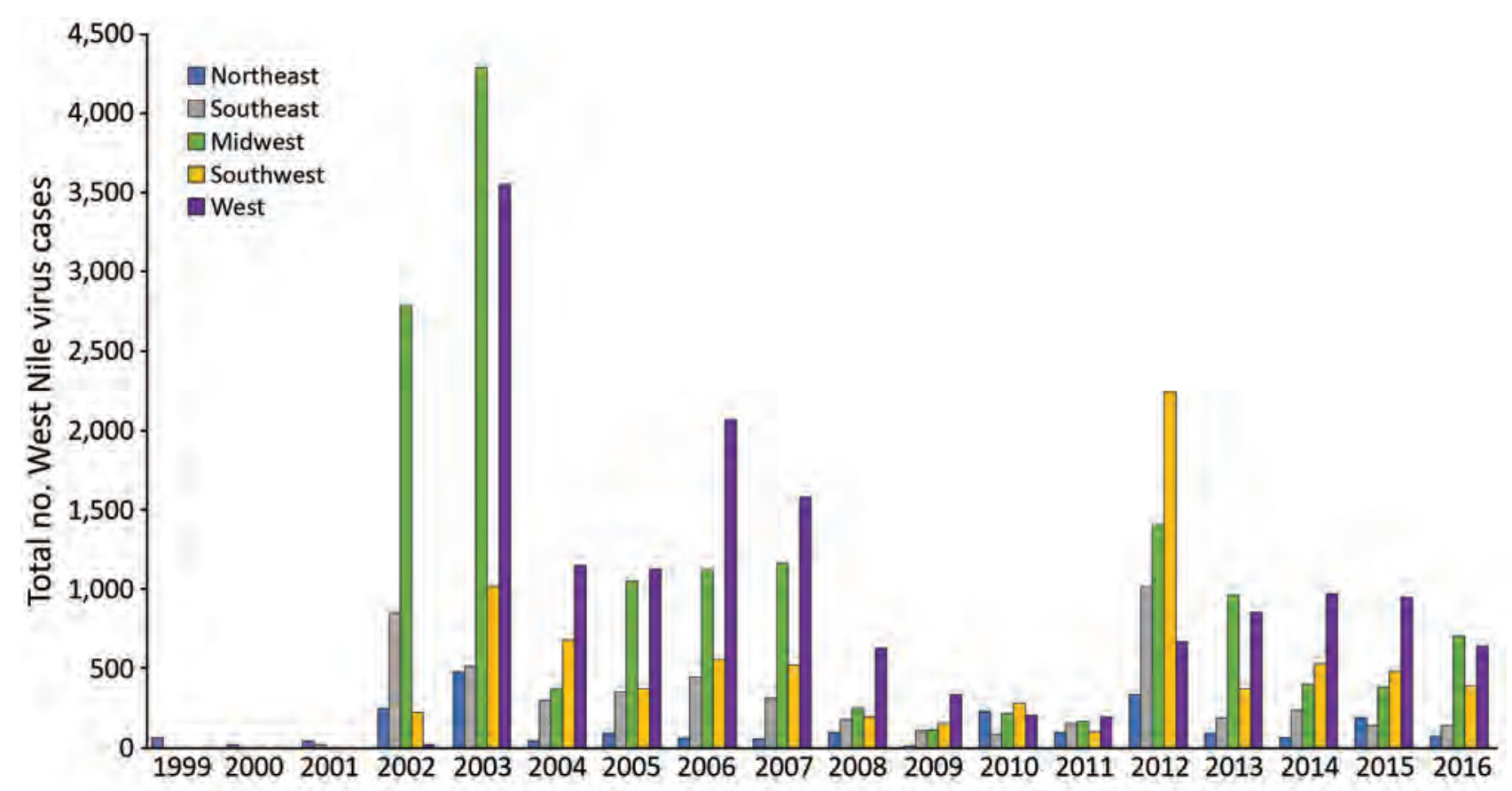

Figure. Total West Nile virus cases reported through ArboNET, by year and region, continental United States, $1999-2016$.

be affected by the changing epidemiology or disease penetration over the past 17 years. For instance, the ratio of neuroinvasive to nonneuroinvasive cases varies by geographic locality and is likely related to differences in testing, surveillance, and access to care $(8,9)$. Furthermore, infection trends might vary during each major epidemic. In 2003, the Midwest states of Nebraska and Colorado had the highest incidence rates (10), but in 2012, Texas had the highest (9). However, a study looking at blood donors indicates that WNND:infection ratios have not changed over time (11) and an additional study has confirmed the accuracy of Carson et al.'s estimates $(6,12)$. This information highlights the need for national standards for localized surveillance and reporting for more accurate estimates of disease burden and predictions of future disease severity.

In reality, the number of infections is likely higher than what was calculated here, as underdiagnosis is evident; a study by Vanichanan et al. indicated that patients are tested for WNV infection only one third of the time when viral encephalitis is clinically diagnosed (8). Increased awareness in the medical community will be needed not only for proper diagnosis of cases but also for quick implementation of control measures to prevent further cases and the improvement of surveillance data.

When evaluating disease burden, we must discuss how vulnerable, high-risk populations, such as those who are homeless, affect estimates. Only 1 study explicitly defines the relationship between WNV and homelessness (13). In that study, $6.8 \%$ of homeless persons in Houston, Texas, were seropositive for WNV infection after only
2 transmission seasons, and seroprevalence was even higher $(17 \%)$ when specifically evaluating those who slept outdoors. According to the US Department of Housing and Urban Development, nearly 550,000 of the US population were homeless on any given day in $2016 ; \approx 32 \%$ of these persons lived in unsheltered conditions, and $\approx 14 \%$ were considered chronically homeless (https://www.hud.gov). Because the burden of disease among homeless persons is difficult to delineate without additional studies, this unique population was not included in our estimate.

Our study has a few other notable limitations. Census data are not an exact representation of the population but an estimate of the number of persons at a given time. We also cannot account for cases in which persons do not seek treatment. Despite these limitations, our updated estimate helps to provide data for future economic burden estimates and cost-effectiveness studies for vaccines and novel therapeutics. A WNV vaccine was previously thought to not be cost-effective (14), but a study published in 2017 indicated an age-targeted vaccination program would improve costeffectiveness (15). Cost-effectiveness data and our new estimates of infection demonstrate that a high proportion of the population is seronegative and still susceptible to WNV infection, providing additional support that region-targeted vaccinations could be beneficial to the US population and should be further explored.

\section{Conclusions}

We estimate that $\approx 7$ (95\% CI 5.7 8.1) million persons in the continental United States were infected with WNV 
during 1999-2016, more than double the 2010 estimate of 3 million infections. Our estimate highlights the need for improved disease surveillance and reporting. As the cumulative incidence continues to climb, our findings provide additional support for the economic benefit of insecticide and vaccine interventions, especially in the Midwest, Southwest, and West of the United States; nearly $98 \%$ of the US population remains vulnerable to WNV infection.

\section{Acknowledgments}

We would like to thank the Centers for Disease Control and Prevention staff, specifically Jennifer Lehman, for providing the data needed to calculate estimates for this study.

This study was generously funded by the Chao Foundation.

\section{About the Author}

Dr. Ronca is a postdoctoral associate at Baylor College of Medicine (Houston, Texas) in the Department of Pediatrics, Section of Pediatric Tropical Medicine, where she focuses researching on viral infectious diseases.

\section{References}

1. Centers for Disease Control and Prevention. ArboNET [cited 2016 Feb 27]. https://wwwn.cdc.gov/arbonet

2. Murray KO, Garcia MN, Rahbar MH, Martinez D, Khuwaja SA, Arafat RR, et al. Survival analysis, long-term outcomes, and percentage of recovery up to 8 years post-infection among the Houston West Nile virus cohort. PLoS One. 2014;9:e102953. http://dx.doi.org/10.1371/journal.pone.0102953

3. Barrett AD. Economic burden of West Nile virus in the United States. Am J Trop Med Hyg. 2014;90:389-90. http://dx.doi.org/ 10.4269/ajtmh.14-0009

4. Staples JE, Shankar MB, Sejvar JJ, Meltzer MI, Fischer M. Initial and long-term costs of patients hospitalized with West Nile virus disease. Am J Trop Med Hyg. 2014;90:402-9. http://dx.doi.org/ 10.4269/ajtmh.13-0206

5. Petersen LR, Carson PJ, Biggerstaff BJ, Custer B, Borchardt SM, Busch MP. Estimated cumulative incidence of West Nile virus infection in US adults, 1999-2010. Epidemiol Infect. 2013; 141:591-5. http://dx.doi.org/10.1017/S0950268812001070

6. Carson PJ, Borchardt SM, Custer B, Prince HE, Dunn-Williams J, Winkelman V, et al. Neuroinvasive disease and West Nile virus infection, North Dakota, USA, 1999-2008. Emerg Infect Dis. 2012;18:684-6. http://dx.doi.org/10.3201/eid1804.111313

7. Mandalakas AM, Kippes C, Sedransk J, Kile JR, Garg A, McLeod J, et al. West Nile virus epidemic, northeast Ohio, 2002. Emerg Infect Dis. 2005;11:1774-7. http://dx.doi.org/10.3201/ eid1111.040933

8. Vanichanan J, Salazar L, Wootton SH, Aguilera E, Garcia MN, Murray KO, et al. Use of testing for West Nile virus and other arboviruses. Emerg Infect Dis. 2016;22. http://dx.doi.org/10.3201/ eid2209.152050

9. Murray KO, Ruktanonchai D, Hesalroad D, Fonken E, Nolan MS. West Nile virus, Texas, USA, 2012. Emerg Infect Dis. 2013;19:1836-8. http://dx.doi.org/10.3201/eid1911.130768

10. Busch MP, Wright DJ, Custer B, Tobler LH, Stramer SL, Kleinman $\mathrm{SH}$, et al. West Nile virus infections projected from blood donor screening data, United States, 2003. Emerg Infect Dis. 2006;12:395-402. http://dx.doi.org/10.3201/eid1205.051287

11. Betsem E, Kaidarova Z, Stramer SL, Shaz B, Sayers M, LeParc G, et al. Correlation of West Nile virus incidence in donated blood with West Nile neuroinvasive disease rates, United States, 2010-2012. Emerg Infect Dis. 2017;23:212-9. http://dx.doi.org/ 10.3201/eid2302.161058

12. Williamson PC, Custer B, Biggerstaff BJ, Lanciotti RS, Sayers MH, Eason SJ, et al. Incidence of West Nile virus infection in the Dallas-Fort Worth metropolitan area during the 2012 epidemic. Epidemiol Infect. 2017;145:2536-44. http://dx.doi.org/ 10.1017/S0950268816000042

13. Meyer TE, Bull LM, Holmes KC, Pascua RF, Travassos da Rosa A, Gutierrez CR, et al. West Nile virus infection among the homeless, Houston, Texas. Emerg Infect Dis. 2007;13:1500-3. http://dx.doi.org/10.3201/eid1310.070442

14. Zohrabian A, Hayes EB, Petersen LR. Cost-effectiveness of West Nile virus vaccination. Emerg Infect Dis. 2006;12:375-80. http://dx.doi.org/10.3201/eid1203.050782

15. Shankar MB, Staples JE, Meltzer MI, Fischer M. Cost effectiveness of a targeted age-based West Nile virus vaccination program. Vaccine. 2017;35:3143-51. http://dx.doi.org/10.1016/ j.vaccine.2016.11.078

Address for correspondence: Kristy O. Murray, Baylor College of Medicine, National School of Tropical Medicine, 1102 Bates St, Ste 550, Houston, TX 77030, USA; email: kmurray@bcm.edu 


\section{Lyme Disease Emergence after Invasion of the Blacklegged Tick, I xodes scapularis, Ontario, Canada, 2010-2016}

\section{Manisha A. Kulkarni, Isha Narula, Andreea M. Slatculescu, Curtis Russell}

Analysis of surveillance data for 2010-2016 in eastern Ontario, Canada, demonstrates the rapid northward spread of Ixodes scapularis ticks and Borrelia burgdorferi, followed by increasing human Lyme disease incidence. Most spread occurred during 2011-2013. Continued monitoring is essential to identify emerging risk areas in this region.

Tyme disease (LD) is the most reported vectorborne dis工ease in North America, where it is caused by Borrelia burgdorferi sensu stricto and principally transmitted by the blacklegged tick (Ixodes scapularis) (1). With northward expansion of $I$. scapularis tick populations from endemic areas in the United States, LD is rapidly emerging in parts of central and eastern Canada (2-4). Although several studies have mapped blacklegged tick populations across Canada and developed models to predict future spread of ticks and LD risk $(2,3)$, little is known about the extent of human LD in relation to tick vector distributions at a fine geographic scale. We examined spatiotemporal trends in the occurrence and expansion of I. scapularis ticks, B. burgdorferi-infected ticks, and human LD cases over a 7-year period to elucidate the process of $L D$ emergence in eastern Ontario, Canada.

\section{The Study}

Our study included 3 public health units in eastern Ontario, Canada: Kingston, Frontenac, and Lennox and Addington (KFL); Leeds, Grenville, and Lanark (LGL); and Ottawa. This region spans from the St. Lawrence River in the south to the Ottawa River in the north, and has several major population centers, including Kingston (2016 population 123,798) and Ottawa (2016 population 934,243) (5). The region is largely characterized by mixed deciduous forest and agricultural land use.

We used data from the Integrated Public Health Information System database to identify human LD cases

Author affiliations: University of Ottawa, Ottawa, Ontario, Canada (M.A. Kulkarni, I. Narula, A.M. Slatculescu); Public Health Ontario, Toronto, Ontario (C. Russell)

DOI: https://doi.org/10.3201/eid2502.180771 on the basis of provincial case definitions (6). We geocoded cases to their forward sortation area (FSA) (i.e., first 3 digits of the postal code) of residence and extracted data on patient sex, age, episode date (onset of symptoms), and reported history of travel (defined as travel outside the municipality of residence within the previous 2 weeks). Data on ticks collected during 2010-2016 through passive tick surveillance activities in Ontario were obtained from Public Health Ontario (PHO) (7). We aggregated $I$. scapularis tick records according to the FSA of the submitter (i.e., location of residence of the person who acquired the tick) and excluded records with missing collection date, submitter FSA, or PCR test result and records with reported history of travel. We similarly excluded human LD records with missing patient FSA or with reported travel history. We obtained FSA-level population data for 2011 and FSA boundary files from Statistics Canada (5).

To examine the association between the invasion of $I$. scapularis ticks and B. burgdorferi and the spread of human LD, we examined associations between FSA-level data on time to first case (in years) and several variables: time to first reported I. scapularis tick, time to first reported $B$. burgdorferi-infected tick, distance to FSA with highest LD incidence in 2010, and population. We constructed bivariable and multivariable linear regression models with time to first case (in years) as the outcome.

To visualize LD spread during 2010-2016, we plotted the annual FSA-level incidence of human LD and $B$. burgdorferi prevalence in ticks by using ArcGIS 10.4 (ESRI, https://www.esri.com). We also assessed the annual weighted mean center and distribution of human LD incidence by using ArcGIS 10.4, after spatial projection of the data to preserve distance (8). We applied Kulldorff's spatial scan statistics (9) by using SaTScan 9.6 (https://www. satscan.org) to assess and compare spatiotemporal patterns in human LD incidence and B. burgdorferi prevalence in ticks at the FSA level (FSA centroids). (For additional methods, see the Appendix, https://wwwnc.cdc.gov/EID/ article/25/2/18-0771-App1.pdf).

A higher proportion of LD cases occurred in men and in adults 50-69 years of age (Table 1), similar to patterns observed in other regions of North America (10). LD incidence increased over time; $55 \%$ of cases occurred during 
Table 1. Incidence of Lyme disease and characteristics of 639 reported human Lyme disease case-patients in 3 public health units, eastern Ontario, Canada, 2010-2016*

\begin{tabular}{|c|c|c|c|}
\hline Characteristic & No. (\%) cases & $\begin{array}{c}\text { Cumulative incidence, } \\
\text { cases } / 100,000 \text { population } \dagger\end{array}$ & $\begin{array}{c}\text { Mean (SD) annual incidence, } \\
\text { cases/100,000 populationt }\end{array}$ \\
\hline \multicolumn{4}{|l|}{ Public health unit } \\
\hline $\mathrm{KFL}$ & $210(33.0)$ & 109.6 & $15.7(13.3)$ \\
\hline LGL & $224(35.1)$ & 135.8 & $19.4(10.4)$ \\
\hline Ottawa & 205 (32.1) & 23.2 & $3.3(2.8)$ \\
\hline Total & 639 (100.0) & 51.5 & $7.4(5.2)$ \\
\hline \multicolumn{4}{|l|}{ Age group, $y$} \\
\hline $0-9$ & $43(6.7)$ & 32.6 & $4.7(4.5)$ \\
\hline 10-19 & $39(6.1)$ & 25.7 & $3.6(2.2)$ \\
\hline $20-29$ & $49(7.7)$ & 29.0 & $4.1(3.3)$ \\
\hline 30-39 & 74 (11.6) & 47.2 & $6.7(4.2)$ \\
\hline $40-49$ & $80(12.5)$ & 42.2 & $6.0(5.0)$ \\
\hline $50-59$ & $161(25.2)$ & 87.9 & $12.6(8.5)$ \\
\hline $60-69$ & $118(18.5)$ & 89.2 & $12.7(9.9)$ \\
\hline $70-79$ & $56(8.8)$ & 74.7 & 10.7 (8.8) \\
\hline$\geq 80$ & $19(3.0)$ & 38.1 & $5.4(4.3)$ \\
\hline \multicolumn{4}{|l|}{$\operatorname{Sex}$} \\
\hline $\mathrm{F}$ & $272(42.6)$ & 42.7 & $6.1(4.5)$ \\
\hline $\mathrm{M}$ & $364(57.0)$ & 60.4 & $8.6(6.1)$ \\
\hline Data missing & $3(0.4)$ & - & - \\
\hline
\end{tabular}

2015 and 2016 (Table 2). Roughly 70\% of cases occurred during June-August, whereas $\approx 20 \%$ occurred during September-December. The number of collected ticks increased annually from 2010 and reached a peak in 2013, with a subsequent decrease because of reductions in passive surveillance activities in KFL and LGL (11); Ottawa received an increasing amount of ticks over time (Table 2 ). The percentage of ticks testing positive for $B$. burgdorferi increased annually, from 12\% in 2010 to 23\% in 2016 $(p<0.001)$. Infection rates were higher among regions of KFL and LGL, although FSAs with high B. burgdorferi prevalence among submitted ticks were observed in parts of Ottawa in more recent years (Figure 1).

Within our study area, the first human LD case was reported an average of 2.2 years after the first reported I. scapularis tick and 1.1 years after the first reported $B$. burgdorferi-infected tick. Time to first case was significantly associated with time to first reported I. scapularis tick (adjusted $\mathrm{r}^{2}=0.56 ; \mathrm{p}<0.001$ ) and time to first $B$. burgdorferiinfected tick (adjusted $\mathrm{r}^{2}=0.67 ; \mathrm{p}<0.001$ ) after adjusting for distance to the FSA with highest LD incidence in 2010. The associated lag between each phase of $\approx 1$ year supports the hypothesis that invasion and establishment of tick populations is followed by colonization of B. burgdorferi (12), or it might reflect the arrival of infected ticks with subsequent increase in B. burgdorferi prevalence. However, drawing conclusions on the exact timing of tick and pathogen invasion is difficult because of the nature of passive surveillance data.

LD incidence was concentrated in southern FSAs in 2010 and 2011 but had spread in a northeasterly direction by 2013 (Figure 2). Overall, a northeast shift of $54 \mathrm{~km}$ occurred between mean centers during 2010-2016, with the greatest spread observed in 2011-2013 (Appendix). We detected a spatiotemporal cluster of high rates of $B$. burgdorferi-infected ticks in the Kingston-Gananoque region bordering the St. Lawrence River, which overlapped with 2 clusters of human LD cases (Appendix Figure 4). The overlapping clusters support the conclusion that increased tick encounter is a determinant of human LD risk. Residence in endemic areas (i.e., where infected ticks

\begin{tabular}{|c|c|c|c|c|c|c|c|}
\hline Characteristic and public health unit & 2010 & 2011 & 2012 & 2013 & 2014 & 2015 & 2016 \\
\hline \multicolumn{8}{|c|}{ Incidence rate, cases $/ 100,000$ population† } \\
\hline KFL & 2.1 & 8.4 & 4.2 & 8.4 & 20.4 & 36.0 & 30.3 \\
\hline LGL & 5.5 & 9.1 & 16.4 & 24.2 & 21.2 & 37.0 & 22.4 \\
\hline Ottawa & 0.2 & 0.7 & 1.8 & 4.1 & 2.4 & 7.6 & 6.5 \\
\hline Total & 1.2 & 3.0 & 4.1 & 7.4 & 7.7 & 15.9 & 12.3 \\
\hline \multicolumn{8}{|l|}{ No. Ixodes scapularis tick submissions } \\
\hline KFL & 209 & 620 & 677 & 864 & 115 & 51 & 23 \\
\hline LGL & 359 & 865 & 870 & 969 & 468 & 69 & 17 \\
\hline Ottawa & 38 & 106 & 134 & 239 & 258 & 216 & 336 \\
\hline Total & 606 & 1,591 & 1,681 & 2,072 & 841 & 336 & 386 \\
\hline
\end{tabular}

*KFL, Kingston, Frontenac, Lennox, and Addington; LGL, Leeds, Grenville, and Lanark.

†Population based on 2011 census. 

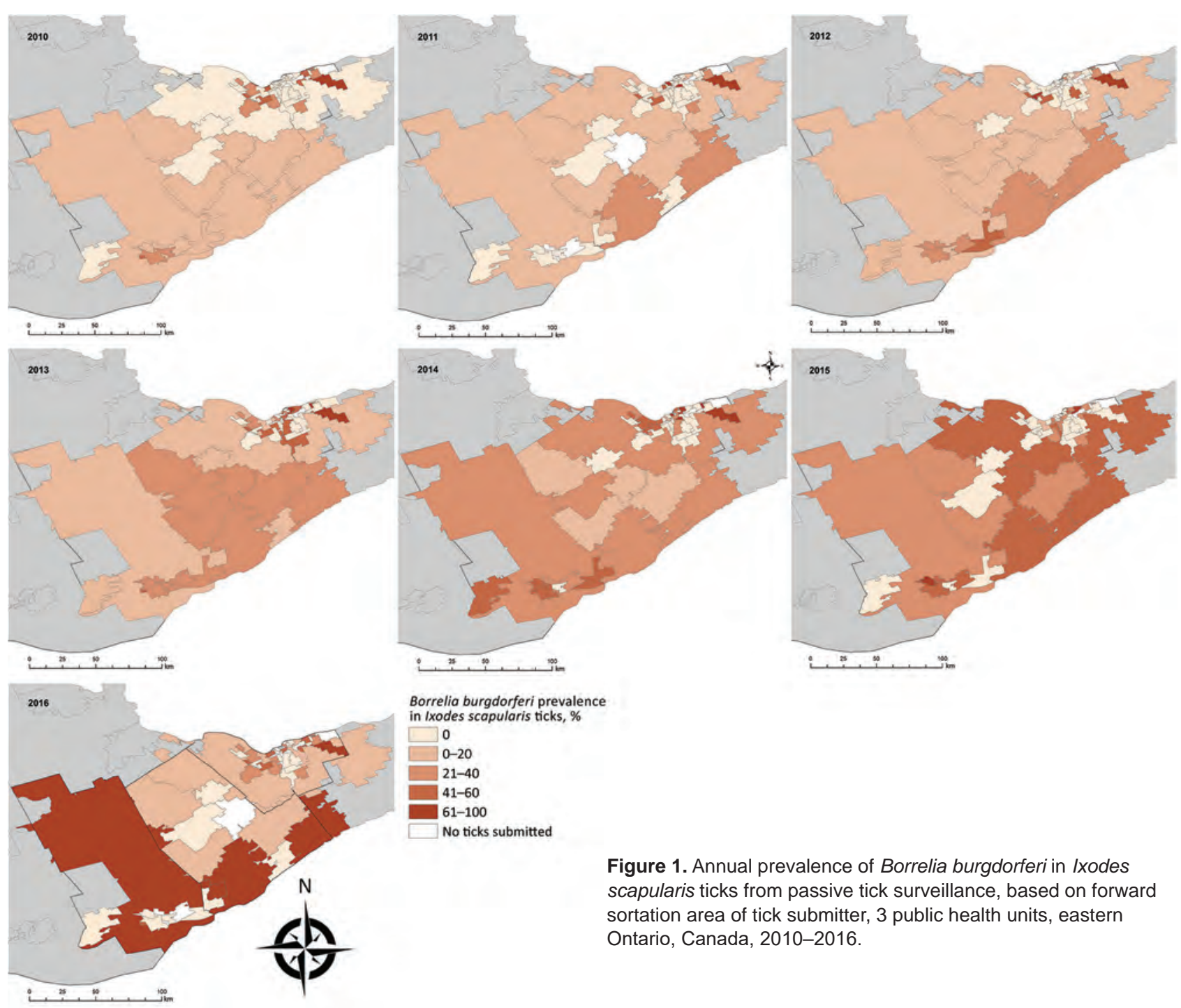

Figure 1. Annual prevalence of Borrelia burgdorferi in Ixodes scapularis ticks from passive tick surveillance, based on forward sortation area of tick submitter, 3 public health units, eastern Ontario, Canada, 2010-2016.

have been found) has been consistently recognized as a risk factor for LD infection $(13,14)$.

\section{Conclusions}

Although LD incidence in Ottawa had reached $\approx 7$ cases/100,000 population by 2015-2016, the observed incidence rates in KFL and LGL during this period were 4 -fold higher ( $\approx 30$ cases/100,000 population). By comparison, these rates are still far below the $\approx 110$ cases/100,000 population observed in the bordering St. Lawrence County of New York state (15). Given the ongoing emergence process, LD incidence will likely continue to increase in eastern Ontario as I. scapularis tick populations and B. burgdorferi continue to establish and fill in suitable habitats (12). This pattern highlights the importance of fine-scale studies to identify patterns and determinants of LD and other tickborne pathogens in different regions and populations.
Our study was limited by the availability of information on location of tick acquisition and patient exposure location. As such, we aggregated data at the FSA level on the basis of location of patient and tick submitter residence and excluded case-patients and tick submitters with reported travel outside their municipality of residence. Spatiotemporal analysis based on the location of exposure would help to more precisely determine the timing and rate of spread.

Altogether, our findings indicate that LD has emerged in eastern Ontario over a relatively short timescale after the invasion of $I$. scapularis ticks and B. burgdorferi. Tick surveillance data can serve to identify areas of risk for LD emergence.

\section{Acknowledgments}

The authors would like to thank Dara Spatz Friedman, John Cunningham, and Adam van Dijk for their epidemiologic assistance and data provision. We also thank Ann Stanton-Loucks, 

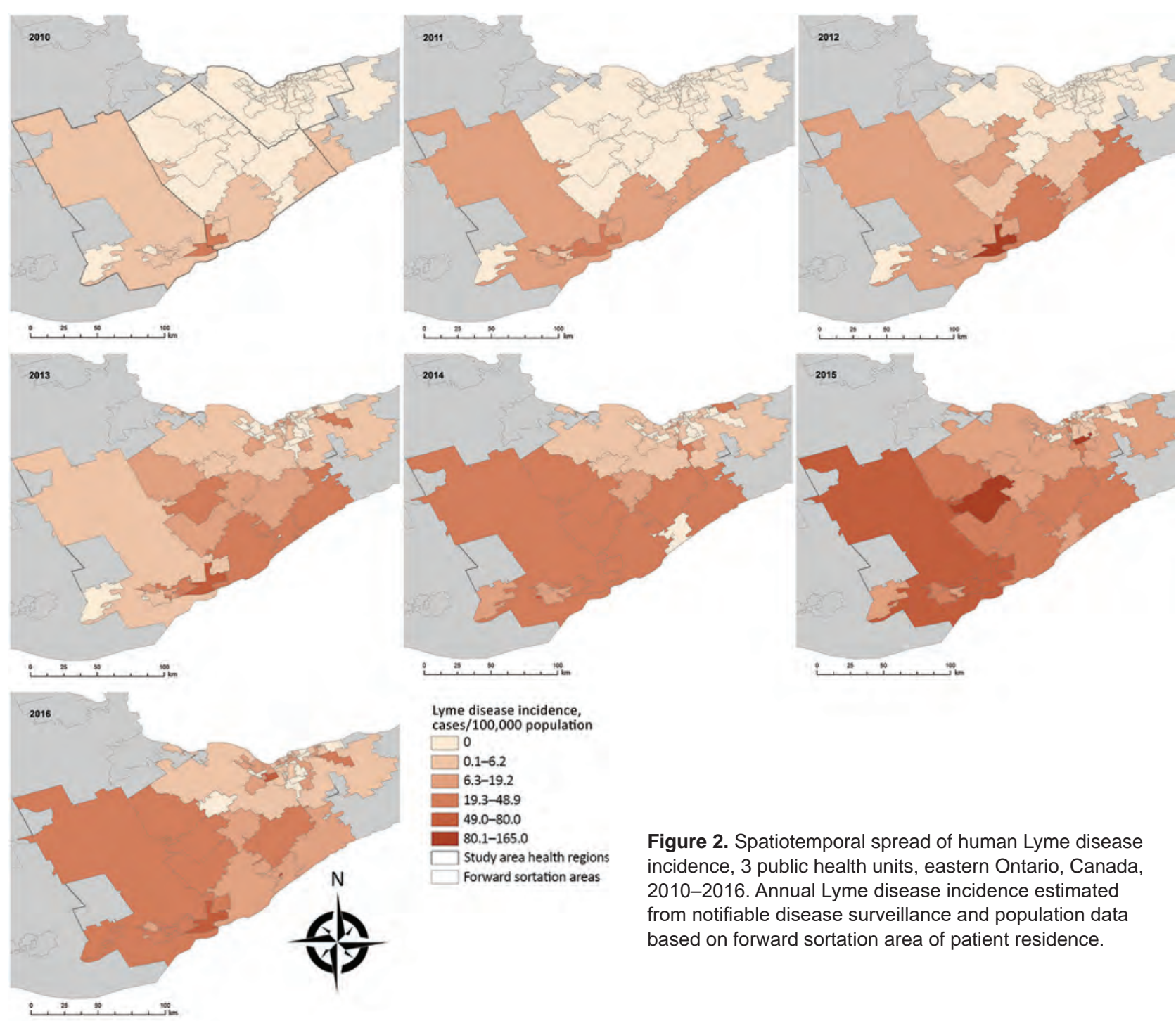

Lyme disease incidence, cases $/ 100,000$ population

$\square 0$

$\square$
$\square$

$6.3-19.2$

$19.3-48.9$

$49.0-80.0$
$80.1-165.0$

7 Study area health regions

Forward sortation areas

Figure 2. Spatiotemporal spread of human Lyme disease incidence, 3 public health units, eastern Ontario, Canada, 2010-2016. Annual Lyme disease incidence estimated from notifiable disease surveillance and population data based on forward sortation area of patient residence.

Michael Bennitz, and the Ottawa Public Health Innovation Fund for their collaboration and data sharing on tick surveillance activities in Ottawa.

M.A.K. is supported by a grant from the Canadian Institutes for Health Research and by an Early Researcher Award from the Ontario Ministry of Research and Innovation.

Ethics approval for this study was obtained from the Ottawa Public Health Research Ethics Board (no. 226-16) and the University of Ottawa Science and Health Sciences Research Ethics Board (H06-16-22). Access to Integrated Public Health Information System data was granted through data-sharing agreements with participating public health units. All data were aggregated to preserve anonymity.

\section{About the Author}

Dr. Kulkarni is a medical entomologist and assistant professor in the School of Epidemiology and Public Health at the University of Ottawa. Her research interests include vectorborne diseases with a focus on mosquitoborne and tickborne diseases in Canada and sub-Saharan Africa.

\section{References}

1. Bacon RM, Kugeler KJ, Mead PS; Centers for Disease Control and Prevention (CDC). Surveillance for Lyme disease-United States, 1992-2006. MMWR Surveill Summ. 2008;57:1-9.

2. Ogden NH, Bouchard C, Kurtenbach K, Margos G, Lindsay LR, Trudel L, et al. Active and passive surveillance and phylogenetic analysis of Borrelia burgdorferi elucidate the process of Lyme disease risk emergence in Canada. Environ Health Perspect. 2010;118:909-14. http://dx.doi.org/10.1289/ehp.0901766

3. Ogden NH, St-Onge L, Barker IK, Brazeau S, Bigras-Poulin M, Charron DF, et al. Risk maps for range expansion of the Lyme disease vector, Ixodes scapularis, in Canada now and with climate change. Int J Health Geogr. 2008;7:24. http://dx.doi.org/ 10.1186/1476-072X-7-24

4. Ogden NH, Lindsay LR, Morshed M, Sockett PN, Artsob H. The emergence of Lyme disease in Canada. CMAJ. 2009;180:1221-4. http://dx.doi.org/10.1503/cmaj.080148 
5. Statistics Canada. Focus on Geography Series, 2016 census. Statistics Canada catalogue no. 98-404-X2016001. Ottawa (Ontario, Canada): Statistics Canada; 2017.

6. Ministry of Health and Long-Term Care. Infectious disease protocol appendix B: provincial case definitions for reportable diseases. Toronto (Ontario, Canada): Ministry of Health and Long-Term Care; 2017.

7. Nelder MP, Russell C, Lindsay LR, Dhar B, Patel SN, Johnson S, et al. Population-based passive tick surveillance and detection of expanding foci of blacklegged ticks Ixodes scapularis and the Lyme disease agent Borrelia burgdorferi in Ontario, Canada. PLoS One. 2014;9:e105358. http://dx.doi.org/ 10.1371/journal.pone.0105358

8. Mitchell A. The ESRI guide to GIS analysis. Vol. 2. Redlands (CA, USA): ESRI; 2005.

9. Kulldorff M. A spatial scan statistic. Commun Stat Theory Methods. 1997;26:1481-96. http://dx.doi.org/10.1080/ 03610929708831995

10. Schwartz AM, Hinckley AF, Mead PS, Hook SA, Kugeler KJ. Surveillance for Lyme disease-United States, 2008-2015. MMWR Surveill Summ. 2017;66:1-12. http://dx.doi.org/10.15585/ mmwr.ss6622a1

11. Ontario Agency for Health Protection and Promotion. Technical report: update on Lyme disease prevention and control. Toronto
(Ontario, Canada): Ontario Agency for Health Protection and Promotion; 2016.

12. Clow KM, Leighton PA, Ogden NH, Lindsay LR, Michel P, Pearl DL, et al. Northward range expansion of Ixodes scapularis evident over a short timescale in Ontario, Canada. Wooten RM, editor. PLoS One. 2017;12:e0189393.

13. Cromley EK, Cartter ML, Mrozinski RD, Ertel S-H. Residential setting as a risk factor for Lyme disease in a hyperendemic region. Am J Epidemiol. 1998;147:472-7. http://dx.doi.org/10.1093/ oxfordjournals.aje.a009473

14. Finch C, Al-Damluji MS, Krause PJ, Niccolai L, Steeves T, O'Keefe CF, et al. Integrated assessment of behavioral and environmental risk factors for Lyme disease infection on Block Island, Rhode Island. PLoS One. 2014;9:e84758. http://dx.doi.org/10.1371/journal.pone.0084758

15. New York State Department of Health. Lyme disease incidence per 100,000. Bureau of Communicable Disease Control Data 20132015. New York: New York State Department of Health; 2017.

Address for correspondence: Manisha A. Kulkarni, University of Ottawa Faculty of Medicine, School of Epidemiology and Public Health, 600 Peter Morand Crescent, Ottawa, ON K1G 5Z3, Canada; email: manisha.kulkarni@uottawa.ca

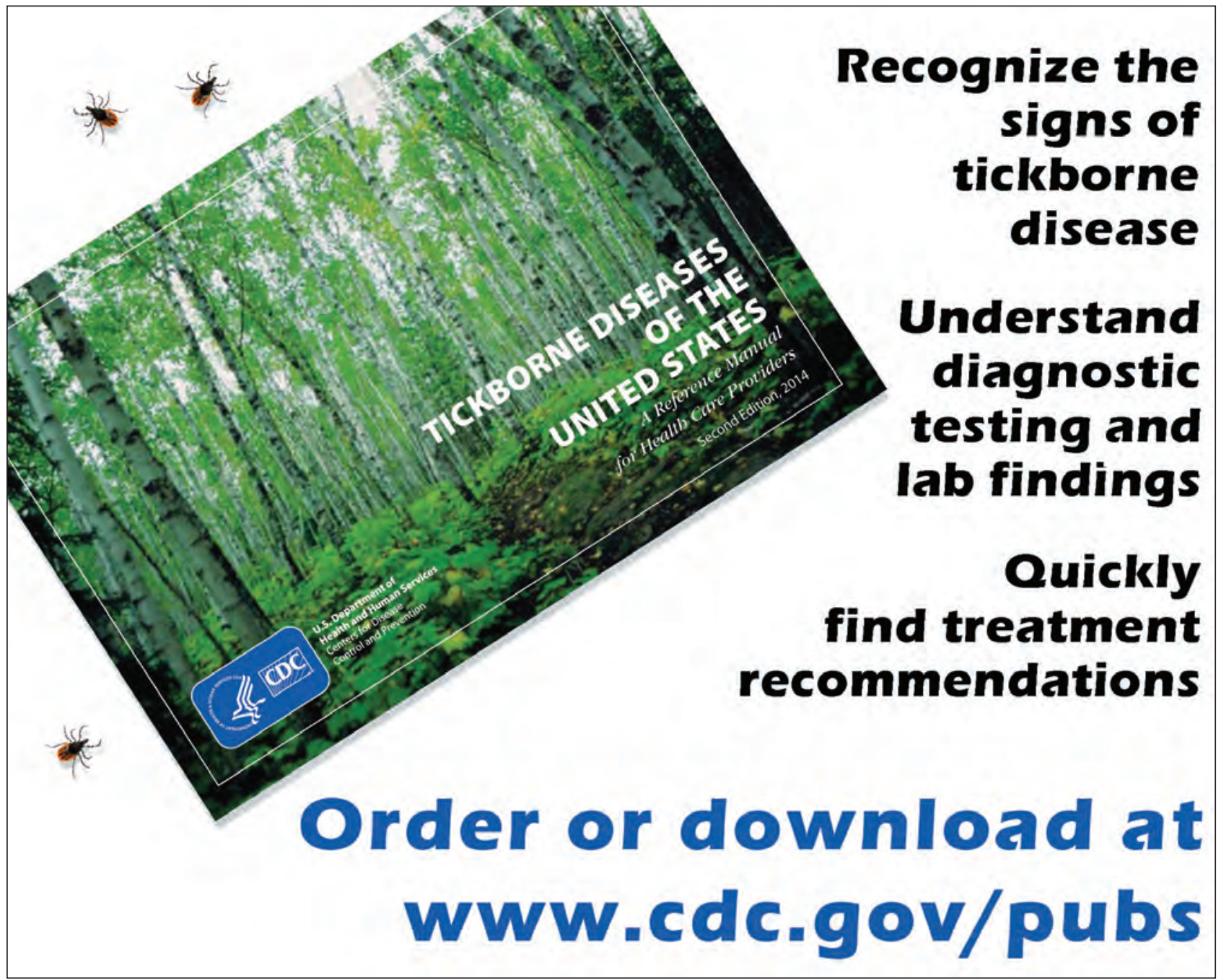




\section{Bat Influenza $A(H L 18 N L 11)$ Virus in Fruit Bats, Brazil}

\author{
Angélica Cristine Almeida Campos, \\ Luiz Gustavo Bentim Góes, Andres Moreira-Soto, \\ Cristiano de Carvalho, Guilherme Ambar, \\ Anna-Lena Sander, Carlo Fischer, \\ Adriana Ruckert da Rosa, \\ Debora Cardoso de Oliveira, \\ Ana Paula G. Kataoka, Wagner André Pedro, \\ Luzia Fátima A. Martorelli, \\ Luzia Helena Queiroz, Ariovaldo P. Cruz-Neto, \\ Edison Luiz Durigon, ${ }^{1}$ Jan Felix Drexler ${ }^{1}$
}

Screening of 533 bats for influenza A viruses showed subtype HL18NL11 in intestines of 2 great fruit-eating bats (Artibeus lituratus). High concentrations suggested fecal shedding. Genomic characterizations revealed conservation of viral genes across different host species, countries, and sampling years, suggesting a conserved cellular receptor and wide-ranging occurrence of bat influenza $A$ viruses.

I nfluenza A viruses are major causes of human disease and are predominantly maintained in avian reservoirs (1). The segmented influenza A genome facilitates reassortment events in birds or intermediate hosts, such as swine and horses, leading to emergence of new variants potentially capable of causing zoonotic infections (2). Bats are major sources of zoonotic pathogens (3). In pioneering studies from 2012 and 2013, the first bat influenza A viruses,

Author affiliations: Charité-Universitätsmedizin Berlin, corporate member of Freie Universität Berlin, Humboldt-Universität zu Berlin, and Berlin Institute of Health, Institute of Virology, Berlin, Germany (A.C.A. Campos, L.G.B. Góes, A. Moreira-Soto, A.-L. Sander, C. Fischer, J.F. Drexler); Universidade de São Paulo-USP, Instituto de Ciências Biomédicas-ICB, São Paulo, Brazil (A.C.A. Campos, L.G.B. Góes, E.L. Durigon); Universidade Estadual Paulista Faculdade de Medicina Veterinária de Araçatuba, Araçatuba, Brazil (C. de Carvalho, W.A. Pedro, L.H. Queiroz); Universidade Estadual Paulista, Instituto de Biociências, Rio Claro, Brazil (G. Ambar, A.P. Cruz-Neto); Centro de Controle de Zoonoses, São Paulo (A.R. da Rosa, D.C. de Oliveira, L.F.A. Martorelli, A.P.G. Kataoka); German Centre for Infection Research, Germany (J.F. Drexler); Martsinovsky Institute of Medical Parasitology, Tropical and Vector-Borne Diseases, Sechenov University, Moscow, Russia (J.F. Drexler) termed H17N10 and H18N11, were discovered in 2 bat species, Sturnira lilium (little yellow-shouldered bat) and Artibeus planirostris (flat-faced fruit-eating bat) $(4,5)$.

Bat-associated influenza A viruses are phylogenetically highly divergent from avian-associated influenza A viruses in their hemagglutinin (HA) and neuraminidase (NA) genes, suggesting these viruses represent ancient influenza A strains (2). Consistent with their genetic divergence, batassociated influenza A surface proteins lack typical hemagglutination and neuraminidase activities (6), leading to the terminology HA-like (HL) and neuraminidase-like (NL) for bat-associated influenza surface proteins.

So far, only 4 individual bat specimens yielded influenza A genomic sequences during the pivotal investigations $(4,5)$. HL18NL11 has only been found in 1 A. planirostris bat captured in Peru in 2010 (5), challenging definite host assessments. To investigate bat influenza A virus epidemiology, we investigated bats in southern Brazil during 2010-2014.

\section{The Study}

For this study, we sampled 533 individual bats representing 26 species and 3 families across 28 sampling sites (Table 1). Bats were captured using mist nets, euthanized, and necropsied and were identified on the basis of morphological criteria by trained field biologists as described previously (7). Only intestine samples were available for virological analyses. The Instituto Brasileiro do Meio Ambiente e dos Recursos Naturais (21748-1), Instituto Ambiental do Paraná (235/10), and the ethics committee of the Institute of Biomedical Science from the University of São Paulo (56-18-03/2014) authorized sampling.

We tested intestine specimens from all bats using 2 highly sensitive, broadly reactive nested reverse transcription PCRs targeting different regions of the influenza A polymerase basic (PB) 1 gene $(5,8)$. Positive results on both tests came from only 2 samples, from Artibeus lituratus great fruit-eating bats captured on March 7 and March 12, 2012, at 2 locations separated by $12 \mathrm{~km}$ in an Atlantic rainforest patch. No other sample was positive, yielding a $10.0 \%(2 / 20)$ overall detection rate in this site and $16.7 \%(2 / 12)$ detection in A. lituratus bats from this site (Table 1; Figure 1, panel A). Neither bat testing positive for influenza A virus showed signs of disease. 
Table 1. Bat species screened for influenza A virus, Brazil, 2010-2014*

\begin{tabular}{|c|c|c|c|c|c|}
\hline Species & Family & $\begin{array}{c}\text { No. } \\
\text { samples }\end{array}$ & $\begin{array}{l}\text { No. (\%) PCR } \\
\text { positive }\end{array}$ & Sampling site & Sampling years \\
\hline Artibeus fimbriatus & Phyllostomidae & 3 & 0 & Iguaçu & 2012 \\
\hline Artibeus lituratus & Phyllostomidae & 129 & $2(1.6)$ & $\begin{array}{c}\text { Iguaçu, Central Paraná state, } \\
\text { São Paulo cities }\end{array}$ & $\begin{array}{c}2010,2011,2012 \\
2013,2014\end{array}$ \\
\hline Artibeus obscurus & Phyllostomidae & 1 & 0 & São Paulo cities & 2013 \\
\hline Artibeus planirostris & Phyllostomidae & 4 & 0 & $\begin{array}{c}\text { Iguaçu, Central Paraná state, } \\
\text { São Paulo cities }\end{array}$ & $2010,2012,2014$ \\
\hline Carollia perspicillata & Phyllostomidae & 44 & 0 & Iguaçu, Central Paraná state & 2010-2012 \\
\hline Cynomops planirostris & Molossidae & 6 & 0 & São Paulo cities & 2014 \\
\hline Desmodus rotundus & Phyllostomidae & 15 & 0 & São Paulo cities & 2014 \\
\hline Eptesicus furinalis & Vespertilionidae & 8 & 0 & São Paulo cities & 2013-2015 \\
\hline Eumops auripendulus & Molossidae & 1 & 0 & São Paulo cities & 2014 \\
\hline Eumops glaucinus & Molossidae & 44 & 0 & São Paulo cities & 2013-2015 \\
\hline Eumops perotis & Molossidae & 8 & 0 & São Paulo cities & 2014-2015 \\
\hline Glossophaga soricina & Phyllostomidae & 27 & 0 & São Paulo cities & 2013-2015 \\
\hline Lasiurus cinereus & Vespertilionidae & 1 & 0 & São Paulo cities & 2013 \\
\hline Lasiurus ega & Vespertilionidae & 1 & 0 & São Paulo cities & 2014 \\
\hline Molossus molossus & Molossidae & 115 & 0 & São Paulo cities & 2013-2015 \\
\hline Molossus rufus & Molossidae & 63 & 0 & São Paulo cities & 2013-2015 \\
\hline Myotis nigricans & Vespertilionidae & 13 & 0 & São Paulo cities & 2013-2015 \\
\hline Myotis riparius & Vespertilionidae & 1 & 0 & São Paulo cities & 2013 \\
\hline Nyctinomops laticaudatus & Molossidae & 3 & 0 & São Paulo cities & 2014-2015 \\
\hline Nyctinomops macrotis & Molossidae & 1 & 0 & São Paulo cities & 2014 \\
\hline Phyllostomus discolor & Phyllostomidae & 2 & 0 & São Paulo cities & 2014 \\
\hline Platyrrhinus lineatus & Phyllostomidae & 4 & 0 & São Paulo cities & 2014 \\
\hline Promops nasutus & Molossidae & 1 & 0 & São Paulo cities & 2014 \\
\hline Sturnira lilium & Phyllostomidae & 28 & 0 & Iguaçu, Central Paraná state & 2010-2012 \\
\hline Tadarida brasiliensis & Molossidae & 9 & 0 & São Paulo cities & 2014 \\
\hline Vampyressa pusila & Phyllostomidae & 1 & 0 & Central Paraná state & 2012 \\
\hline Total & & 533 & $2(0.4)$ & & \\
\hline
\end{tabular}

A. lituratus bats were the most abundantly sampled species (Table 1).

The low overall influenza virus detection rate in this study $(0.4 \%$, 95\% CI $0.0 \%-1.5 \%)$ was not significantly different by Fisher exact test from the previous 2 studies (1/110 bats for HL18NL11 [0.9\%, 95\% CI 0.0\%-5.5\%; p $=0.43] ; 3 / 316$ bats for HL17NL10 [1.0\%, 95\% CI 0.0\%$2.9 \% ; \mathrm{p}=0.37])$. Apparently low rates of acute influenza A virus infection in bats are not consistent with high seroprevalence of $72 \%$ in different bat species according to a preliminary investigation (5) and may hint at seasonal variation in bat influenza virus infections, comparable to other batborne RNA viruses (9).

Sanger sequencing of the screening PCR amplicons suggested close genetic relatedness of the strains circulating in Brazil with the HL18NL11 strain circulating in Peru. Virus concentrations in the positive intestine specimens as determined by strain-specific quantitative real-time reverse transcription RT-PCR (Appendix Table 1, https://wwwnc. cdc.gov/EID/article/25/2/18-1246-App.pdf) were high $\left(1.5 \times 10^{9}\right.$ and $4.9 \times 10^{10}$ RNA copies/g of tissue). High HL18NL11 concentrations in intestinal specimens are consistent with qualitative data from the pioneering study on HL18NL11 (5) and may suggest intestinal tropism and potential fecal shedding into the environment.
We determined the full coding sequence of all 8 segments of the viral genomes using primers aiming at amplifying overlapping regions of bat influenza A virus genomes (GenBank accession nos. MH682200-15) (Appendix Table 1). The 2 HL18NL11 variants in Brazil differed by $15 \mathrm{nt}$ from each other across the combined 8 genomic segments. Four of those substitutions were nonsynonymous, causing amino acid exchanges in the PB2 (V203I), PB1 (R334K), nucleoprotein (G484S), and NA (V191I) genes (Table 2; Figure 1, panel B). This finding suggests recent common ancestry of the HL18NL11 variants identified in the 2 positive bats and was consistent with their detection in the same site 5 days apart. Comparison of the full coding sequence of the novel HL18NL11 variants revealed high sequence identity between the Peru and the Brazil strains, 93.5\%-96.9\% nucleotide identity across all 8 genomic segments (Table 2). The genomic relatedness of Peru and Brazil HL18NL11 strains was surprising given a time span of 2 years, a geographic distance exceeding 2,000 km, and 2 different bat species that tested positive in our study and the previous study (5).

All critical amino acid residues associated with influenza A virus replication and entry $(4,5)$ were conserved between the Brazil and the Peru HL18NL11 strains, including the HA monobasic cleavage site motif 
Figure 1. Bat influenza $\mathrm{A}(\mathrm{HL} 18 \mathrm{NL} 11)$ virus detection and genomic characterization, Brazil, 2010-2014. A) Distribution of Artibeus species bats carrying HL18NL11 in Central and South America, according to the Red List of Threatened Species from the International Union for Conservation of Nature (https:// www.iucnredlist.org). Orange star indicates the sampling site of an HL18NL11-positive bat in Peru (5); blue star indicates the sampling site of the HL18NL11positive bats in Brazil for this study. Maps were created using QGIS2.14.3 (http://www.qgis.org) with data freely available from http://www.naturalearthdata.com. B) Top, schematic representation of the genome organization of A/great fruit-eating bat/ Brazil/2301/2012 (HL18NL11) and amino acid exchanges (black lines) compared with A/great fruit-eating bat/Brazil/2344/2012 (HL18NL11) and Peru HL18NL11 (GenBank accession nos. CY125942-49). Nucleotide sequence identities between the concatenated HL18NL11 (Brazil), HL17NL10, and HL18NL11 (Guatemala and Peru) sequences were calculated in SSE version 1.2 (http://www.virus-evolution.org/Downloads/Software) with a sliding window of 200 and step size of $100 \mathrm{nt}$. C) Homology model of the $\mathrm{HL}$ protein of A/great fruit-eating bat/Brazil/2301/2012 viewed from the top, modeled on the published crystal structure retrieved from the SWISS-MODEL repository (https://www.swissmodel.expasy.org). The putative RBS is shown in blue, 3 highly conserved residues (W153, H183, and Y195) in HAs and HLs are in purple, and amino acid substitutions between Brazil strains and the Peru prototype strain are in red. D) Homology model of the NL of A/great fruit-eating bat/Brazil/2301/2012 viewed from the top, constructed as in panel $C$. The putative active site is shown in a blue circle, the 6 residues (R118, W178, S179, R224, E276 and E425) conserved in influenza A virus neuraminidase genes are in purple, and amino acid substitutions between Brazil strains and the Peru prototype strain are in red. HA, hemagglutinin; HL, hemagglutinin-like; NL, neuraminidase-like; RBS, receptor-binding site.
PIKETR/GLF (5). Thermodynamic modeling revealed that the amino acid exchanges observed between the Brazil and Peru HL18NL11 strains did not alter the tridimensional structure of the HL and NL proteins, and neither mapped to the putative receptor binding site of the HL protein (Figure 1, panel C), nor to the putative active site of the NL protein (Figure 1, panel D) (6). This result suggests preservation of the biologic activity of these glycoproteins in different bat species and supported a broadly conserved cellular receptor of bat influenza A viruses that differs from sialic acid receptors used by avian-associated influenza A viruses (10). Significantly fewer amino acid exchanges were observed between the HL proteins of Brazil and Peru bat influenza virus than between the respective NL proteins ( $\mathrm{p}$ $=0.007$ by Fisher exact test) (Table 2). The apparently

\begin{tabular}{|c|c|c|c|}
\hline & & \multicolumn{2}{|c|}{ Amino acid exchange site } \\
\hline Gene & $\begin{array}{l}\text { Nucleotide sequence } \\
\text { identity }\end{array}$ & $\begin{array}{l}\text { A/great fruit-eating bat/Brazil/2301/2012 } \\
\text { (HL18NL11a) }\end{array}$ & $\begin{array}{l}\text { A/great fruit-eating bat/Brazil/2344/2012 } \\
\text { (HL18NL11b) }\end{array}$ \\
\hline PB2 & $93.6 \%$ & $\begin{array}{c}\text { V76I, R471K, T473N, V478I, I559V, R574K, } \\
\text { S631N }\end{array}$ & $\begin{array}{c}\text { V76I, V203I, R471K, T473N, V478I, I559V, } \\
\text { R574K, S631N }\end{array}$ \\
\hline PB1 & $93.7 \%$ & V54I, T56V & V54I, T56V, R334K \\
\hline PA & $94.4 \%$ & $\begin{array}{l}\text { T70A, R116K, D158N, V231I, T254S, I552V, } \\
\text { R711G }\end{array}$ & $\begin{array}{c}\text { T70A, R116K, D158N, V231I, T254S, I552V, } \\
\text { R711G }\end{array}$ \\
\hline $\mathrm{HL}$ & $96.0 \%$ & N167T, F251L & N167T, F251L \\
\hline NP & $96.8 \%-96.9 \%$ & N20T, K350R, L357M, I380L, I387V & N20T, K350R, L357M, I380L, I387V, G484S \\
\hline NL & $93.5 \%$ & $\begin{array}{l}\text { I11V, I15L, V82I, V200I, L254I, A264T, V284I, } \\
\text { D332E, V378I, G382E }\end{array}$ & $\begin{array}{l}\text { I11V, I15L, V82I, V191I, V200I, L254I, A264T, } \\
\text { V284I, D332E, V378I, G382E }\end{array}$ \\
\hline M & $95.4 \%$ & None & None \\
\hline NS1 & $94.4 \%$ & R57K & R57K \\
\hline
\end{tabular}

*Bold indicates amino acid exchanges occurring in only 1 of the 2 Brazil strains compared to the Peru prototype strain. HA, hemagglutinin; HL, HA-like; M, matrix; NA, neuraminidase; NL, neuraminidase-like; NS, nonstructural protein; NP, nucleoprotein; PA, polymerase acidic; PB, polymerase basic. 

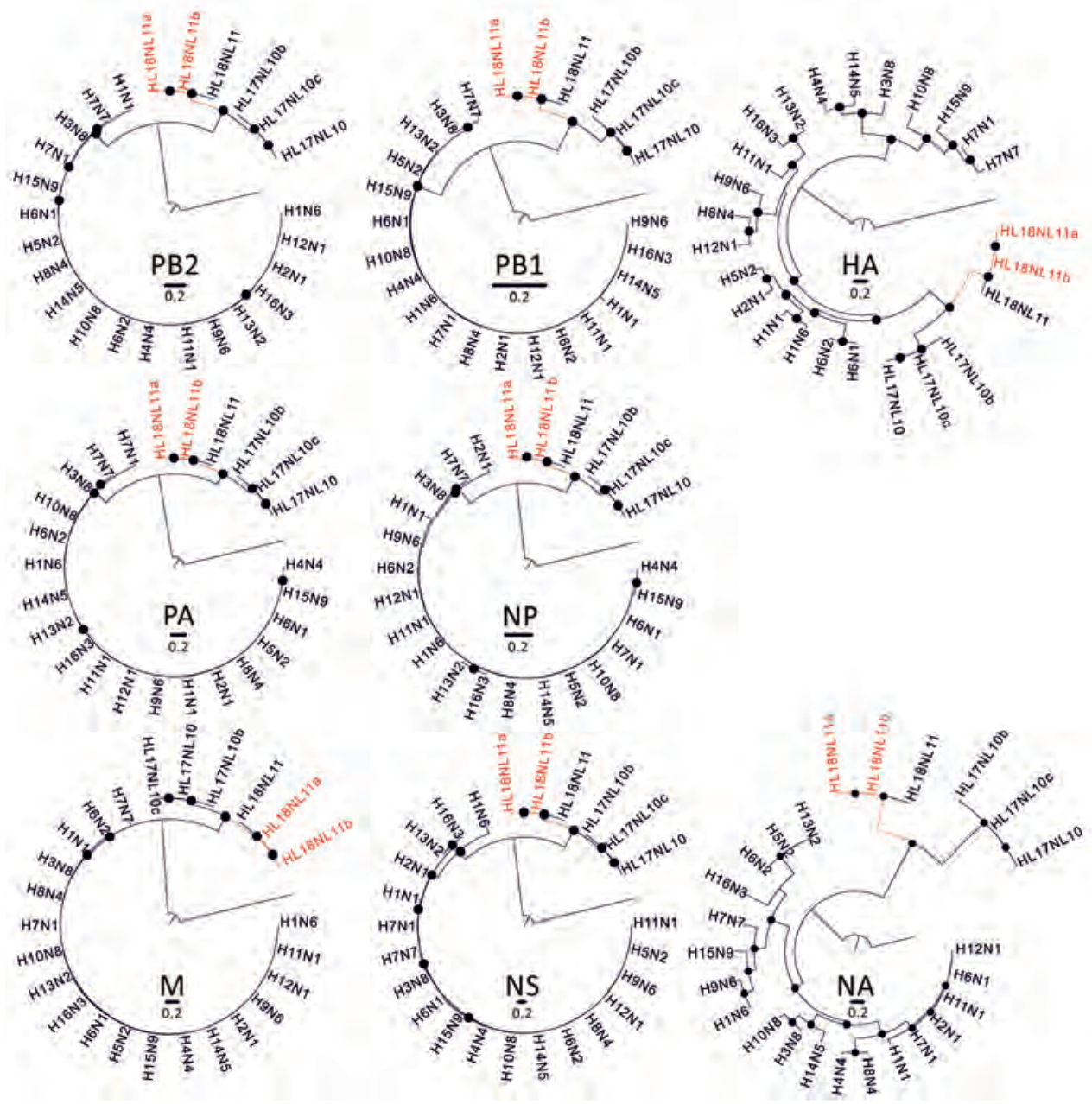

Figure 2. Phylogenetic relationships between bat influenza A viruses from Brazil and reference viruses. Phylogenetic trees show comparison of the 8 segments of representative influenza $A$ virus genomes (PB2, PB1, PA, HA/HL, NP, NA/ $\mathrm{NL}, \mathrm{M}, \mathrm{NS}$ ) with A/great fruiteating bat/Brazil/2301/2012 (HL18NL11a; GenBank accession nos. MH682200-7) and A/great fruit-eating bat/ Brazil/2344/2012 (HL18NL11b; GenBank accession nos. MH682208-15), shown in red. Maximum-likelihood trees were inferred using a general timereversible substitution model with a gamma distribution and invariant sites. Black dots represent bootstrap values $\geq 75 \%$ (1,000 replicants). Trees were generally rooted using influenza B/Lee/1940 (GenBank accession nos. DQ792894-901) (data not shown). Trees were constructed by using MEGA 6.0 (http://www.megasoftware. net). $H A$, hemagglutinin; $M$, matrix; NA, neuraminidase; NS1, nonstructural protein 1; NP, nucleoprotein; PA, polymerase acidic; PB, polymerase basic. Scale bars indicate nucleotide substitutions per site. low rate of nonsynonymous substitutions in the HLencoding genes of bat influenza A virus variants was reminiscent of strong purifying selection acting on the hemagglutinin genes in avian-specific influenza A virus strains (11). This finding may suggest comparable evolutionary dynamics between chiropteran and avian reservoirs. Definite assessments will require considerably larger datasets of bat influenza A virus strains.

A. lituratus bats and A. planirostris bats, in which HL18NL11 was originally detected in Peru, represent closely related, yet genetically and morphologically clearly distinct bat species (12). The distribution of these bat species overlaps (Figure 1, panel A), potentially facilitating virus exchange across the populations. Phylogenetic analyses confirmed the close genetic relationship between Peru and Brazil HL18NL11 variants across all 8 segments (Figure 2; Appendix Table 2), suggesting lack of reassortment events according to the available data. Our data thus suggest host associations of HL18NL11 beyond the species level, comparable to genus-level host associations of other batborne RNA viruses such as coronaviruses (13).

\section{Conclusions}

The zoonotic potential of HL18NL11 is unclear, yet humanderived cell lines were susceptible to infection by chimeric vesicular stomatitis virus pseudotyped with HL18 (14). The abundance of A. lituratus bats within Latin America (Figure 1, panel A) may thus facilitate spillover infections into other vertebrates across an underrecognized geographic and host range. Finally, Artibeus spp. bats have been used previously for infection studies including viruses with evolutionary origins in bats, such as Middle East respiratory syndrome coronavirus (15). The relatively large body size of $A$. lituratus bats $(\approx 65 \mathrm{~g})$ and ease of keeping these bats under laboratory conditions may thus facilitate experimental infection studies for HL18NL11 to elucidate the exact sites of HL18NL11 replication, receptor usage, and mode of transmission.

\section{Acknowledgments}

We thank Mariana Cristine Pereira de Souza, Cairo Monteiro de Oliveira, and Luciano Matsumiya Thomazelli for laboratory support. 
This work was supported by FAPESP (São Paulo Research Foundation) through grants 2017/20744-5, 2014/15090-8, 2014/16320-7, 2013/11006-0, and 2008/57687-0 and the European Union's Horizon 2020 research and innovation programme through the ZIKAlliance project (grant agreement no. 734548 ) to J.F.D.

\section{About the Author}

Dr. Campos is a postdoctorate researcher affiliated with the University of Sao Paulo and Charité-Universitätsmedizin Berlin. Her research focuses on emerging viruses from bats.

\section{References}

1. Olsen B, Munster VJ, Wallensten A, Waldenström J, Osterhaus ADME, Fouchier RAM. Global patterns of influenza a virus in wild birds. Science. 2006;312:384-8. http://dx.doi.org/10.1126/ science. 1122438

2. Brunotte L, Beer M, Horie M, Schwemmle M. Chiropteran influenza viruses: flu from bats or a relic from the past? Curr Opin Virol. 2016;16:114-9. http://dx.doi.org/10.1016/j.coviro.2016.02.003

3. Olival KJ, Hosseini PR, Zambrana-Torrelio C, Ross N, Bogich TL, Daszak P. Host and viral traits predict zoonotic spillover from mammals. Nature. 2017;546:646-50. http://dx.doi.org/10.1038/ nature22975

4. Tong S, Li Y, Rivailler P, Conrardy C, Castillo DA, Chen LM, et al. A distinct lineage of influenza A virus from bats. Proc Natl Acad Sci U S A. 2012;109:4269-74. http://dx.doi.org/10.1073/ pnas.1116200109

5. Tong S, Zhu X, Li Y, Shi M, Zhang J, Bourgeois M, et al. New World bats harbor diverse influenza A viruses. PLoS Pathog. 2013;9:e1003657. http://dx.doi.org/10.1371/journal.ppat.1003657

6. García-Sastre A. The neuraminidase of bat influenza viruses is not a neuraminidase. Proc Natl Acad Sci U S A. 2012;109:18635-6. http://dx.doi.org/10.1073/pnas.1215857109

7. Goes LGB, Campos ACA, Carvalho C, et al. Genetic diversity of bats coronaviruses in the Atlantic Forest hotspot biome, Brazil. Infect Genet Evol. 2016;44:510-3.
8. Anthony SJ, Islam A, Johnson C, Navarrete-Macias I, Liang E, Jain K, et al. Non-random patterns in viral diversity. Nat Commun. 2015;6:8147. http://dx.doi.org/10.1038/ncomms9147

9. Drexler JF, Corman VM, Wegner T, Tateno AF, Zerbinati RM, Gloza-Rausch F, et al. Amplification of emerging viruses in a bat colony. Emerg Infect Dis. 2011;17:449-56. http://dx.doi.org/ 10.3201/eid1703.100526

10. Zhu X, Yu W, McBride R, Li Y, Chen LM, Donis RO, et al. Hemagglutinin homologue from H17N10 bat influenza virus exhibits divergent receptor-binding and $\mathrm{pH}$-dependent fusion activities. Proc Natl Acad Sci U S A. 2013;110:1458-63. http://dx.doi.org/10.1073/pnas.1218509110

11. Rejmanek D, Hosseini PR, Mazet JAK, Daszak P, Goldstein T. Evolutionary dynamics and global diversity of influenza A virus. J Virol. 2015;89:10993-1001. http://dx.doi.org/10.1128/ JVI.01573-15

12. Larsen PA, Marchán-Rivadeneira MR, Baker RW. Speciation dynamics of the fruit-eating bats (genus Artibeus): with evidence of ecological divergence in Central American populations. In: Adams RA, Pedersen SC, editors. Bat evolution, ecology, and conservation. New York: Springer Science + Business Media; 2013. p. 315-339. https://doi.org/10.1007/ 978-1-4614-7397-8

13. Drexler JF, Corman VM, Drosten C. Ecology, evolution, and classification of bat coronaviruses in the aftermath of SARS. Antiviral Res. 2014;101:45-56. http://dx.doi.org/10.1016/ j.antiviral.2013.10.013

14. Moreira ÉA, Locher S, Kolesnikova L, Bolte H, Aydillo T, García-Sastre A, et al. Synthetically derived bat influenza A-like viruses reveal a cell type- but not species-specific tropism. Proc Natl Acad Sci U S A. 2016;113:12797-802. http://dx.doi.org/ 10.1073/pnas.1608821113

15. Munster VJ, Adney DR, van Doremalen N, Brown VR, Miazgowicz KL, Milne-Price S, et al. Replication and shedding of MERS-CoV in Jamaican fruit bats (Artibeus jamaicensis). Sci Rep. 2016;6:21878. http://dx.doi.org/10.1038/srep21878

Address for correspondence: Jan Felix Drexler, Helmut-Ruska-Haus, Institute of Virology, Campus Charité Mitte, Charitéplatz 1, 10098 Berlin, Germany; email: felix.drexler@charite.de

\section{EID Podcast: Bat Flight and Zoonotic Viruses}

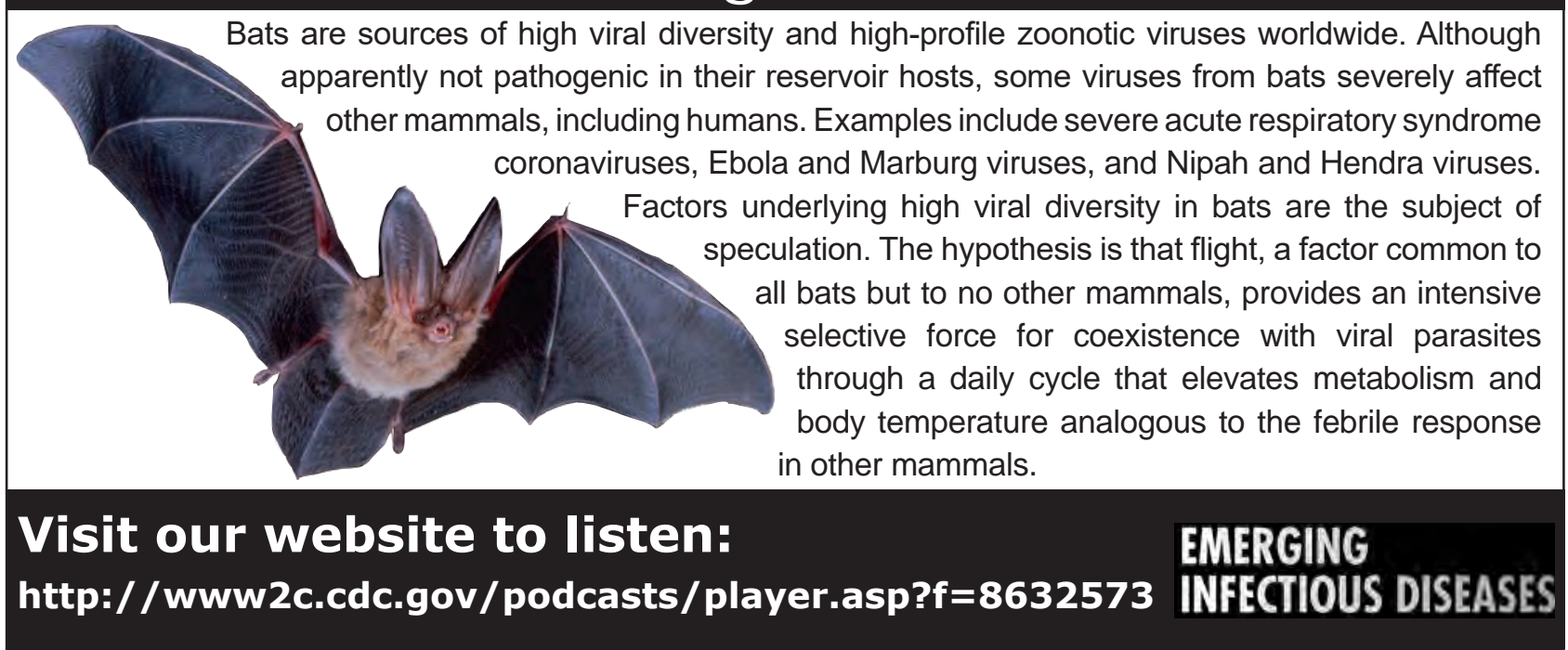




\section{Rift Valley Fever Reemergence after 7 Years of Quiescence, South Africa, May 2018}

\author{
Petrus Jansen van Vuren, Joe Kgaladi, \\ Veerle Msimang, Janusz T. Paweska
}

Phylogenetic analysis of Rift Valley fever virus partial genomic sequences from a patient infected in South Africa in May 2018 suggests reemergence of an endemic lineage different from that of the epidemic in South Africa during 2010-2011. Surveillance during interepidemic periods should be intensified to better predict future epidemics.

$\mathrm{R}_{\mathrm{i}}^{\mathrm{i}}$ ift Valley fever (RVF) epidemics occur at irregular intervals in Africa, on the Arabian Peninsula, in Madagascar, and on other Indian Ocean islands (1). South Africa has experienced 3 major epidemics during 1950-1951, 1974-1976, and 2008-2011, with smaller sporadic outbreaks in between $(2,3)$. Phylogenetic analyses of isolates spanning 70 years have shown widespread dispersal of RVF virus (RVFV) genotypes throughout the regions where the virus is endemic and a high level of diversity within small geographic areas $(4,5)$. We report the laboratory confirmation of 8 RVF cases in humans in South Africa in 2018 and phylogenetic analysis of the virus responsible for the outbreak.

\section{The Study}

Communicable disease surveillance and outbreak investigation activities of the National Institute for Communicable Diseases (Johannesburg, South Africa) are approved by the Human Research Ethics Committee of the University of the Witwatersrand, Johannesburg, South Africa (M160667). In mid-May 2018, an outbreak of RVF in sheep on a farm in Free State Province, South Africa, was reported, followed by 4 probable cases in humans detected by RVFV serology (6). The affected farm is located in Jacobsdal District, a farming community close to the border of Northern Cape Province, where sheep are the main livestock species. In addition to the 6 patients sampled on May 21, 2018, described previously (6), another 4 were sampled on June 4, 2018. These patients experienced headache, muscle pain, fever, body ache, rigors, and nausea, as reported previously (6). A recent history of influenza-like illness was reported

Author affiliation: National Institute for Communicable Diseases of the National Health Laboratory Service, Johannesburg, South Africa

DOI: https://doi.org/10.3201/eid2502.181289 for only 2 of these 4 patients. All 4 lived and worked on the farm and were involved in high-risk activities, such as slaughtering, autopsying, disposal and burial of carcasses, or handling of raw meat. We obtained followup samples from all 10 patients for paired serologic testing (Appendix Table 1, https://wwwnc.cdc.gov/EID/ article/25/2/18-1289-App1.pdf).

We performed the serologic assays, hemagglutination inhibition assay, virus neutralization test, and IgM ELISA with all serial serum samples collected from all 10 patients (7) and real-time reverse transcription PCR (RT-PCR) (8) on the serum fractions of clotted blood collected from the first 6 patients with suspected cases described previously (6). We extracted nucleic acid from EDTA whole blood samples collected from the initial 4 patients with probable cases using the MagMax Pathogen RNA/DNA Kit (Applied Biosystems, https://www.thermofisher.com) and then tested by RT-PCR. We determined the partial genome sequences of viruses from RT-PCR-positive whole blood samples using sequence-independent single-primer amplification combined with sequencing in triplicate on an Illumina MiSeq (https://www.illumina.com) and raw data processing, as described previously (9). After quality and host filtering and using a requirement of $\geq 3 \times$ coverage per base, we mapped raw reads to reference sequences representing the RVFV large (L), medium (M), and small (S) segments (GenBank accession nos. KX611605-7). We concatenated sequence fragments of segments, prepared alignments in MEGA6 (https://www.megasoftware.net), performed phylogenetic analyses using RAxML version 8.2.10 (http:// evomics.org/learning/phylogenetics/raxml), and visualized trees with Figtree version 1.4.3 (http://tree.bio.ed.ac.uk/ software/figtree).

Of 10 patients sampled, 8 seroconverted after 2 or 3 serial bleeds, as evidenced by a 4 -fold increase in the hemagglutination inhibition assay or virus neutralization test titers (Appendix Table 1), and had RVFV-specific IgM, confirming their recent RVFV infection status. We detected RVFV RNA in EDTA whole blood samples of 3 of 4 patients sampled 7 days after estimated symptom onset (Appendix Table 1). Sequence-independent singleprimer amplification sequencing yielded sequence fragments of the $M$ and $L$ segments in 1 (SA344-18) of 3 samples (GenBank accession nos. MH753234-41). We concatenated these partial sequence fragments (Appendix Table 2) and attained $86 \%(3,341 / 3,885 \mathrm{nt})$ of the $\mathrm{M}$ 
segment and $77.7 \%(4,975 / 6,404 \mathrm{nt})$ of the $\mathrm{L}$ segment. Only a single fragment was obtained of the S segment (776 nt, 45.9\%) spanning nucleotides 18-793 (GenBank accession no. MH753233). Partial sequence fragments of the L segment from another sample (SA343-18) were also obtained; this sequence had a 165-bp overlap with sample SA344-18 (at nucleotides 3,276-3,440) and a single-nucleotide mismatch (A3305T, 99.4\% identical) but was not included in phylogenetic analyses because of its close identity to SA344-18 and small fragment size. We prepared alignments with similarly concatenated $\mathrm{L}$ and $\mathrm{M}$ or partial S sequences from GenBank (Appendix Table 3) and a separate alignment with a 490-nt portion of the M segment of SA344-18 and sequences available from GenBank from a previous study, including sequences from the 2010 RVF outbreak in South Africa (5).

In phylogenetic analyses of the $\mathrm{L}$ and $\mathrm{M}$ segments, isolate SA344-18 grouped with lineage E (Figure 1; Appendix Figure 1), according to the lineage nomenclature of Bird et al. (4). In analyses of all segments, this RVFV isolate had the closest relationship to Beijing-01, an isolate from a 2016 case exported to China from Angola (10), and to a 2009 sheep isolate from Kakamas, Northern Cape Province, South Africa (11) (Figures 1, 2; Appendix Figures 1, 2). The E lineage also included 25010-24, an isolate from a camel sampled during an outbreak in Mauritania in 2010 (Appendix Figure 1) (11). Nodes of the partial S segment tree were poorly supported, probably because the fragments were small (Appendix Figure 2). The overall pairwise nucleotide differences were $3.1 \%$ for $\mathrm{L}, 3.6 \%$ for $\mathrm{M}$, and $3.1 \%$ for S (nonstructural protein gene), similar to values reported previously $(4,5)$.

According to the partial 490-nt M segment tree and lineage nomenclature of Grobbelaar et al. (5), SA344-18 is lineage K (Figure 2). All 2010 RVFV sequences from humans in South Africa, except SA184-10, group in lineage $\mathrm{H}$, distant from SA344-18. Isolate SA184-10 (lineage K) was obtained from a patient who had a needle-stick injury

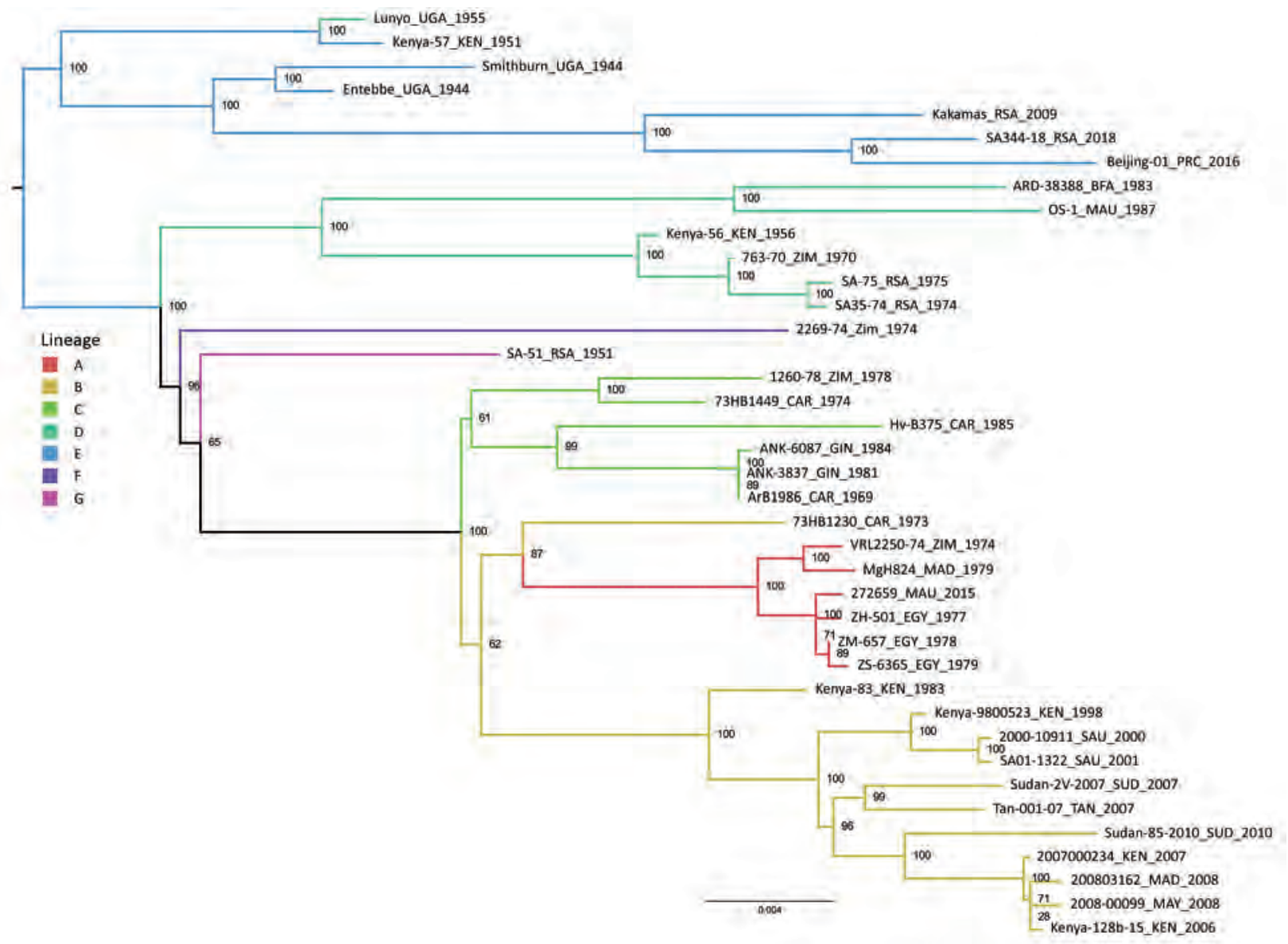

Figure 1. Maximum-likelihood tree showing the phylogeny of Rift Valley fever virus isolate SA344-18, collected in South Africa in May 2018, on the basis of the concatenated large segment. Lineage names according to the nomenclature of Bird et al. (4) are indicated. Maximum-likelihood analysis was performed in RAxML version 8.2.10 (http://evomics.org/learning/phylogenetics/raxml); 10,000 bootstrap replicates were performed. Bootstrap values are shown at nodes. Scale bar indicates nucleotide changes per base pair. BFA, Burkina Faso; CAR, Central African Republic; EGY, Egypt; GIN, Guinea; KEN, Kenya; MAD, Madagascar; MAU, Mauritania; MAY, Mayotte; PRC, China; RSA, South Africa; SAU, Saudi Arabia; SUD, Sudan; TAN, Tanzania; UGA, Uganda; ZIM, Zimbabwe. 


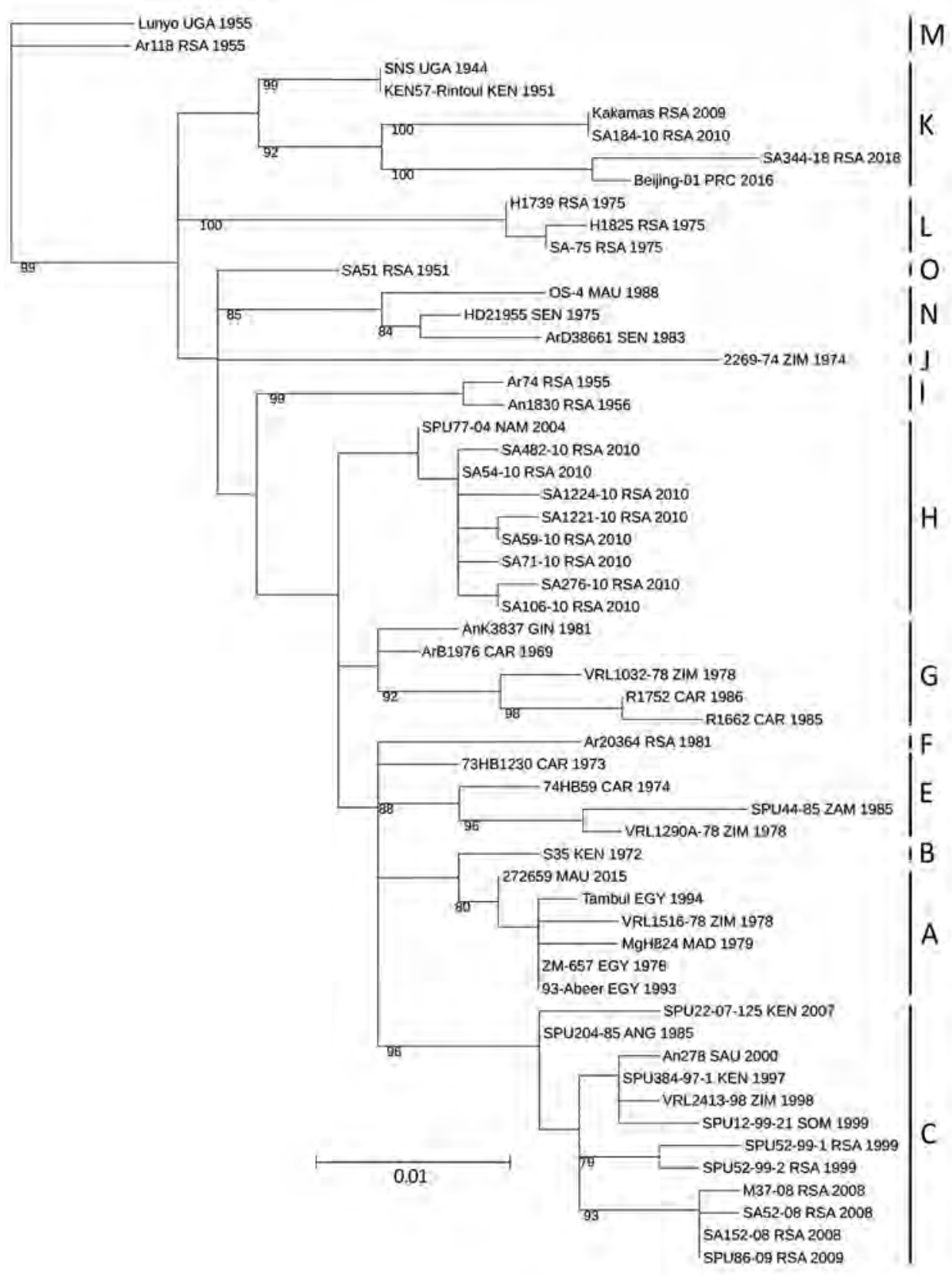

Figure 2. Maximum-likelihood tree showing the phylogeny of Rift Valley fever virus isolate SA344-18, collected in South Africa in May 2018, on the basis of a 490-nt fragment of the medium segment. Lineage names according to the nomenclature of Grobbelaar et al. (5) are indicated. Maximum-likelihood analysis was performed in RAxML version 8.2.10 (http://evomics. org/learning/phylogenetics/ raxml); 100,000 bootstrap replicates were performed. Bootstrap values are shown at the nodes. Scale bar indicates nucleotide changes per base pair. ANG, Angola; CAR, Central African Republic; EGY, Egypt; GIN, Guinea; KEN, Kenya; MAD, Madagascar; MAU, Mauritania; NAM, Namibia; PRC, China; RSA, South Africa; SAU, Saudi Arabia; SEN, Senegal; SOM, Somalia; UGA, Uganda; ZAM, Zambia; ZIM, Zimbabwe.

while vaccinating sheep with Smithburn vaccine (5). The 490-nt partial M sequence of SA184-10 is identical to that of the 2009 Kakamas sheep isolate (Figure 2). The only RVFV sequence from a human in Northern Cape Province (SA404-09, GenBank accession no. HM587096) grouped in lineage $\mathrm{H}$ (data not shown) (5).

\section{Conclusions}

The major RVF epidemic in South Africa during 20102011 included mostly lineage H RVFV isolates, and the smaller outbreaks during the 2 preceding years included lineage C (5). The virus detected in Free State Province in 2018 groups in the distant lineage $\mathrm{K}$, despite extensive transmission of lineage $\mathrm{H}$ during 2010-2011 in the same province. The 2018 isolate, SA344-18, detected in the absence of a major epidemic, is closely related to viruses from isolated cases, such as Kakamas-2009 and Beijing-01. These isolates group in the lineage that includes Smithburn vaccine viruses and its parent strain, Entebbe, isolated in Uganda in 1944 (4). Camel isolate 25010-24 also falls in this lineage, despite most other RVFV isolates from Mauritania grouping with distant lineages (11).

Intensified surveillance during interepidemic periods would enhance our knowledge of the genetic evolution of 
RVFV. Isolated outbreaks, similar to the one reported here, probably have occurred more frequently than recorded. Establishment of sentinel herds of susceptible animals and increased vector surveillance could yield isolates more frequently and lead to a better characterization of the strains maintained at low levels between epidemics. Our results indicate an ongoing activity and evolution of RVFV during interepizootic periods and highlight the importance of a cryptic transmission cycle that enables establishment of endemicity, which at times inevitably emerges in the form of an explosive outbreak.

The work presented here was partly funded by the Poliomyelitis Research Foundation (grant no. PRF12/63) and partly through the routine arbovirus reference diagnostic work of the Centre for Emerging Zoonotic and Parasitic Diseases, National Institute for Communicable Diseases.

\section{About the Author}

Dr. Jansen van Vuren is a medical scientist at the National Institute for Communicable Diseases in Johannesburg, South Africa. His research interests are diagnostics and viral hemorrhagic and arboviral diseases.

\section{References}

1. Nanyingi MO, Munyua P, Kiama SG, Muchemi GM, Thumbi SM, Bitek AO, et al. A systematic review of Rift Valley fever epidemiology 1931-2014. Infect Ecol Epidemiol. 2015;5:28024. http://dx.doi.org/10.3402/iee.v5.28024

2. Archer BN, Thomas J, Weyer J, Cengimbo A, Landoh DE, Jacobs C, et al. Epidemiologic investigations into outbreaks of Rift Valley fever in humans, South Africa, 2008-2011. Emerg Infect Dis. 2013;19:1918-25. http://dx.doi.org/10.3201/eid1912.121527

3. Pienaar NJ, Thompson PN. Temporal and spatial history of Rift Valley fever in South Africa: 1950 to 2011. Onderstepoort J Vet Res. 2013;80:384. http://dx.doi.org/10.4102/ojvr.v80i1.384

4. Bird BH, Khristova ML, Rollin PE, Ksiazek TG, Nichol ST. Complete genome analysis of 33 ecologically and biologically diverse Rift Valley fever virus strains reveals widespread virus movement and low genetic diversity due to recent common ancestry. J Virol. 2007;81:2805-16. http://dx.doi.org/10.1128/ JVI.02095-06

5. Grobbelaar AA, Weyer J, Leman PA, Kemp A, Paweska JT, Swanepoel R. Molecular epidemiology of Rift Valley fever virus. Emerg Infect Dis. 2011;17:2270-6. http://dx.doi.org/10.3201/ eid1712.111035

6. Jansen van Vuren P, Kgaladi J, Patharoo V, Ohaebosim P, Msimang V, Nyokong B, et al. Human cases of Rift Valley fever in South Africa, 2018. Vector Borne Zoonotic Dis. 2018;vbz.2018.2357. http://dx.doi.org/10.1089/vbz.2018.2357

7. Paweska JT, Burt FJ, Swanepoel R. Validation of IgG-sandwich and IgM-capture ELISA for the detection of antibody to Rift Valley fever virus in humans. J Virol Methods. 2005;124:173-81. http://dx.doi.org/10.1016/j.jviromet.2004.11.020

8. Drosten C, Göttig S, Schilling S, Asper M, Panning M, Schmitz H, et al. Rapid detection and quantification of RNA of Ebola and Marburg viruses, Lassa virus, Crimean-Congo hemorrhagic fever virus, Rift Valley fever virus, dengue virus, and yellow fever virus by real-time reverse transcription-PCR. J Clin Microbiol. 2002;40:2323-30. http://dx.doi.org/10.1128/ JCM.40.7.2323-2330.2002

9. Ladner JT, Wiley MR, Mate S, Dudas G, Prieto K, Lovett S, et al. Evolution and spread of Ebola virus in Liberia, 2014-2015. Cell Host Microbe. 2015;18:659-69. http://dx.doi.org/10.1016/ j.chom.2015.11.008

10. Liu J, Sun Y, Shi W, Tan S, Pan Y, Cui S, et al. The first imported case of Rift Valley fever in China reveals a genetic reassortment of different viral lineages. Emerg Microbes Infect. 2017;6:e4. http://dx.doi.org/10.1038/emi.2016.136

11. El Mamy AB, Lo MM, Thiongane Y, Diop M, Isselmou K, Doumbia B, et al. Comprehensive phylogenetic reconstructions of Rift Valley fever virus: the 2010 northern Mauritania outbreak in the Camelus dromedarius species. Vector Borne Zoonotic Dis. 2014;14:856-61. http://dx.doi.org/10.1089/ vbz.2014.1605

Address for correspondence: Janusz T. Paweska, Center for Emerging Zoonotic and Parasitic Diseases, National Institute for Communicable Diseases of the National Health Laboratory Service, 1 Modderfontein Rd, Sandringham 2131, Johannesburg, South Africa; email: januszp@nicd.ac.za 


\section{Tick-Borne Encephalitis Virus Antibodies in Roe Deer, the Netherlands}

\author{
Jolianne M. Rijks, Margriet G.E. Montizaan, \\ Nine Bakker, Ankje de Vries, Steven Van Gucht, \\ Corien Swaan, Jan van den Broek, \\ Andrea Gröne, Hein Sprong
}

To increase knowledge of tick-borne encephalitis virus (TBEV) circulation in the Netherlands, we conducted serosurveillance in roe deer (Capreolus capreolus) during 2017 and compared results with those obtained during 2010. Results corroborate a more widespread occurrence of the virus in 2017. Additional precautionary public health measures have been taken.

$\mathrm{T}$ ick-borne encephalitis virus (TBEV) was detected in the Netherlands during 2016. Retrospective screening of 297 roe deer (Capreolus capreolus) serum samples obtained during 2010 showed 6 samples contained TBEVneutralizing antibodies. Five of these 6 serum samples had been obtained in Sallandse Heuvelrug National Park (Figure 1). A strain of the virus subtype from Europe (TBEVEU) was subsequently detected in Ixodes ricinus ticks collected at this national park (1).

Shortly after TBEV was reported to health professionals in the Netherlands, 2 probable autochthonous human tickborne encephalitis (TBE) cases were identified, followed by a third case in 2017 . The first case-patient probably got infected in the central part of the Netherlands in Utrechtse Heuvelrug National Park (Figure 1) (2); the second and third case-patients resided near Sallandse Heuvelrug National Park, where the TBEV-positive ticks were found $(3,4)$. A tick removed by the first case-patient contained RNA of a virus strain more closely related to the TBEV-EU Neudörfl strain than to the TBEV-EU strain from Sallandse Heuvelrug National Park (2). This finding implied multiple infection sites and multiple strains of TBEV-EU in the Netherlands.

Given these developments, there was a renewed need to locate potential TBEV foci and identify signs of increased TBEV circulation, in view of taking appropriate

Author affiliations: Dutch Wildlife Health Centre, Utrecht, the Netherlands (J.M. Rijks, M.G.E. Montizaan, N. Bakker, A. Gröne); National Institute for Public Health and the Environment, Bilthoven, the Netherlands (A. de Vries, C. Swaan, H. Sprong); Sciensano, Brussels, Belgium (S. Van Gucht); Utrecht University, Utrecht (J. van den Broek, A. Gröne)

DOI: https://doi.org/10.3201/eid2502.181386 public health decisions. Therefore, we collected roe deer blood samples during 2017, tested them for TBEV and TBEV-neutralizing antibodies, and compared results with those from 2010 (1).

\section{The Study}

Hunters submitted EDTA blood and serum samples by using the S-Monovette collection system (Sarstedt, https:// www.sarstedt.com/en/home) from roe deer in locations across the Netherlands (Figure 1; Appendix 1, https:// wwwnc.cdc.gov/EID/article/25/2/18-1386-App1.xlsx). To enable comparison between years, most samples were requested through game management units by using the same method as in 2010, which had been designed for prevalence studies (random sampling). Samples from 592 roe deer were obtained. Furthermore, given the focal nature of TBE occurrence (5), specific game management units were asked during the year to supply extra samples (purposive sampling 48 samples), which were administered separately.

As during 2010 (1), we first screened 640 serum samples for TBEV-reactive antibodies by using a commercial ELISA (Immunozym FSME IgG all species with inactivated TBEV coating; PROGEN Biotechnik GmbH, https://www.progen.com). We then conducted a TBEV serum neutralization test (SNT) on ELISA-positive ( $>126$ Vienna units/mL) or borderline (63-126 Vienna units/ $\mathrm{mL}$ ) samples. The serum dilution at which $50 \%$ of the Neudörfl strain (prototype TBEV-EU) is neutralized was calculated according to the method of Reed and Muench (6). At a $50 \%$ dilution $\geq 1: 20$, the SNT result was considered positive.

We also conducted PCR on RNA extracted from whole blood with primers as described $(7,8)$ to detect early infection. A potential focus was defined by the presence of a TBEV SNT-confirmed or PCR-positive roe deer case. A confirmed focus was defined as a site with molecular evidence of the virus. Considering the home range size for roe deer, we arbitrarily considered a case within $10 \mathrm{~km}$ part of the same focus.

A total of 22/640 specimens had SNT-positive results: 17/592 (10/20 ELISA-positive and 7/55 ELISA-borderline cases) in the random sample and 5/48 (4/5 ELISA-positive and 1/8 ELISA-borderline cases) in the purposive sample (Table). No sample showed positive results by PCR. The SNT-confirmed cases occurred in the known focus of 
Figure 1. Geographic distribution of tick-borne encephalitis virus (TBEV) based on serosurveillance of roe deer, the Netherlands, during A) 2010 and B) 2017. Data for 2010 were reproduced from Jahfari et al. (1). Red indicates roe deer serum samples that showed positive results in the TBEV neutralization test, and blue indicates roe deer serum samples that showed negative results in this test or an ELISA. Numbers indicate confirmed or potential foci, and red stars indicate location of 2016 TBEV-RNA positive ticks in Sallandse Heuvelrug National Park. Circles indicate sites of random sampling, and diamonds indicate sites of purposive sampling. Arrow in the right map indicates location of Utrechtse Heuvelrug National Park. Maps were constructed by using Arc-GIS software (ESRI, https://www.esri.com).
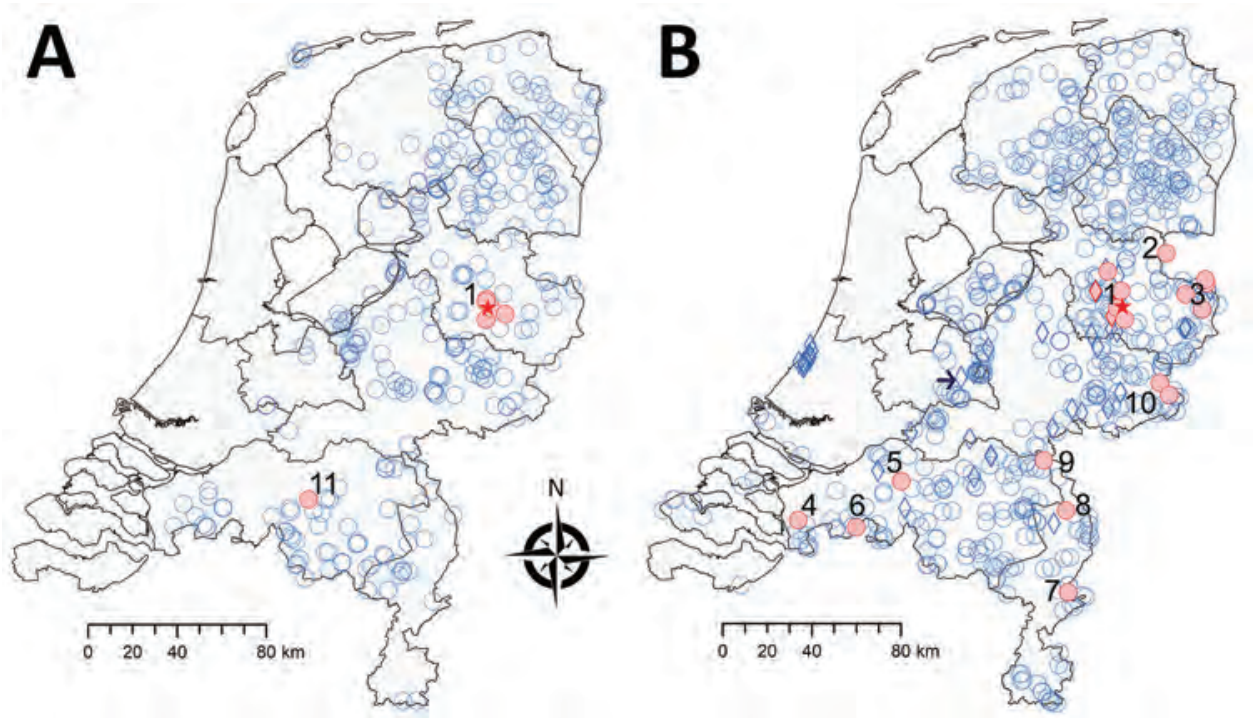

Sallandse Heuvelrug National Park (focus no. 1) and 9 potential foci (foci nos. 2-10) (Table; Figure 1). All 10 foci were detected by random sampling. Purposive sampling confirmed the known focus (no. 1).

We investigated probabilities of an increase in TBEV circulation and geographic expansion of TBEV by using random sampling results for 2010 and 2017 and R statistical software packages (https://www.r-project.org). Underlying assumptions were that SNT-confirmed roe deer cases had been infected with TBEV, and that there was no effect of hunter participation level. For roe deer, we used logistic regression with year, sex, age category (juvenile, immature, mature), and nutritional condition (good, moderate, poor) as independent variables to analyze whether year of sampling affected the likelihood of antibodies against TBEV
(R scripts) (Appendix 2, https://wwwnc.cdc.gov/EID/ article/25/2/18-1386-App2.pdf). We applied the Akaike information criterion for model reduction on all independent variables except year. The model was not improved by the other variables, which were then removed. We calculated the odds ratio for year and $95 \%$ profile (log) likelihood CI as 1.43 (95\% CI of 0.59-4.01), which showed no clear effect of year. The results provide no evidence for an increase in roe deer cases in 2017 compared with 2010.

For focal diseases, such as TBE, sampling intensity might affect the detection rate for foci. Sampling intensity was greater in 2017 (592 events) than in 2010 (297 events). To investigate TBE expansion during 2010-2017, we randomly selected 297 events (samples) from the 592 events in the 2017 distribution (the study in 2017) and recorded the

\begin{tabular}{|c|c|c|c|c|}
\hline \multirow[b]{2}{*}{ Province } & \multirow[b]{2}{*}{ No. (\%) deer counted $\dagger$} & \multicolumn{2}{|c|}{ No. TBEV SNT-positive samples/no. tested } & \multirow{2}{*}{$\begin{array}{c}\text { Identification } \\
\text { no. of foci }\end{array}$} \\
\hline & & Random sampling & Purposive sampling & \\
\hline Drenthe & $10,728(16)$ & $0 / 99$ & NA & NA \\
\hline Flevoland & $2,358(4)$ & $0 / 37$ & NA & NA \\
\hline Friesland & $6,217(10)$ & $0 / 62$ & $0 / 1$ & NA \\
\hline Gelderland & $10,687(16)$ & $2 / 97$ & $0 / 12$ & 10 \\
\hline Groningen & $4,649(7)$ & $0 / 32$ & NA & NA \\
\hline Limburg & $4,674(7)$ & $3 / 46$ & $0 / 1$ & 7,8, and 9 \\
\hline North Brabant & $9,618(15)$ & $3 / 101$ & $0 / 5$ & 4,5, and $6 \ddagger$ \\
\hline North Holland§ & $935(1)$ & $0 / 0$ & NA & NA \\
\hline Overijssel & 9,933 (16) & $9 / 87$ & $5 / 18$ & $1, \mathbb{1} 2$, and 3 \\
\hline South Holland & $1,103(2)$ & $0 / 7$ & $0 / 10$ & NA \\
\hline Utrecht & $2,485(4)$ & $0 / 16$ & $0 / 1$ & NA \\
\hline Zealand§̧ & $1,293(2)$ & $0 / 8$ & NA & NA \\
\hline Total & $64,680(100)$ & $17 / 592$ & $5 / 48$ & NA \\
\hline
\end{tabular}

*NA, not applicable; SNT, serum neutralization test; TBEV, tick-borne encephalitis virus.

†Provided by the game management units.

$\ddagger$ f fourth potential focus (no. 11) was identified by using serum samples obtained from roe deer during 2010 but not reconfirmed in 2017.

§No hunting, only victims of traffic accidents.

ISallandse Heuvelrug National Park (the confirmed site, also identified by using serum samples obtained from roe deer during 2010). 


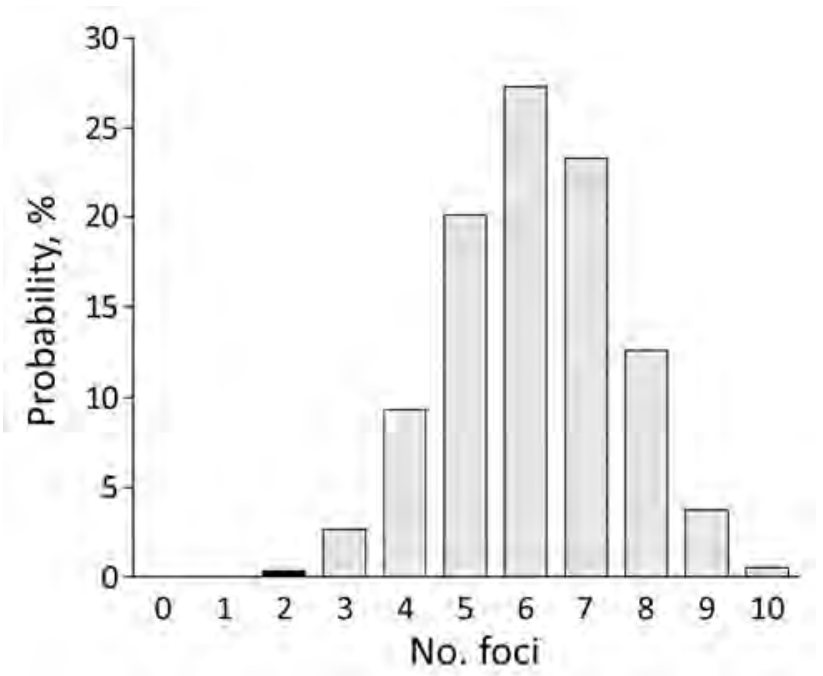

Figure 2. Probability distribution of number of potential foci containing tick-borne encephalitis virus expected to be detected during 2017 if only 297 of 590 roe deer samples had been submitted for testing, the Netherlands. Black column indicates the probability corresponding to the number of foci detected during the retrospective study of 297 samples obtained during 2010.

number of distinct foci that occurred. We repeated this procedure 100,000 times to obtain a probability distribution for the number of foci (Appendices 1, 2). The probability of obtaining $\leq 2$ foci in 2017 was low (0.4\%) (Figure 2). This finding indicates that the number of TBE foci probably increased during 2010-2017.

\section{Conclusions}

Our study corroborates a more widespread occurrence of TBEV foci in the Netherlands than that identified on the basis of roe deer samples obtained during 2010. The lack of evidence for a major increase in roe deer exposure to TBEV could indicate these foci are recent, small, and possibly poorly established. Both focus size and sample distribution will affect detection and could explain why no foci were detected in Utrechtse Heuvelrug National Park or at site no. 11 during 2017. Identification of human cases and wildlife surveillance data are consistent with a general trend of geographic expansion of TBE that was concluded by an international working group on TBEV on the basis of data obtained from across Europe during 2007-2009 (9).

Many of the new potential foci we found are located near border areas with Germany or Belgium. Border districts in Germany are not reported to be risk areas for TBE. However, recent autochthonous human cases of TBEV infection were detected in Borken (2015) and Emsland (2016 and 2017) (10). In Flanders, wildlife had TBEV-neutralizing antibodies $(11,12)$.

TBEV-infected areas are preferably identified through TBEV-specific antibodies in sentinel species (13). Roe deer have small home ranges, are often infested with $I$. ricinus ticks, seroconvert well $(14,15)$, and are proven good sentinel species $(1,14,15)$. However, if one considers serologic cross-reactivity among flaviviruses, potential foci identified need to be confirmed by other methods, such as PCRs for detecting TBEV in ticks from these sites $(1,16)$.

These and other findings led to several public health measures in the Netherlands over the past 2 years. Microbiologists and clinicians are alerted regularly about TBE, its clinical appearance, and appropriate laboratory tests. Information on TBE is incorporated in tick bite prevention information, including on the website of the National Institute for Public Health and the Environment (https://www.rivm.nl/en). Professionals have been informed and reminded of measures to prevent tick bites. In the Sallandse Heuvelrug National Park area, inhabitants and general practitioners are specifically informed about TBE, including the availability of vaccines, by the Regional Public Health Services. We show that outcomes of surveillance in a sentinel wildlife species can directly contribute to public health interventions, which is an illustrative example of an effective One Health approach.

\section{Acknowledgments}

We thank all persons who provided data and samples for testing.

This study was supported by the Dutch Ministry of Health, Welfare and Sport (Min VWS).

\section{About the Author}

Dr. Rijks is a postdoctoral researcher at the Dutch Wildlife Health Centre in Utrecht, the Netherlands. Her primary research interests are wildlife diseases and epidemiology.

\section{References}

1. Jahfari S, de Vries A, Rijks JM, Van Gucht S, Vennema H, Sprong $\mathrm{H}$, et al. Tick-borne encephalitis virus in ticks and roe deer, the Netherlands. Emerg Infect Dis. 2017;23:1028-30. http://dx.doi.org/10.3201/eid2306.161247

2. de Graaf JA, Reimerink JH, Voorn GP, Bij de Vaate EA, de Vries A, Rockx B, et al. First human case of tick-borne encephalitis virus infection acquired in the Netherlands, July 2016. Euro Surveill. 2016;21:30318. http://dx.doi.org/ 10.2807/1560-7917.ES.2016.21.33.30318

3. Weststrate AC, Knapen D, Laverman GD, Schot B, Prick JJ, Spit SA, et al. Increasing evidence of tick-borne encephalitis (TBE) virus transmission, the Netherlands, June 2016. Euro Surveill. 2017;22:30482. http://dx.doi.org/10.2807/1560-7917. ES.2017.22.11.30482

4. Dekker M, Laverman GD, de Vries A, Reimerink J, Geeraedts F. Emergence of tick-borne encephalitis (TBE) in the Netherlands. Ticks Tick Borne Dis. 2019;10:176-9. http://dx.doi.org/10.1016/ j.ttbdis.2018.10.008

5. Tonteri E, Kurkela S, Timonen S, Manni T, Vuorinen T, Kuusi M, et al. Surveillance of endemic foci of tick-borne encephalitis in Finland 1995-2013: evidence of emergence of 
new foci. Euro Surveill. 2015;20:30020. http://dx.doi.org/10.2807/ 1560-7917.ES.2015.20.37.30020

6. Reed LJ, Muench H. A simple method of estimating fifty percent endpoints. Am J Hyg. 1938;27:493-7.

7. Jahfari S, Hofhuis A, Fonville M, van der Giessen J, van Pelt W, Sprong H. Molecular detection of tick-borne pathogens in humans with tick bites and erythema migrans, in the Netherlands. PLoS Negl Trop Dis. 2016;10:e0005042. http://dx.doi.org/10.1371/ journal.pntd.0005042

8. Kupča AM, Essbauer S, Zoeller G, de Mendonça PG, Brey R, Rinder $\mathrm{M}$, et al. Isolation and molecular characterization of a tick-borne encephalitis virus strain from a new tick-borne encephalitis focus with severe cases in Bavaria, Germany. Ticks Tick Borne Dis. 2010;1:44-51. http://dx.doi.org/10.1016/ j.ttbdis.2009.11.002

9. Donoso Mantke O, Escadafal C, Niedrig M, Pfeffer M; Working group for tick-borne encephalitis virus C. Tick-borne encephalitis in Europe, 2007 to 2009. Euro Surveill. 2011;16:19976. http://dx.doi.org/10.2807/ese.16.39.19976-en

10. Seedat J. TBE: risk areas in Germany (April 2018) [in German]. Epidemiologisches Bulletin. 2018 April [cited 2018 Nov 25]. https:/www.rki.de/DE/Content/Infekt/EpidBull/Archiv/2018/ Ausgaben/17_18.pdf?_blob=publicationFile

11. Tavernier P, Sys SU, De Clercq K, De Leeuw I, Caij AB, De Baere M, et al. Serologic screening for 13 infectious agents in roe deer (Capreolus capreolus) in Flanders. Infect Ecol Epidemiol. 2015;5:29862. http://dx.doi.org/10.3402/iee.v5.29862

12. Roelandt S, Suin V, Van der Stede Y, Lamoral S, Marche S, Tignon M, et al. First TBEV serological screening in Flemish wild boar. Infect Ecol Epidemiol. 2016;6:31099. http://dx.doi.org/10.3402/iee.v6.31099

13. Valarcher JF, Hägglund S, Juremalm M, Blomqvist G, Renström L, Zohari S, et al. Tick-borne encephalitis. Rev Sci Tech. 2015;34:453-66. http://dx.doi.org/10.20506/rst.34.2.2371

14. Duscher GG, Wetscher M, Baumgartner R, Walder G. Roe deer sera used for TBE surveillance in Austria. Ticks Tick Borne Dis. 2015;6:489-93. http://dx.doi.org/10.1016/j.ttbdis.2015.03.018

15. Balling A, Plessow U, Beer M, Pfeffer M. Prevalence of antibodies against tick-borne encephalitis virus in wild game from Saxony, Germany. Ticks Tick Borne Dis. 2014;5:805-9. http://dx.doi.org/ 10.1016/j.ttbdis.2014.06.007

16. van der Poel WH, Van der Heide R, Bakker D, De Looff M, De Jong J, Van Manen N, et al. Attempt to detect evidence for tickborne encephalitis virus in ticks and mammalian wildlife in The Netherlands. Vector Borne Zoonotic Dis. 2005;5:58-64. http://dx.doi.org/10.1089/vbz.2005.5.58

Address for correspondence: Jolianne M. Rijks, Dutch Wildlife Health Centre, Yalalaan 1, Rm. O.177, Utrecht 3584 CL, the Netherlands; email: j.m.rijks@uu.nl

\section{EID Spotlight Topic Ticks}
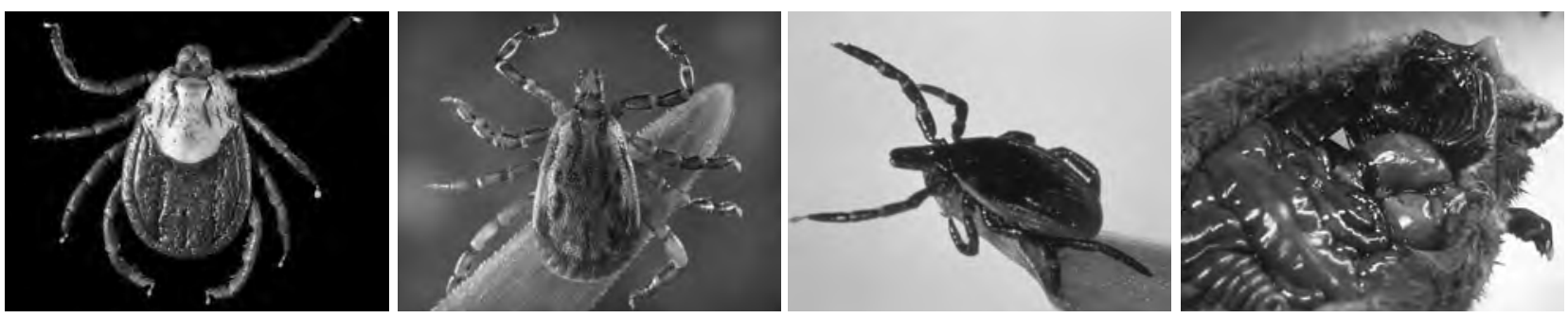

Ticks transmit a variety of different pathogens including bacteria, protozoa, and viruses which can produce serious and even fatal disease in humans and animals. Tens of thousands of cases of tickborne disease are reported each year, including Lyme disease. See the EID Lyme Disease Spotlight. Lyme disease is the most well-known tickborne disease. However, other tickborne illnesses such as Rocky Mountain spotted fever, tularemia, babesiosis, and ehrlichiosis also contribute to severe morbidity and more mortality each year. Symptoms of tickborne disease are highly variable, but most include sudden onset of fever, headache, malaise, and sometimes rash. If left untreated, some of these diseases can be rapidly fatal. 


\section{Vector Competence of Aedes caspius and Ae. albopictus Mosquitoes for Zika Virus, Spain}

\author{
Rafael Gutiérrez-López, Sean M. Bialosuknia, \\ Alexander T. Ciota, Tomás Montalvo, \\ Josue Martínez-de la Puente, Laura Gangoso, \\ Jordi Figuerola, Laura D. Kramer
}

We assessed the vector competence of Aedes caspius and Aedes albopictus mosquitoes in Spain for the transmission of Zika virus. Whereas Ae. albopictus mosquitoes were a competent vector, Ae. caspius mosquitoes were unable to transmit Zika virus. We also identified high levels of vertical transmission of Zika virus in Ae. albopictus mosquitoes.

$\mathrm{Z}$ ika virus is an emerging arbovirus of the family Flaviviridae primarily transmitted by Aedes aegypti mosquitoes, but other Aedes species mosquitoes could be competent vectors (1). Ae. aegypti mosquitoes are absent from most countries in Europe (2), and the invasive $A e$. albopictus mosquito and other native species could create novel epidemiologic scenarios for Zika virus. Indeed, Ae. albopictus mosquito populations from Europe are competent vectors for Zika virus $(3,4)$. However, the vector competence for transmission of Zika virus of most mosquito species of Europe is currently unknown and may vary across virus strains and mosquito populations (5).

Although no autochthonous vectorborne Zika virus transmission has been reported in Spain, $\geq 316$ imported cases of Zika virus have been confirmed (6). The confirmed cases, together with the presence of both the Ae. albopictus mosquito $(7)$ and the native Ae. caspius mosquito $(8,9)(a$ potential vector of chikungunya virus [10] and Rift Valley fever virus [11]), indicate a risk for Zika virus transmission in Spain. Accurately quantifying this risk requires evaluating the competence of these mosquito species for Zika virus.

We determined vector competence at different days postinfection (dpi) by exposing F0 generation of Ae. caspius

\footnotetext{
Author affiliations: Estación Biológica de Doñana, Seville, Spain

(R. Gutiérrez-López, J. Martínez-de la Puente, L. Gangoso,

J. Figuerola); New York State Department of Health, Slingerlands, New York, USA (S.M. Bialosuknia, A.T. Ciota, L.D. Kramer); Agència de Salut Pública de Barcelona, Barcelona, Spain (T. Montalvo); Centro de Investigación Biomédica en Red de Epidemiología y Salud Pública (CIBERESP), Barcelona

(T. Montalvo, J. Martínez-de la Puente, J. Figuerola)
}

DOI: https://doi.org/10.3201/eid2502.171123 mosquitoes (collected as larvae in Huelva, Spain, because we were unable to rear it under laboratory conditions) and F2 generation of Ae. albopictus mosquitoes (collected as eggs in Barcelona, Spain) to Zika virus through infectious blood meals. We used F8 generation of colonized populations of Ae. aegypti mosquitoes (collected in Poza Rica, Mexico) as a control population and Zika virus strains CAM (2010 Cambodia; GenBank accession no. JN860885) and PR (2015 Puerto Rico; GenBank accession no. KU501215), passaged 4 times on Vero cells and 2 times on C6/36 cells. We propagated on C6/36 cells for 4 days, and freshly harvested supernatant was mixed 1:1 with sheep blood (Colorado Serum Company, http://www.thepeakofquality.com) and $2.5 \%$ sucrose (5).

We offered to 4- to 7-day-old Ae. albopictus and Ae. aegypti female mosquitoes infectious blood meals containing either the CAM or PR strain at a final concentration of $7.6 \log _{10} P F U / m L$. Infection rates were determined by screening mosquitoes' bodies, dissemination rates by screening legs, and transmission rates by screening saliva, at 3 different time points (7, 14 and $21 \mathrm{dpi}$ ) using Zikaspecific quantitative reverse transcription PCR including negative controls in each reaction (12) (Table 1; Appendix, https://wwwnc.cdc.gov/EID/article/25/2/17-1123-App1. pdf). We calculated Zika titers from standard curves on the basis of infectious particle standards created from matched virus stocks (5).

We further exposed 4- to 10-day-old Ae. caspius female mosquitoes to the PR strain as described. We conducted 3 independent trials using different Zika virus concentrations at different time points $(7,14$, or $21 \mathrm{dpi})$ for each trial (Table 1; Appendix).

To determine the ability of Ae. albopictus mosquitoes to vertically transmit Zika virus, 4- to 7-day-old females were infected with Zika PR as described, and noninfectious blood meals were offered weekly after the first oviposition. We collected eggs laid in the second oviposition and hatched them for subsequent testing. We grouped second instar larvae in pools of 5 individuals and tested them for Zika virus (13). We estimated vertical transmission rate, measured as filial infection rate using the maximumlikelihood method (PoolInfRate version 4.0, https://www. cdc.gov/westnile/resourcepages/mosqSurvSoft.html) (13).

We performed generalized linear models with binomial error distribution and logit link function to assess the effect of mosquito species, virus strains, and dpi on the 
Table 1. Infection, dissemination, and transmission rates of mosquitoes experimentally infected with 2 Zika virus strains, Spain

\begin{tabular}{|c|c|c|c|c|c|c|}
\hline $\begin{array}{l}\text { Days } \\
\text { postinfection }\end{array}$ & Mosquito species & $\begin{array}{c}\text { Zika virus } \\
\text { strain* }\end{array}$ & $\begin{array}{c}\text { Blood meal titers, } \\
\log _{10} \text { PFU/mL }\end{array}$ & $\begin{array}{c}\% \text { Infected (total } \\
\text { no.) }\end{array}$ & $\begin{array}{c}\% \text { Infected } \\
\text { disseminating }\end{array}$ & $\begin{array}{l}\% \text { Infected } \\
\text { transmitting }\end{array}$ \\
\hline \multirow[t]{5}{*}{7} & \multirow[t]{2}{*}{ Aedes aegypti } & CAM & 7.6 & $24.2(33)$ & 75 & 12.5 \\
\hline & & PR & 7.6 & $61.8(34)$ & 38.1 & 0 \\
\hline & \multirow[t]{2}{*}{ Ae. albopictus } & CAM & 7.6 & 90.5 (21) & 42 & 10.5 \\
\hline & & PR & 7.6 & $97.0(33)$ & 31.3 & 0 \\
\hline & Ae. caspius & PR & 7.7 & 21.4 (14) & 0 & 0 \\
\hline \multirow[t]{5}{*}{14} & \multirow[t]{2}{*}{ Ae. aegypti } & CAM & 7.6 & $22.6(31)$ & 71.4 & 14.3 \\
\hline & & PR & 7.6 & $45(40)$ & 77.8 & 16.7 \\
\hline & \multirow[t]{2}{*}{ Ae. albopictus } & CAM & 7.6 & $81.5(27)$ & 81.8 & 9.1 \\
\hline & & PR & 7.6 & $93.3(30)$ & 67.9 & 0 \\
\hline & Ae. caspius & PR & 8.7 & $40(25)$ & 0 & 0 \\
\hline \multirow[t]{5}{*}{21} & \multirow[t]{2}{*}{ Ae. aegypti } & CAM & 7.6 & $35.7(28)$ & 100 & 40 \\
\hline & & PR & 7.6 & $56.3(32)$ & 88.9 & 38.9 \\
\hline & \multirow[t]{2}{*}{ Ae. albopictus } & CAM & 7.6 & $94.4(18)$ & 82.4 & 23.6 \\
\hline & & PR & 7.6 & $96.2(26)$ & 96 & 36 \\
\hline & Ae. caspius & PR & 7.6 & $18.5(27)$ & 0 & 0 \\
\hline
\end{tabular}

infection, dissemination, and transmission rates. We also considered the interactions between virus strain and dpi and between virus strain and mosquito species. We determined differences in mean viral titers between mosquito species, virus strains, and dpi in mosquito body, legs, and saliva using Kruskal-Wallis tests. Analyses were run in JMP version 9 (SAS Institute, http://www.jmp.com).

Infection rate was higher in Ae. albopictus than in Ae. aegypti mosquitoes, and Zika PR had a higher infection rate than Zika CAM. Dissemination rate increased with time (dpi) but was similar between mosquito species and Zika strains. Transmission rate also increased with time, and mosquitoes infected with Zika CAM showed a higher transmission rate than those infected with Zika PR. Transmission rate did not differ between Ae. albopictus and Ae. aegypti mosquitoes (Table 1, 2). Mean viral titers in bodies differed between mosquito species and Zika strains, with higher titers in Ae. albopictus compared with Ae. aegypti mosquitoes $\left(\chi^{2}=5.09\right.$, $\left.\mathrm{df}=1 ; \mathrm{p}<0.02\right)$ and higher titers for Zika PR compared with Zika CAM $\left(\chi^{2}=6.92\right.$, $\mathrm{df}=1$; $\mathrm{p}<0.009)$. Mean viral titers in legs were similar for both Zika strains $\left(\chi^{2}=0.95, \mathrm{df}=1 ; \mathrm{p}=0.33\right)$, but were higher in Ae. aegypti relative to Ae. albopictus mosquitoes $\left(\chi^{2}=9.53\right.$, $\mathrm{df}=1 ; \mathrm{p}<0.002)$. Mean viral titers did not differ in saliva secretions between mosquito species $\left(\chi^{2}=1.7\right.$, df $=1$; $\mathrm{p}$ $=0.19)$ or Zika strains $\left(\chi^{2}=1.02, \mathrm{df}=1 ; \mathrm{p}=0.31\right)$. We detected Zika virus infection in Ae. caspius mosquitoes at 7, 14, and $21 \mathrm{dpi}$, but detected no virus dissemination or transmission at any point (Table 1). Five larval pools of
Ae. albopictus mosquitoes (29.4\%; $\mathrm{N}=17$ ) were positive for Zika virus, with a filial infection rate of $72.2(95 \% \mathrm{CI}$ 27.6-156.1) and mean viral load of $2.5 \log _{10} \mathrm{PFU} / \mathrm{mL}$. This value equates to a ratio of 1:14.

Our results suggest Ae. albopictus mosquitoes in Spain are competent vectors of Zika virus at levels similar to Ae. aegypti mosquitoes. We detected Zika CAM in saliva earlier than Zika PR, which suggests that genetically variable strains may have different transmission potential (5). Although a similar transmission rate was found in Ae. albopictus mosquitoes from Spain and Italy (3), lower rates were measured in populations in France (4). In addition, Ae. albopictus mosquitoes from Spain could transmit Zika virus at 7 dpi, 4 days earlier than mosquitoes in Italy (4). These discrepancies may be explained by variation in vector competence between mosquito populations and virus strains (5). Although Zika virus can infect Ae. caspius mosquitoes, it is unable to escape the midgut and be effectively transmitted (14).

Zika virus is vertically transmitted by the population of Ae. albopictus mosquitoes in Spain at substantially higher rates than found in Ae. albopictus mosquitoes from New York and Italy $(4,13)$ and for other flaviviruses $(15)$. These results suggest that the ability of Zika virus to be transmitted vertically is highly population dependent and could contribute to maintenance of the virus in Ae. albopictus mosquitoes in Spain.

Our results confirm that populations of Ae. albopictus mosquitoes increase the risk for Zika virus transmission in

\begin{tabular}{|c|c|c|c|c|c|c|c|c|c|}
\hline \multirow[b]{2}{*}{ Variable } & \multicolumn{3}{|c|}{ Infection rate } & \multicolumn{3}{|c|}{ Dissemination rate } & \multicolumn{3}{|c|}{ Transmission rate } \\
\hline & $\chi^{2}$ & df & $p$ value & $\chi^{2}$ & df & $p$ value & $\chi^{2}$ & df & $\mathrm{p}$ value \\
\hline Mosquito species & 110.95 & 1 & $<0.001$ & 2.08 & 1 & 0.15 & 2.37 & 1 & 0.12 \\
\hline Zika virus strain & 10.43 & 1 & 0.001 & 1.28 & 1 & 0.26 & 4.91 & 1 & 0.03 \\
\hline dpi & 0.15 & 1 & 0.70 & 39.61 & 1 & $<0.001$ & 26.77 & 1 & $<0.001$ \\
\hline Zika virus strain $\cdot d p i$ & 1.17 & 1 & 0.28 & 1.34 & 1 & 0.25 & 6.70 & 1 & 0.01 \\
\hline Mosquito species $\cdot$ Zika virus strain & 0.01 & 1 & 0.90 & 0.76 & 1 & 0.39 & 0.01 & 1 & 0.94 \\
\hline
\end{tabular}

*Bold indicates significant effect; • indicates interaction between variables; dpi, days postinfection. 
Spain. The high number of imported Zika virus cases and the rapid spread of Ae. albopictus mosquitoes contribute to the risk for autochthonous transmission of Zika virus. The risk for transmission by Ae. caspius mosquitoes, however, may be considered extremely low.

\section{Acknowledgments}

We thank A. Díez, M. Ferraguti, A. Pastoriza, and L. Gómez for helping during fieldwork. We thank members of the New York State Department of Health Arbovirus Laboratory staff for their assistance.

Projects CGL2012-30759 (BES-2013-065274) and CGL2015-65055P from MINECO supported this study.

\section{About the Author}

Dr. Gutiérrez-López is a researcher at Estación Biológica de Doñana interested in the study of vector competence of European mosquitoes for different vectorborne pathogens.

\section{References}

1. Weger-Lucarelli J, Rückert C, Chotiwan N, Nguyen C, Garcia Luna SM, Fauver JR, et al. Vector competence of American mosquitoes for three strains of Zika virus. PLoS Negl Trop Dis. 2016;10:e0005101. http://dx.doi.org/10.1371/journal.pntd.0005101

2. European Centre for Disease Prevention and Control and European Food Safety Authority. Mosquito maps. 2018 [cited 2018 Dec 7]. https://ecdc.europa.eu/en/disease-vectors/surveillance-and-diseasedata/mosquito-maps

3. Jupille H, Seixas G, Mousson L, Sousa CA, Failloux AB. Zika virus, a new threat for Europe? PLoS Negl Trop Dis. 2016;10:e0004901. http://dx.doi.org/10.1371/journal.pntd.0004901

4. Di Luca M, Severini F, Toma L, Boccolini D, Romi R, Remoli ME, et al. Experimental studies of susceptibility of Italian Aedes albopictus to Zika virus. Euro Surveill. 2016;21:30223. http://dx.doi.org/10.2807/1560-7917.ES.2016.21.18.30223

5. Ciota AT, Bialosuknia SM, Zink SD, Brecher M, Ehrbar DJ, Morrissette MN, et al. Effects of Zika virus strain and Aedes mosquito species on vector competence. Emerg Infect Dis. 2017;23:1110-7. PubMed http://dx.doi.org/10.3201/ eid2307.161633

6. Ministerio de sanidad, servicios sociales e igualdad del gobierno de España. Rapid assessment of the risk of transmission of Zika virus infection in Spain [in Spanish]. 2017 Mar 23 [cited 2018 Dec 7]. https://www.msssi.gob.es/profesionales/saludPublica/ ccayes/alertasActual/DocsZika/ERR_Zika_8-actualizacion.pdf

7. Millet JP, Montalvo T, Bueno-Marí R, Romero-Tamarit A, Prats-Uribe A, Fernández L, et al.; Zika Working Group in Barcelona. Imported Zika virus in a European city: how to prevent local transmission? Front Microbiol. 2017;8:1319. http://dx.doi.org/10.3389/fmicb.2017.01319

8. Balenghien T, Fouque F, Sabatier P, Bicout DJ. Horse-, bird-, and human-seeking behavior and seasonal abundance of mosquitoes in a West Nile virus focus of southern France. J Med Entomol. 2006;43:936-46. http://dx.doi.org/10.1093/ jmedent/43.5.936

9. Fontenille D, Failloux AB, Romi R. Should we expect chikungunya and dengue in southern Europe? In: Takken W, Knols B, editors. Emerging pests and vectorborne diseases in Europe. Wageningen (the Netherlands): Wageningen Academic Publishers; 2007. p. 169-84.

10. Vazeille M, Jeannin C, Martin E, Schaffner F, Failloux AB. Chikungunya: a risk for Mediterranean countries? Acta Trop. 2008;105:200-2. http://dx.doi.org/10.1016/j.actatropica. 2007.09.009

11. Turell MJ, Presley SM, Gad AM, Cope SE, Dohm DJ, Morrill JC, et al. Vector competence of Egyptian mosquitoes for Rift Valley fever virus. Am J Trop Med Hyg. 1996;54:136-9. http://dx.doi.org/10.4269/ajtmh.1996.54.136

12. Lanciotti RS, Kosoy OL, Laven JJ, Velez JO, Lambert AJ, Johnson AJ, et al. Genetic and serologic properties of Zika virus associated with an epidemic, Yap State, Micronesia, 2007. Emerg Infect Dis. 2008;14:1232-9. http://dx.doi.org/10.3201/ eid1408.080287

13. Ciota AT, Bialosuknia SM, Ehrbar DJ, Kramer LD. Vertical transmission of Zika virus by Aedes aegypti and Ae. albopictus mosquitoes. Emerg Infect Dis. 2017;23:880-2. http://dx.doi.org/ 10.3201/eid2305.162041

14. Hardy JL, Houk EJ, Kramer LD, Reeves WC. Intrinsic factors affecting vector competence of mosquitoes for arboviruses. Annu Rev Entomol. 1983;28:229-62. http://dx.doi.org/10.1146/annurev. en.28.010183.001305

15. Smartt CT, Stenn TMS, Chen TY, Teixeira MG, Queiroz EP, Souza Dos Santos L, et al. Evidence of Zika virus RNA fragments in Aedes albopictus (Diptera: Culicidae) field-collected eggs from Camaçari, Bahia, Brazil. J Med Entomol. 2017;54:1085-7. http://dx.doi.org/10.1093/jme/tjx058

Address for correspondence: Rafael Gutiérrez-López, Estación Biólogica de Doñana CSIC—Wetland Ecology, Av. Americo Vespucio, 26, Seville 41092, Spain; email: rgutierrez@ebd.csic.es 


\section{Submicroscopic Malaria in Migrants from Sub-Saharan Africa, Spain}

\begin{abstract}
Joaquín Pousibet-Puerto, $M^{\mathrm{a}}$ Teresa Cabezas-Fernández, Ana B. Lozano-Serrano, José Vázquez-Villegas, Manuel J. Soriano-Pérez, Isabel Cabeza-Barrera, José A. Cuenca-Gómez, Joaquín Salas-Coronas
\end{abstract}

In a screening program, we detected submicroscopic malaria in $8.9 \%$ of recent migrants to Spain from subSaharan Africa. Hemoglobinopathies and filarial infection occurred more frequently in newly arrived migrants with submicroscopic malaria than in those without. Our findings could justify systematic screening in immigrants and recent travelers from malaria-endemic areas.

Cubmicroscopic malaria (SMM) is defined as low$\checkmark$ density Plasmodium infection detected only by molecular methods (1). SMM only occasionally causes acute disease but can infect mosquitoes and contribute to transmission (2).

In malaria-endemic countries, SMM prevalence varies widely. It is highest in areas of low transmission, where SMM represents a large proportion of the malaria reservoir (2). In regions to which malaria is not endemic, such as Europe, SMM prevalence is unknown but might account for up to one third of imported malaria cases (3). In areas such as Spain, Anopheles atroparvus mosquitoes can transmit strains of $P$. vivax (4), and SMM patients can be a reservoir for malaria reintroduction. We explored the frequency of imported SMM by PCR testing of a selected population of migrants to Spain from sub-Saharan Africa and describe the epidemiologic characteristics and main laboratory findings for SMM patients.

\section{The Study}

We conducted a retrospective observational study based on data obtained after the application of an SMM screening protocol in immigrant patients of sub-Saharan Africa origin seen at the Tropical Medicine Unit of the Poniente Hospital (El Ejido, Almeria, Spain) during October 2004-December 2016. This hospital's protocol comprised a series of complementary tests to screen for imported diseases, including chest and abdominal radiographs; blood count; liver and renal function tests; iron metabolism tests; serologic screening for syphilis, HIV, hepatitis B virus,

Author affiliation: Hospital de Poniente, El Ejido, Spain

DOI: https://doi.org/10.3201/eid2502.180717 hepatitis C virus, Strongyloides, and Schistosoma; and screening for fecal parasites, urine parasites, and blood microfilariae. Finally, the hospital tested for hemoglobinopathies using high-performance liquid chromatography.

The study population comprised patients who had lived in Europe for $<1$ year (newly arrived migrants [NAM]) or who had visited their home country (i.e., visiting friends and relatives [VFR]) within the previous year who sought care for any reason other than patent malaria and were screened for SMM using the conventional nested multiplex malaria PCR. The nested multiplex malaria PCR can identify 4 human malaria species ( $P$. vivax, $P$. falciparum, $P$. ovale, and $P$. malariae) in 2 consecutive multiplexing amplifications. The first reaction amplifies Plasmodium DNA from blood samples. The second reaction enables identification of the infecting species of Plasmodium (5). SMM was diagnosed when a patient had a positive malaria PCR result and a negative direct microscopic examination result, either a thin or a thick smear, and a negative rapid diagnostic test (SD. BIOLINE Malaria Ag P.f/Pan test, Abbott, https:// www.alere.com). We excluded from the study patients $<14$ years of age and patients for whom no smear and/ or rapid diagnostic test for malaria was available. All SMM patients were treated according to World Health Organization guidelines (6).

We conducted 3 statistical analyses. First, we compared SMM patients with non-SMM patients. Then, within the SMM patient group, we compared those with and without filarial co-infection. We conducted a descriptive statistical analysis in which continuous variables were expressed as medians and interquartile ranges. Categorical variables were described as frequencies and percentages. We analyzed differences in continuous data between groups using nonparametric Mann-Whitney $U$ test and used the Fisher exact test or $\chi^{2}$ test, as appropriate, to compare categorical data. Finally, we conducted an explanatory multivariate logistic regression analysis to evaluate possible risk factors predicting SMM in the study population. The model used variables with $\mathrm{p}<0.2$ in the bivariate analysis and those that were clinically relevant. Variables were excluded from the logistic regression model based on likelihood ratio test results (7). Hosmer-Lemeshow test and the area under the receiver operating characteristic curve were used to validate the model. We conducted statistical analyses using STATA software version 12 (https://www.stata.com). 
Of 2,719 sub-Saharan Africa patients seen, 370 (13,6\%) were included in the study (Table 1, https://wwwnc.cdc.gov/ EID/article/25/2/18-0717-T1.htm). SMM was diagnosed in $33(8.9 \%)$ patients, of whom 11 were VFRs and 22 were NAMs. The proportion of SMM was similar in both groups: 8.7\% (11/126) for VFRs and 9.0\% (22/244) for NAMs ( $\mathrm{p}=$ 0.93). For SMM patients, time spent in Spain after leaving malaria-endemic areas was shorter for VFRs (2 months) than for NAMs (6 months) $(\mathrm{p}=0.001)$.

The Plasmodium species most frequently found was $P$. falciparum (26 [78.8\%] patients), followed by $P$. malariae (4 [12.1\%]), P. ovale (2 [6.1\%]), and 1 mixed parasitization by $P$. falciparum and $P$. malariae (1 [3.0\%]). Patients with and without SMM did not differ in baseline laboratory data, except for the presence of hemoglobinopathies, which occurred more frequently among SMM patients (42.4\% vs. 21.3\%; $\mathrm{p}=0.01$ ).

When we analyzed other associated infections (Table 2), we found an important difference between SMM and non-SMM patients regarding filarial co-infection. Filariasis was present in up to $24.2 \%$ of SMM patients but in only $5.3 \%$ of non-SMM patients $(\mathrm{p}<0.01)$. Mansonella perstans nematodes were responsible of all filarial infections; in addition, 3 patients were infected by Loa loa eyeworms.

Among SMM patients, all filariasis was found in NAMs. These co-infected patients had higher IgE values $(1,080 \mathrm{IU} / \mathrm{mL}$ vs. $293.7 \mathrm{IU} / \mathrm{mL}$ [reference $0-100 \mathrm{IU} /$ $\mathrm{mL}] ; \mathrm{p}<0.01)$ and higher total eosinophil counts $(601.5$ cells $/ \mu \mathrm{L}$ vs. 270 cells $/ \mu \mathrm{L}$ [reference $20-450$ cells $/ \mu \mathrm{L}$; $\mathrm{p}=0.01$ ) than those who had only SMM. The coinfected group also tended to have higher platelet levels (Figure 1).
Multivariate regression analysis applied to all 370 patients showed that having filarial infection increased the odds of having SMM by 6.49 and the existence of $\geq 1$ hemoglobinopathies increased the odds by 3.93. Time after leaving a malaria-endemic area correlated inversely with risk for SMM $(p=0.038)$ (Figure 2). For NAMs, filariasis increased the risk for SMM by 8.47 and hemoglobinopathies by 4.70 . For VFRs, however, the only risk factor was time since last visit to their home country (the shorter the time, the higher the risk).

\section{Conclusions}

Screening for SMM in patients from sub-Saharan Africa in a reference unit in Spain showed a prevalence of $8.9 \%$. The presence of filarial infection or hemoglobinopathies and a shorter time since leaving malaria-endemic areas were associated with a higher risk for SMM.

SMM is usually asymptomatic. Infrequently, it produces acute disease, especially in children (8). During pregnancy, SMM has been linked to maternal anemia and to low birth weight (9). SMM screening in risk groups, such as pregnant women and immunosuppressed persons (10), could therefore be of special interest.

Our study highlights 2 important differences between patients with and without SMM. First, the proportion of patients infected by filariasis was higher among SMM patients. In areas to which malaria is not endemic, RamírezOlivencia et al. also reported a greater number of filariasis among SMM patients than among patients with patent microscopic malaria (3). Nematodes can alter immune system response to concomitant infections, such as Plasmodium spp. Modulation of immune response produced

\begin{tabular}{|c|c|c|c|c|}
\hline Co-infection & All, no. (\%), N = 370 & Non-SMM, no. (\%), n= 337 & SMM, no. (\%), $\mathrm{n}=33$ & $\mathrm{p}$ value \\
\hline Blastocystis hominis & $91(24.6)$ & $85(25.2)$ & $6(18.2)$ & 0.33 \\
\hline Entamoeba hystolitica/dispar & $56(15.1)$ & $53(15.7)$ & $3(9.1)$ & 0.28 \\
\hline Giardia lamblia & $25(6.8)$ & $24(7.1)$ & $1(3.0)$ & 0.35 \\
\hline Strongyloides stercoralis & 73 (19.7) & 67 (19.9) & $6(18.2)$ & 0.75 \\
\hline Hookworms & 39 (10.5) & $37(11.0)$ & $2(6.1)$ & 0.36 \\
\hline Trichuris trichiura & $11(3.0)$ & $10(3.0)$ & $1(3.0)$ & 0.99 \\
\hline Ascaris lumbricoides & $10(2.7)$ & $8(2.4)$ & $2(6.1)$ & 0.23 \\
\hline Schistosomiasis & $34(9.2)$ & $31(9.2)$ & $3(9.1)$ & 0.94 \\
\hline S. haematobium & $21(5.7)$ & $19(5.6)$ & $2(6.1)$ & 0.95 \\
\hline S. mansoni & $7(1.9)$ & $7(2.1)$ & 0 & 0.40 \\
\hline S. intercalatum & $1(0.3)$ & $1(0.3)$ & 0 & 1 \\
\hline Schistosoma spp. & $5(1.4)$ & $3(0.9)$ & $1(3.0)$ & 0.45 \\
\hline Hymenolepis nana & $7(1.9)$ & $6(1.8)$ & $1(3.0)$ & 0.64 \\
\hline Taenia spp. & $2(0.5)$ & $2(0.6)$ & 0 & 1 \\
\hline Filariae $\dagger$ & $26(7.0)$ & $18(5.3)$ & $8(24.2)$ & $<0.01$ \\
\hline Mansonella perstans & $26(7.0)$ & $18(5.3)$ & $8(24.2)$ & $<0.01$ \\
\hline Loa loa & $3(0.8)$ & $1(0.3)$ & $2(6.1)$ & 0.02 \\
\hline Syphilis & $39(10.5)$ & $33(9.8)$ & $6(18.2)$ & 0.12 \\
\hline Hepatitis B virus & $111(30)$ & $98(29.1)$ & $13(39.4)$ & 0.17 \\
\hline Hepatitis $C$ virus & $5(1.4)$ & $4(1.2)$ & $1(3.0)$ & 0.37 \\
\hline HIV & $2(0.5)$ & $1(0.3)$ & $1(3.0)$ & 0.17 \\
\hline
\end{tabular}

*SMM, submicroscopic malaria.

†All 3 patients infected with Loa loa eyeworms were co-infected with Mansonella perstans nematodes. 


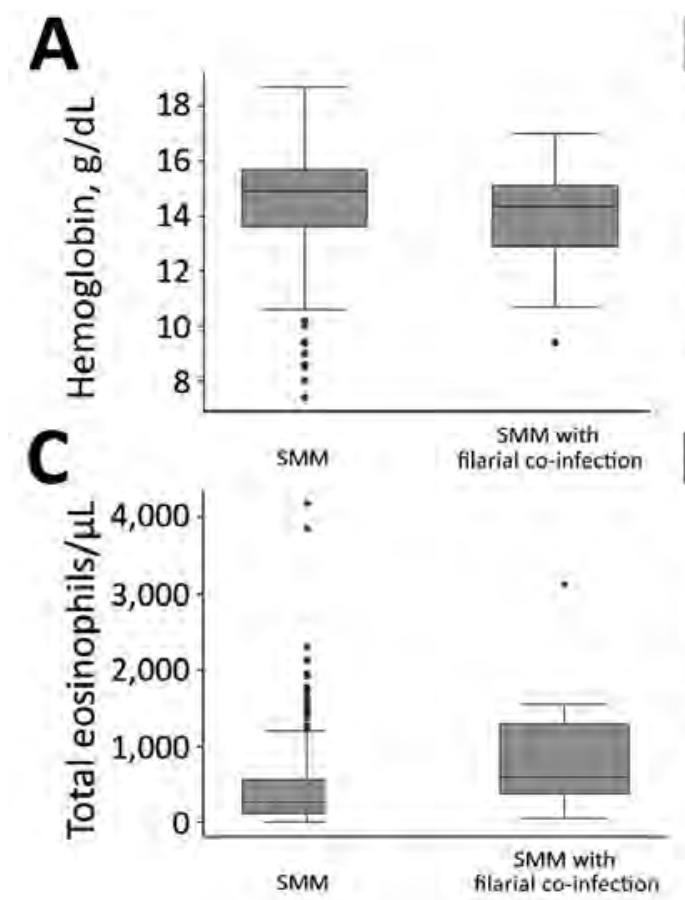

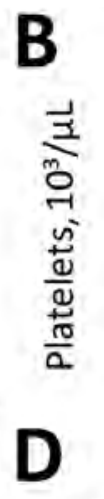
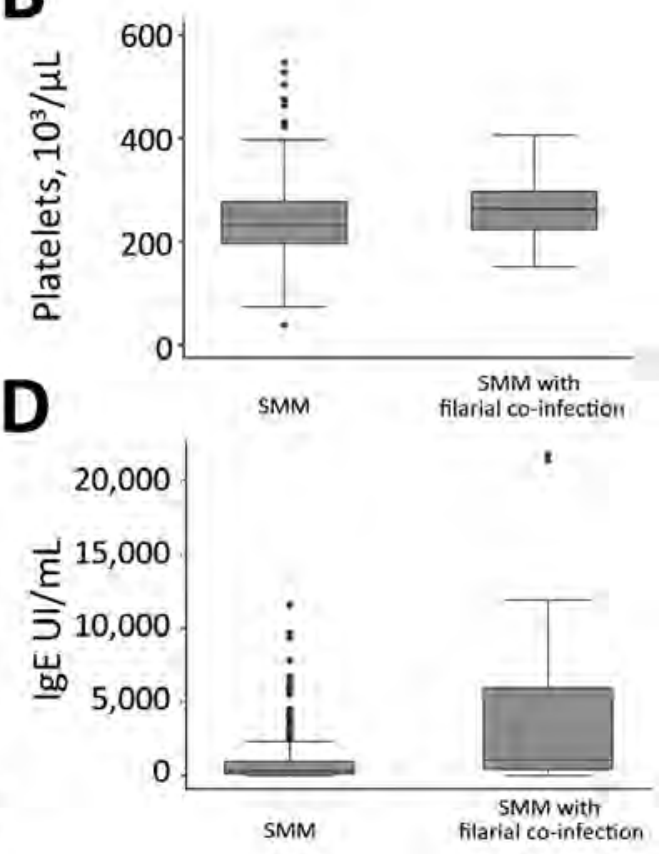

Figure 1. Differences in analytical values of blood tests among SMM patients with and without filarial co-infections, Spain, October 2004December 2016. A) Hemoglobin; B) platelets; C) total eosinophils; D) IgE. Box and whiskers plot features are defined as follows: horizontal line within box is median, bottom line of box is 25th percentile, top line of box is 75th percentile, bottom whisker is quartile $1-1.5$ interquartile range, top whisker is quartile $3+1.5$ interquartile range, and dots are outliers. SMM, submicroscopic malaria. by helminthoses, such as filariasis, might exert some protective effect against malaria, leading to lower parasitic loads, which in turn might translate into clinical protection against severe malaria $(11,12)$.

The second disparity was the presence of hemoglobinopathies, a finding much more frequent among SMM patients that resulted in an SMM risk only for NAMs.
Hemoglobinopathies exert a protective effect against severe malaria, favoring milder clinical manifestations and the existence of SMM $(13,14)$.

The relatively high prevalence of imported SMM we found could justify implementation of systematic screening in immigrants and travelers who recently stayed in malariaendemic areas, mainly for persons with risky conditions

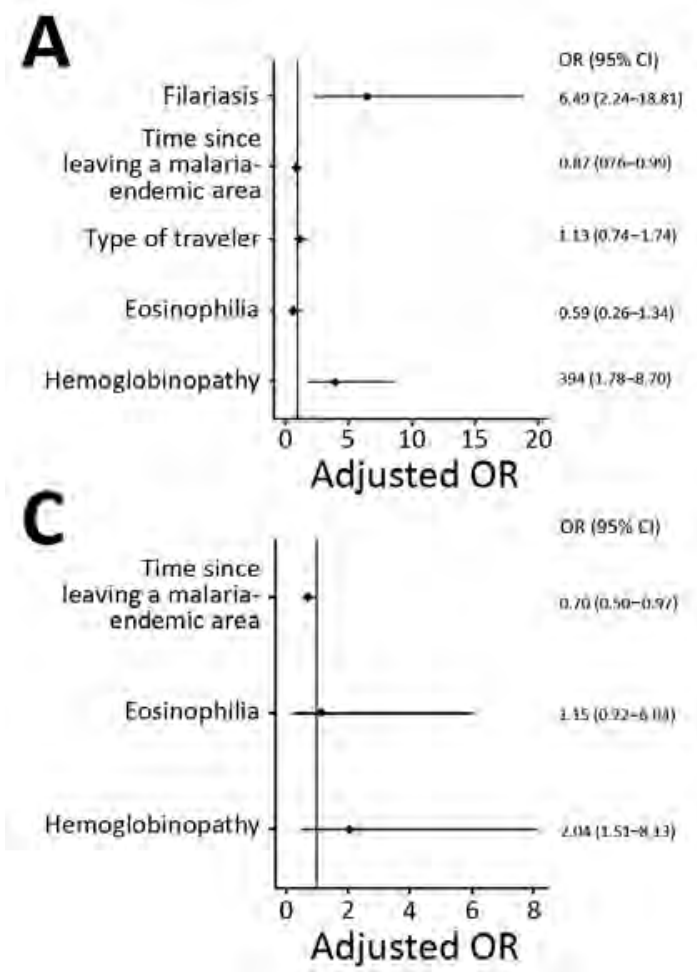

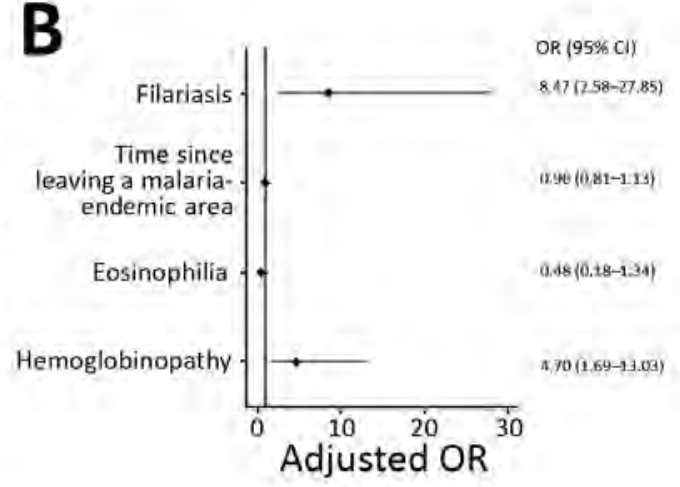

Figure 2. Multivariate logistic regression analysis for study of submicroscopic malaria in migrants from sub-Saharan Africa, Spain, October 2004December 2016. A) All patients; B) newly arrived migrants; C) migrants visiting friends and family. OR, odds ratio. 
such as immunosuppression (especially those with HIV infection) and for pregnant women. The diagnosis and treatment of SMM also can prevent future reactivations and the existence of an occult malaria reservoir in countries to which it is not endemic. Our results suggest that the presence of filariasis, hemoglobinopathies, or both should also prompt a search for SMM because these patients are at higher risk.

\section{Acknowledgments}

We thank $\mathrm{M}^{\mathrm{a}}$ del Carmen Olvera Porcel and technicians in Research Methodology and Biostatistics from the Fundación para la Investigación Biosanitaria para Andalucía Oriental Alejandro Otero for providing invaluable support for the statistical analysis of the data.

This study was conducted within the activities developed by the research group Plan Andaluz de Investigación, Desarrollo e Innovación CTS 582 of the regional Ministry of Gender, Health and Social Policy of the Government of Andalusia, RICET (Red de Investigación Cooperativa en Enfermedades Tropicales, co-financing FEDER, RD16/0027/0013) and the CEMyRI (Center for the Study of Migration and Intercultural Relations) of the University of Almeria (Spain).

\section{About the Author}

Dr. Pousibet-Puerto is a researcher of the Research Group of the Tropical Medicine Unit of the Hospital de Poniente. His primary research interests include malaria, helminthosis, and protozoal intestinal diseases.

\section{References}

1. Hermsen CC, Telgt DS, Linders EH, van de Locht LA, Eling WM, Mensink EJ, et al. Detection of Plasmodium falciparum malaria parasites in vivo by real-time quantitative PCR. Mol Biochem Parasitol. 2001;118:247-51.http://dx.doi.org/ 10.1016/S0166-6851(01)00379-6

2. Lin JT, Saunders DL, Meshnick SR. The role of submicroscopic parasitemia in malaria transmission: what is the evidence? Trends Parasitol. 2014;30:183-90.http://dx.doi.org/10.1016/ j.pt.2014.02.004

3. Ramírez-Olivencia G, Rubio JM, Rivas P, Subirats M, Herrero MD, Lago M, et al. Imported submicroscopic malaria in Madrid. Malar J. 2012;11:324.http://dx.doi.org/10.1186/1475-2875-11-324
4. Bueno-Martí R, Bernués-Bañeres A, Jiménez-Peydró R. Updated checklist and distribution maps of mosquitoes (Diptera: Culicidae) of Spain. European Mosquito Bulletin. 2012;30:91-126.

5. Rubio JM, Post RJ, van Leeuwen WM, Henry MC, Lindergard G, Hommel M. Alternative polymerase chain reaction method to identify Plasmodium species in human blood samples: the semi-nested multiplex malaria PCR (SnM-PCR). Trans R Soc Trop Med Hyg. 2002;96(Suppl 1):S199-204.http://dx.doi.org/10.1016/ S0035-9203(02)90077-5

6. World Health Organization. World malaria report 2015. Geneva: The Organization; 2015.

7. Hosmer DW, Lemeshow S. Applied logistic regression. New York: Wiley; 1989.

8. Akiyama T, Pongvongsa T, Phrommala S, Taniguchi T, Inamine Y, Takeuchi R, et al. Asymptomatic malaria, growth status, and anaemia among children in Lao People's Democratic Republic: a cross-sectional study. Malar J. 2016;15:499. http://dx.doi.org/10.1186/s12936-016-1548-3

9. Cottrell G, Moussiliou A, Luty AJF, Cot M, Fievet N, Massougbodji A, et al. Submicroscopic Plasmodium falciparum infections are associated with maternal anemia, premature births, and low birth weight. Clin Infect Dis. 2015;60:1481-8. http://dx.doi.org/10.1093/cid/civ122

10. Monge-Maillo B, Norman F, Pérez-Molina JA, Díaz-Menéndez M, Rubio JM, López-Vélez R. Plasmodium falciparum in asymptomatic immigrants from sub-Saharan Africa, Spain. Emerg Infect Dis. 2012;18:356-7.http://dx.doi.org/10.3201/ eid1801.111283

11. Metenou S, Kovacs M, Dembele B, Coulibaly YI, Klion AD, Nutman TB. Interferon regulatory factor modulation underlies the bystander suppression of malaria antigen-driven IL- 12 and IFN- $\gamma$ in filaria-malaria co-infection. Eur J Immunol. 2012;42:641-50. http://dx.doi.org/10.1002/eji.201141991

12. Dolo H, Coulibaly YI, Dembele B, Konate S, Coulibaly SY, Doumbia SS, et al. Filariasis attenuates anemia and proinflammatory responses associated with clinical malaria: a matched prospective study in children and young adults. PLoS Negl Trop Dis. 2012;6:e1890.http://dx.doi.org/10.1371/journal.pntd.0001890

13. Danquah I, Ziniel P, Eggelte TA, Ehrhardt S, Mockenhaupt FP. Influence of haemoglobins $\mathrm{S}$ and $\mathrm{C}$ on predominantly asymptomatic Plasmodium infections in northern Ghana. Trans R Soc Trop Med Hyg. 2010;104:713-9.http://dx.doi.org/10.1016/ j.trstmh.2010.08.001

14. Crompton PD, Traore B, Kayentao K, Doumbo S, Ongoiba A, Diakite SA, et al. Sickle cell trait is associated with a delayed onset of malaria: implications for time-to-event analysis in clinical studies of malaria. J Infect Dis. 2008;198:1265-75. http://dx.doi.org/10.1086/592224

Address for correspondence: Joaquín Salas-Coronas, Hospital de Poniente, Unidad de Medicina Tropical Ctra., Almerimar sn El Ejido Almería 04700, Spain; email: joaquin.salas@ephpo.es 


\section{Cytauxzoon felis Infection in Domestic Cats, Yunnan Province, China, 2016}

\section{Feng-Cai Zou, ${ }^{1}$ Zhao Li, ${ }^{1}$ Jian-Fa Yang, Jiang-Yan Chang, Guo-Hua Liu, Yan Lv, Xing-Quan Zhu}

We performed a molecular survey for Cytauxzoon felis infection in 311 domestic cats in Yunnan Province, China, in 2016 and found a prevalence of $21.5 \%$. C. felis infection in domestic and wild cats in other provinces should be investigated to determine parasite prevalence and genetic diversity among cats throughout China.

$\mathrm{C}$ ytauxzoonosis is a tickborne hemoprotozoal disease of both domestic cats and wild felids caused mainly by Cytauxzoon felis protozoa $(1,2)$. In the late 1900 s, $C$. felis protozoa were reported exclusively in North America, particularly in the mid-Atlantic states of the United States (3), but in the early 2000s, this pathogen was reported in some countries of South America, and in Europe, several other Cytauxzoon species were identified (4). Cytauxzoonosis of domestic cats has long been considered contagious and deadly (2). However, as research progressed, the virulence of different $C$. felis isolates was found to be inconsistent; some cats were able to survive the infection and potentially serve as natural reservoirs (5).

The number of pet cats around the world is increasing, but the information about the prevalence of $C$. felis infection in domestic cats is limited worldwide. Because of the seriousness of feline cytauxzoonosis and its geographic expansion to more and more regions, informing veterinarians, pet owners, and the general public about this disease has become imperative. The objective of this study was to examine whether $C$. felis infection is present in domestic cats in China.

\section{The Study}

During November-December 2016, we collected whole blood from the femoral vein of 311 domestic cats (74 stray

Author affiliations: Key Laboratory of Veterinary Public Health of Higher Education of Yunnan Province, College of Veterinary Medicine, Yunnan Agricultural University, Kunming, China (F.-C. Zou, Z. Li, J.-F. Yang, J.-Y. Chang, Y. Lv); State Key Laboratory of Veterinary Etiological Biology, Lanzhou Veterinary Research Institute, Chinese Academy of Agricultural Sciences, Lanzhou, China (Z. Li, X.-Q. Zhu); College of Veterinary Medicine, Hunan Agricultural University, Changsha, China (G.-H. Liu)

DOI: https://doi.org/10.3201/eid2502.181182 cats and 237 pet cats) in Yunnan Province in southwestern China using EDTA tubes. We stored these EDTA whole blood samples at $-20^{\circ} \mathrm{C}$ and then performed genomic DNA extraction with the TIANamp Genomic DNA Kit (TianGen, http://www.tiangen.com) following the manufacturer's protocol. To detect $C$. felis infection, we performed a PCR targeting the second internal transcribed spacer (ITS-2) of ribosomal DNA (6). We sequenced amplicons in both directions and compared these sequences with those of other relevant C. felis isolates available in GenBank. We analyzed differences in C. felis prevalence in domestic cats according to lifestyle, region, sex, and age using the $\chi^{2}$ test in SPSS 22.0 standard version for Windows (IBM Corporation, https:// www.ibm.com). We considered differences statistically significant when the $p$ value obtained was $<0.05$.

In total, 67 (21.5\%) of 311 examined domestic cats were positive for the $C$. felis protozoan. We sequenced these $C$. felis-positive PCR products and obtained 67 ITS2 sequences; 4 representative sequences were deposited in GenBank (accession nos. MF966369-72). The 67 C. felis ITS-2 sequences shared $98.4 \%-100 \%$ similarity. These sequences had $95.6 \%-100 \%$ similarity with corresponding C. felis ITS-2 sequences available in GenBank.

The prevalence of $C$. felis protozoa in domestic cats in Yunnan Province was 21.5\% (Table), lower than the prevalence in domestic cats in the United States (30.3\%, 27/89) (7) but higher than that in Brazil $(0.66 \%, 1 / 151)(8)$. The $C$. felis prevalence in stray cats $(51.4 \%, 38 / 74)$ was significantly higher $(\mathrm{p}<0.001)$ than that in pet cats $(12.2 \%, 29 / 237)$ (Table), probably because stray cats often live outdoors with poor sanitation, thus having high probability of contact with ticks. However, no significant difference in C. felis prevalence was found among domestic cats of different sexes or age groups.

Distinct C. felis genotypes of different virulences in domestic cats have been identified, and genetic diversity among $C$. felis populations has been studied by comparisons of 18S rRNA, ITS-1, and ITS-2 sequences (1). ITS-1 and ITS-2 rDNA are better genetic markers for assessing $C$. felis genotypic variability (9) because these sequences evolve faster than the 18S rRNA gene. A combination of ITS-1 and ITS2 sequences has been used to identify the $C$. felis genotypes present in various domestic cats and wild felids (1).

C. felis protozoa are transmitted to domestic cats by ticks, such as Amblyomma americanum and Dermacentor

${ }^{1}$ These authors contributed equally to this article. 
Table. Prevalence of Cytauxzoon felis protozoan in whole blood samples from domestic cats determined by PCR, Yunnan Province, China, 2016

\begin{tabular}{|c|c|c|c|c|}
\hline Variable & No. positive/no. tested & Prevalence, \% (95\% Cl) & $p$ value & Odds ratio $(95 \% \mathrm{Cl})$ \\
\hline \multicolumn{5}{|l|}{ Lifestyle } \\
\hline Stray & $38 / 74$ & $51.4(40.0-62.7)$ & \multirow[t]{2}{*}{$<0.001$} & $7.6(4.2-13.7)$ \\
\hline Pet & $29 / 237$ & $12.2(8.1-16.4)$ & & Referent \\
\hline \multicolumn{5}{|l|}{ Region } \\
\hline Banna Prefecture & $19 / 38$ & $50.0(34.1-65.9)$ & \multirow[t]{5}{*}{$<0.001$} & $10.8(4.8-24.5)$ \\
\hline Honghe Prefecture & $5 / 15$ & $33.3(9.5-57.2)$ & & $5.4(1.6-17.8)$ \\
\hline Lincang City & $14 / 21$ & $66.7(46.5-86.8)$ & & $21.6(7.6-61.3)$ \\
\hline Kunming City & $16 / 189$ & $8.5(4.5-12.4)$ & & Referent \\
\hline Yuxi City & $13 / 48$ & $27.1(14.5-39.7)$ & & $4.0(1.8-9.1)$ \\
\hline \multicolumn{5}{|l|}{ Sex } \\
\hline $\mathrm{F}$ & $38 / 172$ & $22.1(15.9-28.3)$ & \multirow{2}{*}{0.89} & $1.1(0.6-1.9)$ \\
\hline $\mathrm{M}$ & 29/139 & $20.9(14.1-27.6)$ & & Referent \\
\hline \multicolumn{5}{|l|}{ Age, y } \\
\hline$<5$ & $21 / 83$ & $25.3(15.9-34.7)$ & \multirow[t]{3}{*}{0.18} & $1.8(0.9-3.4)$ \\
\hline $5-10$ & $22 / 133$ & $16.5(10.2-22.9)$ & & Referent \\
\hline$>10$ & $24 / 95$ & $25.3(16.5-34.0)$ & & $1.7(0.9-3.3)$ \\
\hline Total & $67 / 311$ & $21.5(17.0-26.1)$ & & \\
\hline
\end{tabular}

variabilis (1). Raising pet cats indoors and preventing and treating ectoparasites of outdoor stray cats would help reduce risk for infection in $C$. felis protozoa-endemic areas. Some effective antitick insecticides can be used for preventing transmission of this parasite (10).

\section{Conclusions}

Our study revealed a high (21.5\%) C. felis prevalence in domestic cats in Yunnan Province, China. Further studies are warranted to assess the prevalence of the $C$. felis protozoan in wild felids and domestic cats in other regions of China to estimate its geographic distribution and genetic diversity and to investigate its potential tick vectors.

This study was supported by the Excellent Scientist Fund of Yunnan Agricultural University (grant no. 2015JY03), the Open Funds of the State Key Laboratory of Veterinary Etiological Biology, Lanzhou Veterinary Research Institute, Chinese Academy of Agricultural Sciences (grant no. SKLVEB2017KFKT008), the Elite Program of Chinese Academy of Agricultural Sciences, and the Agricultural Science and Technology Innovation Program (grant no. CAAS-ASTIP-2016-LVRI-03).

\section{About the Author}

Dr. Zou is professor of veterinary parasitology at the Key Laboratory of Veterinary Public Health of Higher Education of Yunnan Province, College of Veterinary Medicine, Yunnan Agricultural University, Kunming, Yunnan, China. His research focuses on the epidemiology and molecular biology of parasitic protozoa and control strategies for parasitic infections of animals and humans.

\section{References}

1. Wang JL, Li TT, Liu GH, Zhu XQ, Yao C. Two tales of Cytauxzoon felis infections in domestic cats. Clin Microbiol Rev. 2017;30: 861-85. http://dx.doi.org/10.1128/CMR.00010-17

2. Sherrill MK, Cohn LA. Cytauxzoonosis: diagnosis and treatment of an emerging disease. J Feline Med Surg. 2015;17:940-8. http://dx.doi.org/10.1177/1098612X15610681
3. Birkenheuer AJ, Le JA, Valenzisi AM, Tucker MD, Levy MG, Breitschwerdt EB. Cytauxzoon felis infection in cats in the mid-Atlantic states: 34 cases (1998-2004). J Am Vet Med Assoc. 2006;228:568-71. http://dx.doi.org/10.2460/ javma.228.4.568

4. Carli E, Trotta M, Chinelli R, Drigo M, Sinigoi L, Tosolini P, et al. Cytauxzoon sp. infection in the first endemic focus described in domestic cats in Europe. Vet Parasitol. 2012;183:343-52. http://dx.doi.org/10.1016/j.vetpar.2011.07.025

5. Rizzi TE, Reichard MV, Cohn LA, Birkenheuer AJ, Taylor JD, Meinkoth JH. Prevalence of Cytauxzoon felis infection in healthy cats from enzootic areas in Arkansas, Missouri, and Oklahoma. Parasit Vectors. 2015;8:13. http://dx.doi.org/10.1186/s13071-014-0618-z

6. Brown HM, Latimer KS, Erikson LE, Cashwell ME, Britt JO, Peterson DS. Detection of persistent Cytauxzoon felis infection by polymerase chain reaction in three asymptomatic domestic cats. J Vet Diagn Invest. 2008;20:485-8. http://dx.doi.org/ $10.1177 / 104063870802000411$

7. Brown HM, Lockhart JM, Latimer KS, Peterson DS. Identification and genetic characterization of Cytauxzoon felis in asymptomatic domestic cats and bobcats. Vet Parasitol. 2010;172:311-6. http://dx.doi.org/10.1016/j.vetpar.2010.04.041

8. André MR, Herrera HM, de Jesus Fernandes S, de Sousa KCM, Gonçalves LR, Domingos IH, et al. Tick-borne agents in domesticated and stray cats from the city of Campo Grande, state of Mato Grosso do Sul, midwestern Brazil. Ticks Tick Borne Dis. 2015;6:779-86. http://dx.doi.org/10.1016/j.ttbdis.2015.07.004

9. Shock BC, Birkenheuer AJ, Patton LL, Olfenbuttel C, Beringer J, Grove DM, et al. Variation in the ITS-1 and ITS-2 rRNA genomic regions of Cytauxzoon felis from bobcats and pumas in the eastern United States and comparison with sequences from domestic cats. Vet Parasitol. 2012;190:29-35. http://dx.doi.org/10.1016/ j.vetpar.2012.06.010

10. Reichard MV, Thomas JE, Arther RG, Hostetler JA, Raetzel KL, Meinkoth JH, et al. Efficacy of an imidacloprid 10\%/flumethrin $4.5 \%$ collar (Seresto, Bayer) for preventing the transmission of Cytauxzoon felis to domestic cats by Amblyomma americanum. Parasitol Res. 2013; 112(Suppl 1):11-20. http://dx.doi.org/10.1007/ s00436-013-3277-7

Address for correspondence: Xing-Quan Zhu, State Key Laboratory of Veterinary Etiological Biology, Lanzhou Veterinary Research Institute, Chinese Academy of Agricultural Sciences, 1 Xujiaping, Yanchangbu, Lanzhou, Gansu 730046, China; email: xingquanzhu1@hotmail.com 


\section{Molecular Detection and Species Determination of Malaria Parasites, Venezuela}

\section{César Pacheco, Jorge Moreno, Flor Herrera}

In southeastern Venezuela, malaria cases have increased since 2013 . We found that $46 \%$ of 352 blood samples from symptomatic patients in 1 municipality tested positive for Plasmodium spp. In addition, the number of cases increased by 10 times in 4 years (2014-2017) and by 3 times in 1 year (2016-2017).

$\mathrm{I}$ n 1961, the Bolivarian Republic of Venezuela was the first country to be certified by the World Health Organization as malaria-free (1). However, because of economic and political crises since 2013, the number of malaria cases has increased alarmingly, especially in mining towns in the Sifontes municipality, Bolivar State (2). The estimated number of malaria cases reported by surveillance systems in 2017 was higher than the annual average documented during the previous 29 years (1988-2016) (3). Plasmodium falciparum and $P$. vivax are the most important species of Plasmodium in Venezuela. P. falciparum causes the most severe malaria and can develop multiresistance to conventionally used antimalarial drugs (4). We aimed to assess the number of malaria cases, distributed by species, in symptomatic patients at a public health center in Sifontes municipality during epidemiologic week 50, 2016, and compare them with cases from the same week during 2014, 2015, and 2017.

\section{The Study}

We conducted our study in Sifontes municipality $\left(6^{\circ} 00^{\prime} 7^{\circ} 54^{\prime} \mathrm{N}, 60^{\circ} 44^{\prime} 61^{\circ} 39^{\prime} \mathrm{W}\right)$, Bolivar State, Venezuela (Figure 1). This municipality is a meso-endemic focus of unstable malaria, and transmission occurs during the entire year; outbreaks are associated with gold mining activities (5). Sifontes is divided into 3 parishes: Tumeremo in the north, El Dorado in the middle, and San Isidro in the south. San Isidro Parish has one of the largest deposits of gold in the country (Las Cristinas mine) and represents the focus with the highest malaria incidence during the last decade (5).

Author affiliations: University of Carabobo, Aragua, Venezuela

(C. Pacheco, F. Herrera); IAE Dr. Arnoldo Gabaldon, Field

Research Center "Dr. Francesco Vitanza," Tumeremo, Venezuela (J. Moreno)

DOI: https://doi.org/10.3201/eid2502.181279
Blood was collected by ear prick from 352 patients (247 male, 105 female) who had malaria symptoms (high fever, profuse sweating, headache, nausea, abdominal pain, diarrhea) after they provided informed consent approved by the Bioethics Committee of the Biomedical Research Institute of the University of Carabobo (BIOMED-UC). Most ( $\approx 90 \%)$ patients came from San Isidro Parish to be treated at the Field Research Center "Dr. Francesco Vitanza," a public health center in the city of Tumeremo, during epidemiologic week 50 (December 12-17), 2016. First, blood samples $(\approx 3$ drops) were collected directly on microscope slides and then a similar amount of blood was collected on filter paper. Microscopic diagnosis of malaria was performed promptly; filter papers were air dried, stored in vials, transported at $4^{\circ} \mathrm{C}$ to BIOMED-UC, and stored at $-20^{\circ} \mathrm{C}$ until processing.

The principal method for malaria detection has been microscopic and in Venezuela is performed as part of a regular procedure for diagnosing malaria (6). However, previous studies have found that PCR typing has higher sensitivity $(97.2 \%)$ and specificity (100.0\%) than microscopy (7); therefore, we used PCR to detect parasitic infections. We extracted DNA from individual samples using the phenol/ chloroform method, resuspended in $50 \mu \mathrm{L}$ sterilized water, and stored at $-80^{\circ} \mathrm{C}(8)$. We detected and typed Plasmodium spp. in blood samples using a previously described assay (9). This nested PCR uses Plasmodium genus-specific primers rPLU6 (5'-TTAAAATTGTTGCAGTTAAAACG-3') and rPLU5 (5'-CCTGTTGTTGCCTTAAACTTC-3') for the initial PCR amplification, followed by speciesspecific primers for the second amplification: $P$. falciparum rFAL1 (5'-TTAAACTGGTTT GGGAAAACCAAATATA TT-3') and rFAL2 (5'-ACACA ATGAACTCAATCATGACT ACCCGTC-3') and $P$. vivax rVIV1 (5'-CGCTTCT AGCTTAATCCA CATAACTGATAC-3') and rVIV2 (5'- ACTTCCAAGC CGAAGCAAAGAAAGTCC TTA-3'). The PCR amplifications were conducted in $25-\mu \mathrm{L}$ reaction volumes using $50 \mathrm{ng}$ of template DNA in a PTC-100 thermal cycler (MJ Research, Inc., http://mj-research.com). Negative controls (all reagents except template) were run to detect possible contamination. The amplified products were visualized by electrophoresis in $2 \%$ agarose gel stained with syber green. We estimated the percentage of parasite species in the detected cases as the percentage of positive Plasmodium samples divided by the total number of samples assayed. 


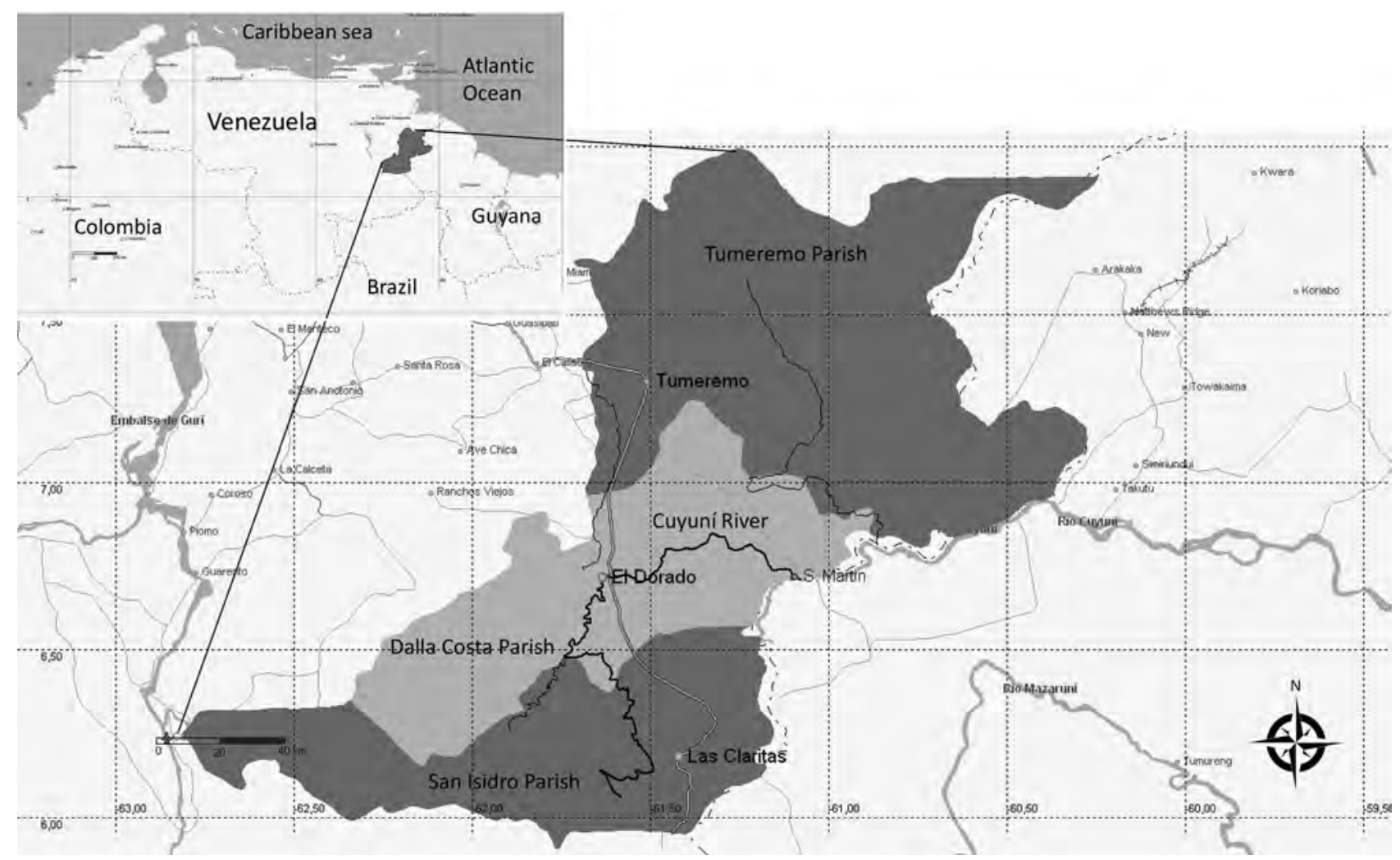

Figure 1. Geographic area of the Sifontes municipality, Bolivar state, Venezuela, with its parishes. Inset shows location of Bolivar state within Venezuela and proximity to other countries.

Microscopy and PCR revealed the presence of $P$. falciparum and $P$. vivax in blood samples from patients with suspected malaria infections. However, microscopy failed to detect malaria parasites in 2 samples in which PCR detected it, and 1 infection determined to be mixed by PCR was detected as monoinfection by microscopy. We can state therefore that microscopy and PCR yielded similar results. Figure 2 shows the specific size DNA amplicons of each species seen in the agarose gel. The negative control was consistently negative in all PCR runs. The malariapositive rate by PCR was $46.0 \%$ (162/352). Among these 162 positive samples, 124 (76.5\%) were detected in men and 38 (23.5\%) in women; 115 (92.7\%) of 124 infected men worked in mines. P. vivax accounted for 101 (62.3\%) infections, P. falciparum for 50 (30.9\%) infections, and mixed species for 11 (6.8\%) infections.

Malaria infections and their breakdown by species, detected in the same center by microscopy in the same week 50 in other years, were as follows: 2014, 50 cases, $76 \%$ P. vivax and 24\% P. falciparum; 2015, 64 cases, 95.3\% P. vivax and 4.7\% P. falciparum; 2017, 503 cases, $68.4 \%$ P. vivax, $28.4 \%$ P. falciparum, and $3.2 \%$ mixed infections. The number of cases during these 4 years in this public health center averaged $14 \%$ of all cases in Sifontes municipality.
The Venezuela Ministry of Health has not published epidemiologic data since November 2015. Therefore, we obtained comparison data on the number of positive cases directly from the healthcare center staff. In other states in Venezuela, malaria is also increasing. Reports from the Sucre State Department of Health indicated a 126-fold increase of $P$. falciparum malaria from 2011 to 2015 (10). Persons from Venezuela and other countries, attracted to mining activities, are moving to Bolivar state to work there for periods of time and then return home, especially when sick (11). Therefore, malaria could spread from the Sifontes municipality to other regions through the action of malaria vectors.

\section{Conclusions}

The rate of malaria infection (46\%) we found could represent the current malaria prevalence among symptomatic patients (115 [71\%] men of 162 malaria patients worked in mines) attending the public health center during week 50 in Bolivar state. The results also show that the number of positive cases increased by 10 times in 4 years (20142017) and by 3 times in only 1 year (from 2016 to 2017). Therefore, the tendency of malaria cases to increase is very high. With respect to the $P$. falciparum infections, results suggest that this species is increasing with time except for 2015, when infection rates were low. 


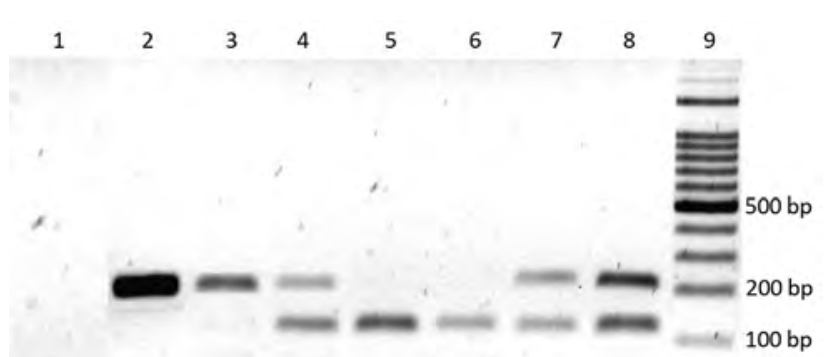

Figure 2. Detection of Plasmodium spp. in blood samples by gel electrophoresis on a $2 \%$ agarose gel, Venezuela. DNA amplicons generated by nested PCR of the DNA extracted from malaria parasites in blood samples from patients. Lane 1, negative control; lanes 2 and 3, P. falciparum-infected samples; lanes 4 and 7 , mixed infection ( $P$. falciparum $+P$. vivax) samples; lanes 5 and $6, P$. vivax-infected samples; lane 8 , mixed positive controls of $P$. falciparum (205 bp) and $P$. vivax (120 bp); lane 9, 100-bp ladder marker.

Several reasons could explain the increase in malaria prevalence in the public health center during epidemiologic week 50 from 2014 to 2017: 1) insufficient antimalarial drugs, which creates irregular distribution and unsupervised administration of them (12); 2) resistance to antimalarial drugs (4); and 3) increases in mosquito breeding habitats and rise in secondary vectors from malaria transmission attributable to deforestation by mining activities (13). Therefore, Venezuela, as well as neighboring countries that receive malaria patients from Venezuela, should strengthen vector-control efforts and improve malaria diagnosis and treatment.

\section{Acknowledgments}

We are grateful to all the patients who participated in the study and to the staff of the Field Research Center "Dr. Francesco Vitanza," Tumeremo, Bolivar State, Venezuela, who provided technical assistance in collecting samples.

This work was supported by Fondo Nacional de Ciencia, Tecnología e Innovación, Venezuela (grant 2008000911-1).

\section{About the Author}

Mr. Pacheco is a researcher at BIOMED-UC. His primary research interests include tropical infectious diseases and control solutions to policy makers.

\section{References}

1. Griffing SM, Villegas L, Udhayakumar V. Malaria control and elimination, Venezuela, 1800s-1970s. Emerg Infect Dis. 2014;20:1697-704. http://dx.doi.org/10.3201/eid2010.130917
2. World Health Organization. World malaria report 2017 [cited 2018 Jun 10]. http://www.who.int/malaria/publications/world-malariareport-2017/en

3. Pan American Health Organization/World Health Organization. Epidemiological alert: increase of malaria in the Americas. 30 January 2018 [cited 2018 Jun 10]. https://www.paho.org/hq/index. php?option $=$ com_docman\&task $=$ doc_view\&Itemid $=270 \&$ gid $=434$ 34\&lang=en

4. Thu AM, Phyo AP, Landier J, Parker DM, Nosten FH. Combating multidrug-resistant Plasmodium falciparum malaria. FEBS J. 2017;284:2569-78. http://dx.doi.org/10.1111/febs.14127

5. Moreno J, Rubio-Palis Y, Martínez A, Acevedo P. Evolución espacial y temporal de la malaria en el municipio Sifontes del estado Bolívar, Venezuela. 1980-2013. Bol Malariol Salud Ambient. 2014;54:236-49 [cited 2018 Jun 10]. http://www.scielo.org.ve/scielo.php?script=sci_arttext\&pid $=$ S1690-46482014000200012

6. Centers for Disease Control and Prevention. Malaria diagnosis (United States) [cited 2018 Jun 17]. https://www.cdc.gov/malaria/ diagnosis_treatment/diagnosis.html

7. Abou Orm S, Jiménez A, Agrela I, Torres N, Herrera F. Is the polymerase chain reaction (PCR) an alternative to microscopic diagnosis of malaria in Bolivar State, Venezuela? Comparison of both methods. Bol Malariol Salud Ambient. 2014;54:95-9 [cited 2018 Jun 10]. http://www.scielo.org.ve/scielo.php?script=sci_arttex t\&pid=S1690-46482014000100010

8. Rivero J, Urdaneta L, Zoghbi N, Pernalete M, Rubio-Palis Y, Herrera F. Optimization of extraction procedure for mosquitos DNA suitable for PCR-based techniques. Int J Trop Insect Sci. 2004;24:266-9. http://dx.doi.org/10.1079/IJT200430

9. Snounou G, Viriyakosol S, Zhu XP, Jarra W, Pinheiro L, do Rosario VE, et al. High sensitivity of detection of human malaria parasites by the use of nested polymerase chain reaction. Mol Biochem Parasitol. 1993;61:315-20. http://dx.doi.org/10.1016/0166-6851(93)90077-B

10. Oletta JF. Peligrosa expansión de malaria en el estado Sucre. Caracas (Venezuela): Sociedad Venezolana de Salud Pública, Red Defendamos la Epidemiología Nacional; June 21, 2015 [cited 2018 July 7]. http://revistasic.gumilla.org/wp-content/ uploads/2015/06/Peligrosa-expansio\%C3\% ACn-de-malaria-en-elestado-Sucre-2.pdf

11. Recht J, Siqueira AM, Monteiro WM, Herrera SM, Herrera S, Lacerda MVG. Malaria in Brazil, Colombia, Peru and Venezuela: current challenges in malaria control and elimination. Malar J. 2017;16:273. http://dx.doi.org/10.1186/s12936-017-1925-6

12. Hotez PJ, Basáñez M-G, Acosta-Serrano A, Grillet ME. Venezuela and its rising vector-borne neglected diseases. PLoS Negl Trop Dis. 2017;11:e0005423. http://dx.doi.org/10.1371/journal.pntd.0005423

13. Abou Orm S, Moreno J, Carrozza M, Acevedo P, Herrera F. Plasmodium spp. infection rates for some Anopheles spp. from Sifontes municipality, Bolivar State, Venezuela. Bol Malariol Salud Ambient. 2017;57:17-25 [cited 2018 Jul 7]. http://www.scielo.org.ve/ scielo.php?pid=S1690-46482017000100002\&script $=$ sci_abstract\&tlng=en

Address for correspondence: Flor Herrera, Universidad de Carabobo, BIOMED, Urb. Cantarrana, Avda Las Delicias Maracay, Aragua 2115, Venezuela; email: flormhq@gmail.com 


\section{Seroprevalence of Heartland Virus Antibodies in Blood Donors, Northwestern Missouri, USA}

\author{
Nicole P. Lindsey, Jay E. Menitove, \\ Brad J. Biggerstaff, George Turabelidze, \\ Pat Parton, Kim Peck, Alison J. Basile, \\ Olga I. Kosoy, Marc Fischer, J. Erin Staples
}

We estimated the seroprevalence of Heartland virus antibodies to be $0.9 \%(95 \% \mathrm{Cl} 0.4 \%-4.2 \%)$ in a convenience sample of blood donors from northwestern Missouri, USA, where human cases and infected ticks have been identified. Although these findings suggest that some past human infections were undetected, the estimated prevalence is low.

$I^{\prime}$ n 2012, Heartland virus, a novel virus in the family Phenuiviridae, genus Phlebovirus, was identified in blood specimens obtained from 2 residents (men) of northwestern Missouri, USA (1). Given the clinical manifestations of illness and history of tick bites of the patients, both men were initially believed to have ehrlichiosis but they failed to improve after being given doxycycline.

Before identification of Heartland virus in these 2 patients, to our knowledge, there were no known phleboviruses that caused human disease in the United States $(1,2)$. Subsequent field work identified Amblyomma americanum ticks, which are widely distributed across the eastern and central United States, as the likely vector for the virus $(3,4)$. Wild animals in Florida, Georgia, Illinois, Indiana, Kansas, Kentucky, Maine, Missouri, New Hampshire, North Carolina, Tennessee, Texas, and Vermont have been found to be seropositive for Heartland virus antibodies (5). Investigations are underway to identify more disease cases, but little is known about the incidence of Heartland virus infection in humans. The objective of this study was to estimate the seroprevalence of antibodies against Heartland virus in a convenience sample of blood donors who reside in northwestern Missouri where human cases and infected ticks have been identified $(1,3,6)$.

Author affiliations: Centers for Disease Control and Prevention, Fort Collins, Colorado, USA (N.P. Lindsey, B.J. Biggerstaff, A.J. Basile, O.I. Kosoy, M. Fischer, J.E. Staples); Community Blood Center of Greater Kansas City, Kansas City, Missouri, USA (J.E. Menitove, P. Parton, K. Peck); Missouri Department of Health and Senior Services, St. Louis, Missouri, USA (G. Turabelidze)

DOI: https://doi.org/10.3201/eid2502.181288

\section{The Study}

Because the anticipated seroprevalence of Heartland virus was unknown, we calculated a sample size that would enable us to conclude with reasonable confidence that infections were rare in case no positive results were detected. To this end, we calculated that serum from 500 individual blood donors was required to infer that the true prevalence was $<0.5 \%$ with $95 \%$ confidence. In addition, this sample size ensured that the prevalence would be estimated with precision no worse than $\pm 4.5 \%$ with $95 \%$ confidence.

Most blood donors in northwestern Missouri donate through community blood drives operated by the Community Blood Center of Greater Kansas City (Kansas City, MO, USA). Specimens were collected from consecutive blood drives conducted during November 4-December 3, 2013. The study population included blood donors $\geq 16$ years of age who had adequate residual specimens remaining after standard screening was performed. We originally intended to include residents of 15 counties surrounding the area where the first cases were identified (Figure). However, because 5 of those counties had $<5$ donations, analysis was restricted to residents of the remaining 10 counties. At the time of donation, blood donors consented to have residual specimen used for research. If a donor did not provide this consent, their sample was excluded. All specimens were deidentified before shipment to the Centers for Disease Control and Prevention (CDC; Fort Collins, CO, USA) for testing. The only data included with the specimens were patient age, sex, and county of residence. Testing of deidentified, residual samples was deemed by CDC to not involve human subjects under 45 CFR 46.102 (https://www.hhs.gov/ohrp/regulations-and-policy/regulations/regulatory-text/index.html\#46.102), and human subjects regulations were not applicable.

We screened all serum specimens for IgG against Heartland virus by using a Clinical Laboratory Improvement Amendments-approved microsphere assay as described (7). For specimens yielding IgG-positive results, we performed a more specific plaque reduction neutralization test (PRNT), which can differentiate between related phleboviruses in the United States, by using Vero E6 cells to confirm the presence of virus-specific neutralizing antibodies and a $90 \%$ plaque reduction criteria $(8,9)$. We calculated seroprevalence by using the 2013 US Census 


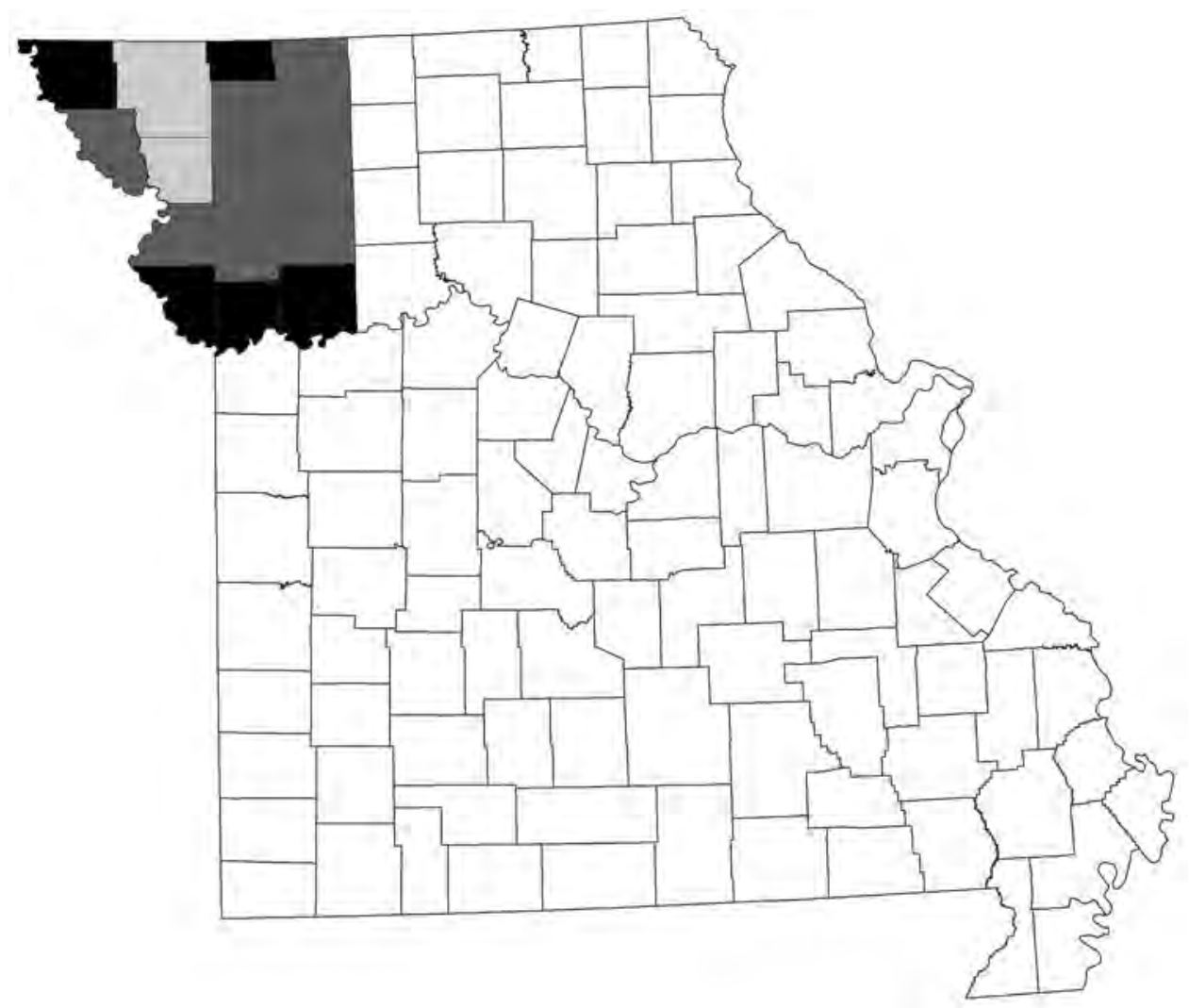

Figure. Location of counties targeted for study of seroprevalence of Heartland virus in blood donors, northwestern Missouri, USA. Gray shading indicates 10 counties included in analysis; lighter gray shading indicates counties where first cases were identified. Black shading indicates 5 counties excluded from analysis because they had $<5$ blood donors. midyear population estimate for persons $\geq 16$ years of age for the area.

For the 487 blood donors tested, median age was 52 years (range 16-87 years), and 225 (46\%) were men. Twelve serum specimens were positive for IgG against Heartland virus, and 7 of those were confirmed for Heartland virus neutralizing antibodies by PRNT. For the 7 donors with Heartland virus neutralizing antibodies, median age was 33 years (range 30-78 years) and 4 (57\%) were men. Five (71\%) of the 7 positive persons were residents of Daviess County.

Because there were differences in the rates of blood donors per population in the included counties, we computed the estimate of the seroprevalence within the region by using a stratum-weighted estimate and 95\% CI (10). We estimated a seroprevalence of $0.9 \%(95 \%$ CI $0.4-4.2 \%)$ in blood donors $>16$ years of age in the 10-county region. Assuming this seroprevalence estimate was representative of the general population in the study region, we estimate that 1,431 (95\% CI 660-6,708) adult residents in the area had been previously exposed to Heartland virus.

The findings of this analysis are subject to several limitations. Blood donors differ from the general population in age ( $\geq 16$ years), sex, health status, and potentially exposures. Therefore, these results might not be applicable to the general population in northwestern Missouri. For instance, $46 \%$ of our donors were men, compared with
$51 \%$ of persons $\geq 18$ years of age who live in 10 -county areas included in our analysis. Furthermore, because we excluded counties without an adequate number of donors, data collected might not be representative of the entire region of northwestern Missouri that included counties in or near where human disease cases and infected ticks have been identified.

Because blood donors are required to not have had a recent illness and no information was collected regarding previous illnesses, we did not test for evidence of acute infection and cannot state whether identified infections were asymptomatic or might have resulted in symptomatic disease. In addition, because we were only identifying evidence of past infections to determine the seroprevalence in the area, we do not know the timing of identified human infections and whether these persons were infected in their county of residence.

\section{Conclusions}

We estimated a prevalence of $0.9 \%$ for Heartland virus infection in northwestern Missouri, where the virus is known to have circulated. These results suggest that several infections have gone unidentified because they were asymptomatic or the infected persons did not seek care, were not tested, or were ill before the identification of Heartland virus as a cause of human disease. The finding 
that most identified infections were in 1 county could be a chance occurrence but also might suggest that the virus is geographically focally distributed.

On the basis of available data for $>30$ reported cases of Heartland virus disease, healthcare providers should consider testing for patients who have an acute febrile illness and leukopenia or thrombocytopenia not explained by another condition or who were suspected to have another tickborne disease but did not improve after appropriate treatment (e.g., doxycycline) $(6,11)$. Testing should be limited to patients who resided in or traveled to an area with previous evidence of Heartland virus or had a known tick exposure $(5,6)$.

Because Heartland virus is transmitted by infected ticks, prevention depends on using insect repellents, wearing long sleeves and pants, avoiding bushy and wooded areas, and performing tick checks after spending time outdoors. The clinical spectrum of Heartland virus disease remains to be described, including determination of whether asymptomatic infections can occur. In addition, research is needed to determine whether there are other modes of transmission for Heartland virus, including bloodborne transmission.

\section{About the Author}

Ms. Lindsey is an epidemiologist at the Centers for Disease Control and Prevention, National Center for Emerging and Zoonotic Infectious Diseases, Fort Collins. Her primary research interests are arbovirus disease surveillance and epidemiology.

\section{References}

1. McMullan LK, Folk SM, Kelly AJ, MacNeil A, Goldsmith CS, Metcalfe MG, et al. A new phlebovirus associated with severe febrile illness in Missouri. N Engl J Med. 2012;367:834-41. http://dx.doi.org/10.1056/NEJMoa1203378

2. Beaty BJ, Calisher CH. Bunyaviridae-natural history. Curr Top Microbiol Immunol. 1991;169:27-78. http://dx.doi.org/10.1007 /978-3-642-76018-1_2
3. Savage HM, Godsey MS Jr, Lambert A, Panella NA, Burkhalter KL, Harmon JR, et al. First detection of heartland virus (Bunyaviridae: Phlebovirus) from field collected arthropods. Am J Trop Med Hyg. 2013;89:445-52. http://dx.doi.org/10.4269/ ajtmh.13-0209

4. Godsey MS Jr, Savage HM, Burkhalter KL, Bosco-Lauth AM, Delorey MJ. Transmission of heartland virus (Bunyaviridae: Phlebovirus) by experimentally infected Amblyomma americanum (Acari: Ixodidae). J Med Entomol. 2016;53:1226-33. http://dx.doi.org/10.1093/jme/tjw080

5. Riemersma KK, Komar N. Heartland virus neutralizing antibodies in vertebrate wildlife, United States, 2009-2014. Emerg Infect Dis. 2015;21:1830-3. http://dx.doi.org/10.3201/ eid2110.150380

6. Centers for Disease Control and Prevention. Heartland virus: statistics and maps [cited 2018 Oct 24]. https://www.cdc.gov/ heartland-virus/statistics/index.html

7. Johnson AJ, Noga AJ, Kosoy O, Lanciotti RS, Johnson AA, Biggerstaff BJ. Duplex microsphere-based immunoassay for detection of anti-West Nile virus and anti-St. Louis encephalitis virus immunoglobulin $\mathrm{M}$ antibodies. Clin Diagn Lab Immunol. 2005;12:566-74.

8. Beaty BJ, Calisher CH, Shope RE. Arboviruses. In: Lennette EH, Lennette DA, Lennette ET, editors. Diagnostic procedures for viral, rickettsial and chlamydial infections. 7th ed. Washington (DC): American Public Health Association; 1995. p. 189-212.

9. Bosco-Lauth AM, Panella NA, Root JJ, Gidlewski T, Lash RR, Harmon JR, et al. Serological investigation of Heartland virus (Bunyaviridae: Phlebovirus) exposure in wild and domestic animals adjacent to human case sites in Missouri 2012-2013. Am J Trop Med Hyg. 2015;92:1163-7. http://dx.doi.org/10.4269/ ajtmh.14-0702

10. Yan X, Gang X. Stratified Wilson and Newcombe confidence intervals for multiple binomial proportions. Stat Biopharm Res. 2010;2:329-35. http://dx.doi.org/10.1198/sbr.2009.0049

11. Pastula DM, Turabelidze G, Yates KF, Jones TF, Lambert AJ, Panella AJ, et al.; Centers for Disease Control and Prevention. Notes from the field: Heartland virus diseaseUnited States, 2012-2013. MMWR Morb Mortal Wkly Rep. 2014;63:270-1.

Address for correspondence: Nicole P. Lindsey, Centers for Disease Control and Prevention, 3156 Rampart Rd, Fort Collins, CO 80526, USA; email: frd3@cdc.gov 


\section{Identification of Leishmania Species in Naturally Infected Sand Flies from Refugee Camps, Greece}

\author{
Emmanouil A. Fotakis, loannis A. Giantsis, \\ Aimilia Avgerinou, Sofoklis Kourtidis, \\ Evangelia Agathaggelidou, Christina Kapoula, \\ Glykeria Dadakou, John Vontas, \\ Alexandra Chaskopoulou
}

High infection rates of Leishmania donovani and L. tropica were detected in Phlebotomus spp. sand flies collected from refugee camps in Greece, indicating increased risk of infection among local populations. Detection and treatment of leishmaniasis, community education, and vector control are essential measures to prevent pathogen transmission and protect public health.

$\mathrm{L}$ eishmaniasis is a parasitic disease caused by protozoa of the genus Leishmania, which are transmitted by sand flies of the genus Phlebotomus. Visceral leishmaniasis (VL) and cutaneous leishmaniasis (CL) are endemic in southern Europe; L. infantum is the primary causative agent (1). An emerging problem regarding leishmaniasis control in Europe is the potential introduction of new Leishmania species, such as $L$. donovani and $L$. tropica, through travelers, refugees, and immigrants from countries where these species are endemic. L. tropica, which has a limited presence in Europe and is reported mostly in Greece, causes anthroponotic CL; $L$. donovani, recently reported in Cyprus, causes anthroponotic VL and CL (2).

More than 1 million refugees and immigrants arrived in Greece in 2015 and 2016 (3), mostly from Syria, Iraq, and Afghanistan, where leishmaniasis poses a serious economic and social burden (4). Most of these persons are hosted in temporary accommodation sites (camps)

Author affiliations: Agricultural University of Athens, Athens, Greece (E.A. Fotakis, J. Vontas); Foundation for Research and Technology Hellas, Heraklion, Greece (E.A. Fotakis, J. Vontas); US Department of Agriculture, Agricultural Research ServiceEuropean Biological Control Laboratory, Thessaloniki, Greece (I.A. Giantsis, A. Avgerinou, A. Chaskopoulou); General Directorate of Public Health and Social Welfare, Region of Central Macedonia, Thessaloniki (S. Kourtidis, E. Agathaggelidou, C. Kapoula, G. Dadakou)

DOI: https://doi.org/10.3201/eid2502.181359 throughout Greece. A vectorborne pathogen surveillance network targeting refugee camps was deployed in Greece during June-September 2017. Here we report major findings related to sand fly activity and Leishmania transmission associated with these temporary settlements.

\section{The Study}

We surveyed 4 refugee camps in Greece in 2017: the Lagadikia and Diavata camps in the Thessaloniki Regional Unit, northern Greece, and the Vial and Souda camps on the island of Chios in the Northeastern Aegean Islands complex. Sand flies were collected from camps every 2 weeks from June through September by using CDC light traps (John W. Hock, Gainesville, FL, USA) baited with dry ice. For this analysis, we further included sand flies collected from the metropolitan area of Thessaloniki during 2011-2015 (5).

Wild-caught sand flies were stored in ethanol. The head from each female sand fly was dissected from the body and stored individually to be used for sand fly species identification using a multiplex diagnostic assay based on species-specific single-nucleotide polymorphisms of the nuclear 18S rRNA gene (6); positive controls were previously identified sand flies (6). Sand fly heads were also used for Leishmania detection. The remaining parts of the abdomen and thorax from each female sand fly were pooled based on species, sampling site (refugee camp), and collection date (6-16 female specimens per pool). We extracted DNA from the pooled samples and individual sand fly heads using the NucleoSpin Tissue kit (Macherey-Nagel, Düren, Germany) according to the manufacturer's instructions.

We screened DNA extracted from pools for the presence of Leishmania by amplification of a 300-350-bp fragment of the Leishmania DNA ribosomal internal transcribed spacer 1 (ITS1), as described by Rêgo et al. (7). We used Phlebotomus argentipes pools originating from laboratory colonies infected with $L$. donovani or $L$. infantum as positive controls and used male sand flies as negative controls. We analyzed amplicons by electrophoresis on a $2 \%$ agarose gel.

We individually screened the extracted DNA from the female heads corresponding to the positive pools for 
the presence of Leishmania as described, followed by Leishmania species identification applying the restriction fragment length polymorphism diagnostic test of Schönian et al. (8). Leishmania species were further confirmed in a subset of samples using ITS1 product sequencing and BLAST analysis (https://www.ncbi.nlm.nih.gov/BLAST). We depicted the phylogenetic relationships of the ITS1 sequences with conspecific haplotypes obtained from the GenBank database by constructing a neighbor-joining dendrogram using MEGA version 6.05 (9) using pairwise gap deletion and performing 1,000 bootstrap replicates.

For discriminating between members of the $L$. donovani complex, we analyzed the cysteine protease $\mathrm{b}(\mathrm{cpb})$ gene, applying the species-specific PCR assay described by Hide and Bañuls (10). We amplified a segment of Heatshock protein 70 (Hsp70) as described by Van der Auwera et al. (11) and then sequenced the amplicons.

We analyzed 10 sand fly pools $(\mathrm{n}=127$ individuals) from Thessaloniki refugee camps, 240 pools $(n=1200)$ from the Thessaloniki metropolitan region, and 5 pools ( $\mathrm{n}$ $=61$ ) from Chios refugee camps, comprising 6 different species (Figure 1; 5). ITS1 PCR detected Leishmania DNA in 10 pools, all of which originated from the Thessaloniki refugee camps (Table 1). Of the 127 sand fly heads that were analyzed individually from the positive pools, we detected Leishmania in 26 sand flies from Lagadikia and 35 sand flies from Diavata (Table 2), corresponding to a natural Leishmania infection frequency of $43 \%$ for Lagadikia and 52\% for Diavata. We detected Leishmania parasites in the dissected heads of all 3 prevalent sand fly species ( $P$. perfiliewi, $P$. tobbi, $P$. simici), indicating late-stage transmissible infection. The absence of parasite detection from the broader region of Thessaloniki, in parallel with the unusually high infection frequencies observed in both Thessaloniki refugee camps, strongly indicates high levels of focal parasite transmission (12) in the Thessaloniki refugee camps.

Leishmania species identification through restriction fragment length polymorphism assays revealed 2 different

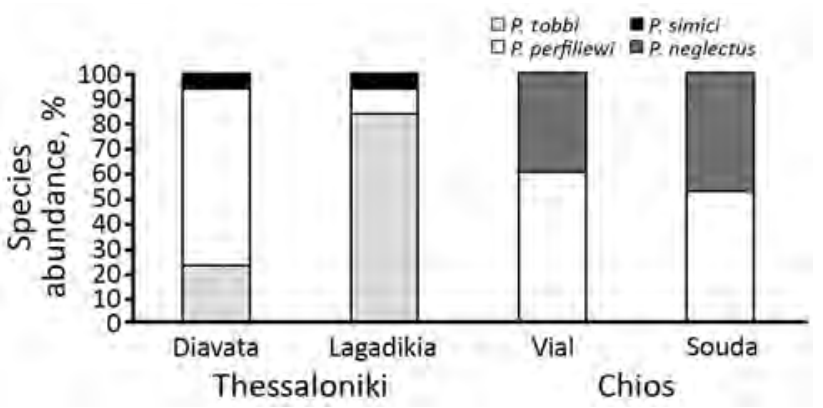

Figure 1. Phlebotomus spp. sand fly species composition and relative species abundance in Thessaloniki and Chios refugee camps, Greece.

restriction profiles, demonstrating the presence of $L$. donovani complex in 40 sand flies and L. tropica in 21 sand flies (Table 2). Sequencing results in a subset of the positive samples confirmed the identity of the Leishmania species. Two ITS1 haplotypes were found corresponding to each species and were deposited into GenBank (accession nos. MH763642 for L. donovani and MH763643 for L. tropica). Both cpb and Hsp70 gene analyses confirmed the identity of all $40 \mathrm{~L}$. donovani complex isolates as $L$. donovani donovani. The cpb species-specific PCR assay amplified the 741-bp product that characterizes L. donovani (10). Hsp70 analysis resulted in a single haplotype (GenBank accession no. MH788969), 541 bp in length, that showed $100 \%$ sequence similarity with the Hsp70 reference sequences for $L$. donovani (11).

Phylogenetic analysis demonstrated clustering of the detected $L$. donovani haplotype with conspecific haplotypes, mainly from Syria, Iraq, India, Sudan, and Ethiopia (Figure 2), that have been associated with VL in humans. The $L$. tropica haplotype was clustered with haplotypes from Syria, Afghanistan, and Iran.

\section{Conclusions}

The leishmaniasis disease status of the refugee populations hosted in the temporary accommodation sites in

\begin{tabular}{lcccc}
\hline \multicolumn{4}{l}{ Table 1. Sand fly pool grouping of refugee camp samples and Leishmania detection at pool level, Greece } \\
\hline Refugee camp & Sand fly species & No. specimens & No. pools & No. (\%) Leishmania- \\
Lagadikia & P. tobbi & 45 & 3 & $3(100.0)$ \\
& P. perfiliewi & 9 & 1 & $1(100.0)$ \\
& P. simici & 6 & 1 & $1(100.0)$ \\
& Total & 60 & 5 & $5(100.0)$ \\
\hline Diavata & P. tobbi & 15 & 1 & $1(100.0)$ \\
& P. perfiliewi & 45 & 3 & $3(100.0)$ \\
& P. simici & 7 & 1 & $1(100.0)$ \\
& Total & 67 & 5 & $5(100.0)$ \\
\hline Souda & P. perfiliewi & 11 & 1 & 0 \\
& P. neglectus & 10 & 1 & 0 \\
& Total & 21 & 2 & 0 \\
\hline Vial & P. perfiliewi & 24 & 2 & 0 \\
& $P$. neglectus & 16 & 1 & 0 \\
\hline
\end{tabular}


Table 2. Leishmania detection and species identification in individual sand flies in refugee camps, Greece

\begin{tabular}{|c|c|c|c|c|c|c|}
\hline \multirow[b]{2}{*}{ Refugee camp } & \multirow[b]{2}{*}{ Sand fly species } & \multirow[b]{2}{*}{ No.* } & \multicolumn{4}{|c|}{ Leishmania infection } \\
\hline & & & L. donovanit & L. tropicał & Total§̧ & Infection rate, \%ף \\
\hline \multirow[t]{3}{*}{ Lagadikia } & P. tobbi & 45 & 14 & 7 & 21 & 43 \\
\hline & P. perfiliewi & 9 & 3 & 1 & 4 & \\
\hline & P. simici & 6 & 0 & 1 & 1 & \\
\hline \multirow[t]{3}{*}{ Diavata } & P. tobbi & 15 & 1 & 2 & 3 & 52 \\
\hline & P. perfiliewi & 45 & 21 & 9 & 30 & \\
\hline & P. simici & 7 & 1 & 1 & 2 & \\
\hline
\end{tabular}

*Total number of specimens tested per sand fly species per camp.

$\dagger$ Total number of sand flies infected with $L$. donovani per sand fly species, per camp.

$\ddagger$ Total number of sand flies infected with $L$. tropica per sand fly species, per camp.

$\S$ Total number of sand flies infected with $L$. donovani or $L$. tropica per sand fly species, per camp.

ITotal Leishmania infection rate per refugee camp.

Thessaloniki or elsewhere in Greece and Europe remains unknown. L. donovani is one of the main causative agents of anthroponotic VL, a dangerous form of leishmaniasis that is lethal if left untreated. CL is more benign, but lesions caused by L. tropica are generally more difficult to treat with antimonial drugs because of the development of drug resistance (13). An epidemic of CL was recently recorded in camps housing refugees from Syria within Lebanon's borders; $85 \%$ of the reported cases were caused by $L$. tropica (14). The high $L$. donovani and $L$. tropica infection rates detected in natural sand flies from the refugee camps in northern Greece suggest that the persons accommodated in these settings face an increased risk for infection. It is therefore imperative to take all necessary precautions to prevent

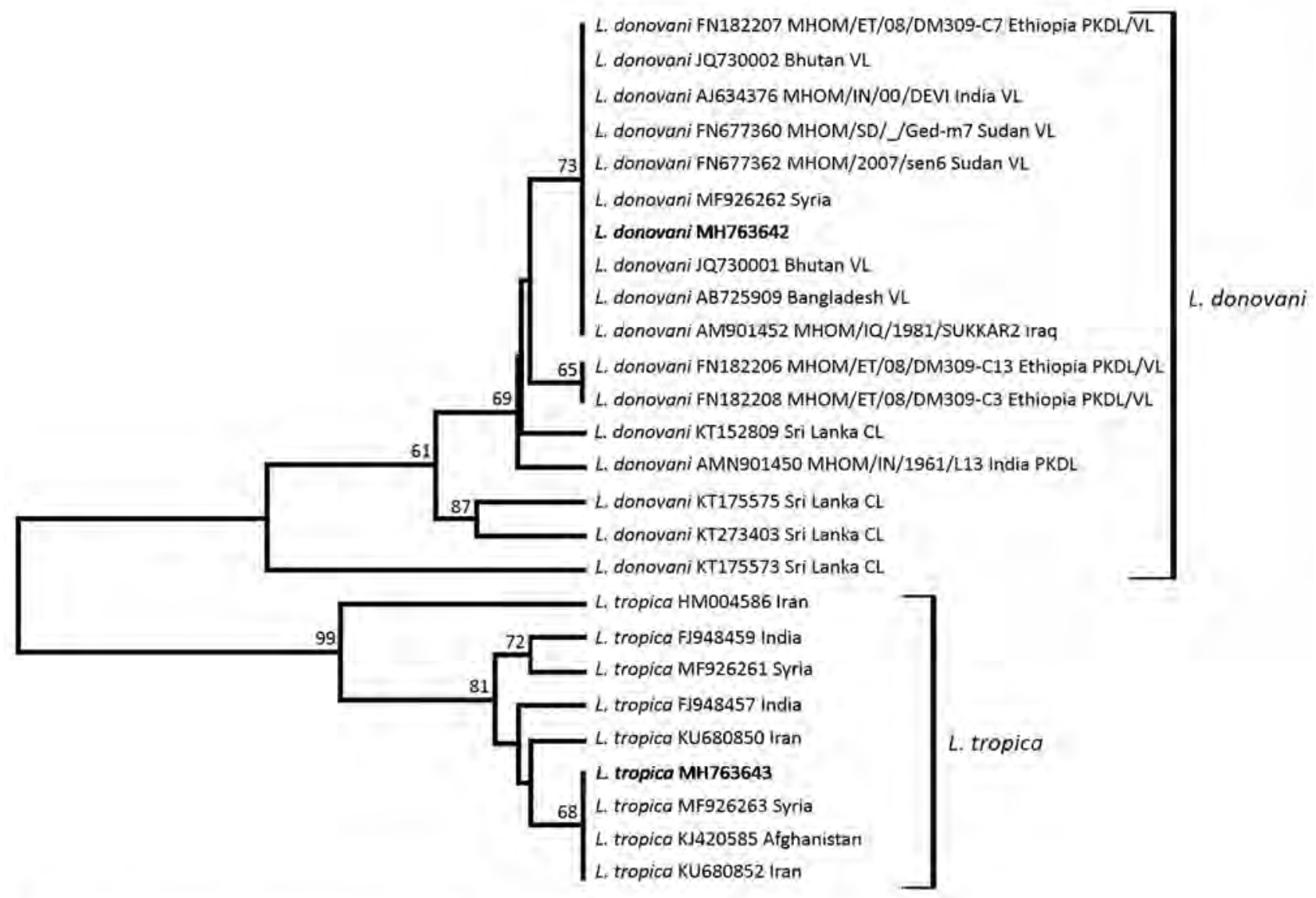

\begin{tabular}{lll}
\hline 0.015 & 0.010 & 0 \\
0
\end{tabular}

Figure 2. Dendrogram depicting internal transcribed spacer 1 genetic relationships of the 2 Leishmania haplotypes (bold) found in study of Leishmania spp. in naturally infected sand flies in refugee camps, Greece, compared with conspecific Leishmania haplotypes obtained from GenBank. Cls $>60 \%$ are indicated next to the branches. Each taxon is identified by species name, GenBank accession number, World Health Organization code if available, country, and type of disease caused, if known. Scale bar indicates nucleotide substitutions per site. CL, cutaneous leishmaniasis; VL, visceral leishmaniasis. 
transmission within refugee populations, as well as in the surrounding communities.

Systematic active and passive detection of leishmaniasis within the refugee populations, effective treatment of infected patients, access to adequate living conditions, health education of the community, and establishment of targeted vector control activities are essential steps necessary to protect public health, as well as to avert the colonization of the local sand fly vectors by exotic Leishmania species. Studies investigating the initial Leishmania disease burden in refugee and immigrant populations when entering Europe and risk factors associated with disease transmission within the camp settlements are also required for efficient disease control.

\section{Acknowledgments}

We thank the Region of Central Macedonia, Greece and the Greek Ministry of the Interior and Administrative Reconstruction for providing access to the refugee settlements and for facilitating our surveillance activities. We thank Petr Volf and Jovana Sadlova for providing us with $P$. argentipes sand flies infected with $L$. donovani and $L$. infantum. We thank pest control companies NovaFarm and Zountas N. for their significant contributions in our surveillance activities.

This work was supported by the General Secretariat for Research and Technology and the Hellenic Foundation for Research and Innovation in the context of the action 1st Proclamation of Scholarships from ELIDEK for PhD Candidates (scholarship code 532).

\section{About the Author}

Mr. Fotakis is a PhD candidate in the Department of Crop Science, Pesticide Science Laboratory, at the Agricultural University of Athens, Greece. His research interests include the monitoring of vectorborne diseases in sites of increased epidemiological importance, analysis of vector insecticide resistance, and innovative methods for vector control.

\section{References}

1. Dujardin JC, Campino L, Cañavate C, Dedet JP, Gradoni L, Soteriadou K, et al. Spread of vector-borne diseases and neglect of leishmaniasis, Europe. Emerg Infect Dis. 2008;14:1013-8. http://dx.doi.org/10.3201/eid1407.071589

2. Ntais P, Sifaki-Pistola D, Christodoulou V, Messaritakis I, Pratlong F, Poupalos G, et al. Leishmaniases in Greece. Am J Trop Med Hyg. 2013;89:906-15. http://dx.doi.org/10.4269/ajtmh.13-0070
3. European Commission. European civil protection and humanitarian aid operations. Fact sheet, Greece. 2018 [cited 2018 Aug 22]. https://ec.europa.eu/echo/where/europe/greece_en

4. World Health Organization. Leishmaniasis epidemiological situation [cited 2018 Aug 22]. http://www.who.int/leishmaniasis/ burden/en/

5. Chaskopoulou A, Giantsis IA, Demir S, Bon MC. Species composition, activity patterns and blood meal analysis of sand fly populations (Diptera: Psychodidae) in the metropolitan region of Thessaloniki, an endemic focus of canine leishmaniasis. Acta Trop. 2016;158:170-6. http://dx.doi.org/10.1016/ j.actatropica.2016.03.006

6. Giantsis IA, Chaskopoulou A, Claude Bon M. Direct multiplex PCR (dmPCR) for the identification of six phlebotomine sand fly species (Diptera: Psychodidae), including major Leishmania vectors of the Mediterranean. J Econ Entomol. 2017;110:245-9.

7. Rêgo FD, Rugani JMN, Shimabukuro PHF, Tonelli GB, Quaresma PF, Gontijo CMF. Molecular detection of Leishmania in phlebotomine sand flies (Diptera: Psychodidae) from a cutaneous leishmaniasis focus at Xakriabá Indigenous Reserve, Brazil. PLoS One. 2015;10:e0122038. http://dx.doi.org/10.1371/ journal.pone.0122038

8. Schönian G, Nasereddin A, Dinse N, Schweynoch C, Schallig HDF, Presber W, et al. PCR diagnosis and characterization of Leishmania in local and imported clinical samples. Diagn Microbiol Infect Dis. 2003;47:349-58. http://dx.doi.org/10.1016/S0732-8893(03) 00093-2

9. Tamura K, Stecher G, Peterson D, Filipski A, Kumar S. MEGA6: Molecular Evolutionary Genetics Analysis version 6.0. Mol Biol Evol. 2013;30:2725-9. http://dx.doi.org/10.1093/molbev/mst197

10. Hide M, Bañuls AL. Species-specific PCR assay for L. infantum/ L. donovani discrimination. Acta Trop. 2006;100:241-5. http://dx.doi.org/10.1016/j.actatropica.2006.10.012

11. Van der Auwera G, Maes I, De Doncker S, Ravel C, Cnops L, Van Esbroeck M, et al. Heat-shock protein 70 gene sequencing for Leishmania species typing in European tropical infectious disease clinics. Euro Surveill. 2013;18:20543. http://dx.doi.org/ 10.2807/1560-7917.ES2013.18.30.20543

12. Katholi CR, Unnasch TR. Important experimental parameters for determining infection rates in arthropod vectors using pool screening approaches. Am J Trop Med Hyg. 2006;74:779-85. http://dx.doi.org/10.4269/ajtmh.2006.74.779

13. Hadighi R, Mohebali M, Boucher P, Hajjaran H, Khamesipour A, Ouellette M. Unresponsiveness to glucantime treatment in Iranian cutaneous leishmaniasis due to drug-resistant Leishmania tropica parasites. PLoS Med. 2006;3:e162. http://dx.doi.org/10.1371/ journal.pmed.0030162

14. Saroufim M, Charafeddine K, Issa G, Khalifeh H, Habib RH, Berry A, et al. Ongoing epidemic of cutaneous leishmaniasis among Syrian refugees, Lebanon. Emerg Infect Dis. 2014;20: 1712-5. http://dx.doi.org/10.3201/eid2010.140288

Address for correspondence: Alexandra Chaskopoulou, US Department of Agriculture, Agricultural Research Service-European Biological Control Laboratory, Tsimiski 43 St, 7th Fl, Thessaloniki 54623, Greece; email: achaskopoulou@ars-ebcl.org 


\section{Schistosoma haematobium- Schistosoma mansoni Hybrid Parasite in Migrant Boy, France, 2017}

\author{
Yohann Le Govic, Julien Kincaid-Smith, \\ Jean-François Allienne, Olivier Rey, \\ Ludovic de Gentile, Jérôme Boissier
}

Author affiliations: Université Bretagne Loire, Angers, France (Y. Le Govic); Centre Hospitalier Universitaire d'Angers, Angers (Y. Le Govic, L. de Gentile); Université de Montpellier, Perpignan, France (J. Kincaid-Smith, J.-F. Allienne, O. Rey, J. Boissier)

DOI: https://doi.org/10.3201/eid2502.172028

Schistosomiasis is frequently detected in persons entering Europe. In 2017, we detected a Schistosoma mansoniSchistosoma haematobium hybrid parasite infection in a migrant boy from Côte d'Ivoire entering France. Because such parasites might be established in Europe, as illustrated by an outbreak on Corsica Island, vectors of these parasites should be investigated.

$I^{\prime}$ n 2017, a 14-year-old boy from Côte d'Ivoire who had crossed the Sahara Desert through Niger and reached Europe by sea from Libya was referred to the Consultation Board at the Parasitology Unit of Angers University Hospital (Angers, France) for painless gross hematuria. Aside from hematuria, his physical examination was unremarkable. Blood tests revealed microcytic anemia (hemoglobin $103 \mathrm{~g} / \mathrm{L}$, mean corpuscular volume $57.1 \mathrm{fL}$, mean corpuscular hemoglobin concentration $285 \mathrm{~g} / \mathrm{L}$ ) and a low serum ferritin level (8 $\mu \mathrm{g} / \mathrm{L})$. Leukocyte and eosinophil counts and biochemical markers of liver and kidney function were within reference limits. Serologic test results were negative for antibodies to HIV, hepatitis B and C virus, and Treponema pallidum. Serodiagnostic test results were negative for cystic and alveolar echinococcoses and strongyloidiasis, and schistosomiasis screening test results were inconclusive: positive by Schistosoma mansoni-specific ELISA (optical density 1.02, threshold 0.53; Bordier Affinity Products, http://www.bordier.ch/) and negative by S. mansoni indirect hemagglutination test (titer 1:40, threshold 1:160; Bilharziosis Fumouze; https://www.biosynex.com/).

To clarify diagnosis, we performed the SCHISTO II Western Blot IgG (LDBio Diagnostics, http://www. ldbiodiagnostics.com/), which showed 5 unequivocal bands, including a large band at 22-24 kDa and 30-34 kDa, results indicative of schistosomiasis. We corroborated our results by microscopic examination of patient feces and urine. We detected lateral-spined eggs (typical of $S$. mansoni parasites) in a fecal specimen processed by using the Kato-Katz method and, surprisingly, lateral-spined eggs and terminal-spined eggs (typical of Schistosoma haematobium parasites) in a 24-hour urine specimen filtered through a 12-micron membrane (Figure, panel A). The patient received a single $40 \mathrm{mg} / \mathrm{kg}$ dose of praziquantel. The patient experienced no more episodes of hematuria for the following 6 months; however, we could not assess his parasitological responses.

We genotyped both terminal- and lateral-spined eggs individually using a previously described protocol (1). All terminal-spined eggs were characterized by mitochondrial cox1 genes (GenBank accession nos. MG562514-5) and the nuclear internal transcribed spacer (ITS) (GenBank accession no. MG554667) specific to S. haematobium schistosomes. All chromatograms of ITS genes from lateral-spined eggs showed a double profile: 1 identical to S. mansoni schistosomes (GenBank accession no. MG554659) and 1 identical to S. haematobium (GenBank accession no. MG554667). Moreover, the cox 1 haplotypes of these eggs were either specific to S. haematobium (GenBank accession no. MG562514) or S. mansoni (GenBank accession nos. MG562512-3) parasites. The phylogenetic tree of $S$. mansoni cox 1 sequences indicates that the parasite responsible for this infection originated from Far West Africa; the hybrid parasite's haplotypes clustered with those of schistosomes from Niger, Senegal, and Mali (Figure, panel B).

Schistosomiasis represents a serious disease burden worldwide and is ranked the 12th most common travel-associated infection in Europe (2). The migration crisis has led to a large flow of persons (notably children) from West Africa. Unaccompanied foreign minors are protected under the 1989 United Nations Convention on the Rights of the Child (https:// www.ohchr.org/en/professionalinterest/pages/crc.aspx). Moreover, because of the high prevalence of schistosomiasis in their countries of origin, these children receive care for this disease upon their arrival in Maine-et-Loire Department (Loire Valley, France). This preventive strategy enabled us to diagnose schistosomiasis in $\approx 25 \%$ of travelers and migrants (Y. Le Govic, unpub. data), a result in accordance with a similar screening program in Italy (3). This strategy also enabled us to detect the case of mixed Schistosoma parasite infection with ectopic egg elimination described in this report.

Ectopic egg elimination (i.e., S. haematobium schistosome eggs in feces and S. mansoni eggs in urine) frequently occurs in endemic areas; in a study in northern Senegal, $53 \%$ of patients infected with Schistosoma parasites had simultaneous infections with S. mansoni and S. haematobium parasites, of which $15 \%$ displayed ectopic egg elimination (4). This phenomenon can occur because of parasite hybridization. Hybrids resulting from S. mansoni and S. haematobium schistosome cross-breeding have been documented in northern Senegal (5). The fact that the patient we describe 

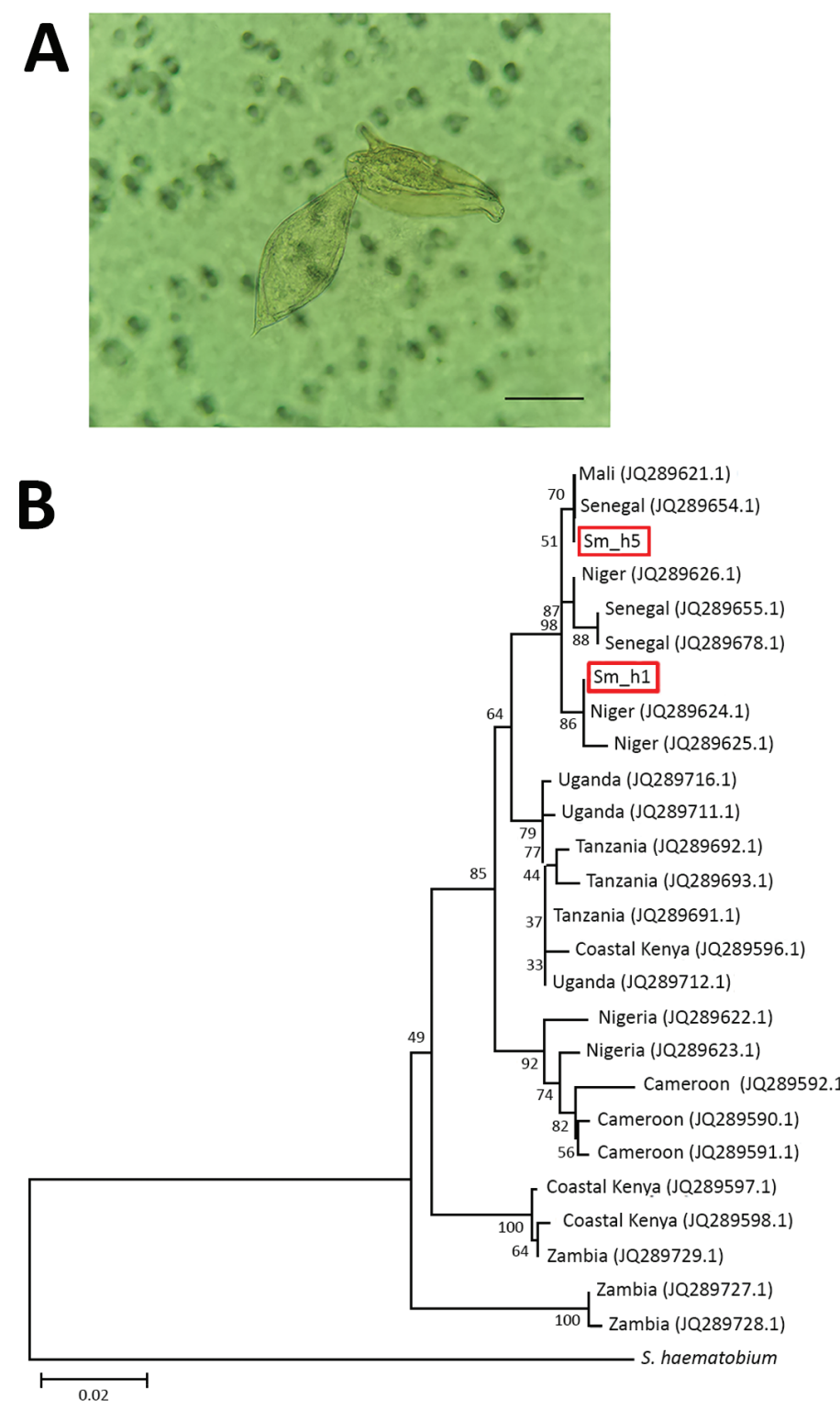

Figure. Characterization of Schistosoma parasites detected in 14-year-old migrant boy from Côte d'Ivoire in France, 2017.

A) Co-detection of terminalspined schistosome eggs (typical of Schistosoma haematobium parasites) and lateral-spined schistosome eggs (typical of Schistosoma mansoni parasites) in urine sample from migrant boy. Sample was microscopically examined after filtration. Original magnification $\times 400$. Scale bar represents $50 \mu \mathrm{m}$. B) Phylogenetic analysis of $S$. mansoni cox 1 gene haplotypes present in migrant boy (boxes). Tree was constructed by using the neighbor-joining method,

Far West Africa the Hasegawa-Kishino-Yano plus gamma distribution model, and 1,000 bootstrap replicates. GenBank accession numbers of haplotypes sampled are provided. Scale bar indicates nucleotide substitutions per residue.
East Africa

Central Africa

Central Africa

East Africa never traveled through Senegal strongly suggests that such hybrids are more widespread than previously observed.

Hybrid schistosomes are particularly worrisome. The outbreak in Corsica Island involved infections with $S$. haematobium-Schistosoma bovis hybrid parasites $(1,6)$, which might be more difficult to diagnose (7). Experimental studies have revealed that interspecific hybridization might enhance infectivity, virulence, and longevity and accelerate cercarial maturation. Also, hybrids can have wider host spectrums, potentially expanding their epidemiologic consequences (8).

The risk for emergence of $S$. mansoni schistosome infection might exist in Europe; the Biomphalaria snail vector (namely B. tenagophila) has been detected for several years in Romania (9). Given the nonnegligible prevalence of mansonic schistosomiasis in travelers and migrants entering Europe $(3,10)$ and global warming, the probability of encounters between $S$. mansoni miracidia and their snail hosts might have increased. Moreover, whether $S$. mansoni-S. haematobium hybrid parasites are capable of infecting the Bulinus snail vector of the S. haematobium schistosome, which is widely distributed throughout Europe (France, Spain, Italy, Greece, Portugal) (11), remains unknown and deserves further investigation.

\section{About the Author}

Dr. Le Govic is a clinical biologist and researcher in Angers University Hospital Center, University of Angers, Angers, France. His primary research interests include emerging fungal and parasitic infections, with a special emphasis on epidemiology, pathophysiology, and diagnosis. 


\section{References}

1. Boissier J, Grech-Angelini S, Webster BL, Allienne JF, Huyse T, Mas-Coma S, et al. Outbreak of urogenital schistosomiasis in Corsica (France): an epidemiological case study. Lancet Infect Dis. 2016;16:971-9. http://dx.doi.org/10.1016/ S1473-3099(16)00175-4

2. Schlagenhauf P, Weld L, Goorhuis A, Gautret P, Weber R, von Sonnenburg F, et al.; EuroTravNet. Travel-associated infection presenting in Europe (2008-12): an analysis of EuroTravNet longitudinal, surveillance data, and evaluation of the effect of the pre-travel consultation. Lancet Infect Dis. 2015; 15:55-64. http://dx.doi.org/10.1016/S1473-3099(14)71000-X

3. Beltrame A, Buonfrate D, Gobbi F, Angheben A, Marchese V, Monteiro GB, et al. The hidden epidemic of schistosomiasis in recent African immigrants and asylum seekers to Italy. Eur J Epidemiol. 2017;32:733-5. http://dx.doi.org/10.1007/ s10654-017-0259-6

4. Meurs L, Mbow M, Vereecken K, Menten J, Mboup S, Polman K. Epidemiology of mixed Schistosoma mansoni and Schistosoma haematobium infections in northern Senegal. Int J Parasitol. 2012;42:305-11. http://dx.doi.org/10.1016/j.ijpara.2012.02.002

5. Huyse T, Van den Broeck F, Hellemans B, Volckaert FA, Polman K. Hybridisation between the two major African schistosome species of humans. Int J Parasitol. 2013;43:687-9. http://dx.doi.org/10.1016/j.ijpara.2013.04.001

6. Moné H, Holtfreter MC, Allienne JF, Mintsa-Nguéma R, Ibikounlé M, Boissier J, et al. Introgressive hybridizations of Schistosoma haematobium by Schistosoma bovis at the origin of the first case report of schistosomiasis in Corsica (France, Europe). Parasitol Res. 2015;114:4127-33. http://dx.doi.org/10.1007/ s00436-015-4643-4

7. Moné H, Holtfreter MC, Mouahid G, Richter J. Difficulties in schistosomiasis assessment, Corsica, France. Emerg Infect Dis. 2016;22:762-3. http://dx.doi.org/10.3201/eid2204.160110

8. Webster BL, Southgate VR. Compatibility of Schistosoma haematobium, S. intercalatum and their hybrids with Bulinus truncatus and B. forskalii. Parasitology. 2003;127:231-42. http://dx.doi.org/10.1017/S0031182003003597

9. Majoros G, Fehér Z, Deli T, Földvári G. Establishment of Biomphalaria tenagophila snails in Europe. Emerg Infect Dis. 2008;14:1812-4. http://dx.doi.org/10.3201/eid1411.080479

10. Lingscheid T, Kurth F, Clerinx J, Marocco S, Trevino B, Schunk M, et al.; TropNet Schistosomiasis Investigator Group. Schistosomiasis in European travelers and migrants: analysis of 14 years TropNet surveillance data. Am J Trop Med Hyg. 2017;97:567-74. http://dx.doi.org/10.4269/ajtmh.17-0034

11. Welter-Schultes F. European non-marine molluscs, a guide for species identification. Gottingen, Germany: Planet Poster Editions; 2012.

Address for correspondence: Jérôme Boissier, CNRS, UMR 5244, 52 Avenue Paul Alduy, Perpignan 66000, France; email: boissier@univ-perp.fr

\section{West Nile Virus I nfection in Travelers Returning to United Kingdom from South Africa}

\author{
Vivak Parkash, Kate Woods, \\ Liana Kafetzopoulou, Jane Osborne, \\ Emma Aarons, Katharine Cartwright
}

Author affiliations: Royal Hallamshire Hospital, Sheffield, UK (V. Parkash, K. Cartwright); Public Health England, Porton Down, UK (K. Woods, L. Kafetzopoulou, J. Osborne, E. Aarons)

DOI: https://doi.org/10.3201/eid2502.172101

West Nile virus (WNV) is an arthropod-transmitted flavivirus that causes West Nile fever and may infrequently cause neuroinvasive disease in humans. We present 2 cases of confirmed WNV infection, 1 of severe encephalitis and 1 of mild febrile illness, in a couple returning to the United Kingdom from South Africa.

W est Nile virus (WNV) is a mosquitoborne flavivirus maintained in an enzootic cycle between culicine mosquitoes and birds. Approximately $80 \%$ of human infections are subclinical, although symptomatic cases can vary from influenza-like symptoms to neurotropic manifestations (1). West Nile neuroinvasive disease, which manifests as encephalitis, meningitis, or acute flaccid paralysis, occurs in $<1 \%$ of all cases ( 2 ).

To date, human disease caused by WNV has been attributed to WNV phylogenetic lineages 1 and 2 (3). Lineage 2 consists of viruses found in South Africa, Madagascar, and, more recently, in Europe and Russia (4). Lineage 2 was previously described as less pathogenic than lineage 1 , but it has subsequently been demonstrated that lineage 2 can also lead to neuroinvasive disease (5). We describe a couple from the United Kingdom with confirmed WNV infection who were admitted to a hospital in February 2017 on return from a holiday to South Africa, where they most likely acquired WNV in the Kruger National Park region.

A previously healthy 76-year-old woman was admitted with acute confusion to Doncaster Royal Infirmary, Doncaster, UK. She and her husband had returned that day following a 3-week holiday visiting family in South Africa (Appendix Figure, http://wwwnc.cdc.gov/EID/article/25/2/172101-App1.pdf). The patient and her husband had stayed in Johannesburg, except for a 5-day safari in Kruger National Park 5 days into their trip. They had both sustained several mosquito and tick bites. No malaria prophylaxis had been taken, and no pretravel advice had been sought.

The patient boarded an airplane independently in Johannesburg but her condition deteriorated in flight; on arrival, 
Table. Diagnostic investigations for the index case of West Nile virus infection in a woman from the United Kingdom who traveled to South Africa*

\begin{tabular}{|c|c|c|c|}
\hline Test & Result & Reference range & Day of testing $\dagger$ \\
\hline \multicolumn{4}{|l|}{ Blood tests } \\
\hline White cell count & $12.2 \times 10^{9} \mathrm{cells} / \mathrm{L}$ & $3.5-9.5 \times 10^{9} / \mathrm{L}$ & 1 \\
\hline C-reactive protein & $81 \mathrm{mg} / \mathrm{L}$ & $0-5 \mathrm{mg} / \mathrm{L}$ & 1 \\
\hline Creatine kinase & $593 \mathrm{U} / \mathrm{L}$ & $25-200 \mathrm{U} / \mathrm{L}$ & 1 \\
\hline Glucose & $7 \mathrm{mmol} / \mathrm{L}$ & 3-6 mmol/L & 1 \\
\hline \multicolumn{4}{|l|}{ Liver function tests } \\
\hline Alkaline phosphatase & $60 \mathrm{IU} / \mathrm{L}$ & $30-130 \mathrm{IU} / \mathrm{L}$ & 3 \\
\hline Aspartate aminotransferase & $33 \mathrm{IU} / \mathrm{L}$ & 0-32 IU/L & 3 \\
\hline Gamma glutamyl transferase & $78 \mathrm{IU} / \mathrm{L}$ & 0-40 IU/L & 3 \\
\hline Gamma glutamyl transferase & $155 \mathrm{IU} / \mathrm{L}$ & 0-40 IU/L & 11 \\
\hline Alanine aminotransferase & $35 \mathrm{IU} / \mathrm{L}$ & 0-33 IU/L & 3 \\
\hline Alanine aminotransferase & 37 IU/L & 0-33 IU/L & 6 \\
\hline \multicolumn{4}{|l|}{ Malaria testing } \\
\hline Rapid antigen detection $\ddagger$ & Negative & & 1 \\
\hline Thick/thin blood films & Negative & & $1,2,3$ \\
\hline \multicolumn{4}{|l|}{ Lumbar puncture } \\
\hline Visual appearances & Clear, colorless CSF & & 2 \\
\hline Opening pressure & $22 \mathrm{~cm} \mathrm{H}{ }_{2} \mathrm{O}$ & $5-18 \mathrm{~cm} \mathrm{H}_{2} \mathrm{O}$ & 2 \\
\hline Leukocyte count & $102 \times 10^{6} \mathrm{cells} / \mathrm{L}$ & $\leq 5 \times 10^{6} \mathrm{cells} / \mathrm{L}$ & 2 \\
\hline Leukocyte differential & $\begin{array}{l}80 \% \text { polymorphonuclear cells; } \\
20 \% \text { lymphocytes }\end{array}$ & & \\
\hline CSF protein & $1.24 \mathrm{~g} / \mathrm{L}$ & $0.15-0.45 \mathrm{~g} / \mathrm{L}$ & 2 \\
\hline CSF glucose & $3 \mathrm{mmol} / \mathrm{L}$ & $3.3-4.4 \mathrm{mmol} / \mathrm{L}$ & 2 \\
\hline \multicolumn{4}{|l|}{ CSF molecular assays } \\
\hline Herpes simplex virus DNA & Not detected & & 2 \\
\hline Varicella zoster virus DNA & Not detected & & 2 \\
\hline Enterovirus RNA & Not detected & & 2 \\
\hline Meningococcus DNA & Not detected & & 2 \\
\hline Pneumococcus DNA & Not detected & & 2 \\
\hline Listeria DNA & Not detected & & 2 \\
\hline \multicolumn{4}{|l|}{ Serology and blood cultures } \\
\hline Blood cultures & No growth after $5 \mathrm{~d}$ & & $1,3,5$ \\
\hline HIV screen & Negative & & 3 \\
\hline Syphilis screen & Negative & & 3 \\
\hline \multicolumn{4}{|l|}{ Imaging and EEG } \\
\hline Chest radiograph & Unremarkable & & 1 \\
\hline Contrast MRI of the brain & $\begin{array}{l}\text { No leptomeningeal } \\
\text { enhancement; established } \\
\text { right cerebellar infarct }\end{array}$ & & 5 \\
\hline EEG & $\begin{array}{l}\text { Rhythmic irregular delta slow- } \\
\text { wave activity (suggestive of } \\
\text { encephalopathy) }\end{array}$ & & 11 \\
\hline $\begin{array}{l}\text { cerebrospinal fluid; EEG, elec } \\
\text { hospital admission. } \\
\text { modium lactate dehydrogenas }\end{array}$ & $\begin{array}{l}\text { IRI, magnetic resonance imagir } \\
\text { AL-IT, Bio-Rad, http://www.bio-r }\end{array}$ & & \\
\hline
\end{tabular}

she was transferred directly to the hospital. She was febrile, hypotensive, and agitated, with a Glasgow Coma Score fluctuating between 7 and 14, and had intermittent vacant episodes (Table). She was empirically treated for meningoencephalitis with intravenous cefotaxime, amoxicillin, and aciclovir. Because of her travel history, intravenous artesunate was added for possible malaria and doxycycline for possible rickettsial infections. On the second day of admission, the patient was transferred to the Department of Infection and Tropical Medicine (Sheffield, UK).

After discussion with the Imported Fever Service, we sent blood, cerebrospinal fluid (CSF), and urine samples to the Public Health England Rare and Imported Pathogens Laboratory (RIPL) for testing (Appendix Figure). By ELISA, serum was strongly positive for WNV IgM but negative for IgG. WNV RNA was detected in urine by reverse transcription PCR (RT-PCR), confirming the diagnosis. CSF test results were abnormal (Table) but negative for both WNV RNA and IgM. Follow-up serum specimens taken 2 weeks later demonstrated seroconversion of WNV IgG (ELISA). Subsequent whole-genome sequencing of virus detected in the urine sample demonstrated that it belonged to WNV lineage 2.

Empirical antimicrobial drug treatment was stopped, and the patient's Glasgow Coma Score improved to 14, with residual mild cognitive impairment, ongoing balance disorder, and improving myalgia. Inflammatory markers and all other blood parameters normalized before discharge 5 weeks later. At follow-up 12 weeks after presentation, the patient's cognition had 
improved, but she still required use of a cane for persistent balance disturbance.

One day after the index patient's admission, her 72-year-old husband was admitted with an influenza-like illness. He had stage 3 chronic kidney disease but no other concurrent conditions. Urine and serum samples were obtained, and test results confirmed that he, too, had had a recent WNV infection. WNV IgM and IgG were positive in serum 5 days after symptom onset; WNV RT-PCR on urine was negative. He had no neurologic component to his illness and made a rapid clinical recovery.

WNV was initially isolated from a febrile patient in Uganda in 1937 (6). The virus was not correlated with severe human disease until the 1990s, when outbreaks in Europe were associated with higher rates of West Nile neuroinvasive disease (7). WNV is sporadically reported from South Africa (8). Imported cases to the United Kingdom are rare, and autochthonous infections have yet to be reported. One other RT-PCR-confirmed case of acute WNV infection has been reported in a traveler returning to the United Kingdom since 2012; 7 other clinically suspected cases have shown compatible WNV serologic test results (Public Health England, unpub. data).

Clinicians should bear in mind the value of urine sampling to detect WNV RNA by RT-PCR in addition to serologic testing. WNV is excreted in high concentrations in urine and may be detected for several weeks postinfection, whereas detectable virus in serum and CSF is transient and generally not present by the time of symptom onset (9). Detection of WNV IgM in CSF is used to confirm neuroinvasive disease. WNV IgG appears shortly after IgM but remains positive in the long term and is therefore not a useful marker of recent infection unless seroconversion is demonstrated.

Clinicians should be alert to the possibility of arthropodborne infections in travelers returning from South Africa. These include WNV, African tick-bite fever, chikungunya, and Plasmodium falciparum malaria. In addition, an outbreak of arboviral infections, particularly Sindbis virus, had been reported in the Johannesburg area coinciding with the travel dates of the patients we report (10).

\section{Acknowledgments}

We acknowledge the Emerging Zoonotic Infections team at Colindale and Lucille Blumberg and the travel health team at the National Institute for Communicable Diseases, South Africa, for their liaison on the public health aspects of these cases. We also extend our gratitude to Gillian Slack for her work on the molecular diagnosis of the index case and to Joyeeta Palit, who was involved in the clinical care of both patients.

\section{About the Author}

Dr. Parkash is a general internal medicine and infectious diseases clinician at Sheffield Teaching Hospitals NHS Foundation Trust, United Kingdom. His research interests include leishmaniasis and imported tropical infectious diseases.

\section{References}

1. Suthar MS, Diamond MS, Gale M Jr. West Nile virus infection and immunity. Nat Rev Microbiol. 2013;11:115-28. http://dx.doi.org/ 10.1038/nrmicro2950

2. Hart J Jr, Tillman G, Kraut MA, Chiang HS, Strain JF, Li Y, et al.; NIAID Collaborative Antiviral Study Group West Nile Virus 210 Protocol Team. West Nile virus neuroinvasive disease: neurological manifestations and prospective longitudinal outcomes. BMC Infect Dis. 2014;14:248. http://dx.doi.org/10.1186/ 1471-2334-14-248

3. David S, Abraham AM. Epidemiological and clinical aspects on West Nile virus, a globally emerging pathogen. Infect Dis (Lond). 2016;48:571-86. http://dx.doi.org/10.3109/23744235.201 6.1164890

4. May FJ, Davis CT, Tesh RB, Barrett ADT. Phylogeography of West Nile virus: from the cradle of evolution in Africa to Eurasia, Australia, and the Americas. J Virol. 2011;85:2964-74. http://dx.doi.org/10.1128/JVI.01963-10

5. Botha EM, Markotter W, Wolfaardt M, Paweska JT, Swanepoel R, Palacios G, et al. Genetic determinants of virulence in pathogenic lineage 2 West Nile virus strains. Emerg Infect Dis. 2008; 14:222-30. http://dx.doi.org/10.3201/eid1402.070457

6. Smithburn KC, Hughes TP, Burke AW, Paul JH. A neurotropic virus isolated from the blood of a native of Uganda. Am J Trop Med. 1940;20:471-2.

7. Eberhard ML, da Silva AJ, Lilley BG, Pieniazek NJ. Morphologic and molecular characterization of new Cyclospora species from Ethiopian monkeys: C. cercopitheci sp.n., C. colobi sp.n., and C. papionis sp.n. Emerg Infect Dis. 1999;5:651-8. http://dx.doi.org/10.3201/eid0505.990506

8. Hernández-Triana LM, Jeffries CL, Mansfield KL, Carnell G, Fooks AR, Johnson N. Emergence of West Nile virus lineage 2 in Europe: a review on the introduction and spread of a mosquito-borne disease. Front Public Health. 2014;2:271. http://dx.doi.org/10.3389/fpubh.2014.00271

9. Barzon L, Pacenti M, Franchin E, Squarzon L, Sinigaglia A, Ulbert S, et al. Isolation of West Nile virus from urine samples of patients with acute infection. J Clin Microbiol. 2014;52:3411-3. http://dx.doi.org/10.1128/JCM.01328-14

10. ProMED-mail. Arbovirus clusters-South Africa: West Nile, Sindbis, alert. 2017 Feb 24 [cited 2017 May 15]. http://promedmail.org, archive no. 20170224.4861086.

Address for correspondence: Vivak Parkash, Royal Hallamshire Hospital, Department of Infection and Tropical Medicine, Glossop

Road, Sheffield S10 2JF, UK; email: vivak.parkash@sth.nhs.uk 


\section{East/ Central/ South African Genotype in a Chikungunya Outbreak, Dhaka, Bangladesh, 2017}

\section{Mizanur Rahman, Junya Yamagishi, Rummana Rahim, Abu Hasan, Abu Sobhan}

Author affiliation: Apollo Hospitals Dhaka, Dhaka, Bangladesh

(M. Rahman, R. Rahim, A. Hasan, A. Sobhan); Hokkaido

University, Sapporo, Japan (J. Yamagishi)

DOI: https://doi.org/10.3201/eid2502.180188

In 2017, an unprecedented increase in febrile illness was observed in Dhaka, Bangladesh. Real-time reverse transcription PCR confirmed that $603(40.2 \%)$ of 1,500 cases were chikungunya fever. Phylogenetic analysis revealed circulation of the non-A226V East/Central/South African genotype of chikungunya virus in Bangladesh.

C hikungunya fever is a mosquito-transmitted viral disease caused by chikungunya virus (CHIKV; genus $\mathrm{Al}-$ phavirus, Togaviridae). Since first isolation from a febrile patient in Tanzania in 1952, CHIKV has been responsible for numerous well-documented outbreaks and epidemics in Africa and Southeast Asia, involving hundreds of thousands of cases (1).

CHIKV strains are clustered into 3 separable genotypes: West African, East/Central/South African (ECSA), and Asian. During 1960-1999, outbreaks in Thailand, Cambodia, Vietnam, Myanmar, the Philippines, Malaysia, Indonesia, Pakistan, and India were caused by strains of the Asian genotype (1). However, since 2005, massive epidemics in the Indian Ocean islands and the worldwide increase in travel have altered circulating genotypic distribution of CHIKV. Studies have shown that different lineages of CHIKV epidemic strains of the ECSA genotype have expanded locally and spread to new areas in Africa, Europe, Asia, and the Americas, in addition to Africa and Asia $(2,3)$. Dengue virus (DENV) is another important arbovirus, spread by the bite of the same group of mosquitoes, Aedes aegypti and Ae. Albopictus, that transmit CHIKV. DENV and CHIKV are often found co-circulating during outbreaks and have an overlapping clinical presentation; thus, misdiagnosis and underreporting of chikungunya infection in dengue-endemic areas is common (4).

In Bangladesh, dengue fever was reported in the mid1960s and dengue hemorrhagic fever in 2000; both diseases are now endemic to Bangladesh (5). In contrast, CHIKV infection in Bangladesh was serologically confirmed for the first time in 2008 (6). Thereafter, sporadic cases of chikungunya have been reported (7); however, in 2017, chikungunya emerged as an important public health issue (8).

Most patients seek healthcare during the acute, febrile phase of the disease, when IgG and IgM titers are typically below the level of detection limits of serologic diagnostic approaches. Therefore, molecular methodologies to detect viral RNA are highly advantageous to detect and differentiate between co-circulating arboviruses and thus facilitate rapid diagnosis and appropriate treatment.

During June 29-October 31, 2017, a total of 1,500 patients visited Apollo Hospitals Dhaka (Dhaka, Bangladesh) with acute onset of fever (days 1-7 from onset), myalgia, arthralgia, and headache; some patients experienced a maculopapular rash, gastrointestinal symptoms, or both. We collected serum samples from these patients for routine serologic testing and for molecular detection of CHIKV and DENV by real-time reverse transcription PCR (rRT-PCR). We extracted RNA from serum by using QIAamp MinElute Virus Spin Kit (QIAGEN, https://www.qiagen.com) according to the manufacturer's instructions. We used purified RNA in a 1-step multiplex rRT-PCR test for the simultaneous detection and differentiation of CHIKV and DENV (Fast Track Diagnostics, http://www.fast-trackdiagnostics.com) on the Rotor Gene Q platform (QIAGEN). Among the 1,500 acute-phase serum samples, rRT-PCR confirmed $603(40.2 \%)$ as CHIKV positive, 233 (15.73\%) as DENV positive, and $10(0.66 \%)$ as CHIKV and DENV positive (Appendix Table, https://wwwnc. cdc.gov/EID/article/25/2/18-0188-App1.pdf).

Because of heightened public awareness and government efforts taken to control mosquitoes, the chikungunya cases gradually decreased (Appendix Figure). We then set out to determine the genotype causing the massive CHIKV outbreak.

By using stored RNA, serum samples, or both from deidentified samples, we performed a 1-step rRT-PCR with the SuperScript III 1-step rRT-PCR system with platinum Taq DNA polymerase (ThermoFisher, https://www.thermofisher.com) and a published oligonucleotide primer set (20F and 20R) targeting the E1 gene (9). We randomly selected high-titer viral RNA samples from 32 rRT-PCR-positive samples with a cycle threshold $<30$. We verified PCR products of correct molecular weight by gel electrophoresis and directly sequenced 4 randomly selected amplicons by using Sanger method. We submitted these sequences to DDBJ (accession nos. LC364266-LC364269).

In parallel, we added custom index adaptors with a second rRT-PCR test and sequenced them by using MinION sequencer with the R9.5 flowcell (FLO-107) and 1D2 sequencing kit (LSQ-308) (Nanopore Technologies, https://nanoporetech.com), following the manufacturer's protocol. We determined the consensus sequences of the E1 gene for $27 \mathrm{CHIKV}$ samples with enough reads by using the Canu assembler, even though a couple of inconsistencies were noted between the Sanger and MinION sequences, 


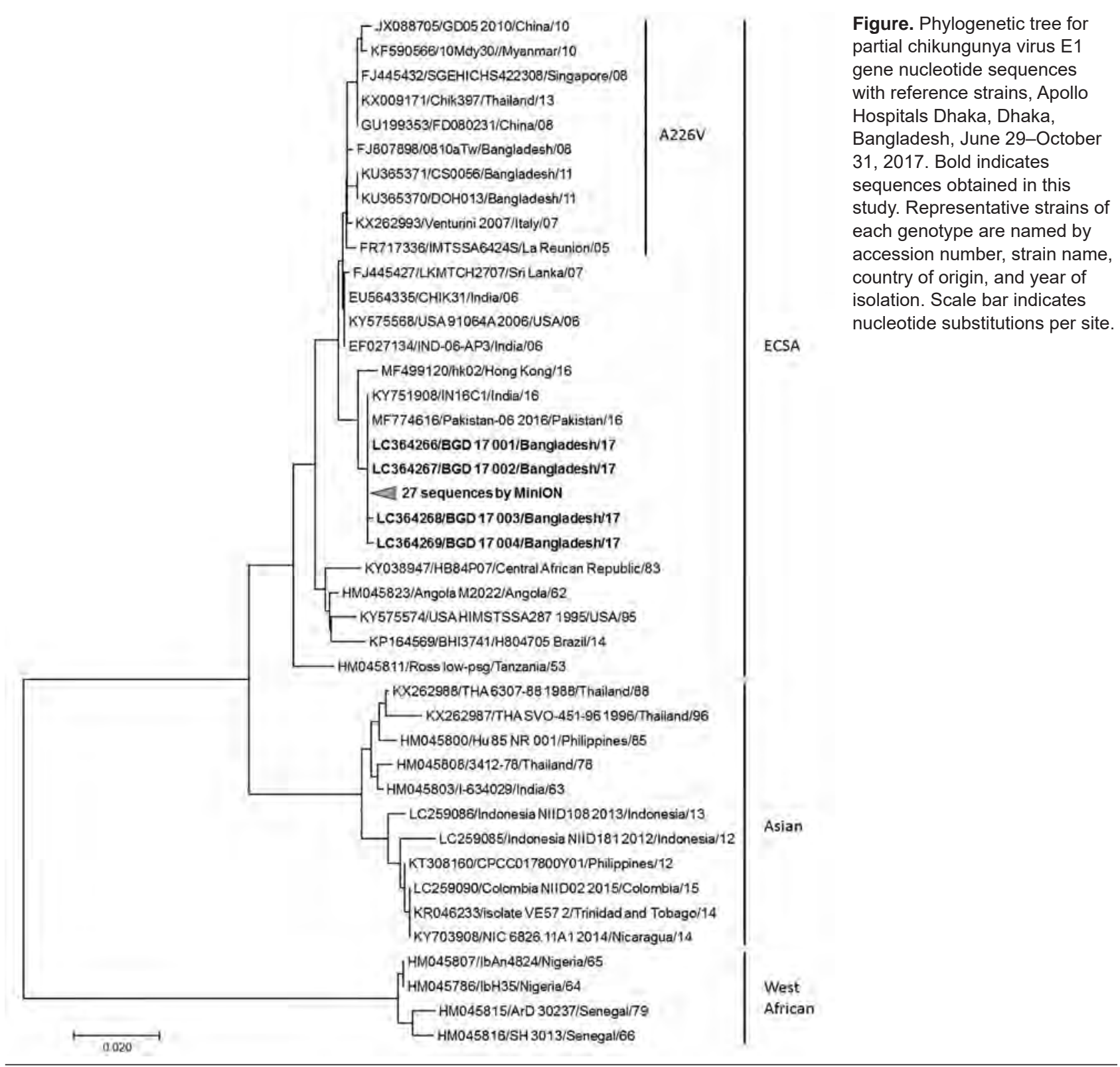

which probably were attributable to the lower sequencing accuracy of the MinION sequencer. We aligned the sequences obtained with the reference strains available from GenBank and constructed a phylogenetic tree (Figure) by using MEGA7 (https://www.megasoftware.net).

The results suggested that all the CHIKV E1 sequences obtained from Bangladesh patients in 2017 belonged to the ECSA genotype and did not harbor the A226V mutation, which is different from the previously reported CHIKV strain detected in Bangladesh in 2008 (10) and 2011 and more genetically related to the lineage circulating endemically in India and Pakistan in 2016. An extensive genome analysis of recent strains of CHIKV along with research on environmental factors is necessary to better understand the factors underlying the recent outbreak to inform efforts to mitigate potential outbreaks in the future.

\section{Acknowledgment}

We thank Junya Yamagishi for his support in sequencing.

This study was approved by the research and ethics committee of Apollo Hospitals Dhaka (ERC 16/2017-1).

\section{About the Author}

Dr. Rahman is a senior consultant at Molecular Diagnostics of Apollo Hospitals Dhaka, Bangladesh. His field of interest was cytokine research, and his current research interest is molecular characterization of arboviruses in Bangladesh. 


\section{References}

1. Powers $\mathrm{AM}$, Logue $\mathrm{CH}$. Changing patterns of chikungunya virus: re-emergence of a zoonotic arbovirus. J Gen Virol. 2007;88:236377. http://dx.doi.org/10.1099/vir.0.82858-0

2. Schuffenecker I, Iteman I, Michault A, Murri S, Frangeul L, Vaney MC, et al. Genome microevolution of chikungunya viruses causing the Indian Ocean outbreak. PLoS Med. 2006;3:e263. http://dx.doi.org/10.1371/journal.pmed.0030263

3. Leparc-Goffart I, Nougairede A, Cassadou S, Prat C, de Lamballerie X. Chikungunya in the Americas. Lancet. 2014; 383:514. http://dx.doi.org/10.1016/S0140-6736(14)60185-9

4. Chahar HS, Bharaj P, Dar L, Guleria R, Kabra SK, Broor S. Co-infections with chikungunya virus and dengue virus in Delhi, India. Emerg Infect Dis. 2009;15:1077-80. http://dx.doi.org/ 10.3201/eid1507.080638

5. icddr,b. Seroprevalence of dengue virus infection in Dhaka, Bangladesh, 2012. Health Sci Bull. 2014;2:1-6.

6. icddr,b. First identified outbreak of chikungunya in Bangladesh, 2008. Health Sci Bull. 2009;7:1-6.

7. Khatun S, Chakraborty A, Rahman M, Nasreen Banu N, Rahman MM, Hasan SMM, et al. An outbreak of chikungunya in rural Bangladesh, 2011. PLoS Negl Trop Dis. 2015;9:e0003907. http://dx.doi.org/10.1371/journal.pntd.0003907

8. Kabir I, Dhimal M, Müller R, Banik S, Haque U. The 2017 Dhaka chikungunya outbreak. Lancet Infect Dis. 2017;17:1118. http://dx.doi.org/10.1016/S1473-3099(17)30564-9

9. Sam IC, Loong SK, Michael JC, Chua CL, Wan Sulaiman WY, Vythilingam I, et al. Genotypic and phenotypic characterization of chikungunya virus of different genotypes from Malaysia. PLoS One. 2012;7:e50476. http://dx.doi.org/10.1371/journal.pone.0050476

10. Huang JH, Yang CF, Su CL, Chang SF, Cheng CH, Yu SK, et al. Imported chikungunya virus strains, Taiwan, 2006-2009. Emerg Infect Dis. 2009;15:1854-6. http://dx.doi.org/10.3201/eid1511.090398

Address for correspondence: Mizanur Rahman, Molecular Diagnostics, Apollo Hospitals Dhaka, Plot-81, Block-E, Bashundhara, Dhaka-1229, Bangladesh; email: mizanur.rahman@apollodhaka.com

\section{Dolphin Morbillivirus in Eurasian Otters, I taly}

\section{Iolanda Padalino, Giovanni Di Guardo, Antonio Carbone, Pasquale Troiano, Antonio Parisi, Domenico Galante, Maria Assunta Cafiero, Marta Caruso, Lucia Palazzo, Laura Guarino, Laura De Riso, Cinzia Centelleghe, Sandro Mazzariol, Antonio Petrella}

DOI: https://doi.org/10.3201/eid2502.180256

Author affiliations: Istituto Zooprofilattico Sperimentale della Puglia e della Basilicata, Foggia, Italy (I. Padalino, A. Carbone,

P. Troiano, A. Parisi, D. Galante, M.A. Cafiero, A. Petrella);
University of Teramo, Teramo, Italy (G. Di Guardo); Istituto Zooprofilattico Sperimentale della Puglia e della Basilicata, Matera, Italy (M. Caruso); Istituto Zooprofilattico Sperimentale della Puglia e della Basilicata, Potenza, Italy (L. Palazzo); Istituto Zooprofilattico Sperimentale della Puglia e della Basilicata, Taranto, Italy (L. Guarino); Ente Parco Nazionale del Cilento, Salerno, Italy (L. De Riso); University of Padua, Padua, Italy (C. Centelleghe, S. Mazzariol)

We report biomolecular evidence of dolphin morbillivirus in 4 wild Eurasian otters (Lutra lutra) from southern Italy; 2 animals showed simultaneous immunohistochemical reactivity against morbilliviral antigen. These cases add further concern and support to the progressively expanding host range of dolphin morbillivirus in the western Mediterranean Sea.

$\mathrm{T}$ he genus Morbillivirus comprises several lympho-epithelio-neurotropic, highly pathogenic RNA viruses of domestic and wild vertebrates, including aquatic mammals. Among them, cetacean morbillivirus (CeMV) has been responsible since the 1980s for dramatic epidemics in freeranging cetaceans worldwide (1). Specifically, the CeMV strain termed dolphin morbillivirus (DMV) has caused at least 4 unusual mortality events (UMEs) among striped dolphins (Stenella coeruleoalba) in the western Mediterranean Sea and, to a lesser extent, long-finned pilot whales (Globicephala melas) and other wild cetaceans from the same region (1-3).

We report evidence of DMV infection in 4 wild Eurasian otters (Lutra lutra) from southern Italy (Apulia and Basilicata regions). The animals, all adult females, belonged to a group of 7 individuals found dead at Parco Nazionale del Cilento, a large national park that extends to the coastline of southwestern Italy. The animals underwent necropsy at Istituto Zooprofilattico Sperimentale della Puglia e della Basilicata (Foggia, Italy) during 2016 and 2017, according to an official agreement between the institute and the park aimed at assessing the health and conservation status of the otter population.

Within a multidisciplinary approach framework, we conducted in-depth histopathologic, microbiologic, parasitologic, and ecotoxicologic analyses on the 7 otters, along with biomolecular (reverse transcription PCR [RTPCR]) and immunohistochemical (IHC) investigations for Morbillivirus spp. After using a technique amplifying a highly conserved fragment of the Morbillivirus nucleoprotein (NP) gene (4), we applied 2 additional methods aimed at detecting DMV-specific hemagglutinin (HA) (5) and NP gene sequences (6) for more detailed analysis. To increase the biomolecular results' reliability, we performed all the extraction, amplification, and sequencing steps in 3 different laboratories. We also conducted the histopathological and IHC analyses in 3 different 
Figure. Evidence of dolphin morbillivirus infection in Eurasian otters (Lutra lutra), southwestern Italy. A) Comparison of nucleoprotein gene amplification products from infected otters, obtained by reverse transcription PCR. A specific band at the expected molecular weight of $287 \mathrm{bp}$ is shown. Lane 1, molecular weight marker (Tracklt 100bp DNA Ladder; Invitrogen, http://www.thermofisher.com); lane 2, positive control (lung tissue from an infected striped
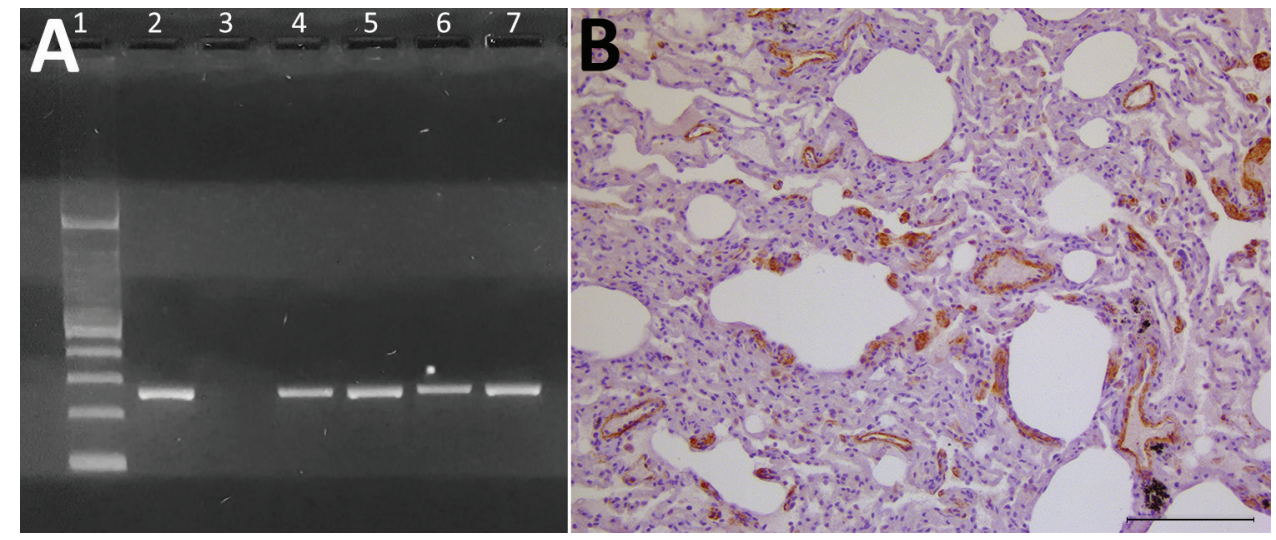
dolphin, Stenella coeruleoalba); lane 3, negative control (distilled water); lanes 4-7, samples from morbillivirus-positive Eurasian otters: LL-290, lung (lane 4); LL-291, kidney (lane 5); LL-3380, lung (lane 6); LL-7318, lung (lane 7). B) Mayer's hematoxylin counterstain of lung tissue shows marked and widespread immunohistochemical labeling for morbillivirus antigen (dark areas), particularly evident at the level of vascular walls and endothelial cells and, to a lesser extent, of alveolar epithelial cells (morphologically consistent, or not, with hyperplastic type II pneumocytes) as well as of thickened alveolar septa. Scale bar indicates $100 \mu \mathrm{m}$.

laboratories. For IHC analysis, we used a commercial monoclonal antibody (VMRD, https://www.vmrd.com) against the NP antigen of canine distemper virus (CDV), including adequate morbillivirus-positive and -negative control tissues in each run.

At necropsy, we found multiple traumatic injuries, probably caused by motor vehicles and deemed the putative cause of death, in all 7 otters. Microscopically, we observed a bilateral, subacute-to-chronic, broncho- or bronchiolo-interstitial pneumonia, showing endobronchial, endobronchiolar, or endoalveolar macrophage infiltration, thickening of alveolar septa, and lympho-histiocytic septal infiltration, in 2 otters; 1 also showed a multifocal, portal and lobular, nonsuppurative hepatitis. Lungs and kidneys from these 2 animals were molecularly positive for DMV (Figure, panel A). Their pulmonary tissue showed positive morbilliviral antigen immunostaining in vascular walls and endothelial cells, as well as in alveolar epithelial cells (consistent, or not, with hyperplastic type II pneumocytes); we also found positive immunostaining in thickened alveolar septa and endoalveolar macrophages (Figure, panel B). Although the advanced postmortem autolysis did not enable us to obtain reliable histopathological information from the 5 remaining otters, biomolecular analyses yielded positive results from several tissues (submandibular lymph node, parotidal gland, lung, brain, heart, kidney, urinary bladder, and liver) in 2 of them (Figure, panel A).

Sequencing of all the 200-bp NP gene viral amplicons obtained (GenBank accession nos. MG836265-8) showed remarkable differences from the available CDV sequences but high homology (99\%) with 2 DMV sequences (GenBank accession nos. EF469546.1, KU720625.1). We compared an additional 456-bp HA gene fragment (GenBank provisional accession no. MG905831), obtained from the kidney of 1 of the otters we tested, with $2 \mathrm{DMV}$ isolates recovered from Mediterranean striped dolphins in 2007; this fragment displayed $100 \%$ homology with $1 \mathrm{DMV}$ isolate (GenBank accession no. HQ829973) and 99.56\% homology with the other (accession no. AJ608288).

Susceptibility to morbilliviruses is not new to L. lutra otters; CDV infection has been documented, with subsequent risk for viral spillover to coastal pinnipeds (7). In this respect, the endemic behavior and the progressively expanding host range of DMV in the western Mediterranean Sea are a matter of concern $(2,3,8)$, as exemplified by a peculiar case of infection in a captive harbor seal (Phoca vitulina), a species with a mixed marine-terrestrial ecology (9).

How the otters in this study may have acquired DMV infection is unknown. Of note, 8 cases of DMV infection were detected during 2016 and 2017 in dolphins stranded along the Ionian Sea coast, in an area geographically consistent with that in which the $4 \mathrm{DMV}$-infected otters were found. It is possible that $\geq 1$ dolphins with DMVassociated brain lesions could have entered the rivers or lagoons inhabited by the otters and transmitted the virus to them. Alternatively, the otters' movement toward and placement close to the sea, clearly documented for 1 of them (A. Petrella, unpub. data), could underlie a subsequent encounter with DMV-infected dolphins. As an additional or complementary option, susceptible invertebrate hosts might have acted as DMV reservoirs, similarly to what has been reported for Baicalia carinata and Limnaea auricularia mollusks, which probably were a source of infection during the CDV epidemic among Baikal seals (Pusa sibirica) in 1987 (10).

In conclusion, we identified DMV infection among Eurasian otters in southwestern Italy, along the coast of the 
western Mediterranean Sea. The effect of DMV infection on the health and conservation of the threatened Eurasian otter populations warrants further investigation.

\section{Acknowledgments}

We thank Antonio Lo Polito, Maria Luigia Prencipe, and Fabio Gisoldo for their valuable technical support. We also thank Gabriella Di Francesco, Alessio Lorusso, Daniela Malatesta, and Guendalina Zaccaria for their valuable support in performing histopathological, immunohistochemical, and biomolecular analyses as well as for their greatly appreciated contribution to fruitful and insightful discussions on the data reported in the manuscript.

\section{About the Author}

Dr. Padalino works at the Virology Department of Istituto Zooprofilattico Sperimentale della Puglia e della Basilicata, Foggia, Italy, where she is in charge of the Molecular Biology and Cell Culture Laboratory. Her research is mainly focused on the molecular diagnosis and epidemiologic surveillance of viral infectious diseases in domestic and wild animals.

\section{References}

1. Van Bressem MF, Duignan PJ, Banyard A, Barbieri M, Colegrove KM, De Guise S, et al. Cetacean morbillivirus: current knowledge and future directions. Viruses. 2014;6:5145-81. http://dx.doi.org/10.3390/v6125145

2. Mazzariol S, Centelleghe C, Beffagna G, Povinelli M, Terracciano G, Cocumelli C, et al. Mediterranean fin whales (Balaenoptera physalus) threatened by dolphin morbillivirus. Emerg Infect Dis. 2016;22:302-5. http://dx.doi.org/10.3201/eid2202.150882

3. Mazzariol S, Centelleghe C, Di Provvido A, Di Renzo L, Cardeti G, Cersini A, et al. Dolphin morbillivirus associated with a mass stranding of sperm whales, Italy. Emerg Infect Dis. 2017;23: 144-6. http://dx.doi.org/10.3201/eid2301.160239

4. Frisk AL, König M, Moritz A, Baumgärtner W. Detection of canine distemper virus nucleoprotein RNA by reverse transcription-PCR using serum, whole blood, and cerebrospinal fluid from dogs with distemper. J Clin Microbiol. 1999;37:3634-43.

5. Centelleghe C, Beffagna G, Zanetti R, Zappulli V, Di Guardo G, Mazzariol S. Molecular analysis of dolphin morbillivirus: a new sensitive detection method based on nested RT-PCR. J Virol Methods. 2016;235:85-91. http://dx.doi.org/10.1016/ j.jviromet.2016.05.005

6. Verna F, Giorda F, Miceli I, Rizzo G, Pautasso A, Romano A, et al. Detection of morbillivirus infection by RT-PCR RFLP analysis in cetaceans and carnivores. J Virol Methods. 2017; 247:22-7. http://dx.doi.org/10.1016/j.jviromet.2017.05.009

7. Mos L, Ross PS, McIntosh D, Raverty S. Canine distemper virus in river otters in British Columbia as an emergent risk for coastal pinnipeds. Vet Rec. 2003;152:237-9. http://dx.doi.org/10.1136/ vr.152.8.237

8. Jo WK, Osterhaus AD, Ludlow M. Transmission of morbilliviruses within and among marine mammal species. Curr Opin Virol. 2018;28:133-41. http://dx.doi.org/10.1016/j.coviro.2017.12.005

9. Mazzariol S, Peletto S, Mondin A, Centelleghe C, Di Guardo G, Di Francesco CE, et al. Dolphin morbillivirus infection in a captive harbor seal (Phoca vitulina). J Clin Microbiol. 2013;51:708-11. http://dx.doi.org/10.1128/JCM.02710-12

10. Kondratov IG, Denikina NN, Belikov SI, Durymanova AA, Ustinova EN, Shestopalov AM. Mollusks as a natural reservoir of morbilliviruses. Dokl Biol Sci. 2003;389:154-6. http://dx.doi.org/10.1023/A:1023435312334

Address for correspondence: Giovanni Di Guardo, University of Teramo, Faculty of Veterinary Medicine, Località Piano d'Accio, 64100, Teramo, Italy; email: gdiguardo@unite.it

\section{Little Evidence of Zika Virus I nfection in Wild Long-Tailed Macaques, Peninsular Malaysia}

\section{Chong Long Chua, Yoke Fun Chan, Eva S.G. Soh Andu, Jeffrine J. Rovie-Ryan, Frankie Thomas Sitam, Khebir Verasahib, I-Ching Sam}

Author affiliations: University of Malaya, Kuala Lumpur, Malaysia (C.L. Chua, Y.F. Chan, E.S.G. Soh Andu, I-C. Sam); Department of Wildlife and National Parks Peninsular Malaysia, Kuala Lumpur (J.J. Rovie-Ryan, F.T. Sitam); National Public Health Laboratory, Sungai Buloh, Malaysia (K. Verasahib)

DOI: https://doi.org/10.3201/eid2502.180258

We tested a sample of 234 wild long-tailed macaques ( $\mathrm{Ma}$ caca fascicularis) trapped in Peninsular Malaysia in 2009, 2010, and 2016 for Zika virus RNA and antibodies. None were positive for RNA, and only $1.3 \%$ were seropositive for neutralizing antibodies. Long-tailed macaques are unlikely to be reservoirs for Zika virus in Malaysia.

$\mathrm{Z}$ ika virus, first isolated from a rhesus macaque (Macaca mulatta) in the Zika Forest in Uganda, reemerged in the Pacific Islands and Americas in 2015 and caused unprecedented outbreaks associated with serious congenital syndromes (1). The role of animal reservoirs for Zika virus is unclear, although in Africa, nonhuman primates (NHPs) are suspected to be involved in maintaining a sylvatic cycle, as they are for 2 other flaviviruses (yellow fever and dengue viruses) also transmitted by Aedes mosquitoes. The presence of a sylvatic cycle for Zika virus in Africa is supported by a seroprevalence of $0 \%-16 \%$ in African green monkeys (Chlorocebus sabaeus) and vervet monkeys (Chlorocebus 
pygerythrus) (2). However, even less is known about the potential role of NHPs in sylvatic cycles in Asia.

In Malaysia, Zika virus seropositivity has been reported in residents $(3,4)$, monkeys (5), and orangutans (4), suggesting endemicity. Continual encroachment of human settlements into monkey habitats potentially increases human risk for exposure to monkey-associated zoonotic pathogens. We therefore evaluated Zika virus prevalence in long-tailed macaques ( $M$. fascicularis), the most common macaque in Peninsular Malaysia, which is also widespread throughout Southeast Asia.

Staff of the Department of Wildlife and National Parks Peninsular Malaysia (also called Jabatan Perlindungan Hidupan Liar dan Taman Negara Semenanjung Malaysia [PERHILITAN]) traps monkeys foraging in humanpopulated areas and relocates them to deep forest areas (6). As part of PERHILITAN's Wildlife Disease Surveillance Program, serum samples were collected from 234 long-tailed macaques trapped at $>30$ sites throughout Malaysia in the states of Selangor, Negeri Sembilan, Perak, Pahang, Penang, and Johor (approval no. PERHILITAN JPHL\&TN(IP):100-34/1.24) and stored at $-80^{\circ} \mathrm{C}$. This collection comprised 145 samples acquired during October-November 2009 and October 2010 (6) and 89 acquired in March and August 2016, coinciding with the Zika virus global epidemics.

After extracting viral RNA from samples with a QIAamp Viral RNA Mini Kit (QIAGEN, https://www. qiagen.com), we tested samples with sufficient serum volume $(n=228)$ for Zika virus envelope gene by real-time PCR (7); none were positive. We tested all 234 samples for Zika virus neutralizing antibody by $50 \%$ plaque reduction neutralization test $\left(\mathrm{PRNT}_{50}\right.$ ) on Vero cells (Appendix, https://wwwnc.cdc.gov/EID/article/25/2/18-0258-App1. pdf). In total, 6 (2.6\%) samples had screening Zika virus $\mathrm{PRNT}_{50}$ titers $\geq 20$ (Table); we confirmed results with a $50 \%$
Zika virus focus reduction neutralization test $\left(\mathrm{FRNT}_{50}\right)$, and samples had titers identical to or within 1 dilution of the $\mathrm{PRNT}_{50}$ titer.

Because flavivirus antibodies are known to cross-react, these 6 samples were further examined for antibodies specific to the major known circulating flaviviruses in Malaysia, dengue virus serotypes 1 (DENV-1) and 2 (DENV-2), by $\mathrm{FRNT}_{50}$. A sample was considered to have evidence of Zika virus neutralizing antibody if the Zika virus $\mathrm{PRNT}_{50}$ titer was $\geq 20$ and DENV- 1 and DENV-2 FRNT ${ }_{50}$ titers were $<20$ (2 samples) or if the Zika virus PRNT $_{50}$ titer was $\geq 20$ and 4 -fold greater than the DENV-1 and DENV-2 FRNT titers (1 sample). Only 3 of 6 samples fulfilled these criteria; the remaining 3 contained detectable Zika virus, DENV-1, and DENV-2 antibodies, indicating past flavivirus infection of an indeterminate type. Thus, 3 (1.3\%) of 234 samples were Zika virus seropositive, although we did not test for other flaviviruses.

The 3 Zika virus-seropositive monkeys were captured $35 \mathrm{~km}$ away (in Bukit Serendah, Selangor), $77 \mathrm{~km}$ away (in Kuala Lipis, Pahang), and $164 \mathrm{~km}$ away (in Manong, Perak) from Bentong (Pahang), where Zika virus was first isolated outside of Africa in 1966 (5). Of note, 5 of 6 samples with detectable Zika virus antibodies were collected in 2016, when human Zika virus cases were occurring in Malaysia and neighboring Thailand and Singapore. The rate of Zika virus antibody detection was higher in the 2016 collection $(5.6 \%, 5 / 89)$ than the 2009-2010 collection $(0.7 \%$, $1 / 145 ; p=0.031$ by Fisher exact test).

Our results indicate that wild long-tailed macaques in Peninsular Malaysia are exposed to Zika virus but at low levels, without evidence of viremia. This finding suggests that long-tailed macaques are unlikely involved in maintaining Zika virus sylvatic cycles in Malaysia, although the long-term dynamics of Zika virus antibodies and infection (including shedding) in macaques is unknown. This in-

Table. Zika virus, DENV-1, and DENV-2 neutralization titers of serum samples collected from long-tailed macaques in Peninsular Malaysia, 2009, 2010, and 2016*

\begin{tabular}{|c|c|c|c|c|c|c|c|}
\hline \multirow[b]{2}{*}{$\begin{array}{l}\text { Sample collection period } \\
\text { and size }\end{array}$} & \multirow[b]{2}{*}{$\begin{array}{l}\text { No. } \\
\text { samples } †\end{array}$} & \multirow[b]{2}{*}{$\begin{array}{l}\text { Macaque sex and } \\
\text { age group, ID no. }\end{array}$} & \multirow[b]{2}{*}{$\begin{array}{c}\text { Town/City, } \\
\text { state, coordinates }\end{array}$} & \multicolumn{4}{|c|}{ Neutralization titers } \\
\hline & & & & $\begin{array}{c}\text { Zika virus } \\
\text { PRNT }_{50}\end{array}$ & $\begin{array}{c}\text { Zika virus } \\
\text { FRNT }_{50}\end{array}$ & $\begin{array}{l}\text { DENV-1 } \\
\text { FRNT }_{50}\end{array}$ & $\begin{array}{l}\text { DENV-2 } \\
\text { FRNT }_{50}\end{array}$ \\
\hline $\begin{array}{l}\text { October-November } 2009 \\
\text { and October } 2010, \mathrm{n}=145\end{array}$ & 1 & $\begin{array}{l}\text { Male adult, } \\
\text { ZMW604 }\end{array}$ & $\begin{array}{c}\text { Bukit Serendah, Selangor, } \\
3.36^{\circ} \mathrm{N}, 101.60^{\circ} \mathrm{E}\end{array}$ & 640 & 640 & $<20$ & $<20$ \\
\hline \multirow[t]{5}{*}{$\begin{array}{l}\text { March and August 2016, } \\
n=89\end{array}$} & 5 & $\begin{array}{l}\text { Female juvenile, } \\
\text { PMW804 }\end{array}$ & $\begin{array}{c}\text { Manong, Perak, } 4.61^{\circ} \mathrm{N} \\
100.90^{\circ} \mathrm{E}\end{array}$ & 40 & 20 & $<20$ & $<20$ \\
\hline & & $\begin{array}{l}\text { Female adult, } \\
\text { WDSP/16/009 }\end{array}$ & $\begin{array}{c}\text { Kuala Lipis, Pahang, } \\
4.18^{\circ} \mathrm{N}, 102.05^{\circ} \mathrm{E}\end{array}$ & 80 & 80 & $<20$ & 20 \\
\hline & & $\begin{array}{c}\text { Male adult, } \\
\text { WDSP/16/006 }\end{array}$ & $\begin{array}{c}\text { Kuala Lipis, Pahang, } \\
4.18^{\circ} \mathrm{N}, 102.05^{\circ} \mathrm{E}\end{array}$ & 80 & 80 & 640 & 160 \\
\hline & & $\begin{array}{c}\text { Male adult, } \\
\text { WDSP/16/012 }\end{array}$ & $\begin{array}{l}\text { Kuala Lipis, Pahang, } \\
4.18^{\circ} \mathrm{N}, 102.05^{\circ} \mathrm{E}\end{array}$ & 40 & 40 & 20 & 40 \\
\hline & & $\begin{array}{c}\text { Male adult, } \\
\text { WDSP/16/086 }\end{array}$ & $\begin{array}{c}\text { Batu Pahat, Johor, } 1.85^{\circ} \mathrm{N}, \\
102.94^{\circ} \mathrm{E}\end{array}$ & 40 & 20 & 40 & 20 \\
\hline
\end{tabular}

*DENV-1, dengue virus serotype 1; DENV-2, dengue virus serotype 2; FRNT $50,50 \%$ focus reduction neutralization test; ID, identification; PRNT $50,50 \%$ plaque reduction neutralization test.

†Number of samples from the first batch $(n=234)$ that were positive by Zika virus PRNT 50 and further tested by FRNT 50 . 
formation is arguably needed before an animal can be designated a reservoir (8). Despite intense Zika outbreaks in humans, no active Zika virus infection and a low seroprevalence $(2.9 \%)$ with low antibody titers was found in various NHP species in Brazil, suggesting that New World NHPs are unlikely to sustain sylvatic transmission cycles (9). Antibody responses after flavivirus infection are broadly cross-reactive and cross-neutralizing in the first few months after infection (10), but the effects against heterologous flaviviruses are poorly understood in wild macaques. Also, the circulation of Zika virus in macaques could be affected by the sylvatic cycles of other endemic flaviviruses. In conclusion, the low seroprevalence of Zika virus antibodies in long-tailed macaques reinforces the need to study other NHPs and mammals as reservoirs in Malaysia to elucidate Zika virus transmission and emergence.

\section{Acknowledgments}

We thank the outbreak response team of the Wildlife Disease Surveillance Program, PERHILITAN, for collecting monkey samples.

This study was supported by a Malaysia One Health University Network research grant and the US Agency for International Development.

\section{About the Author}

Dr. Chua is a postdoctoral research fellow at University of Malaya. His primary interest is host antibody responses to arbovirus infection.

\section{References}

1. Dick GW, Kitchen SF, Haddow AJ. Zika virus. I. Isolations and serological specificity. Trans R Soc Trop Med Hyg. 1952;46:50920. http://dx.doi.org/10.1016/0035-9203(52)90042-4

2. Buechler CR, Bailey AL, Weiler AM, Barry GL, Breitbach ME, Stewart LM, et al. Seroprevalence of Zika virus in wild African green monkeys and baboons. mSphere. 2017;2:e00392-16. http://dx.doi.org/10.1128/mSphere.00392-16

3. Smithburn KC. Neutralizing antibodies against arthropod-borne viruses in the sera of long-time residents of Malaya and Borneo. Am J Hyg. 1954;59:157-63.

4. Wolfe ND, Kilbourn AM, Karesh WB, Rahman HA, Bosi EJ, Cropp BC, et al. Sylvatic transmission of arboviruses among Bornean orangutans. Am J Trop Med Hyg. 2001;64:310-6. http://dx.doi.org/10.4269/ajtmh.2001.64.310

5. Marchette NJ, Garcia R, Rudnick A. Isolation of Zika virus from Aedes aegypti mosquitoes in Malaysia. Am J Trop Med Hyg. 1969;18:411-5. http://dx.doi.org/10.4269/ajtmh.1969.18.411

6. Sam IC, Chua CL, Rovie-Ryan JJ, Fu JY, Tong C, Sitam FT, et al. Chikungunya virus in macaques, Malaysia. Emerg Infect Dis. 2015;21:1683-5. http://dx.doi.org/10.3201/eid2109.150439

7. Lanciotti RS, Kosoy OL, Laven JJ, Velez JO, Lambert AJ, Johnson AJ, et al. Genetic and serologic properties of Zika virus associated with an epidemic, Yap State, Micronesia, 2007. Emerg Infect Dis. 2008;14:1232-9. http://dx.doi.org/10.3201/ eid1408.080287
8. Kuno G, Mackenzie JS, Junglen S, Hubálek Z, Plyusnin A, Gubler DJ. Vertebrate reservoirs of arboviruses: myth, synonym of amplifier, or reality? Viruses. 2017;9:185. http://dx.doi.org/ 10.3390/v9070185

9. Moreira-Soto A, Carneiro IO, Fischer C, Feldmann M, Kümmerer BM, Silva NS, et al. Limited evidence for infection of urban and peri-urban nonhuman primates with Zika and chikungunya viruses in Brazil. mSphere. 2018;3:e00523-17. http://dx.doi.org/10.1128/mSphere.00523-17

10. Collins MH, McGowan E, Jadi R, Young E, Lopez CA, Baric RS, et al. Lack of durable cross-neutralizing antibodies against Zika virus from dengue virus infection. Emerg Infect Dis. 2017; 23:773-81. http://dx.doi.org/10.3201/eid2305.161630

Address for correspondence: I-Ching Sam, University of Malaya, Department of Medical Microbiology, Faculty of Medicine, Kuala Lumpur 50603, Malaysia; email: jicsam@ummc.edu.my

\section{Severe Fever with Thrombocytopenia Syndrome Virus in Dogs, South Korea}

\author{
Jun-Gu Kang, Yoon-Kyoung Cho, Young-Sun Jo, \\ Jeong-Byoung Chae, Young-Hoon Joo, \\ Kyoung-Wan Park, Joon-Seok Chae
}

Author affiliations: Seoul National University, Seoul, South Korea (J.-G. Kang, Y.-K. Cho, Y.-S. Jo, J.-B. Chae, J.-S. Chae); Military Working Dog Training Center of the Republic of Korea Army, Chuncheon, South Korea (Y.-H. Joo, K.-W. Park)

DOI: https://doi.org/10.3201/eid2502.180859

Of 103 serum samples collected from dogs in South Korea, $3(2.9 \%)$ were positive for severe fever with thrombocytopenia syndrome virus (SFTSV) and 22 (21.4\%) were positive for antibodies against SFTSV. A dog-derived isolate of SFTSV clustered with many South Korea SFTSV strains in the Japanese clade.

Severe fever with thrombocytopenia syndrome virus (SFTSV), a new tickborne phlebovirus of the Phenuiviridae family (previously Bunyaviridae), causes severe fever with thrombocytopenia syndrome (SFTS) in China, Japan, and the Republic of Korea (South Korea) (1). After identification of the first human case of SFTS in South Korea in 2013 (1), 335 cases (73 deaths; case-fatality rate $21.8 \%$ ) were reported during 2013-2016 (2). 
SFTSV is primarily transmitted through a tick bite. The Haemaphysalis longicornis tick is the main vector for SFTSV, promoting its circulation and transmission (3). Investigations have been conducted to determine the frequency of exposure of companion animals, wild animals, and livestock to SFTSV (4-7). Of particular importance, dogs are companion animals that have frequent contact with humans. Therefore, their infection status has major implications for public health. We isolated SFTSV from dog serum and determined the prevalence of SFTSV in dogs in South Korea.

We collected 103 serum samples during June-October 2016 from the following dog breeds: 42 Belgian Malinois, 58 German shepherds, and 3 Labrador retrievers. All dogs were military dogs in a training camp in Gangwon Province, South Korea, at the time of serum collection. The animals had no significant clinical signs associated with febrile disease. Information about body temperature, evidence of tick bites, blood chemistry, and complete blood count was unavailable.

Of the 103 samples, 3 (2.9\%), obtained from dog 16, a German shepherd; dog 22, a Belgian Malinois; and dog 56, a German shepherd were positive for the small (S [346 bp]), medium (M [859 bp]), and L (large [1,165 bp]) segments of SFTSV by reverse transcription PCR (the L segment of dog 16 was not amplified). The sequences of the SFTSV S, M, and L segments differed from each other. The results of phylogenetic analysis of partial S, M, and L segments showed that sequences of SFTSV obtained from dogs were more related to strains from Japan than to strains from China (Appendix, https:// wwwnc.cdc.gov/EID/article/25/2/18-0859-App1.pdf). Moreover, 22 (21.4\%) samples were positive for SFTSV antibodies by immunofluorescence assay. SFTSV

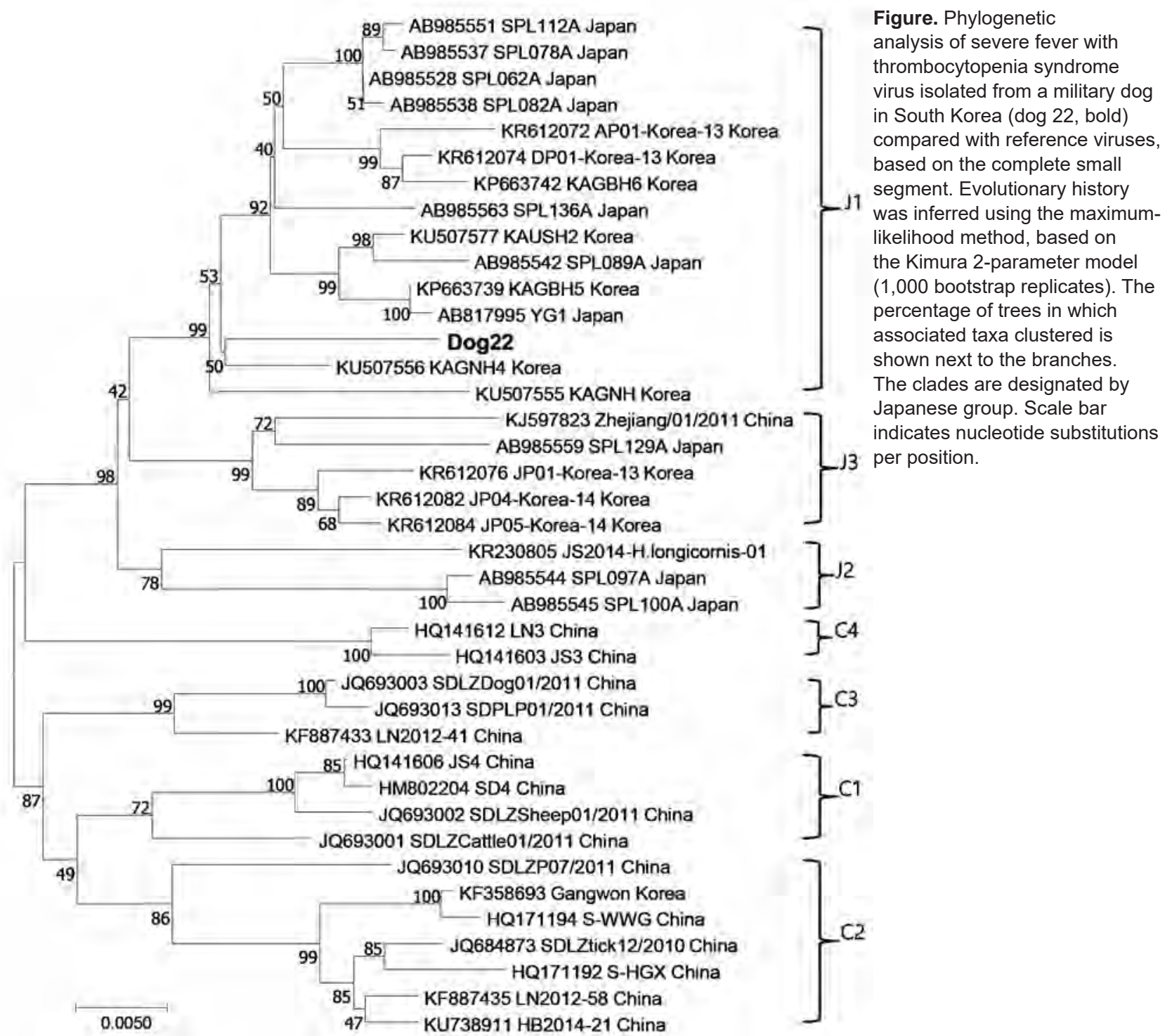


seroprevalence was 25.9\% (15/58) for Belgian Malinois, $16.7 \%$ (7/42) for German shepherds, and 0\% (0/3) for Labrador retrievers. Among seropositive dogs, 22.2\% $(12 / 54)$ were male and $20.4 \%(10 / 49)$ were female.

We used Vero cells to isolate the virus from positive serum. We observed cytopathic effect in only 1 of 3 positive samples. The results of phylogenetic analysis of the complete S segment indicated that the SFTSV strain isolated from dog 22 had not previously been isolated; this strain clustered with many SFTSV strains from South Korea and Japan (Figure).

$H$. longicornis ticks are the main vector of SFTSV and the dominant tick species collected from vegetation and animals in South Korea $(3,7,8)$. However, because of the low SFTSV prevalence in ticks, mammalian hosts might be necessary for the circulation and maintenance of SFTSV in nature. Therefore, studies measuring the prevalence of SFTSV infection across various animal species have been undertaken (4-7). Only a few studies on SFTSV in dogs have been reported; these studies found that 1) the positive rates for SFTSV RNA were 5.3\% (19/359) for domesticated dogs in China (5) and 0.2\% (1/426) for shelter dogs in South Korea (6) and that 2) $28.9 \%-37.9 \%$ of domesticated dogs in China $(4,5,9)$ and $13.9 \%$ of shelter dogs in South Korea (10) were seropositive for antibodies against SFTSV.

The detection rates of SFTSV RNA and antibodies in our study were $2.9 \%$ and $21.4 \%$, respectively, which were higher than those observed in shelter dogs in South Korea (6). These results have 2 possible explanations. First, we collected samples during the summer, when dogs most easily and frequently have contact with ticks infected with SFTSV. In contrast, in the shelter dog study, the timing of sample collection was random and occurred throughout multiple seasons. Second, we drew serum from military dogs, which typically spend most of their time outside of the home; conversely, the shelter dog study examined small dogs that resided indoors before their relocation to a shelter.

Although we isolated only a few SFTSV strains from animals and our results could not represent all characteristics of SFTSV, our findings could indicate that SFTSV might not be host-specific and that various SFTSV clades circulate and are distributed in South Korea. Further studies continuously surveilling animals for SFTSV, along with whole-genome analysis of dog-derived Korean isolates of SFTSV, would help clarify the mechanisms of transmission and molecular evolution of SFTSV.

This research was supported by the Government-wide R\&D Fund for Infectious Diseases Research (HG18C0021) and the Basic Science Research Program through the National Research Foundation of Korea funded by the Ministry of Education (NRF-2015R1C1A1A01054518).

\section{About the Author}

Dr. Kang is a research assistant professor at the Laboratory of Veterinary Internal Medicine, BK21 Plus Program for Creative for Veterinary Science Research, Research Institute of Veterinary Science and College of Veterinary Medicine, Seoul National University. His primary research interests include vector-borne zoonotic diseases and veterinary internal medicine.

\section{References}

1. Kim KH, Yi J, Kim G, Choi SJ, Jun KI, Kim NH, et al. Severe fever with thrombocytopenia syndrome, South Korea, 2012. Emerg Infect Dis. 2013;19:1892-4. http://dx.doi.org/10.3201/ eid1911.130792

2. Korea Centers for Disease Control and Prevention. Infectious disease surveillance yearbook, 2016 [in Korean]. 2017 Jun [cited 2018 May 8]. http://www.cdc.go.kr/npt/biz/npp/portal/ nppPblctDtaView.do?pblctDtaSeAt=1\&pblctDtaSn=22

3. Luo LM, Zhao L, Wen HL, Zhang ZT, Liu JW, Fang LZ, et al. Haemaphysalis longicornis ticks as reservoir and vector of severe fever with thrombocytopenia syndrome virus in China. Emerg Infect Dis. 2015;21:1770-6. http://dx.doi.org/10.3201/ eid2110.150126

4. Ding S, Yin H, Xu X, Liu G, Jiang S, Wang W, et al. A cross-sectional survey of severe fever with thrombocytopenia syndrome virus infection of domestic animals in Laizhou City, Shandong Province, China. Jpn J Infect Dis. 2014;67:1-4. http://dx.doi.org/ 10.7883/yoken.67.1

5. Niu G, Li J, Liang M, Jiang X, Jiang M, Yin H, et al. Severe fever with thrombocytopenia syndrome virus among domesticated animals, China. Emerg Infect Dis. 2013;19:756-63. http://dx.doi.org/10.3201/eid1905.120245

6. Lee SH, Kim HJ, Byun JW, Lee MJ, Kim NH, Kim DH, et al. Molecular detection and phylogenetic analysis of severe fever with thrombocytopenia syndrome virus in shelter dogs and cats in the Republic of Korea. Ticks Tick Borne Dis. 2017;8:626-30. http://dx.doi.org/10.1016/j.ttbdis.2017.04.008

7. Oh SS, Chae JB, Kang JG, Kim HC, Chong ST, Shin JH, et al. Detection of severe fever with thrombocytopenia syndrome virus from wild animals and Ixodidae ticks in the Republic of Korea. Vector Borne Zoonotic Dis. 2016;16:408-14. http://dx.doi.org/10.1089/vbz.2015.1848

8. Kim BJ, Kim H, Won S, Kim HC, Chong ST, Klein TA, et al. Ticks collected from wild and domestic animals and natural habitats in the Republic of Korea. Korean J Parasitol. 2014; 52:281-5. http://dx.doi.org/10.3347/kjp.2014.52.3.281

9. Gong L, Jiang M, Liu J, Han W, Liu J, Sun Z, et al. Prevalence and homology analysis on human and animals severe fever with thrombocytopenia syndrome virus infection in Yantai of Shandong province [in Chinese]. Zhonghua Liu Xing Bing Xue Za Zhi. 2014;35:524-7.

10. Lee SH, Kim HJ, Lee MJ, Byun JW, Kim DY, Kim NH, et al. Prevalence of antibodies against severe fever with thrombocytopenia syndrome virus in shelter dogs in the Republic of Korea. Ticks Tick Borne Dis. 2018;9:183-7. http://dx.doi.org/10.1016/j.ttbdis.2017.09.002

Address for correspondence: Joon-Seok Chae, Laboratory of Veterinary Internal Medicine, BK21 Plus Program for Creative for Veterinary Science Research, Research Institute of Veterinary Science and College of Veterinary Medicine, Seoul National University, 1 Gwanak-ro, Gwanak-gu, Seoul 151-742, Republic of Korea; email: jschae@snu.ac.kr 


\section{Pin-Site Myiasis Caused by Screwworm Fly in Nonhealed Wound, Colombia}

\author{
Wilmer E. Villamil-Gómez, ${ }^{1}$ \\ Jaime A. Cardona-Ospina, ${ }^{1}$ \\ Juan Sebastián Prado-Ojeda, \\ Hugo Hernández-Prado, Mauricio Figueroa, \\ Pedro N. Causil-Morales, Keirim Pérez-Reyes, \\ Leidy A. Palechor-Ocampo, \\ Alfonso J. Rodríguez-Morales
}

DOI: https://doi.org/10.3201/eid2502.181053

Author affiliations: Hospital Universitario de Sincelejo, Sincelejo, Colombia; Universidad del Atlántico, Barranquilla, Colombia (W.E. Villamil-Gómez, J.S. Prado-Ojeda. P.N. Causil-Morales); Universidad Tecnológica de Pereira, Pereira, Colombia (J.A. Cardona-Ospina, L.A. Palechor-Ocampo, A.J. RodríguezMorales); Clínica Santa María, Sincelejo (H. Hernández-Prado, M. Figueroa, K. Pérez-Reyes); Universidad Privada Franz Tamayo/ UNIFRANZ, Cochabamba, Bolivia (A.J. Rodríguez-Morales

Pin-site myiasis is an underreported complication of surgical interventions. We present a case of myiasis caused by the New World screwworm fly (Cochliomyia hominivorax) in a pin site of a chronic nonhealed wound 12 years after the intervention. This infection apparently was the result of poor perfusion of the leg.

$\mathrm{P}$ in-site myiasis, a surgical complication reported since 2005 (1), is an infection with insect larvae in wounds after use of metal stabilizers to treat bone fractures. Although it is considered rare, its real incidence is unknown, probably because of underreporting. However, pin-site myiasis remains an important complication of surgical interventions when it occurs, particularly in patients with risk factors such as medical comorbidities, poor care of pin site, and advanced age (2). Although pin-site myiasis is nonfatal if diagnosed and treated, the tissue damage and secondary bacterial infection are known to have evolved in animals to septicemia and even death (3). For these reasons, it is important to keep this complication in the clinical spectrum of postoperative occurring conditions, especially in susceptible populations. We report a case of pin-site myiasis in an elderly patient with a chronic nonhealed wound.

A 77-year-old man with a history of hypertension who had tibial osteosynthesis in 2006 was admitted to the emergency service of Clínica Santa María, a local private hospital in Sincelejo, Sucre, Colombia, in May 2018. Four days earlier, he had noticed the presence of larvae

${ }^{1}$ These authors contributed equally to this article. as well as ulceration, bone exposure, and osteosynthesis material in a nonhealed wound in his left leg at the site where a pin had been inserted as part of his care 12 years earlier. The surgical wound had never healed after the intervention, and he was caring for the wound with homemade measures under poor hygiene. The patient denied exposure to pets, livestock, or wildlife. At his admission, he was afebrile and nonseptic, and vital signs were within reference levels. Examination of the leg revealed absence of pedial pulse, an ulcer of $8 \mathrm{~cm}$ in diameter, thickness of the skin and soft tissues surrounding the wound, bone exposure and osteosynthesis material, and larvae (Figure, panel A). A radiograph of the leg showed a bone callus and a functional posteriorly blocked pin, which was retired. We performed ultrasonography of arterial vessels, which showed atheromatosis of the popliteal artery with very low flow. After microbiological sampling of the secretions in the wound, we started intravenous cefazoline (1 g every $6 \mathrm{~h}$ ) and washed the ulcer. The microbiological cultures were positive for oxacilin-resistant Staphylococcus aureus. The patient received vancomycin, with posterior negative cultures.

We removed a total of 100 larvae from the wound and identified them, using published methods (4), as larvae of Cochliomyia hominivorax, the New World screwworm fly (Figure, panel B); the larvae have well-differentiated mouthhooks and 12 segments separated by spinose bands with spines arranged in 4 rows and an opened posterior spiracle. The identification of the larvae is based primarily on the presence or absence of internal breathing tubes (Figure, panel C). The life cycle of $C$. hominivorax flies is $\approx 21$ days in warm climates, such as this patient's area of residence, and slightly longer in cooler climates. The adult female mates only once and lays her elongated white eggs along the edges of wounds on warm-blooded animals.

After 4 weeks of antimicrobial therapy and daily debridement and irrigation, the wound appeared to be healing without evidence of bacterial or parasitic infection. Monthly follow-up for up to 6 months is expected.

Other authors have previously reported pin-site infestation with maggots; we found a total of 7 cases since 2005 $(1,2,5-7)$. We did not find reports of a case in which the infestation complicates a chronic nonhealed surgical wound in the pin site 12 years after intervention. This patient had medical comorbidities and poor care of the pin site, as did previously reported case-patients (8). Ultrasonographic evaluation of the leg revealed poor perfusion, which probably affected the healing of the wound.

This case highlights the role of myiasis as a complication of surgical wounds $(2,6)$, especially in pin sites. Appropriate debridement, washing, and antimicrobial treatment for bacteria and ectoparasites should help to prevent evolution of the infection to osteomyelitis and sepsis. 


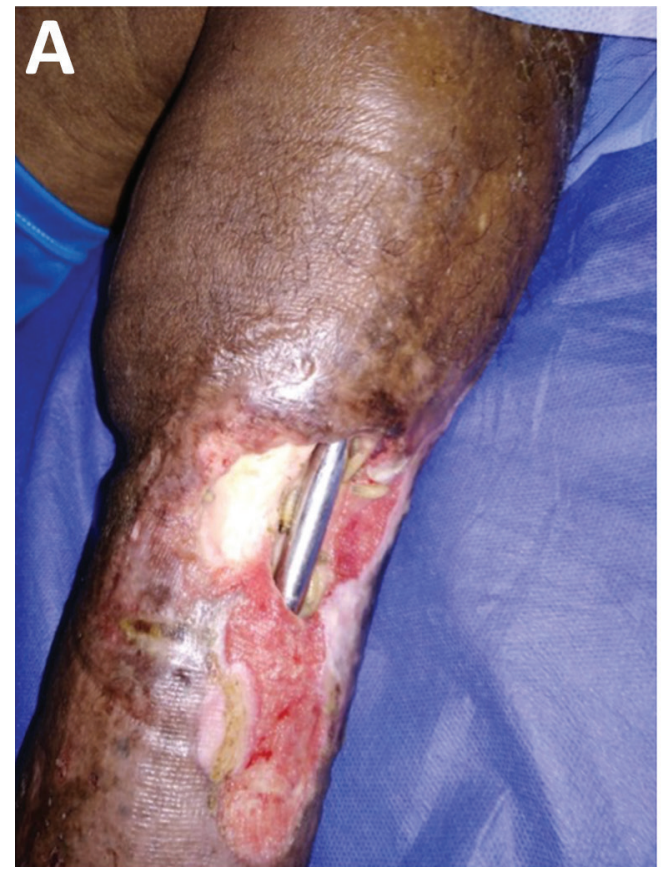

B
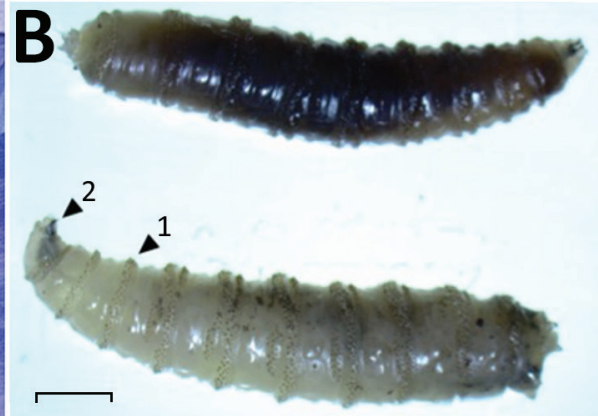

'

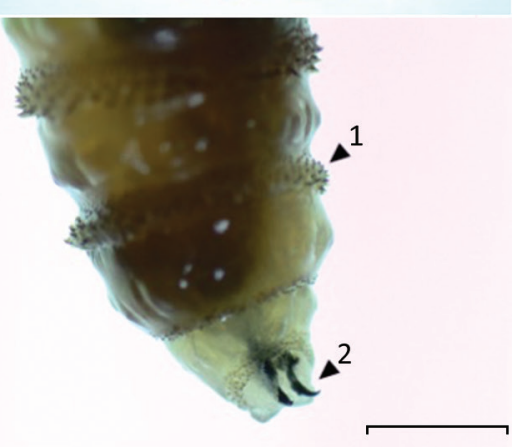

Figure. Pin-site myiasis in a 77-year-old man 12 years after tibial osteosynthesis, Colombia. A) Open wound in the man's left leg, showing multiple insect larvae. B, C) Cochliomyia hominivorax screwworm fly larvae extracted from the wound. Arrow 1 indicates the spinose bands; note the spines arranged in 4 rows that separate each segment. Arrow 2 indicates its mouthhooks. Scale bars indicate $2 \mathrm{~mm}$ (B) and $1 \mathrm{~mm}(\mathrm{C})$.

\section{About the Author}

Dr. Villamil-Gomez is an attending physician in infectious diseases at the Hospital Universitario de Sincelejo and Clínica Santa María, Sincelejo, Sucre, Colombia. His primary research interests include tropical diseases, such as dengue, chikungunya, Zika, and Mayaro viruses; leishmaniasis and Chagas disease; and travel medicine.

\section{References}

1. Park P, Lodhia KR, Eden SV, Lewandrowski KU, McGillicuddy JE. Pin-site myiasis: a rare complication of halo orthosis.

Spinal Cord. 2005;43:684-6. http://dx.doi.org/10.1038/ sj.sc. 3101773

2. Cazorla-Perfetti DJ, Acosta-Quintero ME, Morales P, Bermudez SE, Rodriguez-Morales AJ. Pin-site myiasis: an emerging infectious complication of external bone fixation? Int J Infect Dis. 2009; 13:e514-6.

3. Guerrini VH. Ammonia toxicity and alkalosis in sheep infested by Lucilia cuprina larvae. Int J Parasitol. 1988;18:79-81.

4. Ruth PD, Carolina VAL. Identification of myasis-producing larvae from the Universidad Colegio Mayor de Cundinamarca [in Spanish]. Nova. 2017;15:79-91.

5. Africano FJ, Faccini-Martínez AA, Pérez CE, Espinal A, Bravo JS, Morales C. Pin-site myiasis caused by screwworm fly, Colombia. Emerg Infect Dis. 2015;21:905-6. http://dx.doi.org/10.3201/ eid2105.141680

6. Paris LA, Viscarret M, Uban C, Vargas J, Rodriguez-Morales AJ. Pin-site myiasis: a rare complication of a treated open fracture of tibia. Surg Infect (Larchmt). 2008;9:403-6. http://dx.doi.org/ 10.1089/sur.2007.045

7. Verettas DA, Chatzipapas CN, Drosos GI, Xarchas KC, Staikos C, Chloropoulou P, et al. Maggot infestation (myiasis) of external fixation pin sites in diabetic patients. Trans R Soc Trop Med Hyg. 2008;102:950-2. http://dx.doi.org/10.1016/j.trstmh.2008.05.011

8. Francesconi F, Lupi O. Myiasis. Clin Microbiol Rev. 2012; 25:79-105. http://dx.doi.org/10.1128/CMR.00010-11
Address for correspondence: Alfonso J. Rodríguez-Morales, Public Health and Infection Research Group and Incubator, Office 14-315, Scientific Research Direction, F1 3, Bldg 14, Department of Community Medicine, School of Medicine, Faculty of Health Sciences, Universidad Tecnológica de Pereira, Sector La Julita, Pereira 660003, Risaralda, Coffee-Triangle Region, Colombia; email: arodriguezm@utp.edu.co

\section{Oropouche Virus-Associated Aseptic Meningoencephalitis, Southeastern Brazil}

\author{
Sebastian Vernal, Camila C.R. Martini, \\ Benedito A.L. da Fonseca
}

Author affiliation: University of São Paulo, Ribeirão Preto, Brazil

DOI: https://doi.org/10.3201/eid2502.181189

Oropouche fever is a neglected arthropodborne disease and zoonosis responsible for several outbreaks of a febrile disease in Central and South America. We present a clinical case of aseptic meningoencephalitis in an immunocompetent patient that resulted from Oropouche virus acquired in northern Brazil but diagnosed in a nonendemic region. 
$\mathrm{I}$ April 2016, a 28-year-old man (S.V.) in Ribeirão Preto, southeastern Brazil, with a history of Gilbert syndrome sought care for a sudden high fever, severe 1-sided headache, vomiting, intense photophobia, stiff neck, and confusion. Seventeen days earlier, he had returned from a trip to Mosqueiro Island in northern Brazil; he received yellow fever vaccine 5 days before traveling. His 1 -week visit to the island included outdoor activities that involved entrances into the native Amazon rainforest. The patient returned to Ribeirão Preto and remained asymptomatic for 10 days before becoming acutely ill with fever, chills, myalgia, headache, and dizziness. Symptoms occurred intermittently for 3 days, which prompted him to seek medical care. After evaluation, a diagnosis of dengue fever was considered. Microhematocrit was 54\%, and tourniquet test was negative. Nonstructural protein (NS) 1 antigen detection test was requested, and the patient was treated with medications for his symptoms and prescribed abundant oral hydration and bed rest. Dengue fever was ruled out because NS1 antigen detection and IgM serologic testing provided negative results 6 days after initial symptom onset. Therefore, he was referred to an infectious disease outpatient clinic at another healthcare facility for further investigation. Yellow fever vaccine reaction and malaria were initially the main hypotheses, but thick blood film examination results were negative.

Seven days after initial symptom onset, the patient's headache worsened and became left-sided and pulsatile; intense photophobia, vomiting, and fever $\left(105.8^{\circ} \mathrm{F}\right)$ developed. No hemorrhagic manifestations were observed. He was admitted to the emergency department at the Teaching Hospital in Ribeirão Preto with nuchal rigidity; ceftriaxone was initiated.

At admission, he was confused, including attention deficits and hallucinations. Physical examination found tachypnea (27 breaths/min), heart rate 76 beats/min, and blood pressure 130/80 mm Hg; cardiopulmonary examination results were unremarkable, and the liver was palpable at 3 $\mathrm{cm}$ under the costal margin (spleen was not palpable) with no pain at abdominal palpation. The patient exhibited mild spasticity of lower limbs with positive Babinski sign, without focalities at neurologic exam. Because of clinical examination findings, viral meningoencephalitis emerged as a possible diagnosis, and intravenous acyclovir was started.

Laboratory examination showed complete blood counts within reference ranges (hematocrit 44\%; leukocytes 10,300 cells $/ \mathrm{mm}^{3}$ [no left shift; lymphocytes 2,300 cells/ $\mathrm{mm}^{3}$ ]; platelets $388,000 / \mathrm{mm}^{3}$ ), normal kidney function, and sodium and potassium concentrations within reference ranges. Liver enzymes were slightly elevated (aspartate aminotransferase $30 \mathrm{U} / \mathrm{L}$ [reference 15-46 U/L], alanine aminotransferase 71 U/L [reference 13-69 $\mathrm{U} / \mathrm{L}], \gamma$-glutamyl transferase $107 \mathrm{U} / \mathrm{L}$ [7-60 U/L]); total bilirubin was $0.73 \mathrm{mg} / \mathrm{dL}$ (reference $0.2-1.0 \mathrm{mg} / \mathrm{dL}$ ). Serologic test results were nonreactive for hepatitis $\mathrm{A}$, B, and C; HIV; syphilis; Epstein-Barr virus; Toxoplasma gondii; and Trypanosoma cruzi. Thorax radiograph imaging was unremarkable; cerebral computed tomography scan showed cortical edema on the left frontal lobe (Figure, panel A).

Results of a spinal tap showed a $23 \mathrm{~cm} \mathrm{H}_{2} \mathrm{O}$ opening pressure (reference 5-20 cm $\mathrm{H}_{2} \mathrm{O}$ ) with clear cerebrospinal fluid containing 45 cells $/ \mathrm{mm}^{3}$ (reference $<5$ cells/ $\mathrm{mm}^{3}$ ) (85\% lymphocytes); protein concentration of 53 $\mathrm{mg} / \mathrm{dL}$ (reference $<45 \mathrm{mg} / \mathrm{dL}$ ); and glucose concentration of $62 \mathrm{mg} / \mathrm{dL}$ (capillary $100 \mathrm{mg} / \mathrm{dL}$ [reference 2/3 of capillary glucose]). VDRL test results were negative, and bacterial and fungal antigens were not detected. PCR results were negative for enterovirus, herpes viruses 1 and 2, varicella zoster virus, cysticercosis, tuberculosis, and toxoplasmosis but positive for Oropouche virus (OROV) (fraction S) (1). Blood sample PCR results were also positive for OROV (Figure, panel B) (2), and indirect immunofluorescence antibody testing (Appendix,
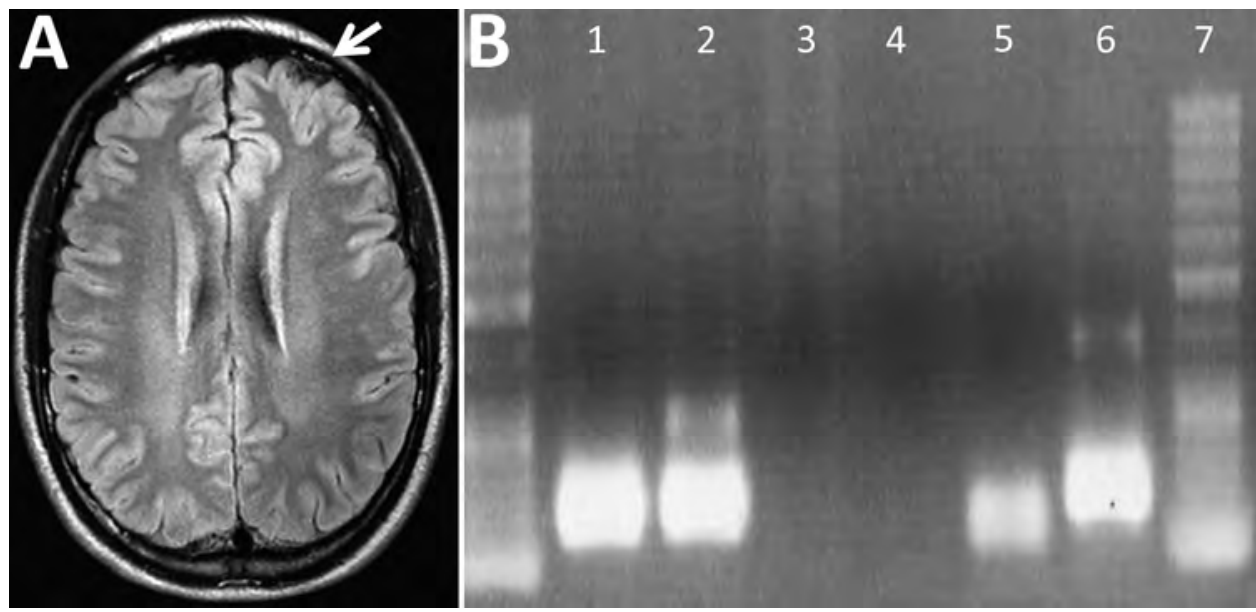

Figure. Imaging and PCR results for a 28-year-old man with Oropouche virus infection, southeastern Brazil. A) Cerebral computed tomography showing a cortical edema on the left frontal lobe (white arrow). B) Agarose gel of reverse transcription PCR products of Oropouche virus $\mathrm{S}$ fraction. Lane 1, patient's serum sample; lane 2, patient's cerebrospinal fluid; lane 3, patient's leukocyte supernatant; lane 4, negative control; lane 5, internal control; lane 6, positive control. 
https://wwwnc.cdc.gov/EID/article/25/2/18-1189-App1. pdf (3) confirmed OROV infection.

After 7 days of hospitalization, the patient recovered all neurologic function with no sequelae (posttreatment electromyography and magnetic resonance imaging findings were unremarkable). He was discharged and has had no additional relapses.

OROV, an RNA virus belonging to the genus Orthobunyavirus, family Peribunyaviridae, is the causative agent of Oropouche fever in humans (4). In a sylvatic cycle, OROV can be transmitted to some animals by mosquitoes and in an urban environment can be transmitted to humans by the midge Culicoides paraensis (5). Usually, humans become infected in forested areas and then can translocate the virus to an urban environment (6).

After a 4- to 8-day incubation period, fever, headache, myalgia, arthralgia, chills, photophobia, dizziness, nausea, and vomiting develop $(2,6)$. Less frequently, patients experience rash, anorexia, retro-orbital pain, and general malaise $(2,6,7)$. Hemorrhagic phenomena also have been described (8). Most patients recover spontaneously after 7 days, although some experience symptoms for as long as 1 month $(2,6,7)$. Some cases can relapse after recovery; the clinical picture is similar to the initial onset or can be more severe, including aseptic meningitis $(9,10)$. These patients may experience neck stiffness, dizziness, vomiting, lethargy, diplopia, and nystagmus, but prognosis without sequel is usually good (10).

There has been an increased concern that Oropouche fever, endemic in northern Brazil, might spread across the country by contiguous urban cycles and by human movement. Physicians working worldwide in areas to which OROV is not endemic should include this neglected disease in the differential diagnosis of acute febrile syndrome, especially in patients visiting high-risk areas for OROV transmission.

\section{Acknowledgments}

We thank the medical and nursing staff of the infectious diseases ward, Teaching Hospital, Ribeirão Preto Medical School, University of São Paulo.

\section{About the Author}

Dr. Vernal, the patient in this report, is a Chilean medical doctor working with neglected diseases in Brazil since
2013 and a PhD student in clinical medicine and a medical resident of infectious disease at University of São Paulo. His primary research interests include tropical infectious diseases with special emphasis on leprosy and tegumentary leishmaniasis.

\section{References}

1. Cardoso BF, Serra OP, Heinen LB, Zuchi N, Souza VC, Naveca FG, et al. Detection of Oropouche virus segment $\mathrm{S}$ in patients and in Culex quinquefasciatus in the state of Mato Grosso, Brazil. Mem Inst Oswaldo Cruz. 2015;110:745-54. http://dx.doi.org/10.1590/0074-02760150123

2. Travassos da Rosa JF, de Souza WM, Pinheiro FP, Figueiredo ML, Cardoso JF, Acrani GO, et al. Oropouche virus: clinical, epidemiological, and molecular aspects of a neglected orthobunyavirus. Am J Trop Med Hyg. 2017;96:1019-30.

3. de Souza Luna LK, Rodrigues AH, Santos RI, Sesti-Costa R, Criado MF, Martins RB, et al. Oropouche virus is detected in peripheral blood leukocytes from patients. J Med Virol. 2017;89:1108-11. http://dx.doi.org/10.1002/jmv.24722

4. Vasconcelos PF, Calisher CH. Emergence of human arboviral diseases in the Americas, 2000-2016. Vector Borne Zoonotic Dis. 2016;16:295-301. http://dx.doi.org/10.1089/ vbz.2016.1952

5. Pinheiro FP, Hoch AL, Gomes ML, Roberts DR. Oropouche virus. IV. Laboratory transmission by Culicoides paraensis. Am J Trop Med Hyg. 1981;30:172-6. http://dx.doi.org/10.4269/ ajtmh.1981.30.172

6. Romero-Alvarez D, Escobar LE. Oropouche fever, an emergent disease from the Americas. Microbes Infect. 2018;20:135-46. http://dx.doi.org/10.1016/j.micinf.2017.11.013

7. Vasconcelos PF, Travassos Da Rosa JF, Guerreiro SC, Dégallier N, Travassos Da Rosa ES, Travassos Da Rosa AP. 1st register of an epidemic caused by Oropouche virus in the states of Maranhão and Goiás, Brazil [in Portuguese]. Rev Inst Med Trop Sao Paulo. 1989;31:271-8. http://dx.doi.org/10.1590/ S0036-46651989000400011

8. Alvarez-Falconi PP, Ríos Ruiz BA. Oropuche fever outbreak in Bagazan, San Martin, Peru: epidemiological evaluation, gastrointestinal and hemorrhagic manifestations [in Spanish]. Rev Gastroenterol Peru. 2010;30:334-40.

9. Bastos MS, Lessa N, Naveca FG, Monte RL, Braga WS, Figueiredo LT, et al. Detection of herpesvirus, enterovirus, and arbovirus infection in patients with suspected central nervous system viral infection in the Western Brazilian Amazon. J Med Virol. 2014;86:1522-7. http://dx.doi.org/10.1002/jmv.23953

10. Pinheiro FP, Rocha AG, Freitas RB, Ohana BA, Travassos da Rosa AP, Rogério JS, et al. Meningitis associated with Oropouche virus infections [in Portuguese]. Rev Inst Med Trop Sao Paulo. 1982;24:246-51.

Address for correspondence: Benedito A.L. da Fonseca, Ribeirão Preto Medical School, University of São Paulo, 3900 Bandeirantes Av, Ribeirão Preto, SP 14049-900, Brazil; email: baldfons@fmrp.usp.br 


\section{Severe Respiratory I IIness Associated with Human Metapneumovirus in Nursing Home, New Mexico, USA}

\author{
Sandra A. Peña, ${ }^{1}$ Sarah Shrum Davis, \\ Xiaoyan Lu, Senthil Kumar K. Sakthivel, \\ Teresa C.T. Peret, Erica Billig Rose, \\ Chad Smelser, Eileen Schneider, \\ Nimalie D. Stone, John Watson
}

DOI: https://doi.org/10.3201/eid2502.181298

\begin{abstract}
Author affiliations: New Mexico Department of Health, Santa Fe, New Mexico, USA (S.A. Peña, S. Shrum Davis, C. Smelser); Centers for Disease Control and Prevention, Atlanta, Georgia, USA (X. Lu, S.K.K. Sakthivel, T.C.T. Peret, E. Billig Rose, E. Schneider, N.D. Stone, J. Watson)
\end{abstract}

Human metapneumovirus is an emerging pathogen that causes upper and lower respiratory illness. Nursing home outbreaks of infection with this virus can cause severe illness and lead to poor patient outcomes. We report an outbreak investigation in a nursing home during 2018 and infection control guidelines to assist in disease control.

$\mathrm{H}$ uman metapneumovirus (HMPV) is an enveloped, single-stranded RNA virus first described in 2001. Almost all children are infected by 5 years of age, but reinfection can occur throughout life, especially in older adults and immunocompromised persons (1-6). In a study of prospective adult cohorts covering 4 consecutive winters, annual HMPV detection varied $(3 \%-3.3 \%$ in the first and third years and $6 \%-$ $7.1 \%$ in the second and fourth years) (5). In the United States, HMPV circulates seasonally from winter through late spring (7). There is no vaccine; treatment is supportive.

On February 22, 2018, a nursing home in New Mexico contacted the New Mexico Department of Health to report acute respiratory illness among 5 residents who had negative rapid diagnostic influenza test results. This rural, 86-bed facility (44 resident rooms [2 residents/room] in 5 contiguous areas, 2 dining rooms, 2 activity rooms, and 120 staff) provides long-term care, short-term rehabilitation, skilled nursing services, and dementia care. The New Mexico Department of Health initiated an investigation to determine the cause of the illness, characterize the clinical manifestations, and limit transmission.

A case of respiratory illness was defined as illness in a nursing home resident with onset during February 15-March 31, 2018, and comprising $\geq 1$ of the following

${ }^{1}$ Current affiliation: Tennessee Department of Health, Nashville, Tennessee, USA. signs and symptoms: cough, fever, shortness of breath, or hypoxia (oxygen saturation $<90 \%$ ). A total of 49 (62\%) of 79 residents were identified as case-patients (Figure); 17 (35\%) were men, and the median age was 81 years (range 55-99 years). Signs and symptoms reported were cough (73\%), temperature $\geq 99.1^{\circ} \mathrm{F}$ (72\%), hypoxia (33\%), shortness of breath (27\%), sore throat (8\%), nasal congestion (8\%), myalgia (6\%), headache (6\%), and wheezing (4\%).

The most common underlying medical conditions among the 49 case-patients were heart disease (69\%), dementia (63\%), other neurologic disease (25\%), diabetes (18\%), chronic lung disease (14\%), and cancer (10\%). Eighteen case-patients (37\%) were in hospice or receiving palliative care. Pneumonia was clinically diagnosed in 9 $(18 \%)$ case-patients and confirmed by chest radiograph. Three case-patients (6\%) visited an emergency department and 9 (18\%) were hospitalized (median length of stay 7.3 days); none were intubated or admitted to the intensive care unit.

We collected nasopharyngeal or nasopharyngeal/ oropharyngeal swab specimens from 38 (78\%) of the 49 case-patients within a median of 3 days of symptom onset. Testing at a commercial laboratory detected HMPV in 5 (71\%) of 7 nasopharyngeal specimens by using the BioFire Respiratory Panel (20 targets), a reverse transcription PCR (RT-PCR) kit (BioFire Diagnostics, https://www.biofiredx.com). No other pathogens were detected. Thirty-one additional nasopharyngeal/oropharyngeal specimens were sent to the Centers for Disease Control and Prevention (Atlanta, GA, USA) and tested by using a singleplex real-time RT-PCR for HMPV (8). HMPV was detected in 10 (32\%) of 31 specimens. All 10 HMPV-positive specimens tested were characterized and found to be HMPV genotype A, subtype 2 (9). Laboratory confirmation of HMPV was obtained for 15 (39\%) of 38 case-patients tested. Respiratory infection was considered contributory to the deaths of 4 (8\%) case-patients; 3 were tested by RT-PCR, and 2 were HMPV positive.

In addition to standard precautions, other infection control interventions were implemented at the nursing home, including instituting contact and droplet precautions with either use of single rooms or cohorting cases for 10 days $(\approx 2$ incubation periods); suspending new admissions; restricting visitation; canceling group activities, including serving meals in the dining hall; intensifying hand hygiene and environmental cleaning; and extensive education for facility staff. Among staff, $8(<7 \%)$ of 120 self-reported respiratory symptoms during the outbreak. Staff who reported respiratory symptoms were furloughed. No laboratory testing was performed for symptomatic staff. Staff illnesses resulted in an average of 3 days of work missed per ill employee. Challenges identified during the outbreak response included 


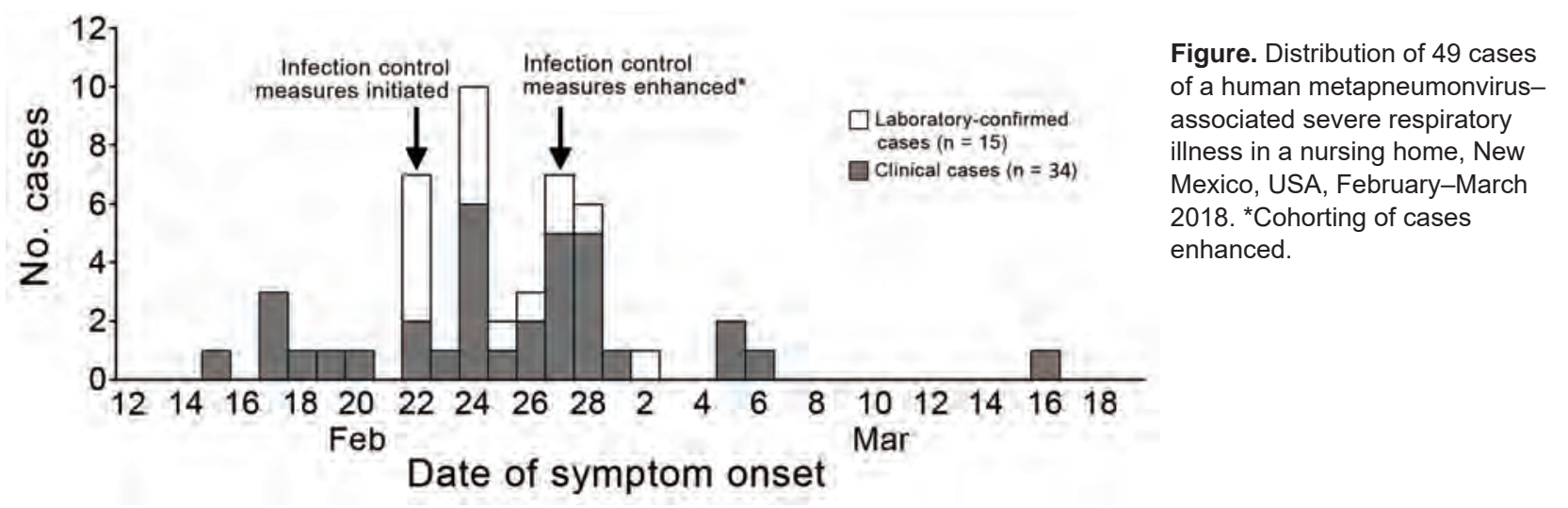

maintaining adequate staffing, maintaining supplies necessary for implementation of infection control precautions, the psychological hardship of restricting residents to their rooms, and difficulties controlling the movement of residents with dementia. The last reported case was on March 16, 2018.

Prompt identification of the pathogen within 2-3 days of specimen collection assisted providers and the facility in coordinating an effective response. Anecdotally, facility staff noted that pathogen identification also promoted credibility. Although diagnostic laboratory testing can be an additional expense, pathogen identification can be invaluable and cost can be reduced by not testing every case-patient once a pathogen has confidently been identified and other pathogens have been ruled out.

We report a large outbreak of HMPV-associated severe respiratory illness in a nursing home that affected $62 \%$ of residents. Respiratory illness outbreaks in nursing homes present unique challenges because of needs of the residents and structural configuration of the facility, which must be considered when implementing infection control measures. This outbreak demonstrates the need for considering and testing for HMPV during respiratory outbreaks in nursing homes and other residential care settings. Prompt recognition of respiratory outbreaks and institution of outbreak control measures are key to preventing disease spread, hospitalizations, and deaths.

\section{Acknowledgments}

We thank the facility staff of the nursing home who worked diligently to implement measures recommended by the New Mexico Department of Health and by Shifaq Kamili.

This study was supported by the Centers for Disease Control and Prevention.

\section{About the Author}

At the time of this study, Ms. Peña was an infectious disease epidemiologist at the New Mexico Department of Health, Santa Fe, NM. She is currently a physician in the Healthcare Associated Infections Program at the Tennessee Department of Health, Nashville, TN. Her research interests include community outreach, education, and response to emerging infectious diseases.

\section{References}

1. Haas LE, Thijsen SF, van Elden L, Heemstra KA. Human metapneumovirus in adults. Viruses. 2013;5:87-110. http://dx.doi.org/10.3390/v5010087

2. Widmer K, Zhu Y, Williams JV, Griffin MR, Edwards KM, Talbot HK. Rates of hospitalizations for respiratory syncytial virus, human metapneumovirus, and influenza virus in older adults. $\mathrm{J}$ Infect Dis. 2012;206:56-62. http://dx.doi.org/10.1093/infdis/jis309

3. Hamelin ME, Côté S, Laforge J, Lampron N, Bourbeau J, Weiss K, et al. Human metapneumovirus infection in adults with community-acquired pneumonia and exacerbation of chronic obstructive pulmonary disease. Clin Infect Dis. 2005;41:498-502. http://dx.doi.org/10.1086/431981

4. Boivin G, DeSerres G, Hamelin ME, Cote S, Argouin M, Tremblay G, et al. An outbreak of severe respiratory tract infection due to human metapneumovirus in a nursing home. Clin Infect Dis. 2007;44:1152-8. http://dx.doi.org/10.1086/513204

5. Walsh EE, Peterson DR, Falsey AR. Another piece of the puzzle: human metapneumovirus infections in adults. Arch Intern Med. 2008;168:2489-96. http://dx.doi.org/10.1001/archinte.168.22.2489

6. Liao RS, Appelgate DM, Pelz RK. An outbreak of severe respiratory tract infection due to human metapneumovirus in a long-term care facility for the elderly in Oregon. J Clin Virol. 2012;53:171-3. http://dx.doi.org/10.1016/j.jcv.2011.10.010

7. Centers for Disease Control and Prevention. The National Respiratory and Enteric Virus Surveillance System (NREVSS) human metapneumovirus national trends. Atlanta: the Centers [cited 2018 Aug 15]. https://www.cdc.gov/surveillance/nrevss/ hmpv/natl-trend.html.

8. Sakthivel SK, Whitaker B, Lu X, Oliveira DB, Stockman LJ, Kamili S, et al. Comparison of fast-track diagnostics respiratory pathogens multiplex real-time RT-PCR assay with in-house singleplex assays for comprehensive detection of human respiratory viruses. J Virol Methods. 2012;185:259-66. http://dx.doi.org/ 10.1016/j.jviromet.2012.07.010

9. van den Hoogen BG, Herfst S, Sprong L, Cane PA, Forleo-Neto E, de Swart RL, et al. Antigenic and genetic variability of human metapneumoviruses. Emerg Infect Dis. 2004;10:658-66. http://dx.doi.org/10.3201/eid1004.030393

Address for correspondence: Eileen Schneider, Centers for Disease Control and Prevention, 1600 Clifton Rd NE, Mailstop H24-5, Atlanta, GA, 30329-4027, USA; email: ees2@cdc.gov 


\section{Zoonotic Leishmaniasis, Bosnia and Herzegovina}

\section{Vito Colella, Adnan Hodžić, Roberta latta, Gad Baneth, Amer Alić, Domenico Otranto}

Author affiliations: Università degli Studi di Bari, Bari, Italy (V. Colella, R. latta, D. Otranto); University of Veterinary Medicine Vienna, Vienna, Austria (A. Hodžić); The Hebrew University of Jerusalem, Rehovot, Israel (G. Baneth); University of Sarajevo, Sarajevo, Bosnia and Herzegovina (A. Alić)

DOI: https://doi.org/10.3201/eid2502.181481

Leishmania infantum causes potentially life-threatening disease in humans. To determine the extent of the animal reservoir for this pathogen in Bosnia and Herzegovina, we tested dogs and cats. We found that a large proportion of dogs were exposed to or infected with $L$. infantum, indicating endemicity in dogs and zoonotic risk for humans.

A mong neglected tropical diseases, visceral leishmaniasis is one of the most deadly parasitic diseases in modern history. Worldwide, it causes an estimated 300,000 new cases and $\approx 20,000$ deaths each year (1). Leishmaniasis has been the hallmark of poverty-related diseases and of tropical infections in humans forced to migrate from and to conflict areas (1).

Like other countries in the Balkan area, Bosnia and Herzegovina is considered a hotspot for neglected infections of poverty (2). The economic, political, and social transformations of this country reflect the armed conflicts of the recent past; $16.9 \%$ of the population lives under the national poverty level (3). In Bosnia and Herzegovina, leishmaniasis is considered hypoendemic, possibly because of lack of awareness among medical personnel (4). Although the first autochthonous cases of leishmaniasis in Bosnia and Herzegovina (in 4 children) occurred in 1949 and 1954 (5), during the past 10 years, only 7 patients in the capital city of Sarajevo have been hospitalized for this disease (4).

In 2013, 8.2\% of the soldiers of the Austrian Armed Forces deployed in peacekeeping missions in Bosnia and Herzegovina were exposed to Leishmania spp. (6). Despite small increases in reports of Leishmania infantum infection in human patients from Bosnia and Herzegovina, little information is available about dogs as reservoirs, the main recognized reservoir of zoonotic infection and the target of integrated control strategies. To determine the role of animals in the spread of leishmaniasis, we assessed their exposure to and infection with $L$. infantum. The study protocol was approved by the Ethical Committee of the Department of Veterinary Medicine of the University of Bari (Prot. UniBa 11/18).

In 2017, we tested blood samples from 408 dogs and 5 cats from different areas of Bosnia and Herzegovina for leishmaniasis (Table). To assess the exposure of dogs to Leishmania spp., we tested 180 dogs (free-roaming, clientowned, and shelter) for $L$. infantum antibodies by using an immunofluorescence antibody test (7); we tested all 408 dogs and 5 cats for the parasites' DNA by using real-time PCR (8). Samples that were positive by real-time PCR were further analyzed by conventional PCR for sequencing confirmation of the kinetoplast DNA (9) and of the partial internal transcribed spacer 2 ribosomal RNA (10).

Overall, we obtained positive results for 16.7\% (95\% CI $11.2 \%-22 \%$ ) of dogs by immunofluorescence antibody test and 3.1\% (95\% CI 1.5\%-4.8\%) of dogs by PCR (Table), indicating that a large proportion of the canine population from Bosnia and Herzegovina has been exposed to or is infected by $L$. infantum. In addition, we obtained positive results for a client-owned cat from Sarajevo tested by real-time PCR. Consensus sequences of the partial internal transcribed spacer

\begin{tabular}{lcc}
\hline $\begin{array}{l}\text { Table. Positivity to Leishmania infantum of dogs and cats kept in different living conditions and from selected geographic areas in } \\
\text { Bosnia and Herzegovina* }\end{array}$ & IFAT positive/total (\%) & Real-time PCR positive/total (\%) \\
\hline Animal characteristic & $30 / 180(16.7)$ & $13 / 413(3.1)$ \\
\hline All tested & & \\
\hline Living condition & $14 / 96(14.6)$ & $0 / 142$ \\
Shelter & $10 / 65(15.3)$ & $3 / 127(2.4)$ \\
Stray & $6 / 19(31.6)$ & $10 / 134(7.5)$ \\
Client-owned & & $7 / 142(4.9)$ \\
\hline Geographic origin & $1 / 22(4.5)$ & $0 / 63$ \\
Sarajevo & $2 / 56(3.5)$ & $0 / 44$ \\
Gračanica & $9 / 39(23.1)$ & $0 / 40$ \\
Zenica & $12 / 34(35.3)$ & $0 / 40$ \\
Goradže & 0 & $6 / 36(16.7)$ \\
Bihać & $4 / 6(66.7)$ & $0 / 14$ \\
Mostar & $2 / 14(14.3)$ & $0 / 12$ \\
Livno & $\mathrm{ND}$ & $0 / 12$ \\
Odžak & $\mathrm{ND}$ & $0 / 9$ \\
Gornji Vakuf-Uskoplje & $0 / 9$ & \\
Tuzla & & \\
\hline
\end{tabular}

*IFAT, immunofluorescence antibody test; ND, not done. 
2 ribosomal RNA and kinetoplast DNA from all animals with positive test results displayed $100 \%$ identity to the nucleotide sequences of $L$. infantum and are available in GenBank (accession nos. MH605316 and MH605317).

After World War II, leishmaniasis was frequently reported for humans and dogs in countries bordering Bosnia and Herzegovina, such as Croatia and Serbia, (4), whereas no information was available for leishmaniasis in dogs in Bosnia and Herzegovina. Our findings indicate the presence of $L$. infantum in the canine reservoir population in Bosnia and Herzegovina and support the pathogen's spread across the country and the consequent infection of soldiers deployed in this region and persons living in this resourcelimited setting. Although infections in children and soldiers from Sarajevo and its neighboring municipalities in central Bosnia (i.e., Fojnica, Kakanj, and Gornji Vakuf-Uskoplje) have been reported, we show that $L$. infantum-infected dogs are broadly distributed throughout the country, indicating a potential risk for more human infections.

In Bosnia and Herzegovina, diagnosis and treatment of leishmaniasis is possible only in specialized hospitals, which entails admission of patients at a progressive and often lethal stage of the disease (4). The World Health Organization prioritizes efforts to control or eliminate leishmaniasis in countries where the incidence of the infection in humans is high and advocates for passive surveillance in countries where leishmaniasis is not endemic. Although these efforts are leading to large improvements in the control of the disease in humans, this direction is not optimal for unraveling and fighting neglected leishmaniasis in low-resource settings where no information about animal reservoirs is available, such as Bosnia and Herzegovina. The high percentage and wide distribution of dogs exposed to $L$. infantum infections implies the existence of autochthonous transmission in the country, thus suggesting that so far, zoonotic leishmaniasis has been neglected in Bosnia and Herzegovina.

Although Bosnia and Herzegovina is located near wealthy countries (Europe includes most of the highly industrialized G8 nations), it ranks in the last quartile of the global human developmental index. Hence, a greater political commitment of European Union policy makers is central to implementation of a proper surveillance system to promptly identify animal reservoirs of $L$. infantum and favor timely diagnosis and treatment for human populations living in poverty and for domestic animals. These data should encourage a One Health approach to provide comprehensive tools and policy recommendations to fight neglected leishmaniasis in Bosnia and Herzegovina.

The European Network for Neglected Vectors and Vector-Borne Infections (EurNegVec TD1303) supported this study.

\section{About the Author}

Dr. Colella is a research fellow at the Department of Veterinary Medicine, University of Bari, Italy. His main research activities focus on the epidemiology of neglected zoonotic diseases of dogs and cats.

\section{References}

1. World Health Organization. Leishmaniasis [cited 2018 Sep 17]. http://www.who.int/leishmaniasis/en

2. Hotez PJ, Gurwith M. Europe's neglected infections of poverty. Int J Infect Dis. 2011;15:e611-9. http://dx.doi.org/10.1016/j. ijid.2011.05.006

3. The World Bank. Bosnia and Herzegovina [cited 2018 Sep 17]. https://data.worldbank.org/country/bosnia-and-herzegovina

4. Alvar J, Vélez ID, Bern C, Herrero M, Desjeux P, Cano J, et al.; WHO Leishmaniasis Control Team. Leishmaniasis worldwide and global estimates of its incidence. PLoS One. 2012;7:e35671. http://dx.doi.org/10.1371/journal.pone.0035671

5. Gvozdenovic M, Miladinovic Z. Epidemiological studies on two autochthonous cases of kala-azar in Bosnia [in undetermined language]. Med Arh. 1959;12:95-101.

6. Obwaller AG, Köhsler M, Poeppl W, Herkner H, Mooseder G, Aspöck H, et al. Leishmania infections in Austrian soldiers returning from military missions abroad: a cross-sectional study. Clin Microbiol Infect. 2018;24:1100e1-6. http://dx.doi.org/ 10.1016/j.cmi.2018.01.006

7. Otranto D, Testini G, Dantas-Torres F, Latrofa MS, Diniz PP, de Caprariis D, et al. Diagnosis of canine vector-borne diseases in young dogs: a longitudinal study. J Clin Microbiol. 2010;48:3316-24. http://dx.doi.org/10.1128/JCM.00379-10

8. Francino O, Altet L, Sánchez-Robert E, Rodriguez A, Solano-Gallego L, Alberola J, et al. Advantages of real-time PCR assay for diagnosis and monitoring of canine leishmaniosis. Vet Parasitol. 2006;137:214-21. http://dx.doi.org/10.1016/ j.vetpar.2006.01.011

9. Cortes S, Rolão N, Ramada J, Campino L. PCR as a rapid and sensitive tool in the diagnosis of human and canine leishmaniasis using Leishmania donovani s.1.-specific kinetoplastid primers. Trans R Soc Trop Med Hyg. 2004;98:12-7. http://dx.doi.org/ 10.1016/S0035-9203(03)00002-6

10. de Almeida ME, Steurer FJ, Koru O, Herwaldt BL, Pieniazek NJ, da Silva AJ. Identification of Leishmania spp. by molecular amplification and DNA sequencing analysis of a fragment of rRNA internal transcribed spacer 2. J Clin Microbiol. 2011;49:3143-9. http://dx.doi.org/10.1128/JCM.01177-11

Address for correspondence: Domenico Otranto, Università degli Studi di Bari, Strada Provinciale per Casamassima km 3, 70010, Valenzano (BA) 70010, Italy; email: domenico.otranto@uniba.it 


\section{Clinical Characteristics of Ratborne Seoul Hantavirus Disease}

\section{Jan Clement, James W. LeDuc, Lorraine M. McElhinney, Jean-Marc Reynes, Marc Van Ranst, Charles H. Calisher}

Author affiliations: University of Leuven, Leuven, Belgium (J. Clement, M. Van Ranst); University of Texas Medical Branch, Galveston, Texas, USA (J.W. LeDuc); Animal and Plant Health Agency, Weybridge, UK (L.M. McElhinney); Institut Pasteur, Paris, France (J.-M. Reynes); Colorado State University, Fort Collins, Colorado, USA (C.H. Calisher)

DOI: https://doi.org/10.3201/eid2502.181643

Although Seoul orthohantavirus is the only globally spread hantavirus pathogen, few confirmed human infections with this virus have been reported in Western countries, suggesting lower medical awareness of the milder, transient, and often chameleon-like symptoms of this zoonosis. We describe lesser known clinical and laboratory characteristics to help improve underreporting of this virus.

$\mathrm{R}_{\mathrm{i}}$ ecent reports from several Western countries, including the United States, have described an ill-known hantavirus disease, commonly called hemorrhagic fever with renal syndrome (HFRS), induced by Seoul orthohantavirus (SEOV) and spread by infected wild, laboratory, and pet rats. These reports might bring to an end the longmaintained concept that human hantavirus infections were to be distinguished between HFRS in the Old World and hantavirus cardiopulmonary syndrome (HCPS) in the New World (1). New World human hantavirus illnesses already described in 1993 were HFRS cases, not HCPS cases, in leptospirosis-suspected patients with acute kidney injury (AKI) and thrombocytopenia, whereas the earliest characterized hantavirus pathogen in the United States was not Sin Nombre orthohantavirus (SNV) but SEOV, isolated from a wharf rat in Philadelphia in 1984 (1).

Geographic distributions of most hantaviruses are limited to the biotope area of their respective natural hosts. The exception is SEOV, which is distributed worldwide, because of the omnipresence of its synanthropic hosts, the brown (Rattus norvegicus) and black (R. rattus) rats. SEOV likely arose in northern China, then spread to Europe and subsequently to the Americas in the 18th century $(2,3)$. By the early 1980s, SEOV-infected rats were detected in Asia, Africa, Europe, and the Americas (4). SEOV strains are all closely related, probably reflecting the recent worldwide spread of rats, speculated to be driven by introduction via sea ports and railways, and resulting now in chronic rat SEOV endemicity $(2,3)$.

Human SEOV infections have long been recognized in all those areas, including the United States $(1,4)$. Consequently, it is counterintuitive to expect that the scant number of SEOV-induced HFRS cases reported so far in Western countries reflects the actual situation, in stark contrast to the many SEOV cases documented in Asia, particularly in South Korea and China, both registering $>90 \%$ of all hantavirus cases worldwide, of which $\geq 25 \%$ are caused by SEOV $(3,5)$. We stress the diagnostic challenge inherent to milder (case-fatality rate $\pm 1 \%$ ), transient, and atypical hantavirus infections, some of which might represent SEOV infections.

HFRS and SEOV HFRS are characterized by the same prodromal symptoms for 3-5 days as for HCPS: fever, myalgia, malaise, and gastrointestinal discomfort (5). All HFRS forms show not only AKI, ranging from strictly normal to severely impeded renal function, but also rapidly changing degrees of proteinuria, microhematuria, and thrombocytopenia (5). However, established presence or absence of initial proteinuria and microhematuria has not been investigated so far in largescale SNV HCPS studies.

Proteinuria and microhematuria, although transient, are considered severity indicators for $\operatorname{HFRS}(5,6)$. The rapidity of increasing/decreasing proteinuria is virtually pathognomonic for HFRS and was noted as early as 1964 . Epidemics of a then ill-defined fever called epidemic hemorrhagic fever, which was later proven serologically to be a wild rat induced HFRS (7), was present principally in the back alleys of Osaka, Japan, and characterized by marked but transient proteinuria that peaked in 32 casepatients on day 6 postonset of symptoms and disappeared completely on day 7 in mild cases and on approximately day 12 in those with severe AKI (8). Moreover, severity of proteinuria was found to be predictive of overall epidemic hemorrhagic fever clinical severity, as confirmed 53 years later in 70 case-patients infected with Puumala orthohantavirus; proteinuria (30\% of nephrotic range), which peaked on day 5 postonset of symptoms, decreased almost completely on day 11, whereas serum creatinine levels peaked on day 9 (6).

Until recently, sudden AKI with nephrotic-range proteinuria and microhematuria was considered a rare nephrologic triad in previously healthy young adults; these adults constituted most HFRS case-patients. AKI with proteinuria, after acute tubular necrosis, is sometimes ascribed to the effect of nonsteroidal antiinflammatory drugs (NSAIDs). Because NSAIDs are often prescribed for the influenza-like myalgiae preceding HFRS, these drugs can obscure the real ensuing cause of AKI (5). However, NSAIDs do not induce thrombocytopenia or the other biochemical hallmarks 
of HFRS (Appendix Table, https://wwwnc.cdc.gov/EID/ article/25/2/18-1643-App1.pdf).

In contrast to severe HCPS caused by SNV or Andes orthohantavirus (ANDV), HFRS cases can be a diagnostic puzzle involving several swollen organs and including the lungs (5). The 2 earliest documented hantavirus infections in Peru were 2 SEOV HFRS case-patients confirmed by reverse transcription PCR, but both case-patients had fatal HFRS with HCPS (9), thus further blurring the boundaries between the 2 syndromes. In Southeast Asia, where the wild rat was and is the major reservoir for pathogenic hantaviruses, HFRS with liver involvement, imitating virus hepatitis, was moreover proposed as a new clinical entity (10).

Finally, laboratory confirmation of diagnosis, even by an expert clinician, can be confounded by use of current commercial serologic assays that use antigens having weak or no cross-reactivity with murine SEOVs, such as European arvicoline Puumala orthohantavirus or American sigmodontine SNV/Andes orthohantavirus. Close attention should be paid to the multifaceted diagnosis of SEOV infection (Appendix Table) in patients exposed to brown or black rat excreta, including pet rat owners.

\section{Acknowledgments}

We thank Sanne Vellinga and Paul Arnouts for their helpful ultrasound measurements of renal size in case-patients during an outbreak of HFRS caused by Puumala virus in Brasschat and Turnhout, Belgium, during 2018.

\section{About the Author}

Dr. Clement is a nephrologist at the National Reference Centre for Hantavirus Infections, Laboratory of Clinical and Epidemiological Virology and Rega Institute for Medical Research, University of Leuven, Leuven, Belgium. His research interests are emerging infections, particularly hantavirus infections, and their effects on renal issues.

\section{References}

1. Clement J, Maes P, Van Ranst M. Hemorrhagic fever with renal syndrome in the New, and hantavirus pulmonary syndrome in the Old World: paradi(se)gm lost or regained? Virus Res. 2014;187:55-8. http://dx.doi.org/10.1016/ j.virusres.2013.12.036

2. Lin XD, Guo WP, Wang W, Zou Y, Hao ZY, Zhou DJ, et al. Migration of Norway rats resulted in the worldwide distribution of Seoul hantavirus today. J Virol. 2012;86:972-81. http://dx.doi.org/10.1128/JVI.00725-11

3. Kim WK, No JS, Lee SH, Song DH, Lee D, Kim JA, et al. Multiplex PCR-based next-generation sequencing and global diversity of Seoul virus in humans and rats. Emerg Infect Dis. 2018;24:249-57. http://dx.doi.org/10.3201/eid2402.171216

4. LeDuc JW, Smith GA, Childs JE, Pinheiro FP, Maiztegui JI, Niklasson B, et al. Global survey of antibody to Hantaan-related viruses among peridomestic rodents. Bull World Health Organ. 1986;64:139-44.

5. Clement J. Acute kidney injury and hantavirus disease. In: Turner N, Lameire N, Goldsmith D, Winearls C, Himmelfarb J, Remuzzi G. eds. Oxford textbook of clinical nephrology. 4th ed. Oxford: Oxford University Press; 2015. p. 2059-66.

6. Mantula PS, Outinen TK, Clement JPG, Huhtala HS, Pörsti IH, Vaheri A, et al. Glomerular proteinuria predicts the severity of acute kidney injury in Puumala hantavirus-induced tubulointerstitial nephritis. Nephron. 2017;136:193-201. http://dx.doi.org/10.1159/000459634

7. Lee HW, Lee PW, Tamura M, Tamura T, Okuno Y. Etiological relation between Korean hemorrhagic fever and epidemic hemorrhagic fever in Japan. Biken J. 1979;22:41-5.

8. Tamura M. Occurrence of epidemic hemorrhagic fever in Osaka city: first cases found in Japan with characteristic feature of marked proteinuria. Biken J. 1964;7:79-94.

9. García PM, Percy S, Herrera AL, Donaires F, Alvarez C, Arrasco J, et al. Etiologic confirmation of the first two cases of human hantavirosis in Peru [in Spanish]. Rev Peru Med Exp Salud Publica. 2011;28:566-7.

10. Wong TW, Chan YC, Joo YG, Lee HW, Lee PW, Yanagihara R. Hantavirus infections in humans and commensal rodents in Singapore. Trans R Soc Trop Med Hyg. 1989;83:248-51. http://dx.doi.org/10.1016/0035-9203(89)90666-4

Address for correspondence: Jan Clement, Laboratory of Clinical and Epidemiological Virology, University of Leuven, U.Z. Gasthuisberg, 3000 Leuven, Belgium; email: jan.clement.dr@telenet.be 


\section{etymologia}

\section{Cochliomyia hominivorax [kok"le-o-mi'yə]}

7rom the Greek kochlias ("snail with a spiral shell") + myia ("fly") and the Latin hominis ("man") + vorax ("consuming"), Cochliomyia hominivorax, or the New World screwworm fly (formerly Callitroga [Greek kallos, "beautiful," + trogein, "to gnaw"] americana), was first described by French entomologist Charles Coquerel in 1858. C. hominivorax larvae enter wounds and feed on living tissue, and if untreated, infestations can be fatal. C. hominivorax was eliminated in the United States in 1982 and in much of Central America in the 1990s, although outbreaks associated with reimportations in infected humans and animals continue to occur.

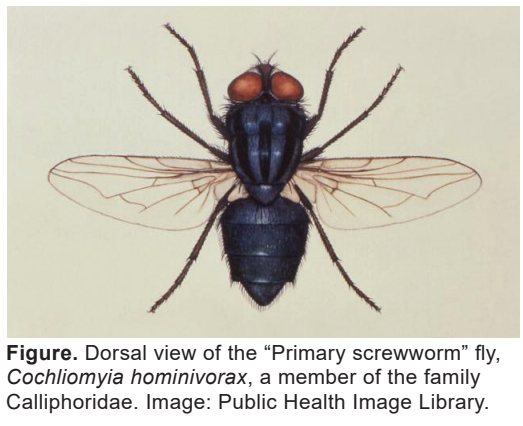

\section{Source}

1. Dear JP. A revision of the New World chrysomyini (Diptera: Calliphoridae). Revista Brasileira de Zoologica. 1985;3:109-69. http://dx.doi.org/10.1590/S0101-81751985000300001

Address for correspondence: Ronnie Henry, Centers for Disease Control and Prevention, 1600 Clifton Rd NE, Mailstop E28, Atlanta, GA 30329-4027, USA; email: boq3@cdc.gov

DOI: https://doi.org/10.3201/eid2502.ET2502

\section{Mycobacterium lepromatosis Lepromatous Leprosy in US Citizen Who Traveled to Disease-Endemic Areas}

\author{
Gaurav Sharma, Vishnu Dutt Sharma \\ Author affiliations: University of Miami, Miami, Florida, USA \\ (G. Sharma); National Jalma Institute for Leprosy and Other \\ Mycobacterial Diseases, Agra, India (V.D. Sharma) \\ DOI: https://doi.org/10.3201/eid2502.171895
}

To the Editor: Virk et al. (1) reported a Mycobacterium lepromatosis infection in a US citizen with a history of multiple international travels and concluded that M. lepromatosis lepromatous leprosy is a travel-related hazard for travelers to endemic areas. The conclusions drawn, however, need extensive support of thoroughly conducted case studies before generalizing $M$. lepromatosis as a travel-related hazard.

In the case report, the exact source of $M$. lepromatosis infection was unclear. Moreover, experimental evidence used in this work are not enough to prove that M. lepromatosis is a travel-related hazard. Confirming a source of infection by DNA fingerprinting of $M$. lepromatosis can be ideal to rule out infection from unreported native patients or environmental reservoirs (2).

It is possible that the patient in this report may have contracted $M$. lepromatosis infection as a result of his hostsusceptible genetic factors. Host genetic susceptibility to leprosy is complicated because of the genetics of M. lepromatosis, interaction between genetic and environmental factors, gene-gene interactions, and ethnicity (3). Host genetics plays a major role in determining a person's risk of developing clinical leprosy. Thus, even a short trip to a leprosy-endemic country is sufficient for a host susceptible to M. lepromatosis to acquire an infection. The host 
immune response influences the course of leprosy infection; it is challenging to understand the genetics of disease susceptibility and immunopathogenesis of leprosy $(4,5)$.

With an inference of only a single case study, it is hard to say that $M$. lepromatosis lepromatous leprosy is a travel-related hazard for all US citizens. More surveillance data, such as patients' immunity toward the disease, their genetic susceptibility, and travel history, are needed to explore the travel-related hazard. In addition, evolutionary knowledge and how widely the disease is circulating in nonendemic regions will help in understanding the nature of the disease.

\section{References}

1. Virk A, Pritt B, Patel R, Uhl JR, Bezalel SA, Gibson LE, et al. Mycobacterium lepromatosis lepromatous leprosy in US citizen who traveled to disease-endemic areas. Emerg Infect Dis. 2017;23:1864-6. http://dx.doi.org/10.3201/eid2311.171104
2. Singh P, Benjak A, Schuenemann VJ, Herbig A, Avanzi C, Busso P, et al. Insight into the evolution and origin of leprosy bacilli from the genome sequence of Mycobacterium lepromatosis. Proc Natl Acad Sci U S A. 2015;112:4459-64. http://dx.doi.org/10.1073/pnas.1421504112

3. Pinheiro RO, de Souza Salles J, Sarno EN, Sampaio EP. Mycobacterium leprae-host-cell interactions and genetic determinants in leprosy: an overview. Future Microbiol. 2011; 6:217-30. http://dx.doi.org/10.2217/fmb.10.173

4. Araújo S, Lobato J, Reis EM, Souza DOB, Gonçalves MA, Costa AV, et al. Unveiling healthy carriers and subclinical infections among household contacts of leprosy patients who play potential roles in the disease chain of transmission. Mem Inst Oswaldo Cruz. 2012;107(Suppl 1):55-9. http://dx.doi. org/10.1590/S0074-02762012000900010

5. Blake LA, West BC, Lary CH, Todd JR IV. Environmental nonhuman sources of leprosy. Rev Infect Dis. 1987;9:562-77. http://dx.doi.org/10.1093/clinids/9.3.562

Address for correspondence: Gaurav Sharma, Department of Chemistry, University of Miami, 1301 Memorial Dr, Coral Gables, FL 33146, USA; email: gxs183@miami.edu

\section{Corrections}

\section{Vol. 24, No. 12}

In Figure 1 of the article Genomic Characterization of $\beta$-Glucuronidase-Positive Escherichia coli O157:H7 Producing Stx2a (Y. Ogura et al.), Shiga toxinproducing Escherichia coli $\mathrm{O} 157$ was mislabeled several times, and the term STEC was incompletely defined. The corrected figure is shown, and the article has been corrected online (https://wwwnc.cdc.gov/eid/article/24/12/18-0404_article).

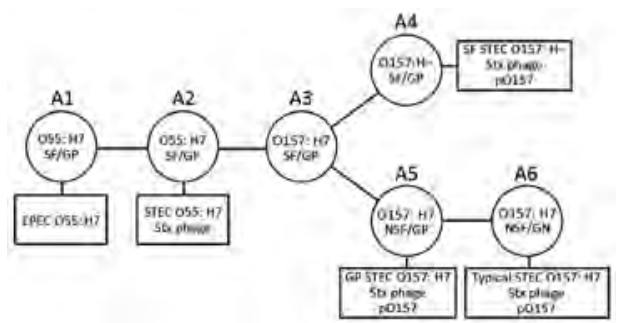

Vol. 25, No. 1

Table 3 misstated the number of animals tested during 2001-2004 and the first author's biographical sketch was incorrect in Multiple Introductions of Domestic Cat Feline Leukemia Virus in Endangered Florida Panthers (E.S. Chiu et al.). The article has been corrected online (https://wwwnc.cdc.gov/eid/article/25/1/18-1347_article).

Author Sang-Ho Choi's name was listed incorrectly and author affiliations were unclear in Clinical and Radiologic Characteristics of Human Metapneumovirus Infections in Adults, South Korea (H.J. Koo et al.). The article has been corrected online (https://wwwnc.cdc.gov/ eid/article/25/1/18-1131_article).

Two locations in Figure 1 were shown incorrectly in Risk Factors for Elizabethkingia Acquisition and Clinical Characteristics of Patients, South Korea (M.H. Choi et al.). , and the article has been corrected online (https://wwwnc.cdc.gov/eid/article/25/1/17-1985_article). 


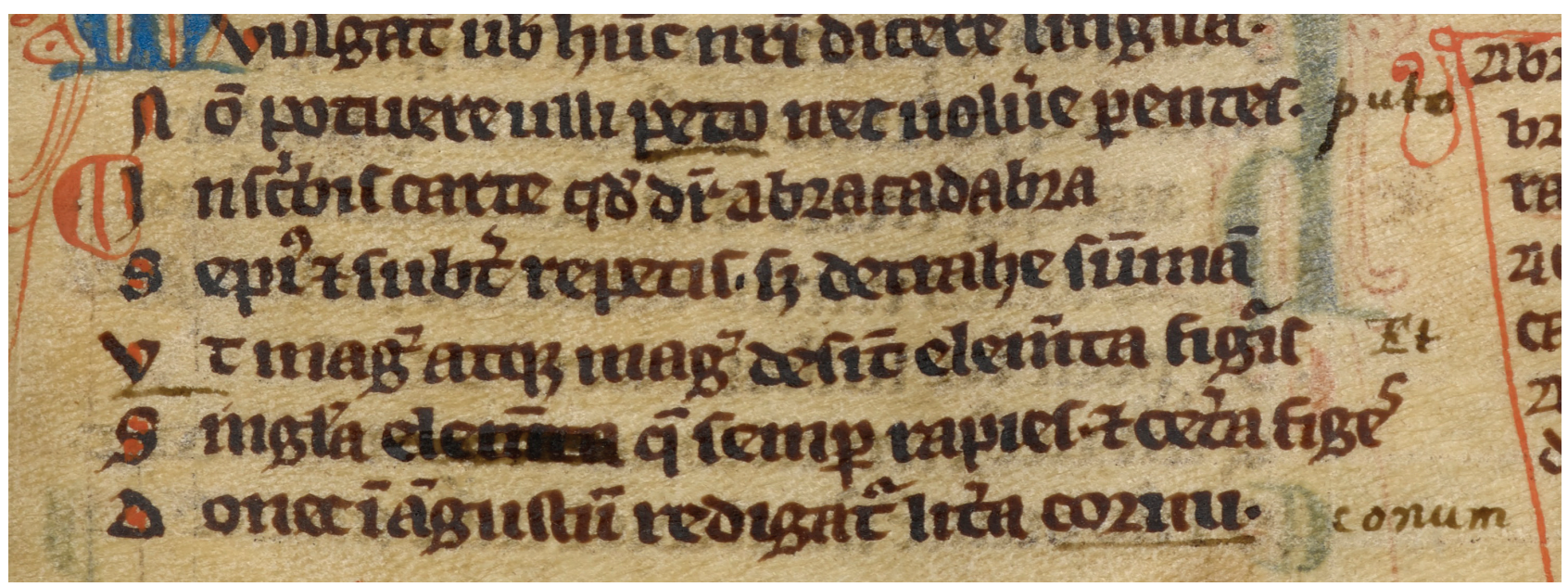

Quintus Serenus Sammonicus (c. 2nd century CE-212 CE), Liber Medicinalis (detail). Unknown transcriber, Abbey of St. Augustine, Canterbury, England. Parchment from 13th century. 7" x 4.7"/180 mm x 120 mm. British Library, London, UK. Public Domain in most countries other than the United Kingdom.

\title{
Malaria Elimination-Not Just a Bunch of Hocus-Pocus
}

\author{
Byron Breedlove and Paul M. Arguin
}

A bracadabra! This ubiquitous incantation remains a staple of stage magicians, children's stories, and purveyors of pseudoscience. The exact origin of the term engenders debate, and pundits have suggested various ancient Aramaic, Hebrew, and Latin terms as the source. What is known is that its first appearance in print is found in the surviving fragments of the third century CE book Liber Medicinalis (sometimes known as De Medicina Praecepta Saluberrima) written by Quintus Serenus Sammonicus. Though Serenus was the physician to the Roman Emperor Caracalla and considered "the learned man of his age," few details of his life are known. ${ }^{1}$

Following the practice of his time, Serenus composed his teachings as didactic poetry. The surviving fragment of Liber Medicinalis includes popular treatments, remedies, and antidotes written in verse.

Among those remedies, Serenus proposed a magical procedure based on the wizardly word Abracadabra for treating "semitertian" fever, known today as malaria. That malady devastated ancient Rome and was sometimes also called "rage of the Dog Star" as the ascendance of Sirius presaged the oppressive heat and humidity thought to cause fever and illness. Some wealthy Romans sought

Author affiliation: Centers for Disease Control and Prevention, Atlanta, Georgia, USA

DOI: https://doi.org/10.3201/eid2502.AC2502 to escape this scourge by moving to villas they had built in the hills away from the "bad air" (malum aeris in Latin) emanating from the marshes and wetlands surrounding Rome. With a bit of alchemical panache, Serenus offered another approach documented in chapter 51 of the Liber Medicinalis:

Inscribis chartae, quod dicitur Abracadabra:

Saepius et subter repetas, sed detrahe summae,

Et magis atque magis desint elementa figuris:

Singula quae semper rapies et coetera figes,

Donec in angustam redigatur litera conum.

His lino nexis collum redimire memento

Various translations of the Latin are available. This one comes from by A. C. Wootton, who, for three decades, served as editor of the trade journal Chemist and Druggist.

"Write several times on a piece of paper the word 'Abracadabra,' and repeat the words in the lines below but take away letters from the complete word and let the letters fall away one at a time in each succeeding line. Take these away ever, but keep the rest until the writing is reduced to

${ }^{1}$ More information about the context of Serenus' writing and a scholarly hypothesis about his life are available in this essay: Edward Champlin. Serenus Sammonicus. Harvard Studies in Classical Philology. 1981;89:189-212 [cited 2018 Dec 11]. https://www.jstor.org/ stable/311172; http://dx/doi.org/10.2307/311172 


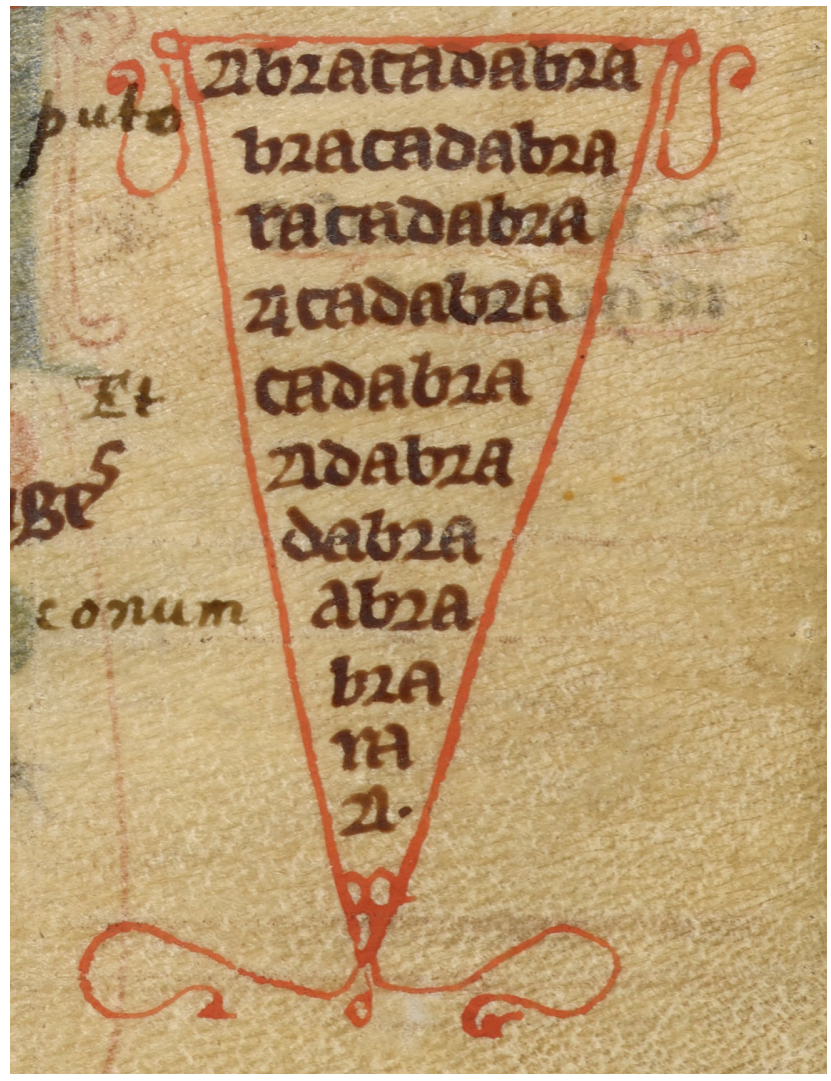

Liber Medicinalis (detail).

a narrow cone. Remember to tie these papers with flax and bind them round the neck."

The idea underscoring this magical thinking was that by making the letters disappear, the illness would likewise vanish. This month's cover image shows a 13th century transcription of this page from Liber Medicinalis and comes from the Benedictine Abbey of St. Augustine, Canterbury, England. Like a slice of pie resting in the margin of the book, the Abracadabra cone is visible near the lower right of the parchment. The original Latin, rendered painstakingly in ornate Gothic and Gothic cursive, explains Serenus' process for creating the triangular charm inscribed with the enchantment and for wearing it as an amulet. Perhaps to hedge his bets, Serenus also suggested smearing lion's fat on one's body or wearing a domestic cat's skin festooned with jewels to ward off these fevers.

Feline byproducts, bejeweled or otherwise, magic words, and amulets all failed, and malaria continues to be one of the most severe global public health problems. Fortunately, though, the scientists of today have been a bit more effective through core interventions of surveillance, diagnosis, prevention, and treatment. In many countries, using artemisinin-based combination therapy, undertaking vector control measures such as using long-lasting insecticides on bed nets and interior walls of houses, and strengthening public health infrastructure have successfully reduced cases and deaths.

While progress is starting to plateau in many highly malaria-endemic countries, several other countries either have eliminated, or are on the verge of eliminating, malaria. Paraguay and Uzbekistan recently celebrated their initiation into the malaria elimination club, receiving certification by the World Health Organization (WHO). El Salvador and China have recently reached zero cases. Both countries will receive their official WHO certification when they have "proven, beyond reasonable doubt, that the chain of local transmission of all human malaria parasites has been interrupted nationwide for at least the past 3 consecutive years; and that a fully functional surveillance and response system that can prevent re-establishment of indigenous transmission is in place."

In just the past 10 years, the number of malaria-endemic countries has decreased from 108 (in 2008) to 90 (in 2018). In 2017, about half of all of the remaining malariaendemic countries had reported fewer than 10,000 cases per year. WHO has outlined a strategy to continue paring down that list of malaria-endemic countries, one by one, with ambitious targets through 2030. Peering into our crystal ball, we hope, one day, to see that final country on the list like Serenus' ultimate letter A and then Abracadabra -all gone.

\section{Bibliography}

1. British Library. Medical miscellany in prose and verse. Royal MS 12 E XXIII (2nd half of the 13th century) [cited 2018 Dec 12]. http://hviewer.bl.uk/IamsHViewer/Default.aspx?mdark=ark:/81055/ vdc_100000000277.0x000325

2. Centers for Disease Control and Prevention. Malaria [cited 2018 Dec 12]. https://www.cdc.gov/parasites/malaria/

3. Hempelmann E, Krafts K. Bad air, amulets and mosquitoes: 2,000 years of changing perspectives on malaria. Malar J. 2013;12:232. http://dx.doi.org/10.1186/1475-2875-12-232

4. Kreston R. Abracadabra! Discover. January 26, 2015 [cited 2018 Dec 11]. http://blogs.discovermagazine.com/bodyhorrors/ 2015/01/26/abracadabra/\#.XBPQb2B1K70

5. Marciniak S, Prowse TL, Herring DA, Klunk J, Kuch M, Duggan AT, et al. Plasmodium falciparum malaria in 1st-2nd century CE southern Italy. Curr Biol. 2016;26:R1220-2. http://dx.doi.org/10.1016/j.cub.2016.10.016

6. Sammonicus QS. Liber medicinalis verse 935-940. Latin text [cited 2018 Dec 21]. https://latin.packhum.org/loc/1515/1/0\#0

7. Shah S. The tenacious buzz of malaria. The Wall Street Journal. July 10, 2010 [cited 2018 Dec 21]. https://www.wsj.com/articles/ SB10001424052748704111704575354911834340450

8. Wootton AC. Chronicles of pharmacy [cited 2019 Jan 4]. https://openlibrary.org/books/OL175998M/Chronicles_of_pharmacy

9. World Health Organization. Malaria: certification process [cited 2018 Dec 19]. https://www.who.int/malaria/areas/elimination/ certification/en/

Address for correspondence: Byron Breedlove, EID Journal, Centers for Disease Control and Prevention, 1600 Clifton Rd NE, Mailstop H16-2,

Atlanta, GA 30329-4027, USA; email: wbb1@cdc.gov 


\section{EMERGING INFECTIOUS DISEASES}

\section{Upcoming Issue}

- Global Systematic Review and Patient Meta-Analysis of Encouraging Treatment Outcomes for Children with Extensively Drug-Resistant Tuberculosis

- University-Based Serogroup B Meningococcal Disease Outbreaks, United States, 2013-2018

- Bacillus Calmette-Guérin Cases Reported to the National Tuberculosis Surveillance System, United States, 2004-2015

- Cross-Border Movement of Highly Drug-Resistant Mycobacterium tuberculosis Strain through Torres Strait, Australia, 2010-2015

- Epidemiology of Extrapulmonary Tuberculosis among Inpatients in China, 2008-2017

- Donor-Derived Genotype 4 Hepatitis E Virus Infection, Hong Kong, China, 2018

- Utility of Whole-Genome Sequencing to Ascertain Locally Acquired Cases of Coccidioidomycosis, Washington, USA

- Increased Risk for Invasive Group A Streptococcus Disease for Household Contacts of Scarlet Fever Cases, England, 2011-2016

- Window Prophylaxis for Children Exposed to Tuberculosis, Houston, Texas, USA 2007-2017

- Emergence and Spread of Neisseria gonorrhoeae with Mosaic penA alleles Associated with Decreased Susceptibility and Resistance to Cephalosporins, South Korea, 2012-2017

- Human-Origin Influenza A(H3N2) Reassortant Viruses in Swine, Southeastern Mexico

- Mycobacterium avium in Community and Household Water, Suburban Philadelphia, Pennsylvania, USA, 2010-2012

- SNP-IT Method for Identifying Subspecies and Associated Lineages of Mycobacterium tuberculosis Complex

- Cronobacter sakazakii in Clinical Samples, Europe, 2017

- Acute Flaccid Myelitis Associated with Enterovirus D68 in Children, Argentina, 2016

- Listeria monocytogenes Associated with Pasteurized Chocolate Milk, Ontario, Canada

- Role of Backyard Flocks in Transmission Dynamics of Highly Pathogenic Avian Influenza A(H5N8) Clade 2.3.4.4, France, 2016-2017

- Seroprevalence of Enterovirus D68 in Children and Adults before 2014 Outbreak, Kansas City, Missouri, USA

- Confirmed Case of Buruli Ulcer, Senegal, 2018

- Rectal Lymphogranuloma Venereum, Buenos Aires, Argentina

- Detection of Influenza C Virus Infection among Hospitalized Patients in Cameroon

Complete list of articles in the March issue at

http://www.cdc.gov/eid/upcoming.htm

\section{Upcoming Infectious} Disease Activities

March 4-7, 2019

Conference on Retroviruses and

Opportunistic Infections

Seattle, WA, USA

http://www.croiconference.org/

April 3-5, 2019

National Foundation for Infectious Diseases

2019 Annual Conference on Vaccinology Research

Baltimore, MD, USA

https://www.eventscribe.com/2019/NFIDACVR/

April 13-16, 2019

European Congress of Clinical Microbiology

and Infectious Diseases

29th Annual Congress

Amsterdam, Netherlands

http://www.eccmid.org/

April 16-18, 2019

International Conference on One Health

Antimicrobial Resistance

Amsterdam, Netherlands

https://www.escmid.org/ICOHAR2019/

May 5-9, 2019

ASM Clinical Virology Symposium

Savannah, GA, USA

https://10times.com/clinical-virology-symposium

June 20-24, 2019

ASM Microbe 2019

San Francisco, CA, USA

https://www.asm.org/index.php/

asm-microbe-2018

June 23-28, 2019

Biology of Vector-borne Diseases

Six-Day Training Course

Moscow, ID, USA

https://www.uidaho.edu/cals/center-for-

health-in-the-human-ecosystem/education/

vector-borne-diseases

July 14-17, 2019

STI and HIV 2019 World Congress

Vancouver, Canada

stihiv2019vancouver.com

July 20-24, 2019

American Society for Virology

Minneapolis, MN, USA

www.asv.org

July 21-24, 2019

International Aids Society 2019

Mexico City, Mexico

www.ias2019.org

August 12-23, 2019

16th International Course on Dengue, Zika and other Emergent Arboviruses 12-23 August 2019 Havana, Cuba

http://instituciones.sld.cu/ipk/

16th-international-course-on-dengue-zika-andother-emergent-arboviruses/

August 28-September 1, 2019

OPTIONS X for the Control of Influenza

Suntec, Singapore

https://www.isirv.org/site/

Email announcements to EIDEditor

(eideditor@cdc.gov). Include the event's date,

location, sponsoring organization, and a website.

Some events may appear only on EID's website,

depending on their dates. 


\section{Earning CME Credit}

To obtain credit, you should first read the journal article. After reading the article, you should be able to answer the following, related, multiple-choice questions. To complete the questions (with a minimum $75 \%$ passing score) and earn continuing medical education (CME) credit, please go to http://www.medscape.org/journal/eid. Credit cannot be obtained for tests completed on paper, although you may use the worksheet below to keep a record of your answers.

You must be a registered user on http://www.medscape.org. If you are not registered on http://www.medscape.org, please click on the "Register" link on the right hand side of the website.

Only one answer is correct for each question. Once you successfully answer all post-test questions, you will be able to view and/or print your certificate. For questions regarding this activity, contact the accredited provider, CME@medscape. net. For technical assistance, contact CME@medscape.net. American Medical Association's Physician's Recognition Award (AMA PRA) credits are accepted in the US as evidence of participation in CME activities. For further information on this award, please go to https://www.ama-assn.org. The AMA has determined that physicians not licensed in the US who participate in this CME activity are eligible for AMA PRA Category 1 Credits $^{\mathrm{TM}}$. Through agreements that the AMA has made with agencies in some countries, AMA PRA credit may be acceptable as evidence of participation in CME activities. If you are not licensed in the US, please complete the questions online, print the AMA PRA CME credit certificate, and present it to your national medical association for review.

\section{Article Title}

\section{Human Pasteurellosis Health Risk for Elderly Persons Living with Companion Animals}

\section{CME Questions}

1. Your patient is a 58-year-old woman with respiratory symptoms after a dog bite. According to the retrospective study and comprehensive review by Körmöndi and colleagues, which of the following statements about baseline characteristics and epidemiological features of patients with Pasteurella spp. infection is correct?

A. The rate of human pasteurellosis remained stable over the 13 years of the study

B. One-quarter of patients were $>60$ years old

C. Invasive infections were more common than localized infections and were caused by animal bites or scratches

D. $68.7 \%$ of pasteurella strains were Pasteurella multocida; $17.1 \%$ were Pasteurella canis; and $5.2 \%$ were Pasteurella pneumotropica

2. According to the retrospective study and comprehensive review by Körmöndi and colleagues, which of the following statements about characteristics of localized and invasive pasteurellosis is correct?

A. Patients with localized infections were more likely to be male and older than patients with invasive infections
B. Half of patients with invasive infections had abscesses

C. $7 \%$ of patients with localized and $77.1 \%$ of patients with invasive infections had underlying diseases $(p<0.0001)$, especially cardiovascular disease, diabetes, and/or cancer

D. Localized infections mostly affected the lower extremities

3. According to the retrospective study and comprehensive review by Körmöndi and colleagues, which of the following statements about complications and mortality after localized and invasive pasteurellosis is correct?

A. 4 patients with invasive pasteurellosis underwent ileostomy, hysterectomy, skin transplantation, or amputation

B. Death rate was $8 \%$ among patients with invasive pasteurellosis

C. Only $5 \%$ of patients had severe complications after localized infection

D. There were no central nervous system infections in this series 


\section{Earning CME Credit}

To obtain credit, you should first read the journal article. After reading the article, you should be able to answer the following, related, multiple-choice questions. To complete the questions (with a minimum $75 \%$ passing score) and earn continuing medical education (CME) credit, please go to http://www.medscape.org/journal/eid. Credit cannot be obtained for tests completed on paper, although you may use the worksheet below to keep a record of your answers.

You must be a registered user on http://www.medscape.org. If you are not registered on http://www.medscape.org, please click on the "Register" link on the right hand side of the website.

Only one answer is correct for each question. Once you successfully answer all post-test questions, you will be able to view and/or print your certificate. For questions regarding this activity, contact the accredited provider, CME@medscape. net. For technical assistance, contact CME@medscape.net. American Medical Association's Physician's Recognition Award (AMA PRA) credits are accepted in the US as evidence of participation in CME activities. For further information on this award, please go to https://www.ama-assn.org. The AMA has determined that physicians not licensed in the US who participate in this CME activity are eligible for AMA PRA Category 1 Credits $^{\mathrm{TM}}$. Through agreements that the AMA has made with agencies in some countries, AMA PRA credit may be acceptable as evidence of participation in CME activities. If you are not licensed in the US, please complete the questions online, print the AMA PRA CME credit certificate, and present it to your national medical association for review.

\section{Article Title \\ Zika Virus Epidemic in Pregnant Women, Dominican Republic, 2016-2017}

\section{CME Questions}

1. Your patient is a 27-year-old pregnant woman with Zika virus infection. According to the retrospective report by Peña and colleagues, which of the following statements about characteristics of pregnant women and pregnancy outcomes of women infected with Zika virus during the Dominican Republic outbreak in 2016-2017 is correct?

A. $10 \%$ of Zika virus infections were diagnosed during the first trimester of pregnancy

B. Among known pregnancy outcomes, $91 \%$ were live births, $6 \%$ were miscarriages, and $3 \%$ were intrauterine fetal demise

C. Three-quarters of women had fever

D. Among live births, median birth weight was $2,975 \mathrm{~g}$, and $6 \%$ were premature

2. According to the retrospective report by Peña and colleagues, which of the following statements about infant outcomes for pregnant women infected with Zika virus during the Dominican Republic outbreak in 2016-2017 is correct?

A. Of 14 congenital malformations reported through SINAVE, 9 had suspected microcephaly; 1 , anencephaly; 1 , hydrocephaly; 1 , palate fissure; 1 , "small heart"; and 1 other, unspecified
B. 7 cases of microcephaly met the case definition of a head circumference $(\mathrm{HC})$ of $<2$ standard deviation below the mean

C. Ophthalmologic and audiologic testing revealed birth defects in 18 additional infants

D. Brain radiographic abnormalities associated with Zika virus infection were identified in 8 additional infants

3. According to the retrospective report by Peña and colleagues, which of the following statements about factors associated with birth outcomes for pregnant women infected with Zika virus during the Dominican Republic outbreak in 2016-2017 and clinical implications of the findings is correct?
A. Early fetal loss was twice as likely among women infected during the first trimester
B. Odds of premature birth were not significantly increased among women who had fever during infection
C. The role of surveillance in detecting and preventing adverse outcomes needs to be determined before the next outbreak
D. This study may have overestimated the true Zika virus disease burden and its effect in pregnancy




\section{Earning CME Credit}

To obtain credit, you should first read the journal article. After reading the article, you should be able to answer the following, related, multiple-choice questions. To complete the questions (with a minimum $75 \%$ passing score) and earn continuing medical education (CME) credit, please go to http://www.medscape.org/journal/eid. Credit cannot be obtained for tests completed on paper, although you may use the worksheet below to keep a record of your answers.

You must be a registered user on http://www.medscape.org. If you are not registered on http://www.medscape.org, please click on the "Register" link on the right hand side of the website.

Only one answer is correct for each question. Once you successfully answer all post-test questions, you will be able to view and/or print your certificate. For questions regarding this activity, contact the accredited provider, CME@medscape. net. For technical assistance, contact CME@medscape.net. American Medical Association's Physician's Recognition Award (AMA PRA) credits are accepted in the US as evidence of participation in CME activities. For further information on this award, please go to https://www.ama-assn.org. The AMA has determined that physicians not licensed in the US who participate in this CME activity are eligible for AMA PRA Category 1 Credits $^{\mathrm{TM}}$. Through agreements that the AMA has made with agencies in some countries, AMA PRA credit may be acceptable as evidence of participation in CME activities. If you are not licensed in the US, please complete the questions online, print the AMA PRA CME credit certificate, and present it to your national medical association for review.

\section{Article Title}

\section{Ac ute and Delayed Deaths after West Nile Virus Infection, Texas, USA, 2002-2012 \\ CME Questions}

1. You are seeing a 55-year-old man with a history of hypertension. He complains of 3 days of fever, malaise, and headache. After a thorough workup, you diagnose him with West Nile fever. On the basis of the current study by Philpott and colleagues, what can you tell him regarding the short-term risk for mortality associated with this infection?

A. Nearly $80 \%$ of all deaths occurred in the acute phase

B. Most acute deaths were in West Nile neuroinvasive disease (WNND) cases

C. The median age of acutely fatal cases was 55 years

D. The most common cause of acute death was cardiovascular

2. The patient develops WNND, but survives the acute infection. According to the results of the current study, which one of the following was a significant risk factor for mortality in the long term?
A. White race
B. WNND
C. Female sex
D. Younger age

3. Which one of the following statements regarding the risk for long-term mortality among patients with West Nile virus infection in the current study is most accurate?

A. Any West Nile virus infection was associated with a higher risk for mortality compared with the general population

B. Only WNND was associated with a higher risk for mortality compared with the general population

C. Only non-WNND was associated with a higher risk for mortality compared with the general population

D. Non-WNND was associated with a lower risk for mortality compared with the general population

4. Which of the following causes of mortality were significantly increased among WNND cases in the current study?
A. Cardiovascular and pulmonary
B. Infectious and genitourinary
C. Gastrointestinal and cancer
D. Cardiovascular and cancer 
Emerging Infectious Diseases is a peer-reviewed journal established expressly to promote the recognition of new and reemerging infectious diseases around the world and improve the understanding of factors involved in disease emergence, prevention, and elimination.

The journal is intended for professionals in infectious diseases and related sciences. We welcome contributions from infectious disease specialists in academia, industry, clinical practice, and public health, as well as from specialists in economics, social sciences, and other disciplines. Manuscripts in all categories should explain the contents in public health terms. For information on manuscript categories and suitability of proposed articles, see below and visit http://wwwnc.cdc.gov/eid/pages/author-resource-center.htm.

\section{Summary of Authors' Instructions}

Authors' Instructions. For a complete list of EID's manuscript guidelines, see the author resource page: http://wwwnc.cdc.gov/eid/page/author-resource-center.

Manuscript Submission. To submit a manuscript, access Manuscript Central from the Emerging Infectious Diseases web page (www.cdc.gov/eid). Include a cover letter indicating the proposed category of the article (e.g., Research, Dispatch), verifying the word and reference counts, and confirming that the final manuscript has been seen and approved by all authors. Complete provided Authors Checklist.

Manuscript Preparation. For word processing, use MS Word. Set the document to show continuous line numbers. List the following information in this order: title page, article summary line, keywords, abstract, text, acknowledgments, biographical sketch, references, tables, and figure legends. Appendix materials and figures should be in separate files.

Title Page. Give complete information about each author (i.e., full name, graduate degree(s), affiliation, and the name of the institution in which the work was done). Clearly identify the corresponding author and provide that author's mailing address (include phone number, fax number, and email address). Include separate word counts for abstract and text.

Keywords. Use terms as listed in the National Library of Medicine Medical Subject Headings index (www.ncbi.nlm.nih.gov/mesh).

Text. Double-space everything, including the title page, abstract, references, tables, and figure legends. Indent paragraphs; leave no extra space between paragraphs. After a period, leave only one space before beginning the next sentence. Use 12-point Times New Roman font and format with ragged right margins (left align). Italicize (rather than underline) scientific names when needed.

Biographical Sketch. Include a short biographical sketch of the first author-both authors if only two. Include affiliations and the author's primary research interests.

References. Follow Uniform Requirements (www.icmje.org/index.html). Do not use endnotes for references. Place reference numbers in parentheses, not superscripts. Number citations in order of appearance (including in text, figures, and tables). Cite personal communications, unpublished data, and manuscripts in preparation or submitted for publication in parentheses in text. Consult List of Journals Indexed in Index Medicus for accepted journal abbreviations; if a journal is not listed, spell out the journal title. List the first six authors followed by "et al." Do not cite references in the abstract.

Tables. Provide tables within the manuscript file, not as separate files. Use the MS Word table tool, no columns, tabs, spaces, or other programs. Footnote any use of boldface. Tables should be no wider than $17 \mathrm{~cm}$. Condense or divide larger tables. Extensive tables may be made available online only.

Figures. Submit editable figures as separate files (e.g., Microsoft Excel, PowerPoint) Photographs should be submitted as high-resolution (600 dpi) .tif or .jpg files. Do not embed figures in the manuscript file. Use Arial $10 \mathrm{pt}$. or $12 \mathrm{pt}$. font for lettering so that figures, symbols, lettering, and numbering can remain legible when reduced to print size. Place figure keys within the figure. Figure legends should be placed at the end of the manuscript file.

Videos. Submit as AVI, MOV, MPG, MPEG, or WMV. Videos should not exceed 5 minutes and should include an audio description and complete captioning. If audio is not available, provide a description of the action in the video as a separate Word file. Published or copyrighted material (e.g., music) is discouraged and must be accompanied by written release. If video is part of a manuscript, files must be uploaded with manuscript submission. When uploading, choose "Video" file. Include a brief video legend in the manuscript file.

\section{Types of Articles}

Perspectives. Articles should not exceed 3,500 words and 50 references. Use of subheadings in the main body of the text is recommended. Photographs and illustrations are encouraged. Provide a short abstract (150 words), 1-sentence summary, and biographical sketch. Articles should provide insightful analysis and commentary about new and reemerging infectious diseases and related issues. Perspectives may address factors known to influence the emergence of diseases, including microbial adaptation and change, human demographics and behavior, technology and industry, economic development and land use, international travel and commerce, and the breakdown of public health measures.

Synopses. Articles should not exceed 3,500 words in the main body of the text or include more than 50 references. Use of subheadings in the main body of the text is recommended. Photographs and illustrations are encouraged. Provide a short abstract (not to exceed 150 words), a 1-line summary of the conclusions, and a brief biographical sketch of first author or of both authors if only 2 authors. This section comprises case series papers and concise reviews of infectious diseases or closely related topics. Preference is given to reviews of new and emerging diseases; however, timely updates of other diseases or topics are also welcome. If detailed methods are included, a separate section on experimental procedures should immediately follow the body of the text.

Research. Articles should not exceed 3,500 words and 50 references. Use of subheadings in the main body of the text is recommended. Photographs and illustrations are encouraged. Provide a short abstract (150 words), 1-sentence summary, and biographical sketch. Report laboratory and epidemiologic results within a public health perspective. Explain the value of the research in public health terms and place the findings in a larger perspective (i.e., "Here is what we found, and here is what the findings mean").

Policy and Historical Reviews. Articles should not exceed 3,500 words and 50 references. Use of subheadings in the main body of the text is recommended. Photographs and illustrations are encouraged. Provide a short abstract (150 words), 1-sentence summary, and biographical sketch. Articles in this section include public health policy or historical reports that are based on research and analysis of emerging disease issues.

Dispatches. Articles should be no more than 1,200 words and need not be divided into sections. If subheadings are used, they should be general, e.g., "The Study" and "Conclusions." Provide a brief abstract (50 words); references (not to exceed 15); figures or illustrations (not to exceed 2); tables (not to exceed 2); and biographical sketch. Dispatches are updates on infectious disease trends and research that include descriptions of new methods for detecting, characterizing, or subtyping new or reemerging pathogens. Developments in antimicrobial drugs, vaccines, or infectious disease prevention or elimination programs are appropriate. Case reports are also welcome.

Research Letters Reporting Cases, Outbreaks, or Original Research. EID publishes letters that report cases, outbreaks, or original research as Research Letters. Authors should provide a short abstract (50-word maximum), references (not to exceed 10 ), and a short biographical sketch. These letters should not exceed 800 words in the main body of the text and may include either 1 figure or 1 table. Do not divide Research Letters into sections.

Letters Commenting on Articles. Letters commenting on articles should contain a maximum of 300 words and 5 references; they are more likely to be published if submitted within 4 weeks of the original article's publication.

Commentaries. Thoughtful discussions (500-1,000 words) of current topics. Commentaries may contain references (not to exceed 15) but no abstract, figures, or tables. Include biographical sketch.

Another Dimension. Thoughtful essays, short stories, or poems on philosophical issues related to science, medical practice, and human health. Topics may include science and the human condition, the unanticipated side of epidemic investigations, or how people perceive and cope with infection and illness. This section is intended to evoke compassion for human suffering and to expand the science reader's literary scope. Manuscripts are selected for publication as much for their content (the experiences they describe) as for their literary merit. Include biographical sketch.

Books, Other Media. Reviews (250-500 words) of new books or other media on emerging disease issues are welcome. Title, author(s), publisher, number of pages, and other pertinent details should be included.

Conference Summaries. Summaries of emerging infectious disease conference activities (500-1,000 words) are published online only. They should be submitted no later than 6 months after the conference and focus on content rather than process. Provide illustrations, references, and links to full reports of conference activities.

Online Reports. Reports on consensus group meetings, workshops, and other activities in which suggestions for diagnostic, treatment, or reporting methods related to infectious disease topics are formulated may be published online only. These should not exceed 3,500 words and should be authored by the group. We do not publish official guidelines or policy recommendations.

Photo Quiz. The photo quiz (1,200 words) highlights a person who made notable contributions to public health and medicine. Provide a photo of the subject, a brief clue to the person's identity, and five possible answers, followed by an essay describing the person's life and his or her significance to public health, science, and infectious disease.

Etymologia. Etymologia (100 words, 5 references). We welcome thoroughly researched derivations of emerging disease terms. Historical and other context could be included.

Announcements. We welcome brief announcements of timely events of interest to our readers. Announcements may be posted online only, depending on the event date. Email to eideditor@cdc.gov. 


\section{In This Issue}

\section{Perspective}

International Biological Reference Preparations for Epidemic Infectious Diseases

\section{Synopses}

Atypical Cowpox Virus Infection in Smallpox-Vaccinated Patient, France .....................212

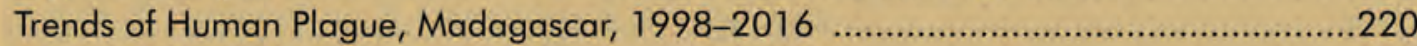

Human Pasteurellosis Health Risk for Elderly Persons Living with Companion Animals....229

Lassa Fever in Travelers from West Africa, 1969-2016 .........................................236

Ebola Virus Infection Associated with Transmission from Survivors.............................240

Zika Virus Epidemic in Pregnant Women, Dominican Republic, 2016-2017 ...............247

\section{Research}

Acute and Delayed Deaths after West Nile Virus Infection, Texas, USA, 2002-2012 2....256

Echinococcus multilocularis Infection, Southern Ontario, Canada

Epidemiologic and Ecologic Investigations of Monkeypox, Likouala Department,

Republic of the Congo, 2017

Oasis Malaria, Northern Mauritania

Macrophage Activation Marker Soluble CD163 Associated with Fatal and Severe

Ebola Virus Disease in Humans

Zika Virus IgM Detection and Neutralizing Antibody Profiles 12-19 Months after Illness Onset

\section{Historical Review}

Killing Clothes Lice by Holding Infested Clothes Away from Hosts for 10 Days to Control Louseborne Relapsing Fever, Bahir Dah, Ethiopia.

\section{Dispatches}

Differential Shedding and Antibody Kinetics of Zika and Chikungunya Viruses, Brazil ....311

Clinical Manifestations, Antimicrobial Drug Susceptibility Patterns, and Outcomes in Melioidosis Cases, India

Crimean-Congo Hemorrhagic Fever, Kosovo, 2013-2016.

Cumulative Incidence of West Nile Virus Infection, Continental United States, 1999-2016

Lyme Disease Emergence after Invasion of the Blacklegged Tick, Ixodes scapularis, Ontario, Canada, 2010-2016

Bat Influenza A(HL18NL11) Virus in Fruit Bats, Brazil

Rift Valley Fever Reemergence after 7 Years of Quiescence, South Africa, May 2018 ...338

Tick-Borne Encephalitis Virus Antibodies in Roe Deer, the Netherlands

Vector Competence of Aedes caspius and Ae. albopictus Mosquitoes

for Zika Virus, Spain.

Submicroscopic Malaria in Migrants from Sub-Saharan Africa, Spain

Cytauxzoon felis Infection in Domestic Cats, Yunnan Province, China, 2016

Molecular Detection and Species Determination of Malaria Parasites, Venezuela

Seroprevalence of Heartland Virus Antibodies in Blood Donors,

Northwestern Missouri, USA

Identification of Leishmania Species in Naturally Infected Sand Flies from

Refugee Camps, Greece 